\title{
A GUIDE TO \\ COMMERCIAL-SCALE \\ ETHANOL PRODUCTION AND FINANCING
}

\section{MASTER}

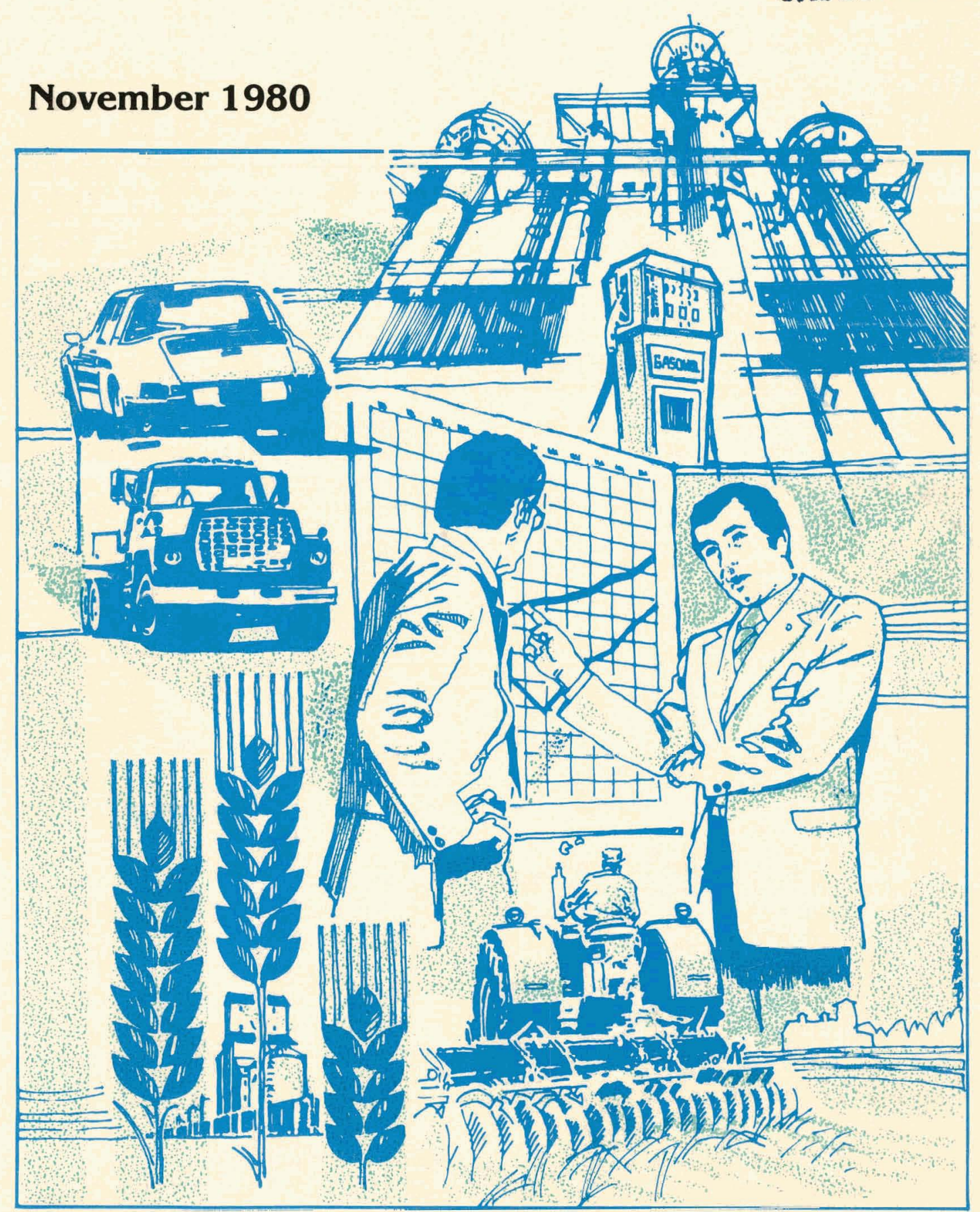




\section{DISCLAIMER}

This report was prepared as an account of work sponsored by an agency of the United States Government. Neither the United States Government nor any agency Thereof, nor any of their employees, makes any warranty, express or implied, or assumes any legal liability or responsibility for the accuracy, completeness, or usefulness of any information, apparatus, product, or process disclosed, or represents that its use would not infringe privately owned rights. Reference herein to any specific commercial product, process, or service by trade name, trademark, manufacturer, or otherwise does not necessarily constitute or imply its endorsement, recommendation, or favoring by the United States Government or any agency thereof. The views and opinions of authors expressed herein do not necessarily state or reflect those of the United States Government or any agency thereof. 


\section{DISCLAIMER}

Portions of this document may be illegible in electronic image products. Images are produced from the best available original document. 


\section{NOTICE}

This guide was prepared as a result of work sponsored by the United States government. Neither the United States nor the U.S. Department of Energy, nor any of its employees, nor any of its contractors, subcontractors, or their employees, makes any warranty, expressed or implied, or assumes any legal liability or responsibility for the accuracy, completeness, or usefulness of any information, apparatus, product, or process disclosed, or represents that its use would not infringe privately owned rights.

A limited number of copies are available at no charge from:

National Alcohol Fuels Information Center

Solar Energy Research Center

1617 Cole Boulevard

Denver Co. 80401

After this supply is exhausted, copies may be purchased from the following sources:

The Superintendent of Government Documents

U.S. Government Printing Office

Washington, DC 20402

Please specify stock number 061-000-00472-6 when ordering.

The National Technical Information Service

U.S. Department of Commerce

5285 Port Royal Road

Springfield, VA 22161

Report No. SERI/SP-751-877

This is the first edition of $A$ Guide to Commercial-Scale Ethanol Production and Financing; your comments, additions, or corrections would be appreciated for future revisions of this handbook. Send them to:

Information Outreach and Dissemination Branch

Solar Energy Research Institute

1617 Cole Boulevard

Golden, CO 80401 


\section{A GUIDE TO COMMERCIAL-SCALE ETHANOL PRODUCTION AND FINANCING}

A Product of the Solar Energy Information Data Bank

Solar Energy Research Institute Operated for the U.S. Department of Energy by the . Midwest Research Institute

Under Contract No. EG-77-C=01-4042

Published November 1980

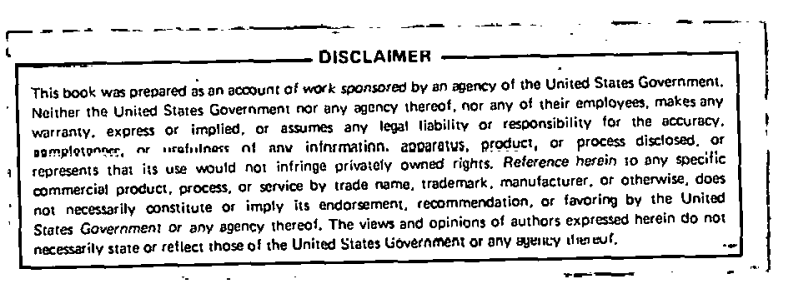

The information contained in this document is current as of October 1980, unless otherwise noted. 


\section{FOREWORD}

The Guide to Commercial-Scale Ethanol Production and Financing was produced by the Solar Energy Research Institute (SER1) on behaif of the U.S. Depattuent of Encrgy. It is one of a ceries of information products aimcd at facilitating the production and adoption of alcohol fuels on a wide scale throughout the United States. It joins many other solar energy information products produced and distributed by SERI through its Solar Energy Information Data Bank, a national information network created by the U.S. Congress to dispense solar energy information to all citizens who have need for it.

This guide was conceived and developed as a special aid to entrepreneurs who have interest in the business of alcohol fuel production on a commercial scale. It is supported by other information that currently is being produced and assembled by the National Alcohol Fuels Information Center (NAFIC), also managed by the Solar Energy Research Institute. This additional information, as well as personal counsel on specific problems, may be obtained by calling the NAFIC toll free "Hot Line" (800) 525-5555. Colorado residents should call (800) 332-8339. Operators are on duty from 8 AM to 5 PM, Mountain Standard Time, to respond to inquiries with written information or referrals to top experts in the field. 


\section{TABLE OF CONTENTS}

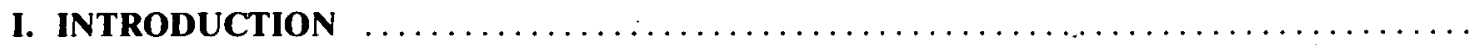

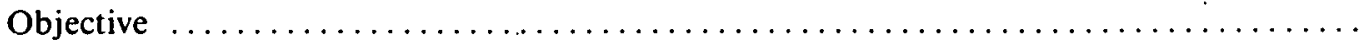

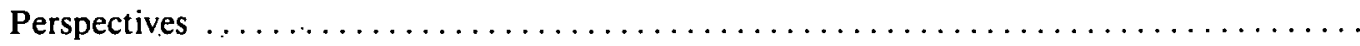

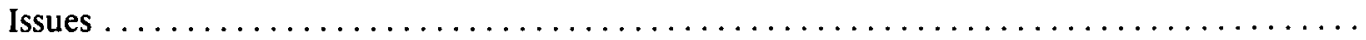

Organization of the Book $\ldots \ldots \ldots \ldots \ldots \ldots \ldots \ldots \ldots \ldots \ldots \ldots \ldots \ldots \ldots \ldots \ldots \ldots \ldots$

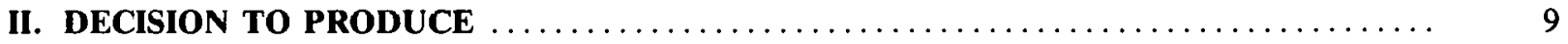

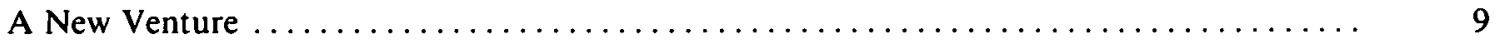

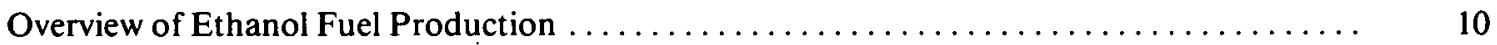

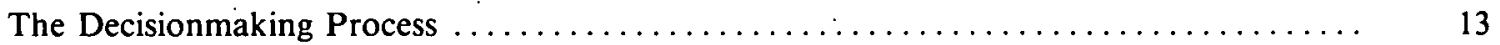

Timeframe for the Decisionmaking Process $\ldots \ldots \ldots \ldots \ldots \ldots \ldots \ldots \ldots \ldots \ldots \ldots \ldots \ldots \ldots$

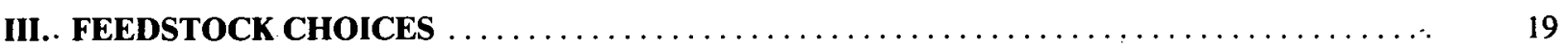

Types of Feedstocks $\ldots \ldots \ldots \ldots \ldots \ldots \ldots \ldots \ldots \ldots \ldots \ldots \ldots \ldots \ldots \ldots \ldots \ldots \ldots \ldots \ldots \ldots \ldots$

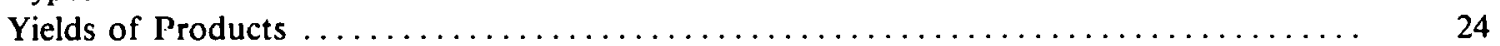

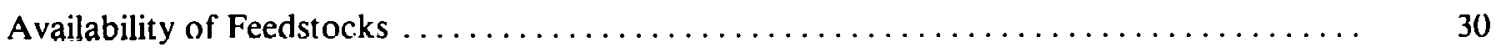

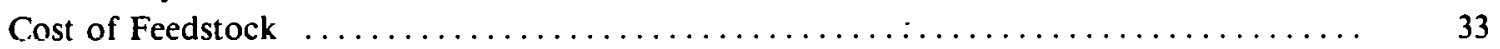

IV. MARKETS FOR ETHANOL AND COPRODUCTS $\ldots \ldots \ldots \ldots \ldots \ldots$

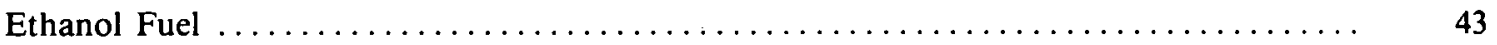

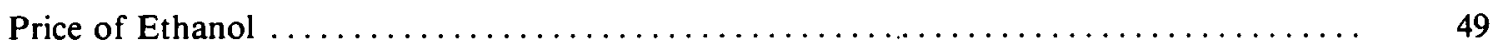

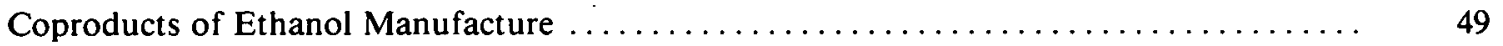

Other Coproducts $\ldots \ldots \ldots \ldots \ldots \ldots \ldots \ldots \ldots \ldots \ldots \ldots \ldots \ldots \ldots \ldots \ldots \ldots \ldots \ldots \ldots \ldots$

Relationship Between the Ethanol and Coproducts Markets and the Feedstock Supplies ... 53

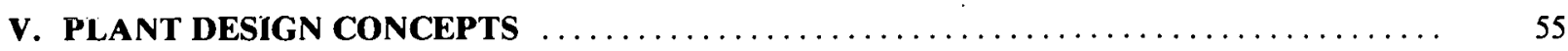

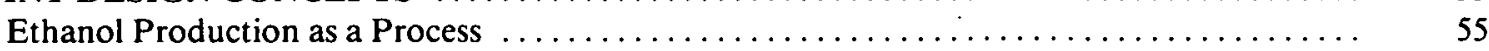

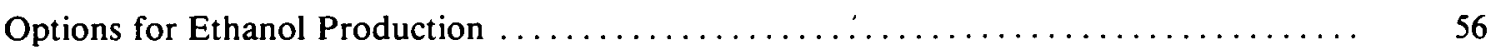

Overall Plant Operation $\ldots \ldots \ldots \ldots \ldots \ldots \ldots \ldots \ldots \ldots \ldots \ldots \ldots \ldots \ldots \ldots \ldots \ldots \ldots \ldots \ldots \ldots \ldots$

Typical Materials and Energy Flow Diagrams $\ldots \ldots \ldots \ldots \ldots \ldots \ldots \ldots \ldots \ldots \ldots \ldots$

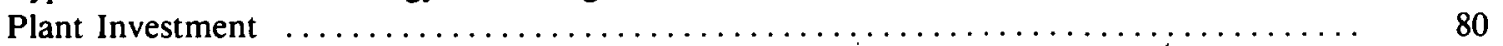

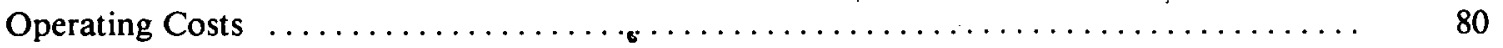

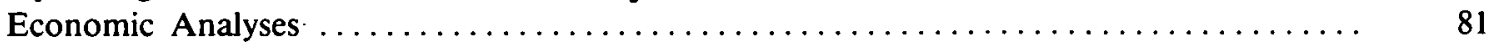

Sensitivity of Ethanol Price $\ldots \ldots \ldots \ldots \ldots \ldots \ldots \ldots \ldots \ldots \ldots \ldots \ldots \ldots \ldots \ldots \ldots \ldots$

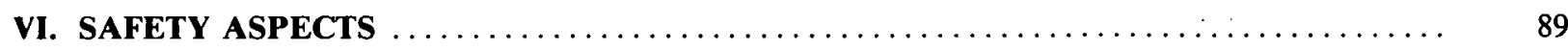

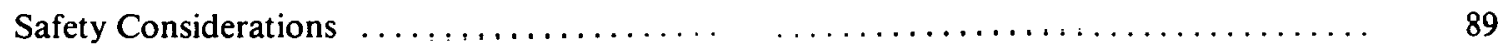

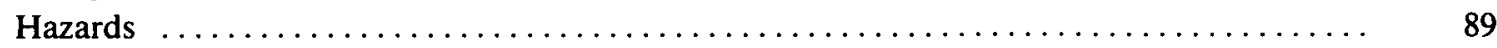

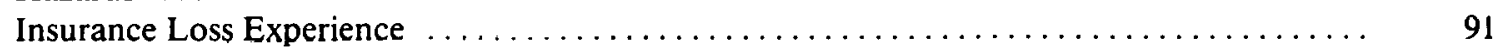

Plant Safety Considerations $\ldots \ldots \ldots \ldots \ldots \ldots \ldots \ldots \ldots \ldots \ldots \ldots \ldots \ldots \ldots \ldots \ldots \ldots$

VI. ENVIRONMENTAL CONCERNS $\ldots \ldots \ldots \ldots \ldots \ldots \ldots \ldots \ldots \ldots \ldots \ldots$

Bioconversion of Grain Feedstocks to Ethanol $\ldots \ldots \ldots \ldots \ldots \ldots \ldots \ldots \ldots \ldots \ldots \ldots$

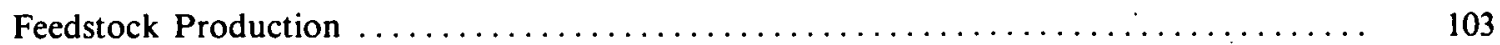

Use of Ethanol/Gasoline Blends in Highway Vehicles . . . . . . . . . . . . . . . 104

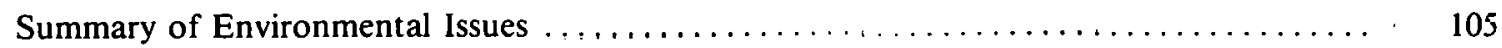

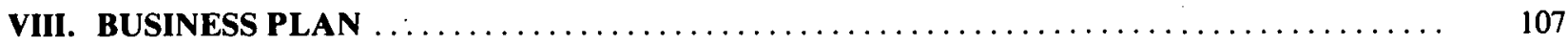

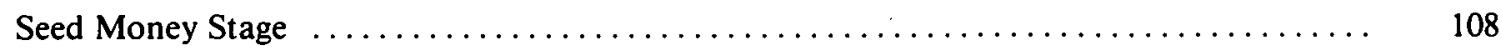

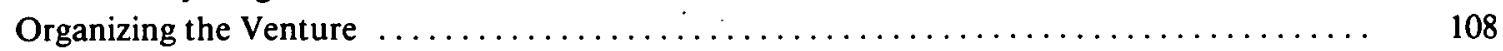

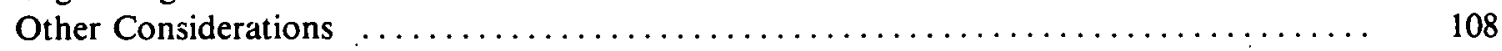

Criteria in Selection of the Project Team $\ldots \ldots \ldots \ldots \ldots \ldots \ldots \ldots \ldots \ldots \ldots \ldots \ldots \ldots$

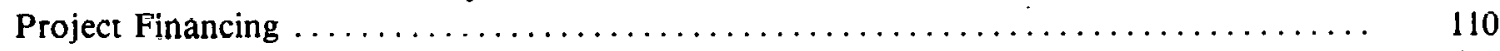

Plant Construction and Operation $\ldots \ldots \ldots \ldots \ldots \ldots \ldots \ldots \ldots \ldots \ldots \ldots \ldots \ldots \ldots \ldots \ldots$ 


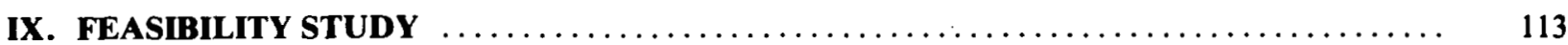

Prefeasibility Phase $\ldots \ldots \ldots \ldots \ldots \ldots \ldots \ldots \ldots \ldots \ldots \ldots \ldots \ldots \ldots \ldots \ldots \ldots \ldots \ldots \ldots \ldots, 113$

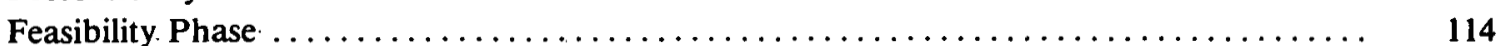

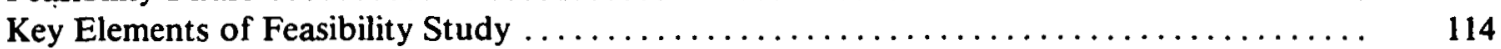

Feasibility Study Format $\ldots \ldots \ldots \ldots \ldots \ldots \ldots \ldots \ldots \ldots \ldots \ldots \ldots \ldots \ldots \ldots \ldots \ldots \ldots, 118$

The Appendices to Feasibility Study $\ldots \ldots \ldots \ldots \ldots \ldots \ldots \ldots \ldots \ldots \ldots \ldots \ldots \ldots \ldots \ldots \ldots \ldots \ldots, \quad 118$

APPENDIX A FINANCIAL ASSISTANCE PROGRAMS $\ldots \ldots \ldots \ldots \ldots \ldots \ldots \ldots \ldots \ldots \ldots$ A-1

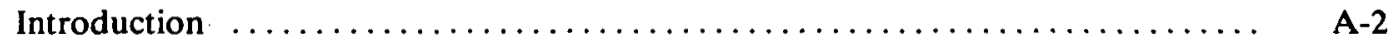

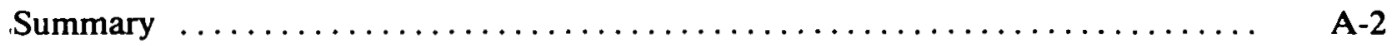

Sources of Financial Support $\ldots \ldots \ldots \ldots \ldots \ldots \ldots \ldots \ldots \ldots \ldots \ldots \ldots \ldots \ldots \ldots \ldots$ A-4

Loan Application Processes $\ldots \ldots \ldots \ldots \ldots \ldots \ldots \ldots \ldots \ldots \ldots \ldots \ldots \ldots \ldots \ldots$ A-8

APPENDIX B REGULATIONS AND PERMITS $\ldots \ldots \ldots \ldots \ldots \ldots \ldots \ldots \ldots \ldots \ldots \ldots$

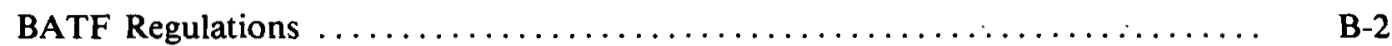

FDA and other $\Lambda$ nimal Feed Regulations $\ldots \ldots \ldots \ldots \ldots \ldots \ldots \ldots \ldots \ldots \ldots \ldots, \quad$ B-22

Transportation Regulations ............................. B-24

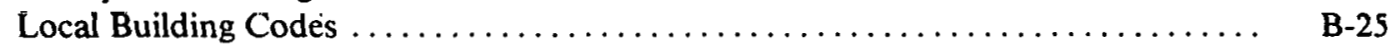

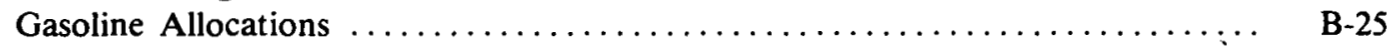

APPENDIX $C$ NATIONAL ALCOHOL FUELS PROGRAM $\ldots \ldots \ldots \ldots \ldots \ldots$

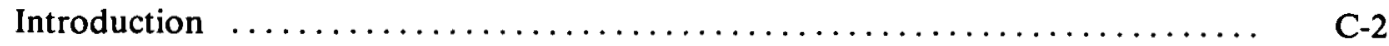

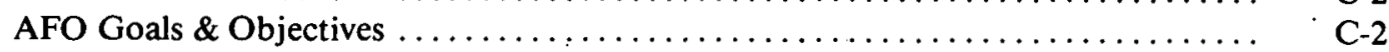

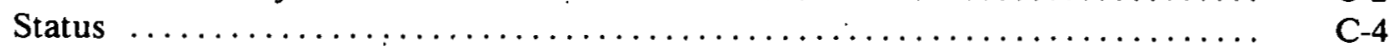

Program Implementation Plan $\ldots \ldots \ldots \ldots \ldots \ldots \ldots \ldots \ldots \ldots \ldots \ldots \ldots \ldots \ldots . . .6$

Office of Alcohol Fuels Mission and Functions $\ldots \ldots \ldots \ldots \ldots \ldots \ldots \ldots \ldots \ldots \ldots$ C-10

APPENDIX D SUMMARY OF ETHANOL LEISLATION $\ldots \ldots \ldots \ldots \ldots \ldots \ldots \ldots \ldots \ldots \ldots \ldots \ldots \ldots$

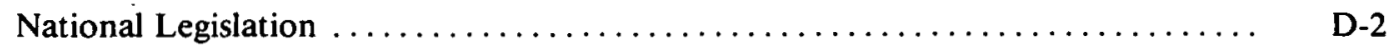

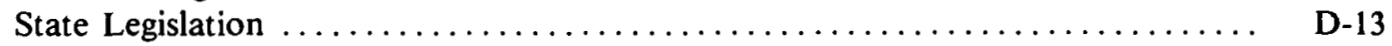

D-1. Summary of State Alcohol Fuel Exemptions . . . . . . . . . . . . . . D-54

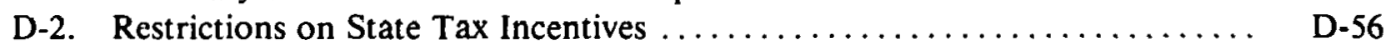

D-3. Sumuary of 3 tate Permit Requirements $\ldots \ldots \ldots \ldots \ldots \ldots \ldots \ldots \ldots \ldots \ldots \ldots$ D-62

D-4. State Volatlilicy Specificatiuns $\ldots \ldots \ldots \ldots \ldots \ldots \ldots \ldots \ldots \ldots \ldots \ldots \ldots$ D. 64

APPENDIX E RESOURCES PEOPLE AND ORGANIZATIONS ............... E

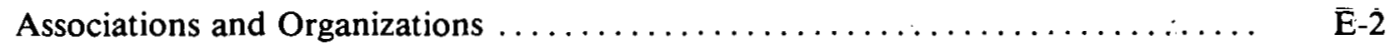

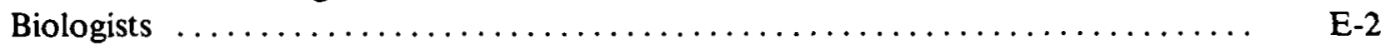

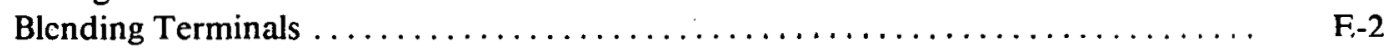

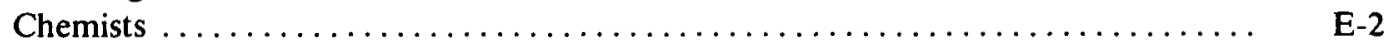

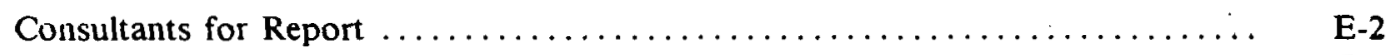

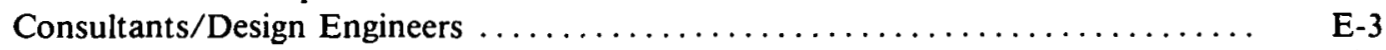

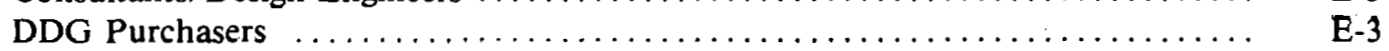

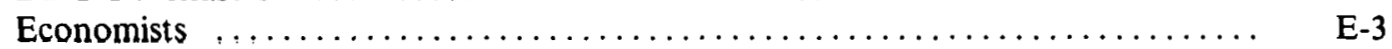

Engineering Firms $\ldots \ldots \ldots \ldots \ldots \ldots \ldots \ldots \ldots \ldots \ldots \ldots \ldots \ldots \ldots \ldots \ldots \ldots$

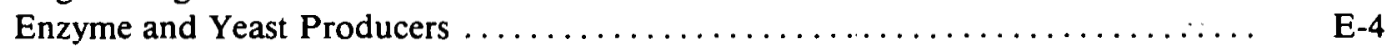

Ethanol Producers/Distributors $\ldots \ldots \ldots \ldots \ldots \ldots \ldots \ldots \ldots \ldots \ldots \ldots \ldots \ldots$ E-4

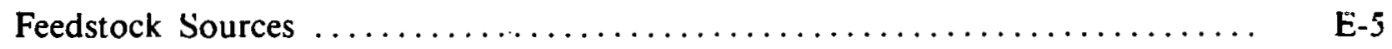

Plant Operation Consultants $\ldots \ldots \ldots \ldots \ldots \ldots \ldots \ldots \ldots \ldots \ldots \ldots \ldots \ldots \ldots \ldots$ E-5

Bureau of Alcohol, Tobacco, and Fircarms Regional Offices . . . . . . . . . . E-5

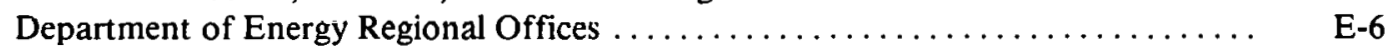

Small Business Administration Regional Offices . . . . . . . . . . . . . . . E-6

Farmers Home Administration State Offices . . . . . . . . . . . . . . . . . $\quad \bar{E}-\overline{8}$

Department of Housing and Urban Development Regional Offices . . . . . . . . . E-12

Economic Development Administration Regional Offices $\ldots \ldots \ldots \ldots \ldots \ldots \ldots \ldots$ E-17 


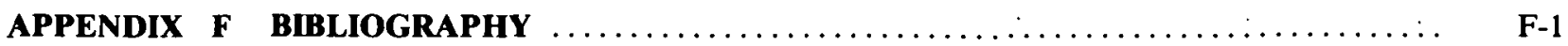

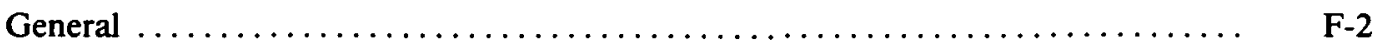

Conversion $\ldots \ldots \ldots \ldots \ldots \ldots \ldots \ldots \ldots \ldots \ldots \ldots \ldots \ldots \ldots \ldots \ldots \ldots \ldots \ldots \ldots \ldots \ldots$ F-3

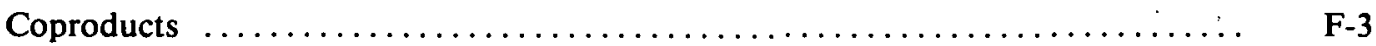

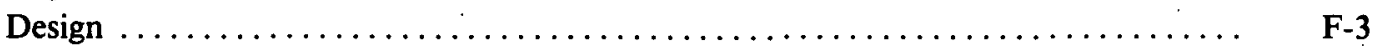

Distillation $\ldots \ldots \ldots \ldots \ldots \ldots \ldots \ldots \ldots \ldots \ldots \ldots \ldots \ldots \ldots \ldots \ldots \ldots \ldots$

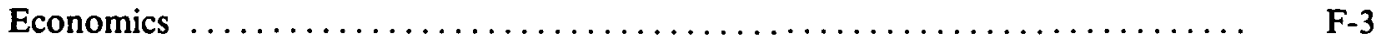

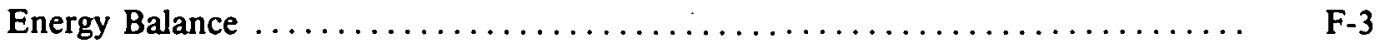

Environmental Considerations $\ldots \ldots \ldots \ldots \ldots \ldots \ldots \ldots \ldots \ldots \ldots \ldots \ldots \ldots \ldots \ldots \ldots \ldots$

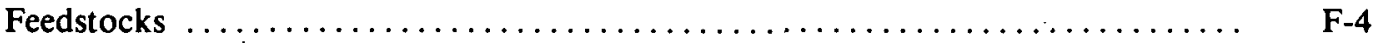

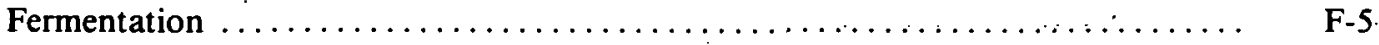

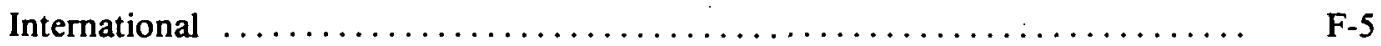

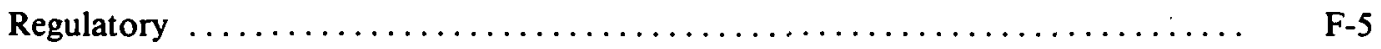

Transportation Use $\ldots \ldots \ldots \ldots \ldots \ldots \ldots \ldots \ldots \ldots \ldots \ldots \ldots \ldots \ldots \ldots$ F-5

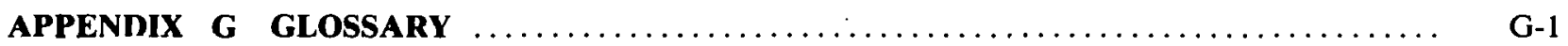

APPENDIX H TECHNICAL REFERENCE DATA $\ldots \ldots \ldots \ldots \ldots \ldots \ldots \ldots \ldots \ldots \ldots \ldots \ldots \ldots \ldots \ldots$

FOR MORE INFORMATION $\ldots \ldots \ldots \ldots \ldots \ldots \ldots \ldots \ldots \ldots \ldots \ldots \ldots \ldots \ldots \ldots$ Inside Rear Cover

\section{TABLES}

Tables

I-1. Major Issues Relating to Alcohol Fuels $\ldots \ldots \ldots \ldots \ldots \ldots \ldots \ldots \ldots \ldots \ldots \ldots \ldots \ldots \ldots$

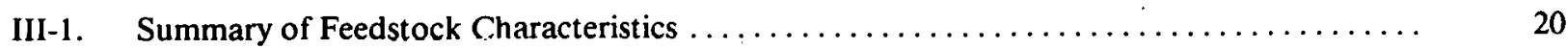

III-2. Probable Commercial Yields of 200-Proof Ethanol From Various Feedstocks . . . . . . . . . 27

III-3. Production Rates of Stillage and Stillage-Derived Products for Ethanol Production Feedstocks $\ldots \ldots \ldots \ldots \ldots \ldots \ldots \ldots \ldots \ldots \ldots \ldots \ldots \ldots \ldots \ldots \ldots \ldots \ldots \ldots \ldots \ldots \ldots \ldots \ldots \ldots$

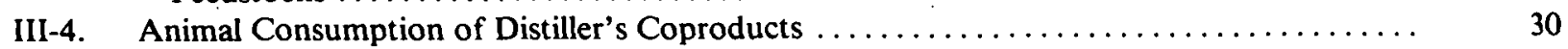

III-5. Animal Population (in Thousands) Required to Utilize the Distiller's Coproducts of Ethanol Plants of Various Sizes . . . . . . . . . . . . . . . . .

III-6. Quantities of Feedstocks for Ethanol Production Potentially Available in the Near-

Term and Their Ethanol Equivalent $\ldots \ldots \ldots \ldots \ldots \ldots \ldots \ldots \ldots \ldots \ldots \ldots \ldots$

III-7. Distribution of the Production of Potential Ethanol Feedstocks in the Continental

U.S. by USDA Regions . . . . . . . . . . . .

1II-8. Wholesale Prices of Corn and Other Commodities on the Chicago Market . . . . . . . . 34

III-9. Historical Trends of Corn Production, Utilization, Stocks and Costs ............

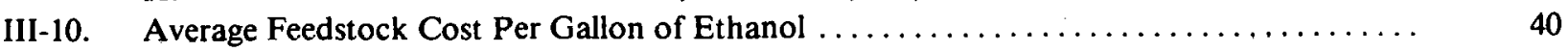

IV-1. Summary of Ethanol and Other Fuel Properties $\ldots \ldots \ldots \ldots \ldots \ldots$

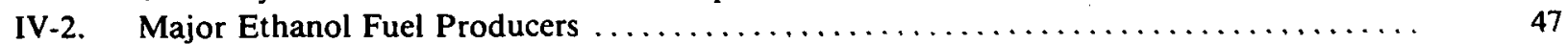

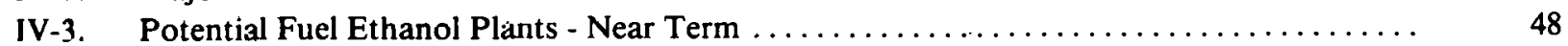

IV-4. Market for Some Commercial Feeds in the United States . . . . . . . . . . . . . .

V-1. Materials Flow for a $50-$ Million-Gallon Ethanol Plant $\ldots \ldots \ldots \ldots \ldots \ldots \ldots \ldots$

V-2. Energy Flow for a 50-Million.Gallon Ethanol Plant $\ldots \ldots \ldots \ldots \ldots \ldots \ldots \ldots \ldots$

V-3. $\quad 50 \mathrm{MM} \mathrm{Gal/Yr} \mathrm{Plant} \mathrm{Investment} \mathrm{Base} \mathrm{Case} \ldots \ldots \ldots \ldots \ldots \ldots \ldots \ldots \ldots$

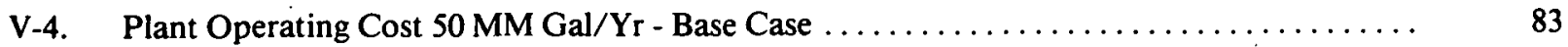

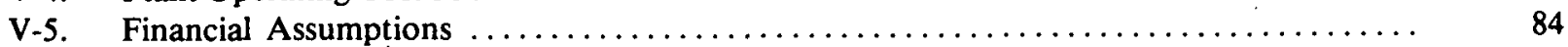

V-6. Ethanol Prices for Various Feedstocks and Fuels (50-Million-Gallon Plant - 1978 Dollars) 
V-7. Sensitivity of Ethanol Price to Financial Parameters $\ldots \ldots \ldots \ldots \ldots \ldots \ldots$

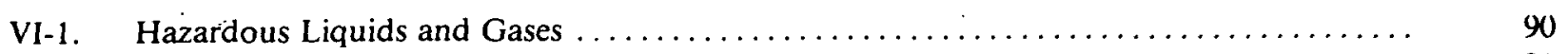

VI-2. Codes and Standards for the Production of Fuel-Grade Ethanol . . . . . . . . . . . . .

VII-1. Bioconversion of Grain to Ethanol Emission and Effluent Sources . . . . . . . . . . . .

VII-2. Nonattainment Areas of 48 Contiguous States $\ldots \ldots \ldots \ldots \ldots \ldots$. $\ldots \ldots \ldots \ldots \ldots \ldots \ldots \ldots$

VIII-1. Project Costs and Possible Funding for an Ethanol Plant $\ldots \ldots \ldots \ldots$

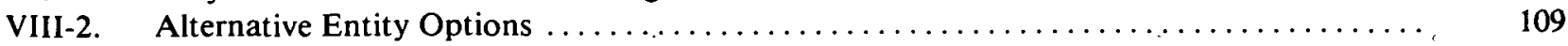

C-1. Presidential, Congressional, and AFO Production Capacity Milestones for the

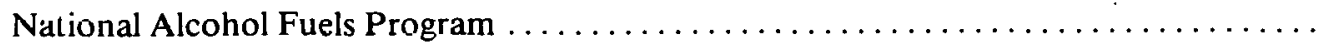

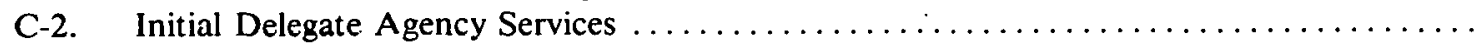

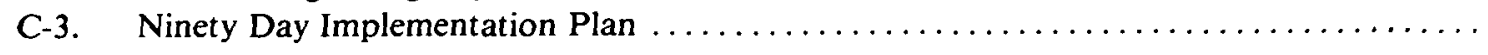

D-1. Summary of State Alcohol Fuel Exemptions $\ldots \ldots \ldots \ldots \ldots \ldots \ldots \ldots \ldots \ldots \ldots$

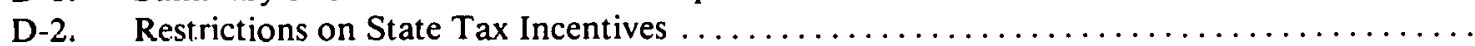

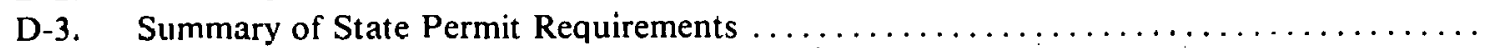

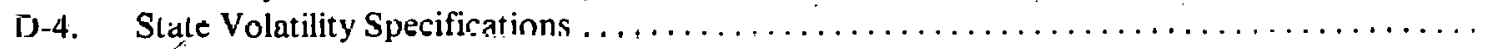

\section{FIGURES}

I-1. U.S. DOE Goals for Alcohol Fuels Production from Biomass . . . . . . . . . . .

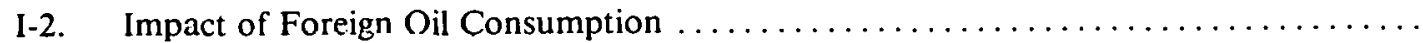

I-3. Number of Retail Gasohol Outlets in each State $\ldots \ldots \ldots \ldots \ldots \ldots \ldots \ldots \ldots \ldots \ldots$

I-4. Ethanol Production in Brazil as Reported in The Brazilian National Alcohol Program ..

I 5. Potential Ethanol Feedstocks and Their Availability by Regions . . . . . . . .........

I 6. Number of Plants Required to Meet Goal for Alculıul Produotion . . . . . . . . . . . . . .

1-7. Breakout of Production Costs for Lithanol $\ldots \ldots \ldots \ldots \ldots \ldots \ldots \ldots \ldots \ldots \ldots \ldots$

I-8. Long-Term Contribution of Ethanol, I.ignocellulose, and Methanol from Biomass ....

II-1 Basic Organization Interfaces for Production of Gasohol $\ldots \ldots \ldots \ldots \ldots \ldots \ldots \ldots$

II-2. Steps Involved in Bringing a Plant to Production $\ldots \ldots \ldots \ldots \ldots \ldots \ldots \ldots \ldots \ldots$

II-3. Decisionmaking Process for Entering the Ethanol Business $\ldots \ldots \ldots \ldots \ldots \ldots \ldots$

III-1. Simple Processing of Corn Prior to Fermentation $\ldots \ldots \ldots \ldots \ldots \ldots \ldots \ldots \ldots \ldots$

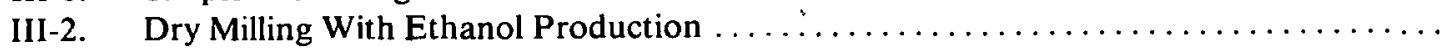

III-3. Wet Milling Process With Ethanol Production $\ldots \ldots \ldots \ldots \ldots \ldots \ldots \ldots \ldots \ldots \ldots$

III-4. Paths of Utilization of Residual Stillage from Grain Feedstock Distillery . . . . . . . . .

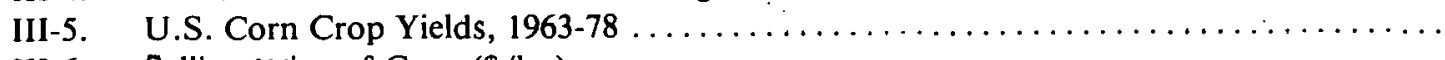

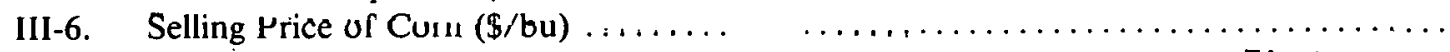

III-7. Corn Produclion Arca Required to Support a 50-Million-Gallon-Per-Year Plant ......

III-8. Trends and Fluctuations in Corn Prices $\ldots \ldots \ldots \ldots \ldots \ldots \ldots \ldots \ldots \ldots \ldots \ldots \ldots$

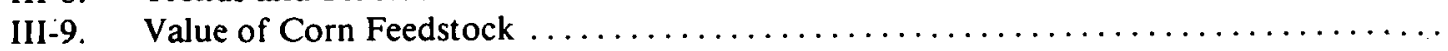

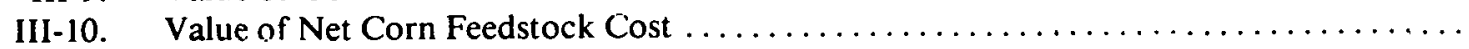

IV-1. Percentage of Motor Vehicles Registered by USDA Farm Regions and Location of

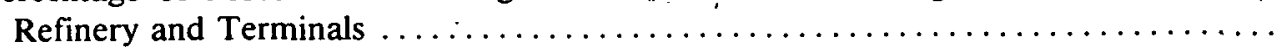

IV-2. Distribution of Cattle and Milk Cows Population and Large Feedlots by Regions ......

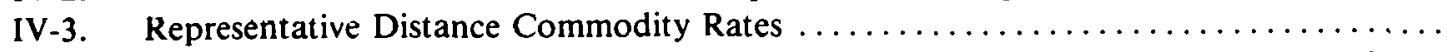

IV-4. Location of Major Grain Feedstock Supplies and Potential Markets for Ethanol and Coproducts 


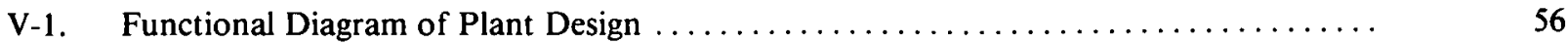

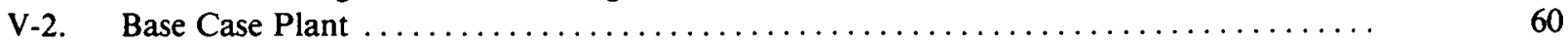

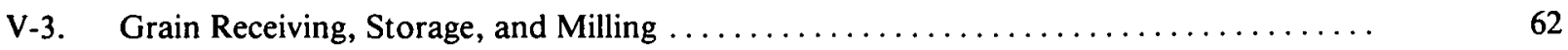

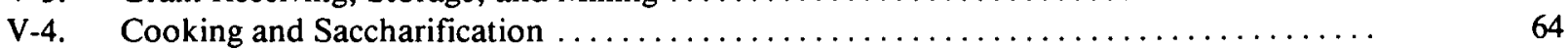

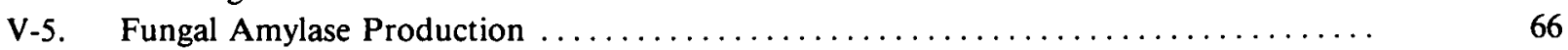

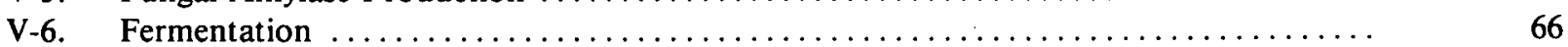

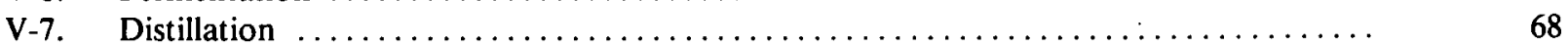

V-8. Residue Feed Processing $\ldots \ldots \ldots \ldots \ldots \ldots \ldots \ldots \ldots \ldots \ldots \ldots \ldots \ldots \ldots \ldots \ldots \ldots$

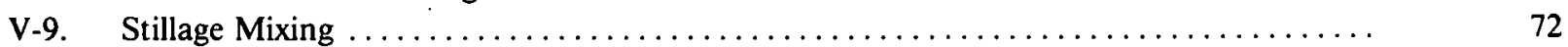

V-10. Storage and Shipping, Dry Grains $\ldots \ldots \ldots \ldots \ldots \ldots \ldots \ldots \ldots \ldots \ldots \ldots$

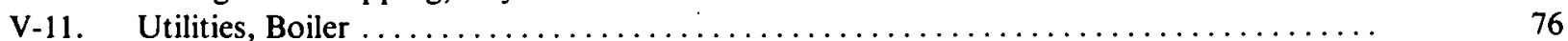

V-12. Utilities, Water Supply .................................. 76

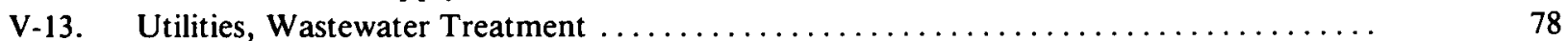

V-14. Utilities, Flue Gas Scrubber . . . . . . . . . . . . . . . . . . . . . . . . . .

V-15. Ethyl Alcohol Plant Costs in \$ Per Annual Gallon . . . . . . . . . . . . . . . .

V-16. Plant Capacities Other Than Base Case Selling Price vs. Production Year . . . . . . . . 85

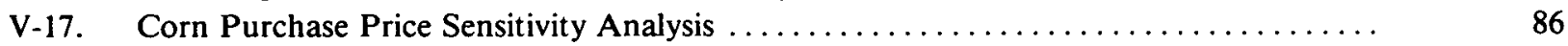

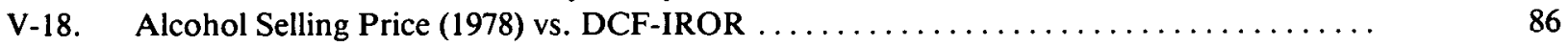

VII-1. Extent of Nonattainment of National Ambient Air Quality Standards in 48 Contiguous States $\ldots \ldots \ldots \ldots \ldots \ldots \ldots \ldots \ldots \ldots \ldots \ldots \ldots \ldots \ldots \ldots \ldots \ldots \ldots \ldots \ldots \ldots \ldots$

IX-1. Likely Schedule of Events/Tasks $\ldots \ldots \ldots \ldots \ldots \ldots \ldots \ldots \ldots \ldots \ldots \ldots \ldots$

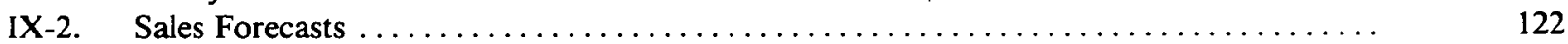

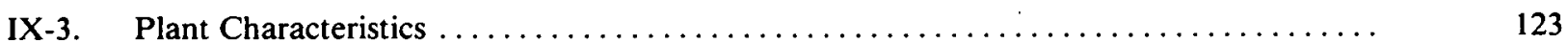

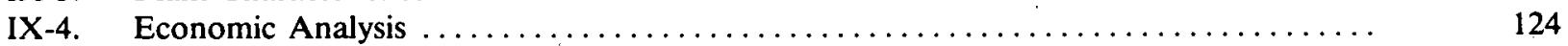

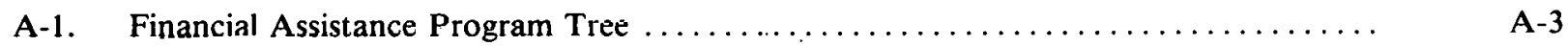

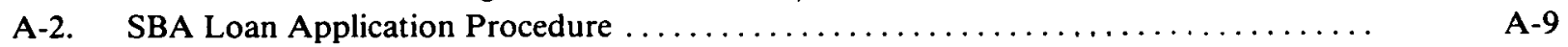

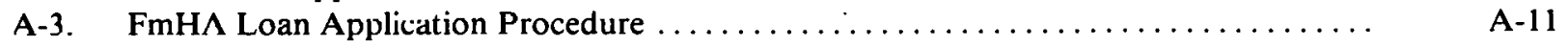

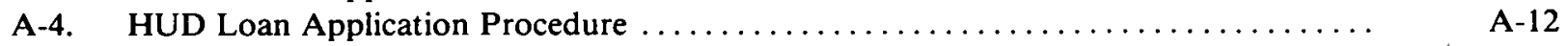

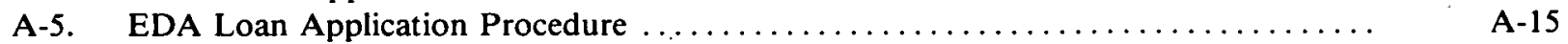

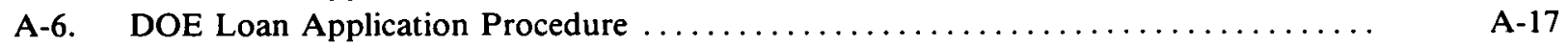

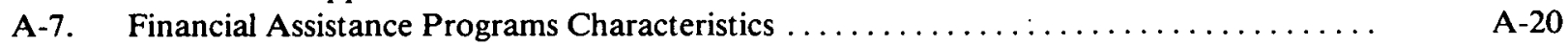

B-1. BATF Form $5110.74 \ldots \ldots \ldots \ldots \ldots \ldots \ldots \ldots \ldots \ldots \ldots \ldots \ldots \ldots \ldots \ldots \ldots$

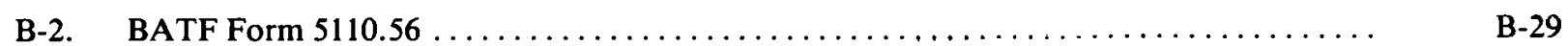

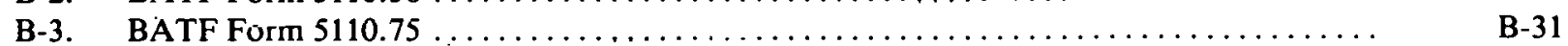

C-1. Organizational Chart for the Office of Alcohol Fuels $\ldots \ldots \ldots \ldots \ldots$

D-1. States Which Have Enacted Alcohol Fuels Legislation . . . . . . . . . . . . . . .

D-1. States Which Have Enacted Tax Incentives for Alcohol Fuels . . . . . . . . . . . . . D-12 


\section{THIS PAGE \\ WAS INTENTIONALLY LEFT BLANK}




\section{ACKNOWLEDGMENTS}

This effort was initiated by Mr. Bert Greenglass, Acting Director, Office of Alcohol Fuels, and was funded as part of the Solar Energy Research Institute's contract for the management and support of the National Alcohol Fuels Information Center. Mr. William Holmberg, Acting Director, Office of Market Development, Office of Alcohol Fuels, served as the Department of Energy director for this project. We acknowledge the financial information support provided by Mr. Ted D. Tarr of the Office of Alcohol Fuels.

The Solar Energy Research Institute's Solar Energy Information Data Bank (SEIDB) staff was requested to prepare this guide to the commercial-scale production and financing of fermentation ethanol. The effort at SEIDB was directed by Mr. Paul Notari and managed by Mr. Richard 'Piekarski of the Information Dissemination Branch.

A competitive contract was awarded to TRW Inc. to prepare this guidebook on commercial-scale fermentation ethanol production and financing. A team was formed to act as advisors to the TRW staff and to SERI in preparation of this text. The team consisted of the following individuals:

Program Manager

Mr. V. Daniel Hunt

TRW Energy Systems Group

\section{Participants/Consultants}

Mr. Milton David

Development Planning and Research Associates

Mr. Samuel F. Eakin

Energy Research Group

Mr. David Freedman

Center for the Biology of Natural Systems

Dr. Cathryn Goddard, et. al.

A.T. Kearney

Dr. M. Edward Goretsky

TRW Energy Systems Group

Dr. Jean-Francois Henry

TRW Energy Systems Group

Ms. Ann Heywood

TRW Energy Systems Group

Office of Alcohol Fuels

Mr. David Jenkins

Battelle Memorial Institute

Dr. Raphael Katzen

Raphael Katzen Associates
Task Manager

Mr. Warren Standley

TRW Energy Systems Group

Mr. Robert Mabee, Attorney

Quaintance and Swanson

Mr. Strud Nash

E. F. Hutton

Mr. Paul Notari

Solar Energy Research Institute

Mr. Richard Piekarski

Solar Energy Research Institute

Dr. Jean Simons

TRW Energy Systems Group

Dr. William Stark

PEDCo International

Mr. Ted D. Tarr

Department of Energy

Mr. Michael Thomas

Arthur Young \& Company

Mr. Arch Wood

TRW Energy Systems Group 


\section{Editorial and Production Suppont}

Our appreciation is extended to

- Production editors Ms. Christine Fuller and Ms. Ann Seely for their careful attention to detail and indepth editing of this book

- Graphic designers, Mr. John Barber, Mr. Vito W. Oporto, Mr. James McComas, and staft

- Word processing, Ms. Carolyn Starr and staff

- Typesetting by Anderson Advertising Art, Lakewood, CO

\section{Photographs .}

The agricultural photographs are reprinted through the courtesy of Grant Heilman Photography.

\section{Kcviewers}

We acknuwledge the following individuals for their helpful reviews of the draft of "A Guide to CommercialScale Ethanol Production and Finuncing". These individuals do not necessat ily ajprove, dicapprọve, nr endorșe the report for which SEIDB ássumes responsibility.

Mr. Jerry Allsup

Bartlesville Energy Technology Center

Mr. Jim Childress

National Alcohol Fuel Commission

Dr. Howard Coleman

Office of Alcohol Fuels,

Department of Energy

Mr. Milton David

Devclopment Planning and

Rcscarch Associates

Mr. T. D. Striggles

PEDCo International Inc.

Mr. Samuel F. Eakin

Energy Research Group

Mr. Don Fluk

U.S. Department of Agriculture

Mr. William H. Foster

U.S. Treasury

Bureau of.Alcohol, Tobacco, and Firearms
Mr. William Holmberg

Office of Alcohol Fuels,

Department of Energy

Mr. Maurice Jones

Hydrocarbon Research Inc.

Dr. Raphael Katzen

Raphael Katzen Associates

International, Inc.

Mr. Edward A. Kirchner

Davy McKee Corporation

Dr. Michael R. Ladisch

Purdue University

Mr. Robert J. Lipshutz

Haas, Holland, Lipshutz, Levison \& Gilbcrt

Mr. Kobert Maluec, Attorncy

Quaintance and Swanson

Mr. Rert Mason

Solar Energy Research Institute 
Mr. Joe Gibbs

Amoco Oil Company

Dr. Cathryn Goddard

A. T. Kearney, Inc.

Mr. C. Paul Green

Navarro Jr. College

Mr. Bert Greenglass

Office of Alcohol Fuels,

Department of Energy

Dr. Harry P. Gregor

Columbia University

Mr. Wiley Harrell

Anheuser Busch, Inc.

Mr. Donald Hertzmark

Solar Energy Research Institute

Mr. Howard Hinten

Midwest Solvents Co. Inc.
Mr. Dwight Miller

U.S. Department of Agriculture

Science and Education Administration

Mr. Strud Nash

E.F. Hutton \& Company

Mr. Ted D. Tarr

Office of Alcohol Fuels,

Department of Energy

Mr. Michael R. Thomas

Arthur Young \& Co.

Dr. Ruxton Villet

Solar Energy Research Institute

Dr. Harlan Watson

Subcommittee on Energy

Nuclear Proliferation and

Federal Services

Mr. Neil Woodley

Solar Energy Research Institute

This document greatly benefitted from the many previous efforts in alcohol fuels, including working groups at universities and colleges, private marketing efforts, private research and development projects, and individual efforts to collect and organize information pertinent to alcohol fuels.

The chapter on Plant Design Concepts is based on Raphael Katzen Associates' report entitled "Grain Motor Fuel Alcohol-Technical and Economic Assessment Study", prepared for the Department of Energy under Department of Energy Contract No. EJ-78-C-01-6639.

The glossary contains additional input from Michael Pete, Department of Energy, Office of Alcohol Fuels. 
THIS PAGE

\section{WAS INTENTIONALLY LEFT BLANK}




\section{CHAPTER I}

\section{Introduction}

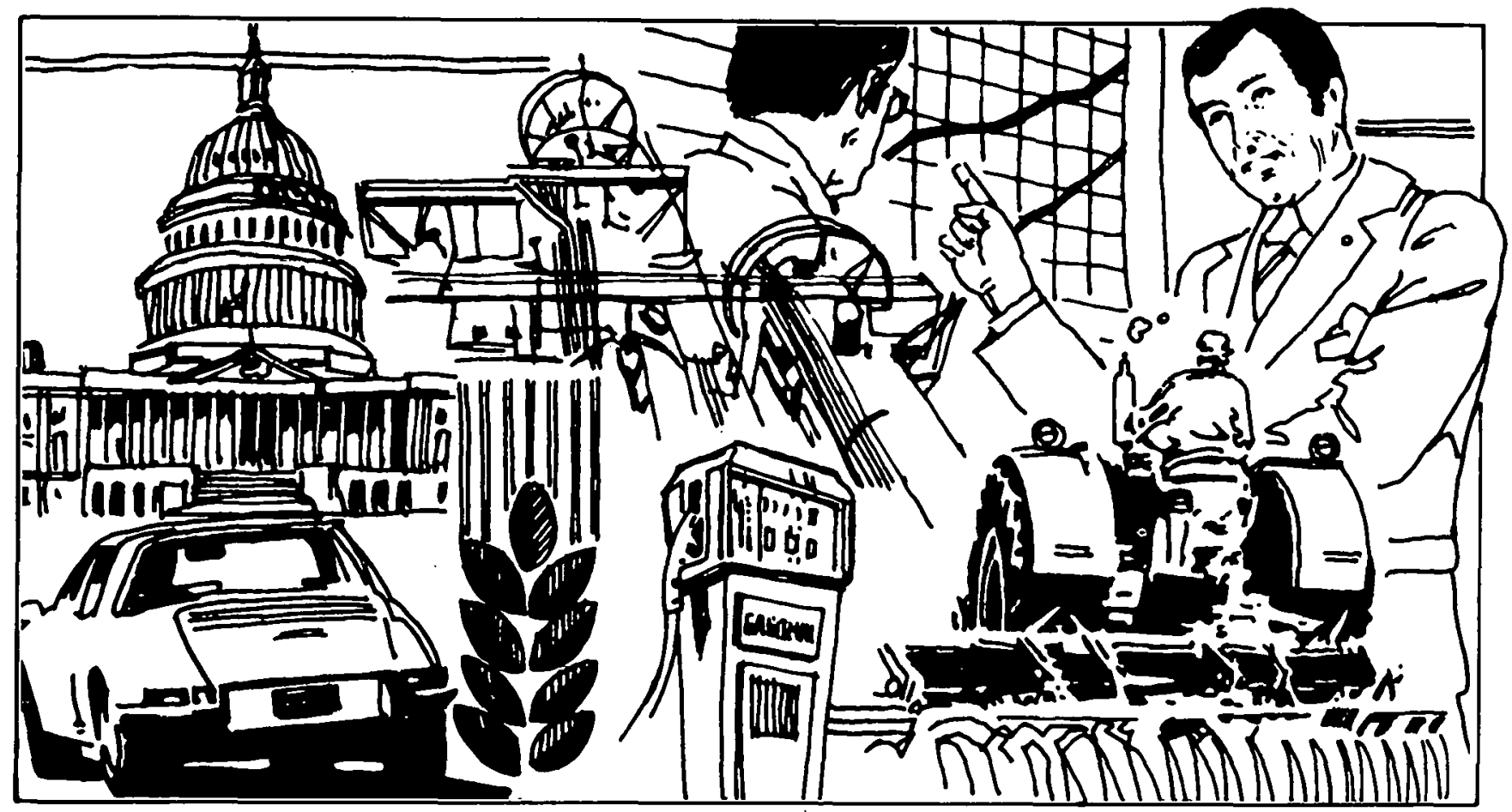

In recent years, fermentation ethanol produced from agricultural feedstocks, in particular grains such as corn; has been demonstrated to bc our most promising near-term option for producing synthetic fuels. For all practical purposes, gasohol, a blend of 10 percent anhydrous (water-free) fermentation ethanol and 90 percent unleaded gasoline delivers comparable engine performance as 100 percent unleaded gasoline, with the added benefit of superior anti-knock properties. The production of fermentation ethanol from agricultural crops or wastes is strongly supported by the farming community and the initial response of the general public to the introduction of gasohol as a altcrnative automotive fuel has been favorable. The Federal government has recognized the potential of fermentation ethanol as a fuel additive or substitute and in November 1978 reduced the excise tax on gasohol by four cents per gallon. Primarily as a result of this encouragement, fermentation ethanol capacity increased from a few million gallons to about 80 million gallons annually by the end of 1979. Of the 80 million gallons of ethannl produced, almost 50 million gallons were blended to obtain gasohol.
Goals for increased production of fermentation ethanol for blending with gasoline have been established by the President and legislation (including P.L. 96-126, Department of the Interior Appropriations for Fiscal Year 1980; P.L. 95-618, The Energy Tax Act; P.L. 96-294, The Energy Security Act of 1980; and P.L. 96-223, The Windfall Profits Tax Act of 1980) has been adopted which encourages the production of fermentation ethanol for fuel. Figure I-1 shows the projected contribution of alcohol fuels to the automotive gasoline market and indicates the magnitude of the President's objectives for ethanol fuel production. Meeting these goals will increase the potential fermentation ethanol fuel market about 10 times over the end of 1979 production in the very near term (1981 to 1982) and about 30 times by 1985 to 1986 .

The overall social and marketing climate suggests that fermentation ethanol production is a promising business venture, ranging from small-scale units often farmbased, producing up to a fcw thousand gallons to commercial-scale units producing more than 15 million gallons of ethanol fuel annually. Small-scale fermentation 


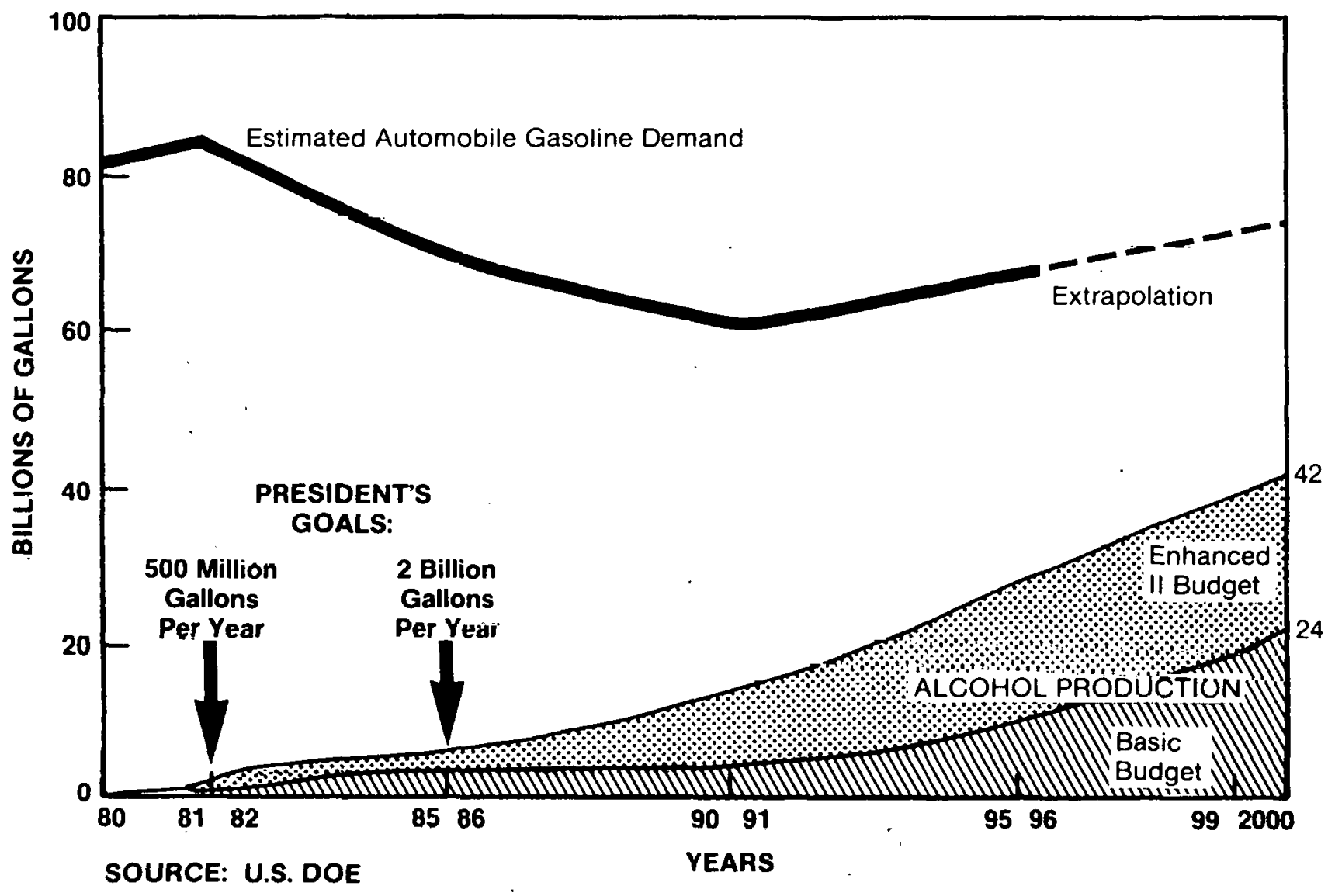

Figure I-1. U.S. DOE Goals for Alcohol Fuels Production from Biomass

ethanol production units and their implementation were discussed in the resently issued SERI report, "Fuel from Falı!s: A Guide to Small-Scale Ethanol Production", addressed to farmers or small investors. This docuntejt, "A Guide to Commercial-Scale Ethanol Production and Financing", is addressed to potential entrepreneurs, designers, contractors, aind finunciers of commercial-scale (more than 15 million gallons per year) fermentation ethanol fuel production facilities.

\section{OBJECTIVE}

The purpose of this document is to provide sufficieint information to allow prospective entrepreneurs to make sound judgments about investing in commercial-scale, fuel-gradc alcohol production and to develop an understanding of the varied aspects of entering the alcohol fuel production field. This document is organized to lead the reader from the initial stages of interest to the preparation of a feasibility study. The feasibility study will serve a dual purpose: to aid investors in devcloping id realistic business analysis for the venture and to provide the necessary supporting evidence in raising the capital to launch the venture.

\section{PERSPECTIVES}

United States' dependence on foreign oil is illustrated in Figure I-2. The United States can no longer afford such a degree of dependence on oil reserves outside its control to meet its energy nccds. Such dependence is hazdrduus lo the U.S. economy and security. Therefore, thc past several yeals have scen an increased emphasis on domestic alternatives, and pressure to develop synthetic fuels such as fermentation ethanol from biomass resources.

Statistics show a drop in crude oil imports over the past 4 years, perhaps implying that the United States public is tespouding to the President's calls to conserve energy.

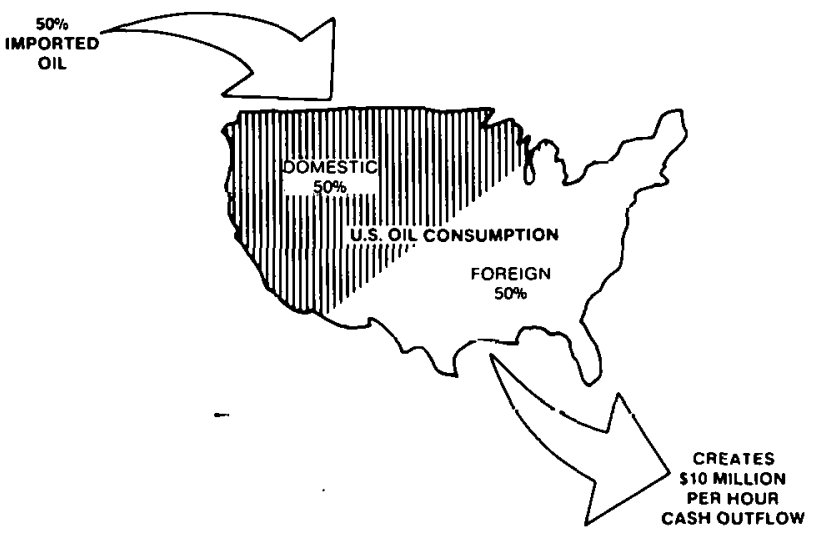

Figure 1-2. Impact of Foreign Oil Consumption 


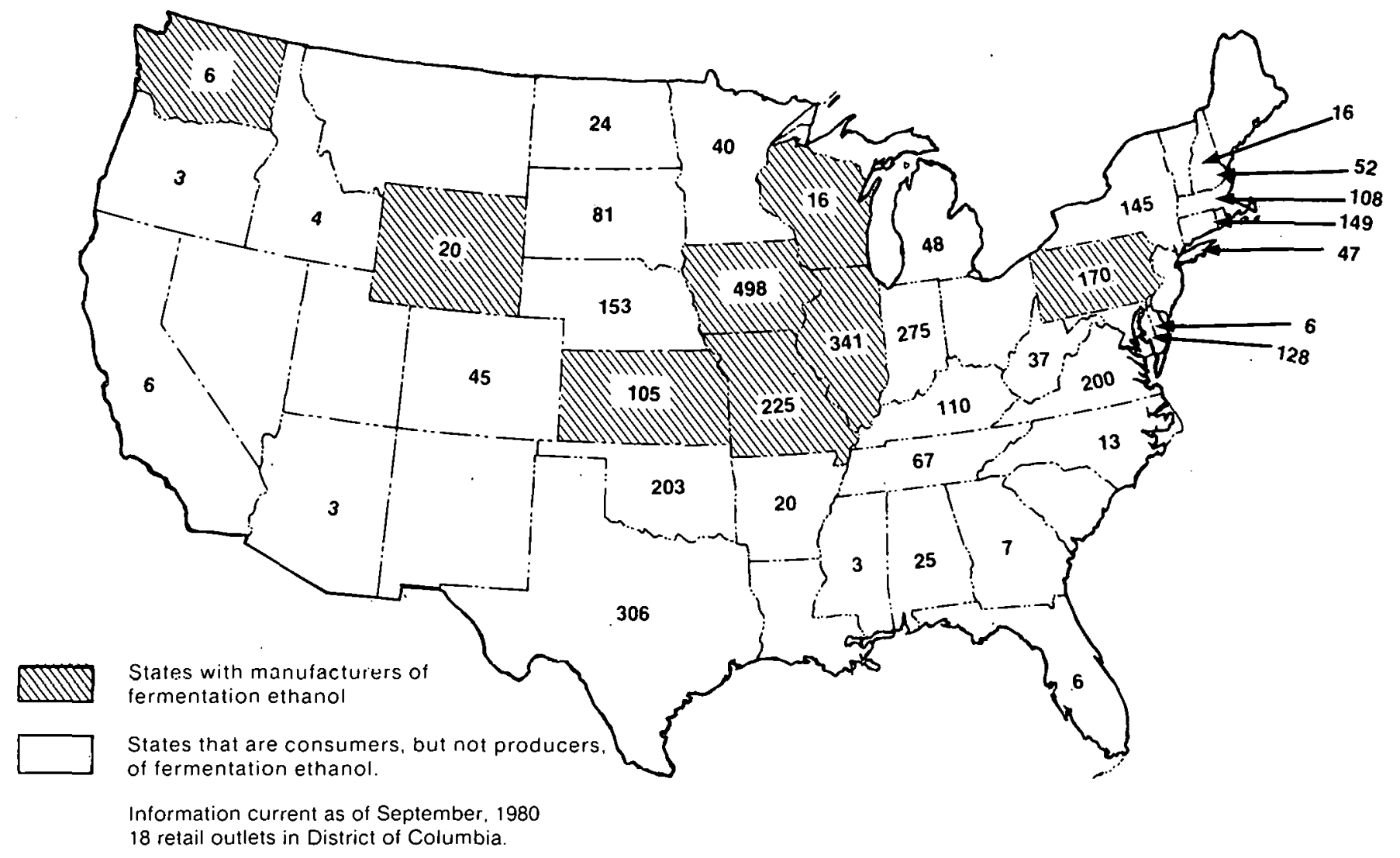

Figure I-3. Number of Retail Gasohol Outlets in each State

However, increased development of United States reserves (particularly in Alaska), increases in the price of gasoline, and public response to gasohol play a role in bringing about this decrease.

While little gasohol was marketed in the mid-1970's, by the end of 1979 about 50 million gallons of fermentation ethanol, blended with unleaded gasoline, were sold across the United States. This marketing effort resulted in the establishment of a network of gasohol retail outlets across the United States, as shown in Figure I-3.

In the current political and economic climates, fermentation ethanol fuels have become increasingly attractive. The Department of Energy (DOE) has supported increased production of fermentation ethanol in smallscale facilities. DOE is also expanding its role by encouraging fermentation ethanol production in commercial-scale facilities. Small-scale is currently defined as under 15 million gallons of fermentation ethanol per year; this category includes the farmer producing 10 tn 25 gallons per day strictly for his own use. Commercial-scale plants may range in size from 15 million to 100 million gallons annually.

In recent years, the increase in gasoline price and the desire for energy independence have made alcohol attractive as a transportation fuel, even though this is not a new idca. Henry Ford was an early supporter of using "home-grown" fuels and his Model-T could be adjusted to burn pure alcohol or gasoline. During World War II many countries relied on alcohol as a fuel source. Since 1975, Brazil has had a huge program in operation to cause a national change from the use of

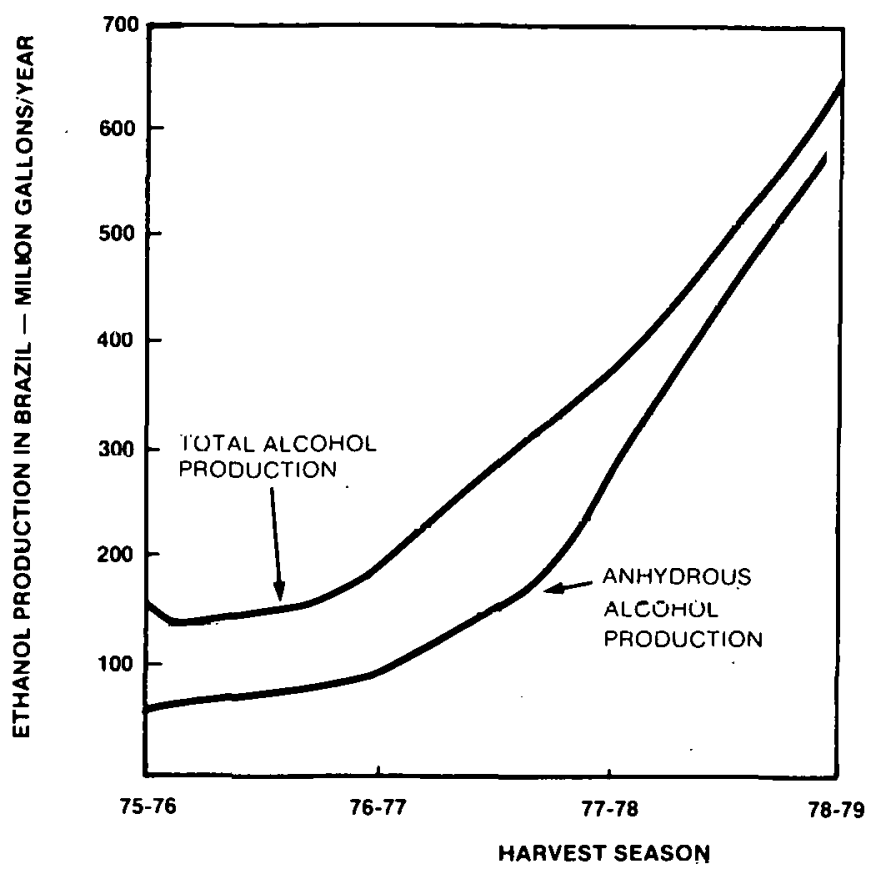

Figure 1.4. Ethanol Production in Brazil as Reported in the Brazilian National Alcohol Program 


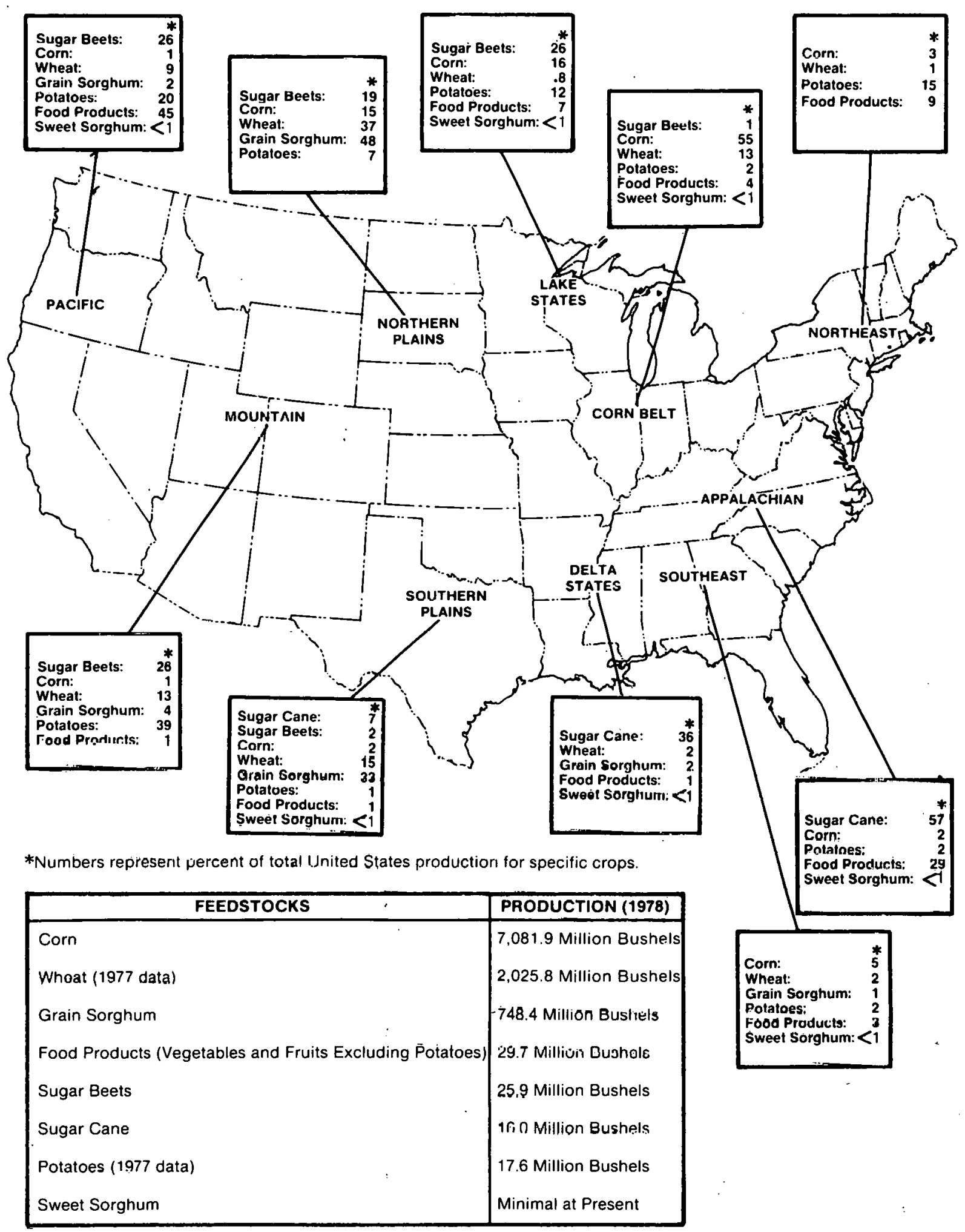

Figure 1-5. Potential Ethanol Feedstocks and their Availability by Regions 
petroleum to the use of alcohol fuels. Brazil is now using 20 percent alcohol blends on a regular basis and large fleets of government- or industry-owned cars run on 100 percent alcohol. Figure $1-4$ shows the trends in ethanol production in Brazil. It is apparent that since the announcement of the Brazilian National Alcohol. Program in November 1975, the total production of ethanol, as well as anhydrous ethanol for blending, has increased dramatically. This experience shows that a dedicated effort to reduce oil imports by developing national renewable resources can produce significant results in a short period of time.

If the need arises, the United States could institute the same kind of intensive ethanol program as Brazil instituted. A significant reduction in gasoline use could be achieved by changing to gasohol. The 10 percent alcohol/90 percent unleaded gasoline blend requires no engine modifications and has the a potential to reduce oil imports.

The raw materials for commercial-scale ethanol production are readily available in various forms. The major feedstocks are: corn, wheat, grain sorghum, barley, potatoes, sugar beets, sweet sorghum, sugar cane, and fodder beets. Since it is possible to use a wide variety of feedstocks for ethanol production, the plant location is closely linked to the lncally available typc of feedstock.
For example, a plant in Nebraska would use corn as feedstock, while one in Texas might use grain sorghum, and a plant in Idaho could consider potatoes or sugar beets. Figure I-5 shows the potential ethanol feedstocks and their availability by regions in the United States.

To meet the President's goal of 500 million gallons of ethanol for 1981, there is a need for increased production of fermentation ethanol. Figure I-6 shows the number of plants of various sizes required to attain annual production goals ranging from 200 to 2700 million gallons. It is apparent from the figures used to develop the chart, that a significant fraction of ethanol fuel is expected to be produced in commercial-sized plants (the medium--and large-sized plants mentioned in the chart).

\section{ISSUES}

The major issues relating to alcohol fuels and the position of the Office of Alcohol Fuels are outlined in Table I-1. There was a feeling of uncertainty about the Government's policies toward alcohol fuels before the President expressed himself firmly in favor of increased fermentation ethanol production and proposed a per-. manent exemption from the $4 \mathbb{4} /$ gallon Federal gasoline excise tax for gasohol. A number of States are providing additional incentives in the form of waivers or reduction

\begin{tabular}{|c|c|c|c|c|c|c|}
\hline \multirow[b]{2}{*}{ PLANT SIZE } & \multicolumn{2}{|c|}{ CV 1980} & \multicolumn{2}{|c|}{ CY 1982} & \multicolumn{2}{|c|}{ CY 1985} \\
\hline & $\begin{array}{l}\text { TOTAL NO. } \\
\text { PLANTS }\end{array}$ & $\begin{array}{l}\text { PRODUCTION } \\
\text { CAPACITY, } \\
\text { MILLION } \\
\text { GALSNYEAR }\end{array}$ & $\begin{array}{l}\text { TOTAL NO. } \\
\text { PLANTS }\end{array}$ & $\begin{array}{l}\text { PRODUCTION } \\
\text { CAPACITY. } \\
\text { MILLION } \\
\text { GALS/YEAR }\end{array}$ & $\begin{array}{l}\text { TOTAL NO. } \\
\text { PLANTS }\end{array}$ & $\begin{array}{l}\text { PRODUCTION } \\
\text { CAPACITY, } \\
\text { MILLION } \\
\text { GALSIYEAR }\end{array}$ \\
\hline $\begin{array}{l}10,000-15 \text { Million } \\
\text { Gallons/Year }\end{array}$ & 96 & 175 & 200 & 375 & 300 & 600 \\
\hline $\begin{array}{l}>15-50 \text { Million } \\
\text { Gallons/Year }\end{array}$ & 6 & 150 & 13 & 450 & 23 & $9 n$ \\
\hline $\begin{array}{l}\text { ¿ } 50 \text { Million } \\
\text { Gallons/Yeäl }\end{array}$ & 1 & 100 & 2 & 200 & 5 & 500 \\
\hline $\begin{array}{l}\text { Cumulative Total } \\
\text { Installed Capacity } \\
\text { (Projected in Million } \\
\text { Gallons Per Year) }\end{array}$ & & 425 & & 1.025 & & 2,000 \\
\hline $\begin{array}{l}\text { National Goals } \\
\text { Milliüı Gallons/Year }\end{array}$ & & $300 *$ & & $1,000^{* *}$ & & $2,000^{*}$ \\
\hline
\end{tabular}

- President's Gools Annouriced 11 January 1980.

**P.L. 96-294.

Figure 1-6. Number of Plants Required to Meet Goal for Alcohol Production 


\begin{tabular}{|c|c|}
\hline ISSUE & OFFICE OF ALCOHOL FUELS VIEW \\
\hline Food Versus Fuel & $\begin{array}{l}\text { States that there are no problems until ethanol production exceeds } 2 \text { billion gal/year. } \\
\text { Beyond that, increasing supplies of food and fuel are possible with scientific and } \\
\text { technical advances already occurring. America can do both. Later cellulosic waste } \\
\text { will replace part of grain and sugar-containing feedstocks. }\end{array}$ \\
\hline Net Energy Balance & $\begin{array}{l}\text { States that if non-petroleum fuels are used to the extent reasonable in farming } \\
\text { operations and in the conversion of carbohydrates intorethanol, each gallon of } \\
\text { alcohol produced that goes into making gasohol will save } 1.53 \text { gallons of oil. }\end{array}$ \\
\hline $\begin{array}{l}\text { Critical Need to } \\
\text { Reduce America's Use } \\
\text { of Foreign Fuels }\end{array}$ & $\begin{array}{l}\text { Highlights the importance of alcohol-formulated fuels to reduce dependence on } \\
\text { imported oil, revitalize rural America, reinforce the family farm, and strengthen the } \\
\text { nation's national defense posture. }\end{array}$ \\
\hline $\begin{array}{l}\text { Current and Projected } \\
\text { Technological } \\
\text { Advances }\end{array}$ & $\begin{array}{l}\text { Recognizes current developments and assumes scientific and technical advances } \\
\text { before } 1985 \text { and beyond as the nation moves out of the petroleum era into an } \\
\text { energy mix where renewable resources play an important role. }\end{array}$ \\
\hline $\begin{array}{l}\text { Potential for Production } \\
\text { Cost Rerluction }\end{array}$ & $\begin{array}{l}\text { Cites evidence indicating that the cost of corn in modern fuel-grade alcohol plants } \\
\text { will be well under } 50 \text { percent of the maniffacturing cost of ethanol. Also, other } \\
\text { non-graln fetulsiuch's, guoh os fonn nrnressing waste, sweet sorghum, todder betls, } \\
\text { hybrid sweet potatoes, Jerusalem artichokes, honey locust, and cassava will be used } \\
\text { to produce fuol and feer. Technological advances, through process research, will } \\
\text { reduce production costs; also save energy. }\end{array}$ \\
\hline Value and Uses of $\mathrm{CO}_{2}$ & $\begin{array}{l}\text { Indicates that } \mathrm{CO}_{2} \text { is a valuable coproduct of the fermentation process. Can be used } \\
\text { in oil recovery, for storage of food and feed, refrigeration, in irrigation water, and in } \\
\text { air and water injection systems to accelerate the growth of terrestial and aquatic } \\
\text { biomass. }\end{array}$ \\
\hline $\begin{array}{l}\text { Realistic Production } \\
\text { Targets }\end{array}$ & $\begin{array}{l}\text { Believes that ethanol production will meet the Administration's goal of } 500 \text { million } \\
\text { gallons during } 1981 \text { and } 2 \text { billion gallons during } 1985 \text {, as well as the congressional } \\
\text { gual of } 920 \text { million gallons in } 1982 \text {. This would save the nation } 3.5 \text { billion gallons, } \\
\text { or } 230,000 \text { barrels of oil a day. }\end{array}$ \\
\hline
\end{tabular}

SOURCE: U.S. UOE, Orlice of Aloohol Fupls

in State taxes. A list ol the stalc's and the incentiver, they provide is shown in Appendix D. The Energy Security Act of 1980 (P.L. 96-294) provides significant financial support for the National Alcohol Fuels Program. The Act establishes national goals for alcohol productlun, creates the Office of Alcohol Fuels within DOE at the Assistant Secretary level, and provides significant financial support in the form of loan guarantees and luans.

The future of ethanol questions arise as to the short-and long-term future of ethanol fuels. In the sliort term, there is an established need to supplement our imported petroleum supplies. The DOE Alcohol Fuels Program addresses the need to increase production of alcohol fucls, and the gnal to reduce the price of ethanol in the long term. These goals are to be attained by a substantial Federal program utilizing loan guarantees, and cooperative agreements to increase production capability to meet the President's goals. The funding of realistic near-term research and development will provide innovative feedstock and new production techniques to help reduce the long-term price of ethanol. A breakdown of ethanol production custs is shown in Figure I-7.

The emphasis for the near term is on the increased production of fermentation ethanol, followed by production of ethanol from lignocellulose and, after the 1990 's, a significant increase in methanol from biomass, as shown in Figure I-8.

\section{ORGANIZATION OF THE BOOK}

Alcohol fuels prnduction can be an attractive, moneymaking venture provided it is approached in a businesslike fashion and full advantage is taken of the various incentives presently available.

The economics and, therefore, the profitability of alcohol fuels production are sensitive to a number of factors ranging from site-specific conditions to national and international policies. Raising the necessary starting capital through conventional financing channels may be difficult because of the unknown risks associated with alcohol production. 


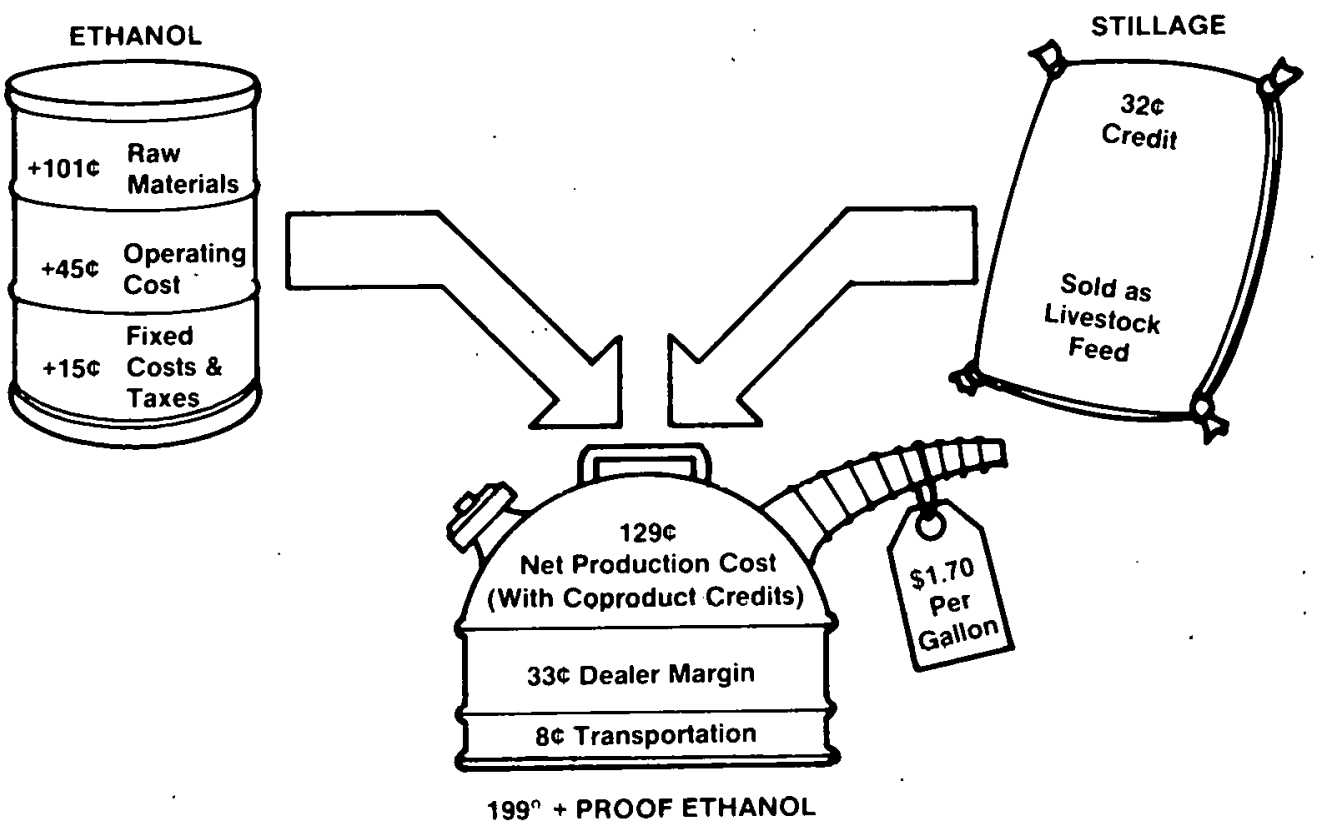

SOURCE: U.S. DOE 1st Annual Report to Congress (Revised)

Figure 1.7. Breakout of Production Costs for Ethanol

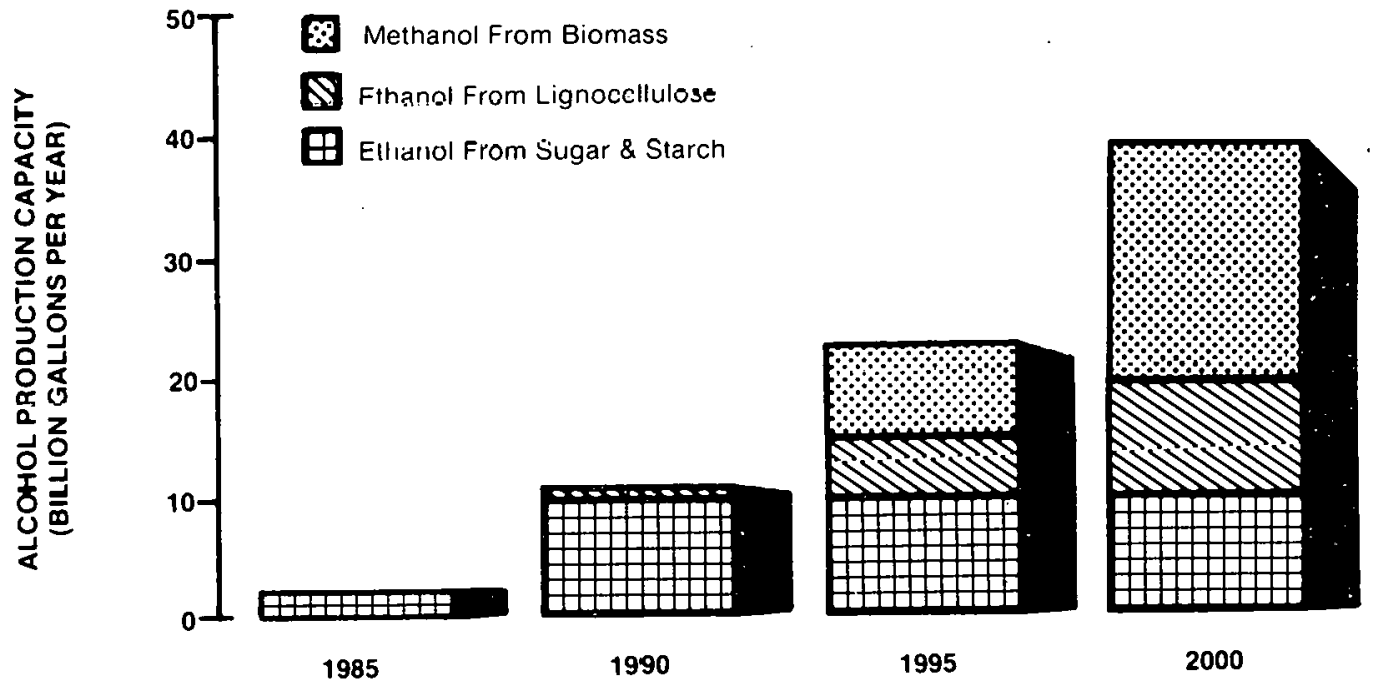

Figure 1-8. Long-Term Contribution of Ethanol, Lignocellulose, and Methanol from Biomass 
This document is designed to lead the potential investor through all the steps necessary to develop a business plan and prepare a feasibility analysis for a site-specific project. Therefore, emphasis is placed on marketing, financing, management, and incentives rather than primarily technical matters. In this context, it is hoped that the book will provide the investor with the required background for involvement in the fermentation ethanol fuel business.

The introduction provides an overview of the perspectives and issues in the alcohol fuels industry. Chapter II, seeks to surface factors which affect the decisionmaking process and which the investor must face before entering the alcohol fuels industry. The chapter attempts to lead the investor step-by-step through the series of decisions and choices to be made before reaching the final desision to enter the business. This final decision to obtain financing for the plant is made after a deralled feasibility study has been performed.

Chapters III to IX discuss in detail some of the important elements to be addressed during the decisionmaking process. Chapter III describes the types of feedstocks available and relates them to areas within the United States. Trends and fluctuations in the price of the major grain feedstocks (which are used predominantly as animal feeds) are also discussed in terms of their potential use and valuc compared to other feeds. Chapter IV discusses the market potential of ethanol and its coproducts, and examines how the locations of the ethanol markets in relation to those of the feedstock supplies may influence selection of a plant site.

Various aspects of plant design are discussed in Chapter V. A 50 million gallon per year plant is analyzed to provide the general technical background and costing data required in analyzing plants of various sizes and designs. Safety aspects and environmental concerns are treated in Chapters VI and VII. The regulations are reviewed and their impact on plant design and operation is discussed. The basic elements of a business plan are described in Chapter VIII, which leads to an approach for development of the feasibility study in Chapter IX. Other information on financial assistance, regulations, current legislation, and reference material is given in the Appendices.

It should be siressed that the initial step of performing a realjstic estimatc of the feasibility of the project is essen tial if the project is to become a successtuil business reality. Irrespective of the possihle outcome of the analysis, sufficient funds must be allocated at the outset to perform a realistic and meaningful feasibility analysis.

In view of the focus for this document, emphasis is placed on describing and analyzing the steps involved in implementing a commercial-scale project. 


\section{CHAPTER II}

\section{Decision to Produce}

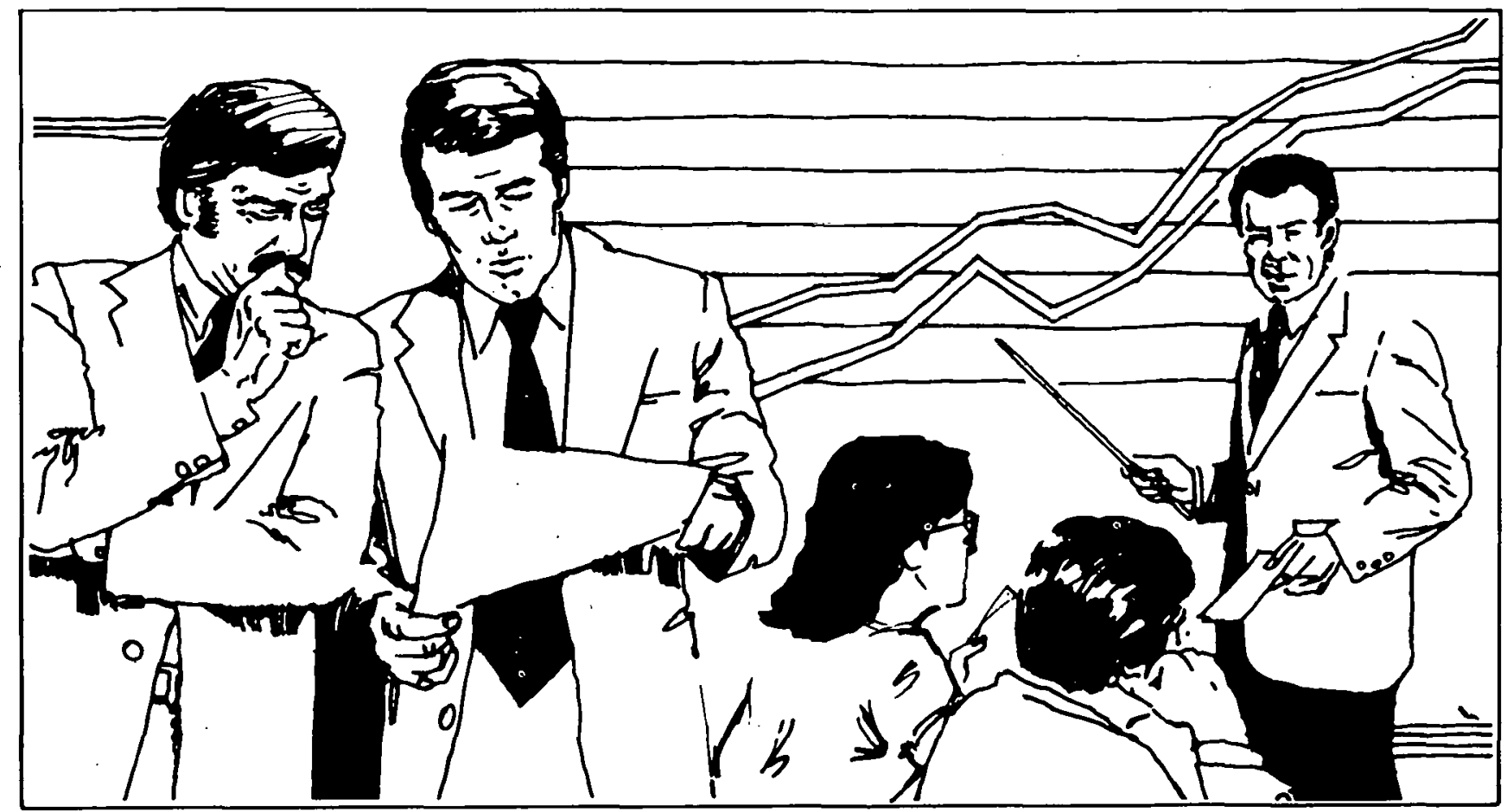

\section{A NEW VENTURE}

Fermentation ethanol fucl production utilizing biomass feedstocks appears to be an attractive business venture for a wide range of potential investors. The production of ethanol fuel from agricultural crops or wastes is strongly supported by the farming community and the public's initial response to the introduction of gasohol as a substitute automotive fuel has been favorable.

Ethanol production raises numerous issues which may complicate the task of the investor when deciding whether to enter the ethanol market. The production of ethanol through fermentation of agricultural feedstocks requires interaction with a variety of producer and consumer groups and local, State, and Federal agencies. The feedstock for production originates from the agricultural community and some of the coproducts of ethanol production may impact on the same farming community. The production and marketing of ethanol fuel are subjected to the same basic regulations as the production of alcoholic beverages; simultaneously, the marketing and distribution of ethanol fuel may require the cooperation of gasoline producers and distributors. The economics of ethanol fuel production benefit from State or Federal incentives, and will also be influenced by uncontrollable factors such as climate or world events which impact on the price of agricultural feedstocks.

The initial idea of entering the ethanol fuel business may stem from a variety of motivations: desire to make a profit; desire to diversify investments; make use of idle or surplus facilities or resources; fill the needs of a perceived market; and others. Whatever the motivation, the decision to produce ethanol must be based on a careful and thorough analysis of all aspects of the proposed business. In view of the factors impacting on the project, it will be necessary for the prospective investor to seek and secure the help of individuals or teams familiar with the various aspects of ethanol fuel production. This groundwork will include the collection of data, analysis of feedstock and production options, and evaluation of financial opportunities which are summarized in the form of the comprehensive feasibility analysis. The conclusion drawn in the feasibility 
analysis should form the basis upon which the decision to produce will be made. The feasibility study is also needed to interest other investors or sources of financing to take part in the project. It must therefore be recognized that a certain amount of front-end money will be required to reach a substantiated decision to enter the fermentation ethanol business.

The objective of the present chapter is to describe the major steps required in deciding to produce ethanol, discuss the data to be gathered and questions to be answered at each of these steps, and indicate the kind of effort needed to complete the feasibility analysis on which the final decision will be based.
OVERVIEW OF ETHANOL FUEL PRODUCTION

\section{The Operating Plant and Its Environment}

Fermentation ethanol fuel production involves multiple interactions among a variety of "players." Each of these aspects must be addressed during the decisionmaking process in order to avoid overlooking a problem which could be detrimental to the economic viability of the project.

Figure II-1 presents an overview of an ethanol business, and identifies some of the major elements and entities involved. Four major areas of concern are identified.

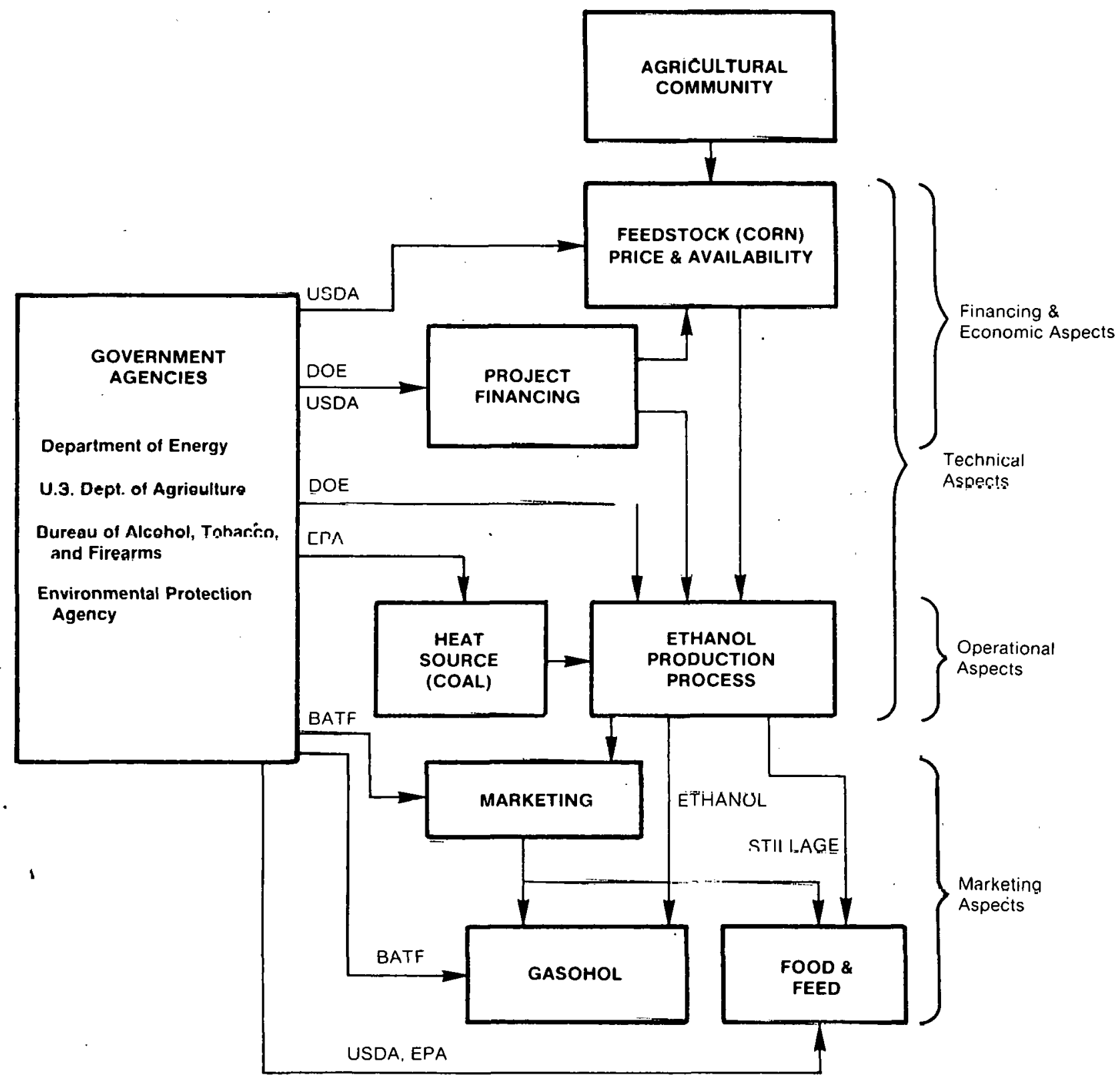

Figure II-1. Basic Organization Interfaces for Production of Gaschol 
Technical Aspects. Ethanol production through fermentation of grain is a well-established technology practiced by the alcoholic beverage industries in the United States. The production of fermentation ethanol fuel is an extension of this technology. The economics involved, however, are quite different. Alcoholic beverage industries are geared toward satisfying a luxury market; therefore, their profitability is not as critically dependent on process efficiency or price of supplies as is that of ethanol fuel plants which must compete with a still relatively cheap product-gasoline. When evaluating the feasibility. of a fermentation ethanol fuel plant, it will be essential to carefully assess the method of procurement of the feedstock (such as corn) over a long period, the availability of resources such as fuel for the process heat source and water, the sale of the stillage, the efficiency of the ethanol production process, and other technical aspects which can impact on the overall economics of the plant.

As indicated in Figure Il-1, various Government agencies influence the process of fermentation ethanol production. The U.S. Department of Agriculture (USDA) may impact on feedstock availability and prices, the Bureau of Alcohol, Tobacco, and Firearms (BATF) requires permits for production, the Environmental Protection Agency (EPA) impacts on stillage disposal, the Department of Energy (DOE) may encourage the use of renewable process fuels, etc.

Marketing Aspects. Successful marketing of both fermentation ethanol fuel as gasohol and the stillage coproducts of ethanol is essential to ensure cconomic viability of the project. A careful identification and evaluation of the long-term market will be required to assess the economic potential of the production plant. Contractual agreements for the sale of ethanol and stillage, prior to piant operation, will develop a sound basis for the venture.

Various government agencies may have an impact on the marketing process. Exemption from the excise tax on fuel blends containing ethanol is controlled by the Federal and/or State governments, government policies concerning the export of food and feed products, and income tax credits for fuel blenders may modify the marketing plans adopted for the products of the plant.

Fintancing and Economic Aspects. Obtaining financing from private sources for the proposed project will, to a large extent, depend on the quality and thoroughness of the feasibility analysis.

In the course of performing the feasibility analysis, Federal loan guarantee or loan programs should be reviewed to determine the eligibility of the fermentation ethanol project being considered. The purpose of the loan guarantee programs is to provide funds to sectors of the economy that otherwise could not obtain credit or could only obtain it under unfavorable conditions through existing commercial financial organizations. Federal agencies having the authority to provide funds to prospective fermentation ethanol fuel producers include DOE, the Small Business Administration (SBA), the Farmers Home Administration (FmHA) of USDA, the Department of Housing and Urban Development (HUD)'s Urban Development Action Grants, and the Economic Development Administration (EDA) of the Department of Commerce. Securing loan guarantees or loans for the project must be considered a priority item for the investor. Indeed, the terms of these loans are usually attractive and can improve the economics of the project, and loan guarantees will facilitate the task of raising funds from private sources. Securing loans or loan guarantees, however, requires the preparation of documented applications which may delay the decisionmaking.

Operational Aspects. The investor must address a number of aspects related to the operation of a fermentation ethanol plant. The availability of trained or trainable labor must be considered. Can the regional labor force provide the technical personnel for the plant? Will the creation of a new industry upset the local or regional organizations and therefore risk antagonizing the community?

The above factors, as well as the possible impact of agencies such as the Occupational Safety \& Health Administration (OSHA) must be carefully evaluated.

\section{Approach to Implementing an Ethanol Plant}

The preceding discussion has shown that many factors may affect the profitable operation of an ethanol plant. Before finalizing the decision to start an ethanol plant, the four key aspects of ethanol production will have to be discussed and evaluated to choose the options or compromises which will optimize financial return to the investors.

Figure II-2 illustrates the major elements in both of the phases involved in bringing a plant to production. The scope and purpose of these elements are described below.

Decisionmaking Phase. The overall purpose is to reach a final decision whether to become involved in a fermentation ethanol project. This phase involves three major steps.

- Prefeasibility Study. Having identified an interest in the production of ethanol, an investor and his partners must be convinced that the project is viable, at least in general terms. Some help from consultants or local/regional sources such 

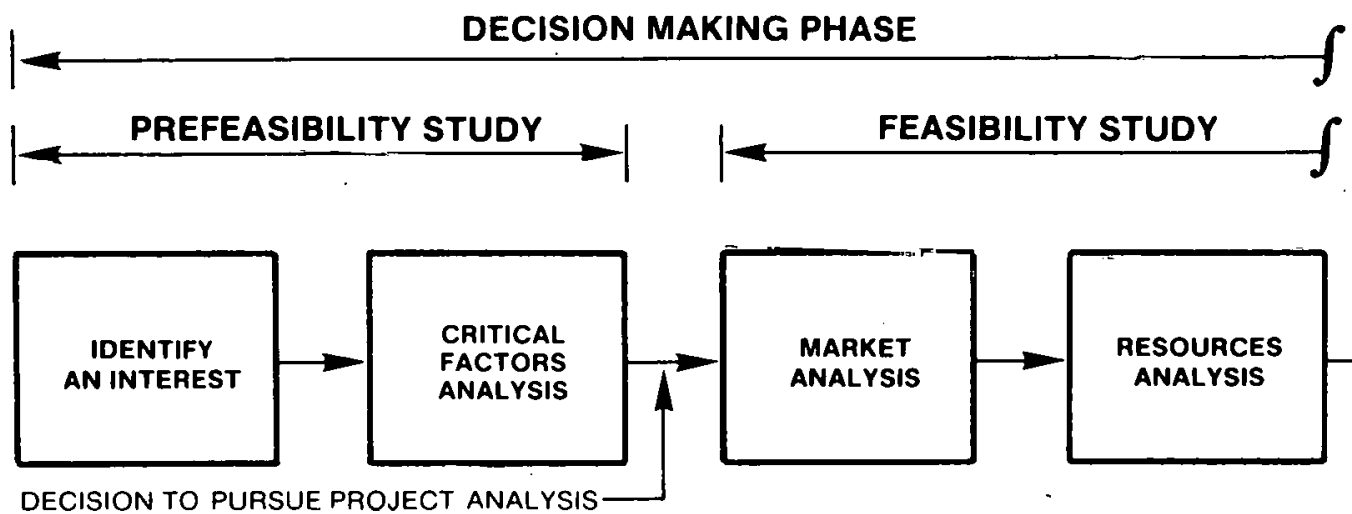

DECISION TO PURSUE PROJECT ANALYSIS
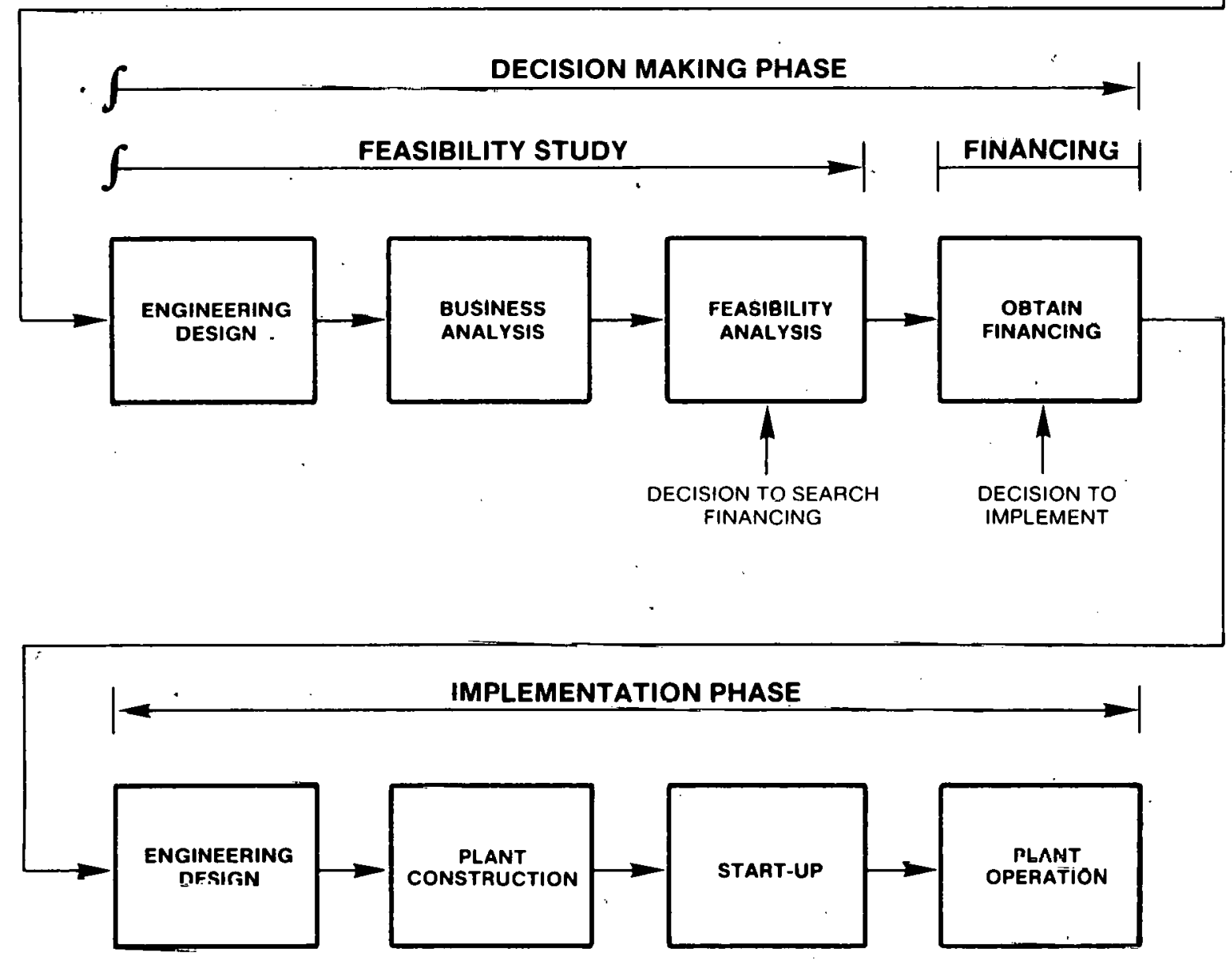

Figure II-2. Steps Involved in Bringing a Plant to Production 
as extension agents, agricultural school staff, or others may be needed in discussing some specific aspects of the project. The product of this step is a prefeasibility study which should establish the rationale for pursuing the project. Some of the key areas to be addressed include: existence of a market for both ethanol and its stillage coproduct, distribution mechanism for the products, selection and availability of a feedstock, approximate size of the proposed plant, availability of non-petroleum fuels for process steam and process water, general design of the fermentation plant, approximate cost of the plant, business plan, potential methods of financing, and economic viability of the project. At the end of this first step, the potential investor in the project should be able to make the decision whether to pursue the project.

- Feaslbility Study. The objective of this step is to perform detailed technical and financial analyses of the viability of the project. The feasibility study will address the four major areas of marketing, technical feasibility, financing and economics, and operation; and will develop a realistic plan. The feasibility study will serve three purposes: 1) confirm and refine the estimates of the prefeasibility study: 2) develop a business plan and business planning schedule; and 3) serve as supporting evidence when negotiating the financing of the project.

Performing a detailed feasibility study will require contributions from many areas: engineering firms, market specialists, suppliers, environmentalists, law firms, accountants, etc. An adequate budget must be earmarked for the purpose of generating a credible, welldocumented study.

At the end of this step, the potential investor will be in a position to decide whether the projert has sufficient commercial potential for the financial community to be interested.

- Financing. The last and most important step is to secure the necessary financing for the project. In these negotiations, the investor will need the support of law firms, accountants, and other specialists familiar with the alcohol fuels industry.

When financing has been secured, the final decision to implement the project can be made.

Implementation Phase. This phase involves the same steps followed for any commercial/industrial project: engineering design; construction; start-up; and operation.
The role of the investor(s) is somewhat reduced in this phase, because at this point a management team should become responsible for the project implementation on behalf of the investors. The primary role of the investor is to assist the team in reaching the final decision of implementing the project. To do so, he must be aware of the questions to be asked, issues to be raised, problems to be solved, and players involved in the overall implementation of such a project. Some of these questions, problems, or issues related to the process of deciding to produce ethanol are more complex than for more conventional ventures. This results from the particular significance of fermentation ethanol in the present energy and international context and because of its intimate relationship with various markets and economic sectors.

\section{THE DECISIONMAKING PROCESS}

The decisionmaking process involves addressing and answering specific questions to reach a decision concerning implementation of the project.

The questions to be addressed are similar to those relating to any business venture. Should one get involved? Is it really worth it? What is the market? Is the project technically fcasible? Is the project economically viable? Is financing available? The approach to answering these questions resembles that used for other similar businesses: market and engineering studies; business analysis; etc. The purpose of this section is to identify some specific questions and options raised by fermentation ethanol production and to indicate sources of data that could help the investors reach a decision.

\section{The Decisionmaking Flow Diagram}

Figure II-3 presents a flow diagram of the decisionmaking process. The figure is an expansion of the first phase of the implementation diagram shown earlier (Figure II-2).

The top row of the matrix identifies questions to be addressed or decisions to be reached. Each column of the matrix suggests an approach to answering the corresponding questions, the type of answer or output desired, the sources of information and possible options, and an estimate of the front-end cost required to obtain an answer or reach a decision. These costs are approximate and may include such items as consultant fees, data gathcring, trips, etc.

\section{Elements of the Decisionmaking Process}

The various steps in the decisionmaking process are discusssed below.

Initial Expression of Interest by the Investor: should he get involved at all in the ethanol fuel business? 


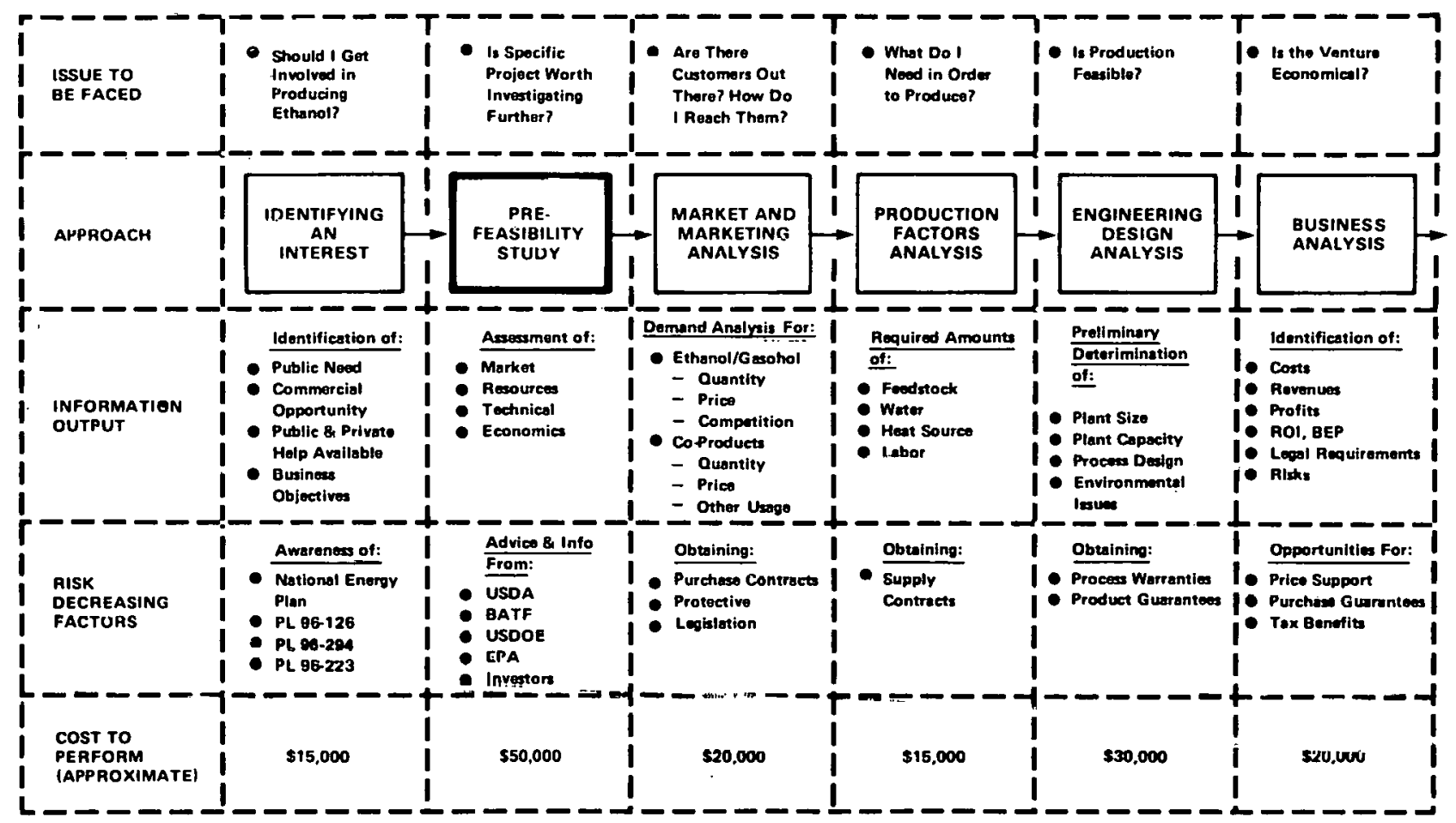

Figure II-3. Decisionmaking Process for Entering the Ethanol Business

The investor will need to identify the existence of interest in ethanol production at the local, regional, or national level. He will need to evaluate the availability of Federal incentives to support his project. His expression of interest could result from his contacts with grain producers, agrihusinesses, or farmers seeking new markets for their products, alternative methods of disposal of stillage or waste products, or distributórs trying to securc a long-term reliable source of substitute fuel. The invcstor will need to evaluate the true level of interest and the commercial opportunity it gencrates and then must. define his objectives. These could range from producing ethanol fuel as a separate business entity, to combining it with current business interests. The alcohol fuel could be marketed through cooperatives for special markets or regional distribution.

In clarifying his objective, the investor will not only have to rely on inquiries but also become familiar with State and Federal programs to determine if his perceived interest matches natiunal and regional policies. Data on the National Alcohol Fuels Program may be found in Appendix $C$ of this document. The cost of this first step is approximately $\$ 15,000$, which will include travel costs, quick inquiries and surveys, and general data and information gathering.

Attractiveness of the Proposed Project: is the identified project worth investigating further?

Having established that significant interest exists for an ethanol fuel project, the investor must determine if the basic elements for a successful business are present. A prefeasibility study will provide this answer.

The major aspects to be considered in a prefeasibility study include:

- Existence of an identified market for the ethanol fuel

- Availability of a market for the stillage and coproducts

- Availability of sufficient feedstocks such as corn and alternate feedstocks io ieducc the project risks

- Availability of a non-petroleum heat source such as coal

- Feasibility of the technical process and plant e.conomics

The initial contact with potential investors or financing institutions should be made during this prefeasibility study to determine if the proposed project has a rcalistic chance of being financed. The product of this study should be a document or a data base sufficient for the investor to determine whether the project appears attractive enough to justify the expenditure of further front-end money. At this time, the investor should also have some knowledge of how liis project will be received by the financing community and whether some other investors or the government may be willing to supply some of the seed money for the forthcoming feasibility study. Formation of a corporation may be justified at this time. 


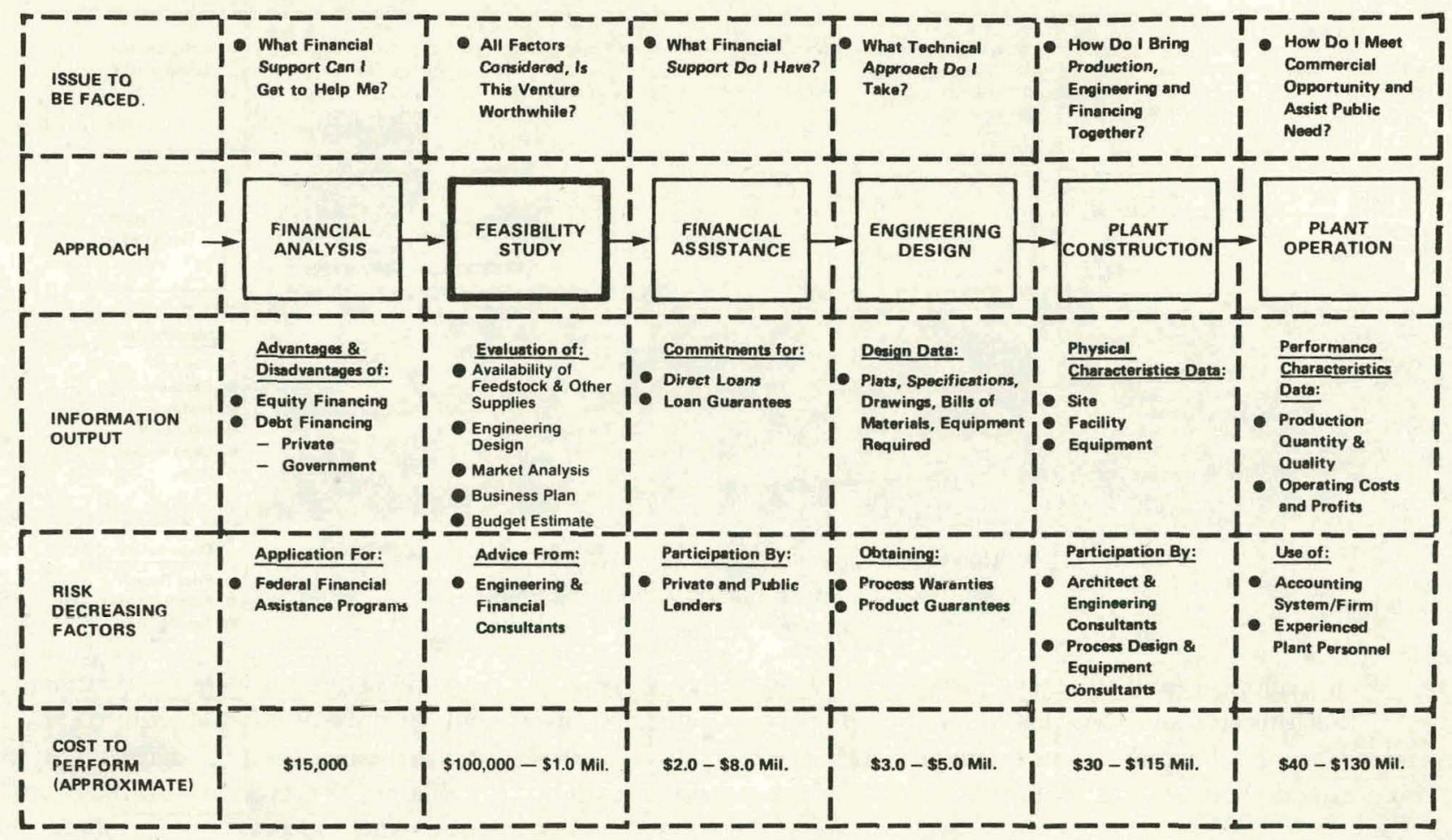

Figure II-3. Decisionmaking Process for Entering the Ethanol Business (Continued)

Sources of information to contact in performing this prefeasibility study may include the DOE, USDA, SBA, and EDA through their regional offices or extension services. State agencies, engineering firms, BATF, and local agricultural economists could be contacted to broaden the information base. Some specialized help will be required, the cost of which could reach about $\$ 50,000$. The timeframe needed for this study may be as short as one or two months but in most cases will probably extend over a four- to six-month period. The following chapters of this book provide the basic data needed to pursue the project, as well as references to information sources.

Having determined that the project is worth pursuing, the investor must analyze in further detail the various aspects of the proposed business. These detailed analyses will result in a feasibility study which will be the basis for the financing and implementation of the project.

Identification of Markets: are there markets for the ethanol and coproducts of the plant and how can the markets be reached?

A market analysis is required to determine such elements as the size of the proposed plant, its location, and the marketing structure required. The size of the potential market, market penetration, market price, location of the market, competition, and other relevant factors will be estimated for both ethanol fuel and its coprod ucts. When feasible, letters of intent, letters of interest, or tentative contractual agreements will be obtained from prospective customers. This market analysis will require expert help from firms specialized in marketing and distribution of both fuel and feed. Background data on these market aspects can be found in Chapters III and IV of this book. The cost of the market analysis has been estimated at about $\$ 20,000$.

Production Factors: what are the resources needed to produce?

Having sized the market, the investor can then size the capacity of his proposed plant. It will be necessary to estimate the resources required for plant uperation. These resources include feedstocks, a non-petroleum process heat source, water, land, and labor. A market for stillage-derived coproducts or a facility for stillage disposal is also required. Materials balances should be performed to estimate the needed gross quantities of production resources.

Where possible, tentative supply contracts will be drawn for feedstock and stillage, zoning or preliminary zuning permits will be searched, and local environmental issues will be reviewed. The result of this analysis will be the identification of a tentative site or sites and a certain degree of confidence that all required production elements are available.

Data cuncerning some of these aspects can be found in Chapters III, IV, V, and VII, and Appendix C of this 


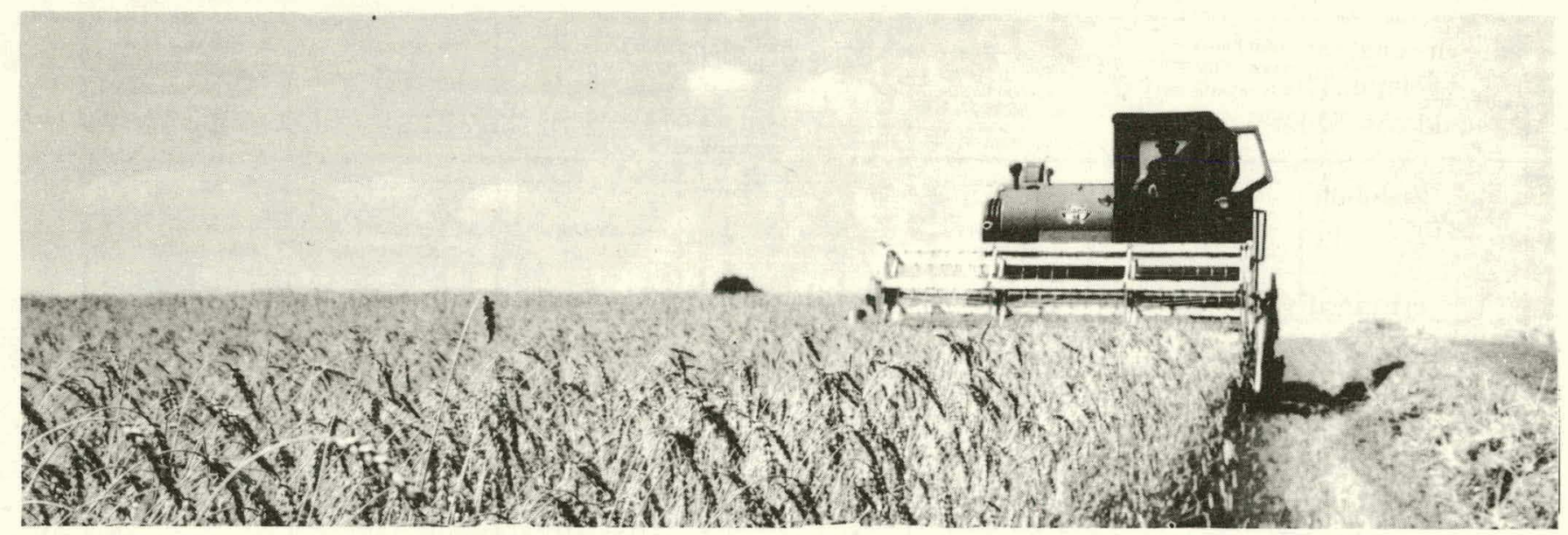

The Written Commitment of a Supplier to Provide Feedstock

Will Help Establish the Viability of the Plant

book. With technical and financial assistance, it is estimated that this step may rnst about $\$ 15,000$. It permits are to be obtained, the time frame to finish this task may extend from several months to a year in the worst case.

Technical Feasibility: is production feasible?

Although conventional ethanol production from sugarstarch feedstock is well-established technology, sitespecific conditions or constraints such as quality of feedstock, source of process heat, water quality, etc., require modifications to the conventional plant design. A preliminary process and engineering design analysis, which will include comparison of available options, must be performed by a reputable, well-recognized engineering firm. This analysis will include an optimized process design, materials requirements and energy flow diagrams, plant capacity, expected on-stream factor, and other aspects required in a complete engineering package. Process warranties and product guarantees should also be stated. Availability of electric power and water should also be discussed.

Background data relative to the plant design aspects can be found in Chapter V, but it is stressed that this analysis must be performed by a well-established firm to lend credibility to the study and facilitate financing. Such a study could cost ahout $\$ 50,000$ and may extend over several months, depending on the number of options to be analyzed.

Economic Viability: is the project economically viable?

This is probably the most crucial element of the feasibility study in terms of securing adequate financing. A complete business plan must be proposed, including period of erection of the plant, planned date of operation, legal status (corporation, cooperative, etc.), capital and working capital requirements, and operating costs. This data then will be used to determine estimated return on investment ( $\mathrm{nr}$ price of ethanol required to obtain a proposed return) using discounted cash flow or other method suitable to the type of busincss envisioned. The financial method used to cstimate the economics of the plant must be flexible enough that sensitivity analyses can be performed to evaluate the potential impact of factors such as fluctuations in feedstock and stillage prices, tax credits, and inflation rate on the economics and return on investment from the plant. It is important that the perceived risks be quantified as much as possible to ensure the development of a viable business plan.

Performing this business analysis will require a data base on feedstocks, chemical and tuel supplies, and market prices of products, as well as appropriate financial data such as inflation rates for fuels, products and labor, prevalent ratc of interest, and others. Major accounting and engineering firms have developed computer software for the business analysis discussed here. Legal and financial advice also will be needed in performance of this task. The business analysis could cost $\$ 20,000$ and extend over several weeks once the necessary data has been collected.

\section{Sources of Financing: what is available?}

P'ossible suuces of financing should be reviewed, including private, governmental, or mixed funding of the project. Loans or loan guarantees should be considered. The impact of each of these options must be reviewed in terms of the overall economic viability of the project. Appendix A provides an in-depth discussion of Federal financial incentives for the investor.

The product of this analysis will be the identification of a preferred method of financing and some alternative methods, if warranted. 
Such an analysis will require legal, financial, and analytical inputs from specialized firms or consultants and could cost $\$ 20,000$ or more.

Overall Feasibility of the Project: is the venture technically feasible and economically viable?

Having performed the detailed market, resources, technical, and economic analyses, an overall evaluation of the project must now be performed. This feasibility study will help in deciding whether or not to seek financing, and in describing the total project and its prospects to future investors.

The feasibility study must address all aspects of the proposed business, attempt to answcr all foreseeable questions, and establish the credibility of the originator(s) of the project and its supporting team (legal, technical, etc.). Letters of commitment or intent from suppliers, markets, permit and zoning agencies, and others should be an important part of this package. The proposed management team and its credentials should be described.

Performing such a feasibility study will require contributions from various teams and individuals and could be quite expensive. An outlinc for a typical feasibility study is described in Chapter IX.

Financing: Prior to completion of the feasibility study, a team must be assembled to prepare a detailed economic and financial analysis of the project and to negotiate and arrange the financing. The qualifications of this financing team are contingent upon the Company's internal management team and the complexity of the financing to be arranged, which generally includes specialists in the following areas: economic and financial analysis; negotiation and placement of debt; placement of stock, partnership interest, or bonds; and grants.

\section{TIMEFRAME FOR THE DECISIONMAKING PROCESS}

Developing a credible feasibility study and negotiating the required financing, i.e., reaching the decision to implement the plant, may be a time-consuming process.

The prefeasibility study must be performed before engaging in the feasibility study.

While performing the feasibility study, several tasks may be conducted in parallel: market evaluation, feedstock supplies, application for permits, negotiation of tentative sales and purchase contracts, etc. This approach could accelerate the process but runs the risk of expending more funds than otherwise necessary if at any point one of the elements of the feasibility package is missing or one of the analyses suggests abandoning the project. For instance, refusal of the necessary permits at a late date or rejection of the project as environmentally unsound could result in the loss of significant amounts of money if all tasks required under the feasibility study are conducted in parallel. The investor will need to decide whether reaching the market at an earlier date is worth risking a large fraction of the front-end investment. 


\section{THIS PAGE \\ WAS INTENTIONALLY LEFT BLANK}




\section{CHAPTER III}

\section{Feedstock Choices}

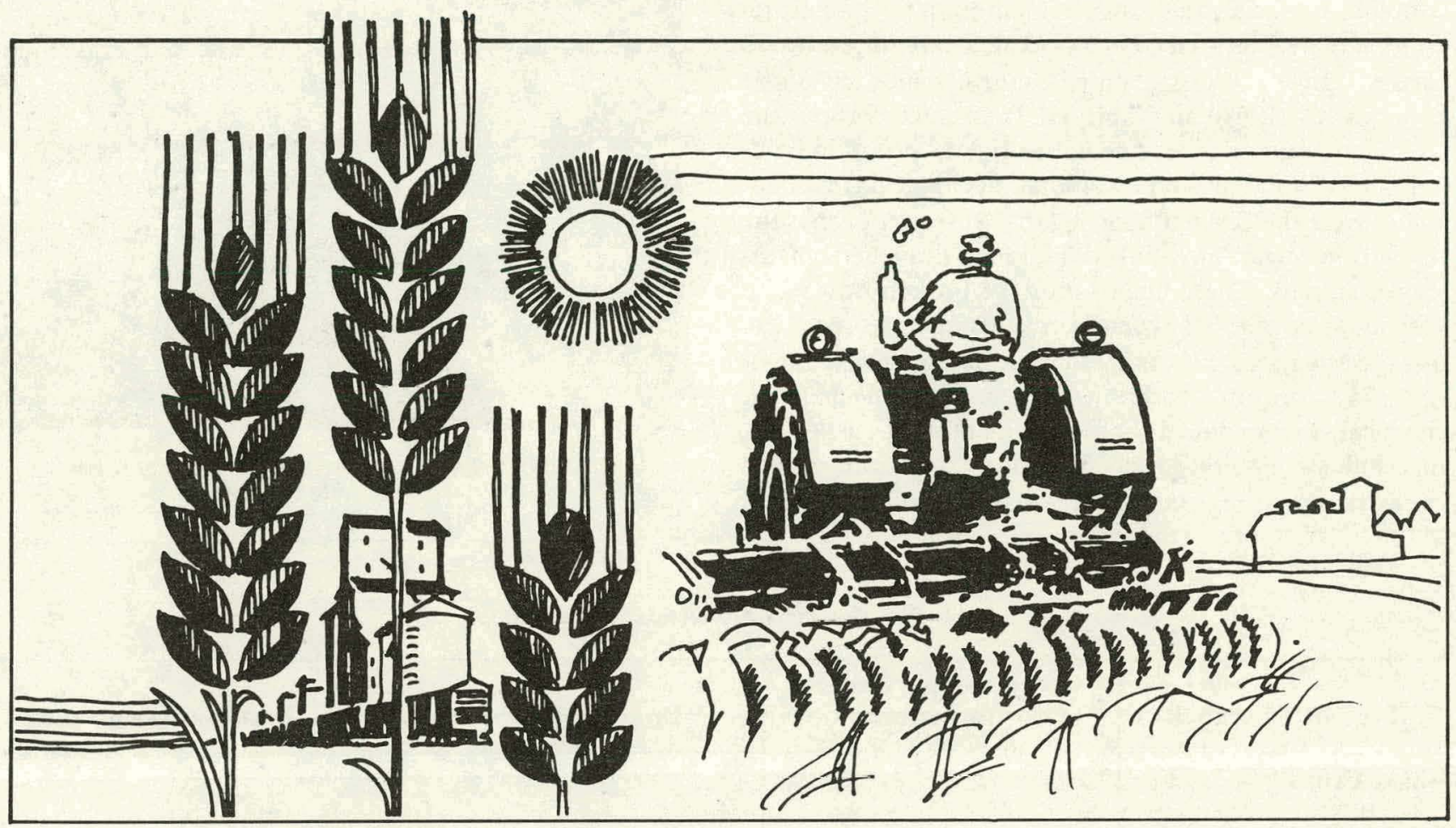

Selection of the feedstock is one of the most critical elements in the process of assessing the feasibility of an ethanol production facility. Closely linked with this decision are: an evaluation of the quantities of the selected feedstock that can be secured annually, or on a long-term basis, to support a plant, and an estimation of the cost of the resource. This first step is essential as it will provide an order of magnitude for the size of the project considered, and for the market required to absorb the ethanol fuel and its marketable coproducts. The selection of a feedstock will affect the design and characteristics of the projected plant and the economics of the overall project.

Many feedstocks can be used to produce fermentation ethanol, as shown in Table III-1. Despite the fact that corn presently offers the largest potential for U.S. grain production, other crops or residuals could be considered. (See Figure III-1.) Particular attention should be given to site- or region-specific conditions that make particular crops or their residues especially attractive as feedstock material. Disposal of food processing resi- dues, damaged crop, or crop residues through ethanol production could result in a credit or attractive feedstock prices for the ethanol producer. Such favorable situations may in some cases make small commercial plants more economically attractive than larger ones using more conventional feedstocks such as grain or sugar cane.

The prospective investor should therefore approach the problem of feedstock selection with an open mind. Also, he should attempt to integrate his operation in the context of the region considered, in order to take advantage of local or regional conditions that could be beneficial. The investor should also consider the existence of other producers in the same area and their feedstock requirements.

Selection of a particular feedstock will have a direct bearing on the design of the plant. Therefore, this chapter discusses some feedstock characteristics, knowledge of which is necessary to the decisionmaking process of the prospective investor. 


\section{TYPES OF FEEDSTOCKS}

The biological production of ethanol is accomplished through the fermentation of six-carbon sugar units (principally glucose) in the presence of yeast. All agricultural crops and crop residues contain six-carbon sugars or compounds of these sugars, and can be used to produce ethanol, provided the six-carbon sugars they contain are accessible for fermentation. Agricultural crops and residues can be subdivided into three broad classes: sugar crops; starch crops; and cellulosic material, as shown in Table III-1. In sugar crops, the six-carbon sugars or fermentable sugars occur individually or in bonded pairs. Minimal mechanical treatment will release the fermentable sugars. In starch crops, the six-carbon sugars are linked in long, branched chains (called starch). These chains must be broken down into individual or pairs of six-carbon sugars before yeast can use the sugars to produce ethanol. These crops, therefore, will require additional treatment (mechankcal, chemical, or biological) before fermentation can occur. In cellulosic materials, the six-carbon sugars are linked in extremely long chains involving strong chemical

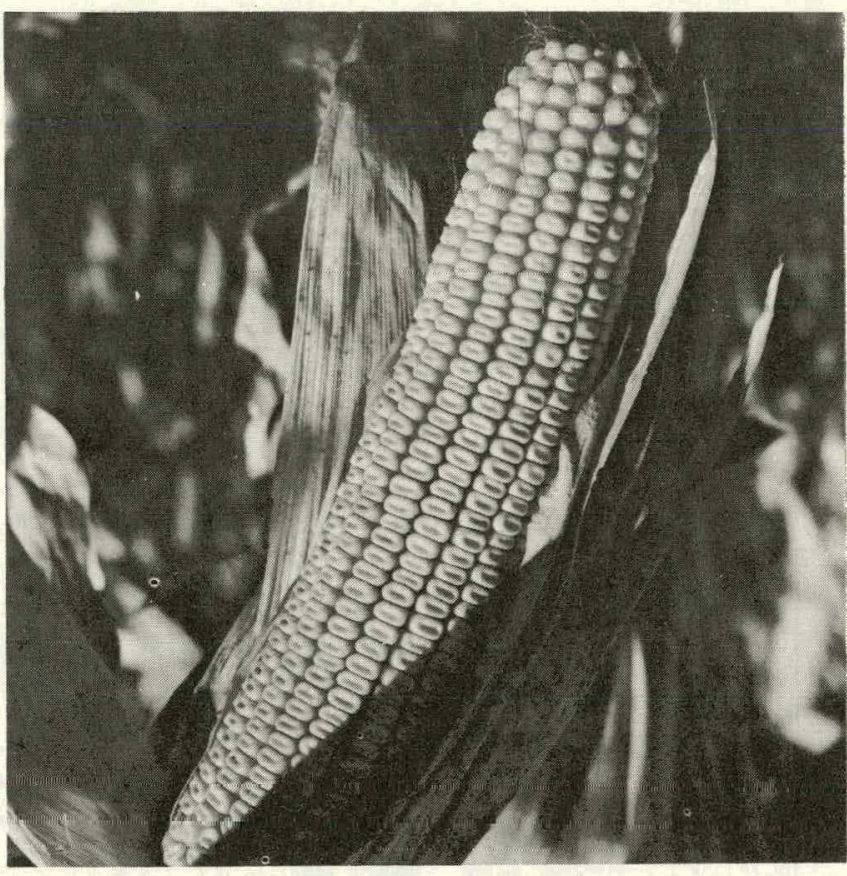

Corn Offers the Largest Potential for Ethanol Production in the United States

Table III-1. Summary of Feedstock Characteristics

\begin{tabular}{|c|c|c|c|}
\hline Type of Feedstock & $\begin{array}{l}\text { Processing Needed } \\
\text { Prior to Fermentation }\end{array}$ & Principal Advantage & Principal Disadvantage \\
\hline $\begin{array}{l}\text { Sugar Crops } \\
\text { (e.g., sugar beets, } \\
\text { sweet sorghum, sugar } \\
\text { canc, fodder beets, } \\
\text { jerusalem artichoke) }\end{array}$ & Milling to extract sugar & $\begin{array}{l}\text { - Preparation is minimal } \\
\text { per acre. } \\
\text { - Crop coproducts have } \\
\text { value as fuel, livestock } \\
\text { feed, or soil amendment. }\end{array}$ & $\begin{array}{l}\text { - Storage may result in loss } \\
\text { of sugar. } \\
\text { - Cultivation practices } \\
\text { vary widely, especially } \\
\text { "nonconventional" } \\
\text { crops. }\end{array}$ \\
\hline $\begin{array}{l}\text { Starch Crops } \\
\text { Grains: corn, wheat, } \\
\text { grain sorghum, barley } \\
\text { Tubers: culled potatocs, } \\
\text { potatoes }\end{array}$ & $\begin{array}{l}\text { Milling, liquefaction, } \\
\text { and saccharification. }\end{array}$ & $\begin{array}{l}\text { - Storage techniques well } \\
\text { developed. } \\
\text { - Cultivation practices are } \\
\text { widespread with grains. } \\
\text { - Livestock coproduct is } \\
\text { relatively high in protein. }\end{array}$ & $\begin{array}{l}\text { Preparation involves } \\
\text { additional cquipment, } \\
\text { labor, and cncrgy costs. } \\
\text { DDG from aflatoxin- } \\
\text { contaminated grain is } \\
\text { not suitable as animal } \\
\text { feed. }\end{array}$ \\
\hline $\begin{array}{l}\text { Cellulosic } \\
\text { Crop Residues: corn } \\
\text { stover, wheat straw } \\
\text { Forages: alfalfa, Sudan } \\
\text { grass, forage, sorghum }\end{array}$ & $\begin{array}{l}\text { Milling and hydrolysis } \\
\text { of the cellulosic } \\
\text { linkages. }\end{array}$ & $\begin{array}{l}\text { Use involves no integra- } \\
\text { tion with the livestock } \\
\text { feed market. } \\
\text { - Availability is } \\
\text { widespread. }\end{array}$ & $\begin{array}{l}\text { No commercially cost- } \\
\text { effective process exists } \\
\text { for hydrolysis of the } \\
\text { cellulosic linkages. }\end{array}$ \\
\hline
\end{tabular}


bonding. Releasing the six-carbon sugars for fermentation requires extensive pre-treatment. The optimum method for recovering the fermentable sugars from cellulosic materials has not been commercially demonstrated and various research programs are being pursued to improve the process.

Specifics regarding crop selection and its impact on the project are given below.

\section{Sugar Crops}

Processing and Storage Requirements. As previously mentioned, fermentable sugars are easily released from sugar crops. Preparation of the crop for fermentation involves milling or crushing and sugar extraction. Variations of the sugar recovery process are used for different crops, i.e., slicing of sugar beets followed by sugar extraction, pressing of citrus crops, etc. The sugar recovery process involves relatively low capital, labor, and energy costs.

The ease of recovery of fermentable sugars from sugar crops is counter-balanced by a significant disadvantage. The high moisture content of these easily accessible sugars make them very susceptible to infestation by micro-organisms, resulting in crop spoilage during storage. Crop spoilage in turn will result in reduced ethanol production. Sugar loss during storage can be reduced or eliminated by treatment of the extracted sugar solution. Two processes for treating the extracted sugars may be used-pasturization of the solution or evaporation of part of the water to obtain a concentrated sugar solution. Both processes, however, are costly in terms of equipment and energy.

Potential Sugar Crops. The two major sugar crops that have been cultivated at a significant commercial level of production are sugar cane and sugar beets. Other alternative sugar crops that are or could be cultivated in the United States include sweet sorghum, Jerusalem artichokes, fodder bects, and fruits.

Sugar Cane - Sugar cane is considered an attractive feedstock because of its high yield of sugar per acre and a correspondingly high yield of residue known as

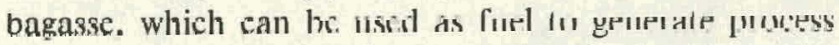
heat. The major drawback of this feedstock is the limited availability of land suitable fó ecunumical production of the crop. The potential for expansion of the production of sugar canc tó suppoìt a laıge ethaıul inclustry appears limited due to specific geographic con ditions necessany to its cultivaliun.

Sweet Surglium - The name sweet sorghum refers specifically to varieties of sorghum bicolor. Sweet sorghum is grown on a small scale for syrup and silage. Other sorghums are grown for grain. Sweet sorghum is a potentially attractive feedstock because of its high yield of ethanol per acre and its adaptability to a wide range of climates and soils. It could make a significant contribution to the feedstock resource for future ethanol production. However, while this feedstock is easier to store than sugar cane, it deteriorates rapidly in storage. The juice from sweet sorghum and milo once extracted could be concentrated and then preserved for later fermentation. Systems for doing this have only been tested at the laboratory level at this time. However, given the initial success of these systems and the development of an appropriate processing infrastructure, sweet sorghum and milo could readily become the principal biomass sources for ethanol production. The full potential of the crop as a feedstock has not yet been realized because genetic improvements and improvements in crop management have not been implemented.

Fodder Beets - Fodder beets are a high-yielding forage crop obtained by crossing two other beet species, sugar beets and mangolds. Fodder beets have higher sugar yields per acre, better storage characteristics, and are less demanding than sugar beets. When fully developed, fodder beets could contribute significantly to the feedstock resource base for ethanol production.

Sugar Beets - Sugar beets tolerate a wide range of climatic and soil conditions and therefore offer a possibility of expanded production to support ethanol production facilities. Widespread expansion of sugar beet cultivation, however, is limited to some extent by the necessity to rotate this with non-root crops on a three-year basis. Sugar beets are considered an attractive feedstock because of their high yield of sugar per acre and correspondingly high yield of beet pulp and beet tops coproducts.

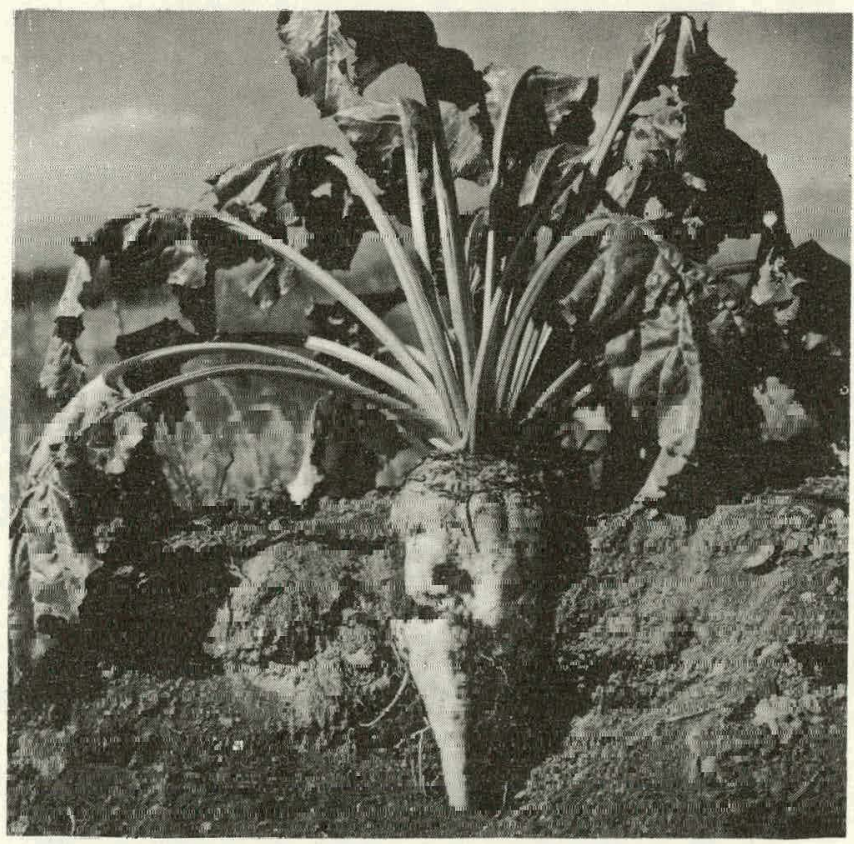

Fermentable Sugars Can Be Recovered from Sugar Beets 
Jerusalem Artichokes - The Jerusalem artichoke has shown potential as an alternative sugar crop. It is well adapted to northern climates and a variety of soils, and is not demanding of soil fertility. With expanded production, this crop could make a significant contribution to the feedstock resource for future ethanol production.

Fruit Crops - Fruit crops are not likely to be used as direct feedstock for ethanol fuel production because of their high market value for direct human consumption. The coproducts of processing fruit crops (citrus molasses, for example) could be used as feedstocks because fermentation is an economical method for reducing the potential environmental impact of disposal of untreated wastes containing fermentable sugars. Although prime fruit crops are too valuable to utilize, distressed fruit crops are an excellent feedstock for ethanol production.

\section{Starch Crop}

The starch crop used as feedstock for ethanol production includes grains (corn, wheat, barley, grain sorghum, etc.) and tubers (potatoes and sweet potatoes).

Processing and Storage Requirements. Yeasts cannot directly use starch, such as long-branched chains of sixcarbon sugars, to produce ethanol. Before fermentation, the starch chains must be broken down into individual or pairs of six-carbon sugar units. This step involves the reaction of the starch-containing material with water (hydrolysis) in the presence of enzymes to produce a simple sugar solution. In the case of grain feedstocks, the process involves milling of the grains to a fine meal to expose the starch, slurrying the meal with water to form a mash, and hydrolysis. Hydrolysis involves the liquefaction of the mash into a solution of high molecular-weight sugars (dextrins) followed by their conversion to fermentable sugars. Both steps are conducted in the presence of enzymes (protein catalysts) under controlled temperature. The preparation process prior to fermentation may include several variations of the general procedure just described. The grains may be prepared under dry or wet milling conditions resulting in the production of various coproducts (germs, oil, hulls, etc.) These process variations are further discussed below, under grains.

The conversion of potatoes or, more generally, tubers to ethanol is similar to that of grains, with minor modifications to the process. The potatoes are washed to remove dirt and soil microbes, sliced, and cooked before the hydrolysis step.

A distinct advantage of starch crops is the relative ease with which these crops can be stored with minimal loss of the fermentable portion. Ease of storage is related to

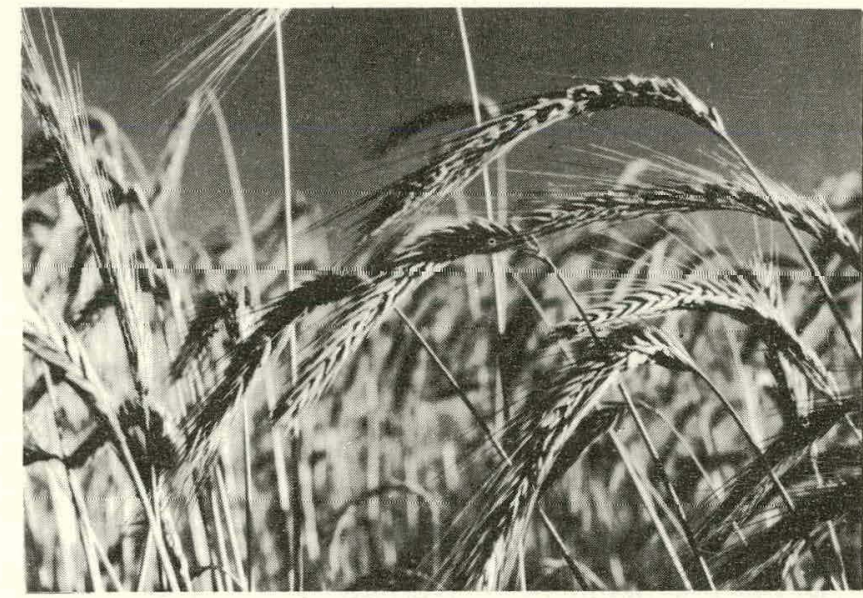

The Starch in Grains Can Be Converted to Fermentable Sugar in a Simple Two-Step Process

the fact that a conversion step is needed before fermentation. Many miciu-urganisms including yeasts can uti lize individual or small groups of sugar units but not long chains. Some micro-organisms present in the environment produce the enzymes needed to break up the chains, but, unless certain conditions such as moisture, temperature, and acidity are just right, the rate of conversion during storage is very low. When crops and other feeds are dried to about 12-percent moisture (the percentage below which most micro-organisms are not active) the deterioration of starch and other valuable components such as proteins and fats, is minimal. Grains are routinely dried before storage and therefore little risk of loss is expected for these feedstocks. Potatoes can usually be stored about six months before significant losses occur.

\section{Potential Starch Crops}

Grains - Potential grain feedstucks include rye, wheat, milo, rice, barley, and corn. Corn presently constitutes the largest potential feedstock supply. The following

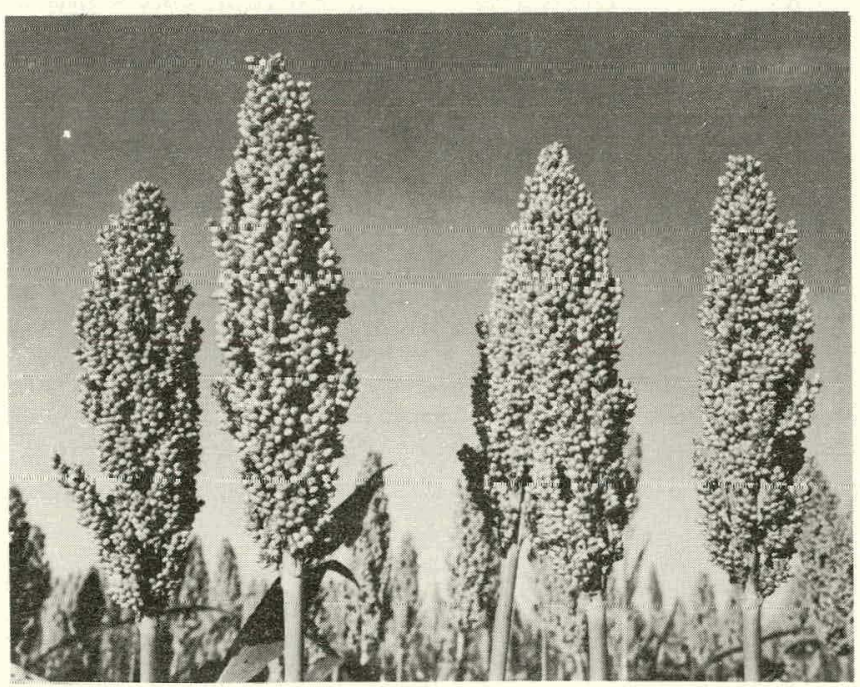

Milo Is A Popular Grain Crop In The Southwest 
discussion nevertheless is applicable to other grains with relatively minor variations of the process described for corn.

Corn kernels are composed of three major constituents: the germ ( 2 to 3 percent of the kernel) which is rich in oil and proteins; the hull and bran layers ( 13 to 17 percent of the kernel) which are rich in protein, cellulose, and minerals; and the endosperm (the remainder of the kernel) which is mostly starch fixed in a matrix of protein. Various food or feed products may be extracted from the kernels through different processing methods. The simplest way of processing corn kernels prior to fermentation to alcohol is shown in Figure III-1. Whole kernels are ground and the resulting meal is treated through slurrying and hydrolyzing to convert the starch contained in the grain to fermentable sugars. The nonfermentable part of the grain or spent grain contains most of the non-starch nutritive elements originally present in the kernels. This coproduct of alcohol production may be retrieved after distillation of the alcohol, as shown in Figure III-1, or at various other steps in the alcohol production chain, such as after hydrolysis or fermentation. More intricate approaches to converting corn into food or feed are the dry- and wet-milling processes.

In some modern dry milling processes, the germ is first removed and treated to produce oil and germ meal used for food or feed (see Figure III-2). After grinding of the degerminated kernel, the hull is separated and used for feed or food additives. The remaining endosperm fraction of the kernel is then milled and used for making a variety of food products, such as corn meal, grits, corn flakes, etc.

A part of the endosperm fraction of the kernel may be used as feedstock for an ethanol production unit. The residue of ethanol production, i.e., the stillage itself, is a valuable coproduct which can be used as animal feed or feed supplement. Figure III 2 thereforc indicates that ethanol production can be integrated into a corn drymilling process having food or feed production as its main objective. The advantage of dry milling over the simple processing described in Figure III-1 is that a variely of high-valued coproducts (oil, food additives, feed, or feed supplements) are produced in addition to ethanol. This advantage, however, is counter-balanced by both the higher capital required for an integrated dry-milling/ethanol production unit and the need for sophisticated marketing to dispose of the coproducts.

In the wet-milling process, the starch contained in the endosperm is further separated from the protein matrix (gluten) in which it is embedded. Figure III-3 illustrates a wet-milling process in which an alcohol production line using part of the starch has been incorporated. Several plants of this type are either in operation or in

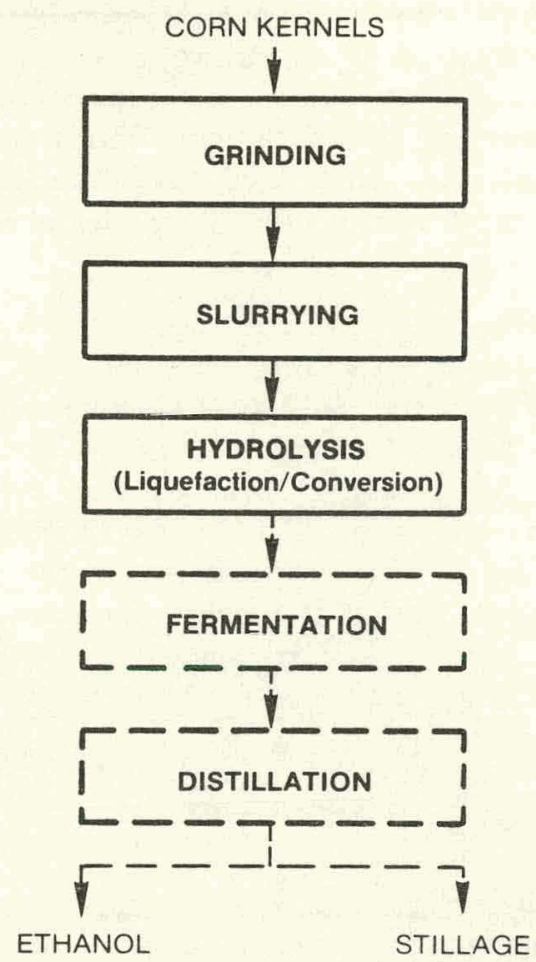

Figure III-1. Simple Processing of Corn Prior to Fermentation

the planning stages. Multiple high-value coproducts are generated during ethanol production via both the wetand dry-milling processes. The largest traditional wetmilling plants process between 150,000 and 209,000 bushels of corn per day. This would correspond to a production capacity of 380,000 to 620,000 gallons per day for a plant of simplified design.

In a combined wet-milling/fermentation ethanol process, however, emphasis is placed on food or feed production, and the ethanol output is only 70 to 80 percent that of a plant of simplified design with the same corn input devoted primarily to ethanol production. The capital cost of the combined wet-milling/fermentation ethanol plant will be higher than that for a simple ethanol plant, and a careful analysis of the potential benefits of generating valuable feed or food coproducts will be required before selecting the corn wet-milling processing routc.

Tubers. Potential tuber feedstocks include potatocs or potato wastes from food processing plants, sweet potatoes, and other starchy tubers. The grinding, slurrying, and hydrolysis operations prior to fermentation are similar to those for grains, but modified to account for the size and moisture content of the tuber feedstock.

\section{Cellulosic Feedstocks}

Enormous amounts of cellulosic materials are potentially available for ethanol production. Although no practical process for converting cellulosic materials to 


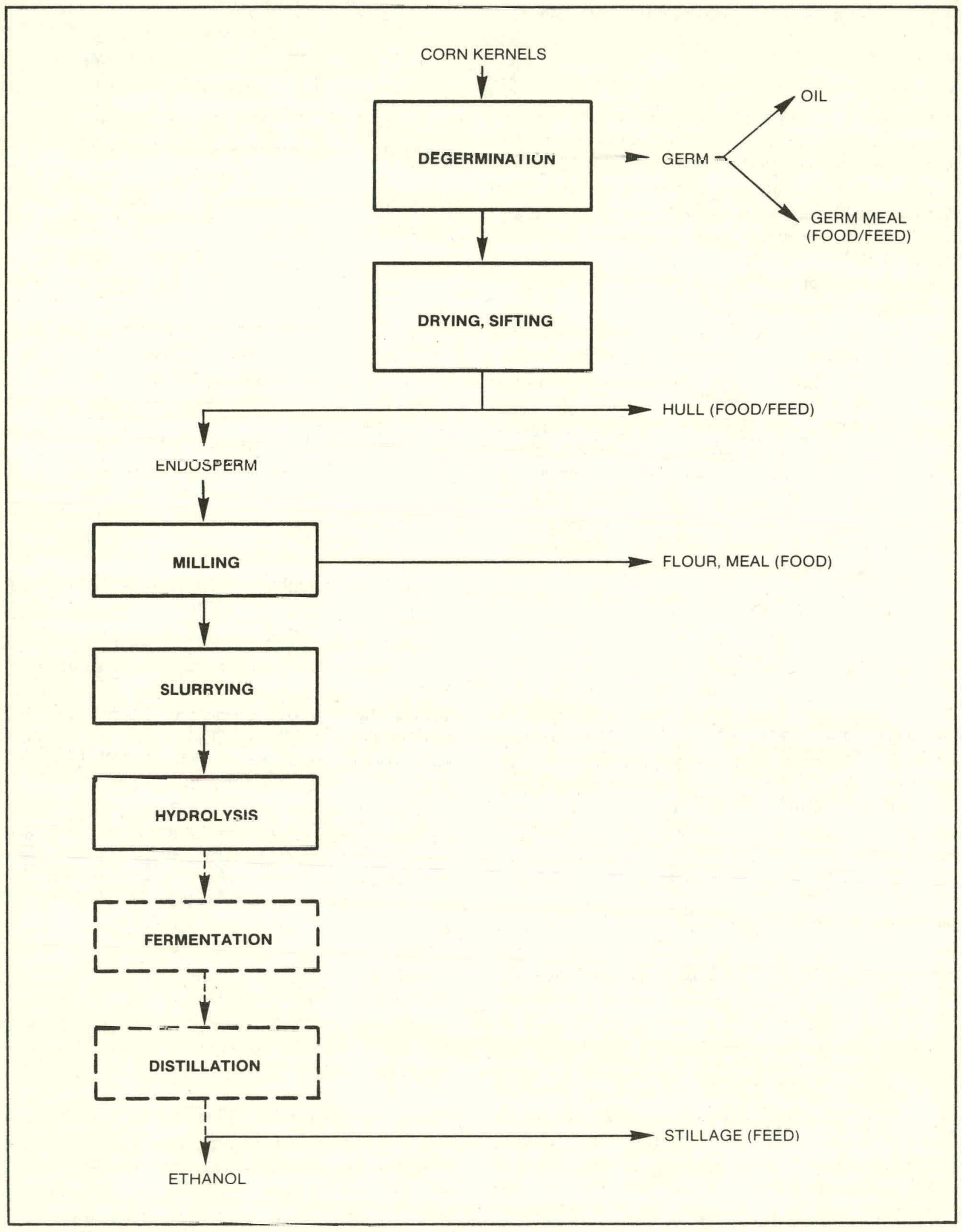

Figure III-2. Dry-milling Process With Ethanol Production 


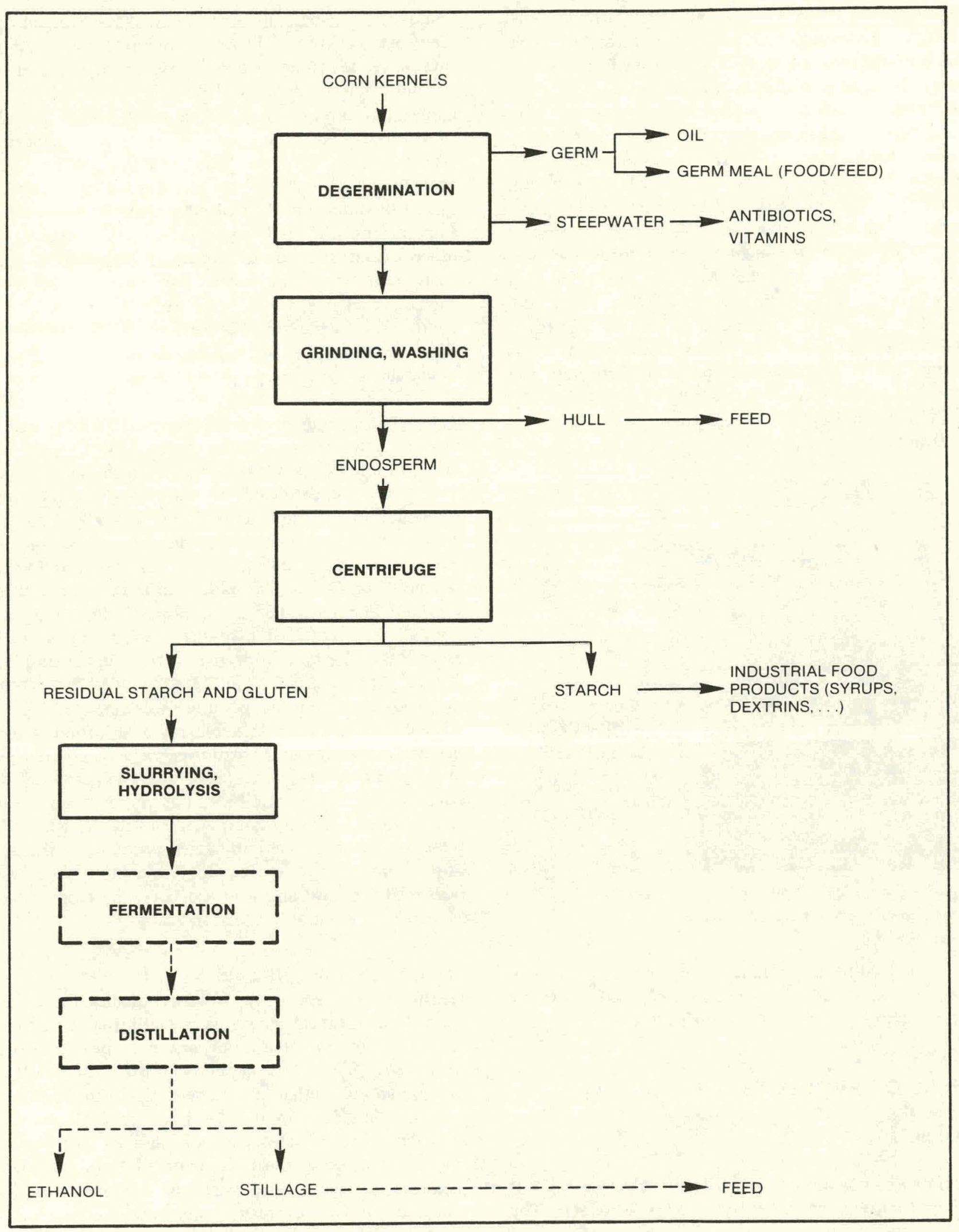

Figure III-3. Wet-Milling Process With Ethanol Production 
ethanol on an industrial scale has been demonstrated, research is underway. Cellulosic materials require extensive preprocessing to release the fermentable sugars. Several processes which may include mechanical, chemical, and biological treatments are presently being investigated. This technology, therefore, must be considered a future method of ethanol production. It is impossible to project its real potential or economic feasibility at present. It should be noted, however, that available data suggest that the preprocessing of cellulose prior to fermentation will be different from that practiced for starch feedstocks. Modification of a plant from starch to a cellulosic crop would require the addition of an appropriate front-end processing area to the original plant and very little if any modifications to the existing starch processing front-end. Moreover, that plant then would have the capability of processing both starch/sugar and cellulosic feedstocks, which could be an advantage.

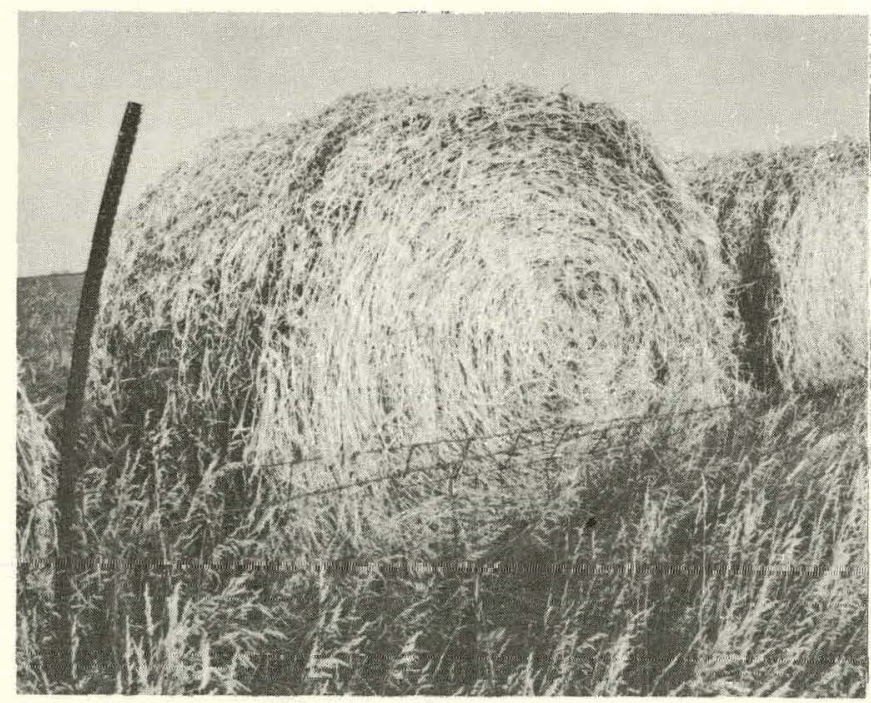

Stover is a Potential Feedstock for Cellulosic Conversion Technologies Presently Under Development

Potential feedstocks include such materials as corn stover, straw, sugar cane bagasse, mill residues, forest residues, and industrial and urban wastes.

\section{YIELDS OF PRODUCTS}

\section{Ethanol}

The potential conversion rate of feedstocks to ethanol is an important element when selecting a feedstock. The ahsolute conversion rate expressed in gallons of ethanol per unit quantity of feedstock, such as gallons per bushel of grain, will establish a relationship between the amount of feedstock required and the size of the plant contemplated or, conversely, will determine the size of the plant which can be supported by the resources available in a certain region. Also, when several feedstocks could be available, all other factors being equal, the feedstock having the highest conversion rate, and requiring the least handling and logistics for procurement of bulky raw material, will be preferred. The relative conversion rate expressed in gallons of ethanol per acre of land devoted to a given crop is also an important aspect of crop selection. This yield per unit land area. provides an estimate of the geographic crop area required to support a plant of given capacity, and, therefore, of the potential impact of an ethanol plant on other users of the crop of interest in the region. A comparison of land requirements for feedstocks, when a choice is available, will indicate which feedstock is most appropriate to the farming patterns of the region and which feedstock has the highest potential for long-term availability.

Table III-2 summarizes conversion yield data (quoted as average values) for various feedstocks. Fluctuations

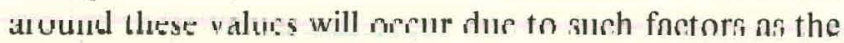
degree of preprocessing of the feedstock prior to fermentation and the quality of the feedstock. As an example, conversion yields as high as 2.7 gallons of ethanol per bushel for corn and other grains, and yields ranging from 75.0 to 60.3 gallons of ethanol per ton for sorghum and citrus molasses, respectively, have been quoted. The conversion yields quoted in the table assume that the main objective of the conversion plant is ethanol production. As indicated in an earlier section, the yields of ethanol fuel per unit feedstock will be lower when ethanol production is integrated with food or feed production processes. (This lower yield of ethanol per unit feedstock does not result from lower sugar to ethanol sonversion efficiency. but rather from a diffcrent utilization of the components of the feedstock. In these food/feed/ethanol integrated processes, a fraction of the starch-the source of fermentable sugars-is recovered for food and feed uses and, therefore, is not available for ethanol production.)

The data on Table III-2 also show that the wastes of feedstocks or feedstocks of lesser quality (depressed grains, for instance) may have yields lower than those mentioned in the table. For instance, potato wastes from french fry processing plants producc about half of the fermentation ethanol obtained from whole potatoes for equal feedstock inputs. These lower yields per unit input and the associated costs of handling larger quantities of feedstock must be compared to the lower feedstock costs for waste materials. In some cases, the utilization of wastes may result in a credit bccause ethanol production may provide a method for disposal of the wastes from food-processing plants. The ethanol production rates per acre are based on averaged U.S. yields of the various crops per acre. Significant regional differences in yields have been recorded. As an example, in 1977, while the United States average yield of corn for grain was 90.8 bushels per acre, yields of 29 bushels 


\begin{tabular}{|c|c|c|c|}
\hline FEEDSTOCK & $\begin{array}{c}\text { GALLONS } \\
\text { PER BUSHEL* }\end{array}$ & $\begin{array}{l}\text { GALLONS } \\
\text { PER TON }\end{array}$ & $\begin{array}{l}\text { GALLONS } \\
\text { PER ACRE** }\end{array}$ \\
\hline $\begin{array}{l}\text { Corn } \\
\text { Grain Sorghum } \\
\text { Wheat } \\
\text { Rye } \\
\text { Oats } \\
\text { Barley } \\
\text { Rice } \\
\text { Potatoes } \\
\text { Potato Wastes } \\
\text { Sweet Potatoes } \\
\text { Yams } \\
\text { Jerusalem Artichokes } \\
\text { Sugar Beets } \\
\text { Sugar Cane } \\
\text { Sweet Sorghum } \\
\text { Apples } \\
\text { Peaches } \\
\text { Molasses }\end{array}$ & $\begin{array}{r}2.5 \\
2.4 \\
2.4 \\
2.2 \\
1.0 \\
2.1 \\
1.8 \\
0.69 \\
- \\
0.94 \\
0.75 \\
0.60 \\
- \\
- \\
\mathrm{NA} \\
0.35 \\
0.28 \\
-\end{array}$ & $\begin{array}{r}89 \\
86 \\
80 \\
79 \\
64 \\
88 \\
80 \\
23 \\
13 \\
34 \\
27 \\
20 \\
22 \\
15 \\
\text { NA } \\
14 \\
12 \\
68\end{array}$ & $\begin{array}{r}228 \\
135 \\
74 \\
54 \\
57 \\
92 \\
175 \\
299 \\
- \\
190 \\
\text { NA } \\
\text { NA } \\
412 \\
555 \\
\text { NA } \\
\text { NA } \\
\text { NA } \\
\text { NA }\end{array}$ \\
\hline $\begin{array}{l}\text { Average Yields } \\
\text { " Based on Average } 197\end{array}$ & & & \\
\hline
\end{tabular}

SOURCE: U.S. Department of Agriculture, "Small-Scale Fuel Alcohol Production," prepared with the assistance of Development Planning and Research Assuciales, Inc., Manhattan, KS, 66502, March 1980. Washington, D.C. 20250.

per acre were reported for Alabama and yields of 116 and 105 bushels per acre were reported for Colorado and Ohio, respectively.

On the basis of the data from Table III-2, a 50-milliongallon-per-year plant would require about 21.3 million bushels of corn per year, the crop harvested from about 233,000 acres of farm land having a productivity of 91 bushels per acre. Assuming that the conversion plant is located in the center of a corn production area and that the crop land is about 50 percent of all land, the ethanol plant would consume all the grain produced within a circle of about 30.4 miles in diameter. For the range of productivities mentioned above (i.e., 30 to 130 bushels per acre-year) the diameter of the land area required to sustain the ethanol plant could range from about 13 to 27 miles. These simplified considerations give an order of magnitude for the crop area which will be affected by the installation of an ethanol plant, and should be kept in mind when siting the plant to avoid direct competition with other users of the feedstock.

The table also shows that sugar crops, such as sugar cane grown at present in the United States, have a higher ethanol productivity per acre than the starch crops presently produced. This yield advantage of sugar crops, huwever, is counter-balanced by the fact that sugar crops spoil more quickly in storage.
Of the starchy feedstocks listed in the table, corn and potatoes have the highest potential for fermentation ethanol production per unit land area.

\section{Coproducts}

The fermentation process resulting in the production of ethanol also yields several coproducts, including carbon dioxide, fusel oil, yeast, and stillage. Other coproducts such as food or feed components also may be generated when ethanol production is integrated in a food processing chain such as the dry or wet milling of grains described earlier. The coproducts of ethanol production may have a beneficial effect on the overall economics of ethanol production if they can be recovered economically in significant quantities, and if a commercial market exists to absorb these coproducts. The amount, quality, and therefore, market value of the coproducts vary widely and depend on the feedstock and the processing steps used in producing ethanol.

Carbon Dioxide. Carbon dioxide is used in carbonated beverages, in fire extinguishers, in the manufacture of dry ice, and as a food preservative. The recovery of carbon dioxide is likely to be practical only for large-scale plants and only when a local market is readily available. In most cases, carbon dioxide recnvery will not be eco nomically justifiable and, except for special conditions, no credit can be expected from carbon dioxide. 
Fusel Oil. Fusel oil is a poisonous liquid mixture of alcohols consisting mostly of normal amyl and iso-amyl alcohol. Where corn is the feedstock for ethanol production, less than one percent of the total amount of alcohol produced is fusel oil. Fusel oil can be used as a denaturing agent for the ethanol produced.

Yeast. Yeast present in the fermentation medium may be recycled or recovered for commercial uses. In either case, its value as a coproduct should be determined. If yeast is not recovered, it will contribute to the high protein content of the stillage.

Stillage. The stillage from fermentation contains fibrous carbohydrate material, high-protein yeast, proteins from the original feedstock, and non-fermentable solids and solubles including various minerals and other nutrients. The actual nutritional value of the stillage will vary among feedstocks and with the ethanol production process used. Whole thn stillage usually contains about 90 percent water. Although whole stıllage is currently used as animal feed or feed supplement, its usefulness is limited by the high water content which prevents animals from consuming large quantities of it. Moreover, whole stillage is very susceptible to microbial degradation and must be delivered and consumed within a short time after removal from the distillery. In summer, it is recommended that the stillage be consumed within 24 hours after recovery from the still. This can result in complex and expensive logistic problems for commercial-scale operations generating large quantities of stillage daily. Stillage may be dried to avoid or reduce the storage, marketing, and distribution problems.

Four types of coproducts are presently recovered from the stillage of distilleries using grain as feedstock: Distillers Dried Solubles (DDS), obtained by evaporating and drying the thin stillage to recover the minerals and nutrients in solution; Condensed vistillers Solubles, obtained by concentrating the thin stillage to a semi-solid form; Distillers Dried Grains (DDG), obtained by separating the coarse grains from the whole stillage and drying the solid fraction recovered; and Distillers Dried Grains with Solubles (DDGS), which result from the blending of DDG and DDS prior to drying. The paths of utilization of stillage and its coproducts are illustrated in Figure III-4. DDG or DDGS is generally marketed at 10 percent moisture and has a protein content of the order of 25 to 28 percent dry basis, i.e., lower than soybean meal (about 45 percent) but significantly higher than corn (about 9 perrent). The. dried cupruducts rccovered from stillage are easier io store, transport, and market than fresh stillage.

Table III-3 summarizes the production rates of stillage and stillage-derived coproducts for some of the major feedstocks presently available for ethanol production. A 50-million-gallon-per-year ethanol plant using corn feedstock will generate about 500 million gallons of fresh stillage annually or about 1.3 million gallons of stillage daily. The same plant will produce about 163,000 tons of dried distillers products annually or

Table III-3. Production Rates of Stillage and Stillage-Derived Products for Ethanol Production Feedśtócks

\begin{tabular}{|c|c|c|c|c|c|}
\hline FEEDSTHOCK & $\begin{array}{l}\text { UNIT } \\
\text { INPUT }\end{array}$ & $\begin{array}{c}\text { WEIGHT } \\
\text { INPUT1 } \\
\text { (LB) }\end{array}$ & $\begin{array}{l}\text { VOLUME UF } \\
\text { STILLACE? } \\
\text { (GAL.) }\end{array}$ & $\begin{array}{l}\text { WEIGHT OF } \\
\text { STILLAGE? } \\
\text { (LB) }\end{array}$ & $\begin{array}{c}\text { WEIGHT OF } \\
\text { DISTILLERS } \\
\text { COPRUDUC I'S } \\
\text { (LB) }\end{array}$ \\
\hline Corn & 0.38 bu & 21.5 & 10.4 & 92.7 & 6.5 \\
\hline Wheat & $0.38 \mathrm{bu}$ & 23.1 & 10.4 & 94.2 & 8.0 \\
\hline Grain Sorghum & $0.38 \mathrm{bu}$ & 21.5 & 10.4 & 92.7 & 6.6 \\
\hline Potatoes & $0.71 \mathrm{cwt}$ & 71.4 & 7.0 & 58.4 & 10.6 \\
\hline Sugar Beets & 0.049 ton & 98.5 & 10.3 & 85.6 & 13.0 \\
\hline Molasses & $2.5 \mathrm{gal}$. & 29.3 & 4.8 & 39.0 & - \\
\hline \multicolumn{6}{|c|}{ 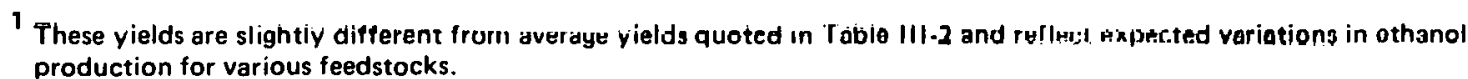 } \\
\hline
\end{tabular}

SOURCE:

M. L. David, G. S. Hammaker, R. J. Buzenberg, and J. P. Wagner, "Gasohol Economic Feasibility Study", Report prepared for Energy Research and Development Center, University of Nebraska, Development Planning and Research, Inc., p. 261, July 1978, Manhattan, KS, 66502. U.S. Department of Agriculture, "Small Scale Fuel Alcohol Production", prepared with the assistancc of Development Planning and Research Associated, Manhattan, KS 66502, March 1980, Washington, D.C. 20250. 


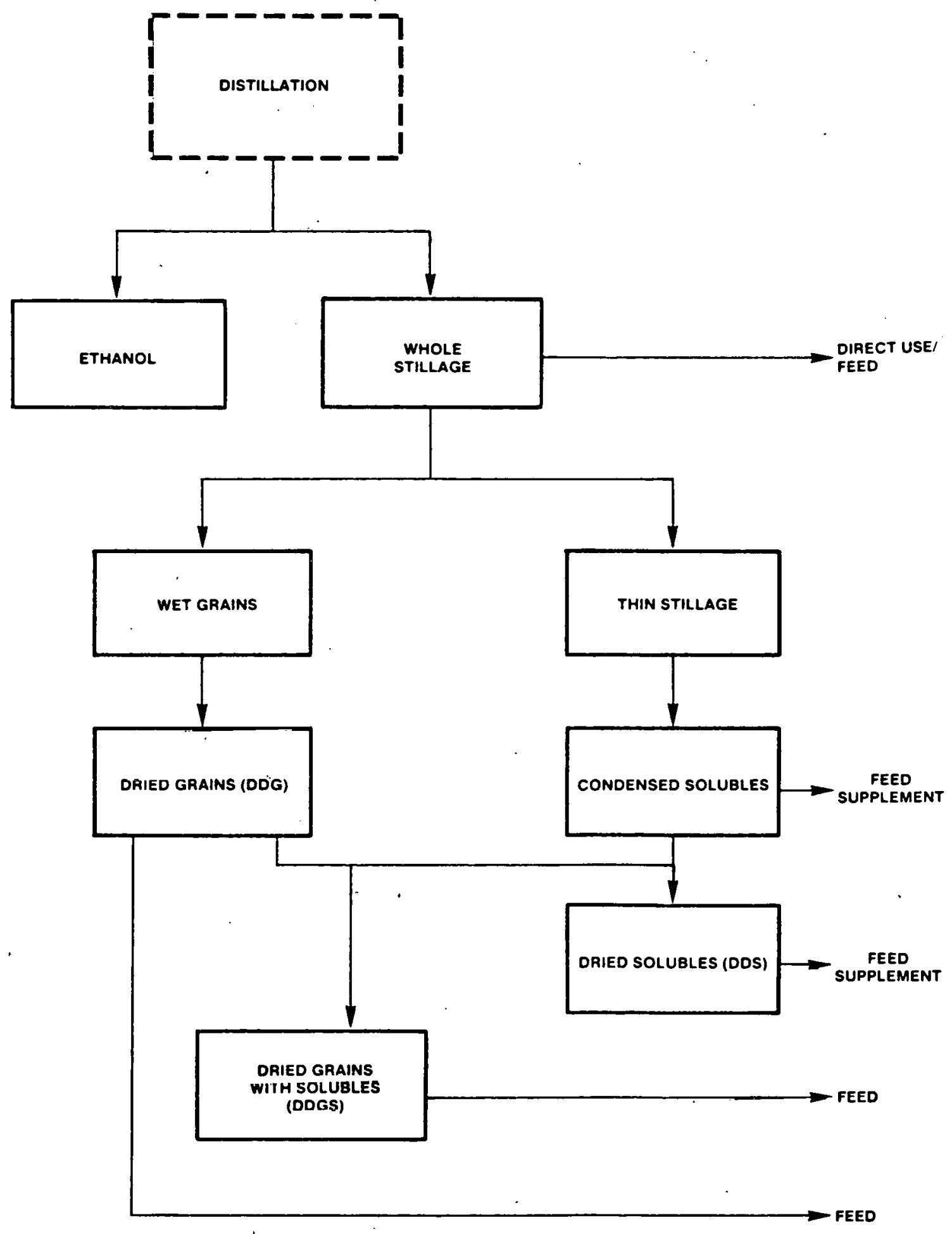

Figure III-4. Paths of Utilization of Residual Stillage from Grain Feedstock Distillery 
about 450 tons of products daily. This comparison suggests that treatment of the stillage to dried distillers products will simplify the logistics of marketing the coproducts of a commercial-size plant.

The output of coproducts shown in Table III-3 refers to a simple fermentation ethanol plant design, i.e., a plant designed primarily for ethanol production. The outputs from an ethanol production plant integrated with a grain processing plant (dry- or wet-milling process) will be quite different. As an example, the treatment of one bushel ( $56 \mathrm{lbs}$ ) of corn through a wet-milling process will result in the production of about 9.2 pounds of feed at about 21 percent protein; 2.7 pounds of gluten meal at about 60 percent protein, 3.5 pounds of germ at about 50 percent oil; and 31.5 pounds of starch. This starch can be partially used for food or totally converted to ethanol. In the latter case, about 2.5 to 2.7 gallons of ethanol would be produced per bushel of corn treated. As most of the food or feed components of the grain has been removed through the wet milling process, only about 3.2 pounds of residual distillers coproducts would be recovered from the stillage. The above-mentioned outputs of a wet-milling process are only indicative and will vary according to the design of the system.

The major market for stillage or stillage-derived coproducts is animal feed or animal feed supplement. The quantity of stillage or stillage-derived products, which can usefully be consumed by animals, is a function of a number of factors, such as: the type of animal, diet needs within its lifecycle, ability to digest and absorb the products, and other factors. Considerable re. search is in progress to optimize the use of distillers residues in formulating animal diets. There is, therefore, some uncertainty as to the exact amount of stillage ur its derivatives which can be tolerated by various types of animals.

Some typical quantities of coproducts which could be fed to various types of animals in combination with other feeds required to supply a balanced ration ar: shown in Table III-4. The animal population required to absorb the distiller's coproducts generated by ethanol plants of various sizes is reflected in the data of Tables III-3 and III-4. Some typical values are shown in Table III-5.

The table shows that the animal population required to absorb the distillers coproducts from commercial-size plants is large. The problem of marketing these coproducts will have to be carefully evaluated before choosing an ethanol plant site.

The available markets for stillage will probably be expanded several fold in the next few years by technological developments which have already been proven at the laboratory level and are going into the pilot testing at this time. Membrane processes show promisc for the low cost denaturing of stillage together with the capability of reducing its salt content. Denaturing costs by membranc proserfes will be nf the order of a few dullars pel thousand gallone as contrasted with well over twenty dollars when accomplished by evaporators. These membrane denaturing plants can also be quite small as contrasted to evaporators which are efficient only in relatively large plants. Membrane processes remove salts, and it has been shown that the salt content is one of the elements which limits the amount of distillers coproducts which can be fed to animals. There is evidence that stillage without excess salt can be fed to animals as readily as any animal feed material.

\section{AVAILABILITY OF FEEDSTOCKS}

\section{Overview of Feedstock Availability}

Near-Tcrm Availability. Table. III-6 summarizes estimatcs of the quantities of feedstocks potentially availablc at presient or in the near term in the United States. These estimatcs assume that none of the fccdstocks is diverted from its present food or feed uses (i.e., the amounts shown in the table are essentially surplus production) and that present patterns of agriculture are

Table III-4. Animal Consumption of Distiller's Coproducts

\begin{tabular}{|l|c|c|c|}
\hline \multicolumn{1}{|c|}{ ANIMALS } & $\begin{array}{c}\text { STII I ARE 10\% } \\
\text { SOLIDS } \\
\text { (GAL/DAY/ANIMAI) }\end{array}$ & $\begin{array}{c}\text { STILLAGE 20\% } \\
\text { SOLIDS } \\
\text { (CAL/DAY/ANIMAI) }\end{array}$ & $\begin{array}{c}\text { DRIED DISTILLERS } \\
\text { GHAINS WITH SOLUDLCO } \\
\text { (LB/DAY/ANIMAL) }\end{array}$ \\
\hline Calf $(550 \mathrm{lb})$ & 6.3 & 3.1 & 5.8 \\
Steer $(770 \mathrm{lb})$ & 9.2 & 4.6 & 8.5 \\
Cow (1,300 lb) & 7.2 & 3.6 & 6.6 \\
Pig (60 lb) & 1.2 & 0.0 & 1.1 \\
Pullet (3.7 weeks) & - & - & 0.13 \\
Pullet (7.5 weeks) & - & - & 0.22 \\
\hline
\end{tabular}

SOURCE: U.S. Department of Agriculture, "Small-Scale Fuel Alcohol Production," prepared with the assistance of Development Planning and Research Associates, Inc., Manhattan, KS, 66502. March 1980. Wáshington. D.C. 20250. 


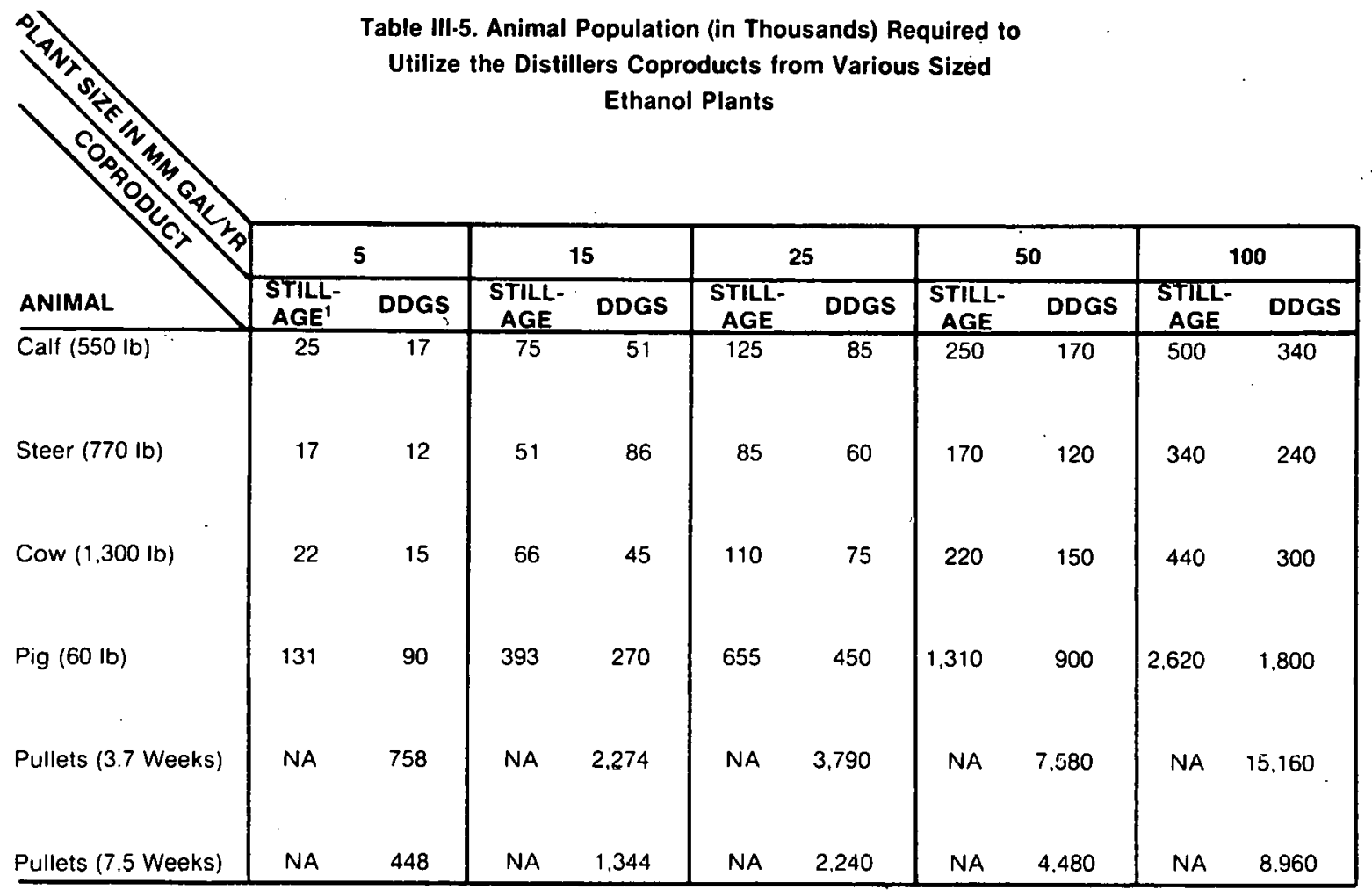

Assumes corn feedstock and 330 days production per year.

'Ten percent solids.

SOURCE: This data was taken from Table III-3 and III-4.

not changed. The table shows that a goal of over one billion gallons of ethanol annually is a realistic objective in the near future. The table also shows that corn, grain sorghum, and other resources which include grains other than corn constitute the backbone of our resources. Citrus wastes, although significant in quantity, are available only on a seasonal basis, which limits their economic attractiveness.

Long-Term Availability. If the goal proposed by the President of 1.8 billion gallons of ethanol per year is to be reached, other sources of feedstock must become available. Traditionally, U.S. agriculture has shown a great degree of flexibility in adjusting to new market demand and technologies. Increasing demand for corn feedstock for ethanol production accompanied by increased availability of distiller's grains feed supplement would result in a gradual shift from soybean and grain sorghum production to corn or other grains. Similarly, the existence of a steady and significant market for ethanol feedstocks may induce farmers to develop marginally used land areas.

Recent estimates by the USDA' indicate that about 78 million acres presently not used for crops have a high potential for cropland development. The development of these areas into cropland could translate to a 33 percent increase of corn production or a 43 percent increase of soybean production in the Northern Plains and Southern Plains, respectively, and a 350 percent in- crease of soybean production in the Southeast. Despite increasing national and foreign demand for farm products, the potential exists to significantly increase the ethanol feedstock resources. It should, however, be mentioned that some development problems such as erosion, periodic flooding, and rocky soil may have to be resolved when bringing some of the potential areas into cropland use.

The above discussion indicates that on a national level, sufficient resources exist to justify an ethanol program in the near term and prospects for maintaining or even expanding an ethanol program in the long term appear favorable.

Regional Availability of Feedstocks. The availability of feedstocks varies from region to region, as climatic and soil characteristics result in specialized crop production. Also, while some crops such as corn are grown in many states, some regions or states will register a surplus of production and others, although producers, will import corn. Surplus regions or the proximity of surplus regions where competition for the feedstock with other users is reduced and prices are less sensitive to changes in demand should obviously be preferred when siting a plant.

'L. K. Lee, "A Perspective on Cropland Availability", U.S. Department of Agriculture-Economics, Statistics, and Cooperative Services, Agricultural Economic Report No. 406, Washington, DC, 1978. 
Figure I-5 shows the distribution of potential ethanol feedstocks production by USDA farm production regions. The productions indicated in notes to the table are the totals. The quantity of feedstock available for ethanol production is only a fraction of the total production, i.e., surplus, distressed crops, or wastes from processing. The data shows that corn, wheat, and grain sorghum are the major potential feedstocks and that half or more of these crops are produced in the Northern Plains, Lake States, and Corn Belt regions. Sugar beet production is spread over many regions but the amounts potentially available are small. Sugar cane production is geographically very limited and its feedstock potential is very small. Potatoes (surplus, distressed crops, or wastes from processing) and wastes from food products processing could supply the feedstock needed in a variety of regions although the total potential resource is limited. Food processing wastes also have the drawback that they are often seasonal feedstocks. As a result. plants relying on these feedstocks could be Idle for part of the year if no alternative feedstock is available to fill the idle periods.

Sweet sorghum, a potentially very attractive feedstock, has been grown in several regions as indicated in Figure I-5. This crop offers an alternative for other feedstocks in those regions.

\section{Factors Affecting Feedstock Availability}

Climate and Productivity. Increased soil management and particularly increased usage of nitrogen fertilizers have resulted in significant increases in average productivity of grains, especially corn. This increased soil management, however, has also resulted in increasing the amplitude of tluctuations in grain ylelds due tu climate variations because positive response to fertilizer and other management techniques depends on favorable weather conditions.

Figure III-5 shows historical trends of corn yields per acre during the 1963 to 1978 period. During the 1970's, yields varied between 72 and 100 bushels per acre, i.e., a variation of about 11 to 26 percent below and above the average productivity of 81 businels per acre. Such fluctuations in productivity and production will have an impact on both food and fermentation ethanol feedstock prices and availability.

Market Demand. Markets for grains include the domestic and foreign food and feed markcts and ethanol production. These markets are defined and predictable to a certain extent. However, unforeseen variations resulting from foreign crop deficits, cancellation of foreign deliveries as a result of political decisions, emergency situations, or climate may change the yearly supply and demand balance for grains in the
Table III-6. Quantities of Feedstocks for Ethanol

Production Potentially Available in the Near.Term and Their Ethanol Equivalent

\begin{tabular}{|c|c|c|}
\hline Feedstocks & $\begin{array}{c}\text { Quantity } \\
\text { (Million Dry } \\
\text { Tons/Year) }\end{array}$ & $\begin{array}{c}\text { Ethanol } \\
\text { Equivalent } \\
\text { (Million } \\
\text { Gallons/Year) }\end{array}$ \\
\hline Corn & 1.8 & 180 \\
\hline Grain Sorghum & 0.3 & 30 \\
\hline Citrus Waste & 1.9 & 210 \\
\hline Whey & 0.9 & 90 \\
\hline Others & 1.7 & 150 \\
\hline TOTAL & & 660 \\
\hline
\end{tabular}

United States. It should be noted that once a significant ethanol industry is established, it will provide a predictable market for feedstocks which can be included in the projections of future United States markets.

Government Policies. As a result of the shift toward capital- and energy-intensive agricultural practices, U.S. agriculture has shown periods of overproduction. The Federal price suppoirt and stabllization pulicy designed to offset this overproduction has included long-term land retirement programs to remuve cropland from intensive cultivation and renewable yearly set-aside programs: Little or no grain cropland is remnved from production under either the long-term diversion or yearly set-aside program at present.

\section{Historic Trends of Feedstock Supplies}

Table III-7 shows trends of corn production, utilization, and carry-uver' stocks from 1965 to 1978. During the 1970 's, an average of about 65 million acres was harvested and the data of Tahle III-7 reflects the variations in productivity reported in Figure III-5. During the 1972 to 1974 period, a sharp decline in productivity and total production was recorded. During that period, foreign demand increased significantly. As a result, stocks, i.e., one of the elements through which fluctuations in supplies and prices can be damped, declined sharply. Concurrently, as discussed below, prices rose by over 60 percent between 1972 to 1974 . The supply and price of other feedstocks could undergo similar fluctuations.

These fluctuations in feedstock supplies are a fact of life which must be faced by ethanol producers. Food proc- 
Table III.7. Historical Trends of Corn Production, Utilization, Stocks, and Costs

\begin{tabular}{ccccc}
\hline Year & $\begin{array}{c}\text { Production } \\
\text { (Million } \\
\text { Bushels) }\end{array}$ & $\begin{array}{c}\text { Utilization } \\
\text { (Million } \\
\text { Bushels) }\end{array}$ & $\begin{array}{c}\text { Stocks } \\
\text { (Million } \\
\text { Bushels) }\end{array}$ & $\begin{array}{c}\text { Price }^{2} \\
\text { (\$/Bushel) }\end{array}$ \\
\hline 1960 & 3,907 & 3,678 & 1,787 & --- \\
1965 & 4,103 & 4,409 & 1,147 & 1.32 \\
1970 & 4,152 & 4,494 & 1,005 & 1.47 \\
1971 & 5,646 & 5,188 & 667 & 1.23 \\
1972 & 5,580 & 6,000 & 1,126 & 1.91 \\
1973 & 5,671 & 5,896 & 708 & 2.95 \\
1974 & 4,701 & 4,826 & 484 & 3.12 \\
1975 & 5,829 & 5,793 & 361 & 2.75 \\
1976 & 6,266 & 5,784 & 399 & 2.30 \\
1977 & 6,357 & 6,110 & 884 & --- \\
1978 & 7,082 & --- & -- & -- \\
\hline
\end{tabular}

'Carryover Stocks, Oct. 1

2Price on the Chicago Market essing plants such as for coffee face some of the same uncertainties in supplies, fluctuations due to variations in productivity, and changes in policies by producers of the raw material. Potential ethanol producers must recognize this and explore ways of reducing the impact of these unavoidable fluctuations on the operation (and profitability) of their plant.

\section{COST OF FEEDSTOCK}

\section{Historic Perspective of Feedstock Costs}

Table III-8 shows wholesale prices for corn, soybean meal, and distiller's grains on the Chicago market for the 1970 to 1979 period for January and July of each year. Also included is the approximate price for stillage, derived from the historical relationship between stillage price and those for soybean meal and corn. The data of the table show that significant fluctuations in prices of corn and the coproducts of distillation occur on a yearly basis. These have been related earlier to fluctuations in production as well as changes in demand (national and foreign). Seasonal variations also occur as shown by comparing the data for January and July; in many cases, summer prices are higher than winter.

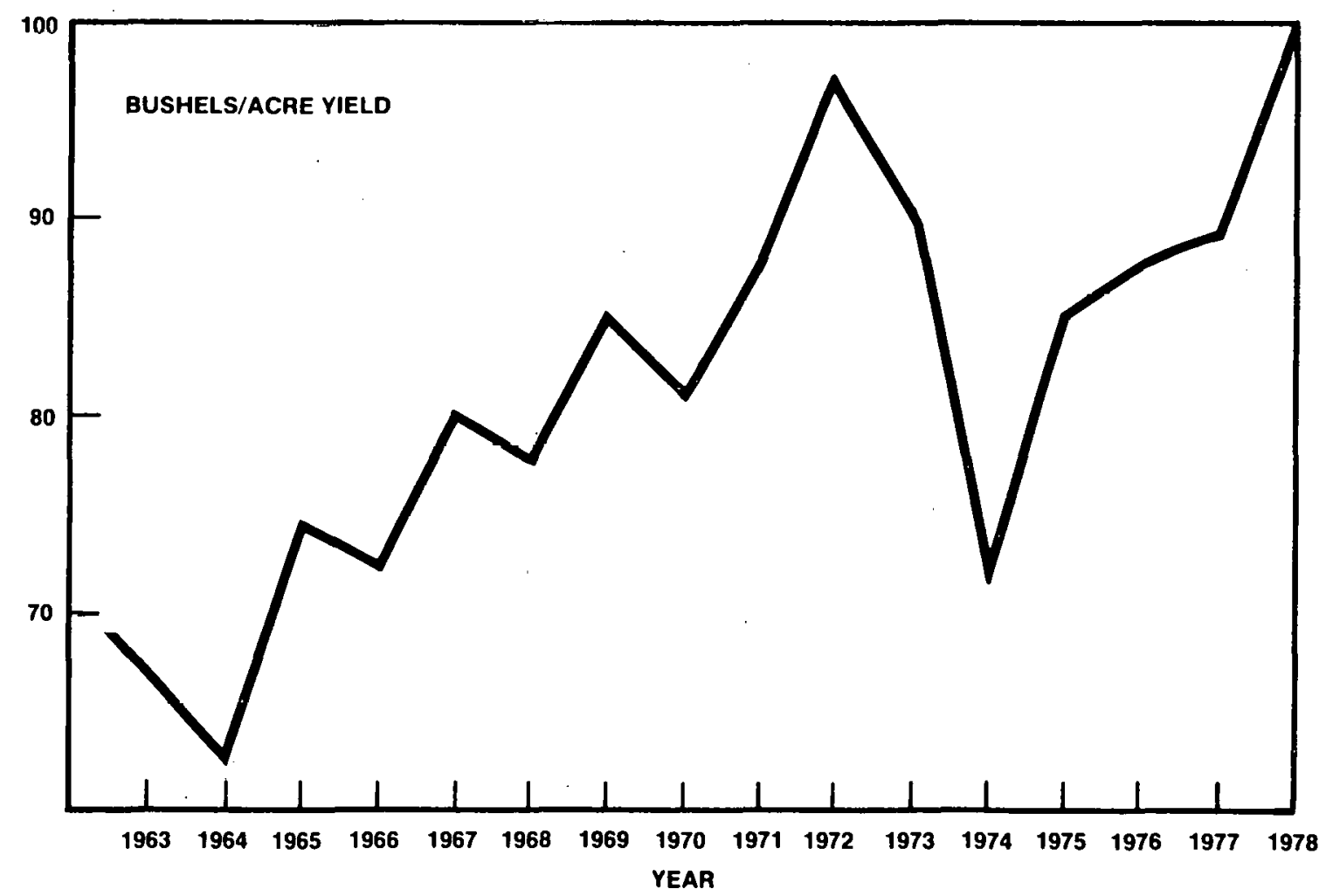

SOURCE: U.S. Department of Agriculture. "Statement of Bob Bergland, Secretary of Agriculture before the Committee on Science and Technology, Subcommittee on Energy Development and Applications, Honorable Richard Ottinger, Chairman. House of Representatives, USDA 1032-79, May 4, 1979

Figure III-5. U.S. Corn Crop Yields, 1963 to 1978 
Another important fact apparent from the data is the correlation between DDG or stillage prices and those of corn and soybean meal: at constant soybean meal price, DDG or stillage prices increase with that of corn and vice versa. At constant corn price, the price of DDG or stillage increases and falls with that of soybean meal. This is an important relationshıp since under cèrtain circumstances, an increase in corn feedstock price resulting from the expected fluctuations in price for this commodity could be partly compensated by the increased value of the coproduct from ethanol production.

As an example, the data of Table III-8 for January 1973 and 1974 show that the per-gallon cost of raw material for ethanol production would have jumped from $\$ 0.62$ in 1973 to $\$ 1.09$ in 1974 , assuming a conversion rate of 2.5 gallons per bushel. The value of DDG, i.e., a credit toward feedstock price, simultaneously would have increased per gallon of ethanol from $\$ 0.33$ in 1973 to $\$ 0.45$ in 1974 on the basis of a production of $6.5 \mathrm{lbs}$ of DDG per gallon of ethanol. The net price of the raw material (feedstock price minus credit) would therefore have been $\$ 0.29$ and $\$ 0.64$ per gallon in 1973 and 1974 , respectively. This is a large increase in feedstock price, i.e., 121 percent, but nevertheless smaller than the increase which would have been incurred had the price of DDG been kept at its 1973 level, i.e., 162 percent.

These related feedstock and coproduct prices also could be advantageous to the producer. Between 1975 and 1976 (January prices, Table III-9), the price of corn decreased by about 22 percent while that of DDG remained essentially constant. As a result, the net price per gallon for the feedstock (feedstock minus credit) decreased from $\$ 0.98$ to $\$ 0.69$ over the same period, i.e., a decrease of about 30 percent.

These two cxamples indicate that the impact of fluctuations in feedstock prices on alcohol production costs, while puleintially very significant, must be evaluated in the context of the overall market situation for the grains and coproducts. The discussion also suggests that the profitability of the ethanol plant should be examined on a plant-life basis, i.e., over a period long enough that the fluctuations in feedstock and coproduct prices compensate each other. This somewhat unpredictable economic performance may be difficult to make acceptable to potential investors. To a certain extent, the investor can anticipate the fluctuations in feedstock prices around a generally predictable trend. (As an example, see Figure III-6 for corn average selling prices.)

\section{Methods of Procurement of the Feedstock}

As indicated in thc previous section, it is necessary for the ethanol producer to explore methods of procurement of feedstocks which will ensure a continuous flow of raw material despite expected fluctuations in production of the crop.

Feedstock purchase on the commodity market is the most direct method of raw material procurement. This option, however, puts the ethanol producer in direct competition with other users of the commodity and therefore, the commodity price will be extremely sensitive io supply and deinand relationships.

Table III-8. Wholesale Prices of Corn and Other Commodities on the Chicago Market

\begin{tabular}{|c|c|c|c|c|c|c|c|c|c|c|}
\hline \multirow{3}{*}{ YEAR } & \multicolumn{5}{|c|}{ JANUARY 1} & \multicolumn{5}{|c|}{ JỤLY 1} \\
\hline & \multicolumn{2}{|c|}{$\begin{array}{l}\text { \#2 YELLOW } \\
\text { CORN }\end{array}$} & \multirow{2}{*}{$\begin{array}{c}\begin{array}{c}\text { SOYBEAN } \\
\text { MEAL }\end{array} \\
\text { S/TON }\end{array}$} & \multirow{2}{*}{$\begin{array}{c}\begin{array}{c}\text { DISTILLERS } \\
\text { GRAINS }\end{array} \\
\text { :TON }\end{array}$} & \multirow{2}{*}{$\begin{array}{c}\text { STILLAGE } \\
\begin{array}{c}1000 \\
\text { GAL2 }\end{array}\end{array}$} & \multicolumn{2}{|c|}{$\begin{array}{l}\text { \#2 YELLOW } \\
\text { CORN }\end{array}$} & \multirow{2}{*}{$\begin{array}{c}\begin{array}{c}\text { SOYBEAN } \\
\text { MEAL }\end{array} \\
\text { SIIUN }\end{array}$} & \multirow{2}{*}{$\begin{array}{c}\begin{array}{c}\text { DISTILLERS } \\
\text { GRAINS }\end{array} \\
\text { TONO }\end{array}$} & \multirow{2}{*}{$\begin{array}{c}\text { STILLAGE } \\
\begin{array}{c}8 / 1000 \\
\text { GAL }\end{array}\end{array}$} \\
\hline & $8 / B U^{i}$ & $8 /$ TON & & & & 8/BU & $8 /$ TON & & & \\
\hline 1979 & 2.24 & 80.00 & 194.60 & 141.00 & 45.76 & 3.04 & 108.60 & 218.30 & 151.10 & 53.03 \\
\hline 1978 & 2.18 & 77.90 & 182.60 & 130.00 & 43.64 & 2.40 & 85.70 & 186.10 & 120.00 & 45.15 \\
\hline 1977 & 2.48 & 88.60 & 209.70 & 140.00 & 49.09 & 2.20 & 78.60 & 184.70 & 140.00 & 43.64 \\
\hline 1976 & 2.58 & 92.10 & 136.00 & 105.00 & 40.61 & 3.05 & 108.90 & 232.40 & 130.00 & 55.45 \\
\hline 1975 & 3.32 & 118.70 & 139.80 & 107.50 & 42.73 & 2.81 & 100.00 & 124.30 & 103.00 & 40.61 \\
\hline 1974 & 2.72 & 97.10 & 174.80 & 138.00 & 46.67 & 3.06 & 109.30 & 107.80 & 92.50 & 39.41 \\
\hline 1973 & 1.54 & 55.00 & 189.10 & 100.00 & & 2.38 & 85.00 & 306.60 & 138.00 & \\
\hline 1972 & 1.20 & 42.90 & 87.50 & 64.00 & & 1.26 & 45.00 & 106.20 & 71.00 & \\
\hline 1971 & 1.58 & 56.40 & 85.90 & 70.00 & & 1.52 & 54.30 & 88.00 & 67.00 & \\
\hline 1970 & 1.23 & 44.00 & 84.50 & $64.00^{\circ}$ & & 1.39 & 49.60 & 85.70 & 61.00 & \\
\hline
\end{tabular}

SOURCE: USDA "Small-Scale Fuel Alcohol Production, "Washington, D.C., March 1980. 


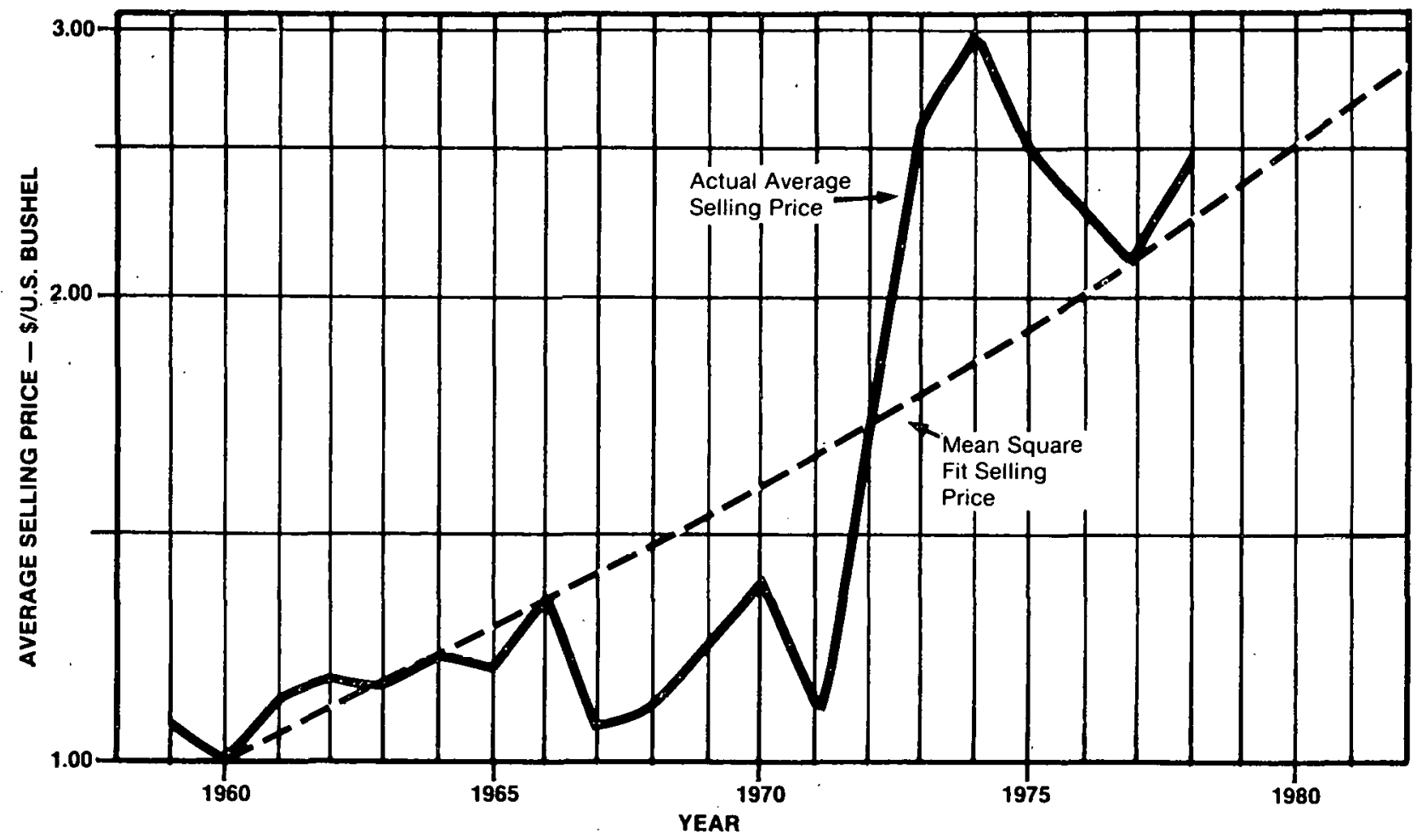

SOURCE: Raphael Katzen Associates, "Grain Motor Fuel Alcohol Technical and Economic Assessment Study," Department of Energy Contract No. EJ-78-C-01-6639, December 1978.

Figure III-6. The Selling Price of Corn

Another option is to secure long-term contracts with farmers for the supply of a fraction of the needed raw material, and rely on the commodity market for the remainder. In this case, purchases on the commodity market can be scheduled to benefit from downward price trends. Long-term contracts with farmers may have to include indexing clauses to account for inflationary trends. Because of the high energy inputs required by intensive farming (fuels and fertilizers), specific indexing agreements addressing these energy costs may have to be negotiated. Also, direct supply contracts with producers may raise problems of storage of the delives ed law materlal.

Other options which address specific or special circumstances may be considered. A cooperative ethanol production facility including farmer members may require delivery from the farmer members of a specified amount of raw material over a certain time as part of the coopcrative cliatler. Agreements could be negotiated between an ethanol producer and food processors whereby a long-tcrm supply of wastes is guaranteed in exchange for the service of disposing of the wastes through ethanol production.

Procurement of feedstocks for a commercial-size plant is a critical function which impacts drastically on the economics of ethanol production. The organizational chart of the proposed plant should therefore identify this function and the needed specialized personnel.

\section{Feedstock Cost Basis}

Table III-9 shows average feedstock costs per gallon of alcohol for some of the major potential feedstocks presently considered. A 15-year average (1963 to 197.7) of prices paid to farmers for the commodities, converted to 1979 dollars by using the GNP price deflator, was used, as were average yields of ethanol per unit of feedstock (data from Table IV-4).

The table shows that corn, grain sorghum, and rye are the least expensive feedstocks. Sugar cane and sugar beets compare to wheat and barley. Fruit and potato wastes have been assumed to be available at $\$ 1 / \mathrm{cwt}$ (hundred pounds) or $\$ 20 /$ ton. On that basis, the cost of these feedstocks is comparable to those of sugar crop and wheat.

\section{Factors Affecting the Cost of Feedstocks}

Productivity ur production, supply and demand relations, and to a certain extent, government policies such as the agricultural stabilization program, will affect feedstock availability and therefore feedstock prices. These have been discussed earlier. Two other factors may also affect the cost of feedstocks or the overall cost of ethanol production: government incentives promoting the use of wastes and the cost of collection of the feedstock for large-scale operations. 


\begin{tabular}{|l|c|c|c|}
\hline FEEDSTOCK & $\begin{array}{c}\text { AVERAGE YIELD } \\
\text { (GAL./TON) }\end{array}$ & $\begin{array}{c}\text { AVERAGE 1963 TO 1977 } \\
\text { PRICE PAID TO } \\
\text { FARMERS (1979 \$) }\end{array}$ & \$/GAL. \\
\hline Rye & 78.8 & $2.3 \mathrm{~b} / \mathrm{bu}$ & 1.07 \\
Grain Sorglium & 79.5 & $2.40 / \mathrm{bu}$ & 1.08 \\
Corn & 84.0 & $2.69 / \mathrm{bu}$ & 1.14 \\
Barley & 79.2 & $2.35 / \mathrm{bu}$ & 1.24 \\
Wheat & 85.0 & $3.46 / \mathrm{bu}$ & 1.36 \\
Oats & 63.6 & $1.46 / \mathrm{bu}$ & 1.43 \\
Sugar Beets & 22.1 & $31.58 /$ ton & 1.54 \\
Fruit Wastes & 13.0 & $20.00 /$ ton & 1.56 \\
Sugar Cane & 15.2 & $23.68 /$ ton & 1.60 \\
Potato Wastes & 12.5 & $20.00 /$ ton & 2.88 \\
Rice & 79.5 & $229.00 /$ ton & 4.35 \\
Potatoes & 22.9 & $99.60 /$ ton & 5.72 \\
Sweet Potatoes & 34.2 & $195.60 /$ ton & \\
\hline
\end{tabular}

SOURCE: USDA "Small-Scale Fuel Alcohol Production," Washington, D.C., March 1980

Governmeat Incentives. Prior to the Windfall Profits Tax Act, Federal law permitted the financing of solid waste disposal facilities through tax-exempt industrial development bonds. The Act expands the definition of solid waste disposal facilities to include property used primarily to process solid waste to alcohol. To be qualified as an alcohol producer under this provision, a facility must satisfy three requirements:

- The primary product obtained from the facility must be alcohol (there is no minimum proof requirement)

- More than half of the feedstock used in the production of alcohol must be solid waste or a feedstock derived from solid waste

- Substantially all of the solid waste-derived feedstock must be produced at a facility located at or adjacent to the site of the alcohol-producing facility and both facilities must be owned and operated by the same person (ownership is meant for tax purposes)

The Windfall Profits Tax Act specifies that such bonds will not be tax-exempt if they are guaranteed by the Federal government or if any payment of the principal or interest is made with funds from a Federal, State, or local energy program. The Windfall Profits Tax Act also expands the definition of a solid waste disposal facility that can be financed through tax-exempt industrial development bonds to include solid waste disposal facilities that produce steam or electricity.
These provisions of the Windfall Profits Tax Act, while not directly affecting the feedstock cost, nonetheless encourage the development of ethanol-producing plants integrated with solid waste-producing operations. The overall economics of an ethanol plant using wastes from food processing plants could therefore be more attractive than suggested by the feedstock costs shown in Table III-9. The provisions of the Act also can favor a plant using wastes to produce the process steam and/or electricity required by an ethanol plant. The use of bagasse, i.e., cellulosic residue from sugar carıe processing, to luel process steam bollers would benefit from the provisions of the Act, for instance.

Grain Assembly Costs. A commercial 50-milliongallon-per-year plant will require about 20 million bushels of grain annually. The cost of gathering this quantity of feedstock will depend on the density of production of grain per unit land area (bushels-p̈èr-acre or tons-per-square mile) and on the fraction of the grain which can be purchased for ethanol production.

The estimated crop production areas required to support a 50 million-gallon-per-year plan (corn feedstock) are shown in Figure 1Il-7 for the States of Illinois, Indiana, and Ohio. The density of corn production per unit land area was estimated for each State by dividing the corn grain production for 1978 (USDA -"Agricultural Statistics 1979" - Washington, DC, 1979) by the area of each state. Production densities ranged from about 21,000 bushels per square mile for Illinois, to about 9,000 bushels per square mile for Ohio. To derive the data in the figure, it is further assumed that ten per- 


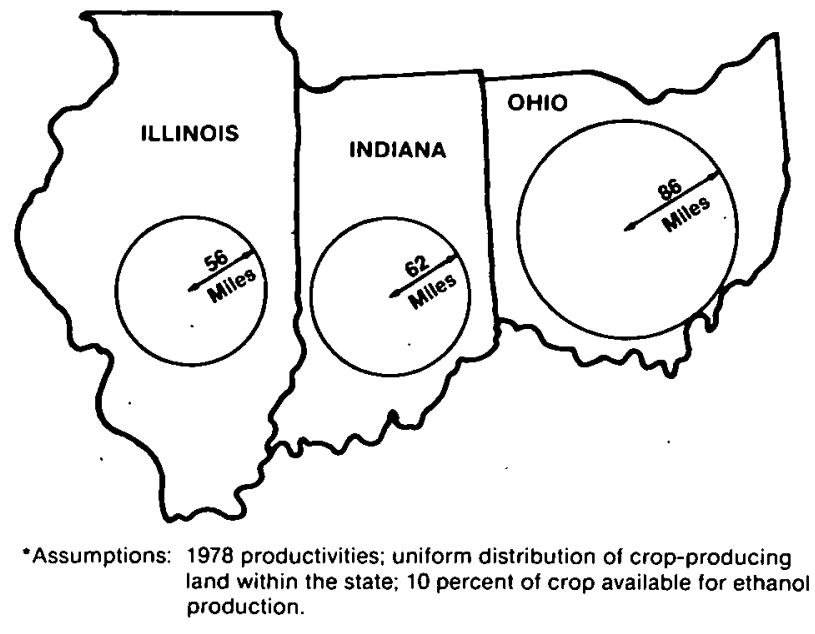

Figure III.7. Corn Production Area Required to Support a 50-million-Gallon-Per-Year Plant (Corn Feedstock)*

cent of the corn produced is available for feedstock use. The average hauling distances (i.e., radius of the circle supplying one half of the feedstock required) range from 40 miles for Illinois to 61 miles for Ohio. On the basis of the data shown in Figure IV-3, corn hauling costs would add about 4 and 5 ccnts per gallon to the cost of ethanol produced in Illinois and Ohio, respectively, for the corn assembly scenario used in the present example. Although these supplementary costs are small in absolute value, they may become significant in terms of overall alcohol production economics.

These transportation costs will become more significant as the capacity of the ethanol plant increases. It therefore will be necessary to carefully evaluate the optimum plant size for which the economy of scale associated with large plants is overridden by the supplementary cost for assembling the feedstock and disposing of the coproducts and effluents.

The cost of assembling the feedstock also will have to be weighed against the cost of marketing the products of the plant: proximity to the markets for the products, i.e., ethanol, and coproducts may be economically more attractive than proximity to the feedstock source. This problem will be discussed further in the marketing section (Chapter IV).

\section{Trends and Fluctuations in Price}

The data from Table III-8-corn prices for January 1 and July 1, 1970 to 1979 on the Chicago Market-are plotted on Figure III-8. The full line shows the trend in prices as obtained by regression of the set of data points. The slope of the line suggests a general price increase at a rate of about 8.4 percent per year, i.e., a rate comparable to the average inflation rate during the period considered.

During the period, wide fluctuations around the general trend line are observed. On the basis of a yield of 2.6 to 2.7 gallons per bushel, a fluctuation of 10 cents per bushel around the price trend line corresponds to a fluctuation of 4 cents in the cost of ethanol. The data on the table show that corn purchased in the winter of 1975 would have been about $\$ 1.00$ over the expected (trend) price line and therefore that the cost of ethanol would have been boosted by about $\$ 0.40$ per gallon during that period. Similarly, corn purchased in January 1979 would have cost about $\$ 0.80$ less than the price expected from the general trend line, resulting in a production cost for ethanol of $\$ 0.32$ per gallon lower than projected. It is therefore apparent that over a period of time, a certain amount of compensation for the fluctuations in feedstock costs could take place, resulting in relatively constant feedstock costs over that period.

Figure III-9 shows the value (July 1979 dollars) of corn feedstock over the 1970 to 1979 period. The full line shows the present values projected on the basis of the price trend shown in Figure III-8 (full line on the figure). These projected present values can be used to estimate the yearly cash flows relating to the purchase of the feedstock. The average present value for the 10-year period is $\$ 3.99$ per bushel. The data points on the figure show the present value obtained from these data points is $\$ 4.24$ per bushel. Over the 10-year period, therefore, the averaged impact of the fluctuations in corn prices around the projected trend amounts to only about $\$ 0.25$ per bushel, or about $\$ 0.10$ per gallon of ethanol. As suggested above, the impact of yearly fluctuations in corn prices could be drastically reduced when averaged over a long period, which could be the lifetime of the plant. Therefore, on that basis, the long-term economics of ethanol production may be more predictable than suggested by the scatter of data points on Figure III-8. The occurrence of the periodic fluctuations in feedstock prices, however, requires that sufficient working capital be available during periods of large fluctuations in feedstock price. This will add a financial burden to the plant cash flow stream which must be recognized and planned for.

As was indicated earlier, the most important cost elemont in determining the economics of an ethanol plant is the net price of the feedstock, i.e., the feedstock price minus the credit received for the coproducts (DDG, for instance). The impact of high corn prices, i.e., prices well above the expected historical trend, may be partially offset or enhanced by the corresponding price for DDG. High DDG prices will tend to reduce the impact of high corn prices, while depressed DDG prices will enhance it. Figure IIJ-10 shows the valuc (July 1979 dollars) of net corn feedstock prices expressed as dollars per gallon of ethanol for the 1970 to 1979 period. The 


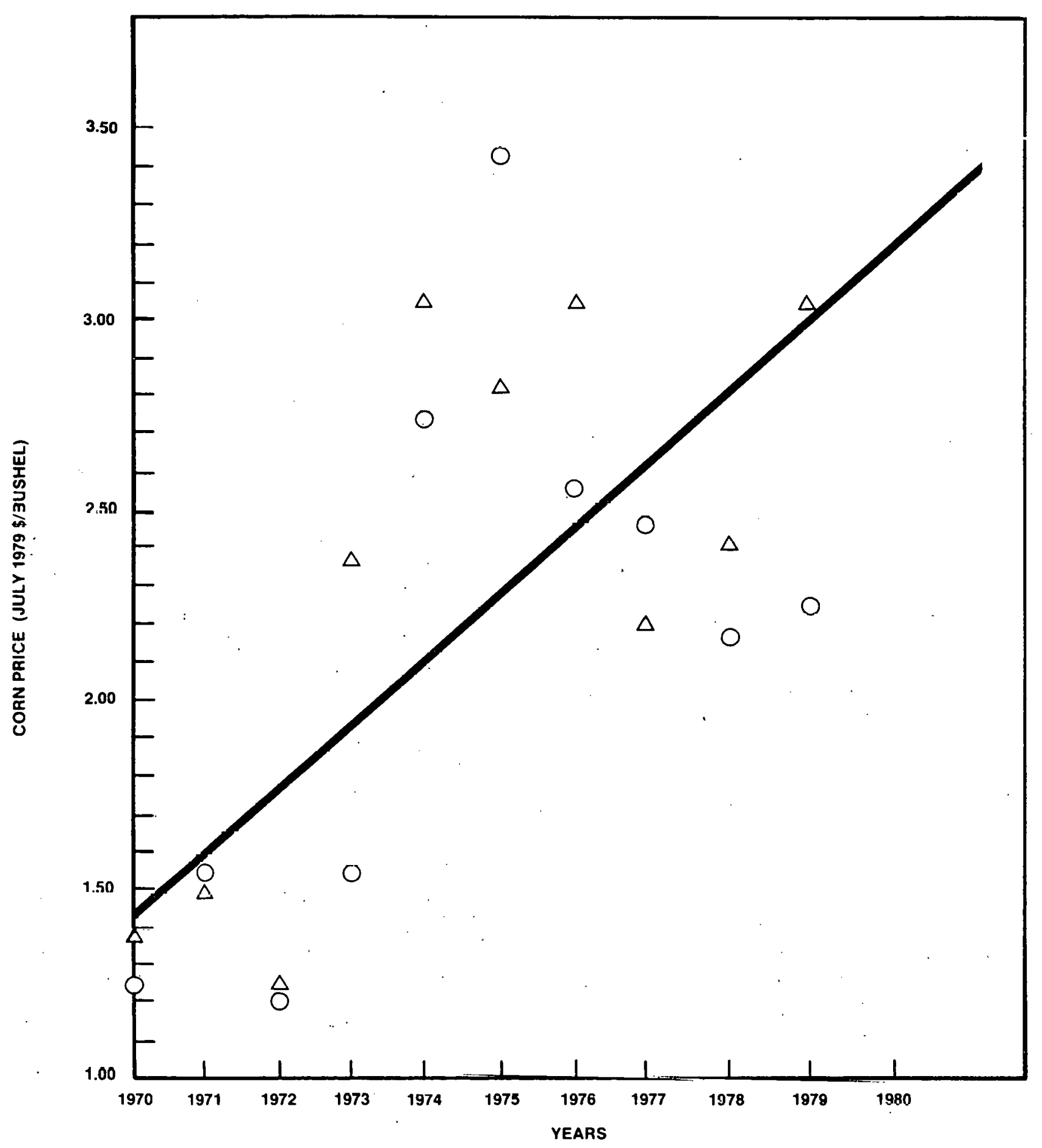

$\triangle$ JULY PRICES

JANUARY PRICES

REGRESSION LINE

'Chicago Market - Data from Table III-9.

Figure 111-8. Trends and Fluctuations in Corn Prices'

38

COMMERCIAL SCALE ETHANOL PRODUCTION AND FINANCING 


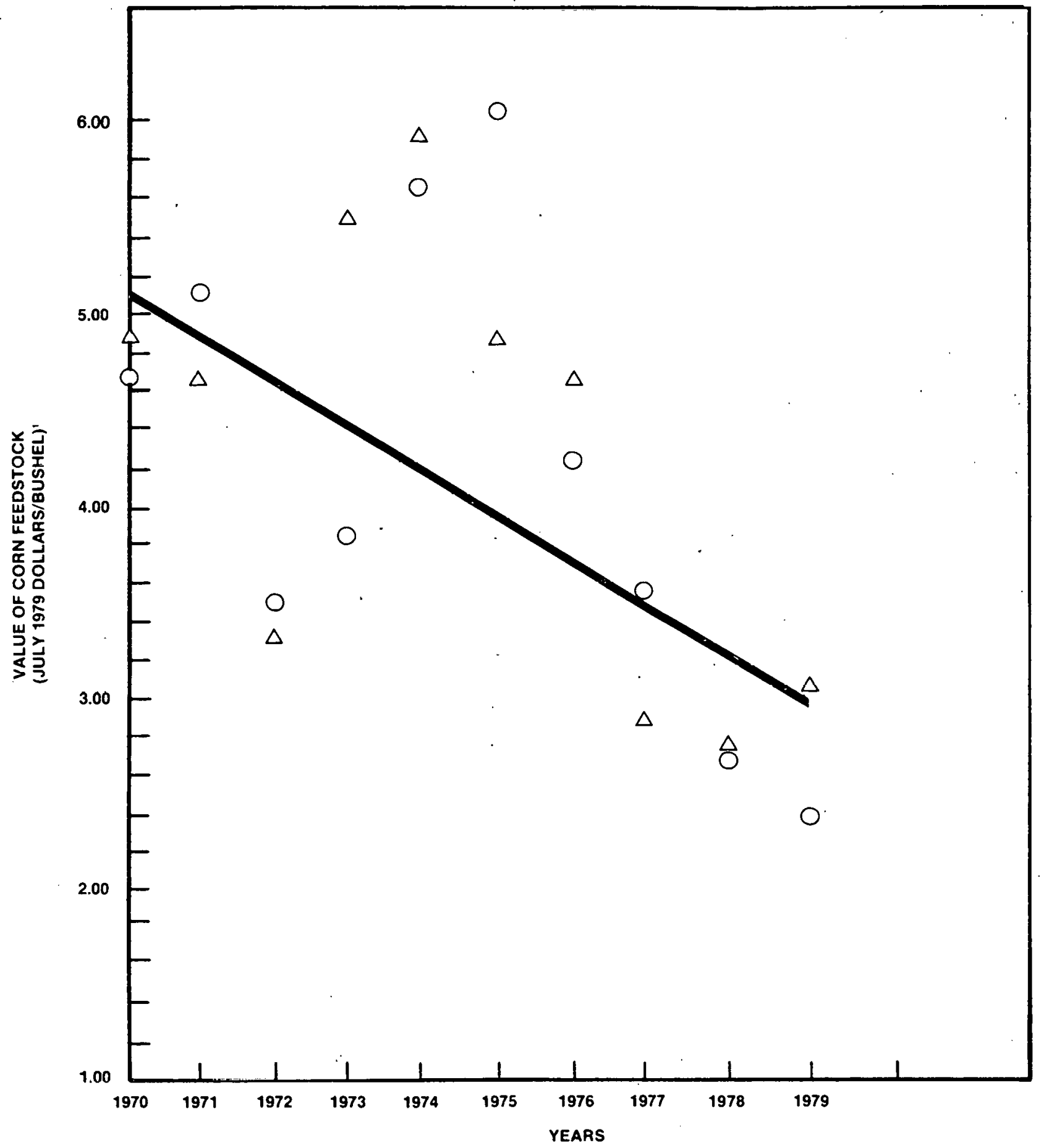

$\triangle$ JULY PRICES

O JANUARY PRICES

- PROJECTED NET WORTH BASED ON TRENDS FOR COMMERCIAL PRICES (DATA OF FIGURE III-12).

'Assumes a discount rate of 15 percent.

Figure III.9. Value of Corn Feedstock 


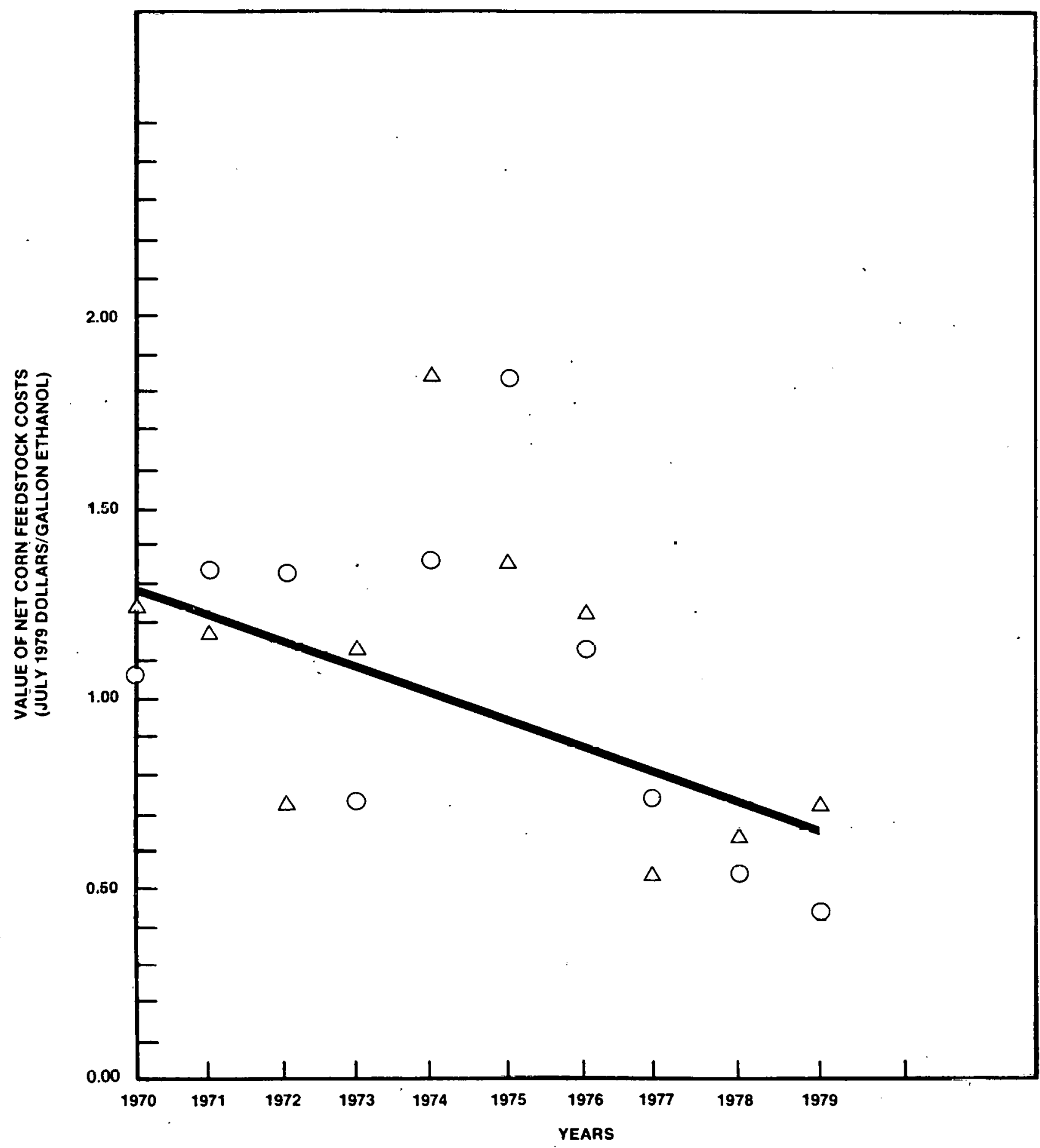
$\triangle$ JULY PRICES
O JANUARY PRICES
Projected net worth based on trends for corn and animal feed prices (Dala lrún figure III-13 and Table III-2)

Figure III-10. Value of Net Corn Feedstock Cost 
data of Table III-8 were used to estimate the data points (a 15 percent discount rate is assumed). The full line shows the projected trend for the value of the feedstock as determined by regression analysis of the data. The average value of the projected net feedstock cost over the 10-year period is about $\$ 0.95$ per gallon of ethanol. Therefore, the average impact of the fluctuations in net feedstock cost, for the 10 years considered, amounts to an average increase in net feedstock of about $\$ 0.12$ per gallon. The value of the working capital needed to purchase a six-month feedstock supply for a typical 50-million-gallon plant at the projected net feedstock cost in 1974 is about $\$ 25$ million (the value of the net feedstock cost is about $\$ 1.00$, as shown in the figure). As a result of the wide fluctuations in net feedstock cost recorded in that year, a working capital having a July 1979 value of about $\$ 46.3$ million would have been required to purchase the same quantity of feedstock at 1974 summer prices. This example illustrates the magnitude of the financial burden which may have to be incurred to secure the feedstock supply under fluctuating market conditions.

As indicated before, this burden could be alleviated if a sizable fraction of the feedstock supply could be obtained under long-term contracts at predictable prices (for instance, at prices following the projected trend lines shown in Figures III-9 and III-10). Corn prices usually rise sharply when there is a poor crop and the supply of grain for food and exports become tight. 


\section{THIS PAGE}

\section{WAS INTENTIONALLY \\ LEFT BLANK}




\section{CHAPTER IV}

\section{Markets for Ethanol and Coproducts}

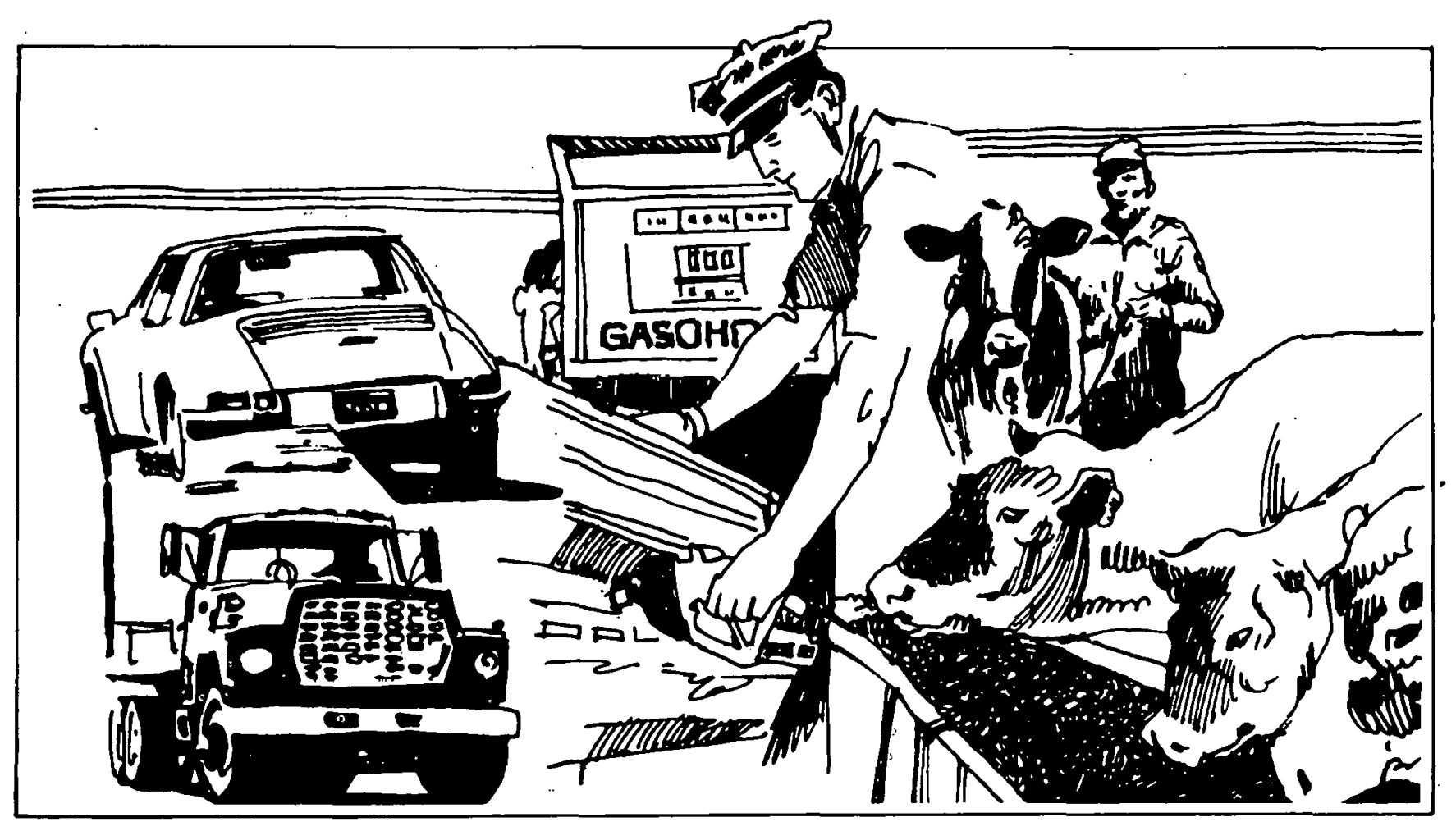

Establishing an economically viable ethanol plant requires four key elements of availability: a reliable, sufficient feedstock supply; the support resources such as process water, process energy, and labor; an adequate market for ethanol and its coproducts; and transportation for feedstock and ethanol. These elements impact directly the selection of a site for the proposed plant and the overall economics of the project. Compromises in the following arcas may need to be made to approach an ideal situation: proximity to the feedstock supply; access to plentiful water resources and renewable process energy sources; and direct access to large enough markets for ethanol and its coproducts to absorb the plant's output.

The problem of availability of the required feedstock resources has been addressed in the preceding chapter. This chapter discusses some of the characteristics of the markets for ethanol and its coproducts and examincs some of the issues to be addressed by a potential investor.

\section{ETHANOL FUEL}

\section{Ethanol as a Fuel and as a Chemical}

Ethanol may be used in various forms for fuel:

- As a blend with gasoline in various proportions

- As hydrated lower-proof ethanol

- As neat anhydrous ethanol

- As fuel supplement in dual-carbureted diesel engines

Ethanol also is used as a chemical in such industries as pharmaceuticals and perfumes. Each of these potential markets for ethanol has some constraints which bear on the decisionmaking process of producing ethanol. Some of these constraints result from the differences in the properties of fuel ethanol compared to petroleum-based fuels now used.

Fuel Properties of Ethanol. Table IV-1 summarizes some of the properties of ethanol and other fuels. 
Table IV.1. Summary of Ethanol and Other Fuel Properties

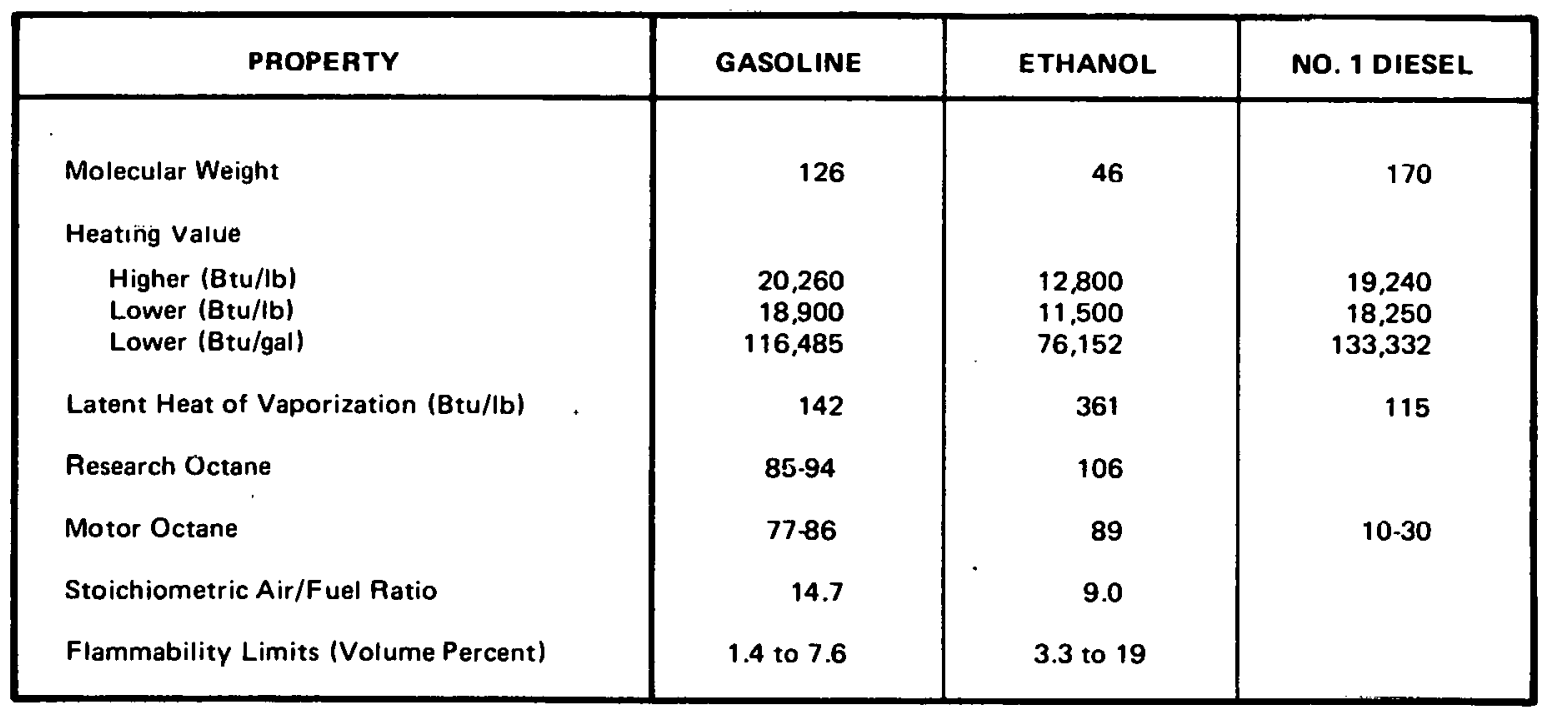

Blending ethanol with other fuels results in mudifica= tions to the properties of the original fuel. Adding 10 percent ethanol to gasoline results in a lowered energy content (about 112,000 Btu per gallon for gasohol versus about 116,000 Btu per gallon for gasoline) but a higher octane number. The stoichiometric air-to-fuel ratio for the blend also will be quite different from that of gasoline as the percentage of ethanol in the blend is increased. Therefore, as more ethanol is added to the blend, the air/fuel mixture of a carburetor set for gasoline becomes less favorable and the driveability of the vehicle may be affected. Comparative fuel econonny for gasohol- or gasoline-operated vehicles is still a mätter of controversy. In some instances, improved mileage has been claimed for gasohol-operated vehicles but in most cases, mileage has not changed. I'he direct use of ethanol in diesel engines is difficult without major engine modifications. Under present engine designs, ethanol does not meet the fuel specifications of diesel engine manutacturers. Therefore, ethanıul cannot presently be substituted for diesel fuel. Ethanol-diesel fuel mixtures have unfavorable self-ignition characteristics due to the low self-ignition tendency of ethanol, and the performance of blend-fed engines is strongly affected. The best approach at present appears to be carbureting ethanol in the diesel engines. This, however, requires engine modifications and separate ethanol and diesel fuel tanks.

If the market for diesel fuel warrants it, there are well established alternative fermentation technologies which can produce diesel fuels from biomass. For example, butanol is readily produced by fermentation and this is an excellent diesel fuel. If the producers wished to switch from ethanol to a diesel fuel, this would require only a change from yeast to another biocatalyst and some modifications in distillation equipment.
Ethanol-Gasoline Blends. Because of the phass separation problems occurring when hydrated ethanol (less than $200^{\circ}$ proof ethanol) is mixed with gasoline, ethanol-gasoline blends usually include anhydrous $\left(200^{\circ}\right.$ proof) ethanol. Such blends have been used for many years in various countries. A blend of 90 percent unleaded gasoline and 10 percent anhydrous ethanol is marketed at present in many states under the name gasohol.

Despite the controversy concerning the fuel efficiency of gasuliul veisus gasoline, gasohol has boen woll received by the public and is yenter ally aciepted as a substitute for gasoline. The present political climate and the desire to reduce the nation's dependence on foreign energy supplies may be some of the motivating factors behind the adoption of gasohol. If the present trends are maintained, i.c., if the use of gasohol continues to be encouraged by state and Federal governments and if the public continues to accept gasohol as a suhstitute for unleaded gasoline, the potential market for ethanol is about 10 billion gallons per year if a 10 percent blend is used.

Hydrated Ethanol. Hydrated ethanol (less than $200^{\circ}$ proof) can be burned efficiently in internal combustion engines with minor engine modifications. The carburetor jet size must be enlarged slightly when converting from gasoline to ethanol because the ethanol component contains less useful energy pcr unit volume than gasoline (see Table IV-1). With most engines, it is also desirable to modify the intake manifold to ensure proper vaporization of the ethanol so that all cylinders will be operated with the same air-to-fuel ratios.

The use of hydrated ethanol fuel would have major advantages for the producer. The last step in the usual 
process of ethanol refining that is the dehydration of the azeotrope could be eliminated. The most likely hydrated ethanol fuel would be one of about $186^{\circ}$ proof, which can easily be obtained at relatively low energy consumption directly by single distillation of the fermenter beer. Major savings both in equipment and energy consumption would result with significant reduction in cost for this product. The use of $186^{\circ}$ proof as 93 percent ethanol is likely because this is the aim of the Brazilian effort and both General Motors and Volkswagen are already producing or will produce automobiles for the Brazilian market which are designed to make use of $186^{\circ}$ proof fuel. Also, the engine modifications required to make appropriate use of this fuel are modest compared to those required for the use of $160^{\circ}$ proof fuel or the like.

The use of hydrated ethanol has certain drawbacks. There will be a reduced mileage range per tank as compared to gasoline. Problems due to the possible accumulation of water are possible but are easily circumvented by appropriate designs and with this fuel there is no danger of freezing at low temperatures. Thus, while the direct hydrated ethanol market may have only a limited attractiveness for a period of time for commercial-sized ethanol plants, a major conversion to the use of this fuel rather than anhydrous ethanol in gasohol could be possible.

Anhydrous Ethanol Fuel. Anhydrous ethanol can be burned directly in spark-ignition engines using essentially the same modifications discussed above for the use of hydrated ethanol. Ethanol may also be used in furnaces, boilers, or gas turbines. In the latter case, efficiencies slightly higher than those obtained with hydrocarbons have been recorded. At present, however, the market for anhydrous ethanol fuel appears limited to blending with gasoline.

Diesel Fuel Supplement. As indicated above, diesel engines can operate on separately carbureted anhydrous ethanol and diesel fuel. Engine modifications and separate tanks for the two fuels are required. Thus, the market for ethanol in this application probably will be limited.

Industrial Applications of Ethanol. The chemical industry consumes large quantities of industrial ethanol as either feedstock or solvent. In the latter case, one of the major consumers is the pharmaceutical industry, requiring extremely pure ethanol. Industrial ethanol also can be the feedstock to produce'two important industrial chemicals: acetic acid and ethylene. Acetic acid can be obtained directly from ethanol by fermentation; ethylene may also be derived from ethanol.

At present, most industrial ethanol is produced from petroleum or natural gas-derived ethylene. The cost of industrial ethanol therefore is directly related to those of petroleum and natural gas. As petroleum-derived industrial ethanol costs continue to climb paralleling the cost of petroleum and natural gas, fermentation-derived ethanol will become more attractive as an industrial feedstock or chemical. The potential annual market for industrial ethanol alone is on the order of 200 million gallons.

Impact of Ethanol Fuel on Petroleum Import Requirements. The previous discussion suggests that the most attractive market for commercial-size fermentation ethanol plants is ethanol to be used as a blend with gasoline, i.e., gasohol. Despite the slightly lower thermal value per unit volume of gasohol compared to gasoline, no significant fuel mileage decrease has been recorded when gasoline is replaced by gasohol. Ethanol, therefore, can displace a quantity of gasoline equivalent to the proportion of ethanol in the gasohol blend.

The addition of ethanol to gasoline increases the octane rating of the blend because anhydrous ethanol is a higher octane fuel. In the past, the octane rating of fuels was increased by adding tetraethyl lead. Because of the adverse effects of lead compounds on humans, the conversion to unleaded gasoline was mandated some years ago. The changes in refinery operations required to produce fuel of a given octane without lead additives reduce the quantity of fuel produced from a barrel of crude oil. The octane-boosting process requires additional energy in the refining process, energy lost from every barrel processed. The addition of ethanol to gasoline gives the required octane boost without the supplementary energy expenditure in the refining process. Therefore, every barrel of ethanol produced decreases the crude oil demand not only by the quantity of gasoline directly replaced by the ethanol but also by the crude oil saved as a result of the value of ethanol as an octane enhancer.

Problems of Storage, Handling, Blending, and Distribution. Small amounts of water in the ethanol will cause the separation of ethanol-gasoline blends in two layers, water-alcohol and gasoline. This separation will result in poor engine performance. It is therefore necessary that ethanol be kept anhydrous during transportation prior to blending with gasoline. The points at which blending of ethanol with gasoline could occur are at the refinery during loading of trucks, the pipeline terminal as the trucks are loaded, or the retail station by means of a blending pump. In view of the bulk quantities involved when dealing with the output of a commercial operation, the first two blending options are preferred. Hydrated ethanol, on the other hand, offers very little problems and is readily handled by commercial equipment.

Blending shortly before use will have an impact on the economics of ethanol fuel. The costs of transportation 
of ethanol from the production facility to the point of blending and the storage of ethanol at the site of blending will have to be added to the retail price of ethanol.

The cost of transportation has been estimated to be about $\$ 0.008$ per gallon for the first 20 miles plus about $\$ 0.003$ per gallon for each additional 20 miles traveling distance (1980 dollars). The cost of storage facilities is estimated to be about $\$ 0.10$ per gallon capacity for a 50-million-gallon-per-year facility. With adequate maintenance, the life of storage facilities may exceed 40 years. The proximity of a pipeline terminal or refinery may therefore be a desirable feature when siting an ethanol plant.

\section{Major Ethanol Producers and Distributors}

The principal promoters of gasohol to date have been independent oil companies. 'l'exaco, Inc. has, taken a lead role and is currently retailing gasohol at most of its outlets. Besides Texaco, prominent distributors of gasohol include Atlantic-Richfield Oil Company and Standard Oil Company (division of Amoco Oil Company). The major companies as a group have shown reserve in entering the market. Nevertheless, some major oil companies are test marketing gasohol. These firms include Cities Service Company, Phillips Petroleum Company, Standard Oil Company of Indiana, and Diamond Shamrock.

In addition, some major oil companies are discussing joint-venture arrangements with large food processors. Three of these joint-venture arrangements include:

- Texaco and CPC International

- Chevron and American Maizc

- Ashland Öil ánd Publickeı lıúlusiti'ies

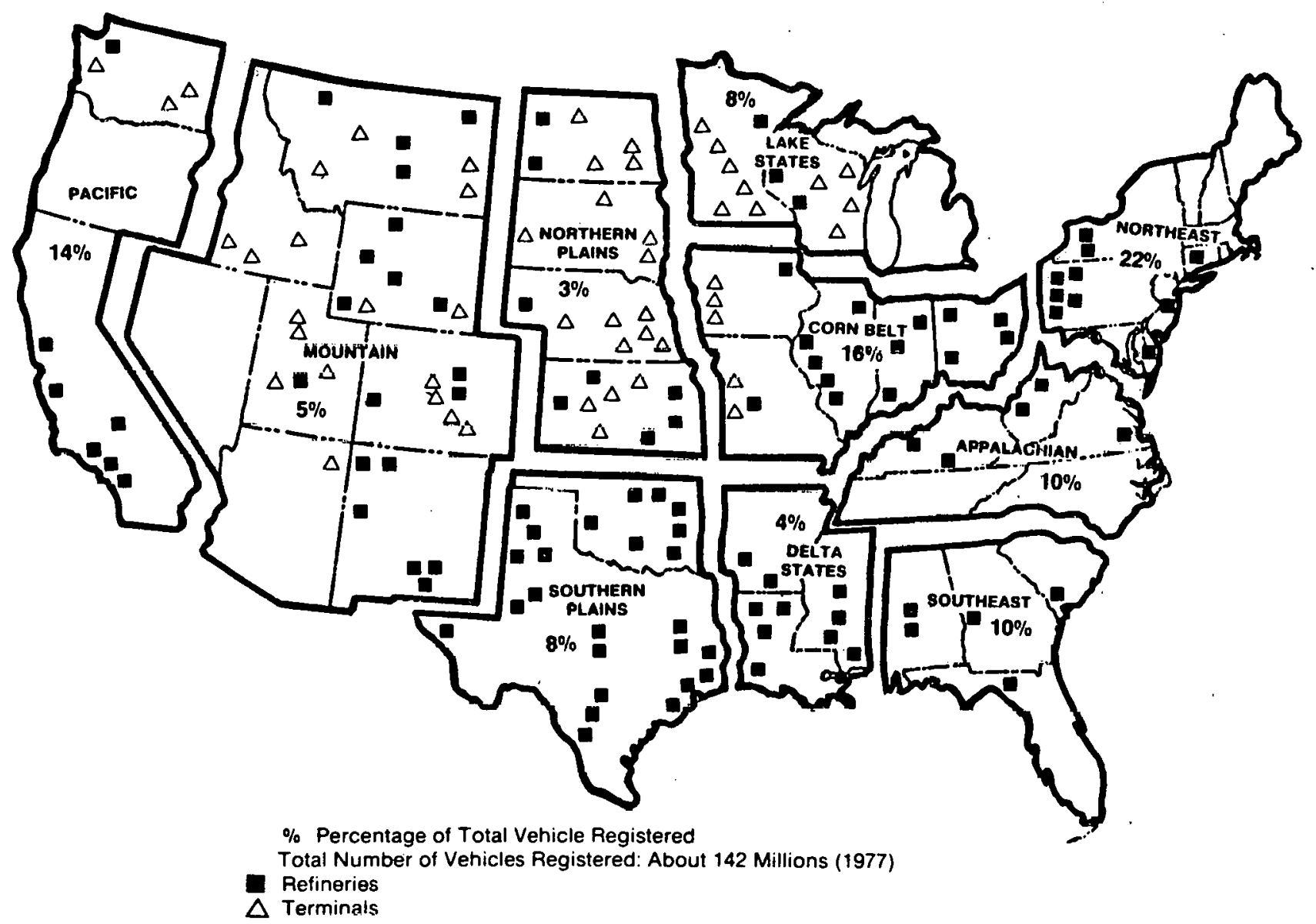

SOURCE:

U.S. Department of Commerce, "Statistical Abstract of the United States, 1978", 99th Annual Edition, Washington,

D.C., 1978.

M. L. David, G. S. Hammaker, R. J. Buzenberg, and J.P. Wagner, "Gasohol Economic Feasibility Study", Report prepared for Energy Research and Development Center. University of Nebraska, Development Planning and Research Associates, Inc., Mannattan Kansas, p. 261, July 1978.

Figure IV-1. Percentage of Motor Vehicles Registered by USDA Farm Regions and Location of Refineries and Terminals 
Some of the major ethanol producers are listed in Table IV-2 and fuel ethanol plants, which have been projected for the near term, are listed in Table IV-3. Neither the total national production capacity including small producers nor the amount of ethanol sold for fuel is well defined at present.

Table IV-2. Major Ethanol Fuel Producers

\begin{tabular}{lc}
\hline Producers & $\begin{array}{c}\text { Capacity } \\
\text { (Million Gallons/Year) }\end{array}$ \\
\hline Eastman & 25 \\
USI & 66 \\
Publicker & 60 \\
Union Carbide & 120 \\
Archer Daniels Midland & 100 \\
$\quad$ Company & 4.6 \\
Georgia Pacific & 15 \\
Midwest Solvents & \\
\hline
\end{tabular}

\section{MARKET FOR ETHANOL}

\section{U.S. Market for Gasohol}

In 1979, approximately 50 million gallons of ethanol were used to produce gasohol in the United States. The gasohol was sold through the almost 2,000 retail outlets. Most of the gasohol was made with unleaded gasoline so it could compete against premium unleaded fuels. However, some gasohol utilized regular gasoline. The latter mixture primarily served to extend gasoline supplies during shortages.

Consumer reaction to gasohol has been very favorable, especially in the farming community. Generally, motorists rate the product high in terms of engine performance. It is no surprise that gasohol acceptance appears to be increasing, as is the number of companies selling gasohol.

Gasohol test market results show penetration rates of 8 to 30 percent of overall gasoline sales. In areas such as the Midwest where gasohol has been promoted extensively, a near-term penetration rate of 20 percent of gasoline sales appears reasonable. In less developed markets, a conservative estimate of 10 percent penetration may be more realistic in the short term.

The near-term gasohol penetration rate could increase significantly under conditions of gasoline shortage or gasoline price rises relative to ethanol. Many motorists contend that gasohol must overcome its price disadvantage relative to gasoline before its use becomes more widespread.
A factor which once constrained gasohol sales was the difficulty for retailers to get unleaded gasoline allocations for blending. However, gasoline supplies currently appear available. To the extent that supplies remain adequate, this constraint will be moderate. In addition, the DOE is considering changes in gasoline allocation rules to assign automatically unleaded gasoline to blenders of gasohol. The oil companies are expected to oppose these changes, however, because such gasoline assignments would take gasoline away from existing customers.

In the future, the sales potential of gasohol as an unleaded fuel may increase. If for no other reason, the percent of gasoline sales comprised of unleaded fuel is increasing as new vehicles (using only unleaded fuels) replace older ones.

\section{Reglonal Markets for Ethanol Fuel}

One important consideration in the siting and planning of an ethanol plant is the proximity of a market for the fuel produced and of blending sites. Figure IV-1 shows the percentage of the total number of vehicles registered by USDA regions. Also plotted on the figure are approximate locations of refineries and pipeline terminals. A few facts are apparent from the figure:

- The preferred sites for blending of ethanol with gasoline, i.e. refineries and terminals, are widely available within most regions and in particular in the Lake States, Northern Plains, and Corn Belt regions where the largest fraction of the grain feedstocks is produced (refer to Figure III-5). .

- Only about 27 percent of the vehicular fleet is registered in the three major grain-producing regions. Marketing of ethanol produced in those regions will therefore have to include shipment of ethanol or gasohol to large vehicular markets such as the Northeast, Appalachian, and Southeast regions (combined fleet: 42 percent of the national total). A compromise between siting of the plant in the vicinity of the feedstock resource and close to the market for ethanol may have to be reached.

Government Policies and the Market for Ethanol. The major impact of government policies on the market for ethanol will be through enhancing the economic attractiveness of ethanol over fossil fuels. The excise tax exemption, as well as a 10 percent additional investment tax credit for facilities that convert alternate feedstocks to liquid fuels are the two major Federal policies encouraging the penetration of ethanol in the fuels market. A number of States have also eliminated the state fuel tax for ethanol blend fuels or gasohol. 
Table IV-3. Potential Ethanol Fuel Plants Near Term (Received Grants Under P.L. 96-126)

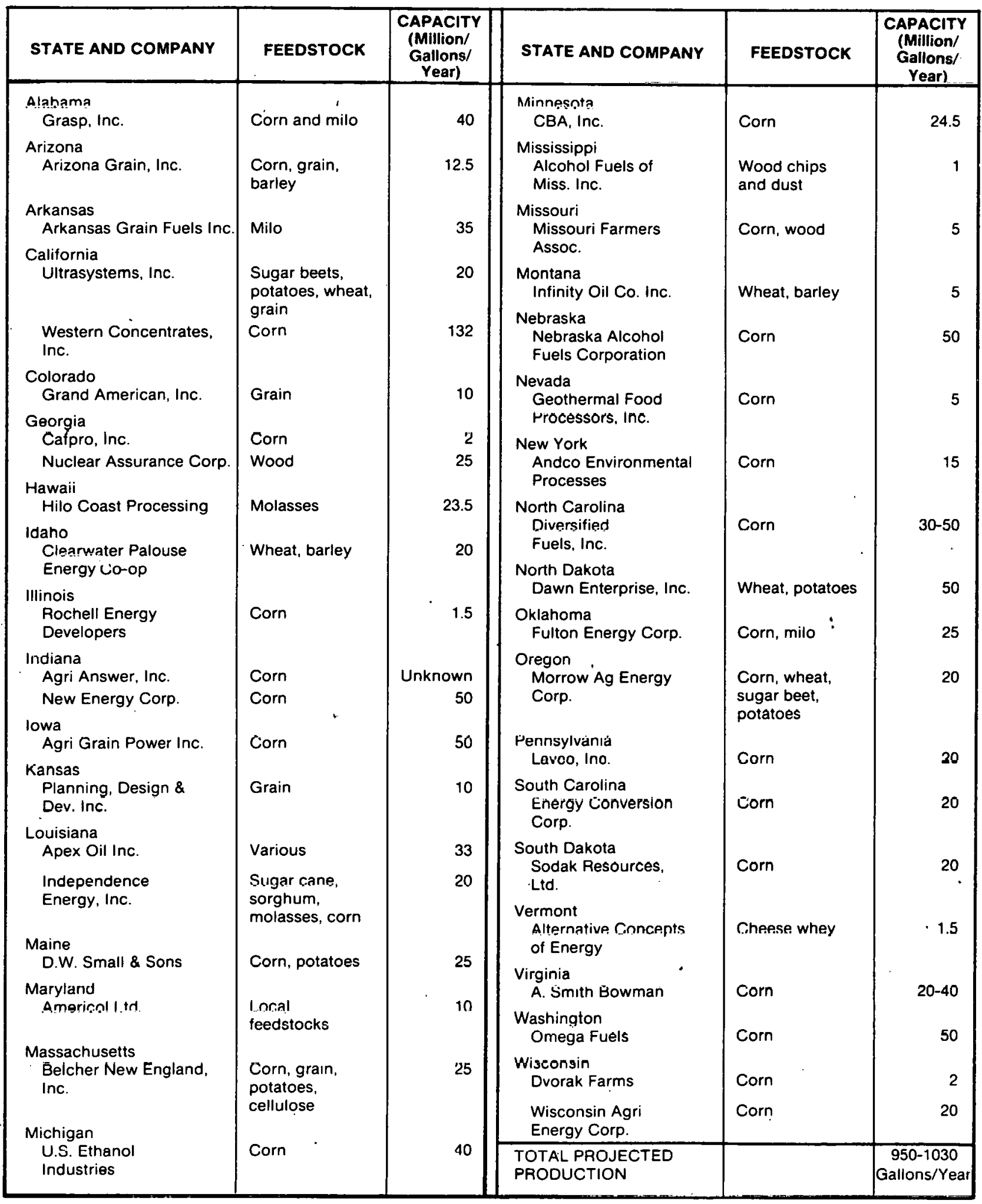


Expected Market Fluctuations. If present price and incentive policies are maintained, tending to make gasohol competitive with gasoline, and if the present reception of gasohol by the public is sustained, no drastic market fluctuations for fuel ethanol are expected. In the long run, the improved average mileage required under Federal law will somewhat tend to decrease the demand for automotive fuel. The impact on the ethanol market will, however, be small.

\section{PRICE OF ETHANOL}

Historic Review of Prices. Industrial ethanol is manufactured from ethylene. As prices of petroleum products increase, so do those of ethanol. The price of anhydrous industrial ethanol is about $\$ 2.02$ per gallon (May 1980, wholesale, f.o.b. plant).

The price of ethanol produced from agricultural feedstocks is dependent on factors such as type and price of the feedstock, plant operating life, financing terms, value of the credit for coproducts, and other factors. Recent estimates suggest market prices ranging from $\$ 1.30$ to $\$ 1.65$ per gallon (1980 dollars) for ethanol from corn and wheat feedstocks under various plant financing conditions. These market prices assume that a credit is received for the coproducts. On an energy-content basis $(\$ / B t u)$, ethanol from grain is still more expensive than gasoline. However, if one accepts equivalence in performance of gasoline and ethanol in a gasohol blend, the price of ethanol is approximately equivalent to that of gasoline. At present, gasohol retail prices (even with the tax exemptions) are equal to or higher than those for unleaded gasoline. As prices of petroleum increase, the price position of ethanol versus gasoline will further improve.

Factors Affecting the Price of Ethanol. As earlier indicated, one of the provisions of the Windfall Profits Tax is to exempt ethanol from renewable feedstocks from the Federal excise tax. This amounts to an exempLion of $\$ 0.40$ per gallon of ethanol or $\$ 0.04$ per gallon of gasohol. Similarly, many states exempt ethanol or gasohol from state taxes. The amount of the exemption varies. (Refer to Appendix D for exemption data.)

Transportation and distribution costs of ethanol increase the cost of ethanol used in gasohol blends. This is particularly true for. markets far from ethanol producinig plants. As an example, the price of gasohol in Virginia (\$0.829 in May 1979) included 1.7 cents per gallon for shipping the ethanol from Illinois.

Projected Prices and Uncertainty of Price. The market price of gasohol will follow closely that of gasoline, i.e., increase at a rate slightly higher than inflation. A 10-cent rise in price for unleaded gasoline raises that for gasohol by 9 cents. The present and nearterm projected production capacities for ethanol suggest that full production will not glut the market and depress the market price of ethanol.

The production cost of ethanol is very sensitive to net feedstock costs (feedstock cost minus credit for coproducts). As was shown in Chapter III, wide fluctuations in net feedstock costs have occurred and must be expected. Over the years, these fluctuations tend to smooth out. Their impact on fermentation ethanol prices has a relatively slight effect on gasohol prices-a 10-cent price rise in ethanol results in only a 1-cent rise in gasohol price.

There is a certain risk involved when entering the ethanol fuel business. The risk is probably related to the uncertainty of the feedstock cost rather than projected changes in demand for fuel ethanol. To minimize the risk, emphasis must be placed on securing long-term reliable feedstock supplies.

\section{COPRODUCTS OF ETHANOL MANUFACTURE}

\section{Human Food Coproducts}

As discussed in Chapter III, an ethanol production unit can be integrated with a dry or met milling grain plant. Dry and wet milling operations are very specialized industries requiring unique marketing efforts to dispose of the variety of products generated and adjust to the changes in demand for food/feed products.

The most common case of integration of an ethanol plant with such operations will probably result from the addition of an ethanol unit to an existing mill rather than the creation of an entirely new milling/ethanol complex. The former case is being implemented at the Archer Daniels Midland Company. In this instance, ethanol is really a coproduct of the major products (food and feed) of the plant and as such, is a manifestation of a desire to diversify by taking advantage of an emerging market. The other approach, i.e., creation of a totally new integrated milling/ethanol complex has some drawbacks for the prospective investor. The capital cost is much higher than for an ethanol plant; the problems of marketing are increased because of the variety of products ranging from animal and human food/feed and pharmaceutical-derivatives to fuel. Each of the components of the integrated project, i.e., milling and ethanol production, is a venture in itself including its own risks. Integrating the two components may provide some hedge against these risks but also may result in accumulated problems and risks unattractive to the investor unfamiliar with these industries. 
The remainder of this chapter will therefore assume that the main objective of the proposed plant is the production of ethanol fuel and that the major coproduct is animal feed (DDG or its equivalent).

\section{Animal Feed Coproducts}

Stillage, the residue of fermentation and distillation in the production of ethanol, contains many nutritive elements. This is particularly true of grain stillage, which has been used as animal feed or feed supplement over the years. Marketing these coproducts is essential to the economics of ethanol production. The present section focuses on coproducts resulting from the production of ethanol from grain. Some of the characteristics of these coproducts have already been discussed in Chapter III but will be briefly summarized as needed here.

Marketing Options for the Coproducts. Fresh stillage is a mixture of various nutrients dissolved or suspended in water. It can be fed directly to animals but is not tolerated in large quantities because of the limited capacity for water intake by cattle and other animals. Fresh stillage also degrades rapidly, particularly in warm climates, and therefore disposing of the stillage output of a commercial plant will result in a complex distribution problem. Fresh stillage can be concentrated or dried. In this form, the product can be stored and shipped, making marketing an easier, more predictable task. This approach, however, requires a supplementary investment in drying equipment and storage facilities for the coproducts. In the forthcoming sections it is assumed that stillage is marketed as a dried product, DDG or DDGS.

Market for Coproducts. Table IV-4 shows thc market for selected animal feeds and the total market in the United States for the years 1963 to 1976. The total market includes oilseed, animal protein, and other mill products. As a point of reference, a 50-million-gallon ethanol plant will produce about 177,000 tons of DDG per year, i.e., about 45 percent of the 1976 market for that commodity. A 600 -million-gallon ethanol program-a near-term objective in the United States-will produce almost 2 million tons of DDG (or the equivalent) or about 7 percent of the total 1976 feedmarket and about five times the amount of DDG sold in the United States in 1976. In the 1963 to 1976 period, the domestic market for all animal feeds incrcascd at an average rate of about 1.2 percent annually. The markct for soybean meal (will which DDG is morc directly competing) expanded at a rate of about 3.5 percent over that period. This expansion is not quite sufficient to $a b-$ sorb the expected expansion in production of DDG as a result of ethanol fuel production. Some substitution bc. tween DDG and soybean may take place and as a result, some readjustment of agricultural production patterns will probably take place as the demand for corn feedstock increases.

Table IV.4. Market for Some Commercial Feeds in the United States

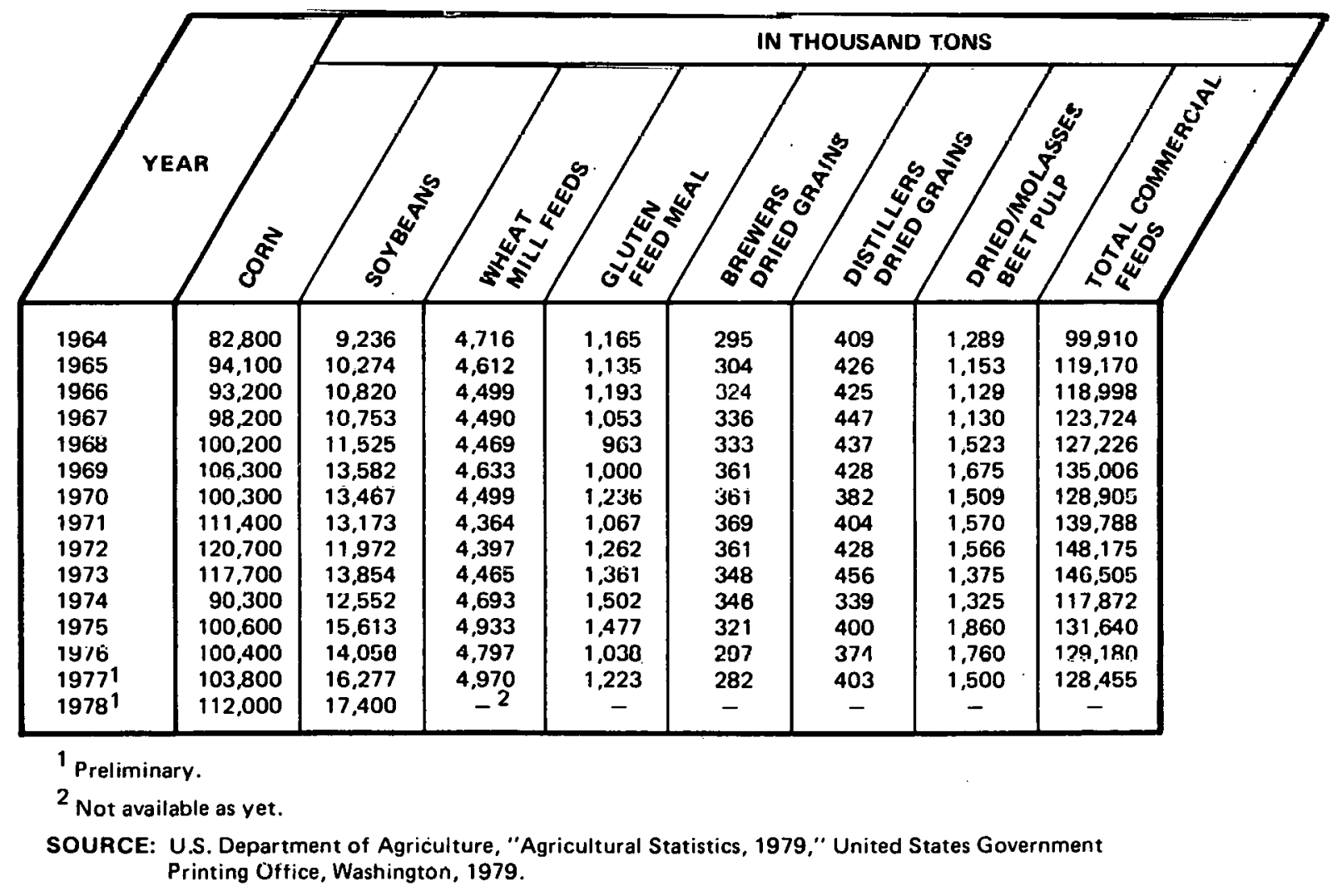




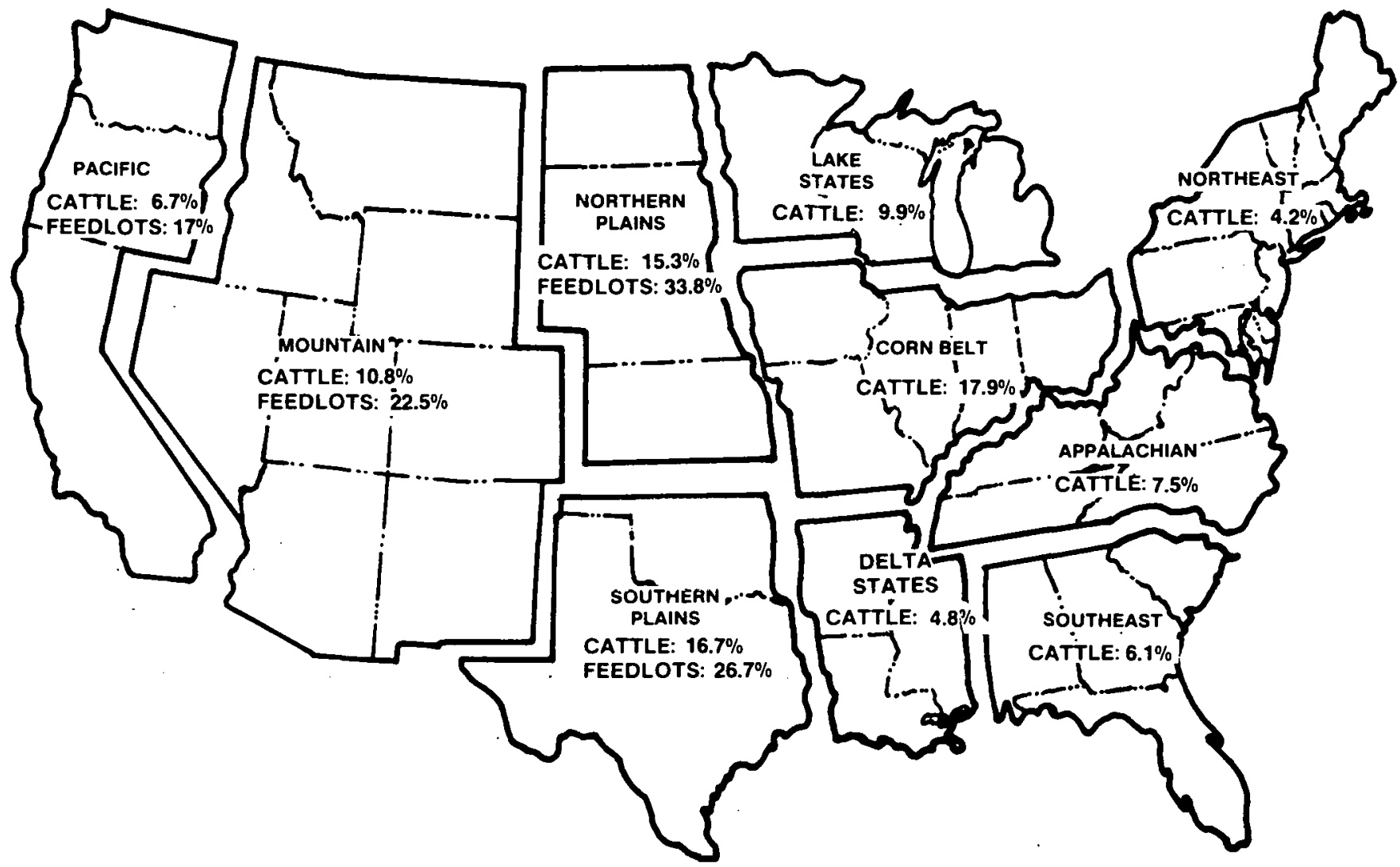

CATTLE. Cattle and milk cows - Total Population: About 125 millions (1978). Number is percentage of total population in the region.

SOURCE: U.S. Department of Agriculture, "Agricultural Statistics 1979", United States Government Printing Office, Washington, D.C. 1979

FEEDLOTS: Percentage of the number of large feedlots (larger than 4,000 head) in the region. Total feedlot number: 551 - Animals marketed in 1976: about 13 millions.

SOURCE: Schooley, F., et al, "Mission Analysis for the Federal Fuels for Biomass Program", SRI International, Menlo Park, Cal., Dec. 1978.

Figure IV.2. Distribution of Cattle and Milk Cow Population and Large Feedlots by Regions

Exports of corn and soybeans have expanded at an average rate of about 11 and 9 percent, respectively, over the 1960 to 1977 period. Part of these exports are used for animal feed and this foreign market could absorb some coproducts such as DDG if the buyers are willing to substitute DDG for the feeds presently used. U.S. exports amounted to about 47 and 17 million tons of corn and soybeans, respectively, in 1976. The potential of the foreign markets should be investigated seriously by ethanol producers.

Geographic Distribution of the Market. As was discussed in Chapter III, the major markets for DDG and DDGS are cattle and milk cows where DDG and DDGS are a protein supplement. Other farm stock, pigs, chickens, and others, provide a significantly smaller market. Figure IV-2 shows the distribution of the cattle population and large feedlots (larger than 4,000 heads) by regions. Over 60 percent of the potential market is located in the Northern and Southern Plains, Mountain, and Corn Belt regions. Over 80 percent of the large feedlots are located in the Mountain and Northern and Southern Plains regions. As a point of reference, a 50-million-gallon-per-year ethanol plant produces enough DDG and DDGS (see Table III-5) to feed about 120,000 steers or about thirty 4,000-head feedlots. As an example, the total cattle population of the Northern Plains region in 1978, i.e., about 18 million head, could have absorbed the DDG and DDGS production of about 120 50-million-gallon-per-year plants if DDG and DDGS were the only sources of feed. The impact of such an approach on other sources of feed would, however, be quite dramatic.

The data presented do indicate that a large potential market for DDG is available, a large fraction of the market is in the major grain-producing or neighboring regions, and a large national ethanol program may induce significant changes in the production patterns of feed-related agricultural products. 
Price of Coproducts. Table III-9 shows the historical trends in the prices of corn, stillage, DDG, and soybean meal. The discussion relating to the data indicates the interdependence of the prices of these commodities as well as the range of price fluctuations to be expected.

- Factors affecting the price of coproducts. The price of the coproducts will be influenced by factors such as processing and transportation. Processing costs will be addressed in a later section. Transportation costs may be an important item because of the relative geographical distribution of the markets for ethanol and its coproducts and of the feedstock supply regions.

Figure IV-3 compares shipping rates for the three commodities involved in a marketing/production effort: grains, feed, and ethanol. Rates are expressed per gallon of ethanol and therefore estimate the impact of market location versus production location directly on the price of ethanol delivered. It must be stressed that the shipping rates shown in the graph are susceptible to significant variance among states. The data show that proximity of the feedstock supply is an important factor, i.e., hauling the grain rather than the products is less favorable, especially where hauling distances reach 100 miles and over. For distances less than 100 miles, it is preferable to look for proximity of the feed market rather than proximity of the ethanol market. Above that distance, the shipping costs of both commodities are comparable.

As an example, assume that the ethanol market for a plant is the East Coast of the United States, about 500 miles away from the feedstock supply and that the DDG will be shipped to European markets. A plant located on the East Coast, at a terminal by a shipping harbor, would incur grain shipping costs of $\$ 0.232$ per gallon of ethanol. A plant located in the feedstock region would incur shipping costs of only $\$ 0.135$ to deliver the ethanol and DDG to their markets. Siting of the plant therefore must be carefully discussed, as it may have a major impact on overall plant economics.

- Projected prices and uncertainties. As was discussed in Chapter III, trends in prices may be derived from historical data and projections of crop yields and demand for crop products. These projections may be dependent on loced uI tegional factors and a careful analysis will have to be performed once a tentative market has been identified. Fairly sophisticated computer routines have been developed by agricultural consulting firms and it is suggested that an analysis of the feedstock supply and products market picture be performed by such consulting firm as part of the feasibility study.

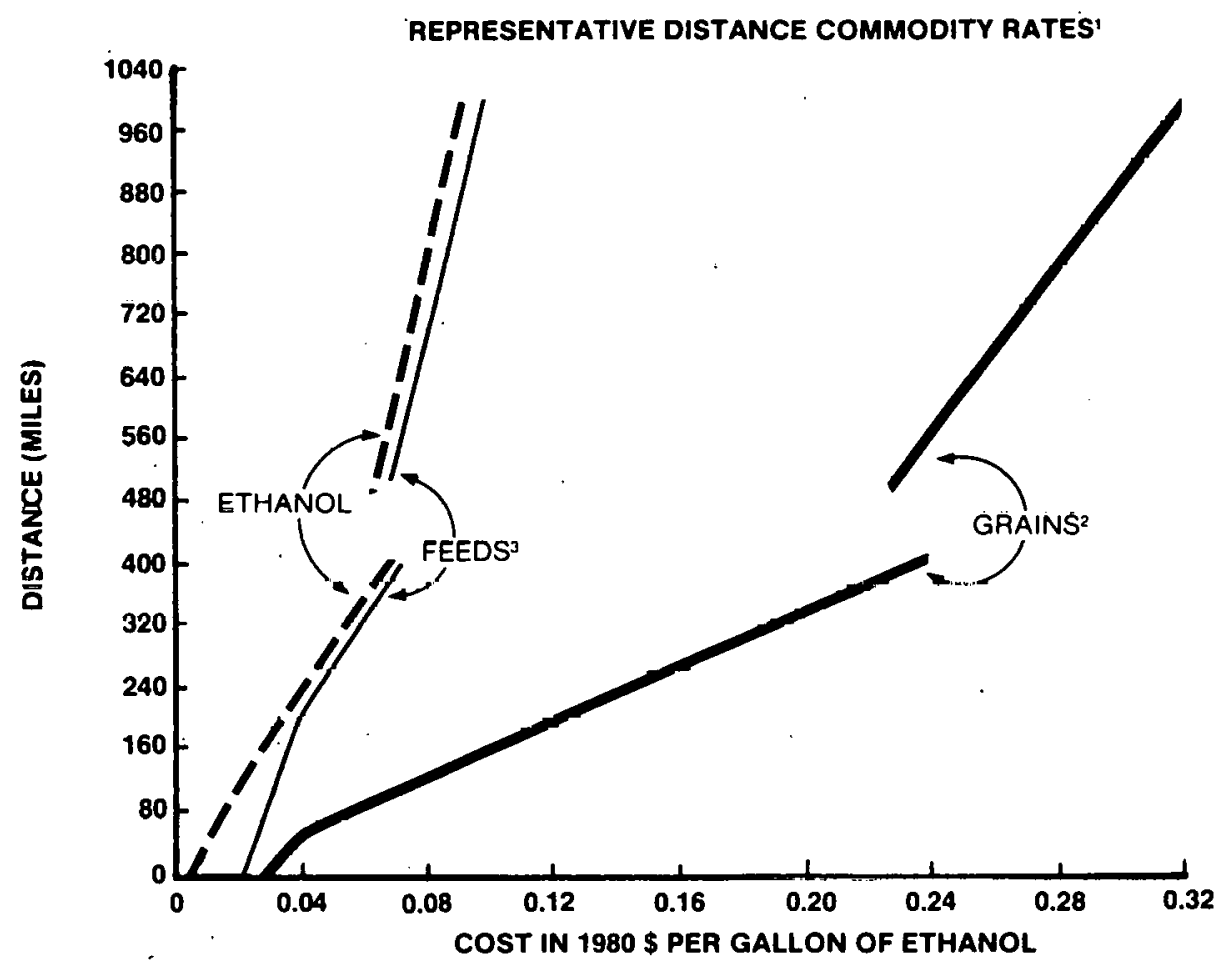

'Rates for 400 miles or less are for $45,000 \mathrm{lb}$. hauling trucks.

Rates for more than $\mathbf{4 0 0}$ miles are for railroad carloads.

${ }^{2}$ Assumes $56 \mathrm{lb}$. per bushel, 2.5 gallons ethanol per bushel.

${ }^{3}$ Assumes $6.6 \mathrm{lb}$. DDG per gallon ethanol

Figure IV-3. Representative Distance Commodity Rates (In 1980 \$ per gallon of Ethanol) 


\section{OTHER COPRODUCTS}

Carbon dioxide is a coproduct of ethanol fermentation. Recovery of carbon dioxide for soft drink production, food processing, or dry ice production is justified only if a local market for these carbon dioxide products is readily available. The value of this coproduct is very site- and demand-specific and cannot be projected on a general basis. Prices of $\$ 3$ to $\$ 5 /$ ton have been reported for uncleaned, uncompressed, raw gas. In most cases, however, no credit for this coproduct should be taken.

\section{RELATIONSHIP BETWEEN THE ETHANOL AND COPRODUCTS MARKETS AND THE FEEDSTOCK SUPPLIES}

Figure IV-4 summarizes the data of Chapters III and IV concerning the respective location of the ethanol and coproducts markets and the feedstock supplies.

The major grain feedstock regions are the Northern Plains and Corn Belt. The major market regions for
DDG are the same, as well as regions to the north and west. Major markets for ethanol are the East and West Coast regions. In view of the discussion presented above on the relative transportation costs of the commodities involved, siting a plant in or close to the grainproducing regions gives direct access to the grain supply and coproduct markets and limits the marketing problem to that of distribution of ethanol in the major market areas. As was discussed, blending points for gasohol are available in all potential market areas for ethanol.

As was discussed in Chapter III, some local feedstock resources exist in other areas such as potatoes in the Mountain region. Figure IV-4 suggests that a plant located in Idaho, close to a potato or potato waste supply, would have good access to both ethanol and coproduct markets.

The conclusions derived from the data of Figure IV-4 will have to be refined to account for site- or regionspecific factors such as water and auxilliary fuel resources.

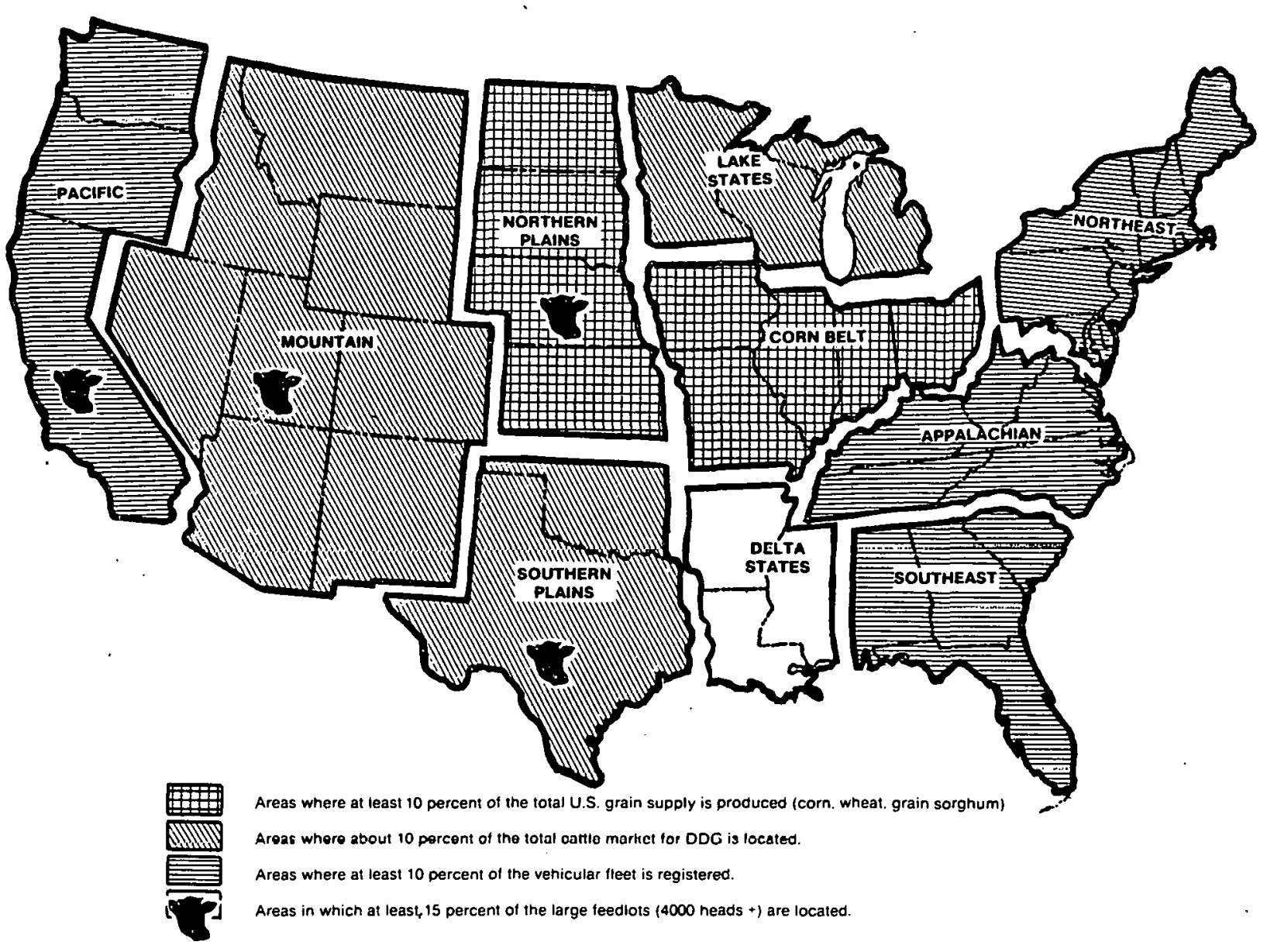

SOURCE: U.S. Department of Agriculture "Agricultural Statistics 1979, U.S. Government Printing Office, Washington, D.C., 1979. U.S. Department of Commerce "Statistical Abstract of the United States 1978", 99th Annual Edition, Washington, D.C., 1978.

Figure IV-4. Location of Major Grain Feedstock Supplies and Potential Markets for Ethanol and Coproducts 


\section{THIS PAGE \\ WAS INTENTIONALLY \\ LEFT BLANK}

54 


\section{CHAPTER V}

\section{Plant Design Concepts}

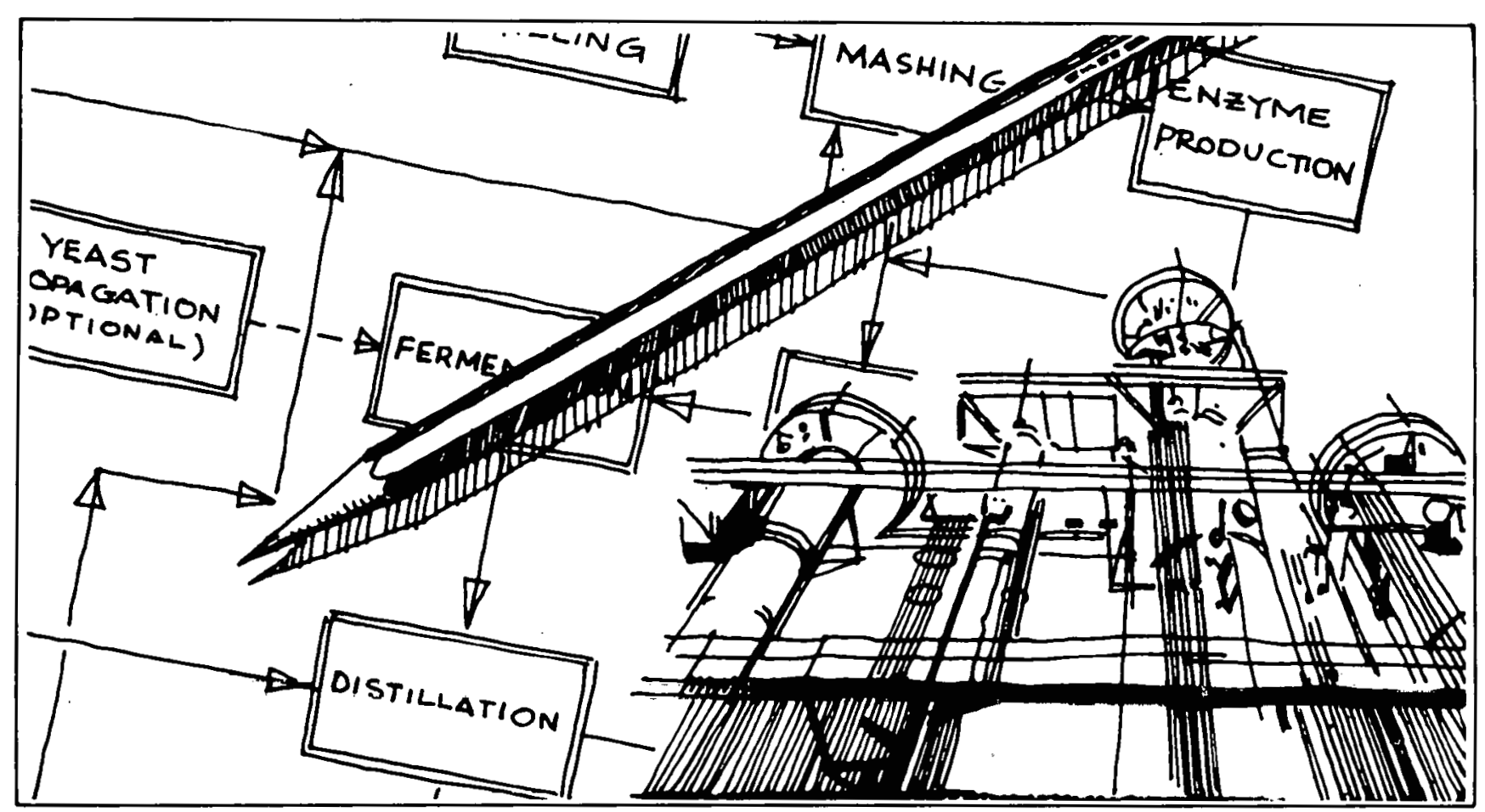

\section{ETHANOL PRODUCTION AS A PROCESS}

Ethanol production through fermentation of renewable feedstocks such as sugars, molasses, grains, or other starchy materials is well-established technology. Most of the ethanol used by the beverage industry is obtained from such feedstocks on a commercial scale. Production of ethanol for fuel uses the same technology, with modifications where necessary, to account for the enduse of the product. For example, ethanol produced for blending to gasohol must be anhydrous (water-free), while neutral spirits for beverage use may contain from 8 to 30 percent water. Such processing differences, however, are merely adaptations of existing technology, which can be incorporated in the design of reliable ethanol fuel plants.

Traditional ethanol production plants, those oriented toward beverage production, are designed to optimize the quality of the distilled spirits. As a result, energy efficiency has not heen a major concern for these plants. When ethanol is produced for fuel, energy efficiency and operating economics become major concerns. As a result, plant design and operation are in a state of evolution, tending toward improved plant performance in response to the goals of the DOE and the public statutes. Enough flexibility must be included in the plant design to permit the integration of new developments as they appear, in order to maintain or improve plant performance.

A few words of caution are appropriate for the investor unfamiliar with the process of ethanol production. Although the process is well known and has been used on a commercial scale, ethanol production through fermentation is a complex process employing biochemical reactions as well as sophisticated engineering concepts. Consistent and reliable operation can be achieved, provided the prudent operator follows precautions required by biological processes and operates the facility according to established engineering practice. These include cleanliness, close control of operating conditions such as temperature, and careful storage of product. Plant operating personnel must have the background and experience to deal with the problems related to the common, but complex, unit processes. 
Ethanol production involves hazardous materials, and plants must be designed and operated to minimize risks. The prospective investor must be cognizant of these aspects of ethanol production and assure that the engineering firm retained to perform the technical part of the feasibility study has the experience and knowledge required to advise him in the design and operation of the proposed plant.

\section{OPTIONS FOR ETHANOL PRODUCTION}

The conversion processes for producing ethanol from sugar-containing feedstocks and starchy grains are discussed in the chapter on feedstocks, Chapter III. The basic fermentation process involves the action of a living organism known as yeast, more specifically, a particular yeast such as Saccharomyces cerevisiae, on a fermentable sugar such as glucose. The products of fermentation are a dilute alcohol solution which contains both yeast and the unfermented portion of the feedstock, including some sugar, protein, and other carbohydrates. The mixture of unreacted feed and termentation products is known in the industry as "beer." The fermentation process can be conducted in a single vessel and the array of other equipment which comprises the typical ethanol plant is required to prepare the feedstock, separate the alcohol from the "beer", purify the alcohol product, recover valuable coproducts, provide for storage and handling of all feedstocks and products, and provide utility and maintenance services for the plant. The assembly of specific items of equipment into a given plant is a process which is managed by an architectural and engineering firm, in coordination with the owner and his engineering consultant. While all plants will embody the same generic types and sequence of operations, each plant is more or less unique in the adaptation to specific regional parameters and in the reflection of the "personality" of the system engineer.

\section{OVERALL PLANT OPERATION}

The plant design discussed in this Chapter is representative of all starchy grain conversions, and its major functional blocks are briefly described below (see Figure V-1).

Grain feedstock is received, unloaded, weighed, and placed in working storage. In use, it is withdrawn from on-site storage bins and cleaned by screening and/or air. classification to remove tramp metal, sand, rocks, and other foreign material which could damage subsequent equipment. The grain is then milled (ground) to produce the fine meal necessary for efficient extraction of the starch which will ultimately be converted to ethanol. The meal is accumulated in "surge" storage hoppers before being weighed, mixed with liquid to form the "mash", and cooked. In the cooking process, the mash

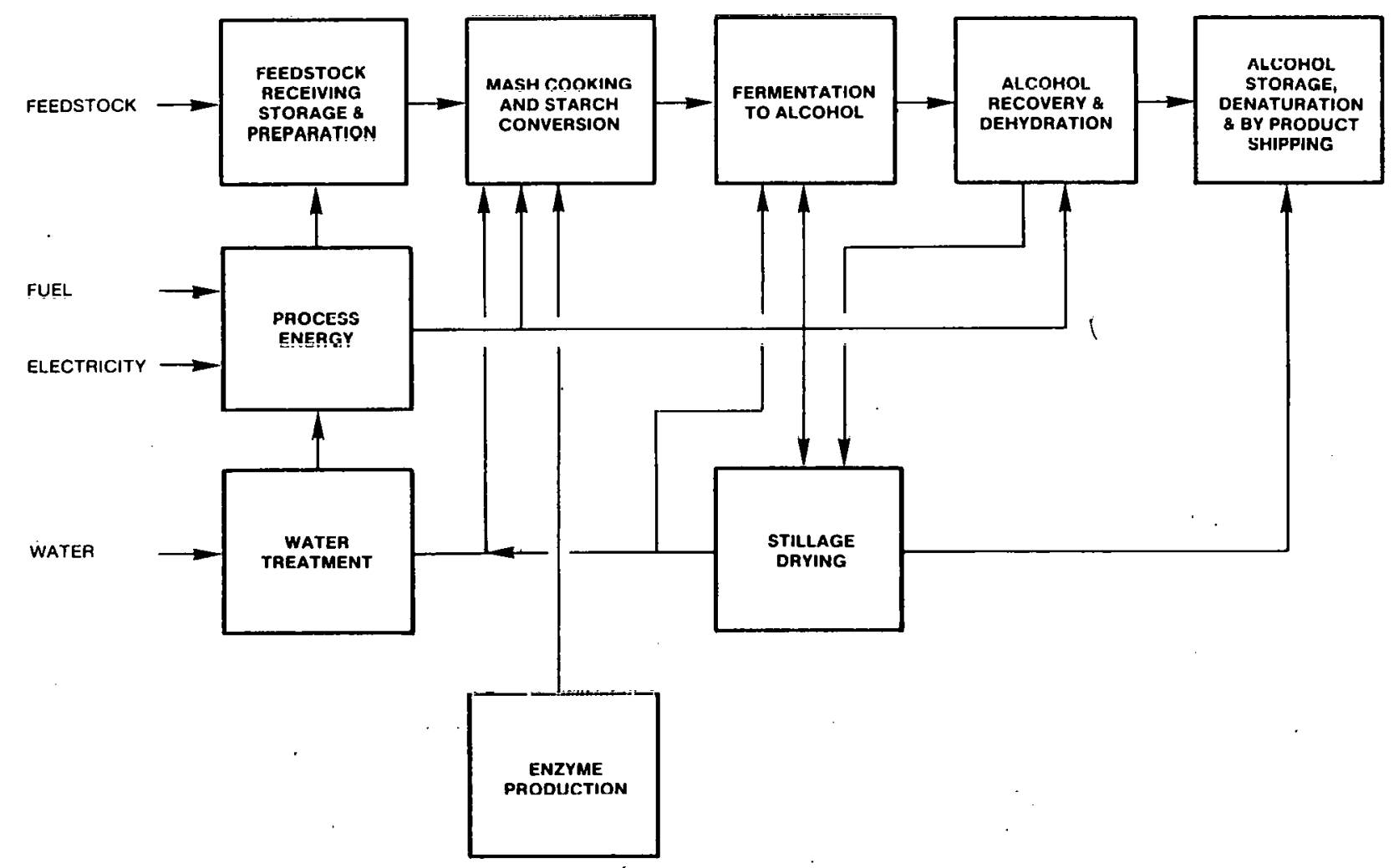

Figure V-1. Functional Diagram of Plant Design 
is mixed at about $145^{\circ} \mathrm{F}$ and heated to a final temperature in the range of 200 to $350^{\circ} \mathrm{F}$. Cooking temperature affects the required cooking time, the yield of usable starch from the grain, and the type of equipment required to conduct the cooking operation. The starch granules in the meal swell and "gelatinize" to produce a dispersion of starch in the mash. The cooking process also serves to sanitize the mash; commercial ethanol fermentation processes are not operated from a sterile mash, although the term sterilization is frequently, and erroneously, used. The cooked mash is cooled to about 150 to $170^{\circ} \mathrm{F}$ and mixed with an enzyme system called fungal amylase to convert the "solubilized" starch to sugars. This process is called saccharification, and the necessary enyzmes may be produced on-site or purchased commercially, depending on the economics of the specific ethanol plant.

The cooked, saccharified mash is cooled to about $80^{\circ} \mathrm{F}$ and pumped into the fermentation vessel. The yeast is added and, in some plant designs, a second addition of amylase enzyme completes the conversion of starch to sugar during the fermentation. The time required to complete the fermentation depends on the initial temperature and the composition of the mash. In general, batch fermentation processes follow an S-shaped curve. They. start slowly as a result of the lag following yeast addition, during which time the yeast cells acclimate to the mash. The mash then passes through a period of rapid activity during which the yeast cells multiply, producing ethanol, carbon dioxide gas, and small quantities of liquid coproducts (known chemically as higher alcohols, aldehydes, etc.). As the sugar in the mash is depleted and alcohol content increases, the yeast progresses to a relatively inactive phase and, eventually, alcohol production ceases.

The fermented mash, containing perhaps 7 to 10 percent alcohol and known as dilute beer, is transferred to a holding tank, known as the beer well, from which it is pumped to the distillation towers. Distillation is a process by which liquid mixtures are separated into two or more product streams. In the case of a fermentation ethanol plant, the beer is separated into an alcohol-rich product containing up to 96 percent ethanol (and 4 percent water) and a coproduct stream known as whole stillage.

The ethanol product is further purified to anhydrous alcohol in a specialized process known as azeotropic distillation. This step is necessary to overcome a property of ethanol-water mixtures which prevents purification beyond about 96 percent ethanol with conventional distillation. The product from the azeotropic distillation section is rendered unfit for beverage use according to procedures established by the BATF. It is then stored on site, pending shipment to market.
The major coproduct of the fermentation process is the whole stillage which leaves the bottom of the beer still.

Whole stillage is separated into two fractions, processed and eventually recombined to form a dried, solid product known as DDGS. The DDGS is stored on site prior to shipment to market. The stillage processing section involves equipment for centrifuging, evaporation, and drying, all of which are common unit operations. Combined with a capital investment for equipment is an operating cost (principally for energy) associated with recovery of this valuable coproduct.

In addition to the process stages directly involved with production and purification of the ethanol product and DDGS, the fuel-ethanol plant will require ancillary operations for wastewater treatment, steam production, and interfacing with the local utility power grid. Each of these utility needs is satisfied with existing technology.

\section{Choice of Feedstocks}

Alcohol produced from starchy grain is the most common form of fermentation ethanol in the United States. The selection of a feedstock for fuel-alcohol production, however, will be guided by economic aspects associated with regional availability of specific feedstocks on a long-term basis. The choice is certainly not restricted to grains; for example, the Brazilian alcohol fuel industry is producing large quantities of fuel-grade ethanol from sugar cane. With modifications in the design of the feedstock receiving, storage, and preparation processes, fermentation ethanol may be produced from a variety of sugar-or starch-containing crops. The modifications are required to accommodate the physical properties of the feedstock, as well as the nature of the carbohydrate (i.e., starch versus sugar).

Sugar crops. In the case of sugar crops, the feedstock will be pressed and/or steamed immediately after receiving and unloading to recover the sugar juice. The juice is concentrated to avoid degradation and loss of sugar during storage. The juices are then fed directly to the fermentation section, thus eliminating the cooking and saccharification required for starchy feedstocks.

Starch crop. Minor variations may be introduced in the process flow of Figure V-1 if grains are replaced by other starch crops. For example, with potatoes as a feedstock, cleaning to eliminate dirt and slicing to expose the starchy interior may be necessary before cooking and saccharification.

When grains are the feedstock, grain preparation may involve more complex methods of products recovery. Dry or wet milling processes may be used to recover germ, oil, meal, vitamins, and nther valuable components before fermentation of the residual starch fraction (processes described in Chapter III). 
It must be recognized that including a dry or wet milling process prior to ethanol production amounts to two processing plants in series. Although there may be situations in which this approach is justified, the integrated system will be more complex in terms of management, labor, and marketing of the products. The capital investment will also be higher; for example, a wet milling plant having a capacity of 60,000 bushels per day-the grain capacity required by a 50-million-gallon-per-year ethanol plant-would cost about $\$ 90$ million (1978 dollars), compared to about $\$ 58$ million dollars for the ethanol plant alone. In addition, because of the conversion of parts of the grain to other products and the losses incurred in the extra processing, the ethanol yield per bushel of corn would be less than for the straight ethanol plant. Integration of grain milling and ethanol production will probably occur when an ethanol plant is added to an existing grain milling plant.

Multi-feedstock options. Many feedstocks, and particularly sugar feedstocks or food processing wastes, are available only on a seasonal basis. Multi-feedstock capability at the front-end of the plant is therefore desirable. However, in view of the different front-end treatment required by sugar and starch crops, multifeedstock capability will require two separate process flows before fermentation if switching from sugar to starch feedstocks is desired.

The ability to switch between different sugar or starch crops, however, may be achieved through incorporation of flexibility in the front-end operations, which permits the adjustment of equipment operating conditions to crop-specific requirements (temperature adjustments, for instance).

\section{Ethanol and Coproducts Options}

The basic plant described in Figure V-1 assumes that anhydrous ethanol and DDG are produced. As was previously discussed, anhydrous ethanol will be easier to market in the near term than lower-proof alcohol. The gasohol market is the primary established outlet for alcohol fuel, and requires anhydrous ethanol for blending. Technically, straight, hydrated ethanol can be used in automobile engines, but its use requires engine modifications. The production of hydraied alculiul would reduce the investment and energy requirements of the plant, but would also limit the marketability of the product. This option is only justified when a captive, long-term market for the product has been secured.

Similarly, the elimination of the stillage-processing portion of the plant would offer savings in capital cost and energy-related operating cost. The option of disposing of the coproduct in the form of wet whole stillage raises enormous logistical problems of preservation, storage, and distribution for commercial-size plants. Here again, unusual site-specific conditions will be necessary for consideration of this processing option.

\section{Process Supplies Options}

Process thermal energy, electricity, water, and chemicals are consumed during opcration of the plant.

Several fuel options are available for an on-site boiler to raise process steam. Coal is the only fossil fuel acceptable for a new plant; however, the option of using renewable fuels such as wood wastes, urban or industrial solid wastes, or biomass should be considered carefully. Adoption of renewable fuels entitles the plant to tax credits which may improve the overall economics of the plant. The selection of an alternate fuel will be based on many factors: availability and price of the fuel, combustion cfficiency, cost of the hniler, and environmental requirements. As an example, wood waste at $\$ 12$ per green ton costs about $\$ 1.40$ per million Btu, compared to $\$ 1.04$ per million Btu for coal at $\$ 25$ per ton $(12,000 \mathrm{Btu} / \mathrm{lb})$. The capital cost of a coal boiler is generally lower than that of a wood-fired boiler of equivalent steam capacity. However, air emission controls may be much more expensive for high- or mediumsulfui coal than for wood. Each case will have to be analyzed on an individual basis.

Electricity can be purchased or cogenerated on site. In the latter casc, the possibility of selling excess electricity back to the local utility must be evaluated against the supplementary capital required by a cogeneration unit.

In the design of Figure V-1, part of the process water is recycled after treatment. A fresh water supply could be used if available and inexpensive. Environmental regulations may, however, require a high degree of treatment of the wastewater befure disposal.

The design of Figure V-1 assumes that enzymes are produced on site. For small plants, it will probably be more economical to purchase the enzyme needed. In the case of sugar crop, this ared of the plant would be eliminated.

\section{Plant Size Options}

Fuel-ethanol plant3, like other industrial plants, benefit from economies of scale. As an example, the capital investment for a 50-million-gallon plant will be only about 2 to 3 times that of a 10-million-gallon plant. The economies resulting from plant size must, however, be balanced against the possible increased cost of feedstock mobilization and increased distribution costs for the ethanol and coproducts. Regional availability of inexpensive feedstocks such as culled potatoes or food processing wastes may justify the proportionally higher investment of a smaller plant. Generally speaking, large plants are more favorable from an economics aspect but 
specific site or regional conditions may favor small plants.

\section{New Technologies}

Several areas of the fuel-ethanol production process are under investigation to improve their efficiency and cost.

Mash cooking with electrical heating or extrusion cooking, instead of through steam injection, is claimed to increase sugar yields from starch and reduce the dilution of the mash. Batch fermentation of the mash is the present conventional method of operation in industry. Continuous fermentation, which could result in faster fermentation and reduced equipment volume, is presently under development but raises problems relating to cleaning and sterilization (sanitization). Vacuum fermentation and ethanol recovery and recycling of yeasts are also under investigation. Various methods for improving ethanol recovery, i.e., improvement or replacement of distillation, are also under investigation. Methods such as liquid extraction, selective absorption by various agents, reverse osmosis, and ultrafiltration are considered, as well as improved methods for the recovery and processing of coproducts. A long-term objective of much research is the design of an economical process by which cellulosic feedstocks could be converted to ethanol by fermentation.

The economics and technical feasibility of most of these new approaches are not fully established. It is, however, essential that the investor management team of the proposed plant keep informed of these new trends.

\section{Plant Design Selection}

Some guidelines must be kept in mind when selecting a plant design. First consideration should be given to locating near a water source such as a river. Consideration must also be given to minimizing the potential impact of unknown quantities, such as disruptions in the supply of energy feedstocks, through design for multi feedstock or multi-fuel capability (wood and coal, for instance). Providing for the incorporation of future improvements in design should also be examined.

The analysis of some of the possible options will require additional front-end expenses that may be well justified in the long run.

\section{TYPICAL MATERIALS AND ENERGY FLOW DIAGRAMS}

The fuel ethanol process described herein is based on a publicly-available technical assessment conducted for the Department of Energy ("Grain Motor Fuel Alcohol Technical and Economic Assessment Study," Raphael Katzen Associates International, Dec., 1978). The process is the result of a detailed design using proven technologies, and represents a system which could be constructed today. No existing fuel ethanol or distilled spirits plant has been constructed to this design, however, and the choice of the Katzen design as a reference fuel alcohol plant in this document is for illustrative purposes only, and does not constitute an endorsement.

\section{Process Description}

The illustrative example used throughout this guide is a hypothetical 50-million-gallon-per-year, corn-based, coal-fired, fuel ethanol plant. The processing elements of the plant are described in this section as a means of familiarizing the reader with the elements of fuel ethanol production at a level of technical detail with which the owner/investor should be familiar in order to work closely with a consulting engineer or architectural and engineering firm. The hypothetical plant is based on a highly integrated, thermally-efficient conceptual design developed for DOE by Raphael Katzen Associates. Energy efficiency and coal-firing are very desirable aspects of this and any design.

The energy and feedstock efficiency claimed for the Katzen-engineered plant are illustrated in the following figures:

$$
\begin{aligned}
& \text { Alcohol yield }=2.57 \text { gallons } / \text { bushel of corn } \\
& \text { DDG yield }=18.2 \text { pounds } / \text { bushel of corn } \\
& \text { Coal required (Illinois \#6) }=41,700 \mathrm{Btu} / \text { gallon of } \\
& \text { alcohol }
\end{aligned}
$$

Electrical energy required $=1.32 \mathrm{kWh} /$ gallon of alcohol

The physical plant layout is illustrated in Figure V-2.

\section{Recoiving, Storage, and Milling}

Shelled corn is delivered to the plant by railroad hopper cars or grain trucks. A single railroad unloading station and two truck unloading stations have been provided. The unloading arrangement has been planned so that a railroad hopper car and a truck can be unloaded simultaneously. (See Figure V-3.) Railroad hopper cars hold about 52.5 tons of grain (1,875 bu of corn). The fully loaded hopper car weighs about 67.4 tons. Grain trucks come in various dimensions, but a typical truck will hold about $800 \mathrm{cu} \mathrm{ft}$ or $643 \mathrm{bu}$ of corn. Unloading conveyors have been specified to accommodate a total unloading rate of $7,500 \mathrm{bu} / \mathrm{hr}$, enough grain in a single 8 -hour shift to operate the plant for a full day.

Trucks delivering grain to the plant are lifted by means of truck dump hoists and are weighed on one of two 


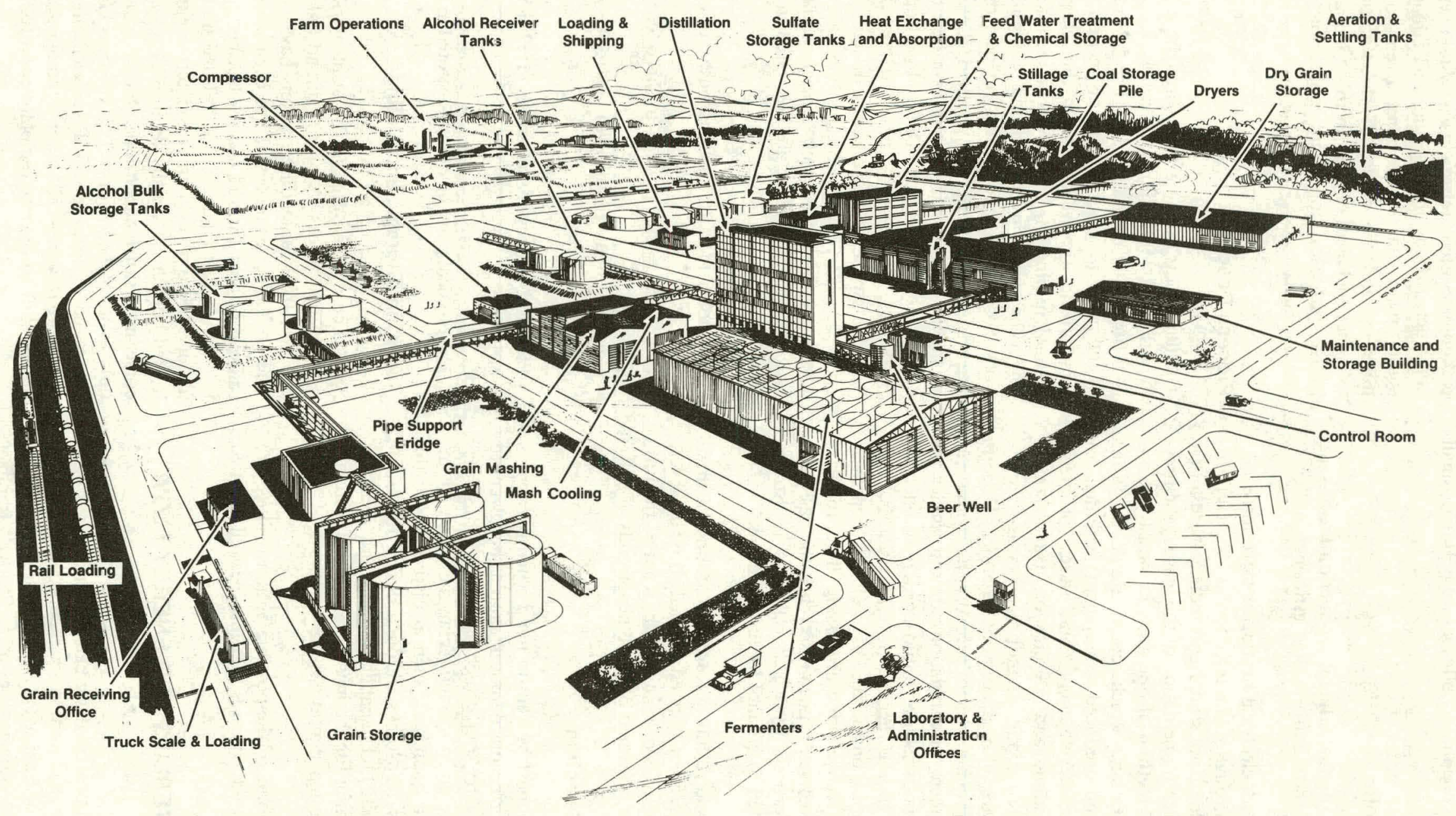

Figure V-2. Katzen Base Case Plant 
truck dump scales. The grain passes from the truck into a bin housed in a pit. Grain is discharged from these bins through star valves into either of two truck unloading conveyors.

In the case of grain delivered to the plant by railroad hopper cars, the car is weighed on a rail car scale and the grain is then dumped from the car through a bin and star valve to rail car unloading conveyor. The grain passes into either of two rail car unloading cross conveyors. A truck unloading conveyor, coupled with a rail car unloading cross conveyor, then can be delivered into bucket elevator. The grain is lifted to a position above the grain storage bins, and passes from the bucket elevator into one of two distributing conveyors. These conveyors are arranged to deliver to the storage bins or may convey their grain directly into storage by-pass conveyors which deliver directly into a surge hopper.

The surge hopper has been sized to hold 7,500 bu of grain. This provides a nominal holdup time of three hours. When the surge hopper is full, grain can be diverted into storage in any of the grain storage bins. The total grain storage capacity is equivalent to grain usage for one week. When grain is being received, operation could have grain passing directly to the surge hopper. When it is filled, grain then would be diverted to the storage bins. When grain is not being received, it would pass from the storage bins to the surge hopper through the individual storage bin bottom conveyors, through a collecting conveyor, and into a bucket elevator. The grain is thus lifted and discharged into the surge hopper.

Grain discharges from the surge hopper at the rate of $2,453 \mathrm{bu} / \mathrm{hr}$ into the grain cleaner, which separates materials in the grain which are foreign to the process, including sand, tramp metal, etc. Light materials in the grain are picked up from the screens and air transported through a blower, to the bag house in the coproduct recovery section, where they become part of DDG. Tramp metal and other oversize materials are rejected from the grain cleaner and periodically removed from a collecting bin.

Grain, suitable for processing, passes into the hammer mills which deliver into a surge bin. The ground grain then passes through a star valve at the base of the surge bin and is pneumatically conveyed to the process section for mash cooking and saccharification.

The grain receiving, storage, and milling area has been separated from other plant processing areas because of the dust problem associated with these front-end operations.

\section{Mash Cooking and Saccharification}

Corn meal is received from the milling area in the surge tank. (See Figure V-4.) This tank is sized to allow con- tinuous meal input while the output to the batch weigh tank is shut off when the batch tank is being emptied into the continuous weigh tank. The batch weigh tank provides an accurate record of the total grain used, and the continuous weigh tank provides a reading of how much grain is used within any given period.

The continuous weigh tank feeds the mash mixing tank where the other mashing ingredients are added. This tank is sized for a 2.5-minute residence time and is fitted with an agitator to promote thorough mixing. The other main ingredients are recycled thin stillage (backset) and water. The water comes from recycled condensates and from makeup fresh water. The condensates are hot, and their use is regulated to maintain a tank temperature of $145^{\circ} \mathrm{F}$. The total water input to this tank is controlled to produce about 22 gallons of mash per bushel of grain input $(56 \mathrm{lb} / \mathrm{bu}$ basis). The thin stillage is added in an amount about 10 percent of the final mash volume going to the fermenters.

The mash is transferred from the mixing tank to the mash pre-cooker. This tank has provision for adding live steam in case insufficient condensate is available to attain the $145^{\circ} \mathrm{F}$ pre-cooking temperature. This tank is sized for a residence time of about 7 minutes.

The mash is further heated in the mash heater located downstream of the pre-cooker. This heater uses 15 psig steam from the pressure flash to heat the mash to $229^{\circ} \mathrm{F}$. Final cooking of the mash takes place in the mash cookers by injection of live steam to attain a temperature of $350^{\circ} \mathrm{F}$. The cookers consist of several 20-foot lengths of 10-inch diameter pipe connected with 180 return bends, and they are sized to provide a cooking time of 1.5 minutes.

The cooked mash is flashed to 15 psig in the pressure flash tanks. Some of the steam from this flash is used to preheat the mash as discussed above, and the remaining flash steam is used for beer heating in the distillation section. Additional water is added at this point in an amount to provide a final mash volume of 30 gallons per bushel. The mash is then further flash-cooled in the vacuum flash tanks. The temperature when leaving these tanks is $145^{\circ} \mathrm{F}$, which corresponds to a pressure of about 3.3 psia. This vacuum is maintained by the flash vapor condenser, its associated steam ejector, and the ejector condenser. The condensate from all of these heaters and condensers goes to a hot well, from where it is pumped back to the mash mixing tank as discussed above.

After the vacuum flash, the mash discharges directly into the fungal amylase mixers, where the fungal amylase is added. From the mixer the mash is pumped to the pipeline saccharifier, where the starch is converted to fermentable sugars. Part of this mash (approximately 1.5 percent) is delivered to the fungal amylase section. 


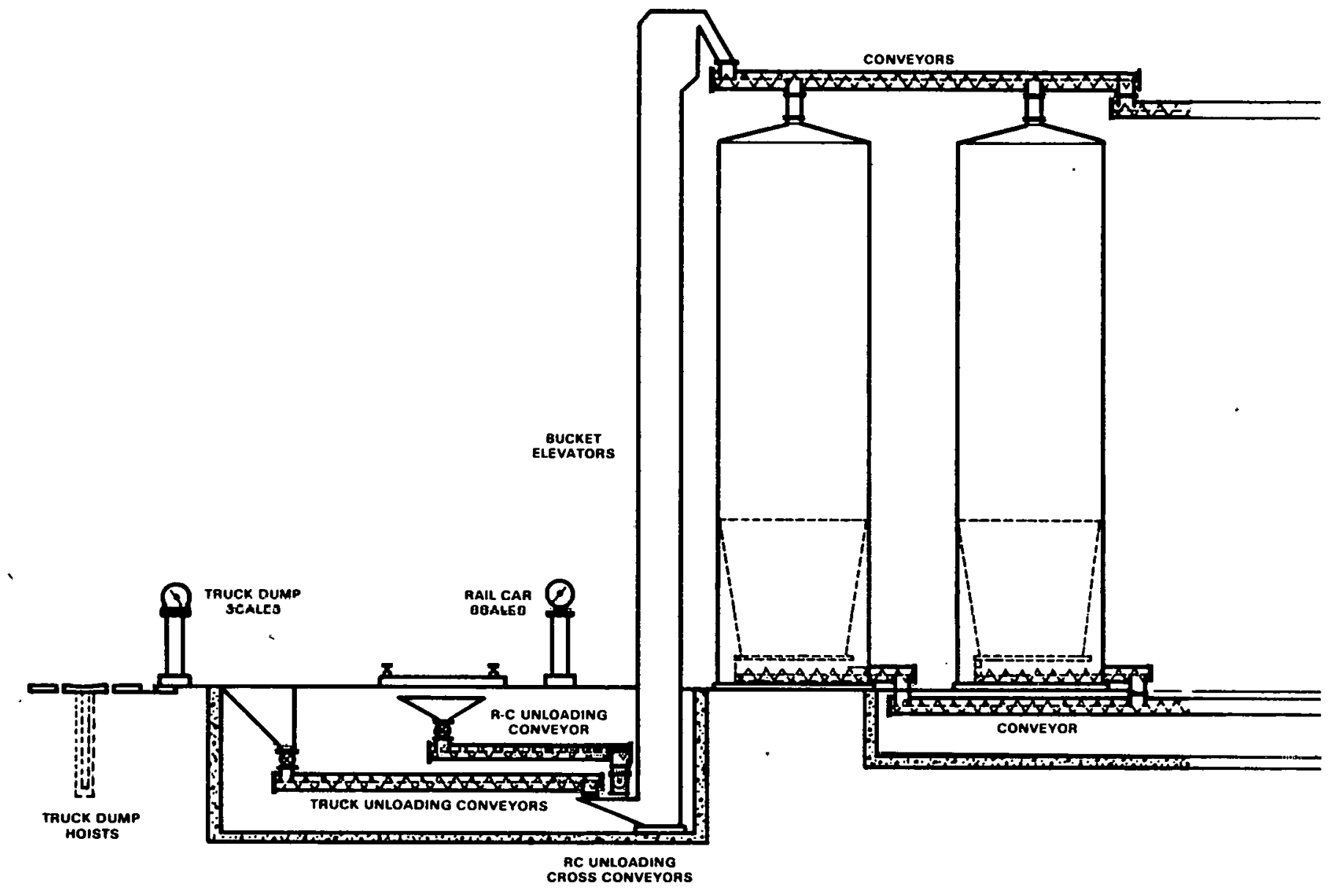

The pipeline saccharifier is sized for a 2-minute residence time. From there, the converted mash is fed thrrough the mash coolers to the fermenters. The first six mash coolers use cooling tower water at $85^{\circ} \mathrm{F}$ to reduce the mash temperature to $100^{\circ} \mathrm{F}$. Then, in the remaining four coolers, well water at $60^{\circ} \mathrm{F}$ is used to complete the cooldown to $80^{\circ} \mathrm{F}$ before the mash enters the fermenters.

\section{Fungal Amylase Production}

The system consists of seven seed tanks, seven batch fermenters, a system for delivering sterile compressed air, and a pump for delivering the product to the cooking and saccharification section. (See Figure V-5.)

Fungal amylase is prepared batch-wise using a seed tank to grow the inoculum which is initially started in the laboratory. One seed tank is used as a starter for a fermenter tank which is sized at 33,750 gallons to provide fungal amylase for one day of operation $(27,000$ gallons plus 25 percent freeboard). The total batch cycle is one week, consisting of one day for tank cleaning, charging, and sterilizing; five days fermentation; and one day for usage. Twelve thousand five hundred $\mathrm{scfm}$ of compressed air is supplied at 25 psig, which corresponds to $0.5 \mathrm{scfm}$ per cu $\mathrm{ft}$ of fermenter volume for five fermenters at a time.
Prior to filling the fermenters with mash, they are thoroughly cleaned, and after filling, the mash is heated to $250^{\circ} \overline{\mathrm{F}}$ using steam in the tank jacket in order to sterilize the tank and its contents. After sterilization, the mash is cooled to $90^{\circ} \mathrm{F}$ using well water in the tank jacket. A small amount of additional cooling will be required throughout the fermentation period in order to remove the heat added by the agitators.

The contents of one seed tank are added to the fermenter atter it has been cooled down. A perlod of about five days is then required for completion of the batch. During this time the tank is agitated and acratcd with compressed air.

Moyno pumps are used to transfer the finished fungal amylase to the saccharification section.

\section{Fermentation (Batch)}

The fermenters receive mash continuously from the mash converter located in the mashing and saccharification section. The fermenters are batch-operated and consist of sixteen 250,000-gallon vessels which are arranged in sets of four with one heat exchanger and circulation pump for each fermenter set. (See Figure V-6). The fermenters are designed for a liquid loading of 80 percent of maximum capacity. Since cooling is needed 


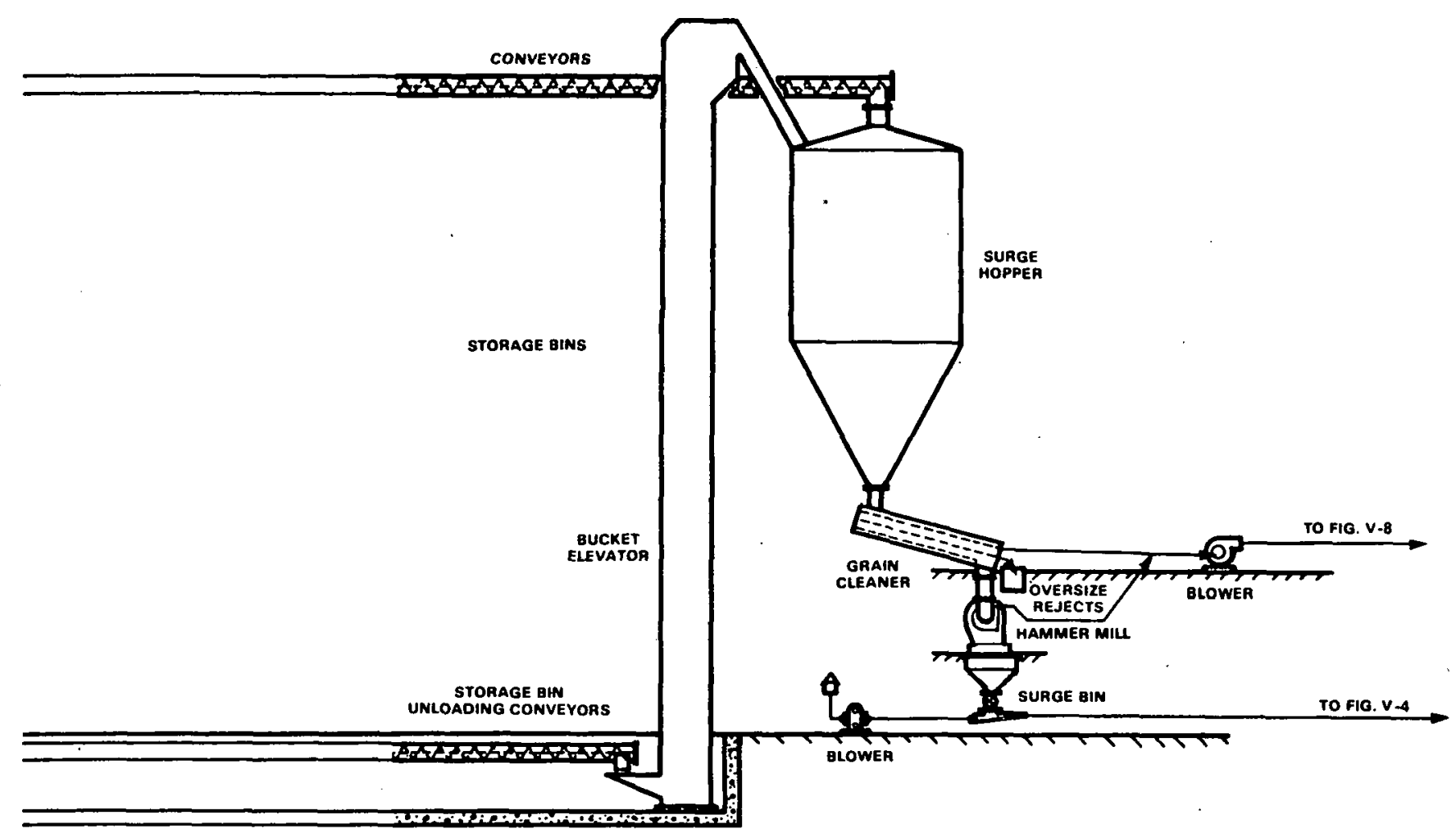

Figure V-3. Grain Receiving, Storage, and Milling

for only about 8 or 10 hours out of the 48 -hour fermentation cycle, one exchanger will service the needs of four fermenters. The fermenters are filled on a threehour cycle.

The yeast, Saccharomyces cerevisiae, is manually added to a yeast mix-tank and then transferred to the fermenter as it is being filled (about $300 \mathrm{lb}$ of yeast per batch). The yeast is purchased rather than manufactured on location. The inlet mash temperature is about $80^{\circ} \mathrm{F}$, and the temperature gradually rises to a maximum of about $95^{\circ} \mathrm{F}$ during the fermentation period. Cooling is provided during peak period by recirculation of the mash through the fermenter cooler; well water at $60^{\circ} \mathrm{F}$ is the cooling medium. Each fermenter requires a flow of approximately $1,200 \mathrm{gal} / \mathrm{min}$ during the peak perind. The recirculation for cooling also serves to agitate the tank. At the end of the fermentation period, the fermenter contents are transferred to the beer well, from which they are pumped continuously to the distillation section.

The fermenters are cleaned and sterilized by means of automatic spraying machines installed in each fermenter tank. Each tank has two such spraying machines. After each fermentation cycle, the tank is washed with a cleaning solution, sterilized with an iodine solution, and rinsed with clean sterile water in preparation for the next cycle.

\section{Distillation}

Dilute beer feed from the fermentation section of the plant is collected in the beer well, from which it passes continuously to a heat exchanger in the distillation section of the plant. (See Figure V-7).

The dilute beer feed, amounting to approximately 1,150 gallons per minute, contains 7.1 weight percent alcohol and 6.92 percent solids. Solids consist of both dissolved solids and suspended solids, in approximately equal amounts. The beer leaves the beer well at a temperature of $90^{\circ} \mathrm{F}$ and undergoes a series of preheating steps before it enters the first stage of distillation. The dilute beer first passes into the tube side of a condenserpreheater. In this unit, approximately 23 percent of the total preheating is accomplished. This first preheating step utilizes a portion of the vapors condensed from the dehydration tower. These vapors are condensed to supply this first-stage preheating. The warmed dilute beer feed next passes to condenser-preheater, where additional preheat amounting to about 8.5 percent of the total is added. In this condenser-preheater, a portion of the overhead vapors from the pressure stripper-rectifier (PSR) is condensed to supply second-stage preheat. The dilute beer feed next passes through two stages of feed preheating, wherein a portion of the heat in the bottoms stream from the PSR tower is utilized in a two-stage flash operation. These stages add about 21.5 percent of 


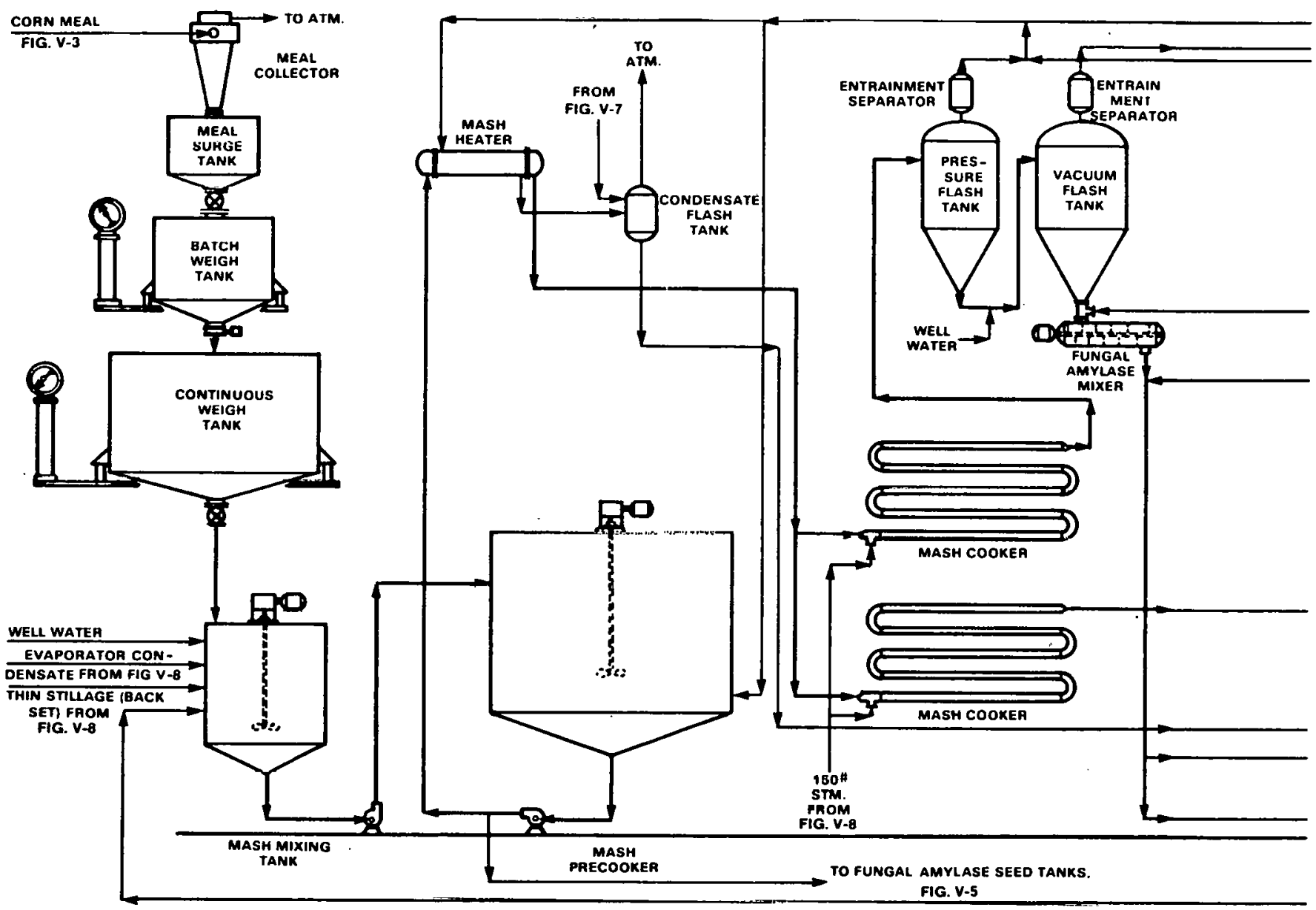

the total feed preheating. The warm dilute beer feed next passes into a steam condenser where low-pressure steam is used to accomplish additional preheating. Approximately 23 percent of the total feed preheat is added in the steam condenser. The heating medium, in this case, consists of low-pressure steam taken from other parts of the plant. The feed is finally preheated, approximately to saturation temperature, in an additional two-stage heating step using flash heat taken from the bottoms stream out of the PSR. Approximately 24 percent of the total feed preheat is accomplished there.

The hot, saturated, dilute beer feed next passes into the degassing drum, where dissolved carbon dioxide is flashed off. This represents one of the products of the fermentation reaction. It is not recovered. Any alcohol or water vapor, accompanying the vented carbon dioxide, is condensed in a vent condenser from which it drains back to the flash drum.

The saturated dilute beer feed enters the midsection of the PSR tower. Because of the high suspended solids content of the beer feed, the lower section of the PSR has been designed as a disc-and-donut type tower. This represents an effective contacting device which tends to be self-purging and does not allow the buldup of solids which would bluck ordinary distillation trays. The PSR operates with a head pressure of $3 U$ psig. The non-volatile dissolved solids and suspended solids in the dilute beer feed wash down through the stripping section of the PSR and a very dilute alcohol steam, containing less than 0.02 weight percent alcohol, is removed from the bottom of the tower. The dilute stillage containing the dissolved and suspended solids leaves the base of the PSR tower at about $304^{\circ} \mathrm{F}$. In the bottom section of the PSR tower, alcohol is effectively stripped trom the dilute beer. The aqueous botions sirean then passes through a series of flash stages. These stillage bottoms are subjected to progressive reductions in pressure through four flash stages. The flash vapor that develops in these stages is. utilized to accomplish a portion of the feed preheating as described previously. In these four flash stages, the temperature of the hot stillage is reduced from $304^{\circ} \mathrm{F}$ to approximately $212^{\circ} \mathrm{F}$. The whole stillage, containing about 7.5 percent total solids, is next pumped to the coproduct recovery section of the plant where the solids in the stillage are recovered as an animal feed coproduct.

Heat is supplied to the base of the PSR by means of condensing 150 psig steam on the shell side of parallel 


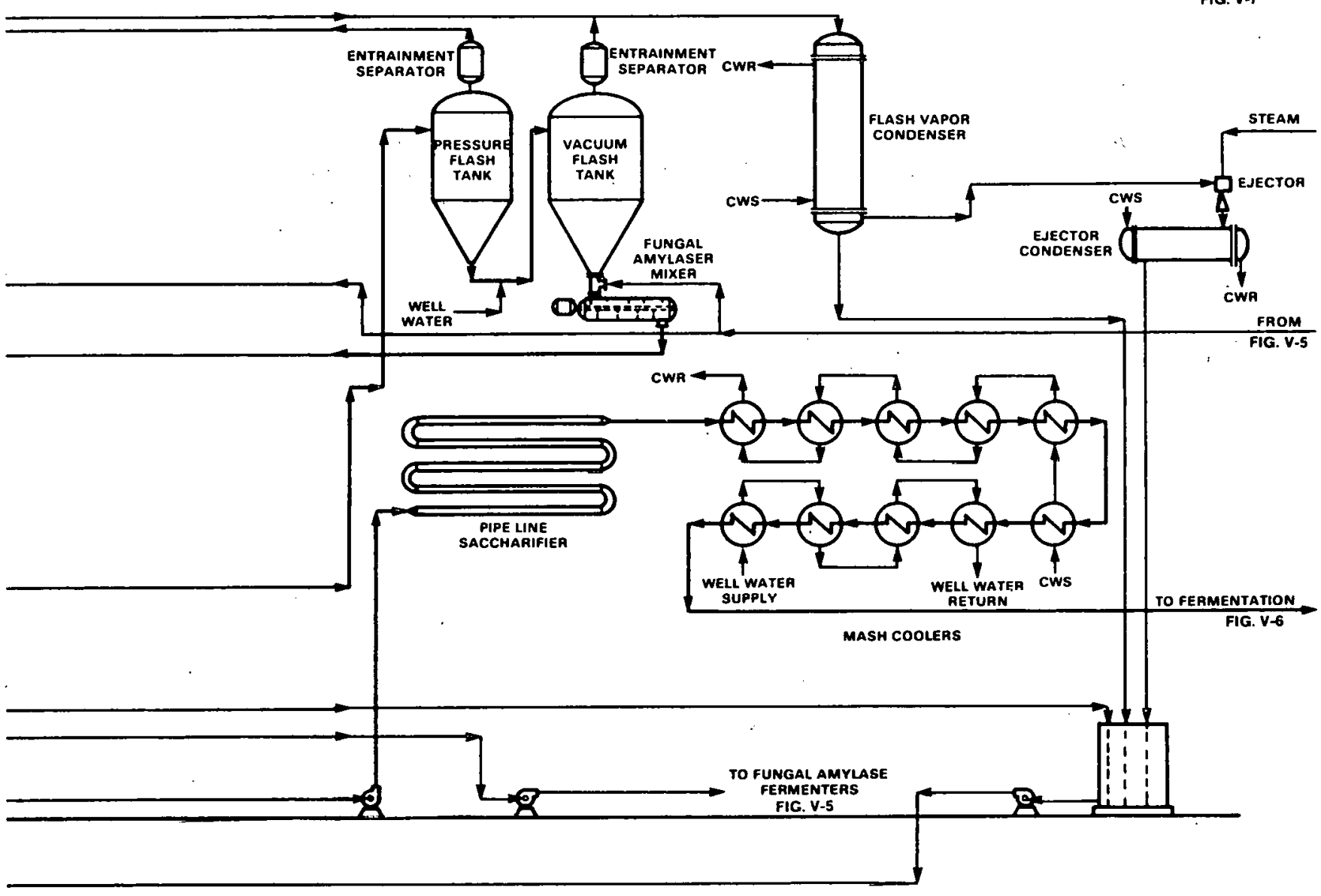

Figure V-4. Cooking and Saccharification

forced-circulation reboilers. Total steam supplied to the base of the PSR tower through the shell sides of the reboilers is 110,000 pounds per hour.

The upper portion of the PSR contains perforated trays and has a reduced diameter compared to the stripping section. The lower section of the PSR tower is 138 inches in diameter while the top section of the tower, containing 28 perforated trays, has a diameter of 102 inches.

Alcohol-rich vapors generated in the PSR pass overhead from the tower at a temperature of about $250^{\circ} \mathrm{F}$ and a pressure of 50 psig. These vapors may be utilized as a source of heat by condensing in the reboilers which are attached to the base of the dehydration tower and the hydrocarbon stripper. Sufficient vapor is generated in the PSR to allow a portion of the total overhead vapor to be utilized in a condenser-preheater to do some of the feed preheating which has been described previously. Of the total overhead vapor generated in the PSR, 10.9 percent is utilized for feed preheating, 81.6 percent is used to supply heat to the dehydration tower, and 7.5 percent is employed to supply heat to the hydrocarbon stripper. The upper five trays of the PSR uperate in a total reflux condition. That is, all of the overhead vapor is condensed and returned to the tap tray of the PSR. The liquid product from the PSR is removed as a liquid side draw stream about five trays from the top of the tower. From there, it passes to the midsection of the dehydration tower.

The dehydration tower is 138 inches in diameter and contains 50 perforated trays. The tower operates at essentially atmospheric pressure. The bottoms stream represents the anhydrous motor fuel-grade alcohol and has a concentration of 99.5 volume percent ethanol $\left(199^{\circ}\right.$ proof); the balance is water. The bottoms stream from the dehydration tower is pumped through a product cooler which utilizes cooling water to reduce the temperature of the product alcohol to about $100^{\circ} \mathrm{F}$. The cooled product next passes to product storage.

Heat is supplied to the base of the dehydration tower through parallel force circulation reboilers. The overhead product from the dehydration tower is a ternary, minimum-boiling azeotrope consisting of hydrocarbon, alcohol, and water. A portion of these overhead vapors is utilized for feed preheating and the balance condensed in the primary condenser, which utilizes cooling water to remove the heat of condensation in 


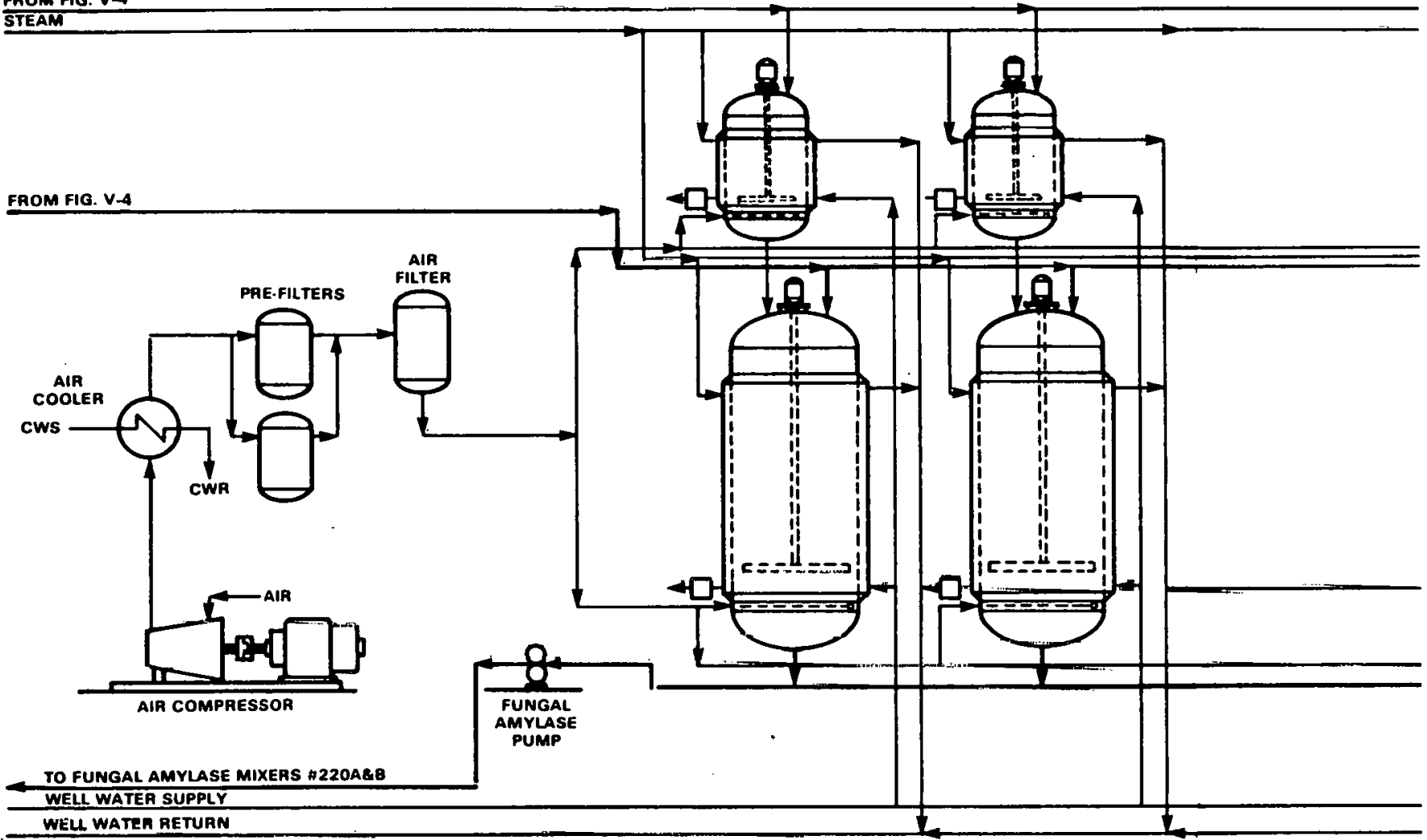

FUNGAL AMYLASE FERMENTERS

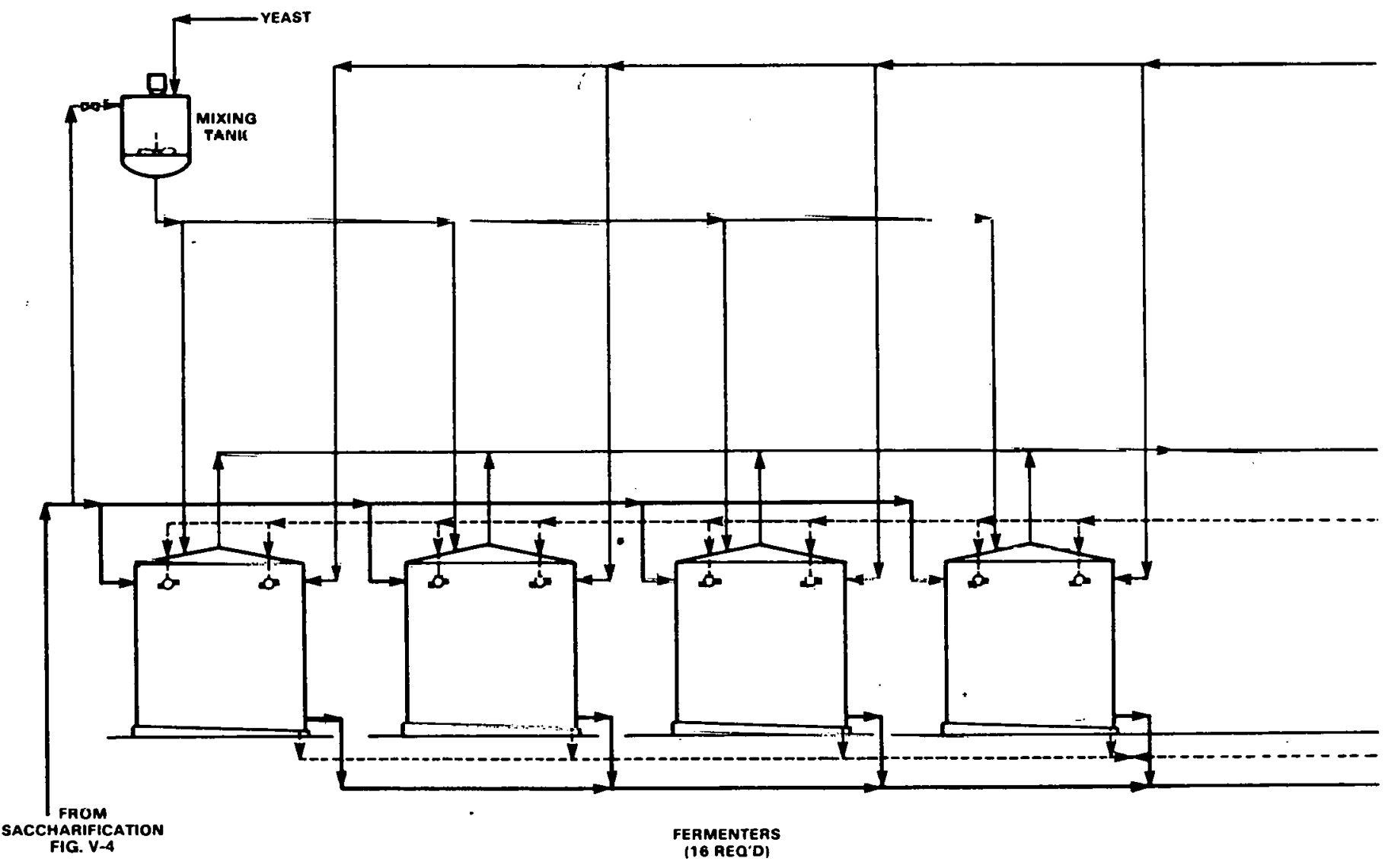




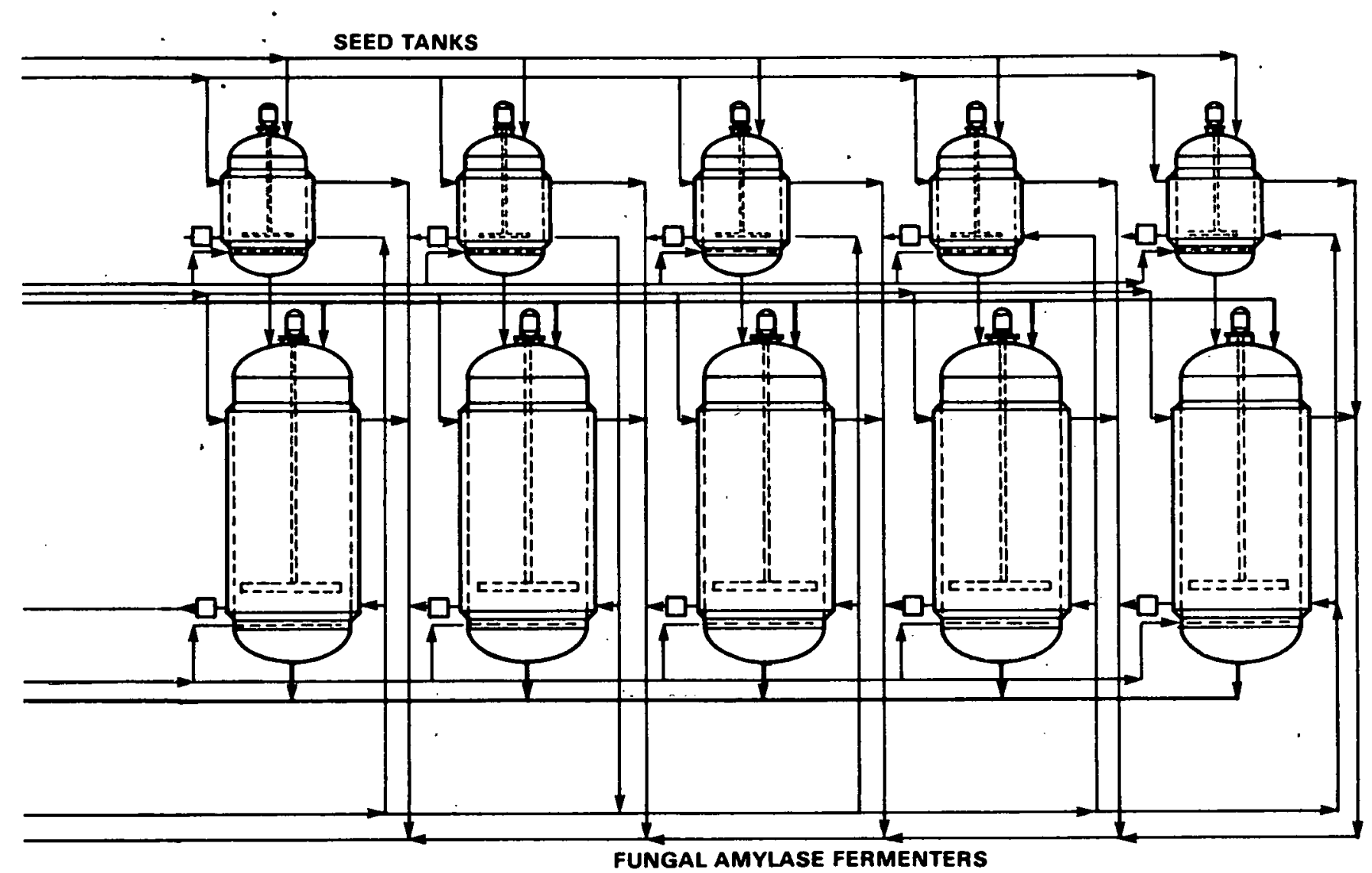

Figure V-5. Fungal Amylase Production

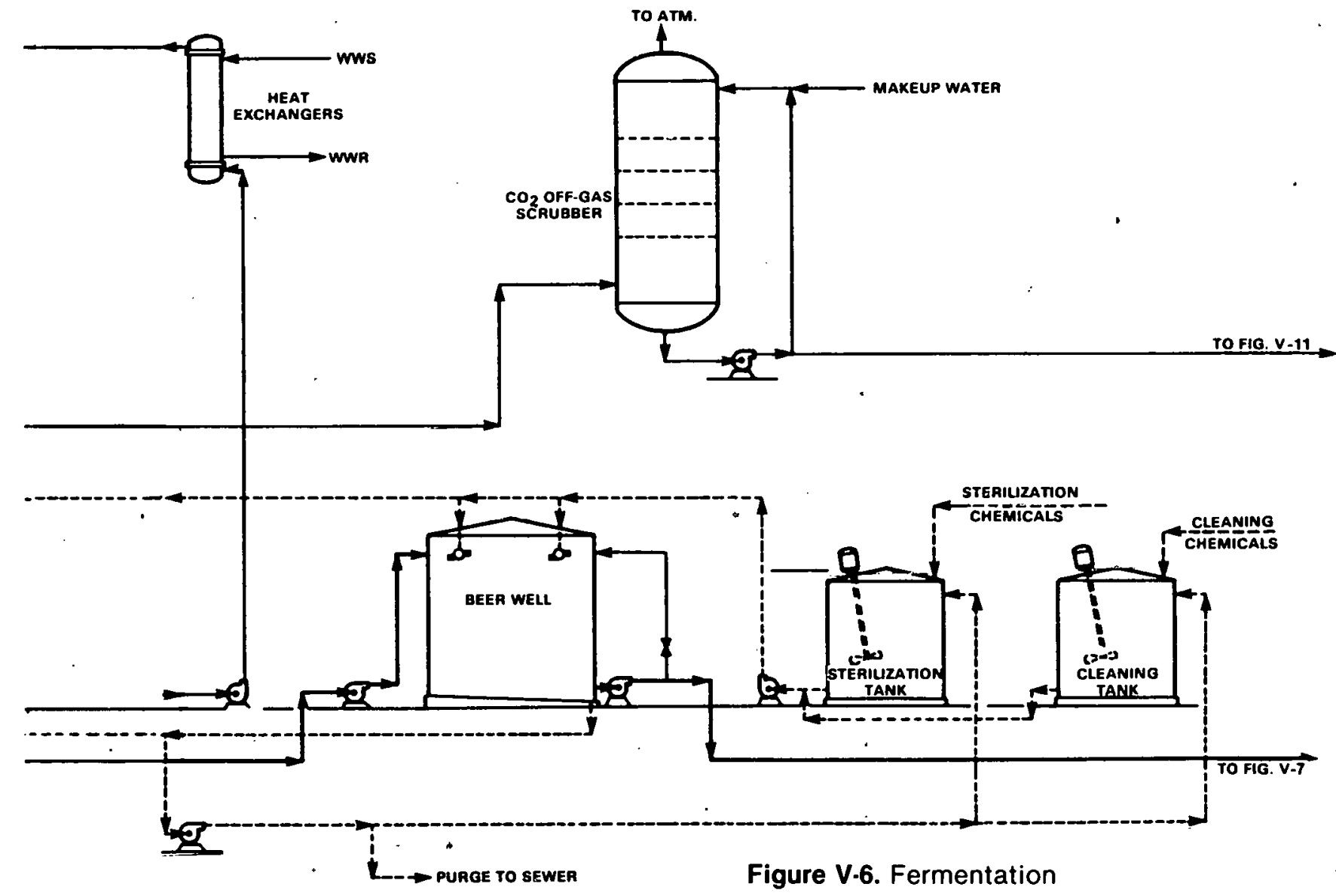




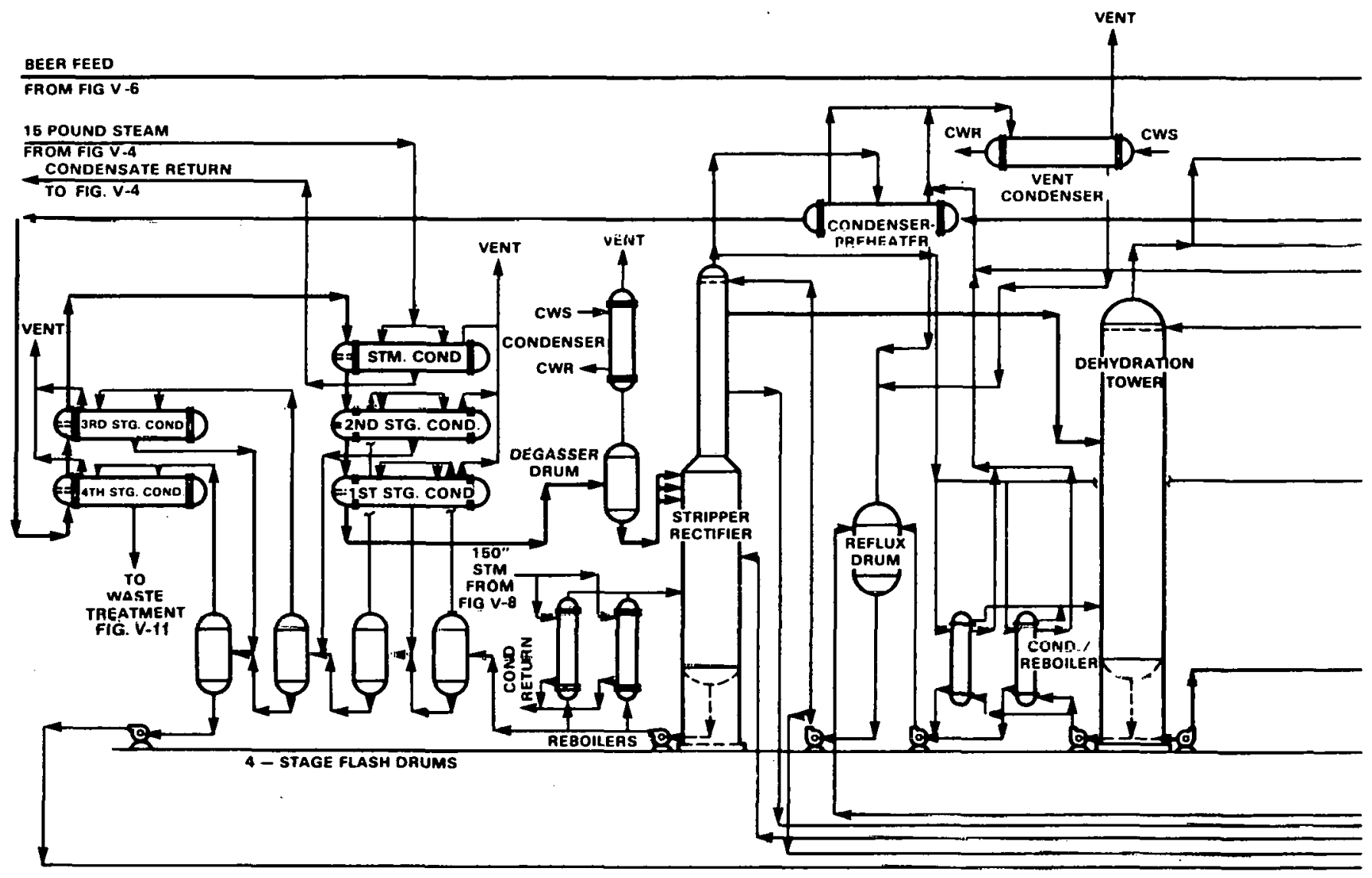

these vapors. The condensed vapors pass to a reflux cooler where they are further subcuoled by cooling water prior to being ted to the decantes. The subcooled liquid entering the decanter separates into two layers. The upper layer is the larger in volume, and represents the hydrocarbon-rich layer. The lower, which separates, is a water layer containing some alcohol and hydrocarbon. The upper layer from the decanter is pumped back to the top tray of the dehydration tower. The lower layer from the decanter is pumped to the top tray of the hydrocarbon stripper which removes the remnants of hydrocarbon and alcohol contained in the feed tu the top tray. The bottoms stream of the hydrocarbon stripper is essentially aqueous, and is removed and sent to the waste treatment plant. Thermal energy is supplied to the base of hydrocarbon stripper via alcohol-rich vapor condensing on the shell-side of a reboiler. The condensed alcohol-rich vapor is passed by to a reflux drum where it joins other vapor condensate before being returned to the top tray of the PSR. Overhead vapors containing alcohol, hydrocarbon, and water from the atmospheric pressure hydrocarbon stripper pass to a condenser-preheater, where they are condensed. The condensate is returned through the reflux cooler to the decanter. The aqueous stream passing from the bottom of the hydrocarbon stripper contains less than 0.02 weight percent alcohol.
This distillation system is covered by a patent allowed, but nont yet issued, to Raphael Katzen Associates, International, Inc.

\section{Fusel Oll and Head nemoval}

In the yeast fermentation process, certain extraneous products, in addition to ethyl alcohol, are formed. These are generally higher alcohols, i.e., higher molecular weight alcohols known as fusel oils, and light ends which include such materials as aldehydes, etc.

The distillation system provides for the removal of these extraneous components in the following manner. (See Figure V-7). The fusel oils have the property of being more volatile than alcohol in dilute aqueous solution, but are less so than alcohol in concentrated alcohol solution. For this reason, they tend to concentrate on some tray in the rectifying section of the PSR. These fusel oils, thus having concentrated, can be removed as a liquid side drawstream from the PSR. They are removed and passed through a fusel oil cooler and to a fusel oil washer, a water washing extraction column in which the alcohol content of the fusel oils is washed from them, under reduced temperature, by counter-currently contacting the cooled fusel oil side stream with a stream of cold water. The heavy aqucous stream, containing the 


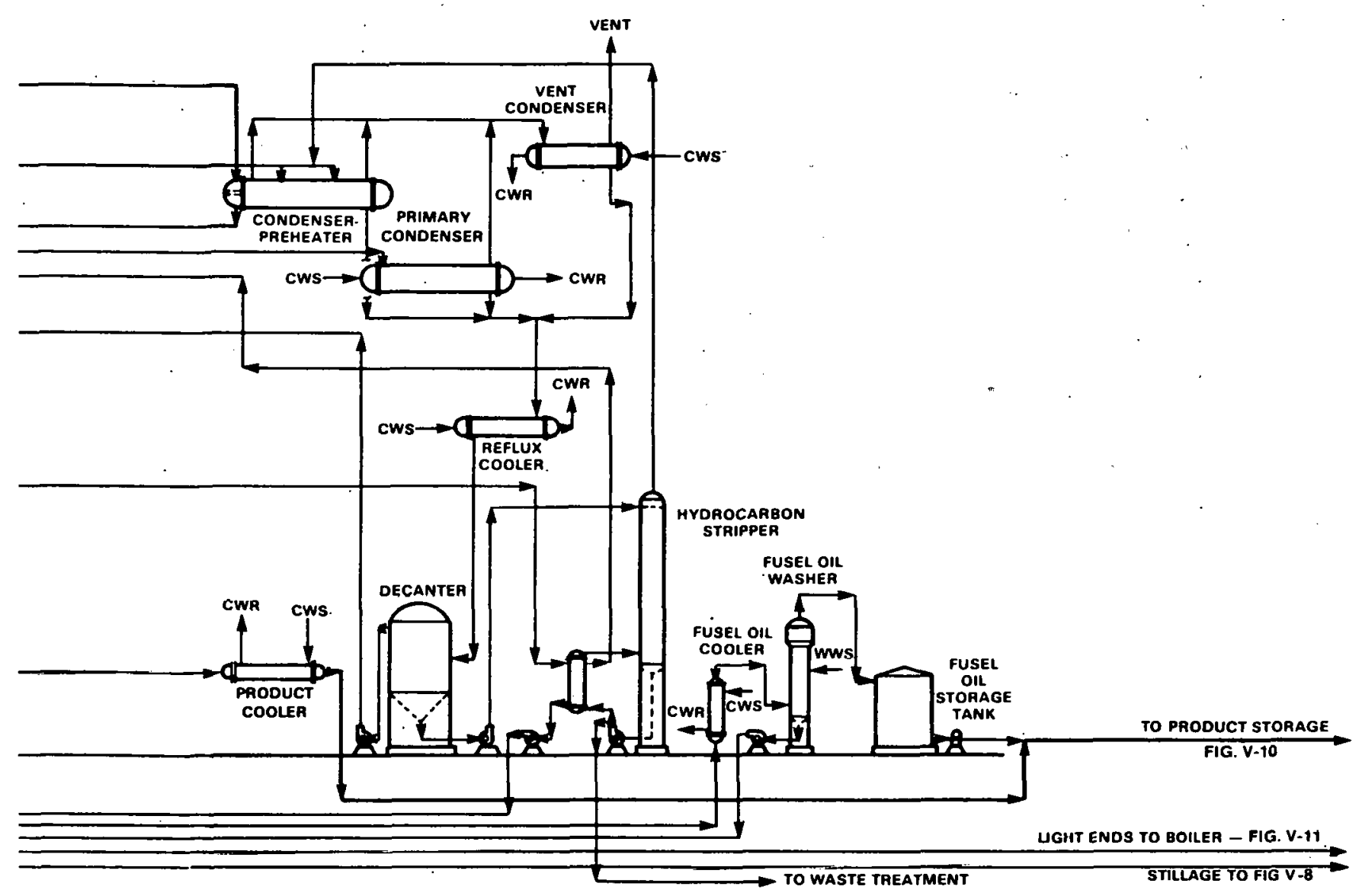

Figure V-7. Distillation

extracted ethyl alcohol, is removed from the base of the fusel oil washer. This stream is returned to the lower section of the PSR for alcohol recovery. The light fusel oil stream is decanted from the top of the fusel oil washer and passes into the fusel oil storage tank.

In general, the fermentation process, when utilizing corn, will produce about 4 to 5 gallons of fusel oil for every 1,000 gallons of anhydrous alcohol product. These fusel oils do have a heating value and can be reblended into the product. If this reblending operation is not desired, then the fusel oils may be passed to the plant boiler where they are used as fuel. Fusel oils should have no harmful effect upon motor fuel-grade alcohol.

Light extraneous fermentation products such as aldehydes are effectively removed in this distillation system by withdrawing a very small purge froin the total reflux stream passing back to the top tray of the PSR. This light component purge, in general, , cannot be reblended into the alcohol to be used for motor fuel blending, because these light products would tend to cause vapor lock when the ethanol is blended with gasoline to produce gasohol. Therefore, these materials are removed and sent to the plant boiler where their fuel value is recovered.
The fusel oil and light ends must be removed because their presence would upset the equilibrium associated with the dehydration step, and could cause problems in the decantation step.

The distillation scheme* for producing motor fuel-grade alcohol, as described here, utilizes only 17.5 pounds of process steam per gallon of anhydrous motor fuel-grade alcohol product. This great reduction in energy use is accomplished by optimizing the feed preheating scheme and by utilizing the heat content of high-pressure vapors produced in the PSR to supply the reboil heat for both the dehydration step and the hydrocarbon-alcohol stripping.

\section{Evaporation and Drying of Stillage Residue}

Stillage from the distillation area is delivered to the whole stillage tank, where it is pumped to the solid bowl centrifugals that operate on a continuous basis. (See Figure V-8). These centrifugals separate the whole stillage into two fractions: thin stillage containing 6.5 to 10 percent total solids and thick stillage containing about 35 percent total solids. Part of the thin stillage, referred to as backset, (corresponding to 10 percent of

*Patents allowed but not yet issued. 


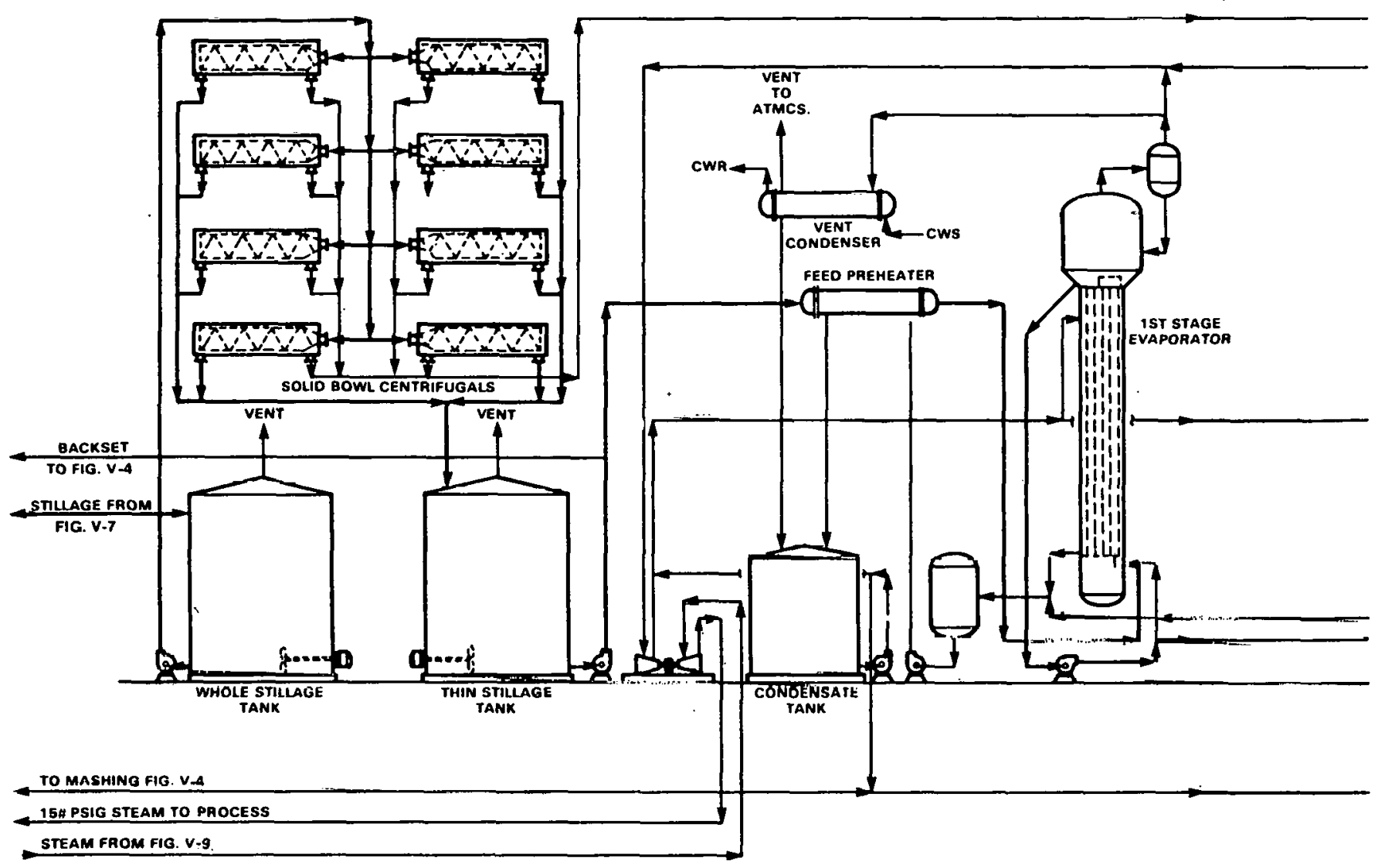

the total mash) is recycled to the mash mixing lank in the cooking and saccharification section.

The remaining thin stillage is evaporated in a vapor recompression evaporator to aboul $5 j$ peicent solids. Because of a cooling effect in the centrifugal separators (caused by evaporation of the stillage in contact with air), the thin stillage must be reheated from about 165 to $208^{\circ} \mathrm{F}$ before it enters the evaporator. Heating is accomplished by using evaporator condensate cooled from 230 to $185^{\circ} \mathrm{F}$. Power for driving the evaporator's vannr compressor (approximately 6,200 hp) is provided by a steam turbine which uses 580 psig steam and exhausts at about 160 psig. This exhaust steam is used for distillation, mash cooking, and heatıng supplemental dil for spent grains drying. The vapor cunne essor opcratcs at approximately atmospheric pressure at the inlet and compresses the vapor to about 21 psia. The compressor outlet steam is superheated, but before it enters the evaporator bodies it is desuperheated by injection of condensate. This is done to get the best heat transfer possible and to prevent "baking" of solids on the evaporator surfaces. The water vapor from the evaporator bodies passes through entrainment separalors and then to the vapor compressor. However, before entering the compressor, it must be superheated by mixing with a recycle flow of superheated vapor from the compressor outlet, to maintain dry, non-corrosive conditions in the vapor compressor.

The thick stillage is mixcd with the concentrated thin stillage and recycled dry grains in the wet grains minglers. (See Figure V-9). The amount of dry grains rccycle is regulated to maintain a wet grains moisture content of 30 percent to minimize stickiness.

The wet grains are then fed to rotary dryers where they are lumbled in contact with hot flue gas from the power boiler. Supplemental hot air for drying is provided by an air heater using 150 psig steam for heating. The hot gas enters the dryers at about $600^{\circ} \mathrm{F}$ with a wet bulb temperature of about $145^{\circ} \mathrm{F}$. The gas and dry grains leave the dryers at ábour $190^{\circ} \mathrm{F}$. The flue gas goco through cyclunte cullectors to remove most entrained solids before it is delivered to the flue gas scrubber.

The dry grains, at about 10 percent muisture, arc transferred to the dry grains hopper. About 75 percent of the dry grains is resycled in order to regulate the moisture content of the wet grains. The remaining net make of dry grains is ground in a hammer mill and then cooled in the product cooler, an auger-type heat exchanger that uses well water to cool the grains to about $100^{\circ} \mathrm{F}$. The cooled coproduct is then transferred pneumatically to storage and shipping. 


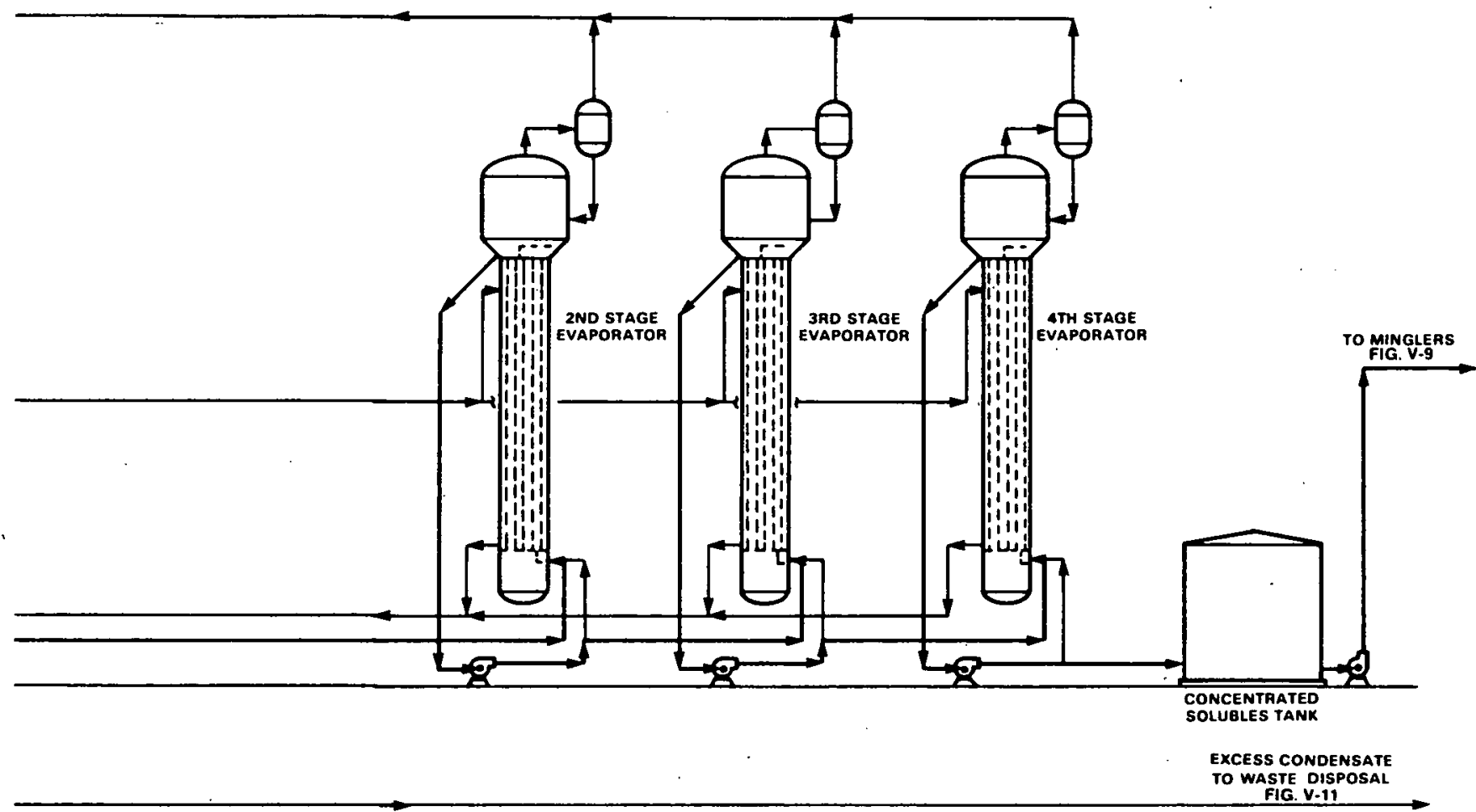

Figure V-8. Residue Feed Processing

\section{Alcohol, Ammonium Sulfate, and Dry Grains Storage and Shipping}

The alcohol is received from the distillation section and stored in receiver tanks, each of which is sized for one day of production. (See Figure V-10). While one tank is being filled, the other is checked for quality and quantity by the government inspector. After inspection, its contents are sent to long-term storage. The four storage tanks hold a total of about 1.2 million gallons-about 28 days of production. Upon transferring the product from storage to a tank car or truck, denaturant (gasuline) is added at a rate of 1 gallon per 100 gallons of alcohol. The denaturant tank holds about 50,000 gallons. Accurate metering is provided by positive displacement meters.

A water solution, containing 40 percent ammonium sulfate, is produced by the flue gas scrubbing system. This solution is to be sold as field fertilizer and is stored in four tanks having a capacity of 1 million gallons each. This corresponds to storage of the total ammonium sulfate production for about 9 months, which allows for storage during the fertilizer off-season.

Dry grains are stored in an A-frame-type building with a storage capacity of about $295,000 \mathrm{cu} \mathrm{ft}$, equivalent to about one week's production. (See Figure V-10). Shipping of the dry grains from storage is done on a first in/first out basis and utilizes a front-end loader to load the pneumatic conveyor system which transfers the grains to the live bottom surge bin at a rate of $88,000 \mathrm{lbs}$ per hour. This rate is based on shipping out the dry grains for an average of 12 hours each day. Shipment may be made by either truck or rail, and shipping scales are provided for weighing the shipments.

\section{Coal-Fired Boiler}

Steam for the plant is provided by a coal-fired boiler rated at $250,000 \mathrm{lb} / \mathrm{hr}$ of steam at $600 \mathrm{psig}$ and $600^{\circ} \mathrm{F}$. (See Figure V-11). Calculated plant usage is about $200,000 \mathrm{lb} / \mathrm{hr}$ of steam. The firing rate is $12.6 \mathrm{~T} / \mathrm{hr}$ of coal, having a gross heating value of $10,630 \mathrm{Btu} / \mathrm{lb}$ (Illinois No. 6 coal). The coal contains approximately 3.8 percent sulfur (moisture-free basis). Small fuel inputs are also provided by light ends from distillation of the alcohol and by de-watered sludge from waste treatment.

The coal unloading facility provides for direct transfer to the coal bunker or to a storage pile. A front-end loader is used to transfer coal from the pile back to the unloading area where it can be transferred to the coal bunker. 


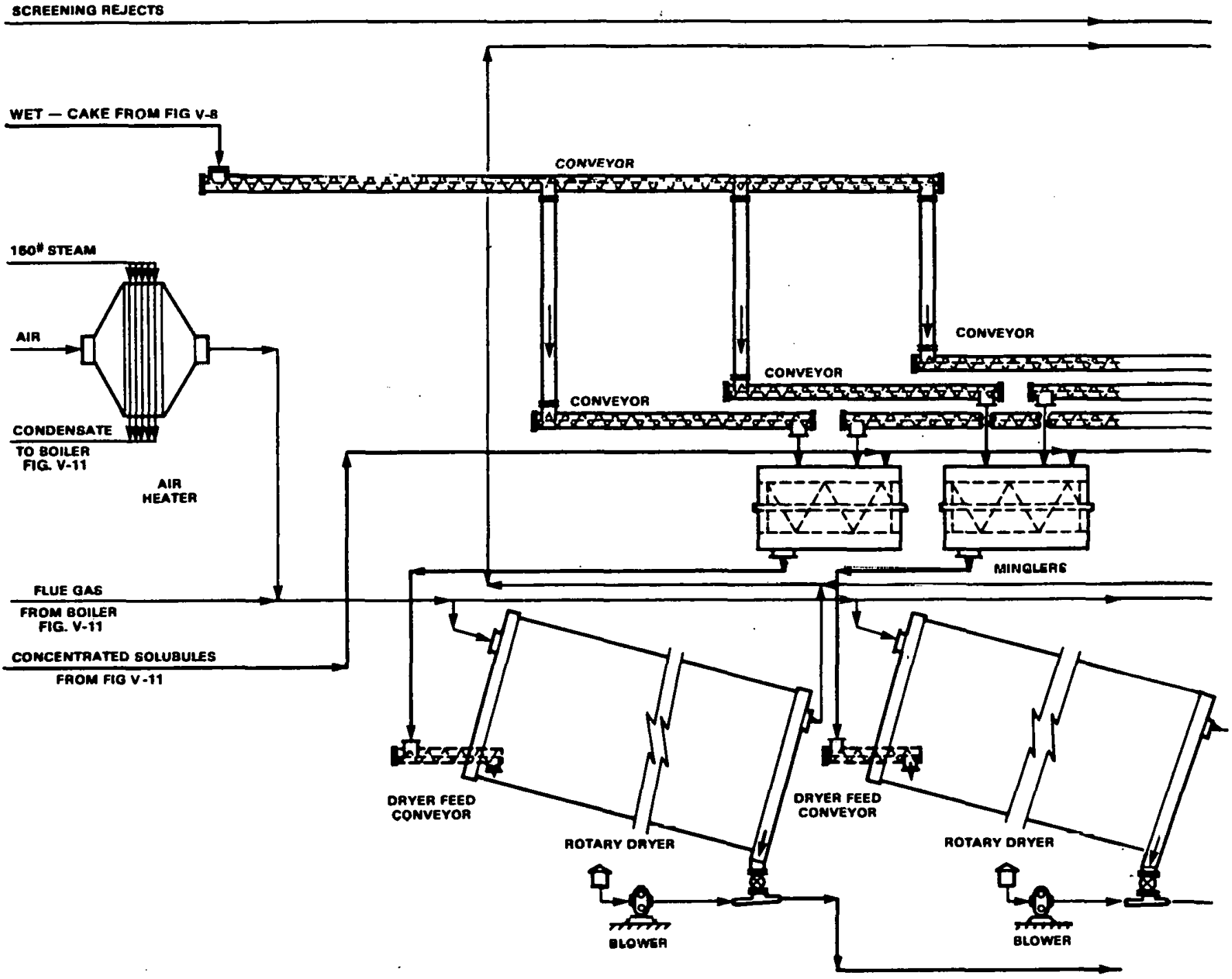

Boiler feedwater is provided by condensate return from the process, where possible, and by makeup water that has bcen filtered and conditioned in a conventional boiler feedwater treatment system. About two-thirds of the boiler feedwatcr is condensate return.

The flue gas passes through the cyclune collcctor for narticulate removal. The collector consists of numerous small cyclones (multi-clones) housed in a single s.hamber. The recovered particulate goes to the boiler at a temperature of about $725^{\circ} \mathrm{F}$. This is a high flue gas temperature by normal standards, but in this cassc, does not adversely affect the overall plant thermal efficiency since the hot flue gas, tempered with air to $600^{\circ} \mathrm{F}$, goes to the stillage drying section where its heat is used to dry the distiller's grains. For this reason, no flue gas heat economizer or tack is required with the boiler.

The coal is fed to the boiler by four stoker-spreader units. The spreader feeding system was selected (rather than pulverized blown coal) because of the small boiler size and hecause the boiler inefficiency, due to excess air, does not affect the process thermal efficiency.

\section{Water Supply}

The water supply system provides well watcr for meeting process makeup requirements, process cooling where cooling tower water is not cool enough, and maintaining a supply of fire protection water. (See Figure V-12). Well water is ulso used to provide makeup to the cooling tower. Three wells are provided with : capacity of $1,800 \mathrm{gpm}$ each. The well water storage tanl has a capacity of 100,000 gallons and provides for surges in demand and alluws sliviletirm shutdowne of the wells, as 1ejuired for maintenance or repairs, without interrupting the supply of water to the plant.

The fire protection system consists of the fire protection tank which has a capacity of 300,000 gallons, four fire water pumps ( 2 electric and 2 diesel), and an underground fire water distribution system, along with the appropriate fire hydrants and spray headers. Each pump has a capacity of $2,000 \mathrm{gpm}$. The diesel-powered pumps are used only in the cvent of an electric power failure. 


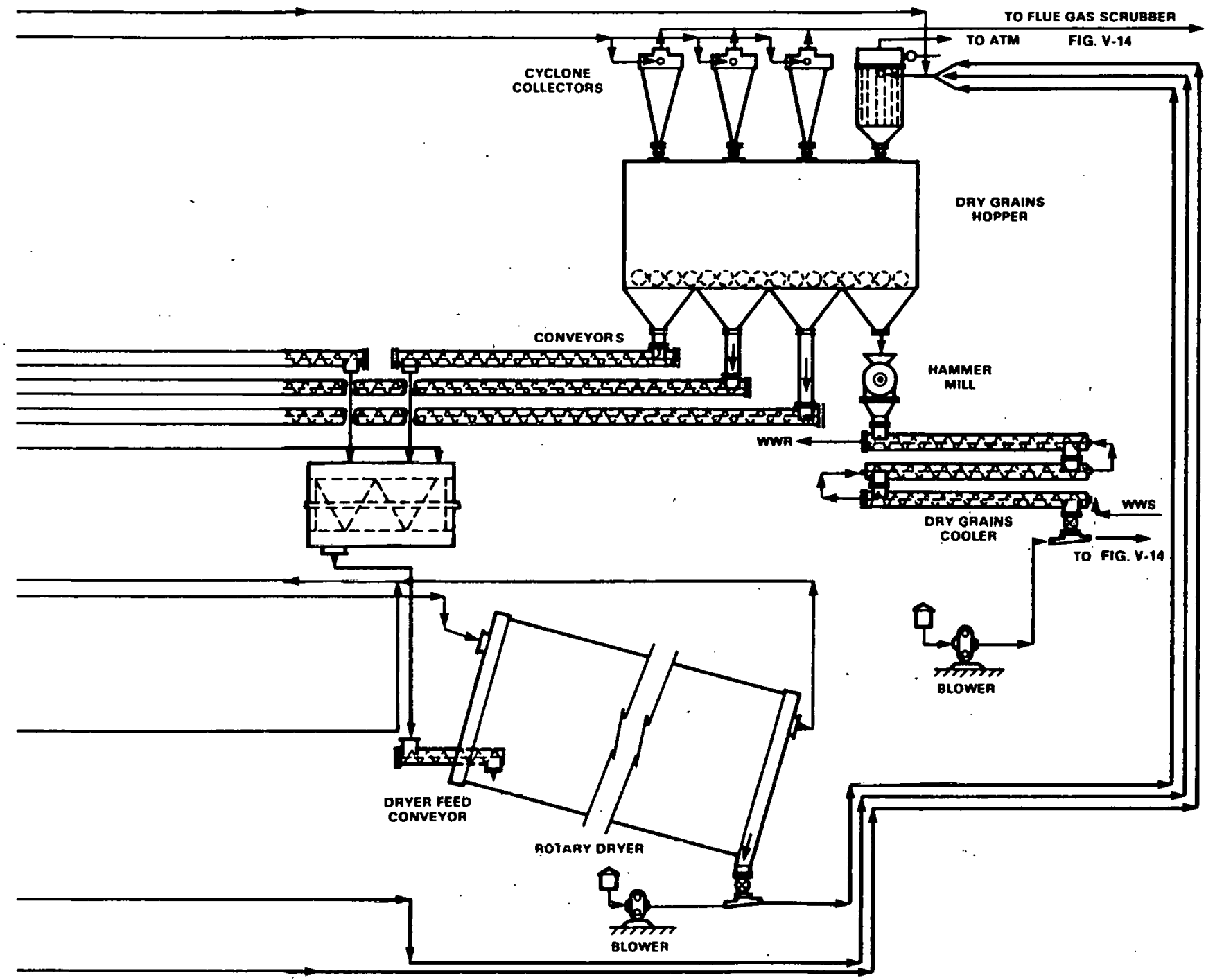

Figure V-9. Stillage Mixing

The cooling tower is designed to provide $16,000 \mathrm{gpm}$ of water at $85^{\circ} \mathrm{F}$ from a warm water return temperature of $115^{\circ} \mathrm{F}$, and an ambient design wet-bulb temperature of $75^{\circ} \mathrm{F}$. The tower consists of two cells with a two-speed fan for cach cell. The three cooling tower pumps are rated at $7,500 \mathrm{gpm}$ each.

\section{Wastewater Treatment}

The wastewater flows include process wastewater and sanitary wastewater. (See Figure V-13). The wastewater is collected at a lift station and pumped to the treatment plant.

The wastewater treatment plant is designed for secondary treatment with two extended aeration tanks and two settling tanks. The aeration tanks are $95 \mathrm{ft}$ in diameter. The sludge thickening tank is $20 \mathrm{ft}$ in diameter.

The influent stream passes through a bar screen and grinder prior to entering the first aeration tank. Water from the first stage is split; the major portion is recycled to the first aeration stage, while the remainder is sent to the thickening tank. Clarified water from the first settling stage overflows to the second aeration tank, where.. by additional biochemical oxygen demand (BOD) is removed. Nutrients may be added to either aeration tank, but due to the nature of the wastewater flows, should not be needed. The water from the second aeration tank overflows to the second-stage settling tank.

The sludge from the second-stage settling tank is recycled to either the first- or second-stage aeration tank. A stream is sent to the thickener. The two-stage aeration system, coupled with the flexibility to recycle sludge from either stage, allows good control of effluent BOD.

The clarified water from the second-stage settling tank flows by gravity to the chlorine contact tank. Chlorine is added to the contact tank for destruction of final traces of impurities. The eftluent from the chlorine tank flows to a nearby river. 


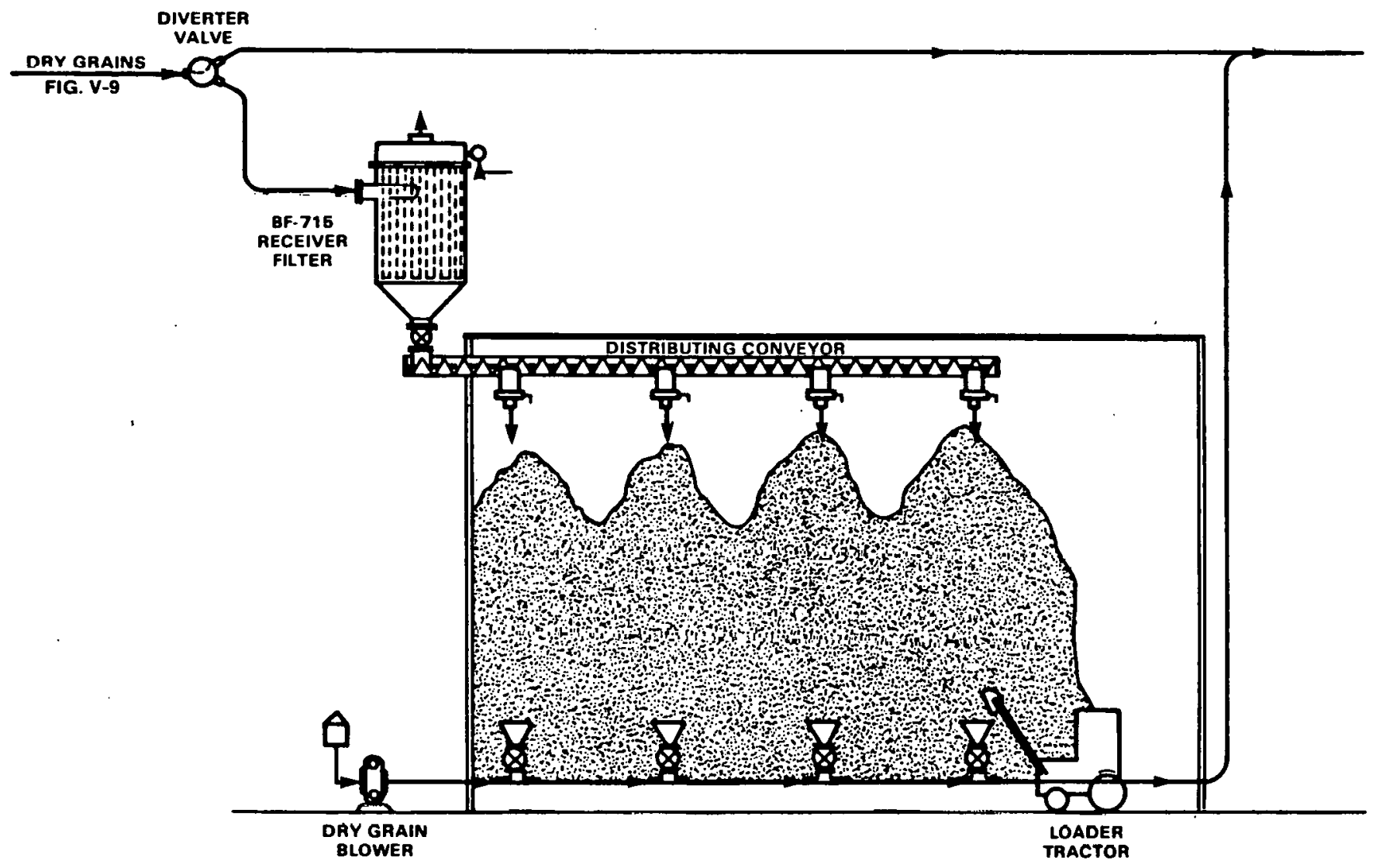

Sludge from both the first- and sccond-stage aeration tanks is collected in the sludge thickener and pumped to the dewatering press. The sludge is mixed with primary sludge collected from the flue gas desulfurization system and dewatered to about 25 percent solids. The solids from the dewatering press are chopped up in a flaker and conveyed to the boiler for burning.

The treatment plant is designed to remove 95 percent of the effluent BOD.

\section{Flue Gas Scrubber}

The hot flue gas from the coal-fired boiler is sent to dry grains recovery where it mixes with dilution air for grains drying prior to being sent on to the flue gas scrubbing system. (See Figure V-14). Because of the high sulfur content of Illinois No. b coal (and alsu thic high purchase price of low-versus high-sulfur coal) n flue gas desulfurization system is required. The desulfurization system recovers the $\mathrm{SO}_{2}$ as ammonium sulfate and differs from the more conventional limestone scrubbing systems in that no calcareous sludge is produced in the system. The only coproduct is thie ammonium sulfate.

In the flue gas scrubbing system, ${ }^{*}$ water sprays cool the gas and remove particulate in three stages. The first stage removes particulate only. The next two stages cool the gas and remove additional particulate. Ammonia is used in a two-stage absorption section for removal of sulfur dioxide from the flue gas. The ammonium sulfite/bisulfite solution from the scrubbers is neutralized to ammonium sulfite and oxidized to ammonium sulfate. The ammonium sulfate is suitablc for sale as agricultural fertilizer. A more detailed description of the system is given helow.

The hot gas enters the spray quench section where it is quenched to within $5^{n}$ of its wet bulb temperature, $143^{\circ} \mathrm{F}$

The saturated gas enters the first section of the flue gas scrubber where it is washed with a very high rate of water flow from spray nozzles. The gas is then cooled in two successive spray cooling sections to $110^{\circ} \mathrm{F}$. Part of the heat removed in the first cooling section is used to itheat the exit flue gas in the heat exchanger, to improve the flue gas buoyancy. The remaining heat from the cooling sections is removed by cooling water using plate-and-frame-type heat exchangers. Particulate matter, removed in the quench and cooling sections, is removed by the cyclone cleaner. This material is concentrated further in a clarifier and then combined with sludge from the waste treatment system. The mixture is

*U.S. Patent $3,957,951$ and patents pending, licensed by Raphael Katzen Associates International. 


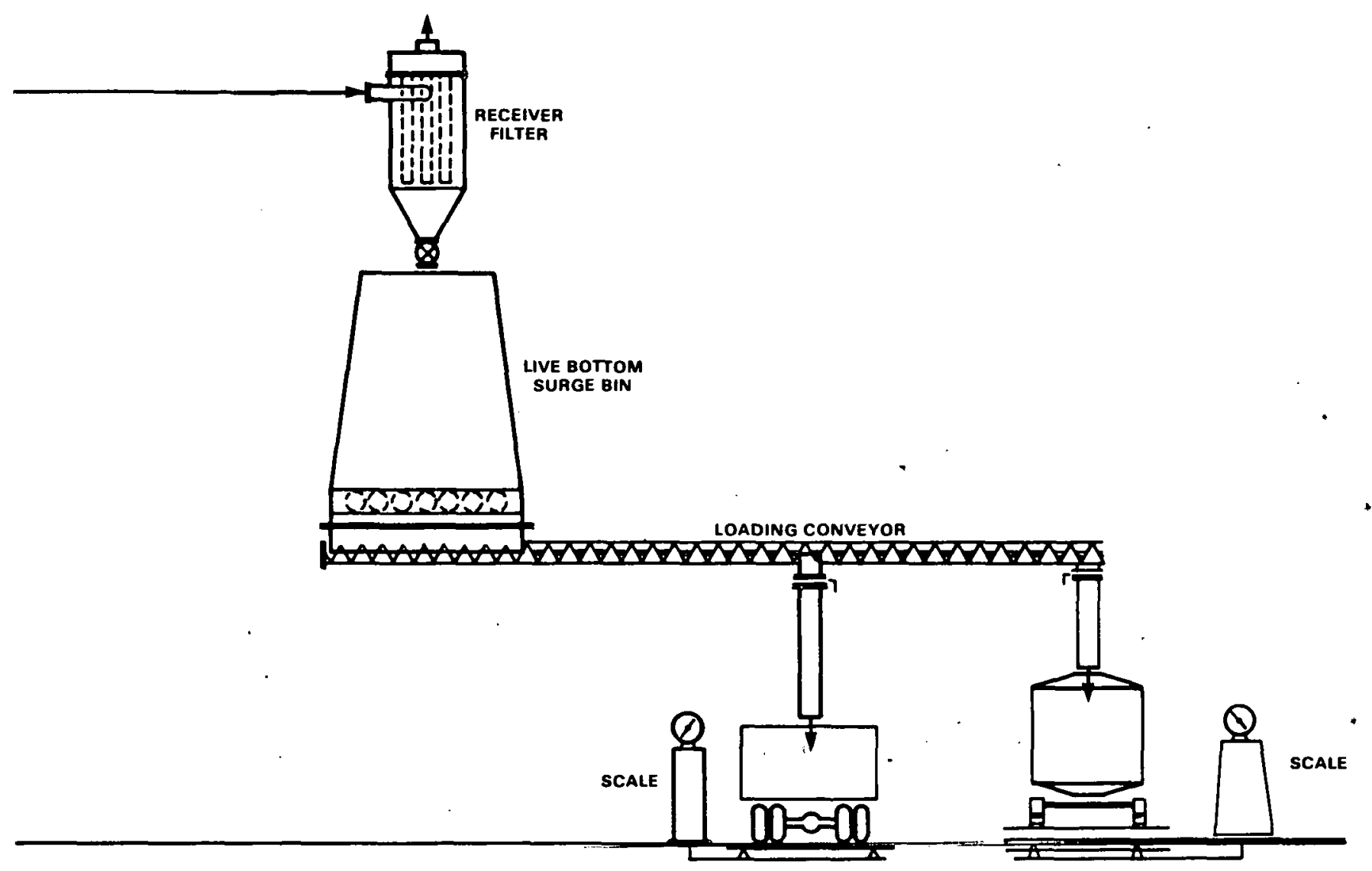

Figure V.10. Storage and Shipping of Dry Grains

then dewatered in the dewatering press and sent to the coal-fired boiler. The boiler is equipped with special feeder/spreaders to handle the sludge.

In the absorption stages, the $\mathrm{pH}$ of the liquid is carefully controlled in order to minimize the gas phase relation between ammonia vapor and sulfur dioxide gas. The $\mathrm{pH}$ is controlled by adjusting the absorption solution circulation rate and the rate of ammonia addition to each stage. The heat of reaction from $\mathrm{SO}_{2}$ absorption is removed by another plate-and-frame exchanger.

The flue gas draft for the scrubbing system, as well as for the spent grains driers and interconnecting ducting, is supplied by the flue gas fan located at the scrubber outlet. The fan is driven with a 1,000-hp motor and will handle $150,000 \mathrm{acfm}$ with a 30 " water guage pressure increase to the flue gas.

The product ammonium sulfite/bisulfite solution from the scrubber is taken from the lower absorption loop downstream of the first-stage absorption loop pump. This solution is neutralized with aqueous ammonia to ammonium sulfite and then oxidized to ammonium sulfate in the oxidizer reactor. This solution is then cooled to $100^{\circ} \mathrm{F}$ in the oxidizer exchanger. The water makeup to the scrubber will be controlled to produce a final oxi- dized solution strength of 40 percent ammonium sulfate, which can be used for direct application to fields for fertilizer or for a blending material by fertilizer manufacturers.

\section{Materials Flow}

Table V-1 summarizes the daily materials flow through the system. Most noticeable is the large amount of water required by the process, i.e., about 7.25 gallons of water per gallon of ethanol produced.

\section{Energy Flows}

Table V-2 summarizes the energy-flows through the system by major operation in the process. Distillation requires over half the steam input to the process, followed by cooking and saccharification, which require about 30 percent of the total. Enzyme production, DDG recovery, and utilities are the major components of electricity demand.

The efficiency of the system (ratio of energy out to energy in) may be expressed in several ways:

- If only the fossil fuel inputs are considered (electricity being based on a 10,000 Btu/kwh equiv- 

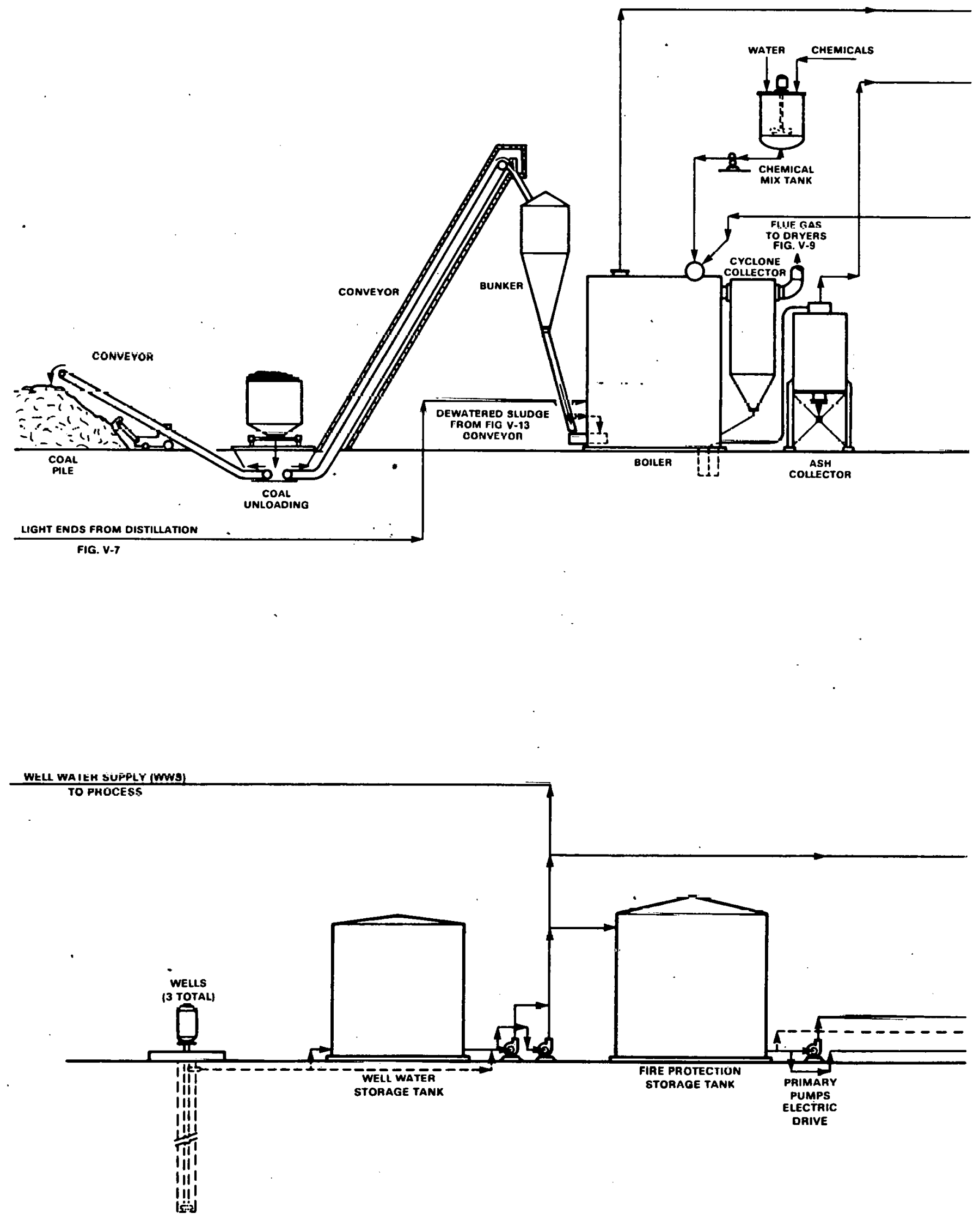


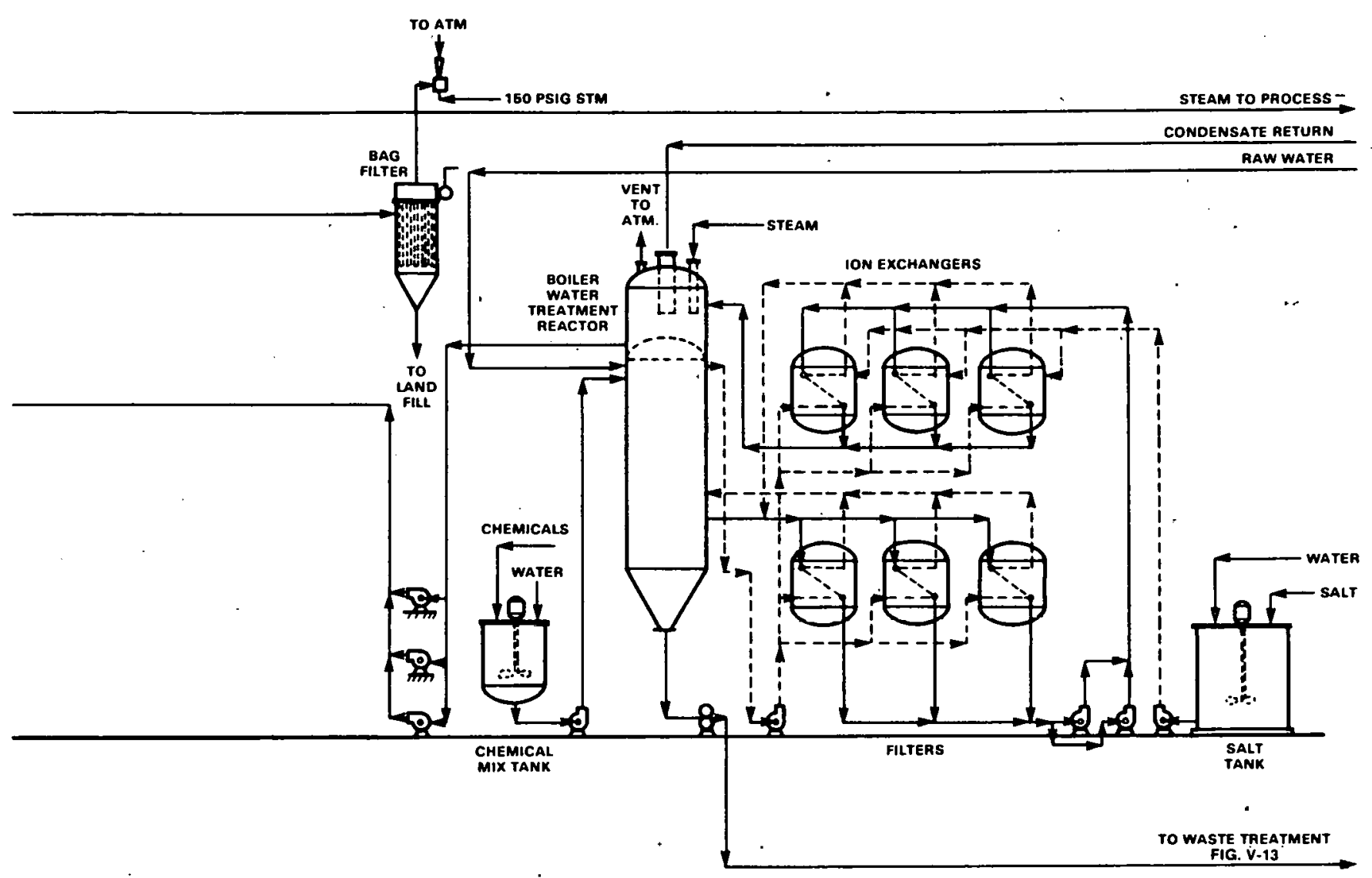

Figure V-11. Utilities, Boiler

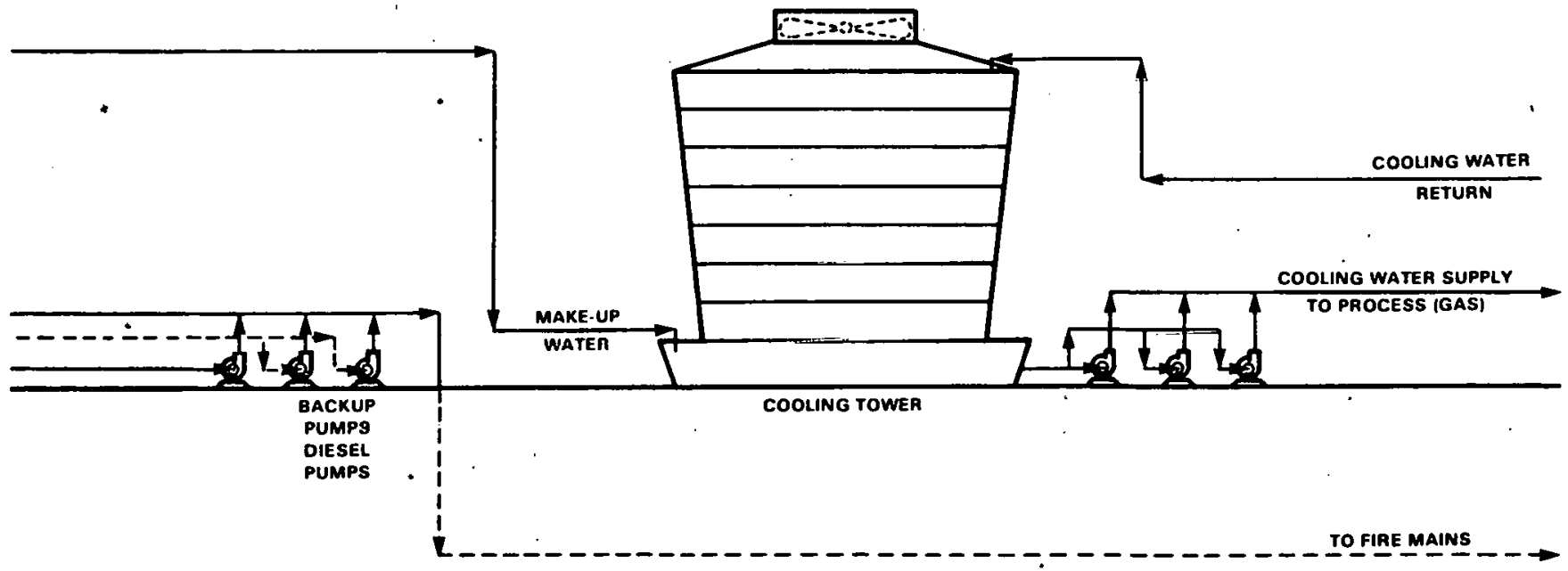

Figure V-12. Utilities, Water Supply 


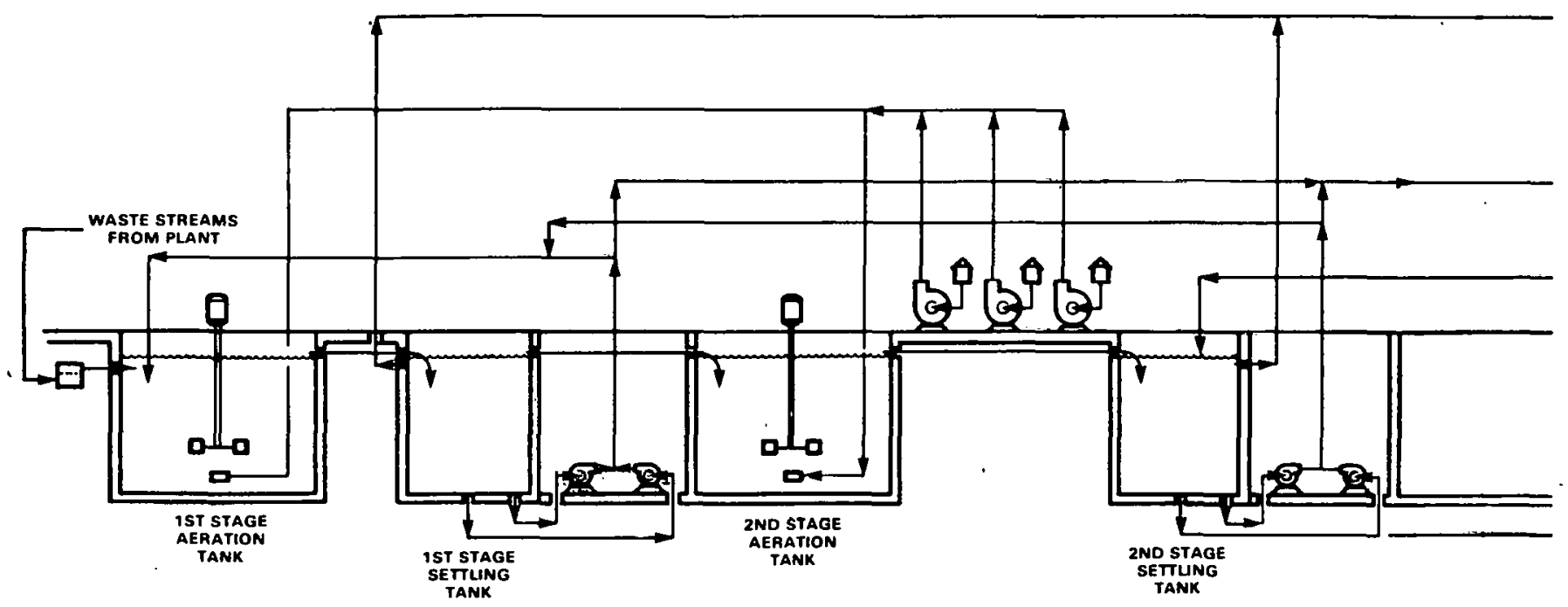

SULFATE

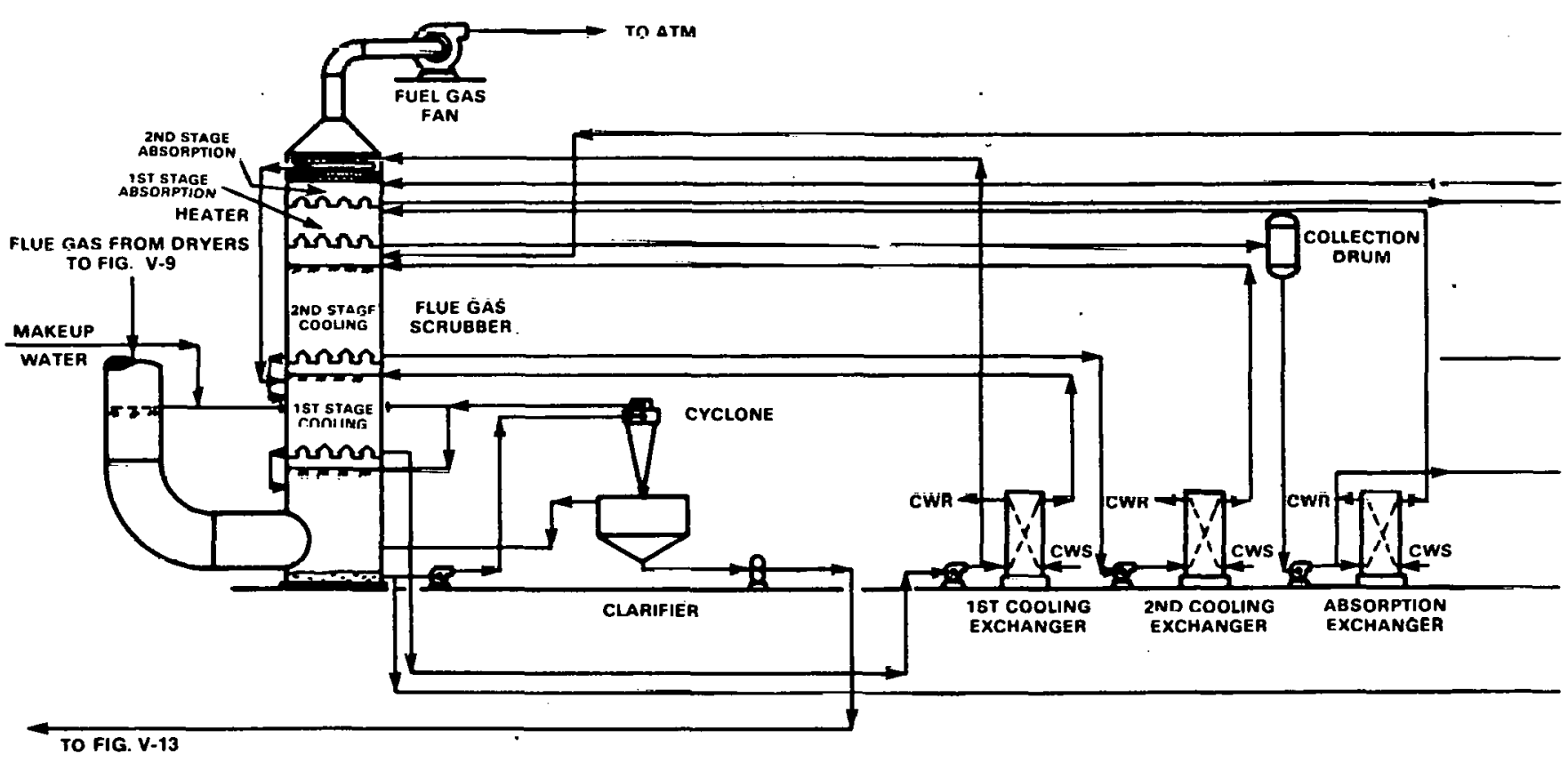

78

COMMERCIAL SCALE ETHANOL PRODUCTION AND FINANCING 


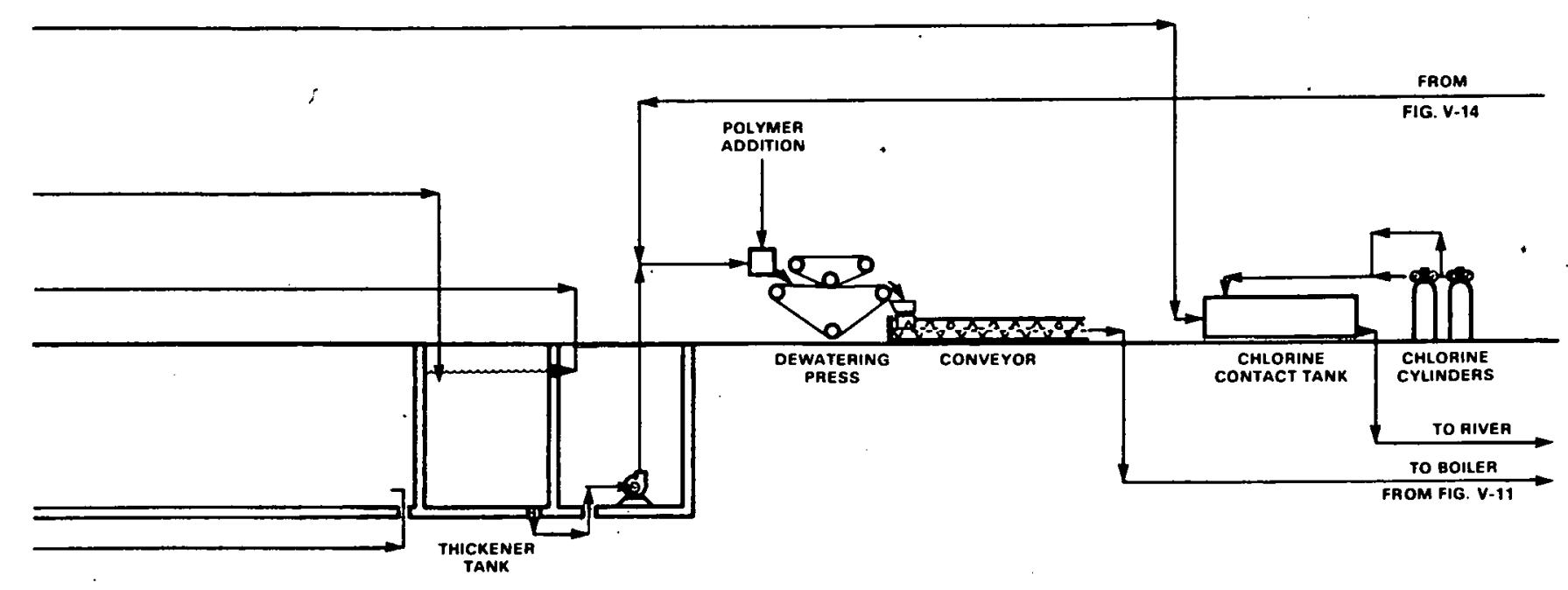

Figure V-13. Utilities, Wastewater Treatment

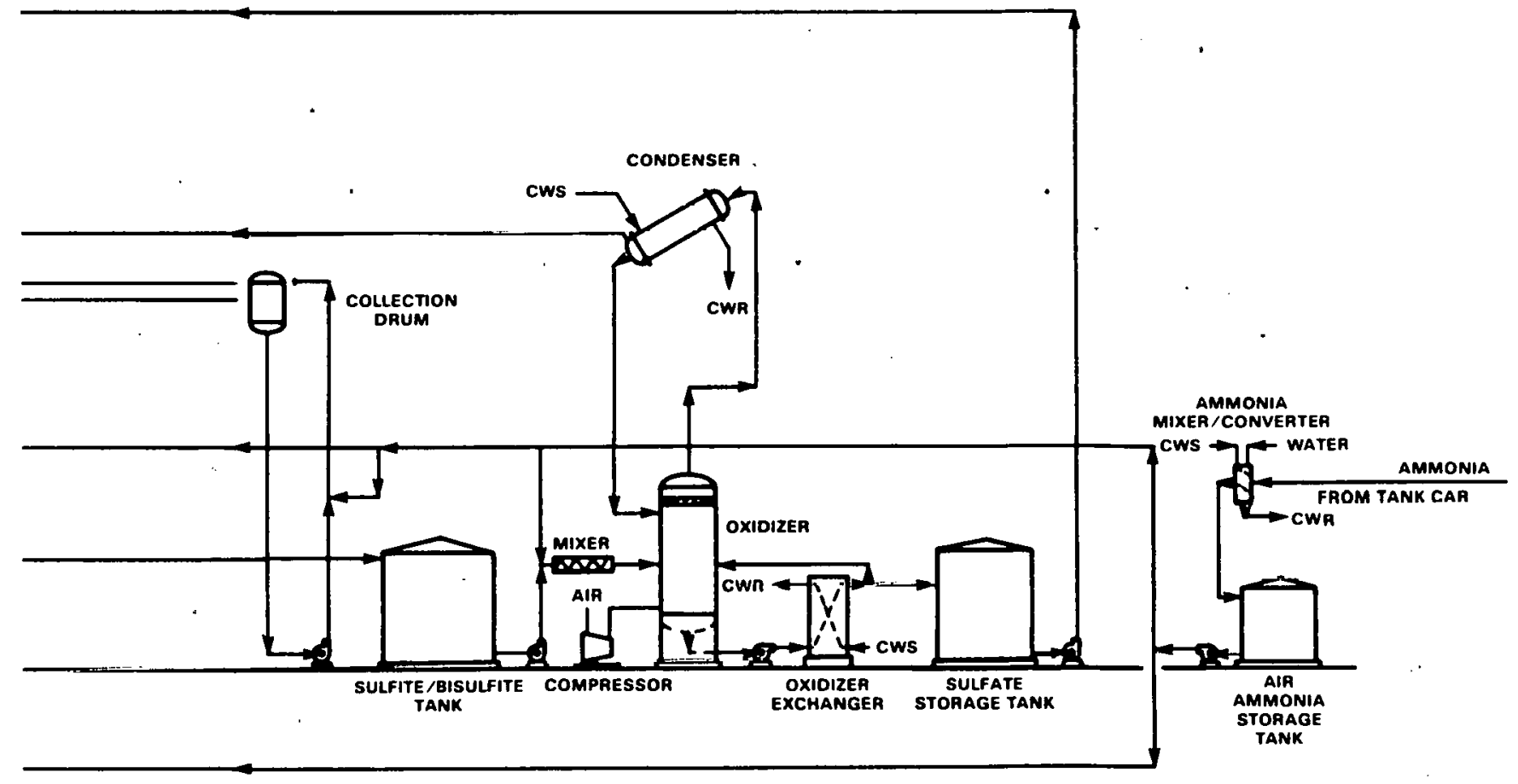

Figure V-14. Utilities, Flue Gas Scrubber 


\begin{tabular}{|l|l|r|}
\hline \multicolumn{1}{|c|}{ ITEM } & \multicolumn{1}{|c|}{$\begin{array}{c}\text { DAILY } \\
\text { QUANTITY }\end{array}$} \\
\hline INPUTS & UNITS & \\
Corn & & 58,900 \\
Coal & Bushel \\
Yeast & Tons & 296.7 \\
Denaturant & Tons & 1.2 \\
Ammonia & Gallons & 1,500 \\
Water & Tons & 9.2 \\
OUTPUTS & Gallons & $1,250,000$ \\
Ethanol & & 151,515 \\
Distillers Dried Grains and Solubles & Gallons & 536.7 \\
Ammonium Sulfate & Tons & 31.6 \\
Wastewater & Tons & $1,100,000$ \\
\hline
\end{tabular}

SOUACE: Katzen, R., '“Grain Motor Fuel Alcohol Technical and Economic Assessment Study". Raphael Katzen ' Associates for the U.S. DOE, Dec., 1978.

alent): alcohol $/($ coal + electricity $)=154.4 \%$ or about 55,000 Btu per gallon of ethanol.

- If the energy used to produce the corn and a credit for DDG production are included: (alcohol $+\mathrm{DDG}) /($ coal + corn + electricity $)=10.5 .1 \%$ (corn production requires about 95,000 Btu/bushel)

- If the total thermal energy in the corn and DDG are considered: (alcohol + DDG)/(coal + corn + electricity $)=68.9 \%$.

Ffficiency is not really a concern to the investor except as it affects economics. It is more a matter of national policy to determine what cost in fossil fuel (coal) can be tolerated to displace a barrel of imported oil.

\section{PLANT INVESTMENT}

The total plant investment is estimated to be $\$ 58$ million (end of 1978 dollars). Table V-3 shows a breakdown of the investment by plant section. The two major items are the utilities and the DDG recovery sections, which together account for over half the total investment. For a plant in the range of 50 million gallons per year, the investment is on the order of $\$ 1.16$ per gallon capacity (1978 dollars).
For plants of 10 million gallons capacity, the investment was estimated at about $\$ 25.2$ million (1978 dollars) or about $\$ 2.50$ per gallon capacity. The investment for a 100 -million-gallon plant was estimated at $\$ 100$ million or about $\$ 1.00$ per gallon capacity. Figure V-15 summarizes the plant investmont data generated by Katzen and others. It is apparent that large investment economies are achieved when the capacily incireases from 10 to about 50 million gallons per year. Above this range, the economies of scale are much less significant, since many pieces of equipment in the larger plants are multiples of those used at the 50-million-gallon capacity and some of the large pieces of equipment. such as the distillation towers must be field- rather than factoryassembled.

\section{OPERATING COSTS}

The annual operating costs for the 50-million-gallon plant are estimated at $\$ 44.51$ million or $\$ 0.89$ per galloni (1978 dollars). The costs include straight line depreciation over 20 years. Table V-4 summarizes the cost items. The first column gives the 1978 equivalent cost and the second, the operating cost for the first year. The major cost item is corn and the second is the credit for the DDG coproduct. The net cost of corn (corn cost minus credit) amounts to about 58 percent of the annual operating cost. Therefore, ethanol production will be very sensitive to fluctuations in feedstock and coproducts market prices. 


\begin{tabular}{|c|c|c|c|c|}
\hline \multirow{2}{*}{ ITEMS } & \multicolumn{2}{|c|}{ PROCESS STEAM } & \multicolumn{2}{|c|}{ ELECTRICITY } \\
\hline & LB/HA & $\%$ & kW & $\%$ \\
\hline Receiving, Storage, Milling & & & 507 & 6.1 \\
\hline Mash Cooking \& Saccharification & 61,000 & 30.5 & 216 & 2.6 \\
\hline Enzyme Production & 1,400 & $0: 7$ & 1,696 & 20.4 \\
\hline Fermentation & 400 & 0.2 & 333 & 4.0 \\
\hline Distillation & 117,000 & 58.5 & 133 & 1.6 \\
\hline DDG Recovery & 12,800 & 6.4 & 2.253 & 27.1 \\
\hline Storage \& Denaturing & & $\therefore$ & 58 & 0.7 \\
\hline Utilities & 5,400 & 2.7 & 3,076 & 37.0 \\
\hline Buildings & 2,000 & 1.0 & 42 & 0.5 \\
\hline TOTAL & 200,000 & 100.0 & 8,314 & 100.0 \\
\hline
\end{tabular}

SOURCE: Katzen, A., "Grain Motor Fuel Alcohol Technical and Economic Assessment Study". Raphael Katzen Assuciales for the U.S. DOE, Dec., 1978.

Table V.3. 50 Million Gallon Per Year Plant Investment Base Case

\begin{tabular}{|l|r|r|}
\hline \multicolumn{1}{|c|}{ IDENTIFICATION } & \multicolumn{1}{|c|}{$\begin{array}{c}\text { DECEMBER 1978 } \\
\text { COST (DOLLARS) }\end{array}$} & $\begin{array}{r}\text { PERCENT OF } \\
\text { INVESTMENT }\end{array}$ \\
\hline Receiving, Storage \& Milling & $\$ 2,086,800$ & 3.96 \\
Cooking and Saccharification & $2,824,300$ & 5.36 \\
Fungal Amylase Production & $3,485,900$ & 6.61 \\
Fermentation & $4,195,600$ & 7.96 \\
Distillation & $5,123,800$ & 9.72 \\
Dried Grain Recovery & $13,018,400$ & 24.69 \\
Alcohol Storage, Denaturing \& Coproduct Starage & $4,399,900$ & 8.34 \\
Utilities & $15,090,000$ & 28.62 \\
Building, General Services, and Land & $2,494,000$ & 4.73 \\
$\quad$ Subtotal & $52,719,000$ & 100.00 \\
+ 10\% Contingency & $5,272,000$ & \\
TOTAL PLANT COST & $\$ 57,991,000$ &. \\
\hline
\end{tabular}

SUURCE: Katzen, R., "Grain Motor Fuel Alcohol Technical and Economic Assessment Study". Raphael Katzen Assoclates for the U.S. DOE, Dec., 1978.

Under the same assumptions as those used in Table V-4 (20 years straight depreciation), the operating costs for 10 - and 100-million-gallon plants are $\$ 1.22$ and $\$ 0.84$ per gallon, respectively.

\section{ECONOMIC ANALYSES}

Economic analyses were performed for the 50-milliongallon plant described above to determine the price of ethanol which will cover the production cost and pro- vide a suitable return on equity. The return on equity is based on a Discounted Cash Flow-Interest Rate of Return (DCF-IROR) analysis.

The schedule of plant life and financial assumptions used in the analysis are summarized in Table V-5.

Figure V-16 summarizes the results of the analysis for three plant sizes. Ethanol price is expected to range from about $\$ 1.40$ to about $\$ 2.20$ per gallon in 1983 . 


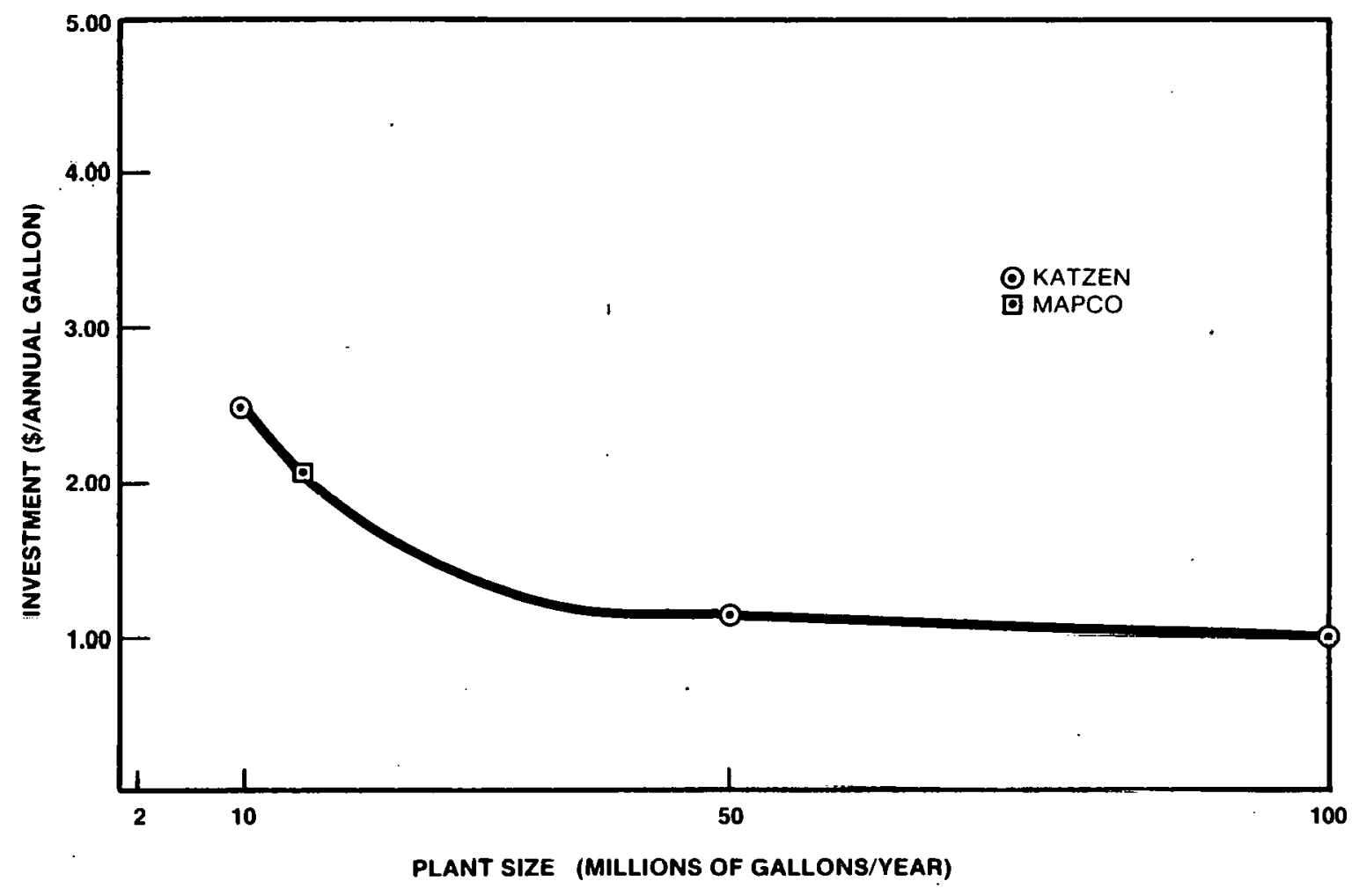

SOURCE: Katzen, R., "Grain Motor Fuel Alcohol-Technical and Economic Assessment Study". Raphael Katzen Associates for the U.S. DOE, Dec., 1978.

Figure V-15. Ethyl Alcohol Plant Costs in \$ Per Annual Gallon

\section{SENSITIVITY OF ETHANOL PRICE}

The sensitivity of ethanol price to various parameters is discussed below.

\section{Sensitivity to Feedstock Price}

The base case discussed above assumed corn price at $\$ 2.30 /$ bushel. Figure V-17 shows the dependence of ethanol price on that of corn for two levels of DCFIROR. As is expected from the previous analysis, ethanol price is very sensitive to corn prices: an increase of 10 cents per bushel in corn price results in an increase of about 5 cents per gallon in ethanol price.

\section{Sensitivity to Coproduct (DDG) Price}

Figure V-18 shows the impact of variations in DDG prices on the price of ethanol. An increase of about 10 percent in DDG price results in a decrease of about 3 percent in cthanol price.

\section{Sensitivity to Changes in Feedstock and Fuel}

An analysis similar to that performed for corn was performed for wheat, milo, and sweet sorghum feedstocks. In the latter case, there is some uncertainty in the results because a complete plant design was not availablc. Tahle V-6 summarizes the results of the analysis for the base case of a 50 -million-gallon plant.

The similarity in design of the corn, wheat, and milo plants is reflected by equivalent investments for the plants. Sweet sorghum is a sugar crop which requires a front-cnd processing unit different from corn (juice extraction and clarification). Swcet sorghum is only available for about 6 months of the year. To avoid extensive storage facilities, it was assumed that the plant operates half of the year on sweet sorghum and half of the year on corn. As was pointed out in an earlier section, the double feedstock capability results in higher investment costs because of the need for two separate front-end feedstock processing trains. 


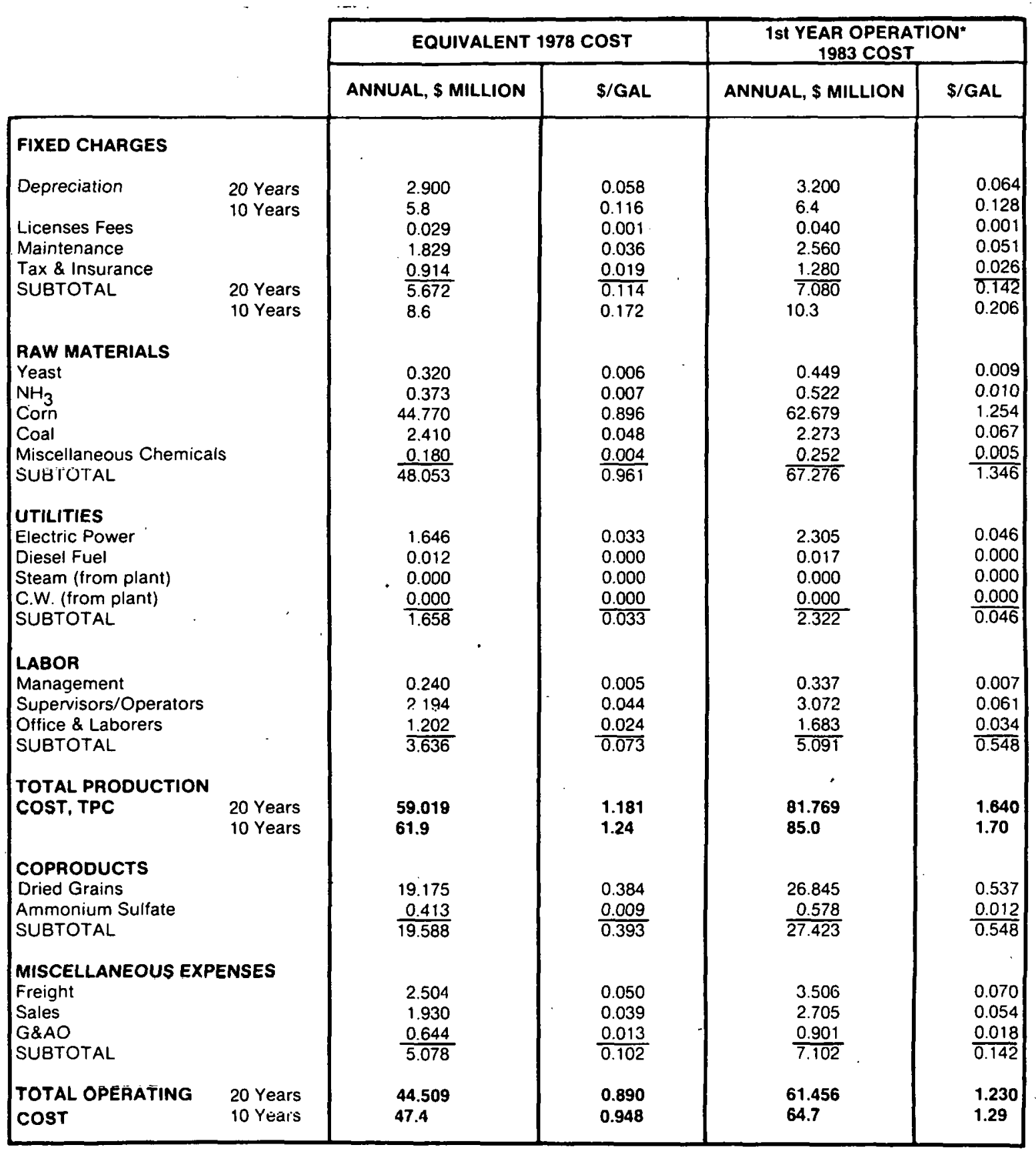

-Assumed 7-percent inflation rate

SOURCE: Katzen, R., "Grain Motor Fuel Alcohol Technical and Economic Assessment Study". Raphael Katzen Associates for the U.S. DOE, Dec., 1978. 


\begin{tabular}{|lc|}
\hline Engineering Period & $1979-80$ \\
Plant Construction & $1980-83$ \\
Start-up & $1982-83$ \\
Operationg Period & 10 or 20 Years \\
DCF-IROR & $15 \%$ \\
Working Capital & $10 \%$ of operating costs \\
Inflation & $7 \%$ \\
Depreciation & 10 or 20 Years \\
Taxes (federal/local) & $10 \%$ \\
Investment Tax Credit & $50 \%$ of profits after expenses \\
Equity & $100 \%$ \\
\hline
\end{tabular}

SOURCE: Katzen. R.. "Grain Motor Fuel Alcohol Technical and Economic Assessment Study". Raphael Katzen Assuciates for the U.S. DOE; Doc., 1978.

Table V-6. Ethanol Prićėé tor various Feedstucks ynud Fuèls (50-Million-Gallon Plant - 1978 dollars)

\begin{tabular}{|c|c|c|c|c|}
\hline FEEDSTOCK & $\begin{array}{l}\text { FEEDSTOCK } \\
\text { PRICE } \\
\text { (\$/bu) }\end{array}$ & $\begin{array}{l}\text { INVESTMENT } \\
\text { (\$ millions) }\end{array}$ & $\begin{array}{l}\text { OPERATING } \\
\text { COSTS } \\
\text { (\$ millions/yr) }\end{array}$ & $\begin{array}{l}\text { ETHANOL } \\
\text { PRICE } \\
\text { (\$/gallon) }\end{array}$ \\
\hline Corn & 2.30 & 50.0 & 11.5 & 10.5 \\
\hline Wheat & 3.15 & 58.0 & 57.1 & 1.31 \\
\hline Milo (grain sorghum) & 2.20 & 58.0 & 42.6 & 1.02 \\
\hline Sweet & & & & \\
\hline Sorghum* & $14.42 /$ ton & 91.6 & 58.8 & 1.40 \\
\hline Fuel & & & & \\
\hline Corn Stover & 25.0/ton" & 57.0 & 46.3 & 1.09 \\
\hline
\end{tabular}

*Half corn, half sweet sorghum feedstock.

**Dry basis, $8000 \mathrm{Btu} / \mathrm{lb}$.

SOURCE: Katzen, R., "Grain Motor Fuel Alcohol Technical and Economic Assessment Study". Raphael Katzen Associates for the U.S. DOE, Dec., 1978. 


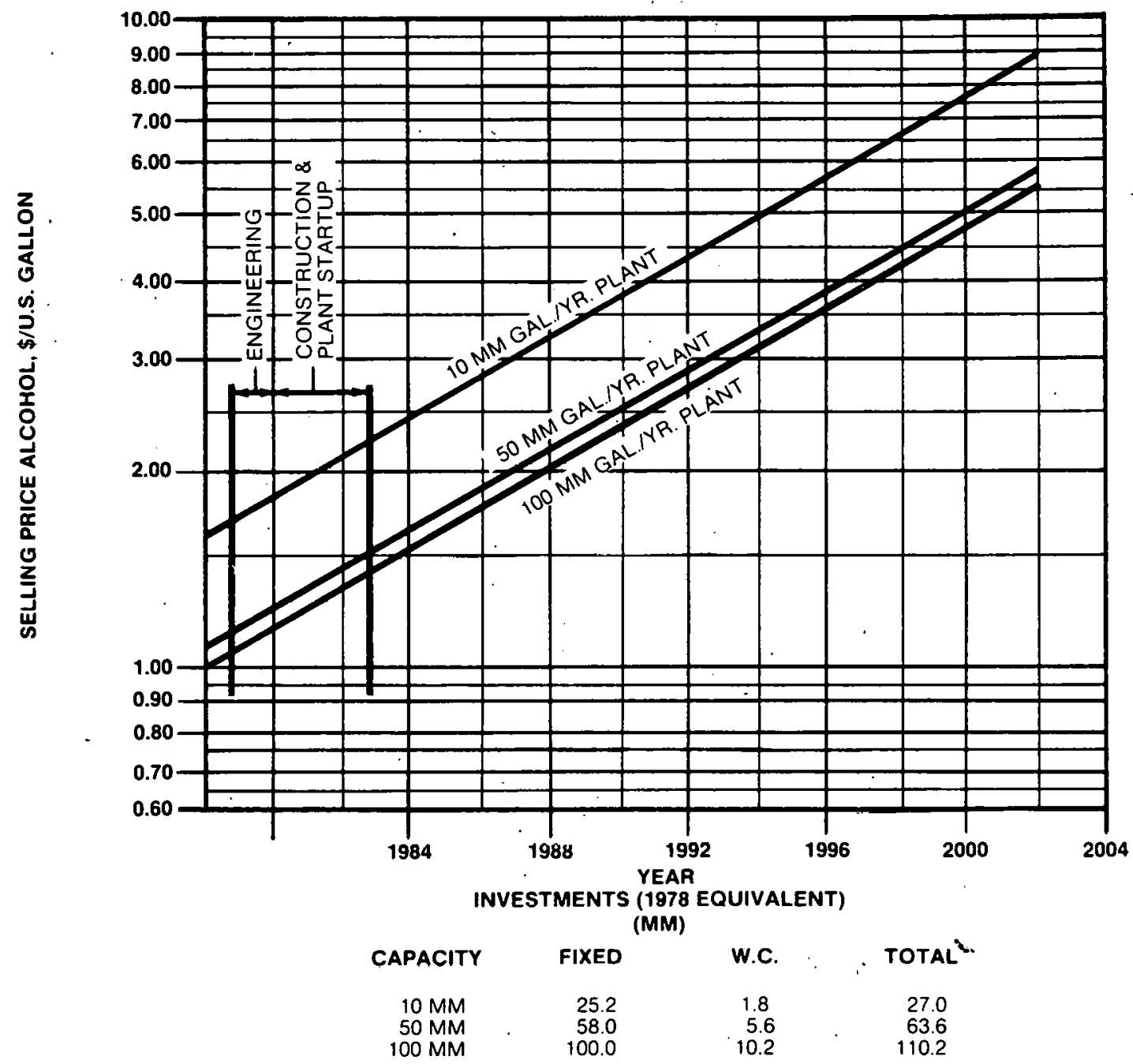

SOURCE: Katzen, R., "Grain Motor Fuel Alcohol Technical and Economic Assessment Study". Raphael Katzen Associates for the U.S. DOE, Dec., 1978.

Figure V-16. Plant Capacities Other Than Base Case - Selling Price vs. Production Year

Of the feedstocks analyzed, grain sorghum shows a slight advantage over corn under the conditions of the analysis.

Switching from coal to corn stover for fuel results in a slight increase in ethanol price. This option could result in environmental problems as the removal of stover from the fields could increase the risk of erosiouil.

\section{Sensitivity to Financial Parameters}

The sensitivity to parameters such as debt-to-equity ratio, DCF-IROR, and Investment Tax Credit is shown in Table V-7. The data were derived from the Katzen report, to which the reader is referred for details. In most cases, the impact of variations in financial parameters is smaller than that resulting from variations in feedstock or DDC $i$ prices. 


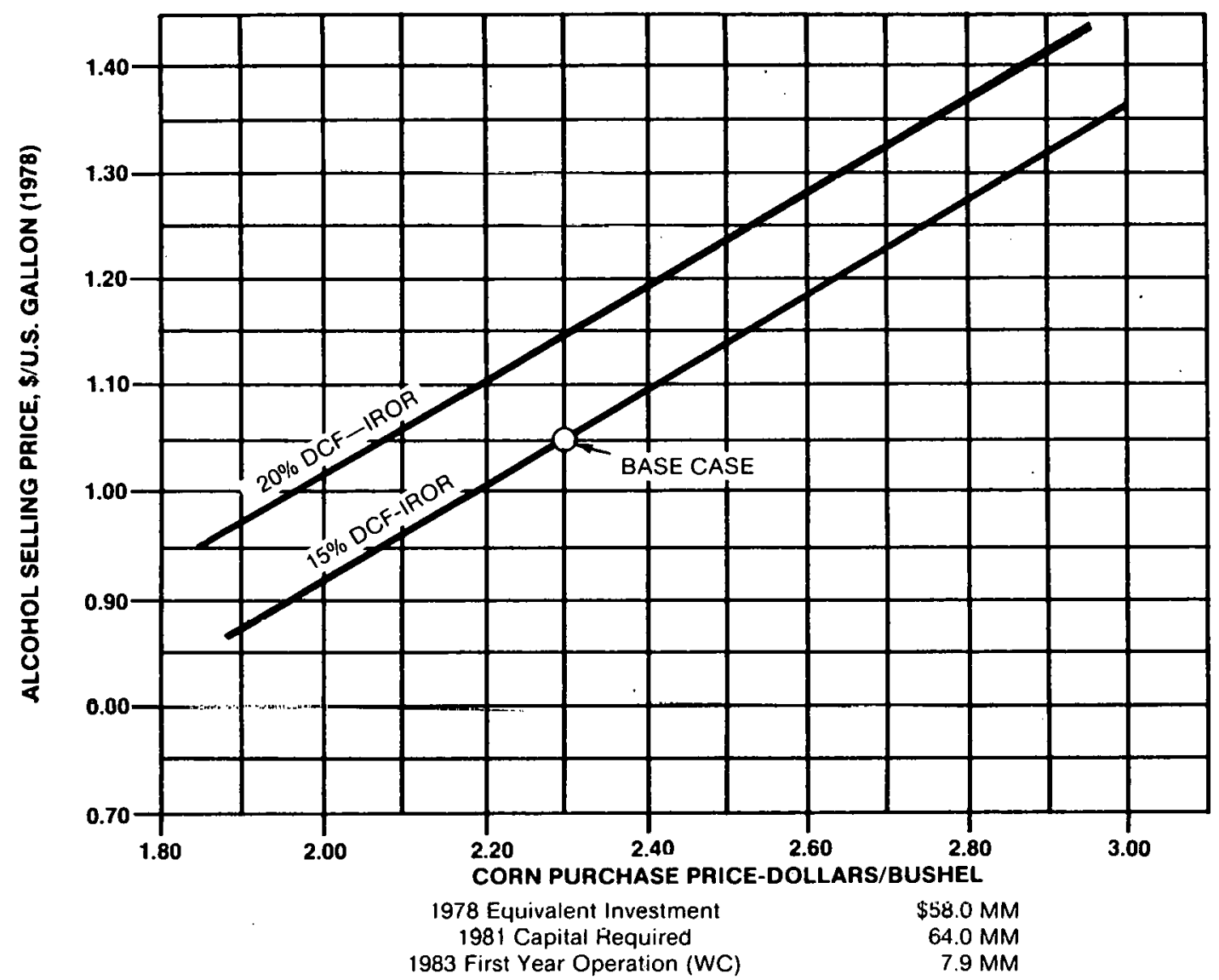

SOURCE: Katzen, R., "Grain Motor Fuel Alcohol Technical and Economic Assessment Study." Raphael Katzen Associates for the U.S. DOE, Dec., 1978.

Figure V-17. Corn Purchase Price Sensitivity Analysis

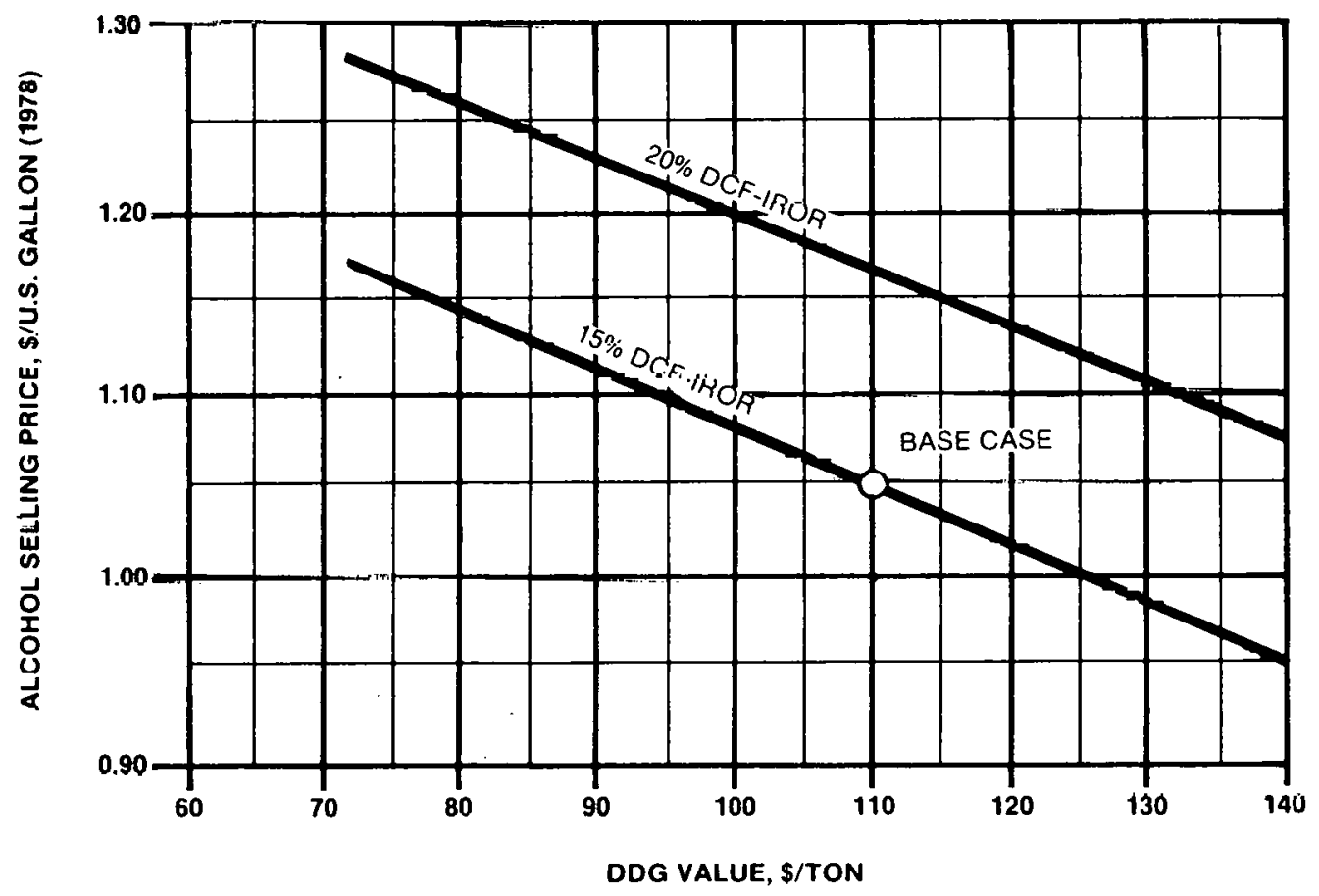

SOURCE: Katzen, R., "Grain Motor Fuel Alcohol Technical and Economic Assessment Study". Raphael Katzen Associates for the U.S. DOE, Dec., 1978

Figure V-18. Alcohol Selling Price (1978) vs. DCF-IROR 
Table V.7. Sensitivity of Ethanol Price to Financial Parameters

\begin{tabular}{|l|c|c|}
\hline \multicolumn{1}{|c|}{ PARAMETERS } & $\begin{array}{c}\text { VARIATION OF } \\
\text { PARAMETER (\%) }\end{array}$ & $\begin{array}{c}\text { IMPACT ON } \\
\text { ETANOL PRICE } \\
(\%)\end{array}$ \\
\hline DCF-IROR & $+33^{\prime}$ & +10 \\
Investment Tax Credit & $+300^{2}$ & -2 \\
Plant Depreciation Period & $+100^{3}$ & +2 \\
Debt/Equity Ratio & $+80^{4}$ & -10 \\
\hline
\end{tabular}

'DCF-IROR increased from 15 to $20 \%$

${ }^{2}$ Investment Tax Credit increased from 10 to $30 \%$

Depreciation Period increased from 10 to 20 years

${ }^{4}$ Debt increased from 0 to 80 percent of capital

SOURCE: Katzen, R., "Grain Motor Fuel Alcohol Technical and Economic Assessment Study". Raphael Katzen Associates for the U.S. DOE, Dec., 1978. 
THIS PAGE

\section{WAS INTENTIONALLY \\ LEFT BLANK}




\section{CHAPTER VI \\ Safety Aspects}

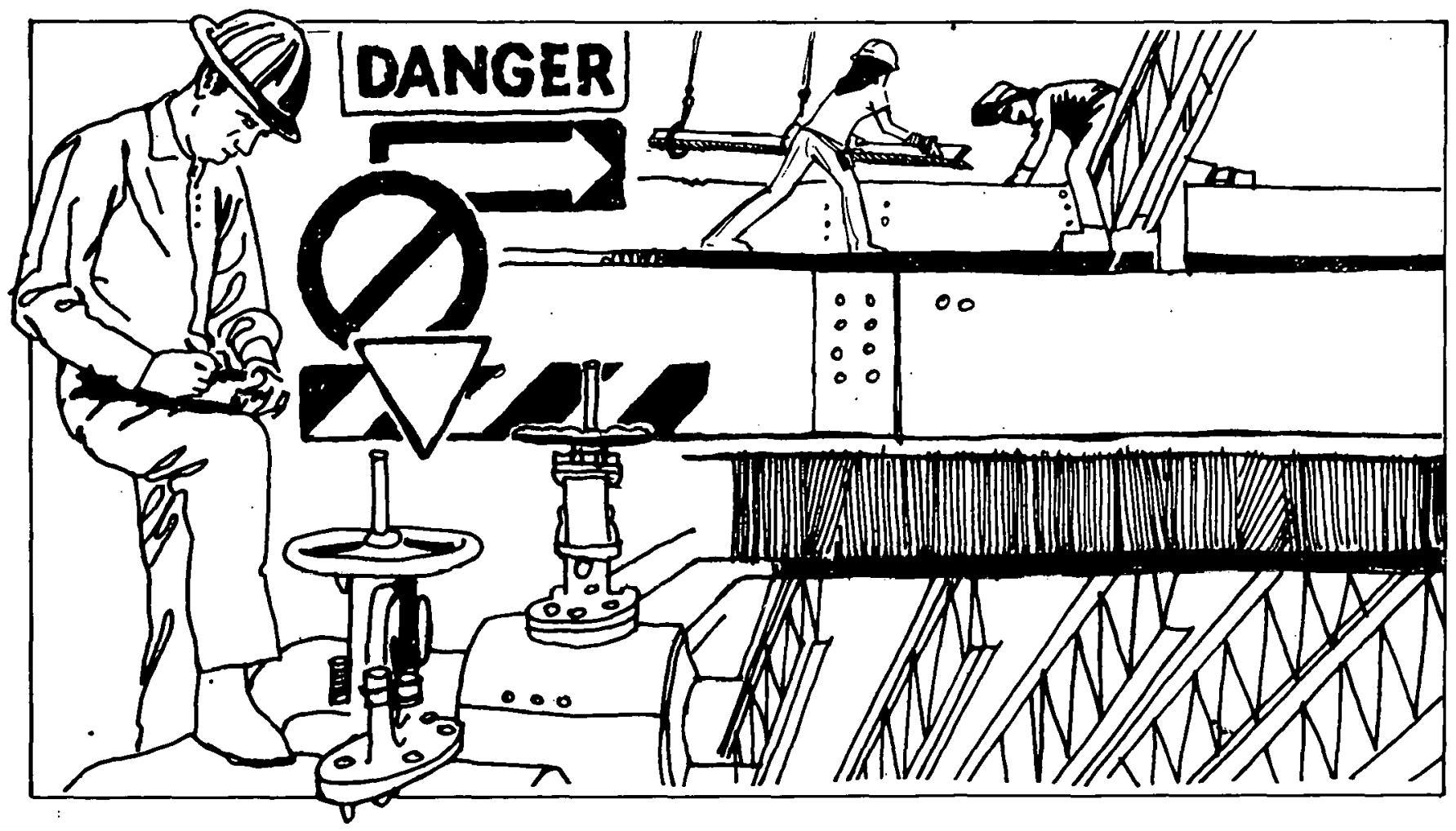

Safety is of primary importance in a system producing a flammable product. In addition to the main product (ethanol), other hazardous compounds are consumed and gencrated in the process system. The chemicals considered hazardous are: sulfuric acid $\left(\mathrm{H}_{2} \mathrm{SO}_{4}\right)$; calcium oxide, (lime, $\mathrm{CaO}$ ); hexane $\left(\mathrm{n}-\mathrm{C}_{6} \mathrm{H}_{14}\right)$; calcium hydroxide (hydrated lime, $\left.\mathrm{Ca}(\mathrm{OH})_{2}\right)$; carbon dioxide $\left(\mathrm{CO}_{2}\right)$; and ethanol (grain alcohol, $\mathrm{C}_{2} \mathrm{H}_{5} \mathrm{OH}$ or $\mathrm{EtOH}$ ). The hazards of these chemicals are briefly described in Table VI-1.

The codes and standards which are applicable to the production of fuel-grade ethanol are listed in Table VI-2.

\section{SAFETY CONSIDERATIONS}

Ethanol, 99.9 percent pure, is stored at ambient temperature and slight positive pressure. The flash point is $55^{\circ} \mathrm{F}$ and flammability limits are 3.3 to 19.0 vol\%. The saturated vapor/air mixture above the liquid ethanol is flammable between 50 and $110^{\circ} \mathrm{F}$. Hence, a $\mathrm{CO}_{2}$ blanket. shnuld be used in the cthanol storage tanks.
$\mathrm{N}$-hexane exists as a superheated vapor at $450^{\circ} \mathrm{F}$ and 10 psig. The flash point is $0^{\circ} \mathrm{F}$. The flammability limits are 1.2 to $7.5 \mathrm{vol} \%$. The saturated vapor/air mixture above the liquid hexane is flammable between -20 and $40^{\circ} \mathrm{F}$.

Benzene has flammability limits of 1.35 to 6.75 vol\% in air, and its flash point is $12^{\circ} \mathrm{F}$. The saturated vapor/air mixture above the liquid is flammable between -10 and $64^{\circ} \mathrm{F}$.

\section{HAZARDS}

Fermentation ethanol plants are often located in rural areas, to be close to their source of feedstock. Remoteness from city water supplies and fire departments places responsibility for fire protection almost entirely on the plant itself. Safety also depends on good construction and proper arrangement and safeguards for processes.

Because of the fire and explosion hazards inherent in handling large quantities of flammable liquids and also the potential for grain dust explosions in the grain 
Table VI.1. Hazardous Liquids and Gases

\begin{tabular}{|c|c|c|c|c|c|c|}
\hline $\begin{array}{l}\text { HAZARDOUS } \\
\text { MATERIAL }\end{array}$ & DESCRIPTION & $\begin{array}{l}\text { FIRE AND } \\
\text { EXPLOSION } \\
\text { HAZARD }\end{array}$ & LIFE HAZARD & $\begin{array}{l}\text { PERSONAL } \\
\text { PROTECTION }\end{array}$ & $\begin{array}{l}\text { EMERGENCY } \\
\text { PROCEDURES }\end{array}$ & $\begin{array}{l}\text { HANDLING } \\
\text { TECHNIQUES }\end{array}$ \\
\hline $\begin{array}{l}\text { Sulfuric Acid } \\
\left(\mathrm{H}_{2} \mathrm{SO}_{4}\right)\end{array}$ & $\begin{array}{l}\text { Colortess (pure) to } \\
\text { dark brown, oily dense } \\
\text { liquid. }\end{array}$ & $\begin{array}{l}\text { Not flammable but } \\
\text { highly reactive. Aeacts } \\
\text { violently with water } \\
\text { and organic materials } \\
\text { with evolution of heat. } \\
\text { nithrve many metals } \\
\text { releasing hydrogen. }\end{array}$ & $\begin{array}{l}\text { Causes severe, deep } \\
\text { burns to tissue when } \\
\text { contarting tiquid. } \\
\text { Vapors are extremely } \\
\text { irritating to eyes } \\
\text { and mucous } \\
\text { membranes (nose and } \\
\text { throat). AVOID } \\
\text { CONTACT! }\end{array}$ & $\begin{array}{l}\text { Wear rubber gloves. } \\
\text { rubber aprón. and } \\
\text { indirectly ventilated. } \\
\text { liquid-tight chemical } \\
\text { goggles when } \\
\text { lransferring acid to } \\
\text { störage turk ul } \\
\text { manually adding acid } \\
\text { to any vcssels. }\end{array}$ & $\begin{array}{l}\text { In case of contact. } \\
\text { Immediately flush skin } \\
\text { or eyes (affected area) } \\
\text { with large quantities } \\
\text { of water for at least } \\
15 \text { minutes: FOR } \\
\text { CYCG: GCT R.AEDICAI } \\
\text { ATTENTION! }\end{array}$ & $\begin{array}{l}\text { Transfer acid by pump } \\
\text { or gravity flow. Never } \\
\text { use a compressed gas } \\
\text { or air to pressurize an } \\
\text { acid cóntainer. Always } \\
\text { add acid to water. } \\
\text { never water to açid. a } \\
\text { violent reaction will } \\
\text { occur causing acid to } \\
\text { be ejected trom con- } \\
\text { tainer. Make addition } \\
\text { slowly to minimize } \\
\text { heating. Use proper } \\
\text { carboy truck and tilter } \\
\text { if acid is received in } \\
\text { carboys. Small glass } \\
\text { containters of acid } \\
\text { shall be handled in } \\
\text { impact- resistant } \\
\text { chemical carriers. }\end{array}$ \\
\hline $\begin{array}{l}\text { Calcium Oxide } \\
(\mathrm{CaO})\end{array}$ & $\begin{array}{l}\text { Colorless crystal; } \\
\text { also known as } \\
\text { unslaked, quick. or } \\
\text { burnt lime. }\end{array}$ & $\begin{array}{l}\text { Noncombustible } \\
\text { but reactive. When } \\
\text { wetted. it swells, gets } \\
\text { not. and becomes } \\
\text { calcium hydroxide. } \\
\text { Ca( }(\mathrm{OH})_{2} \text { (slaked lime. } \\
\text { caustic fime). }\end{array}$ & $\begin{array}{l}\text { Causes skın burns. } \\
\text { Less corrosive than } \\
\text { caustic soda (NaOH } \\
\text { or sodium hydroxide) } \\
\text { or caustic potash } \\
\text { (KOH or potassium } \\
\text { hydroxide). Uust is } \\
\text { lighl' irritatiue } \\
\text { to the eyes and murnus } \\
\text { membranes and } \\
\text { protonged contact } \\
\text { with skin can cause } \\
\text { dermatitis. } \\
\text { Avoid contact. }\end{array}$ & $\begin{array}{l}\text { Wear rubber gloves, } \\
\text { chemical goggles. } \\
\text { and long-sleeved } \\
\text { shirt or jacket. }\end{array}$ & $\begin{array}{l}\text { In case of contact. } \\
\text { immediately flush skin } \\
\text { or eyes (alfected area) } \\
\text { with large quantities } \\
\text { of water for at ieast } \\
15 \text { minutes. For eyes. } \\
\text { get mentical aftention. }\end{array}$ & $\begin{array}{l}\text { Transfer crystals from } \\
\text { container to rubber } \\
\text { pail. Pour required } \\
\text { quantity into empty } \\
\text { addition vessel. Close } \\
\text { vessel cover and add } \\
\text { required quantity of } \\
\text { water to dissolve } \\
\text { clysials. }\end{array}$ \\
\hline $\begin{array}{l}\text { Ethyl Alconal } \\
\text { (EtOH) }\end{array}$ & $\begin{array}{l}\text { Clear. coloric3s. } \\
\text { fragrant liquid. } \\
\text { burning taste. } \\
\text { Also. known as } \\
\text { ethanal or grain } \\
\text { alcohol. }\end{array}$ & $\begin{array}{l}\text { Flammable liquid. } \\
\text { Vapors torm flam- } \\
\text { mable mixtures with } \\
\text { air. BURNS WITH } \\
\text { INVISIBLE FLAME. }\end{array}$ & $\begin{array}{l}\text { Exposure to concen- } \\
\text { trations above } 1000 \\
\text { ppm may cause head- } \\
\text { ache and irritation of } \\
\text { the eyes. nose. and } \\
\text { throat. If continued } \\
\text { for prolonged time. } \\
\text { will cause drowsiness } \\
\text { and stupor. Contact } \\
\text { with liquid can cause } \\
\text { defarting of skin. } \\
\text { No known cumulative } \\
\text { effect as is common } \\
\text { willo intin'il alsuliul. }\end{array}$ & $\begin{array}{l}\text { Wear standard satety } \\
\text { glasses. When break- } \\
\text { ing lines for mainte- } \\
\text { nance. wear neoprene } \\
\text { gloves and liquid- } \\
\text { light chemical } \\
\text { goggles. }\end{array}$ & $\begin{array}{l}\text { In cast of body splash. } \\
\text { flush with large } \\
\text { quantities of water. } \\
\text { Dilute liquid spills } \\
\text { with large volumes of } \\
\text { water. Attack small } \\
\text { spill fires with ABC } \\
\text { dry chemical } \\
\text { exliniuishers. }\end{array}$ & $\begin{array}{l}\text { Product will normally } \\
\text { he handled in a closed } \\
\text { system. When trans- } \\
\text { ferring to transport } \\
\text { vehicle. proper } \\
\text { bonding and } \\
\text { grounding procedures } \\
\text { will be used. }\end{array}$ \\
\hline $\begin{array}{l}\text { Carbon Dioxide } \\
\left(\mathrm{CO}_{2}\right)\end{array}$ & $\begin{array}{l}\text { A colorless. odorless. } \\
\text { tastclcss gas. }\end{array}$ & $\begin{array}{l}\text { None. Is a fire } \\
\text { extinguishing agent. }\end{array}$ & $\begin{array}{l}\text { Is a simple aspliyx- } \\
\text { iant. Symptoms } \\
\text { include dizziness. } \\
\text { headache. Shortness } \\
\text { of breath, muscular } \\
\text { weakness. drowsi- } \\
\text { ness. and ringing in } \\
\text { ears. OSHA standards } \\
\text { require oxygen curl- } \\
\text { centration of } 19.5 \% \\
\text { or greater before } \\
\text { cntry is made int } \\
\text { tanks or vessels. } \\
\text { All vessel entry is } \\
\text { to be made under tne } \\
\text { Sale Work Termit cyc. } \\
\text { tem. Skin contact with } \\
\mathrm{CO} \text { Snow will cause } \\
\text { trost burns. }\end{array}$ & & $\begin{array}{l}\text { Remove viotim from } \\
\text { oxygen-deficient } \\
\text { atmosphere } \\
\text { Rescuers must wear } \\
\text { sell-uuntainod brcath- } \\
\text { ing apparatus if vessel } \\
\text { entry is necessary. If } \\
\text { breathing has ceased. } \\
\text { start mouth-to-mouth } \\
\text { resuscitation. Call for } \\
\text { medical assistance. }\end{array}$ & \\
\hline
\end{tabular}

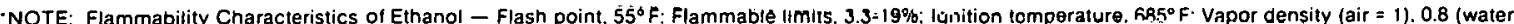

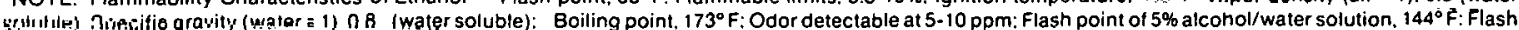

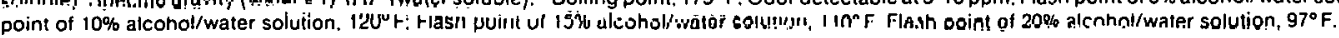


Table VI.2. Codes and Standards for the Production of Fuel-Grade Ethanol

\begin{tabular}{|c|c|}
\hline Title & Code* \\
\hline $\begin{array}{l}\text { Prevention of Dust Explosion in } \\
\text { Industrial Plants }\end{array}$ & NFPA63 \\
\hline $\begin{array}{l}\text { Basic Classification of Flammable } \\
\text { and Combustible }\end{array}$ & NFPA321 \\
\hline Liquids Static Electricity & NFPA77 \\
\hline $\begin{array}{l}\text { Flammable and Combustible } \\
\text { Liquids Code }\end{array}$ & NFPA30 \\
\hline Occupational Noise Exposure & OSHA 191094 \\
\hline Machinery and Machine Guarding & $\begin{array}{l}\text { OSHA } \\
\text { Subpart } 0\end{array}$ \\
\hline Power Piping & ANSI B31,1 \\
\hline $\begin{array}{l}\text { Standard for Steel Aboveground } \\
\text { Tanks for Flammable and } \\
\text { Combustible Liquids }\end{array}$ & UL142 \\
\hline $\begin{array}{l}\text { Boiler and Pressure Vessel Code } \\
\text { (B \& PV) }\end{array}$ & $\begin{array}{l}\text { ASME Code } \\
\text { Section IV \& } \\
\text { VII } \\
\text { Division I }\end{array}$ \\
\hline All electrical instrumentation & NFPA70-1978 \\
\hline National Electric Code & $\begin{array}{l}\text { Class II } \\
\text { Division } \mathrm{I}^{\circ}\end{array}$ \\
\hline
\end{tabular}

*Abbreviations: NFPA - National Fire Protection Association

OSHA-Occupational Safety and Health Administration

UL -Underwriters Laboratory

ASME - American Society of Mechanical Engineers

ANSI -American National Standards Institute

storage areas, safety depends on supervision by welltrained operators, good maintenance, and process equipment safeguards.

Grain handling, milling, and feed preparation at distilleries present dust explosion hazards. Although grains and feeds are slow burning, fires in these materials may be deep-seated and difficult to extinguish. Wet grains will heat and sour if not dried promptly.
Process fire and explosion hazards are present during distilling, but are considered negligible during mashing and fermenting. Strict government regulations that require seals on every pipe joint, valve, and spigot reduce the probability of flammable liquid or vapor being released during distilling operations.

Flammable liquid hazards are also preșent in varying degrees in the various distilled-alcohol handling areas.

Because of alcohol's lower heat of combustion, radiant heat energy, and complete miscibility with water, lower sprinkler system demands are required than with other flammable liquids of equivalent flashpoint.

The quantity of water needed to extinguish fires in alcohol/water mixtures depends upon the temperature of the liquid above its fire point and the effectiveness of mixing. The amount of water can be estimated from the following formula, assuming perfect mixing:

$$
\begin{gathered}
\text { Volumes of water needed per volume } \\
\text { of burning liquids = } \\
\% \% \text { alcohol in solution before fire } \\
\% \text { alcohol at point of fire extinguishment }
\end{gathered}
$$

Assume that a solution will be extinguished when the alcohol concentration is reduced to 20 percent. Applying the formula, a mixture containing 95 percent alcohol would require 3.75 volumes of water to extinguish each volume of burning liquid. A mixture containing 50 percent alcohol would require 1.5 volumes.

\section{INSURANCE LOSS EXPERIENCE}

A survey of industry losses for the years 1933 to 1972 indicated that approximately 75 percent of all property damage resulted from fires in 12 alcohol warehouses without sprinkler systems. However, several serious fire and explosion losses occurred in still-buildings. The most serious losses in still-buildings involved explosions with ensuing fires where sprinkler systems were damaged by the explosion. Several fires also occurred in driers which were processing dried grains from spent stillage or slops.

\section{PLANT SAFETY CONSIDERATIONS}

\section{General}

Grain handling, milling, and feed preparation facilities should be designed, arranged, and safeguarded in accordance with safety standards for grain storage and milling. 
Mashing and Fermenting. Mashịng and fermenting areas should preferably be of fire-resistive or noncombustible construction.

\section{Distilling.}

1. Distilling operations should be separated from other buildings by at least $100 \mathrm{ft}(30 \mathrm{~m})$. Existing still-buildings that adjoin other buildings should be completely cut off by blank fire walls, parapeted above adjoining buildings. Avoid basements, pipe trenches, and other spaces beneath still-buildings.

2. Preferably locate distilling equipment with a minimum of enclosing structure. Structures should be of damage-limiting construction. Load-bearing steel members and exposed steel equipment supports should be fire-proofed with material hāing a minlinum iwu-lıuu fiı:resistance rating. For existing buildings of substantial construction, provide explosion venting capacity through venting windows and roof panels in as high a ratio as practical.

3. Floor cutoffs are advisable at operating levels in high, enclosed buildings. If complete floor cutoffs are not practical, provide solid noncombustible mezzanines with curbs at levels supporting receivers or other equipment containing appreciable quantities of flammable liquids.

4. Innless the maximum possible spill can be extinguished by dilution while confined, provide emergency drainage facilities for the distilling area of buildings to prevent escaping liquids from exposing other areas or buildings.

\section{Distilled Alcohol Handling.}

1. Alcohol handling areas should preferrably be of fire-resistive or noncombustible construction.

2. Distilled-alcohol handling areas should be cut off from surrounding occupancies. Vertical cutoffs should bc provided in multi-story buildings. Cutoffs should have at least a one-hour fireresistance rating.

3. Provide curbs, ramps, or trapped floor drains at doorways and other openings to prevent the spread of flammable liquids to other departments. Floor drains in each distilled-alcohol handling area should be designed to handle expected sprinkler discharge unless the maximum possible spill can be extinguished by dilution while confined.

\section{Occupancy}

Mashing and Fermenting. Grain meal should be discharged to precookers only through tight connections to prevent liberation of dust.

\section{Distilling.}

1. Pressure vessels should be designed and constructed in accordance with applicable codes, standards, State and local laws, and regulations.

2. Stills should be equipped with vacuum and pressure relief devices piped to outdoors. Any condenser vents also should be piped to outdoors. Vents should be sized to discharge the maximum vapor generation possible at zero feed and maximum heating within the pressure limitations of the protected equipment. Vents should terminate at least $20 \mathrm{ft}(6.1 \mathrm{~m})$ above the ground and preferably at least $6 \mathrm{ft}(1.8 \mathrm{~m})$ above roor level and should be located so that vapor will not re-enter the building. Vent terminals should be equipped with flame arresters.

3. Equipment should be designed and maintained to eliminate or at least minimize any liquid and vapor leaks.

4. Where gauges are needed, use Factory Mutualapproved gauging devices. If ordinary gauge glasses are used, both connections normally should be kept closed and provided with weightoperated, quick-closing valves. Protect the glasss from mechanical injury. Where possible, tail boxes should be replaced with armored rotameters and specific gravity indicaturs, or with other instrumentation not subject to accidental breakage or leakage.

5. The steam supply for distillation should be thermostatically controlled and interlocked to shut down and sound an audible alarm on cooling-water failure. Alternately, powered standby pumps or gravity supplies of cooling water should be provided.

6. Stills and other large equipment containing flammable liquids should be purged with steam or an inert gas (steam will be most generally available) before they are open for inspection or repair. Equipment should be washed with water following steaming.

7. Ventilation, designed and installed to ensure air movement throughout the entire structure, should be provided to prevent accumulation of explosive vapor-air concentrations within the 
building. The stack effect (i.e., natural ventilation) may suffice if: the building is high; permanent openings are provided at grade and roof elevations; the equipment can be drained and cleared of vapors during shutdowns; and heat losses from the equipment maintain a temperature above that of the outdoors during all operating periods. If these operating conditions cannot be satisfied, or if blank walls or solid floors interfere with natural ventilation, mechanical exhaust ventilation should be designed to provide $1 \mathrm{cfm} / \mathrm{ft}^{2}\left(0.3 \mathrm{~m}^{3} / \mathrm{min} / \mathrm{m}^{2}\right)$ of floor area. Locate suction intakes near floor level to ensure a sweep of air across the area.

8. Electrical equipment, including wiring and lights, should be suitable for Class 1 , Group $D$ locations. Still-buildings should be considered Division 2 locations.

\section{Distllled Alcohol Handling.}

1. Noncombustible, vapor-tight construction should be used for all tanks containing flammable concentrations of alcohol. Tanks should be kept tightly closed except when taking samples.

2. Tanks should be equipped with vents of adequate size terminating outdoors. Vents should be equipped with Factory Mutual-approved flame arresters if the flashpoint of the contents is less than $100^{\circ} \mathrm{F}\left(38^{\circ} \mathrm{C}\right)$.

3. Factory Mutual-approved liquid-level gauges should be installed on all tanks. If ordinary gauge glasses must be used, weight-operated, normally closed valves should be installed at both tank connections and the glass should be protected against physical damage. Wherever possible, top tank connections should be provided and liquids transferred by pumping through the top rather than by gravity flow. If draw-off stations are located in the same area as the supply tank, automatically operated emergency shutoff valves should be provided in gravity-feed lines. Flexible metallic hose should be used on all connections to scale tanks where fire exposure would release the tank contents or expose its vapor space.

4. Mechanical exhaust ventilation should be provided as needed, and arránged with suction near floor level to ensure air movement throughout the building. At dump troughs and similar installations, localized intakes are desirable.
Careful attention should be given to below-grade installations, windowless buildings, sumps, pipe trenches, and similar installations. Usually, 0.25 $\mathrm{cfm}$ of air $/ \mathrm{ft}^{2}\left(0.075 \mathrm{~m}^{3} / \mathrm{min} / \mathrm{m}^{2}\right)$ of floor area will be adequate. The use of factory approved, portable flammable vapor indicators is recommended.

5. Electrical equipment, including wiring and lights, should be suitable for Class 1, Group D locations. Tank storage areas should be treated as Division 2 locations.

\section{Fire Protection.}

1. Provide automatic sprinkler protection for distillerics, preferably of a type designed to flood the area.

2. Sprinkler control valves, dry-pipe valves, and riser drains should bc readily accessible at all times to plant personnel. This is particularly important for areas under direct government supervision that may be locked during non-operating periods.

3. Small hoses with combination shutoff nozzles should be provided throughout the distillery. Hose stream demand is a minimum of $500 \mathrm{gpm}$ $\left(190 \mathrm{dm}^{3} / \mathrm{min}\right)$ for at least 60 minutes.

4. Suitable portable fire extinguishers should be provided throughout the distillery.

The implementation of adequate safety procedures impacts the number and kinds of personnel needed to run an ethanol plant. It is estimated that a typical 50-million-gallon-per-year ethanol plant would require the services of a medical doctor half-time, assisted by four full-time nurses. Such a plant would also need at least one safety engineer to oversee safety procedures. Thus, ensuring adequate plant safety adds to the operating costs through the addition of 5.5 personnel for a 50-million-gallon-per-year plant.

\section{Training/Operating Procedures}

1. Prior to plant acceptance, detailed operating procedures (including safety procedures) should be documented in a technical operation manual. Detailed process diagrams, with color-coded piping illustrations, must be provided.

2. Operators must be trained to wear hardhats and be aware of plant safety features and location of fire equipment. 


\section{THIS PAGE}

\section{WAS INTENTIONALLY LEFT BLANK}




\section{CHAPTER VII}

\section{Environmental Concerns}

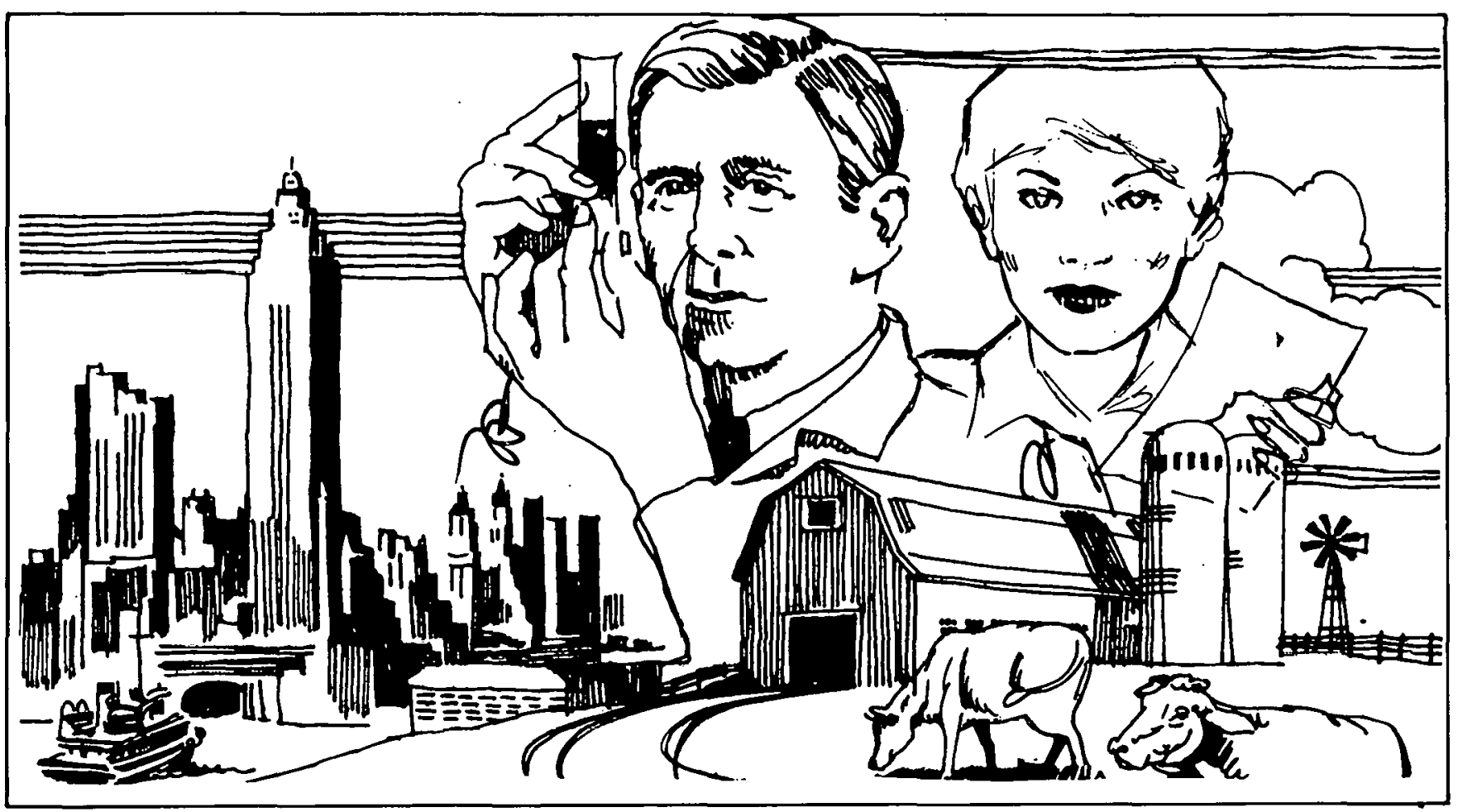

The discussion of environmental considerations will focus on the conversion of feedstock to ethanol, but the major issues associated with feedstock production and end-use of the ethanol in blends with gasoline will be summarized briefly. The role of environmental assessment in business decisions also will be addressed.

The major environmental concerns associated with ethanol production from grain are: emissions from the process heat source; and two multi-source environmental problems, distillery wastewaters and occupational exposure to process and byproduct chemicals.

Distillery wastewaters are acidic and high in suspended solids. BOD, and shemical oxygen demand and may present a potential health hazard if not properly treated or disposed. Stillage is particularly high in BOD and mineral salts (especially alkali salts), and both surface and groundwaters would be affected by improper or inadequate treatment or disposal practices. Standard wastewater treatment systems are commercially available.
Toxic and corrosive process chemicals employed in the conversion of starch feedstocks to ethanol or arising as coproducts in the conversion series include acids, dehydrating agents, denaturants, fusel oil and aldehyde byproducts, and chemicals used for equipment maintenance. Environmental concerns attendant with the use of such substances include spills and other accidental emissions and potential occupational health hazards resulting from long-term exposure. The practice of good industrial hygiene should minimize danger to workers.

Impacts due to air emissions and solid wastes generated during combustion of fossil fuel, especially coal, to meet process heat requirements need to be considered, with special attention to commercial-scale alcohol conversion facilities witl on-site, Industrial-size boilers. Both the environmental problems and the control measures are generic to coal-fired boilers, and thus represent no new problems peculiar to the fuel alcohol industry.

Environmental issues arising in the production of feedstock grains are erosion and use of scarce resources such 
as water and land. Erosion serves not only to reduce soil fertility and productivity, but also as a transport mechanism whereby entry of pollutants into waterways and the food chain as a whole is facilitated.

The utilization of ethanol/gasoline blends as a motor fuel could have environmental consequences for both users of the fuel and the general population. Health and safety risks occur for individual users, and combustion of the fuel entails potential air quality degradation and ecosystem effects.

\section{BIOCONVERSION OF GRAIN FEEDSTOCKS TO ETHANOL.}

\section{Overview of Emission and Effluent Sources}

For the discussion of environmental impacts during fermentation of biomass to ethanol and recovery/ purification of the product, the reference plant will be a 50-million-gallon-per-year facility, employing the cnergy-efficient Katzen design. Dry-milled corn is the biomass feedstock and coal is the fucl for generation of process steam requirements. For such a reference plant, Table VII-1 indicates the major sources of emissions and effluents during the conversion process.

In the feedstock storage and preliminary processing sections of the operation, the major atmospheric emission is particulates from the physical preparation of the feedstock. Liquid effluents include various wash waters and flash cooling condensate. The only solid of concern is grain dust, which may be contaminated by pesticides or fungi. Aflatoxin contamination of midwestern corn is rare.

During hydrolysis and fermentation, the major air emissions arise from fermenter vents; $\mathrm{CO}_{2}$ and accompanying volatile organic fermentation products and byproducts escape to the atmosphere. Wash waters are

Table VIII-1. Bioconversion of Grain to Ethanol - Emission and Effluent Sources.

\begin{tabular}{|c|c|c|c|}
\hline OPERATION & $\begin{array}{l}\text { EMISSIONS TO } \\
\text { ATMOSPHERE }\end{array}$ & $\begin{array}{l}\text { LIOUID } \\
\text { EFFLUENTS }\end{array}$ & SOLID WASTES \\
\hline Feedstock Storage & $\begin{array}{l}\text { Transfer operations (fine } \\
\text { dust) }\end{array}$ & & Grain, dirt \\
\hline Milling and Cooking & $\begin{array}{l}\text { Mechanical collectors for } \\
\text { milling operations } \\
\text { (partioulatea) }\end{array}$ & $\begin{array}{l}\text { Wash water (dissolved and } \\
\text { suspended solids, organics, } \\
\text { pesticides, alkali) } \\
\text { Flash cooling condensate } \\
\text { (dissolved and suspended } \\
\text { solids, organics) }\end{array}$ & $\begin{array}{l}\text { Grain dust (from mechani- } \\
\text { cal collectors) }\end{array}$ \\
\hline $\begin{array}{l}\text { Hydrolysis and } \\
\text { rermentation }\end{array}$ & $\begin{array}{l}\text { Fermentation venis } \mathrm{CCO}_{2} \text {, } \\
\text { hydrocarbonel }\end{array}$ & $\begin{array}{l}\text { Wash wator (dissolved and } \\
\text { suspended solids, organics, } \\
\text { alkali) }\end{array}$ & \\
\hline $\begin{array}{l}\text { Distillation and } \\
\text { Dehydration }\end{array}$ & $\begin{array}{l}\text { Condenser vents on } \\
\text { columns (volatile organics) }\end{array}$ & $\begin{array}{l}\text { Rectifier bottoms } \\
\text { (organics), dehydration } \\
\text { bottomo (organics) }\end{array}$ & \\
\hline Stōràge & $\begin{array}{l}\text { Storage tonkc } \\
\text { (hydrocarbons) }\end{array}$ & & \\
\hline Coproduct Recovery & $\begin{array}{l}\text { Dryer flue gases } \text { NO }_{x}, \\
\text { sO }, \mathrm{CO} \text {, particulates, } \\
\text { liydiucal buins). Evoporator } \\
\text { condenser vents } \\
\text { (hydrocarbons) }\end{array}$ & $\begin{array}{l}\text { Evaporator condensate } \\
\text { (dissolved and suspended } \\
\text { colids, nroanics) }\end{array}$ & $\begin{array}{l}\text { Grain dust (from direct- } \\
\text { contact dryers) }\end{array}$ \\
\hline $\begin{array}{l}\text { Steam Production } \\
\text { (coal-fired) }\end{array}$ & $\begin{array}{l}\text { Flue gases ( } \mathrm{NO}_{\mathrm{X}}, \mathrm{SO}_{\mathbf{X}}, \mathrm{CO} \text {, } \\
\text { particulates) }\end{array}$ & $\begin{array}{l}\text { Boiler blowdown } \\
\text { (inorganics), cooling water } \\
\text { blowdown (dissolved and } \\
\text { suspended solids, organics) }\end{array}$ & $\begin{array}{l}\text { Coal dust, ash (bottom } \\
\text { ash and fly ash) }\end{array}$ \\
\hline $\begin{array}{l}\text { Environmental } \\
\text { Control Systems }\end{array}$ & $\begin{array}{l}\text { Evaporation from bio- } \\
\text { logical treatment ponds } \\
\text { (organics) }\end{array}$ & $\begin{array}{l}\text { Scrubber blowdown } \\
\text { (dissolved and suspended } \\
\text { solids, organics) }\end{array}$ & $\begin{array}{l}\text { Sludge (from tlue gas } \\
\text { treatment), biological } \\
\text { sludge (from wastewater } \\
\text { treatment) }\end{array}$ \\
\hline
\end{tabular}

Source: R. M. Scarberry and M.P.Papai, "Source Test and Evaluation Report: Alcohol Synthesis Facility for Gasohol Production," Radian Corporation, January, 1980. 
high in BOD, dissolved solids, and suspended solids; in addition, they may contain traces of chemicals used as nutrients or used to control the growth of undesired organisms during the fermentation. For starch feedstocks, the associated pesticide residues are thought to be destroyed during the cooking process.

In the alcohol purification (distillation and dehydration) and denaturation steps, the major sources of atmospheric emissions are condenser vents on columns. Evaporator condensates may contain materials that require treatment before disposal. No solid wastes are obtained.

Evolution of criteria pollutants occurs in byproduct processing through the exhaust of flue gas used in drying. In addition, evaporator condensate contains dissolved and suspended solids and various organic materials. The direct-contact dryers generate grain dust.

Steam production using coal-fired boilers causes emissions of criteria pollutants. Aqueous streams of environmental concern include boiler blow-down and cooling water blowdown. Solid wastes include coal dust, fly ash, and bottom ash.

Environmental control systems may produce secondary wastes. For example, biological treatment ponds yield evaporative emissions. Scrubber blowdown contains dissolved and suspended solids, as well as various organics. Biological sludge from wastewater treatment may contain pesticides, benzene, ammonia, and various metals.

\section{Impacts Associated with Specific Process Steps}

Specific impacts in the three major categories of air quality, water quality, and solid wastes are discussed in more detail for each stage of the conversion process. A separate discussion of multi-source environmental problems, specifically wastewater treatment and occupational safety and health, is also presented.

\section{- Feedstock Storage}

Feedstock storage facilities may represent a potential health hazard by serving as breeding grounds for rodents and other pests. Spoilage of grain due to natural fermentation and other decay processes gives rise to a variety of substances which, depending on the degree of containment of the storage area, could be discharged to waterways or the átmosphere. The use of fungicides to retard spoilage could affect worker health, as well as groundwater and surface water quality. Finally, the generation of large amounts of fine dust in the transfer of grain into and out of the storage area results in poten- tial respiratory health hazards to workers, as well as an explosion hazard.

Experience in controlling dust in the grain industry should be transferable to similar operations associated with fuel alcohol plants.

\section{- Milling and Cooking}

If corn is processed by hammer mills, particulates in the form of grain dust can be a problem, along with high levels of noise ( 85 to $88 \mathrm{dBa}$ ) generated by the processing equipment. Controls for dust from grain are similar to those used for fly ash particulates. Grain dust, chaff, and impurities collected in cyclones are not considered solid wastes, as they are cycled to the dryer for inclusion in the DDG byproduct. During the cooking process, a beneficial side effect is the apparent destruction of pesticides, many of which are vulncrable to heat and decompose to simpler compounds during the heat treatment. In a recent sampling program conducted at the Midwest Solvents plant in Atchison, KS, pesticides were detected in the feedstock grains, but no traces were found in the solid wastes or wastewater effluents downstream of the gelatinization step.

Flash cooling of the mash in multi-effect evaporators yields a condensate (from a surface condenser employed at the last stage) which is high in dissolved solids and suspended solids, and volatile organic materials.

\section{- Hydrolysis and Fermentation}

Nearly equal weights of ethanol and $\mathrm{CO}_{2}$ are produced in the fermentation reaction, Other byproducts include a myriad of oxygenated organic compounds, primarily acids, alcohols, and aldehydes. The $\mathrm{CO}_{2}$ can be trapped or merely vented to the atmosphere. If the $\mathrm{CO}_{8}$ is recovered, the gaseous stream is passed through a water scrubber to condense water and volatile organic materials (including ethanol) before the cryogenic recovery of $\mathrm{CO}_{2}$. Alternatively, if $\mathrm{CO}_{2}$ is vented, the water scrubber may still be employed. The gaseous stream is accompanied by volatile organic byproducts, as well as some of the product ethanol. Temperature is carefully controlled during the fermentation reaction to minimize evaporative losses of ethanol, which increase by a factor of 1.5 for every $5^{\circ} \mathrm{C}$ increase in temperature. Closed fermenters with off-gas condensation and scrubbing may be used to minimize ethanol losses to the atmosphere.

A variety of chemicals added to the fermenting mash include acids for $\mathrm{pH}$ control, yeast 
nutrients (ammonium salts, urea, phosphates), and chemicals or antibiotics to control the growth of undesired organisms without affecting the yeast. Because of the variety of byproducts and nutrients/chemicals used in the fermentation process, it is not surprising that the fermentation wash. water contains high levels of dissolved solids, suspended solids, organics, and alkali.

Care must be taken, when personnel enter the fermenters during cleaning, to avoid the possibility of asphyxiation in an atmosphere with a high concentration of $\mathrm{CO}_{2}$.

\section{- Distillation and Dehydration}

During alcohol concentration and purificutiōn, the major atmospheric emissioris are from the vent condensers employed at distillation column openings to retard (but not entirely eliminate) the escape of organic materials to the environment. As the vent streams contain volatile organic materials too dilute for economic recovery, flares are often used to control emissions. Alternatively, the vent streams could be routed to the process burners as air feed. The evaporator condensates, rich in dissolved solids, suspended solids, and organic materials, are sent. to wastewater treatment. Distillation and dehydration bottoms contain benzene (if used as the dehydrating agent) and other organics. Because benzene is a known leukemogen, strict precautions must be taken in work areas during its use. The Federal standard (29 CFR 1910.1000) for exposure to benzene is $10 \mathrm{ppm}$ (8-hour, timewẹighted average), with a ceiling concentration of $2.5 \mathrm{ppm}$ and a peak of $50 \mathrm{ppm}$ allowable for 10 minutes. $\Lambda$ recent sampling program conducted at the Midwest Solvents plant by the Radian Corporation revealed benzene concentrations in the low range of 2.7 to $59.4 \mathrm{ppm}$ for the liquid streams. As these values are near the detection limit for benzene, they are assumed to have limited accuracy; nevertheless, it is known that 27 gallons of benzene (approximately 1 gallon for every 5,500 gallons of product ethanol) would be lost daily somewhere in the process for a 50-million-gallon-per-year plant.

\section{- Hydrocarbon Storage}

Evaporative emissions during storage can be controlled through the use of tanks with floating roofs or internal floating covers to reduce the air space above the stored liquids. Another option is the inclusion of a vapor recovery system.

\section{- Byproduct Recovery}

If stillage is not dried or otherwise treated before disposal, water quality could be degraded by this waste stream. Stillage is relatively high in protein content, as well as unconverted starches and sugars, various fermentation products, and yeast. Stillage drying operations may affect air quality. Particulates, primarily in the form of grain dust generated during the drying process, are emitted, and dryer flue gases, which use boiler flue gases from the plant's heat source, contain criteria air pollutants, including $\mathrm{SO}_{2}, \mathrm{CO}$, and $\mathrm{NO}_{\mathrm{x}}$. Grain dust which is collected may be added to the DDG byproduct. Aqueous wastes, such as evaporator condensate from coproduct recovery operations, are sent to the wastewater treatment system.

$\Lambda$ flatoxin contamination of midwestern corn, the primary source of corn for fuel ethanol production, is rare. Although more than 50 percent of southeastern corn is contaminated, it represents only 8 percent of the national crop, and most of it is confined to intrastate use. In the rural Southeast, contaminated corn is directly ingested, and epidemiological information indicates no higher human liver cancer incidence than in other areas of the United States. As aflatoxins are not distillable, any which survive the fermentation process will be concentrated in the DDG byproduct. It has, however, been demonstrated that mature animals rapidly metabolize and dispose of aflatoxins. The only potential sensitivity could arise from feeding contaminated DDG to dairy cattle, as one type of aflatoxin remains in the milk.

\section{- Steam Production}

Combustion of coal in industrial-size boilers results in atmospheric emissions, aqueous effluents, and solid wastes. To fulfill process stcam requirements for the reference-size ethanol plant, 296.7 tons/day of coal is consumed, and 27.4 tons/day of ash is generated. Ash from a typical plant would be hauled to a nearby landfill for disposal. Coal dust collected during storage and transfer of the fuel can be routed to the boller.

The atmospheric emissions from a coal-fired boiler at a fuel alcohol plant that are most. likely to require controls are sulfur dioxide and particulates. Control of nitrogen oxides is required in some states, but emission levels are expected to be within legislated limits in most.

Several standard options are available for control of particulates, including fly ash and coal dust 
entrained in the flue gas. For systems of the size required for a commercial-scale fuel alcohol plant, fabric filters are usually the best alternative for particulate control.

For sulfur dioxide emissions, the simplest control in many cases is the use of low-sulfur coal, which could obviate the need for sophisticated control systems downstream. Several flue gas desulfurization systems are commercially available, but are expensive in terms of both capital costs and operating expenses. To remove both sulfur dioxide and particulates, a flue gas scrubbing system may be employed (at an initial cost of $\$ 4.2$ million in 1978). Ammonia is used to remove sulfur dioxide, followed by neutralization of the ammonium sulfite/bisulfite solution and its oxidation to ammonium sulfate, which can be sold as a fertilizer. This type of chemical recovery desulfurization system has the advantage of producing no calcareous sludge, the secondary waste generated in conventional limestone scrubbing systems.

Water quality could be affected by leachate from coal or ash storage or ash disposal piles (although coal ash is generally disposed of in offsite landfills), as well as by cooling tower blowdown. Depending on the soil and groundwater characteristics in the area, leachate collection and treatment may become necessary. Boiler and cooling water blowdown are routed to the wastewater treatment section of the plant.

Because a fossil fuel-fired steam generator represents one of the major emission sources at an ethanol production facility, an obvious allaround envirommental control measure is the reduction of the amount of process steam required. Any improvement in plant efficiency will result in a corresponding decrease in fossil fuel combustion and its associated atmospheric emissions, and aqueous and solid waste disposal problems.

Besides improvements in engineering design, substantial gains in this area can be obtained by using waste heat from other industries or by siting new plants imaginatively.

\section{- Environmental Control Systems}

Environmental control systems may generate secondary pollutants, such as wastewater from various scrubbers. As mentioned above, certain types of flue-gas treating systems give rise to sludge, as does the wastewater treatment system. The only secondary atmospheric pollutant is the evaporative loss from biological treatment ponds; this emission consists of an assortment of volatile organic compounds.

\section{Multi-Source Environmental Concerns}

Wastewater streams arise from numerous separate sources in a fuel ethanol plant and potential health and safety hazards pervade the occupational environment. These two multi-source problems are discussed briefly.

\section{- Wastewater}

Wastewaters from distilleries (approximately 1.1 million gallons per day for a 50-milliongallon-per-year plant, if extensive efforts are made to recycle water) are acidic and contain high levels of total solids $(25,000$ pounds per day for the reference-size plant); suspended solids ( 3,000 pounds per day); and BOD $(7,300$ pounds per day). Experience in the beverage alcohol industry indicates that levels of dissolved organics are below concentrations that require treatment before discharge to surface waters. Moreover, no significant problems are expected with regard to acidity levels in wastewaters, as the $\mathrm{pH}$ can be adjusted before discharge. High BOD loadings, however, will necessitate treatment. Suspended solids can be removed by preliminary screening and sedimentation in a holding tank before the biological oxidation step. Several biological oxidation systems are commercially available; spare aeration or equalization basins are recommended for added safety. Treatment can occur at the alcohol plant site or at publicly owned treatment works (POTW), if the latter have sufficient spare capacity to treat the large volumes of wastewaters associated with ethanol production. At many potential Farm Belt locations for ethanol plants, the local POTW may have insufficient capacity to receive distillery effluents, and treatment systems will thus become necessary parts of fuel alcohol facilities.

\section{- Occupational Safety and Health}

In a fuel alcohol plant, the major potential threats to worker health and safety are explosion, fire hazards, and various modes of exposure to toxic and corrosive chemicals. Adequate controls or mitigating measures are currently available to cope with the problems.

Chemical Exposures Ethanol itself can cause mild irritation of the eye and nose and can defat the skin, causing dermatitis. Prolonged inhalation produces irritation of the eyes and upper respiratory tract, headache, drowsiness, tremors, 
and fatigue. It may increase the toxicity of other inhaled, absorbed, or ingested chemical agents. Moreover, since ethanol and some common prescription drugs interact unfavorably when ingested, the possibility of synergism between these drugs and inhaled or absorbed ethanol should be considered. The Federal standard for workplace exposure to ethanol is $1000 \mathrm{ppm}\left(1,900 \mathrm{mg} / \mathrm{m}^{3}\right)$. Work areas should be well ventilated, and normal safety precautions should be taken in handling the liquid.

The same general considerations apply to exposures to other organic compounds employed in or generated during the ethanol production process. The primary entry routes to the body are inhalation and dermal absorption. Workers should be educated regarding the proper handling of chemicals; protective gloves and aprons should be worn when appropriate; and emergency spill containment procedures should be well established in the occupational environment.

Fire/Explosion/Burn Hazards Whenever any volatile organic compounds are in use, standard precautions must be taken to prevent ignition of leaks or fumes. Explosion-proof motors, for example, along with other specially protected electrical equipment, should be routinely used. Equipment should be available and emergency procedures in place to deal with chemical fires.

In any industry that employs large quantities of process heat, particularly when it is in the form of steam, precautions need to be taken against burns. Certain routine preparations and minor equipment modifications, such as using baffles to direct steam gasket leaks away from the work area, can be made. Prevention of contact burns from steam lines can be accomplished by making the lines conspicuvius or by insulation.

\section{Environmental Control Costs}

As indicated throughout the preceding discussion, hardware for adequate control of various pollutants generated in the production of fuel alcohol from biomass is commercially available and is similar to equipment used in other industries (e.g., food processing, drug manufacture, chemical manufacture, and beverage alcohol production). The major capital items include a flue gas scrubbing system, $\$ 4.2$ million; wastewater treatment system, $\$ 2.0$ million for the reference 50-million-gallon-per-year fuel ethanol plant; fire protection system, $\$ 0.60$ million; ash collection package, $\$ 0.17$ million; vapor-controlled storage tanks, \$0.16 million (incremental cost over cone roof tanks); and assorted vent condensers, $\$ 0.13$ million. The cost of environmental controls, $\$ 7.5$ million, accounts for approximately 13 percent of the total fixed investment for a fuel ethanol plant. This estimate is for direct controls only (i.e., physical hardware) and does not include installation, maintenance and operating costs, or the cost of implementing procedures (such as conducting seminars for employees on appropriate actions during spills and other potential workplace emergencies). It should be mentioned that an alternative to the capitalintensive, on-site wastewater treatment system is the discharge of distillery wastewater to POTW, provided that the latter has the excess capacity to treat the industrial wastes. In a comparison of self-treatment costs to costs of treating at a POTW (including Industrial Cost Recovery charges), it has been shown that for a POTW with a 15-million-gallon-per-day or greater capacity, it would generally be less expensive for distilleries of the reference size to discharge to the POTW. Actual charges for treating distillery effluent at a specific POTW, howcver, vary widely, because they depend nut unly un findacial pas anielci's sueh as interest rate, but also on the assimilative capacity of the stream into which the treated water is discharged.

\section{Regulatory Constraints on Development of the Fuel Ethanol Industry}

There are no current major Federal environmental regulatory obstacles associated with biomass conversion to ethanol; moreover, no roadblocks are anticipated. The major effects of environmental considerations on commercial-scale fuel alcohol development are in the interrelated areas of cost (discussed earlier), siting limitations. and uncertainties for investors.

The major legislation influencing fuel alcohol development is: the Clean Air Act and amendments of 1977, the Federul Water Pollution Control Act of 1972 (Clenn Water Act), and the Resource Conservation and Recovery Act (RCRA) of 1976. The provisions of these acts which pertain to the alcohol industry are summarized briefly below. It should be borne in mind that more stringent state environmentril regulations could be superimposed on any of the existing Federal regulations. The investment climate thus could be adversely affected by the uncertainties in environmental legislation at the State and Federal levels and the attendant uncetlainlies in investment costs.

\section{- Clean Air Act}

All of the criteria pollutants, except lead, subject to the National Ambient Air Quality Standards (NAAQS) are emitted during the preparation and conversion of feedstock to ethanol. Under the Clean Air Act, major existing and new sources of air pollutants within an area presently attaining the primary and secondary NAAQS may be 
Table VII-2. Nonattainment Areas of 48 Contiguous States *

\begin{tabular}{|c|c|c|c|}
\hline STATE & $\begin{array}{c}\text { NO. OF } \\
\text { NONATTAINMENT } \\
\text { COUNTIES (PARISHES) }\end{array}$ & $\begin{array}{l}\text { TOTAL NO. } \\
\text { OF COUNTIES } \\
\text { (PARISHES) }\end{array}$ & $\begin{array}{l}\% \text { OF THE STATE'S } \\
\text { COUNTIES } \\
\text { IN NONATTAINMENT } \\
\text { STATUS }\end{array}$ \\
\hline $\begin{array}{l}\text { Alabama } \\
\text { Arizona } \\
\text { Arkansas } \\
\text { California } \\
\text { Colorado } \\
\text { Connecticut } \\
\text { Delaware } \\
\text { Florida } \\
\text { Georgia } \\
\text { ldaho } \\
\text { Illinois** } \\
\text { Indiana** } \\
\text { lowa** } \\
\text { Kansas } \\
\text { Kentucky } \\
\text { Louisiana } \\
\text { Maine } \\
\text { Maryland } \\
\text { Massachusetts } \\
\text { Michigan } \\
\text { Minnesota } \\
\text { Mississippi } \\
\text { Missouri** } \\
\text { Montana } \\
\text { Nebraska } \\
\text { Nevada } \\
\text { New Hampshire } \\
\text { New Jersey } \\
\text { New Mexico } \\
\text { New York } \\
\text { North Carolina } \\
\text { North Dakota } \\
\text { Ohio* } \\
\text { Oklahoma } \\
\text { Oregon } \\
\text { Pennsylvania } \\
\text { Rhode Island } \\
\text { South Carolina } \\
\text { South Dakota } \\
\text { Tennessee } \\
\text { Texas } \\
\text { Utah } \\
\text { Vermont } \\
\text { Virginia } \\
\text { Washington } \\
\text { West Virginia } \\
\text { Wisconsin } \\
\text { Wyoming } \\
\text { Wyoming }\end{array}$ & 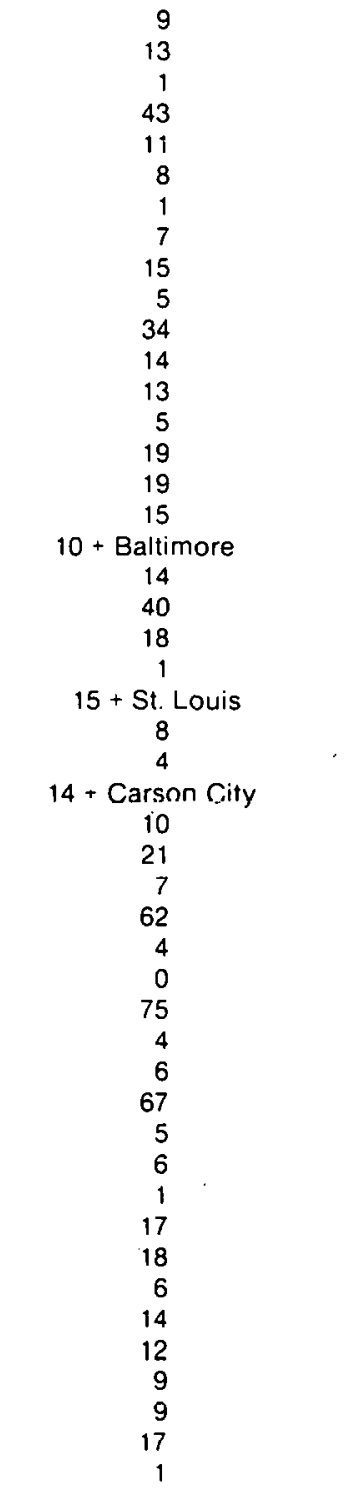 & $\begin{array}{r}67 \\
14 \\
75 \\
58 \\
63 \\
8 \\
3 \\
67 \\
159 \\
44 \\
102 \\
92 \\
99 \\
105 \\
120 \\
64 \\
16 \\
23 \\
14 \\
83 \\
87 \\
82 \\
114 \\
57 \\
93 \\
16 \\
10 \\
21 \\
32 \\
62 \\
100 \\
53 \\
88 \\
77 \\
36 \\
67 \\
5 \\
46 \\
67 \\
95 \\
254 \\
29 \\
14 \\
96 \\
39 \\
55 \\
72 \\
23\end{array}$ & $\begin{array}{r}13 \\
93 \\
1 \\
74 \\
17 \\
100 \\
33 \\
10 \\
9 \\
11 \\
33 \\
15 \\
13 \\
5 \\
16 \\
30 \\
94 \\
43 \\
100 \\
48 \\
21 \\
1 \\
13 \\
14 \\
4 \\
88 \\
100 \\
100 \\
22 \\
100 \\
4 \\
0 \\
85 \\
5 \\
17 \\
100 \\
100 \\
13 \\
1 \\
18 \\
7 \\
21 \\
100 \\
13 \\
23 \\
16 \\
24 \\
4\end{array}$ \\
\hline
\end{tabular}


subject to emission limitations and permitting requirements to ensure the Prevention of Significant Deterioration (PSD) of air quality in the region. Sources thus controlled include coal-fired steam boilers of more than 250 million Btu per hour heat input. (For comparison, the Katzendesigned 50-million-gallon-per-year plant requires heat input of 263.3 million Btu pcr hour.) PSD limitations regulate criteria pollutant emissions so that the secondary NAAQS are not violated within the Air Quality Control Regions (AQCR) concerned. Although all of the criteria pollutants, as well as certain other pollutants not associated with alcohol production, are subject to PSD limitations, to date the permissible emission increments have been announced only for particulates and sulfur dioxide. It is, therefore, possible that standards yet to be proposed by the EPA could have an impact on the siting of energy facilities such as ethanol-trom-biomass plants.

Certain new, modified, and reconstructed stationary sources, including large fossil fuel-fircd steam generators such as those used in distilleries, are subject to EPA's New Source Performance Standards (NSPS). Limitations are placed on particulates, opacity, nitrogen oxides, and sulfur dioxide. Smaller industrial boilers are expected to be covered by revised NSPS standards in 1980 or 1981 .

Siting of new fuel alcohol plants could be barred in so-called nonattainment areas. In order to begin rnnstruction or major modification of a major source in a nonattainment area, a construction permit must be obtaincd. Before the permit is granted, the source must obtain an emissions ofl'set lium existing sources in the region. In addition, the source must limit its air pollutant emissions to the lowest achievable emission rate or the lowest obtainable in practice, regardless of energy and economic considerations. The extent to which the fuel alcohol industry could be affected is demonstrated by noting the number of counties in each of the 48 contiguous states which have been designated as nonattainment areas, as shown in Tablc VII-2. Although the number of conntics affected may not be proportional to their land area, the figures convey at least a general indication of the extent of the problem in a given state. In 31 states, 30 percent or less of the state's counties had been classified as nunaltainment arcas for one or more pollutants as of December, 1979, and in 20 of these states, 15 percent or less of the counties were affected. At the other extreme, in 13 states, 71 percent or more of the counties had been designated as nonattainment areas (see Figure
VII-1), and all counties in Connecticut, Massachusetts, New Hampshire, New Jersey, New York, Pennsylvania, Rhode Island, and Vermont were in nonattainment status.

Because of proximity to feedstock supplies, the states included in the USDA's "Corn Belt" growing region (lowa, Missouri, Illinois, Indiana, and Ohio) are likcly targets for development of the fuel ethanol industry. Of the Corn Belt states, only in Ohio should siting limitations for ethanol plants be severe.

\section{- Federal Water Pollution Control Act}

It is the intent of the Clean Water Act to attain zero discharge of regulated pollutants such as BOD, solids, oil, and grease by 1985 . Technology-based effluent limitations on certain existing sources are predicated on the effectiveness of the best availablè contrul techinology cconomically achievable hy 1983 .

Aqueous discharges from distilleries are relatively easy to monitor and regulate, as they generally involve point sources. There are no current technology-based effluent guidelines for fuel ethanol facilities or for beverage distilleries. Fuel ethanol plants are under consideration by EPA, and a decision on the need for wastewater emission regulations for these facilities will be made in one to two years. The National Pollutant Discharge Elimination System (NPDES) distinguishes between major and minor dischargers, with a major source consisting of une dischurging 100,000 gallons or more per day of wastewater. (Thus, - commercial-scale ethanol plants would be classified as major sources.) Wastewater pretreatment regulations may have an impact on fuel ethanol production. Final pretreatment regulations have been set governing water quality standards for nondomestic waste that is introduced to POTW with design flows of 5 million gallons per day or more. Between now and July 1, 1983, the provision for a pretreatment program will become a condition of all new or reissued NPDES permits and industrial dischargers must be in compliance by that datc.

\section{- Resource Conservation and Recovery Act}

The primary areas of potential solid waste regulatory impacts applicable to ethanol-frombiomass activities are coal ash from boiler operation, grain elevator dust, particulates from the drying of distillers grains (trapped during emission control efforts and disposed of as solid waste, unless recycled), and stillage, if it is applied to soil as fertilizer. If recycling of 


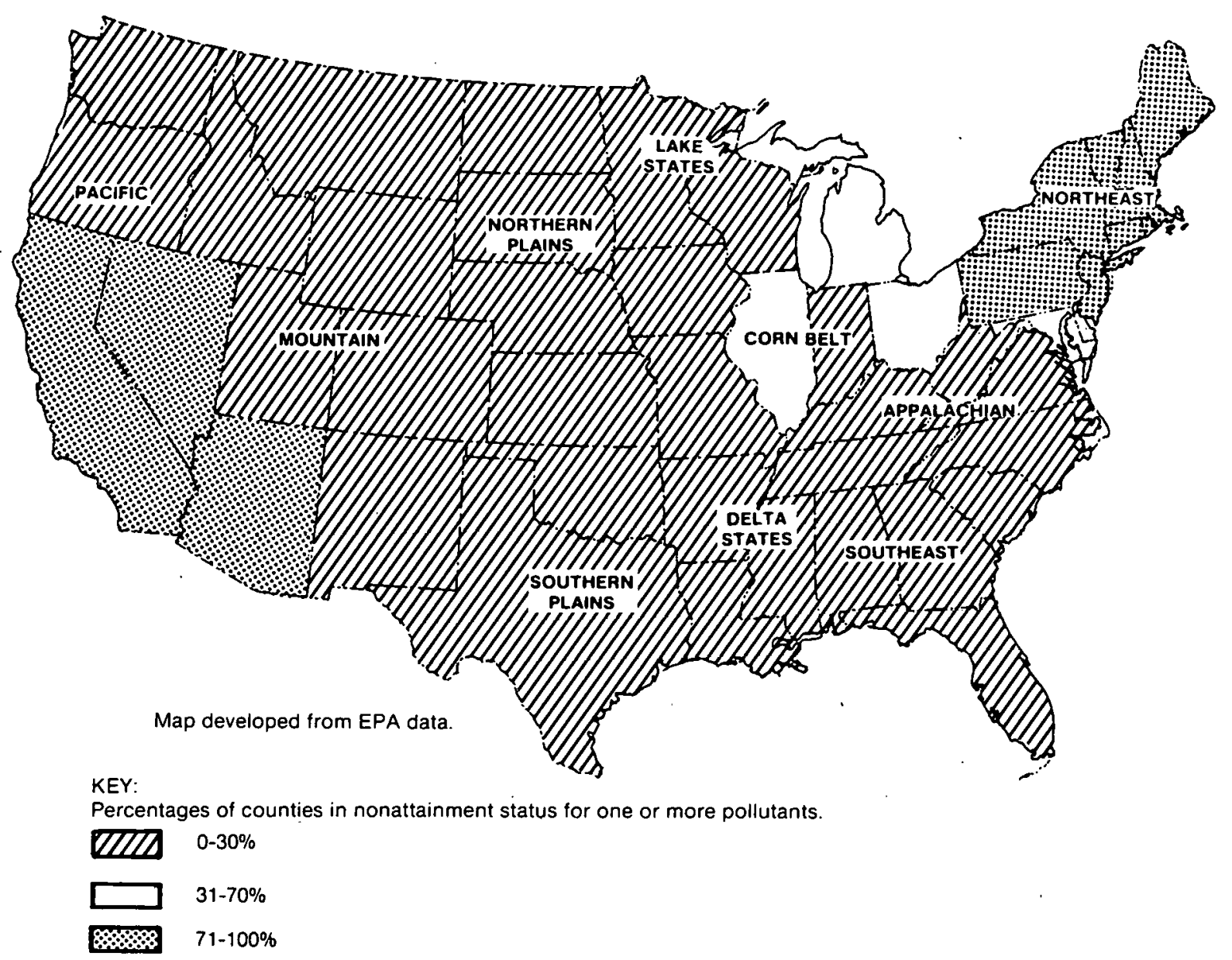

Figure VII-1. Extent of Nonattainment of National Ambient Air Quality Standards in 48 Contiguous States

trapped grain and recovery of DDG from stillage are assumed, then the major Federal legislation bearing on solid wastes from the biomass preparation and conversion steps is the RCRA. The extent of coverage and methods of inplementation of this Act are still being interpreted and developed by EPA and the courts. EPA has considered designating some energy-related hazardous wastes as "special waste" under RCRA. Interim standards would be established for special waste. Coal ash may be assigned to the special waste category until extensive analysis is completed.

\section{Environmental Assessment}

Environmental assessments or impact statements may he required prior to construction of fuel ethanol plants under certain conditions. The need for such assessment is triggered by Federal participation in funding, whether by direct cost-sharing or by loan guarantee. For a large project, which may produce significant environmental effects, formal assessments will be required. The Office of Environmental Compliance and Overview within DOE rules on the need for such assessments.
Even in the absence of a Federal requirement for an environmental assessment, it may be prudent for an investor to gather the pertinent environmental information, as such foresight may expedite the permitting process and facilitate public acceptance of a project. Although a Federal agency must evaluate the environmental evidence, the fact-finding activity may be delegated to the applicant or its independent rnntractor.

\section{FEEDSTOCK PRODUCTION}

In the production of grains as feedstocks for ethanol production, the single inust critical environmental issuc is erosion and its effects on water quality. Erosion serves as a transport mechanism for carrying nutrients, sediments, and pesticides to water resources, and it directly affects crop productivity and soil fertility.

Land and water use are also important issues. The need for irrigation in the western states puts increasing pressure on existing surface and groundwater resources, causing water tables to drop in some areas and the salinity content to increase in return flows to surface watcrs. The land use issue has two major components: 1) the loss of farmland to urban sprawl, and 2) the 
increasing pressure to put marginal farmland into use and convert fallow or natural areas to intensively cultivated farmlands.

\section{Erosion}

The rate of erosion is dependent on several factors, including type of soil, topography, amount and intensity of rainfall, ground cover, and control methods. It is, therefore, highly variable from site to site and over a period of time. The effects on soil are the direct loss of fertility and enhanced potential for water quality degradation. The latter arises as the biological content of the soil is decreased, in turn reducing the rate at which toxic substances applied to the soil are broken down. Hazardous substances thus are more likely to reach waterways.

The loss of sediment to waterways results in silting. Runoff from agricultural lands can cause additional problems, since fertilizer and peesticide residues are carried to the waterways. The major soil nutrients, nitrogen and phosphates, promote algal growth and thereby accelerate eutrophication of surface waters. Corn requires relatively high fertilizer application rates; indeed, although corn comprises only 20 percent of the United States' cropland, it requires approximately 40 percent of the fertilizer used nationwide. Herbicide applications for corn are also higher than the national average.

\section{Water Usage}

The quantity of water used for irrigation can be substantial, and represents only one of several competing uses for a limited resource. Gruundwater currently supplies approximately 40 percent of total United States irrigation needs, primarily in the westein Statcs. The importance of this issue for corn production is not as great as for other feedstocks, as minimal amounts of land are under irrigation in the major corn-producing States. Five of the six largest corn-producing States, for example, have less than one percent of tulal cropland under irrigation.

In addition to the use of water for agriculture, the quality of the returned water is of importance. Irrlgation water picks up mineral salts, und llie iesulting in crease in salinity of the water can have adverse effects on downstream users.

\section{Land Use}

Increased demand for grain crops as ethanol feedstocks would result in the need to increase the amount of land in agricultural production. If marginal land is brought into production, more fertilizer and pesticides would be necessary to attain the average level of productivity for a given crop. These increases in chemical applications would intensify the water quality impacts already associated with agricultural runoff; i.e., erosion from such marginal land would create more environmental impacts per acre, or per unit of output, than the average farmland in use today.

Another potential source of farmland is the conversion of natural areas such as forests to intensively managed crop production. Wildlife habitat would thus be destroyed, and erosion rates would be substantially increased.

The land use issue is further complicated by the loss of farmland to urban development. Annually, 3 million acres of farmland are lost to urban sprawl, and onethird of this total is considered prime farmland. As more of the existing farmland is lost to urban development, a greater proportion of marginal lands may be required for rrop production.

A recent USDA cropland availability study reports that 78 million acres with high potential as cropland remain in this country, with much of it in the Corn Belt and Northern Plains regions. Of this high-potential land, 15 million acres have essentially no limitations on development. The latter acreage, if planted entirely in corn and used exclusively as ethanol feedstock, corresponds to approximately 4 billion gallons of fuel ethanol per year, or 80 of the reference-size, commercial-scale plants.

\section{USE OF ETHANOLIGASOLINE BLENDS IN HIGHWAY VEHICLES}

Environmental impacts which could be assoniatcd with the use of ethannl/gasoline blends as fuel for highway vehicles are dissussed briefly below. Not only users of the fuel but silsn the general population could be affected. Although potential impacts on the latter group are largely undefined, no barriers to the use of gasohol are anticipated.

\section{Impacts on Users}

\section{- Health}

Ethanol is not highly tnxic. Its major routes of entry into the human body are ingestion, inhalation, and absorption through the skin. Effects ol exposure to the substance are primarily ones of discomfort, as described in an carlier section. Ingestion of ethanol/gasoline blends is unlikely, but the ethanol could be separated from the denaturing agents in some formulations. (For example, ethanol can be separated from gasoline denaturant.) A variety of physical symptoms can also arise from exposure to denaturants used with fuel ethanol. 
- Safety

Ethanol is a flammable liquid, with flammability limits of 3.3 to 19 percent by volume in air. Its flash point is above that of gasoline. Typical ethanol/gasoline blends pose explosion or fire hazards comparable to those of gasoline. In storage, however, ethanol presents one additional safety hazard-neat alcohols burn with invisible flames, thus making it possible for ethanol fires to remain undetected and/or to be approached too closely by workers.

\section{Impacts on General Population}

\section{- Air Quality}

Both evaporative and exhaust emissions from ethanol/gasoline blends will differ slightly from those associated with unblended gasoline. Carbon monoxide and hydrocarbon emissions are not changed significantly. The exhaust is sensitive to the original air/fuel setting of the carburetor, whether or not the carburetor has been adjusted for the ncw fuel, the type of emission control system, and the engine configuration. A reduction of nitrogen oxides emissions is obtained with ethanol/gasoline blends, but aldehyde (currently unregulated) and evaporative emissions increase for the blend relative to gasoline. As ethanol contains no sulfur, sulfur dioxide is absent from the combustion products. Moreover, ethanol yields no particulates on combustion.

\section{- Ecosystems}

Little information exists in the realm of potential effects of utilizing ethanol/gasoline blends in highway vehicles except for the above information on combustion. The major area of potential concern appears to be the possibility of introduction of ethanol to waterways through spills or other accidents. Ethanol dissolves readily in water and could, therefore, be transported easily in an aqueous medium.

\section{SUMMARY OF ENVIRONMENTAL ISSUES}

Three major environmental problem areas associated with commercial-scale fuel ethanol production are: 1) safe disposal and treatment of distillery wastewaters; 2) exposure of workers to toxic and/or corrosive chemicals; and 3) atmospheric emissions and solid wastes resulting from combustion of coal to satisfy process steam requirements. Controls, in the form of hardware and procedures, are available commercially. The cost of direct controls amounts to approximately 13 percent of the capital investment for a 50-milliongallon-per-year fuel ethanol plant.

The environmental regulatory climate can influence investment decisions. Current regulations may place limitations on siting of ethanol plants, particularly if they include coal-fired boilers. Besides the siting restrictions arising from air quality considerations, the assimilative capacity of streams will play a role in siting decisions. Beyond the current generation of Federal environmental regulations, investors need to consider the possibility of more stringent ones, as well as existing State and local regulations which may be more restrictive than their Federal counterparts. Anticipated regulations could influence both the economics and the siting of future plants.

Availability of feedstocks for fuel ethanol production is essentially unfettered by Federal environmental laws. Environmental impacts associated with agricultural production tend to be non-point-source problems and are, therefore, difficult to monitor and regulate. The major concerns of increased agricultural production to meet fuel ethanol feedstock requirements are erosion, which impacts water quality, and use of limited land and water resources.

When ethanol is blended with gasoline for use as a highway vehicle fuel, there are potential environmental implications involving both the user group and the general population. Ethanol is not highly toxic, but it does produce definite physical symptoms when inhaled or ingested. The same precautions need to be taken in handling ethanol as with any other explosive and flammable substance. The potential air quality and ecosystem impacts of ethanol combustion in highway vehicles are not fully defined, but no barriers to deployment of ethanol for fuel use are currently foreseen. 
1.

\section{THIS PAGE}

\section{WAS INTENTIONALLY LEFT BLANK}




\section{CHAPTER VIII}

\section{Business Plan}

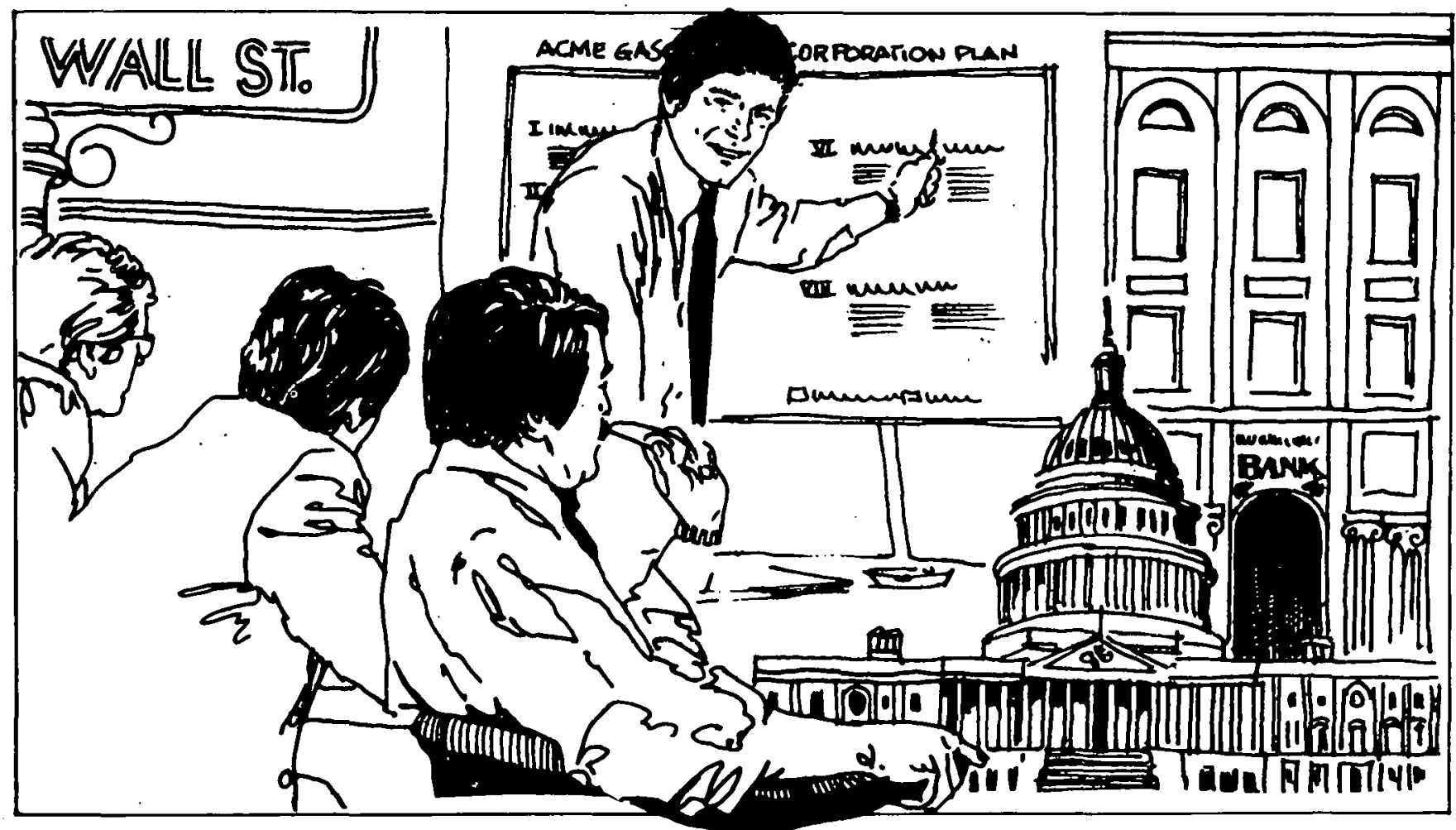

Entry into the alcohol industry requires equal planning from both business and technological perspectives. Many technologically sound projects have never gotten off the ground for lack of business acumen, adequate financing, and a cohesive team capable of transforming ideas and strategies into operational results. These concerns are of particular significance in the alternative energy field where there is insufficient financial and management history to ensure an adequate return on investment. The purpose of a business plan is to blend innovative idcas into a detailed plan of action. The principal objectives of a business plan include:

- The establishment of a project's goals and objectives, such as a monetary return, investment criteria, protection of supply, image, diversification, public or national spirit, etc. As a general rule, the more owners or investors in a project, the more diverse a project's objectives become.

- The development of a decision matrix for "Gu Ahead", "No Go", and modification of plan decisions.
- The assembly of a task force team including both internal and external members capable of accomplishing the project's objectives, and likewise having the ability to advise the investors when to abort an undesirable project. This team should include:

- Investors, whose function is to establish the objectives of the project.

- Internal management and staff personnel, whose function is to carry.out the investors' objectives.

- External consultants and vendors, who will usually include:

Attorneys

Certified Public Accountants

Engineering Consultants

Investment Bankers

Commercial Bankers

Contractors

Insurance Agents and Underwriters 


\begin{tabular}{|c|c|c|c|}
\hline \multirow[b]{2}{*}{ COST ITEM } & \multicolumn{3}{|c|}{ FUNDING SOURCE } \\
\hline & $\begin{array}{l}\text { SEED MONEY } \\
\text { OR EQUITY }\end{array}$ & $\begin{array}{l}\text { MAY BE DEBT } \\
\text { FINANCED }\end{array}$ & $\begin{array}{l}\text { POSSIBLE } \\
\text { GRANT }\end{array}$ \\
\hline Prefeasibility Cost & $x$ & & \\
\hline Underwriting the Cost of Raising Equity & $x$ & & \\
\hline Feasibility Study & $x$ & & $x$ \\
\hline Exploring Sources of Financing & $\mathbf{x}$ & & \\
\hline Preliminary Engineering & $\mathbf{x}$ & & $x$ \\
\hline Final Engineering & & $x$ & \\
\hline Site Options & $x$ & & \\
\hline Acquiring a Site & & $x$ & \\
\hline $\begin{array}{l}\text { Plant and Equipment Cost (Construction } \\
\text { Period) }\end{array}$ & & $x$ & $x$ \\
\hline Plant and Equipment Cost (Permanent) & & $x$ & $\mathbf{x}$ \\
\hline Working Capital Requirement for the Plant & $x$ & $x$ & \\
\hline
\end{tabular}

Once the project team is assembled, the goals have been defined, and a decision matrix established, a detailed schedule or work program should be developed for project control. This detailed schedule or work program should include, as a minimum, the following:

- Designation of a project manager or director, and description of all project members' functions.

- Specific assignment of tasks to project members with definite dates for completioni.

- Definition of the project's objectives and goals.

- A method for interim reporting on the status of each assignment.

- A calendar of expected completion dates for key areas in the project which will require decisions.

The following discussion addresses the key requirements of studying, organizing, financing, constructing and operating an ethanol plant.

\section{SEED MONEY STAGE}

"Seed money" is usually the most difficult to raise for any investment. By definition, seed money pays for expenses incurred during the planning stage of a project, before decisions are made on how best to proceed; consequently, seed money is considered high risk by investors. Because of their greater risk, investors who enter the venture at this time will receive an ownership position in the project greater than their proportional dollar share of investment. Seed money is particularly important to alcohol fuel projects to finance the prefeasibility study. The financing and economic feasibility study requires the accumulation of marketing, legal, economical, technical, and financial information by engineers, attorneys, and C.P.A.'s, to cvaluate the viability of the project.

In planning an ethanol plant, one must oblain funds to cover the various project costs. These costs and possible funding sources are listed in Table VIII-1.

Once a project teanl is assemblcd, sced money acquired, and a financing plan developed, the organizational form of the entity must be considered.

\section{ORGANIZING THE VENTURE}

Alcohol plants may be established in various organizational structures depending on the objectives of investors and applicable regulations. The different entity forms which may be considered include:

- Proprietorship

- General partnership

- Limited partnership

- Joint venture

- New subsidiary of an existing corporation

- New division of an existing corporation

- New corporation

- Acquisition or merger of an existing corporation

Because of the complicated legal, accounting, financial, and tax considerations involved in choosing an organization structure, a decision should not be made until detailed discussions are held with the project's attorncy 
and C.P.A. to determine which entity format is best suited to a given situation.

The key factors and pros and cons of the alternative entity forms are shown in Table VIII-2.

\section{OTHER CONSIDERATIONS}

Establishing a project office within an existing corporation has the following advantages:

- Ability to select from a large, tried and proven management staff

- Lower administrative burden

- Established sources of internal funds

- Existing credit rating

- Existing credit sources

Reliance on internal development has been a rule for many firms, yet the costs and risks involved in such action should be weighed against the opportunities created by acquisition which can often provide more rapid and predictable results. The addition of new corporate capabilities by this method should be investigated as early as possible for any conceivable antitrust implica- tions. The public interest, as reflected in the antitrust laws, prohibits any acquisition or merger that substantially lessens competition or creates a monopoly. In favor of this alternative is the immediate acquisition of trained management, a new source of working capital, and an expanded credit base.

A new corporation is an obvious organizational alternative. A charter defines its purpose and scope, and formation of a new corporation has significant debt and tax advantages. Financing may be obtained by issuing new shares and company assets may be pledged as security for loans and bonds.

A joint venture is a special form of a partnership or corporation created by two or more existing legal entities to accomplish a specific, limited objective. The necessary seed money, management, labor, and board of directors are provided by the sponsoring organizations hut their operational expenses thereafter are borne by the new group.

Once the legal and management structures have been determined, the organization should set regular business sessions and stockholders' meetings. It is not important

Table VIII-2. Alternative Entity Options

\begin{tabular}{|c|c|c|}
\hline Factor of Comparison & $\begin{array}{c}\begin{array}{c}\text { Individual/Partnership or } \\
\text { Consolidated Corporate } \\
\text { Subsidiary }\end{array} \\
\end{array}$ & $\begin{array}{l}\text { New Non-Consolidated } \\
\text { Corporate Ownership }\end{array}$ \\
\hline $\begin{array}{l}\text { Start up cost, } \\
\text { depreciation or } \\
\text { losses may be } \\
\text { deducted when } \\
\text { incurred by investor }\end{array}$ & $\begin{array}{l}\text { Usually passed out to } \\
\text { the investor for a } \\
\text { current deduction }\end{array}$ & $\begin{array}{l}\text { Carried forward to } \\
\text { offset against } \\
\text { future income }\end{array}$ \\
\hline $\begin{array}{l}\text { Tax credit such as } \\
\text { investment tax credit } \\
\text { and energy tax credit }\end{array}$ & $\begin{array}{l}\text { Usually passed out to the } \\
\text { investor for a current } \\
\text { deduction }\end{array}$ & $\begin{array}{l}\text { Carried forward to } \\
\text { offset against } \\
\text { future income }\end{array}$ \\
\hline Rales of taxation & $\begin{array}{l}\text { The personal tax rate of } \\
\text { the individual or } \\
\text { partners; the corporate } \\
\text { rate of corporate parent }\end{array}$ & $\begin{array}{l}\text { From } 17 \% \text { of the } \\
\text { first } \$ 25,000 \text { to } \\
46 \% \text { on income in } \\
\text { excess of } \$ 100,000 \text {. }\end{array}$ \\
\hline Liability of investor & $\begin{array}{l}\text { Unlimited to proprietor } \\
\text { or general partncr, } \\
\text { others usually limited }\end{array}$ & Usually limited \\
\hline Taxation & $\begin{array}{l}\text { To the individual or } \\
\text { corporate owner when } \\
\text { incurred; no taxation of } \\
\text { dividends to individuals } \\
\text { and an } 85 \% \text { exemption for } \\
\text { corporate parents }\end{array}$ & $\begin{array}{l}\text { Taxed at corporate } \\
\text { level when earned; } \\
\text { dividends also } \\
\text { taxed to the individ- } \\
\text { ual when distributed }\end{array}$ \\
\hline
\end{tabular}


at this point to fine-tune the organization; the most pressing detail is building the project team which is capable of structuring the financial arrangements for the project.

\section{CRITERIA IN SELECTION OF THE PRO.IECT TEAM}

Unless the organization is a joint venture among highly sophisticated firms with sufficient resources available, or an organization with an internal source of expertise in all fields necessary for operation of an alcohol project, it will be necessary to turn to external sources for expertise. Outside consultants will probably be needed.

It is important to choose the right professionals to handle the organization's needs. Arrangements or contracts should be negotiated and signed with a recognized engineering design firm, a legal firm, a C.P.A. firm, a construction contractor, and, most likely, an investment banker. Because of the rapld development of the alcohol industry, there are a number of young, highly competitive, and aggressive companies in the marketplace offering services in process design, engineering, construction, and financing. Unfortunately, the rapid growth has also enticed a number of marginally qualified firms into this marketplace. Promoters and investors should take great care in selecting qualified firms in order to assure quality work and to protect their investment. It is advisable to obtain personal and business references, and to utilize firms with experience not only in the field of alcohol distilling, but also to choose those who have structured projects of a similar dollar magnitude rnmpared to the project involved.

In evaluating the engineering firm, it is important to rccognize that there are no munopolies on alcohol production processes; many choices are availuble. As cach process undoubtedly has strengths and weaknesses, both price and quality should be considered in the selection process. Several specific questions are important in the determination of an engineering firm. The organizatiun sliould request:

- A detailed economic analysis and descruption of the process which the firm recommends and an estimated manufacturing cusi per gallon

- Specific projects which the firm has engineered in the alcohol industry

- A copy of the process and performance guarantees used by the firm!

- A copy of the legal contracts which the firm uses in contracting for services

- The current financial statements and bank references of the engineering firm
The above information should be reviewed by the project's attorneys and C.P.A.'s, and the attorney should finalize all contracts with the engineering firm.

In selecting attorneys, C.P.A.'s, and investment bankers, it is essential to consider the following:

- Expericnce in the industry

- Location of the professionals, due to the almost daily contact required in the development stage

- The attorney's specific knowledge in areas of taxation, contracts (possibly. securities law and underwriting), Federal regulations, patents, etc.

- Thc C.P.A. firm's special knowledge in project financing, forecasting, taxation, feasibility studies, management analysis, and, possibly, in SEC and underwriting

- The investment banker's experience in successfully placing project financing and, if necessary, the equity portion of a project

The criteria in selecting the contractor are identical to those of the engineering firm, with the addition that the contractor be bondable.

\section{PROJECT FINANCING}

Once the team is assembled and the feasibility study is underway, the detailed financing package must be assembled by the C.P.A.' $\varepsilon$ and investment bankers. 'I'his package, in atlilition to the feasibility stıdy, must include:

- Persnnel resumes of applicants

- Personal resumes of selected plant managers

- Contracts for supply of raw materials

- Contracts for energy supply

- Cuntracts for sale of production

- Contracts for sale of coproducts

- Corporate/partmership history and histuri: al financial statements

- Summary of collateral offered

- Summary of projected use of funds

- Summary of projected source of funds

It is important to estimate accurately the time required to accumulate all of the legal and financial documentation required. This is especially true where government forms and applications are necessary. It is also important, when requesting federal financial assistance, to consider aspects which address the government's objectives. For example, government agencies are presently encouraged to give priority assistance to projects which utilize a farm cooperative to supply raw materials and thus contribute to the enrichment of the local economy, 
or to projects which utilize municipal wastes to fuel the plant. If such options are reasonable, then the loan package should emphasize their expected effects on the local economy. (See Appendix A, Financial Assistance Programs, for financing available from the federal government.)

Identification of federal involvement has another dimension; i.e., a request for financial assistance should give reference to such Federal incentives as the Crude Oil Windfall Profits Tax Act of 1980. The alcohol fuels sections of the Act will help provide long-term market support for gasohol, cut some of the red tape involved in licensing and regulatory procedures, and offer tax incentives for investors in alcohol fuel plants.

Finally, a banking agent for the project should be identified and the bank itself should make some commitment to the project to act as a supplier of funds. This commitment indicates a solid relationship with the bank and gives further creditability to the project. In virtually all instances, with the exception of the costs of documenting the loan package, financing services should be based on results. Investment banking commitments will normally cost 1 to 2 percent of the total loan requested. C.P.A. firms, which professionally handle government applications for financing, will normally charge a negotiable fee for assisting in the feasibility study and prepa- ration of the financing package. This fee, based on the time and billing rates of the individuals involved in the preparation of the financing package, will generally amount to about 1 to 1.5 percent of the loan amount requested.

\section{PLANT CONSTRUCTION AND OPERATION}

In the final phase of the business plan, management must become actively involved in the project. The owners will need to hire management and operations personnel to work with the engineering and construction companies to gain in-depth knowledge of the plant operations. It is extremely important that cost controls be effected early in the project development. Thus, the company must implement its internal accounting procedures at the earliest possible date.

Regular meetings among management, engineers, and construction personnel should be maintained throughout the construction phase and into start-up operations. Management should locate necessary skilled and semiskilled operations personnel, and plan the initial logistics of start-up operations during the project construction period. A timephased approach will prove most effective in overall business planning. 


\section{THIS PAGE \\ WAS INTENTIONALLY \\ LEFT BLANK}




\section{CHAPTER IX \\ Feasibility Study}

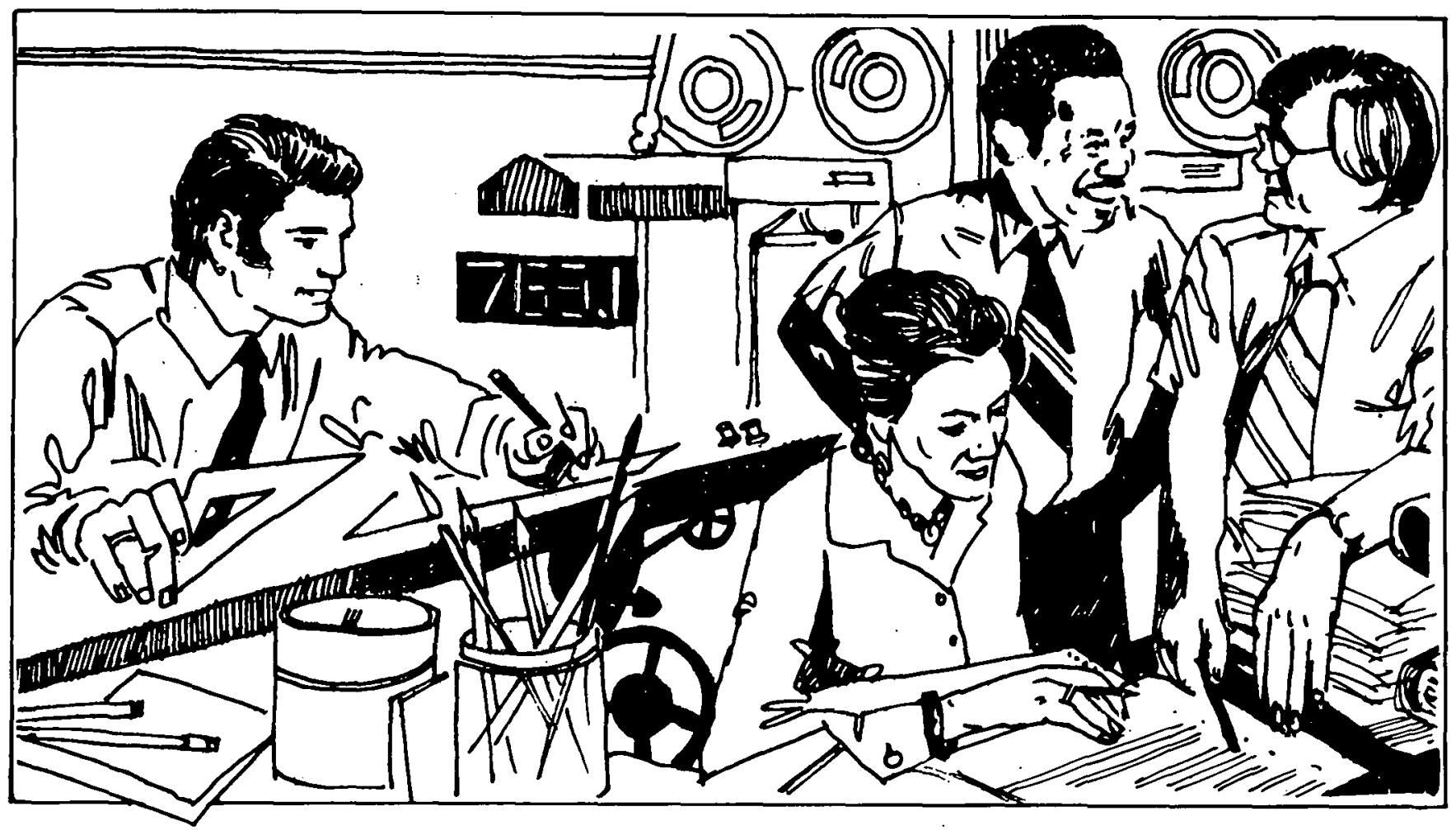

The purpose of this chapter is to identify the significant aspects in performing an effective feasibility study and suggest how best to address them. The form and format proposed should not be taken literally; rather, as guidelines for consideration as needed. Knowledge of the audience is mandatory. If the study is to be prepared for a group of investors with varied backgrounds, then more detailed technical explanations of the basic manufacturing process and a historical overview of the industry are probably required. An enunciation of the potential and inherent risks of the proposed venture must be clearly stated, regardless of the audience addressed. If the study is for use by more informed and experienced lending institutions, then too much preamble may'dilute the primary points of the proposal.

The basic points to be addressed in the study are how successful the venture will be and how much risk is involved to all parties. The length of the study and the amount of detail required are governed by the size of the project and the amount of control the involved parties (the proposed lender as well as the proposed borrower) have over the decision variables. For example, less information need be presented if the process raw materials are already owned or contracted for, or if the sale of all production of the product and coproducts is guaranteed. Discretion should be used as to the volume of information to be provided.

First, the potential investor must be convinced that the project is worth his time and effort, and a few major issues must be addressed for this prefeasibility phase: namely, the availability of markets, feedstock cost and availability, water, power, and status of legislation.

\section{PREFEASIBILITY PHASE}

The initiator of the project must be satisfied that (1) there is a market and it can be reached (conduct market and marketing analysis); (2) resources and 
means of acquiring them have been identified, e.g., feedstock, water, power, and labor (evaluate factors of production); and (3) all applicable Federal, State, and local requirements can be met (determine environmental, health, and safety factors). With respect to the existence of a market for ethanol and coproducts, the investor must determine how firm the need, at what price, and at what risk to the project. With respect to the necessary feedstocks and chemicals, he must determine their availability, at what price, and with what assurance for each. With respect to the availability of needed water, the same considerations need to be faced. For fuel, the potential investor should check the availability and cost of alternative resources, particularly cogeneration, and coal and natural gas. With respect to laws, regulations, and rules, he should determine which are prohibitive and which are supportive of the project.

\section{FEASIBILITYY PHASE}

Once the potential investor is convinced that the project deserves an indepth analysis, a feasibility study should be performed in sufficient detail to define the means by which financing, construction, and operation will be accomplishcd. Each study should address:

- Technical and economic feasibility

- Resource assessment and availability

- Financing alternatives

- Ability to construct and operate a commercial plant in an environmentally acceptable manner on à sèlected site

The marketing, materials, and legal sections must be reviewed to provide more specificity, and sections on technical and engineering design, site selection and suitability, economic and financial analysis, and management planning should be added. Sufficient detail should be provided to facilitate a lender's decision whether or not to provide the support required.

The following discussion, sample, and outline information elements at the end of this chapter only provide a guide to preparing a feasibility study; the investor must do the convincing. The basic goal of the study should be kept in mind at all times: an answer to the question, "Can this specific project make a profit over the anticipated life of the investment?"' The feasibility study should critically examine the proposed project to uncover problem areas and consider all possible risks. Solutions should be offered to reduce risks and unknown economic factors that may cause the venture to fail.

\section{KEY ELEMENTS OF FEASIBILITY STUDY}

\section{INTRODUCTION}

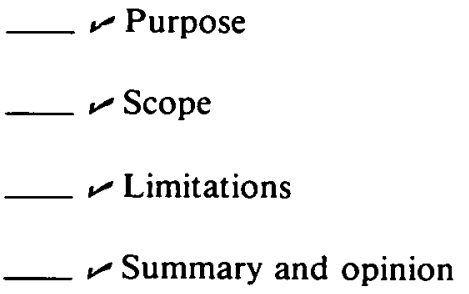

This section sets the foundation for the reader, focusing his attention on the most important conclusions and business factors and their effects on the proposed project. It emphlasizes the positive side of the findings, but also indicales where help is needed. The Summary and opinion are very important because many readers want to know the bottom line before reviewing the project in greater detail.

\section{PART 1. MARKET AND MARKETING ANALYSIS}

\section{A. ETHANOL}

_ _ Market description
$\sim$ Gasoline demand
$\sim$ _ Alcohol dcmand
$\sim$ P Product analysis
$\sim$ C Presecured markets - contracts for sale
of product
$\sim$ Distribution analysis

The uljeclive of this study section is to determine if the total proposed output of the plant can be sold at a profit over the life of the venture. The nature and detail of the analysis will identify and quantify specifics of the market composition, size, and description (e.g., refinters, marketers, consumers, gcographic area); com petitive factors, both current and future; gasoline and alcohol, current and future pricing and anticipated demand. The intent is to develop a realistic evaluation of immediate market conditions and to prepare realistic market projections for the future. 


\section{B. COPRODUCTS}

— Market description

—

$\sim \sim$ Product analysis

$\sim \sim$ Competitive factors

— Promotion analysis - presecured sales

$\sim$ Distribution analysis

The sale of coproducts such as $\mathrm{CO}_{2}$, yeast, stillage (both wet and as distillers dried grains), and gluten can be a large determinant of the profitability of plant operations. It is likely that for such products as DDGS, the future market will be totally new because of the unprecedented volumes of supply and the untested demand. Price fluctuations of the DDGS have been rapid and irregular with the supply drying up during the summer months. Any long-term contracts for selling the coproducts that can be established in advance are invaluable in establishing the viability of the proposal.

\section{PART 2. TECHNICAL AND ENGINEERING DESIGN}

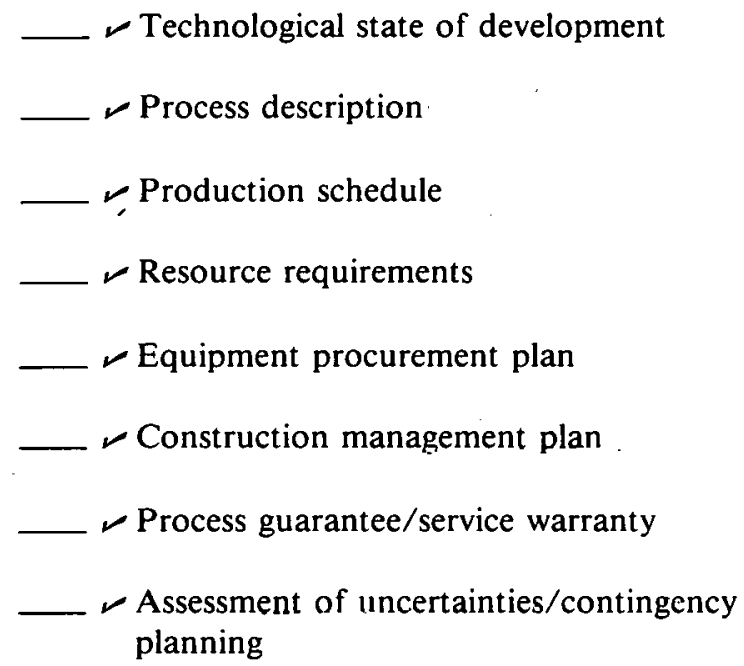

The objective of this analysis is to determine the technological feasibility of the proposed project. The potential investor must provide evidence that the proposed venture has available a viable process ready for construction and installation according to wellconsidered timetables. This section provides the rationale for process selection and should analyze the uncertainties surrounding commercial application of the process. It should clearly identify all major areas of project design and operation that represent significant new technological innovation and should delineate what steps (if any) remain to be taken before commercial readiness is achieved.

The process description should include process flow diagrams, energy and mass balances, mechanical specifications, process specifications, major equipment requirements, plant layout sketches, plot plans and offsite requirements, waste-handling procedures, and other general design requirements. Resource requirements include all necessary raw materials such as water and power. All plans should be time-phased and indicate manpower and subcontractor requirements, where appropriate. Ideally, an involved engineering company can provide a process guarantee and subcontractors and suppliers will provide service warranties. An assessment of the uncertainties surrounding the commercial application of the proposed process must be presented, including presentation of your strategy for dealing with unanticipated events.

\section{PART 3. FACTORS OF PRODUCTION}

\section{A. FEEDSTOCK}

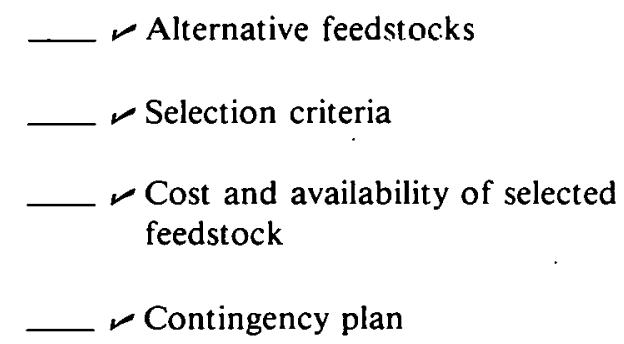

The choice of feedstock for ethanol production varies from region to region, and even from site to site. The financial success of the venture is dependent upon the steady procurement of low-cost feedstock. Present availability as well as future agricultural projections should be evaluated for each proposal. The results of current crop development work will influence future feedstock choices and the investor should have full knowledge of the available alternatives.

All available fermentables need to be catalogued and compared to provide as many options as reasonable. Purchase prices at which the use of each alternative feedstock becomes less economical than another feedstock should be constantly updated to provide a basis for purchasing decisions. Factors affecting feedstock supply and availability should be reviewed in this section of the study, including natural factors as well as likely political or competitive events. During your feasibility study, you should identify sources of supply that can be contracted at favorable prices, particularly, those products of substandard grade ut classified as waste from some other process. 


\section{B. POWER}

_ Alternative sources
$\sim$ Selection criteria
$\sim$ Cost and availability of selected source
$ـ$ Contingency plan

Potential energy sources for process fuel should be analyzed and the best source selected. The criteria usually are availability, cost, and the resulting net energy balance. The better sources of energy, from a national viewpoint, are waste and other renewable resources; and, depending on the site, probably coal and possibly natural gas. Some financing sources, particularly the government, may have explicit guidelines on the use of different fuels. Any likely potential for shortages due to labor shutdowns in other fields should be addressed.

\section{WATER}

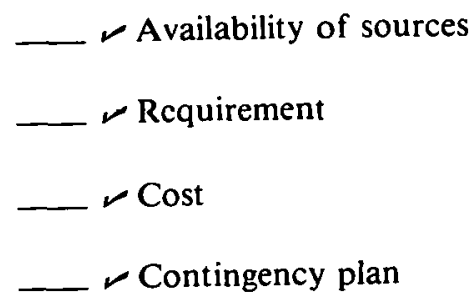

Significant amounts of water are used in the ethanol produrtion process (about 16 gallons of water per gallun of ethanol produced). This demand includes requirements for generating steam, cooling, and preparing mashes. The actual amount of water needed will be significantly less due to the recapture and recycling of water used, but in some regions this may be a critical consideration. The source, process requirements, and cost should be analyzed, and a plan developed for acquisition, showing a complete understanding of pultintial problems.

\section{LABOR}

- Job descriptions/specifications

$\sim \sim$ Availability and rates

_ Recruiting and training

_ L Labor relations

In this infant industry, production manpower requirements are not well known. Different processes should require specific numbers and types of workers, yet as experience is acquired, the work force required will prob- ably change. The first estimate of the number of workers necessary can bc obtained from the engineering design contractor. The feasibility analysis should deal with the quality and characteristics of the available labor pool; how much they will be paid; how they will be recruited, selected, and trained: and an outline of promotion policies and retention means. Any potential for labor disputes or shutdowns should be addressed for each site considered.

\section{PART 4. SITE SELECTION AND SUITABILITY}

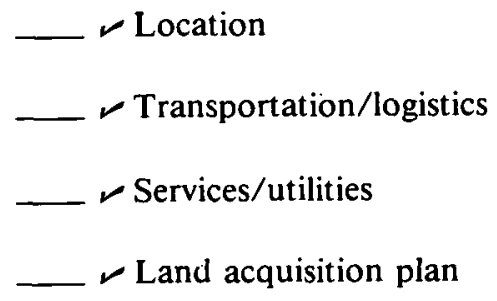

The primary site requirement fus lucation of an ethannl plant is the availability of an abundant water supply. Other site requirements are similar to those for any chemical manufacturing facility, except for the particular material handled and the storage of agricultural and liquid products. In comparing alternative sites, project or anticipate future problcms such as the availability/ cost of railroad service, regional and local political forces, and distance from the raw materials.

A potential site should be near several sources of different raw materials and several different markets. Multiple modes of transportation are likewise desirable. Tlie sitc should be lns.ated where there will be no unusual circumstances preventing licensing and permits. The costs of these factors should be used in evaluating the best site. The recommended site should be readily available for acquisition.

Any firm agreement to purchase or lease the site should bc subject to engineering approval, receipt of required permits, and completion of other legal and environmental reqquiremenits.

PART 5. ECONOMIC ANALYSIS

\section{A. COST OF PRODUCTION}

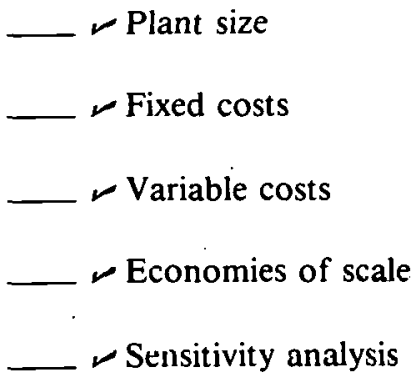


A detailed economic analysis should be presented for the proposed plant. As described elsewhere in this document, the size chosen for the plant can mean the difference between purchasing raw materials and developing, storing, and treating them; thus incurring a different cost structure for the plant. Detailed assumptions concerning the cost of operation, i.e., fixed and variable costs, need to be identified for the near- and long-term, as a function of output. An accounting model of the plant should be developed and the effects of changing the cost of the key variables should be evaluated. This sensitivity analysis will illustrate the range of possible consequences and help the project developer organize a plan to reduce dependence of the project on uncontrollable variables.

\section{B. INVESTMENT ANALYSIS}

$\ldots$... Total capital requirements

_ Income and cash flow projections

— Profitability analysis

An analysis of the total capital requirements must be prepared, including appropriate breakouts of the capital components such as the elements of fixed capital requirements, and others, such as working capital. Of course, the final projections must wait until many of the project characteristics are finalized, such as site-specific construction requirements and the size, terms, and interest rates of the necessary loans. However, assumptions should be made based on findings from other sections of this feasibility study in order to determine bottom-line estimates as early as possible.

Working capital requirements should be estimated in conjunction with operating characteristics of the engineering design. Actual amounts would differ, depending on the inventory requirements, the lines of credit opened with a commercial lender, and the amount of product produced. Less than full-capacity operation should be planned, especially during the start-up period, and most probably thereafter. Allow for sufficient funds to cover contingencies, as well.

As the income and cash flow projections are made, the least favorable conditions also should be considered. Profitability analysis should include projections of the classical ratios, including return on investment, payback period, discounted cash flows, net present value, and so on.

The funding options available to the entrepreneur should be a fundamental part of these analyses. The investor should include the likelihood of Federal, State, and local government support as wcll as taxes, and discuss their effects on the project's financial picture.

\section{RISK ANALYSIS}

$r$ Government intervention

$\checkmark$ Competitive reaction

$\checkmark$ Product/process obsolescence

Examination of the potential risks involved with alcohol fuel production is of primary importance to both the entrepreneur and the investor. Not only will it help to identify the possibilities for failure, but if the project is undertaken, it will identify potential problem areas for management. This early identification of economic risk also will aid in determining the optimum project configuration to allow for the most flexibility in dealing with changing economic and technological climates. In conjunction with the economic analysis, an examination of the available margins at various market conditions should be made to determine the effects of changing markets. The purpose of this section is to highlight potential pitfalls to prevent producing a product which costs too much, or having to sell a product at too low a price.

\section{PART 6. MANAGEMENT PLAN}

— Background and experience

— $\boldsymbol{\sim}$ Responsibilities

- Management systems

As in any new venture, and especially a pioneering effort such as alcohol fuels production, management capabilities are a most critical component. The management plan should indicate the involvement and responsibilities to be assumed for the entire life span of the project. Responsibilities and authorities must be clearly identified and each position filled with an experienced individual. The technical and business backgrounds are critical, with agribusiness, as well as refinery and plant management experience, preferred. The lending institution must be assured that top-rated managers are being hired.

\section{ENVIRONMENTAL HEALTH AND SAFETY AND OTHER REGULATORY REQUIREMENTS}


The purpose of this assessment is examination of those issues likely to have the most impact on the permitting and scheduling of the proposed facility. The potential investor should research all applicable local, State, and Federal statutory and regulatory requirements in order to determine whether the environmental, health, and safety requirements can be met, and if so, on what schedule.

The baseline environmental quality of the proposed site should be defined; a determination of applicable environmental standards and constraints should be presented; a technical description and cost evaluation of mandated environmental control medsures should be prepared; the quantities of air, water, solid, and radiation residuals of the proposed process assuming applicable control technology should be assessed; and an analysis of the impact of residuals on the baseline environmental quality of the site should be presented, using appropriate predictive models.

Assessments of particular concern to the community or state should be included, quantitative analyses should be presented of worker and community exposures to, and disposal of, known or suspected hazardous materials.

Finally, the investor should describe control options, costs and risks, and control measures that will be instituted to meet requirements. The process of making alcohol fuels should be environmentally safe, and the investor should be certain that no moral, ethical; or legal issue will tie up the project for long periods, or èven klll it aftel il is slated.

\section{FEASIBILITY STUDY FORMAT}

This outline contains elements upon which the potential investor may expand in his feasibility study.

\section{Title Page}

- Name of firm submitting the proposal

- Mailing addresses

- Telephone numbers

- Person to contact if further information is nerdra

2. Table of Contents

- All chapters

- All appendices

- All tables, charts, \& maps

3. The Objective

- Who/What/When/Where/Why/Cost/Annual Capacity

\section{Background}

- History of this particular venture and alcohol fuels

5. Market Description of the Feedstock(s) and Products

- Summary of the specific feedstocks for the production of alcohol and the market for the products of the particular plant.

- Who are the sellers and buyers?

6. Organization and Founders

- Briefly describe all the owners

- Outline the organization that will direct this project

- Indicate the distribution of ownership

\section{Project Compunemis}

- Outline the major tasks to accomplish the objeciive

- Delineate the management responsibility for each task

- Indicate the integration of appropriate tasks

8. Time Schedule

- List all tasks in summary form in time sequence

- Depict the tasks on a chart (See example.in Figure (X-1)

9: Projest Cost and Sourres of Funding

- Summarize the costs

- List all sources of funding

\section{THE APPENDICES TO FEASIBILITY STUDY}

\section{A. Market and Marketing Analysis}

The proculement aind retailing of products with all internal and external impacts are estimated. The historical and projected value and cost are determined along with the phases of development and operation. The relationship of the project to regional, State, and local energy policy should be noted. Suggested considerations include:

Feedsțnok(s)

- Sources and locations (gathering radius)

- Cost of collection and transportation

- Quantity and quality for alcohol production

- Historical, current, and prujected cost

- Availability over the life of the plant 


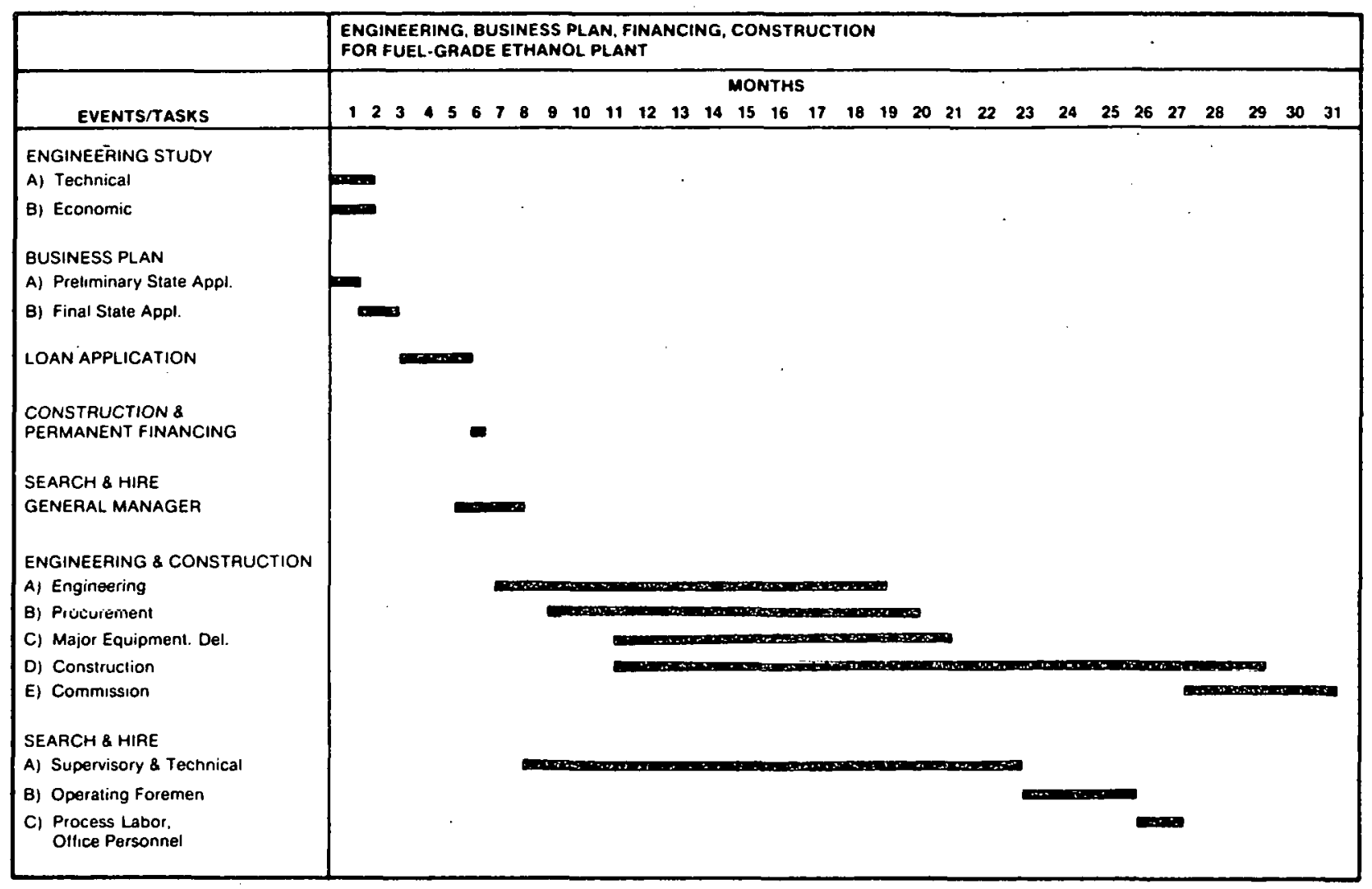

Figure IX-1. Likely Schedule of Eventș/Tasks

\section{Alcohol}

- Market price for expected proof

- Transportation cost

- Current and projected cost

Coproducts

- Value on-site

- Market price

Commitments from sellers, customers, and brokers

Location of the plant

- Include map(s)

- Description of adjacent industries, utilities, general population and the potential complimentary or supplementary relationship with the project

Commitment from utilities, energy suppliers, fire, and police

All written support which has been elicited from the community should be provided. This may take the form of: letters; endorsements; resolutions and ordinances from businesses and non-profit organizations; town, city, county, and State governments; e.g., Jaycees and other community-based organizations; planners; mayors; councils; governors; legislators; or congressmen.

\section{B. Technical and Engineering Design and Factors of Production}

The production cycle design will come from the selection of one particular process. I he following Items need to be taken into account to calculate economic and energy costs of production. Each should be described in the process with particular attention to the production capacity through quantitative descriptions in each step.

Feedstock(s)

- Primary/Alternate

\section{Collection (Harvest and Transportation)}

- Includes methods and distances

Storage of feedstock

Preparation (cleaning $\&$ grincling)

Preliminary conversion (cooking)

Saccharification 
Fermentation

Distillation

Dehydration

Separation of solids

Denaturing

Drying of solids

Sturage of stillage

Use of stillage

Water recycling

Heat source - Primary/Secondary

- Integrated energy generation on-site

- Heat recovery

Use of other coproducts ( $\mathrm{CO}_{2}$, etc.) and wastewater

Detailed energy use calculation on a Btu-per-gallon basis in the plant

- Inputs are all nonrenewable sources for cooking, distillation, \& grinding, augering, site transportation

- Outputs include alcohol plus the coproducts

Equipment (instruments/controls/boiler/engines/ pumps), lead time, availability, and costs

- Laboratory facility and equipment on-site for testing and analyzing parts of the process

- Preliminary process flow diagrams

\section{Economic Analysis and Financial Plan}

A pro forma, or projected, sources and uses of funds statement can be constructed to show how the project plans to acquire and employ funds. This is the basic summary document to show the flow of resources. A projected balance sheet and income statement is required for the financial plan.

An itemized estimate of all project costs including the basis for the estimates is needed for the development of the project:

Cost estimates for the project

- Engineering design

- Site preparation, construction, and installation

- I.ahor

- Production

-Feedstocks

-Utilities

-Chernicals

-Boncling, insurance, and taxes
- Maintenance

- Depreciation

- Other overhead

All private and public financing options that will be explored should be listed in as much detail as possible.

The complete financial plan includes the following time periods:

- Development and construction of plant (with a subtotal for each task in the work plan)

- First year of operation, month by month

- Five-year quarterly projection

- Debt service on a quarterly basis

- Previous three years' profit and losss statement and financial statement of existing businesses

Documentation should be complete for deeds, leases, contracts, agreements, options, appraisals, and insurance.

\section{Management and Staffing Plan}

The organization of the entire project should be detailed with job titles and descriptions. An organization chart provides clarity and brevity for project management structure. List everyone by name, if possible, from the Board of Dircctors througli lhe supervisury and technical personnel.

The education, technical training, empluynnent, and rclated business experience of each participant in the project should be detailed on one pagc in a resume format for each person. Salaries, fccs, and overhead cost for labor are included here.

Engineering and construction companies and subcontractors are included with scheduling and reporting re. quirements. Cost and project management responsibilities need to be clearly indicated.

Provisions for a permanent, trained labor force must be quite specific. This training should be accomplished before the beginning of the operation of the plant.

\section{E. Sample Information Elements}

Sample information elements are shown in Figure IX-2, $\mathrm{IX}-3$, and IX-4. The following information should be provided.

1) With respect to each partner or shareholder (e.g., over 5 percent of total shares outstanding): 
- Name

- Address

- Citizenship

- Principal occupation

- Percentage of ownership

- Personal financial statement

- Credit reliability/analysis

- Personal interest in any concern which shall have some relationship to project

2) With respect to any corporate organization:

- Parent companies, subsidiaries, affiliates

- Charter of organization

- Financial statement of organization

- SEC $10 \mathrm{~K}$ report for companies listed on stock exchange

- Tax status

\section{F. Regulatory Compliance Requirements}

Obtaining building permits and other necessary certifications, and meeting compliance requirements of the appropriate regulatory agencies having jurisdiction over the project, should indicate the following:

Environmental (Federal and State)

Fire and Safety

Building Codes

Zoning

Utilities

BATF (Federal and State)

Equal Employment Opportunity

National Historic Preservation Act

Occupational Safety and Health Administration

Other permits, ordinances, and regulations

Assuming productive use of the alcohol, stillage, and $\mathrm{CO}_{2}$ produced, there still may be a number of environIntiltal factors to bc considered. These might include:
- Odors released during the process

- Disposal of wet thin stillage and wastewater. How much backset (recycling of spent thin stillage into fresh fermentation) is built into the plant design? Is there any concentration of thin stillage into syrup? Is there any digestion of thin stillage? What is the projected discharge of wastewater in volume or quality? Does the plant site encompass additional buffer area that could be used for waste disposal lagooning or irrigation? Will a discharge permit be required for the plant?

- Air pollution in boiler operations. Compliance with local and Federal standards. Are fuel alternatives available? Cogeneration prospects. What is the quality of the stack gases from the boiler? Can they be used for stillage drying by direct contact or indirectly?

- Removal of crop residuals causing erosion. Does crop residual removal for fuel feedstock or alcohol feedstock exceed 50 percent of total crop biomass? Will the production of alcohol result in farm and soil management shifts which are very different from current practices?

- Ethanol use of fuel for vehicles and resulting emissions. Seasonal dir how patterns and local air quality history.

In conjunction with the considerations developed under the sections which contain marketing and economic analyses, and the analysis of the production process, alternatives to the final decision and their consequences should be considered. In addition, the environment to be affected should be described (e.g., quality of soil, air, water) prior to undertaking this project.

Completing sample forms similar to those which follow will provide the basic information elements necessary for the preparation of the feasibility analysis. 


\section{SALES FORECASTS - GOALS}

\section{$\begin{array}{lllll}\underline{81} & \underline{82} & \underline{83} & \underline{84} & \underline{85}\end{array}$}

A. EIHANOL

JOBBER:

JOBBER:

JOBBER:

OTHER:

TOTAL

\section{SALES FORECAST - TONS}

\section{$\underline{81} \quad \underline{82} \quad \underline{83} \quad \underline{84} \quad \underline{85}$}

B. COPRODUCTS

BUYER:

DUYCR:

BUYER:

TOTAL

COPRODUCT CONTENT: PROTEIN

$\%$

ГAT

$\%$

FIBER

$\%$

$\mathrm{ASH}$

$\%$

MOISTURE $\%$

Figure IX-2. Sales Forecasts 
a. plant capacity:

- PRODUCTION ETHANOL:

GAL/HOUR

- PRODUCTION COPRODUCT.

- ethanol pRice, f.o.B. Plant:

- COPRODUCT PRICE, F.O.B. PLANT:

- PLOT SIZE:

- plant size:

$x$

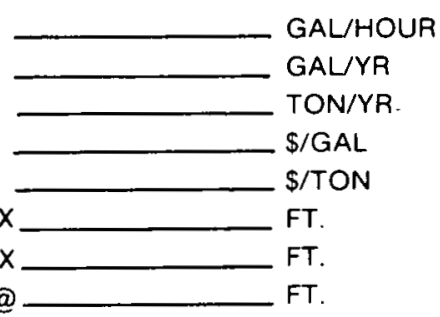

- SOIL STRENGTH:

PSF@ FT.

- PLASTICITY INDEX: -

- RAILROAD SIDING:

RESISTIVITY LEVEL

- ACCESS ROAD QUALITY:

B. - FEEDSTOCK TYPE:

FEEDSTOCK CONTENT: STARCH

PROTEIN

OTHER SOLIDS

MOISTURE

FEET

JOBBER:

NUMBER DAYS INVENTORY

- FEEDSTOCK TYPE:

FEEDSTOCK CONTENT: STARCH

PROTEIN

OTHER SOLIDS

MOISTURE

$\%$ WEIGHT

$\%$ WEIGHT

$\%$ WEIGHT

$\%$ WEIGHT

BUSHELS/YR

JOBBER:

NUMBER DAYS INVENTORY

- ENZYME TYPE:

AMOUNT REQUIRED:

JOBBER:

NUMBER DAYS INVENTORY

- ENZYME TYPE:

AMOUNT REQUIRED:

$\%$ WEIGHT

$\%$ WEIGHT

$\%$ WEIGHT

$\%$ WEIGHT

BUSHELS/YR

JOBBER:

NUMBER DAYS INVENTORY:

C. - POWER SOURCE:

AMOUNT REQUIRED:

JOBBER:

NUMBER DAYS INVENTORY

- POWER SOURCE:

AMOUNT REQUIRED

ELECTRIC

JOBBER:

D. WATER SOURCE:

AMOUNT REQUIRED:

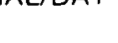

E. - LABOR

NUMBER PLANT OPERATION AND MAINTENANCE NUMBER ADMINISTRATION AND SUPERVISION NUMBER GENERAL ADMINISTRATION AND SALES

Figure IX.3. Plant Characteristics 
A. COST OF PRODUCTION

a. CAPITAL COSTS

- EQUIPMENT

- I ANR

- INVENTORY

- TAXES

- insuRance

- depreciation

- INTEREST

b. OPERATING COSTS

- FEED MATERIAL

- supplies

- FUEL

- waste disposal

- OPERATING LABOR

c. MAINTENANCE COSTS

- LABOR

- sUPFlies

- EUUIPNVEINI

UNSCHEDULED MAINTENANCE

- LABOR

- SUPPLIES

- EOUIPMENT

B. INVESTMENT ANALYSIS

- REVENUES ETHANOL

STILLAGE

- LESS COST OF SALES

FEEDSTOCK

DEPRECIATION

- gROsS PROFII

- llo3 gaA and O H.

- NET PROFIT BEFORE TAXES

- BREAK EVEN QUANTITY

- haYBACK PERIOD

- RETURIN UN INVESI MEN'T
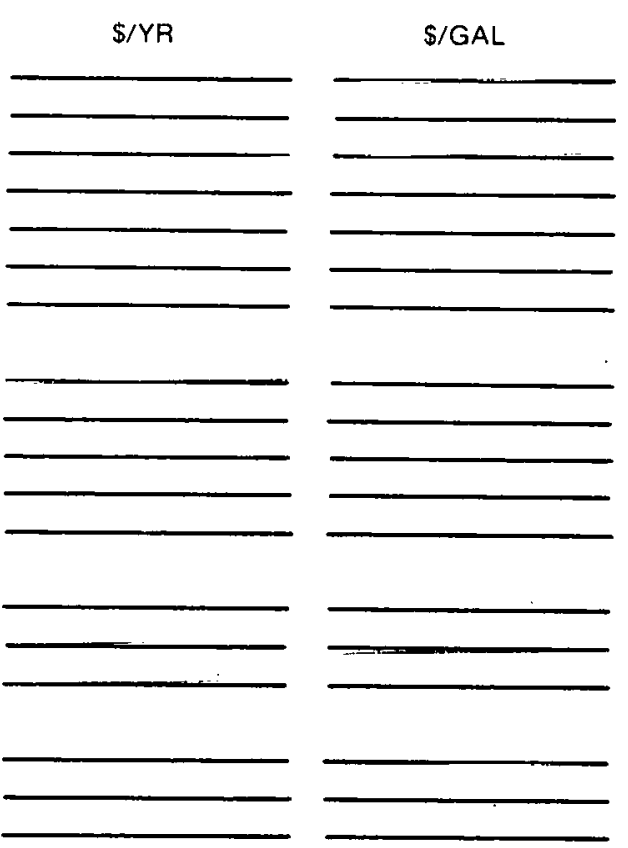

ISK ANALYSIS

PROCESS GUARANTEE:

PERFORMANCE GUARANTEF:

$\$$

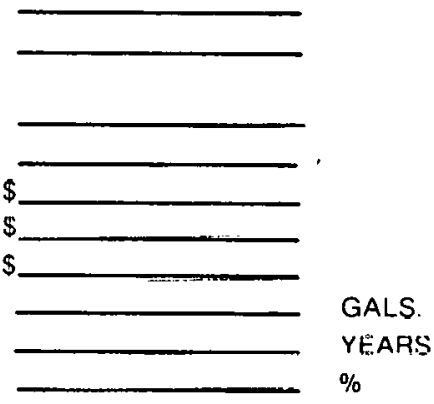

PROOF

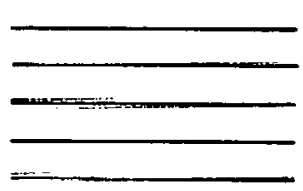

FUSEL OIL CONTENT FRONIITIONN RATE OUANIIIY ENERGY QUANTIT'Y' PER INIPUI

Figure IX-4. Economic Analysis 


\section{Financial Assistance Programs}




\section{INTRODUCTION}

The Federal government affects the distribution of national resources by direct loan and loan guarantee programs aimed, directly or indirectly, at private industry. Tax credits, tax exemptions, and price support programs are other forms, but are not discussed here. The purpose of loan programs is to channel funds to those sectors of the economy which could not otherwise obtain credit or could obtain it only at very high costs. Sometimes the channel is indirect, going through state or local governments or other non-profit organizations. The specific goal, in this case, is to enable private ventures to make more alcohol production capability available than if left to normal business dealings.

In addition to the DOE, the Federal agencies with such authority are the Small Business Administration (SBA); the Farmers Home Administration (FmHA) of USDA; Urban Development Action Grants, the Department of Housing and Urban Development (HUD); and Economic Development Administration (EDA), the Department of Commerce. The existing legislation in all cases has already been interpreted to apply to alcohol fuel production. Several legislative efforts are underway that will more specifically address alcohol fuels, and will probably modify some of the characteristics identified in the following discussions.

\section{SUMMARY}

This section addresses: (1) characteristics of loan and loan guarantee instruments available to prospective investors; and (2) the process that applicants must follow to obtain the desired assistance. Since there are several instruments available and the applicant. can and dnes need guidance as to which best fits his or her needs, Figure A-1 presents a simplified view of the content of thcsc programs.

The figure covers the two types of assistance considered here, i.e., loan guarantees and direct loans. With the exception of DOE (75 percent loan guarantee), the guarantee and direct loan is usually set at 90 percent of the project cost but can be lower or as high as 100 percent (not shown here). The direct loan amount may be as low as 65 percent of cost. The ceiling on funds available per project varies from under $\$ 200,000$ to over $\$ 25$ million. The maturity of the assistance vehicle is defined to be the maximum time available to pay back principal, interest, and other costs. The maturity period varies from 4 to 40 years.

The Farmers Home Administration Business and Industrial Loan Guarantee Program (FmHA-B\&I) provides a guarantee up to 90 percent of the loan, with the applicant responsible for furnishing a minimum of 10 percent of equity (Figure A-1, Item 11). FmHA has imposed an administrative ceiling of $\$ 20$ million for certain ventures in the past; during 1978, the range was from $\$ 11,000$ to $\$ 33$ million, and the average was $\$ 824,000$. Although premature, a ceiling of $\$ 25$ million is shown on this chart for alcohol fuel plants. Maximum maturity terms are 30 years for land, buildings, and permanent fixtures; 15 years for machinery or equipment; and 7 years for working capital.

The Small Business Administration Local Development Companies Program (SBA-LDC) is identified as Item 10 in Figure A-1. The bank loan is guaranteed by SBA to 90 percent of the loan or $\$ 500,000$, whichever is the lesser. Although maximum maturity is 25 years plus the estimated time required to complete construction, conversion, or expansion of the facility, the usual period is 15 to 20 years.

Items 2 and 9 identified under "Source" are the Small Business Administration Business Loans Program (SBA-BL). SBA is obligated to purchase not more than 90 percent of the outstanding balance of the authorized loan in the event of borrower default. The ceiling for guaranteed loans normally is $\$ 350,000$ but may be up to $\$ 500,000$ for exceptional circumstances. For direct and guaranteed loans, the maximum maturity date is normally 10 years, with working capital loans limited to 6 years, and portions of loans for construction and acquisition of real estate may have a maximum of 20 years.

Items 3 and 5 identified under "Source" are the Farmers Home Administration Farm Loan Program (FmHA-FL). The limit on a direct farm operating loan is $\$ 300,000$ and the maximum term is 7 years. The limit on a direct farm ownership loan is $\$ 200,000$ and the maximum term is 40 years.

The program identificd as Item 8 under "Source" is the EDA Program. EDA will guarantee up to 90 percent of the unpaid balance of loans for the acquisition of fixed assets or for working capital. The expected EDA participation for a small-scale fuel plant should generally not exceed $\$ 5$ million and the maximum period for fixed asset loans is 30 years.

Item 7 of Figure A-1 is the DOE loan guarantee program represented by Public Law 96-126. The amount of a loan guarantee shall not exceed 75 percent of the estimated costs, the maximum is to be sufficient to carry out the project, and full repayment is to be made within 20 years. The program identified as Item 6 under "Snurce" is the Department of Housing and Urban Development Action Grant Program (HUD-UDAG). Ideally, HUD is seeking projects that generate substantially more private commitments than the Action Grant money requested. However, HUD will take into account the various types of projects in considering the degree of 


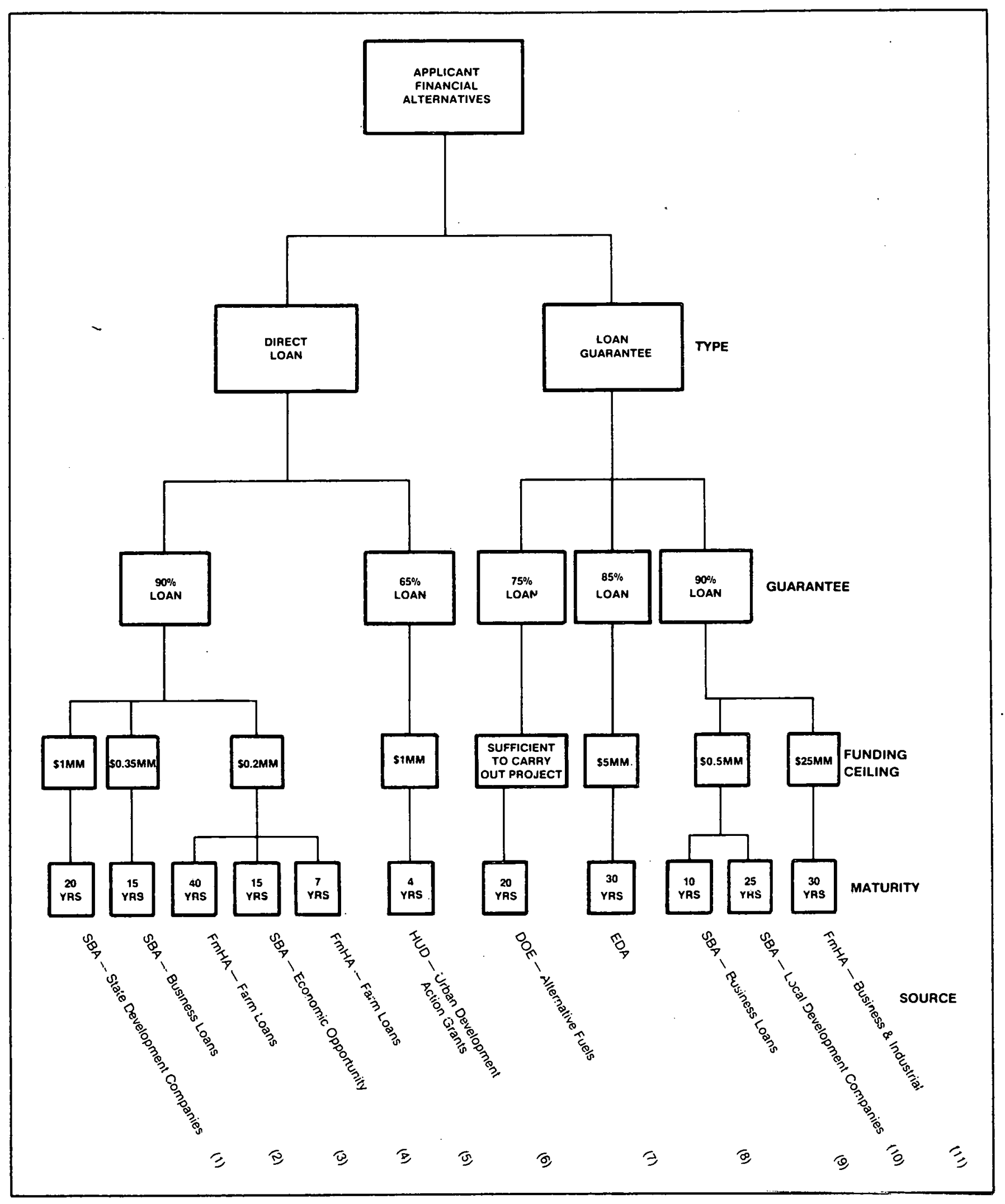

Figure A-1. Financial Assistance Program Tree 
private leverage. This program is shown on the figure at the 65-percent guarantee point of the direct loan portion, for illustrative purposes. The FY 1978 average for small cities was almost $\$ 1$ million, but $\$ 6$ million was contributed in Utah. Assistance is provided for discrete projects that can be completed in approximately four years. The Small Business Administration Economic Opportunity Program (SBA-E()), Item 4, is a direct loan program, 90 percent guarantee, $\$ 200,000$ to any one borrower for a maximum of 15 years fixed assets, and 10 years maximum for working capital.

Finally, the Small Business Administration State Development Companies Program (SBA-SDC), Item 1, covers direct loans, $\$ 500,000$ to $\$ 1$ million, 'for a maximum of 20 years.

\section{SOURCES OF FINANCIAL SUPPORT}

\section{Smail Business Administration}

The objective of the SBA is to aid, counsel, assist, and protect the interests of small business concerns and to help victims of disasters. The basic goal is to provide procurement and technology, management, and financial assistance to those needy firms classified as small businesses.

SBA, in support of alcohol fuels, makes available direct energy loans and energy loan guarantees to begin, continue, or expand small businesses that are developing, manufacturing, selling, installing, or servicing specific. energy conservation measures.

\section{Program Area(s)}

SBA provides a relatively broad range of support to small business firms involved in producing alcohol fuels, including support to local development companies, direct and guaranteed loans to private business, supporting state development companies, purchasing, and/or guaranteeing Small Business Investment Company debentures, and financing economic opportunities to the disadvantaged.

Local Development Companies. SBA is authorized to make loans to local development companies to finance plant acquisition, construction, conversion, or expansion, including the acquisition of land, provided that such loans will assist an identifiable small business concern in accomplishing a sound business purpose. A local development company is a corporation chartered under any applicable State corporation law to operate in a specified area within a State. These loans are otherwise known as Section 502 loans.
Business Loans. SBA is authorized to make both direct loans and participation loans in cooperation with banks and other lending institutions. The loans are commonly referred to as stemming from Section 7(a) and/or $7(1)$ of the Act. The Act provides that all energy loans shall be of such sound value as reasonably to assure repayment, recognizing that greater risk may be associated with energy loans under Section 7(1) than for loans under Section 7(a).

State Development Companies. SBA is authorized to make loans to state development companies organized under or pursuant to a special legislative act to operate on a State-wide basis. The companies must be formed for the purpose of furthering the economic development of their communities and environs, and with authority to promote and assist the growth and development of small business concerns in the areas covered by their operations. The proceeds of loans made to state development companics shall bi: used unly tn provide equity capital or make loing-leuln loans, or both, to small business concerns. These loans are othcrwise known as Section 501 loans.

Small Business Investment Companies. Congress established the Small Business Investment Company (SBIC) program in 1958. SBIC's are privately owned, SBA-licensed and SBA-regulated companies whose primary purpose is to provide equity capital and long-term financing to small firms for the sound financing of their business operations and for their growth, expansion, and modernization. The SBA may purchase debentures of a licensee to augment investment funds available to $\mathrm{him}$, and may also guarantee debentures of the licensee issued to others.

Ecunomic Opportunity Loans. The principal purpose of the Economic Opportunity Loan Program is to make funds available on reasonable terms and maturities to small business concerns located in areas with high proportions of unemployment, low income individuals, or small business concerns owned or to be established by persons with low incomes; and to provide management assistance to such persons. Particular emphasis is placed on preservation or establishment of small business concerns located in urban and rural areas.

\section{Organlzational Struclure}

The central and principal office of the SBA is at $1441 \mathrm{~L}$ Street, N.W., Washington, DC 20416. Field offices include 10 regional offices and 99 district and branch uffices and "posts-of-duty."

Headquarters Office. The Administrator is responsible to the President and Congress for exercising direction, authority, and control over the SBA. Assisting the Administrator are the heads of five offices and one 
council, two Associate Deputy Administrators, five Associate Administrators, and four Assistant Administrators.

The five offices are: Office of Equal Employment Opportunity and Compliance; Office of Hearings and Appeals; General Counsel; the Inspector General; and the Chief Counsel for Advocacy. Staff support is provided to the National Advisory Councils.

Regional Offices. Regional offices, headed by a Regional Administrator, are the principal field offices of the agency and are responsible and responsive to the central office. District offices are headed by a District Director and are located in a city within a defined, limited, and contiguous geographical area within a region. Branch offices are headed by a Branch Manager and are located in a city within a defined, limited, and contiguous geographical, area within a district. Post-ofduty stations are headed by an Officer-in-Charge and are also located in a city within a defined, limited, and contiguous geographical area within a district. Locations of SBA field offices are listed in the References section of this document.

\section{Farmers Home Administration, Department of Agriculture}

The objective of the FmHA is to provide credit for those in rural America who are unable to get crcdit from other sources at reasonable rates and terms. The basic goal is to create and maintain a healthy economic climate in rural communities.

FmHA makes loans under the farm loan program and guarantees those made by private lenders under the business and industrial loan guarantee program for plants for the production of fuel alcohol. Farm loans generally are intended to finance production for onfarm use; commercial production may be financed through the business and industrial loan guarantees.

\section{Program Area(s)}

FmHA makes loans with funds borrowed from the U.S. Treasury and those derived from sales to the Federal Financing Bank of Certificates of Beneficial Ownership, which represent actual loans made by the agensy.

Busincss and Industry Loans. I nans made by private lenders but guaranteed by $\mathrm{FmHA}$ may be provided to any legal entity, including individuals, public and private organizations, and Federally recognized Indian tribal groups. Priority is given to projects in the country and in communities of 25,000 population and smaller. Loans may be made in cities and towns of less than 50,000 population and in immediately adjacent urbanized areas with a population density of fewer than
100 persons per square mile. Non-farm distilleries can qualify under this program.

Farm Loans. Direct loans at cost of borrowing and loan guarantees for farm ownership and farm operations are authorized to farmers and farm cooperatives to improve farm technology, administration, and productivity of farms. The development of alternative energy sources such as biomass conversion and gasohol production has been determined by the USDA to be projects within this program's jurisdiction. Acceptable uses of farm ownership loans include construction, improvement, or repair of farm homes and service buildings; installation of pollution control or energy conservation measures; and establishing nonagricultural enterprises that help farmers supplement their farm income. Operating loans can be uscd for pollution abatement and operation of non-agricultural income-earning enterprises.

\section{Organizational Structure}

The FmHA is one of two such groups (the other is the Rural Electrification Administration) reporting to the Assistant Secretary for Rural Development, USDA. The Headquarters Office of FmHA is located at Fourteenth Street and Independence Avenue, S.W., Washington, DC 20250 . Field support is provided by 46 state offices and numerous county offices.

Headquarters Office.The Administrător directs and supervises the activities of the Deputy Administrator for Financial and Administrative Operations, the Deputy Administrator for Farm and Family, the Deputy Administrator for Rural Development, and the Associate Administrator for Policy Management. The Business and Industry Loan Program reports to the Deputy Administrator for Rural Development, and the Farm Loan Program reports to the Deputy Administrator for Farm and Family.

Regional Offices. Applications for loans are made at the agency's 2,200 local county and district offices, generally located in county-seat towns.

Locations of the FmHA state offices are listed in the References section of this document.

\section{Department of Housing and Urban Development}

The objective of the Department of HUD is to administer the principal programs that provide assistance for housing and development of the nation's communities. The basic goal is to administer mortgage insurance programs; a rental subsidy program; antidiscrimination policies; and other programs that aid neighborhood rehabilitation and the preservalion of urban centers from blight and decay. 
HUD provides grants to cities and urban counties for energy conservation and alternative energy projects. These projects are of particular interest, not only because they are in the national interest with respect to conservation of scarce fuels, but because they can be of importance to distressed urban areas in stabilizing energy costs, making such areas more attractive to commercial and industrial facilities, and helping to alleviate the hardship of escalating energy costs upon low- and moderate-income groups.

\section{Program Area(s)}

The Urban Development Action Grant (UDAG) Program is a highly flexible economic development tool which seeks to create partnerships among government, community, and private industry to overcome problems of development. Action grant funds are available to carry out projects in support of a wide variety of economic revitalization of neighborhood reclamation actlvitles that involve partnerships with the private sector. These activities may include a broad range of development actions like land clearance; site improvements; providing infrastructure; rehabilitation; and building public, commercial, industrial, and residential structures.

The program can be applied to the following situations:

- To provide "front-end" funding that allows communities to capture and leverage significant private investments

- Tó rèspond to unique, perhaps one-time opportunities while they are apprnpriate.

- To make substantial resnurres available when necded to join other Federal departments in meeting distressed cities' reinvestment needs

\section{Organizatlonal Structure}

The department is administered under the supervision and direction of the Secretary, who is responsible for the administration of all programs, functions, and authorities of the department; regulation of the Federal National Mortgage Association; administration of the Government National Mortgage Association; and advising the President on Federal policy, programs, and activities relating to housing and community development. Headquarters is located at 451 Seventh Street, S.W., Washington, DC 20410. Field installations include 10 regional, 39 area, and 38 insuring offices.

Headquarters Office. The Assistant Secretary for Community Planning and Development directs and supervises the UDAG program, among others, along with his Directors of Community Planning and Pro- gram Coordination, Management, Evaluation, Legislative and Urban Policy, Policy Planning, Block Grant Assistance, and Field Operations and Monitoring.

Regional Offices. The field operations are carried out through a series of regional, area, and services offices. The regional offices have boundaries and headquarters locations prescribed by the secretary. Each regional office is headed by a regional administrator, who is responsible to the Secretary and Under Secretary for the overall satisfaction of the department's goals and objectives and for the management of the offices within the region.

Locations of the field offices are listed in the References section of this document.

\section{Economic Development Administration, Depart- ment of Commerce}

The objective of the EDA is to provide assistance to economically distressed areas and regions in order to alleviate conditions of substantial and persistent unemployment and underemployment and to establish stable and diversified economies. The basic goal is the crcation of permanent jobs in areas of high unemployment, job loss, or low incomes.

EDA is authorized to provide grants, direct loans and loan guarantees, technical assistance, and other Title II development finance authorities. Specifically, these will be public works grants to rural communities and nonpiofit ecunumic development organizations, and loan guafantees to private enterprises desiring to establish new alcohol fuel production facilities. Financial assistance is limited by the capacity of the Prnject to create long-term employment opnortunities.

\section{Program Area(s)}

EDA is authorized to provide grants, direct loans and loan guarantees, technical assistance, and other special ecunomic development and adjustment assistance.

Public Works and Development Facility Grants. Direct grants are authorized for: (a) public works, public service, and development facility projects which directly or indirectly contribute to lonig-1 ante economic growth or benefit long-term unemployed and members of low-income facilities in redevelopment areas, and parts of economic development districts; and (b) public works, public service, and development facility projects which provide immediate useful work to the unemployed and underemployed of the project area.

Supplementary grants to augment the direct grants received under the Act or to augment the basic grants under other Federal grant-in-aid programs may be provided to public works, public service growth, or benefit 
long-term unemployed and members of low-income facilities in redevelopment areas and parts of economic development districts.

Loans and Guarantees. Loan guarantees are authorized for loans made to private enterprises by private lending institutions only in designated redevelopment areas and parts of economic development districts.

Technical Assistance. Technical assistance in the form of direct assistance by EDA personnel, payment to other Federal agencies, contracts, and grants may be extended to redevelopment areas and and other areas that have substantial need. Planning and administrative grants are also available to eligible applicants. EDA conducts a continuing program of study, training, and research in the problems of economic development through members of its staff, payments to other Federal agencies, contracts, and grants. EDA also provides technical assistance for national projects to national or public associations or public bodics. Finally, EDA aids redevelopment and other areas by furnishing interested individuals, communities, industries, and enterprises within such areas any assistance, technical information, market research, or other forms of assistance, information, or advice which could be useful in alleviating or preventing conditions of excessive unemployment or underemployment within such areas.

Special Economic Development and Adjustment Assistance. Grants may be made to States, political subdivisions of States, redevelopment areas, economic development districts, and Indian tribes to meet special needs related to existing or threatened long-term unemployment or low family income levels and arising from economic dislocation. Such grants may be used for public facilities, public services, business development, planning, unemployment compensation, rent supplements, mortgage payment assistance, research, technical assistance, training, relocation of individuals, and other appropriate assistance.

\section{Organizational Structure}

The central and principal office of the EDA is in the Department of Commerce, 14th Street at Constitution Avenue, N.W., Washington, DC 20230. Six regional offices cooperate with and assist local areas in organizing and carrying out economic development.

Headquarters Office. The Assistant Secretary for Economic Development directs the programs and is responsiblc for the conduct of all activities of the EDA subject to the policies and directions prescribed by the Secretary of Commerce. The Deputy Assistant Secretary for Economic Development directs and supervises the Investigations and Inspections Staff, the Special Assistant for Environmental Affairs, the Special Assist- ant for Field Operations, and the Special Assistant for Indian Affairs. The Deputy Assistant for Economic Development Operations directs and supervises the Office of Business Development, Office of Public Works, and Office of Technical Assistance. The Deputy Assistant Secretary for Economic Development Planning directs and supervises the Office of Development Organizations, Office of Economic Research, and Office of Planning and Program Support.

Regional Offices. The Regional Director, who reports to and is under the supervision and direction of the Assistant Secretary, directs the program and is responsible for the conduct of all activities of the Regional Office. Each office includes a Civil Rights Division, Special Programs Division, Regional Counsel, Business Development Division, Public Works Division, Technical Assistance Division, Technical Support Division, Planning Division, and Economic Development Representatives.

Locations of the field offices are listed in the References section of this document.

\section{Department of Energy}

The objective of the Office of Alcohol Fuels is to encourage the development and utilization of alcohol fuels. The Office is responsible for providing research, engineering testing, evaluation, and demonstration skills needed to develop programs to support the objertives of the President's Alcohol Fuels Program. The President has set a domestic production capacity target of 500 million gallons of alcohol fuel during 1981 .

The Office provides financial incentives, marketing analysis, technical support, educational programs, and procurement guidance for projects involving alcohol fuels. It also serves as a point-of-contact on alcohol fuels for the DOE, acting as a liaison between the Department and other Federal, regional, state, and local agencies, and consumers.

\section{Program Area(s)}

$\$ 2.208$ billion is available to the Secretary of Entergy lo stimulate domestic commercial production of alternative fuels. ${ }^{*}$ This appropration is divided into the following areas:

\footnotetext{
*This appropriation was established through Public Law 96-126, the Department of Interior and Related Agencies Appropriations Act for FY' 1980, which created an energy security reserve for alternative fuels production of $\$ 19$ billion. Biomass is an acceptable domestic resource and ethanol is an acceptable derivative.
} 
- $\$ 100$ million for project development feasibility studies, not to exceed $\$ 4$ million each, was set aside for applications from eligible applicants during the spring of 1980 . Individuals, businesses, institutions, and communities were considered eligible.

- $\$ 100$ million for cooperative agreements, not to exceed $\$ 25$ million each, to support commercialscale development was available to applicants during the spring of 1980 . Eligibility was open to any individual, business, institution, or community. Federal agencies were excluded from this program.

- $\$ 1.5$ billion for purchase commitments or price guarantees. DOE is currently drafting solicitations for this incentive.

- $\$ 500$ million for a reserve to cover any defaults from loan guarantees issued to finance construction of alternative fuels production facilities, provided that the indebtedness guaranteed or committed to be guaranteed does not exceed $\$ 1.5$ billion. DOE is currently drafting solicitations for this incentive.

- $\$ 8$ million for program management.

\section{Organizational Siructure}

The Office of Alcohol Fuels reports to the Secretary of Energy and is currently headed by an Acting Director. Headquarters are in the Forrestal Building, 1000 Independence Ave., S.W., Washington, DC 20585. Field installations for DOE include 10 regional offices.

Headquarters Office. The Director, Office of Alcohol Fuels, directs and supervises the Financial Incentives Dlvision; the Technology Development and Utilization Division; the Information, Liaison, and Public Response Division; and the Program Control and Fivaluation Divisiún.

Regional Offices. Locations of the field offices are listed in the References section of this dnsument.

\section{LOAN APPLICATION PROCESSES}

\section{Small Business Administration Loan Application Process (See Figure A-2)}

1. A small business concern is independently owned and operated and is not dominant in the field of operation in which it is bidding on government contracts. $\Lambda s$ an cxample, in the petroleum industry, a concern is considered small if its employees do not exceed 1,000 persons and its crude oil capacity does not exceed 30,000 barrels per day.

2. Applications for financial assistance may be considered only when there is evidence that the desired credit is not otherwise available on reasonable terms. Proof of refusal must contain the date, amount and terms requested, and the reasons for not granting the desired credit. (S.120.2)

3. If unable to obtain the entire Inan from a bank or other source, the applicant should ascertain whethcr a financial institution will make the loan if SBA agrees to purchase an immediate participation or if 3BA agrees to guarantee a portion of the bank loan. (S.22.15(b)).

4. The applicant should apply to the SBA office serving the territory in which the applicant's business is located. If he desires to obtain counseling or assistance in filing an application from a regional office which is geographically closer to his business, he may do so. (S.122.15(d))

5. The applicant should file SBA Form 4, Schedule A, Summary of Collateral; and back this up with the following: SBA 641, Request for Counseling; GPO 942, History or Description of Business and Personal Data Management Experience; SBA 035-100, Format for a Business to be Purchased/ A New Business to be Established/or An Existing Business to be Expanded or Improved; SBA-413 Personal Finance Statement; SBA 912 Statement of Personal History; SBA 1100 Monthly Cash Flow Projection; SBA 1099 Operating Plan Forecast. (SBA-0353-101, Literature, Brochures, and Forms).

6. Regional Directors are responsible for the proper evaluation of collateral offered. A technical evaluation by SBA appraisers/engineers is also required. (3.122.16(d) and (e)).

7. When SBA approves a loan application, a formal loan authorization is issued by SBA. This authorization is neither a contract to Icnd nor a luan agreement. Instead, it states the conditions which the borrower must meet before financial assistance will be extended. When the borrower is prepared to meet these conditions, SBA or the financial institution will arrange a date, time, and place for closing the loan. (S.122.19). 


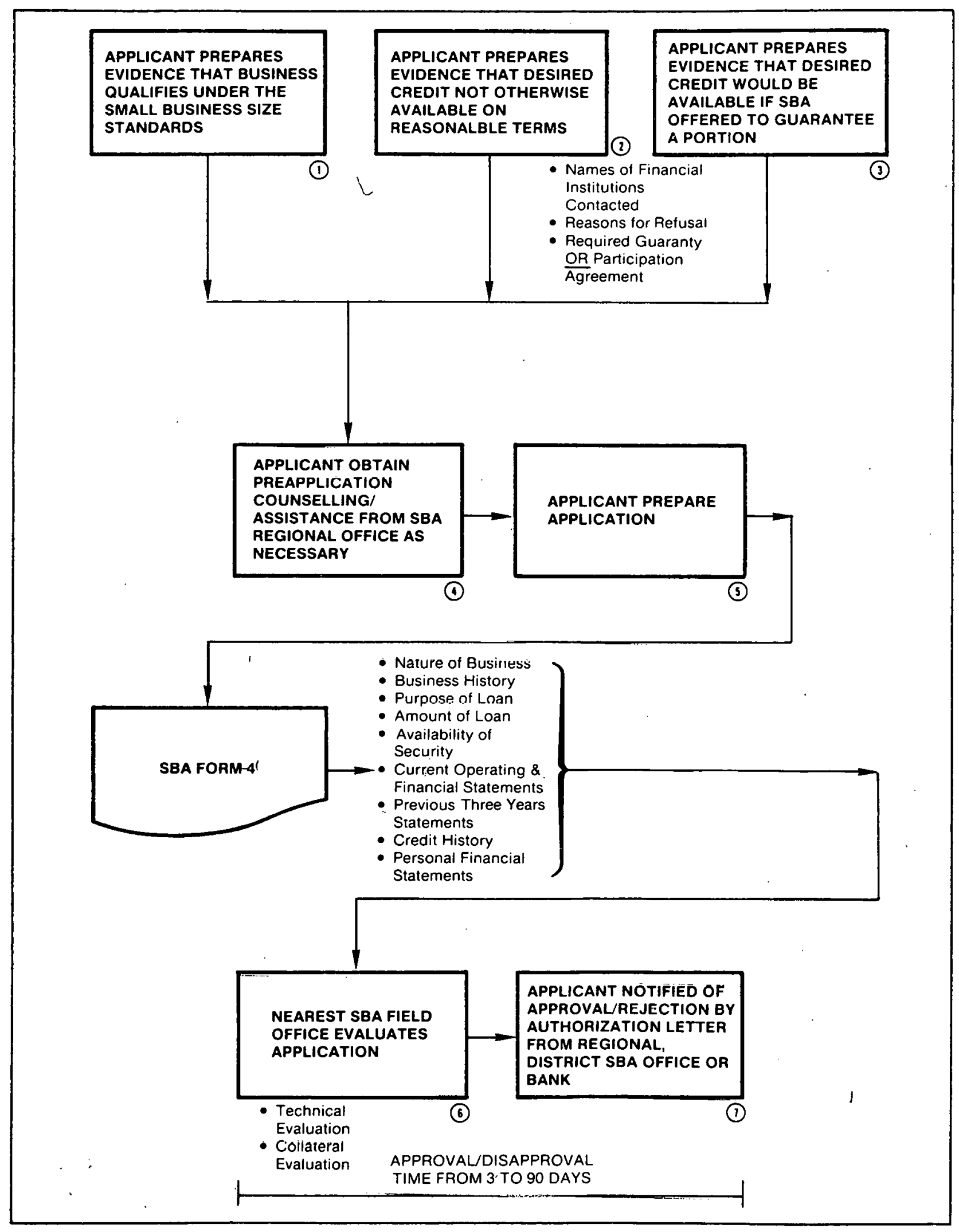

'Figure A-2. SBA Loan Application Procedure 
Farmers Home Administration Loan Application

Process (See Figure A.3)

1. Applicant files 449-1 with the nearest A-95 clearinghouse as notice of intent to file an application. Check : with the appropriate Federal Rcgional Council to obtain name and address of appropriate clearinghousc.

2. Applicant may file a preapplication with the County Office including a description of the project, market information, financial data, A-95 comments, and a personal history. (1980.451(f))

3. Alcohol production must meet certain BATF requirements of the U.S. Treasury Department. It is the applicant's responsibility to satisfy those requirements. (FmHA Alcohol Fuels Fact Sheet.)

4. A-95 clearinghouse reviews completed application and notifies applicant of acceptability of project.

5. BATF reviews application and certifies acceptability of information as provided by the applicant.

6. An eligible lender is any Federal- or Statechartered bank, Federal land bank, production credit association, bank for cooperatives, savings and loan association, building and loan association, or SBIC. Others must file 449-18, "Lenders or Holders Request for Approval", and proof of finlancial capjablitity, charter or lıcense, credit history, etc. (1980.13(b)).

7. FinHA will submit 449-22 to the U.S. Department of Labor for the necessary certification that the proposal will not be in conflict with specified employment/unemployment regulations. (1980.451(h)).

8. If it appears that the project is eligible, has sufficient priority, is economically feasible, and loan guarantee authority is available, FmHA will inform the lender and applicant in writing and request that they complete the application. (1980.45l(g)).

9. Application will include: (1) 449-1, "Application for Loans and Guarantees"; (2) 449-2, "Statement of Collateral"; (3) 449-10, "Applicant's Environmental Impact Evaluation"; (4) A\&E plans; (5) cost estimates and contingency funding requirements; (6) appraisal reports; (7) financial reports for existing businesses; (8) financial forecasts for new business; (9) credit reports; (10)
400-1, for construction costs greater than $\$ 10,000$; (11) building permits; (12) personal and corporate statements from guarantors; (13) proposed loan agreement; (14) completed feasibility study, when required; and, (15) other such data. (1980.451(i)).

10. The County Supervisor and District Director determine if material and information submitted are complete. They then prepare comments and recommendations and submit them to the State Director. The County Supervisor furnished 410-9 and 410-10 forms dealing with Privacy Act statements to all individuals involved.

11. The State Director: (1) provides assistance to the County Supervisor; (2) prepares additional explanatory forms; (3) forwards all forms to the National Office; (4) checks the applicant's credit; and (5) submits transmittal letter with recommendations. (1980.4.51(b)).

12. FmHA will make a determination whether the borrower is eligible, the proposed loan is for an eligible purpose, and there is reasonable assurance of repayment ability, sufficient collateral, and sufficient equity. If FmHA is able to guarantee the loan, it will provide the lender and the applicant with 449-14, listing all requirements for such guarantees. (1980.452).

13. As conditions for FmHA making or guaranteeing a loan, the applicant must provide written statements dealing with the National Register of Historic Places (1980.44) and other Federal, Statc, and local requirements. (1980.45).

14. When FmHA finds that all rcquircments have been met, the lender and FmHA will execute 449-35, "Lender's Agreement." Upon receipt of a signed 449-35, and after all requirements have been met, FmHA will execute 449-34, "Loan Note Guarantee." In the event the lender assigns the guaranteed portion of the loan to a holder(s), the lender, holder, and FniHA will execute 449-36, "Assignment Guarantee Agreement." (1980.61(a) (b) (c)).

\section{Department of Housing and Urban Development Grant Application Process (See Figure A.4)}

1. Only applicants whose eligibility has been determined in accordance with requircments sct forth in 24 CFR Part 570.452 of the Regulations may apply for Action Grants. Potential applicants must request a determination of cligibility from the HUD Area Office, using Standard Form 424, as modified. (UDAG Application Contents, p.1). 

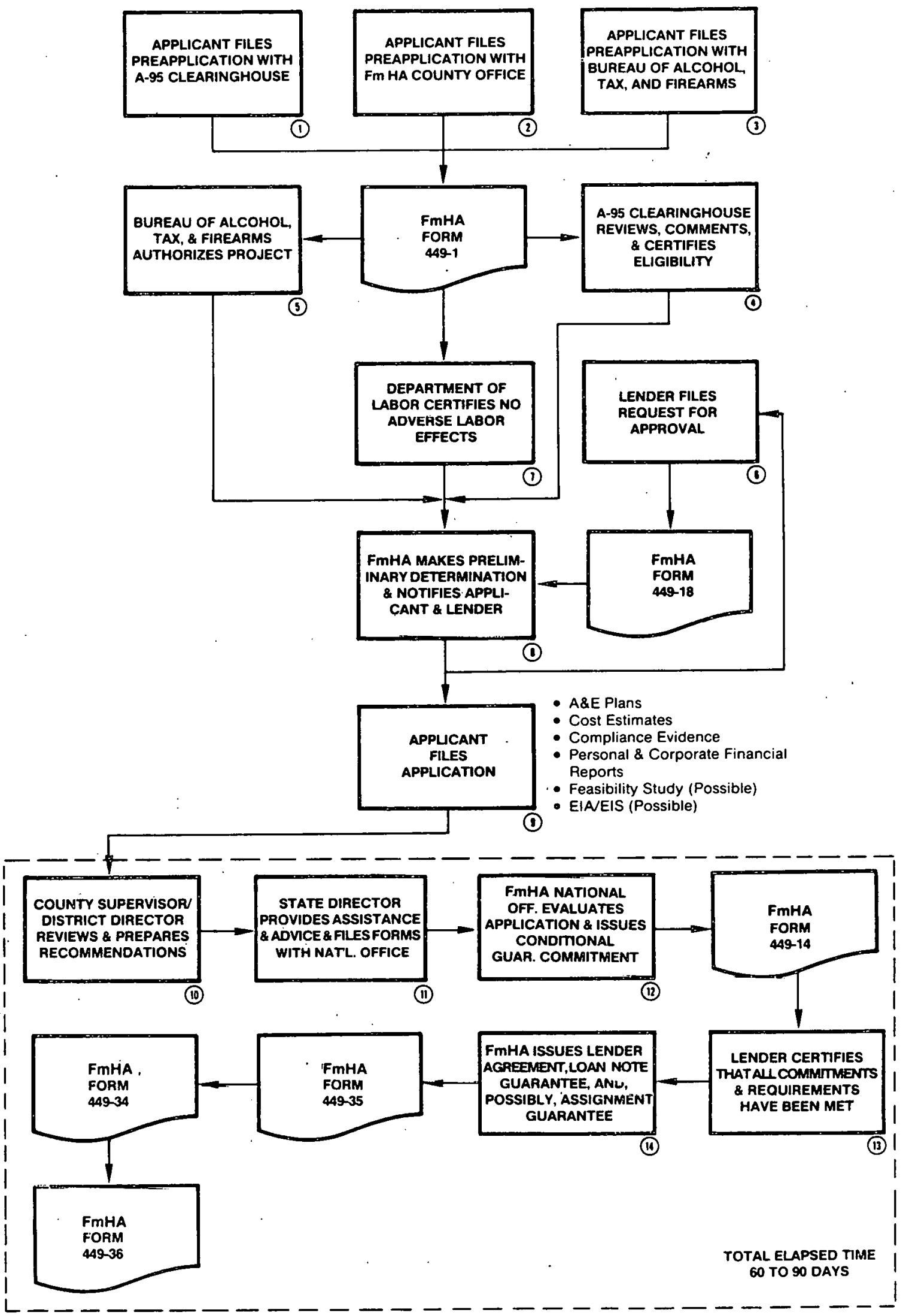

Figure A.3. FmHA Loan Application Procedure 


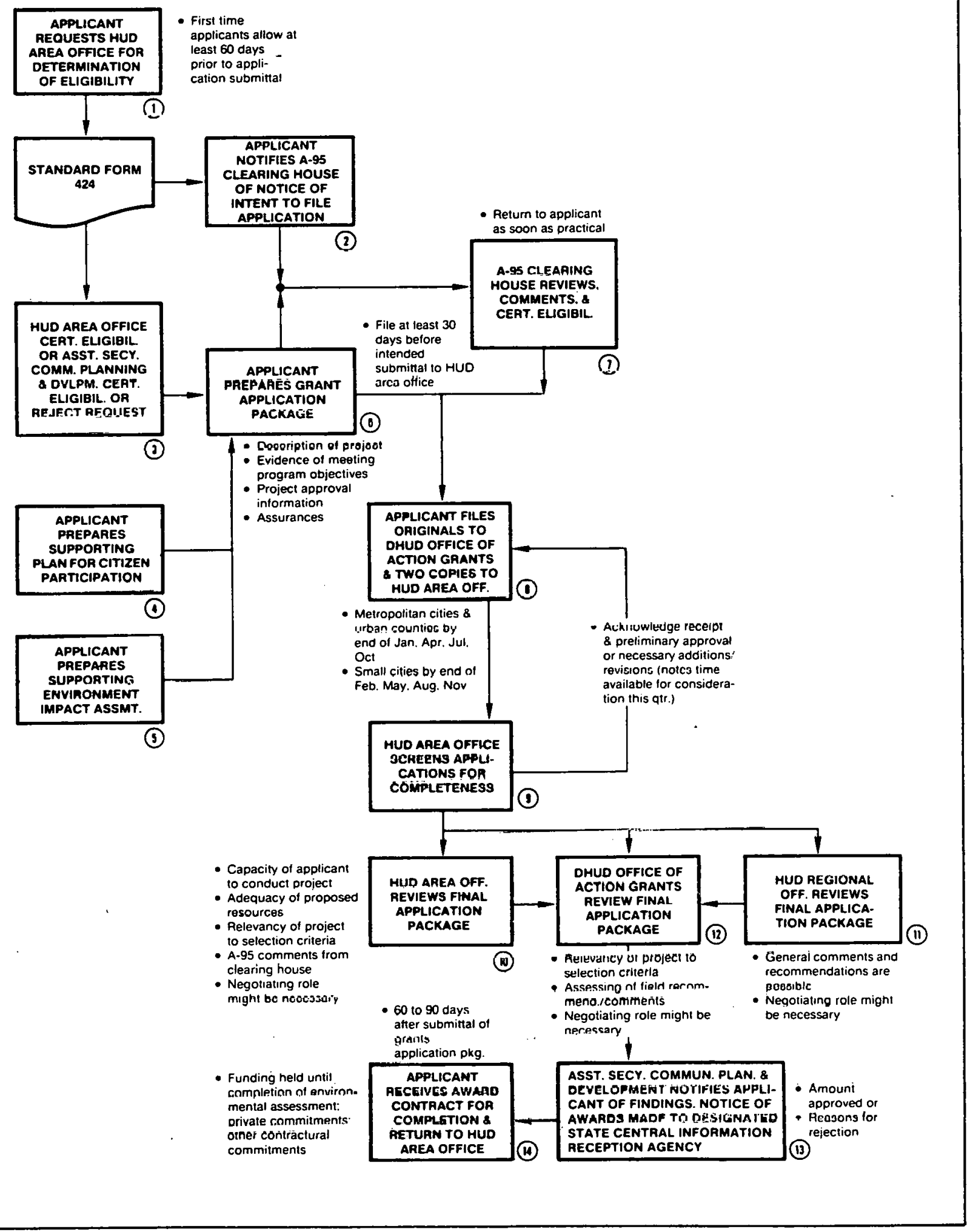

Figure A-4. HUD Loan Application Procedure 
2. At the same time as the Standard Form 424 is filed with the HUD Area Office, submit it or a summary to the A-95 clearinghouse as notice of the intent to file an application (UDAG Application Contents, p.1.)

3. To certify eligibility, determination must show that the community: (1) meets the minimum level of physical and economic distress; (2) has demonstrated results in providing housing for low- and moderate-income persons; and (3) has demonstrated results in providing equal opportunity in housing and employment for low- and moderateincome persons and members of minority groups. If the HUD Area Office is unable to conclude that a community is eligible, the case will be referred to the Assistant Secretary for Community Planning and Development for a final dctermination. (The Action Cirant Information Book, p.j).

4. Public hearings and other citizen participation activities must take place before a community can submit an application. (The Action Grant Information Book, p.4.).

5. HUD will not accept applications for funding consideration unless a level of environmental clearance has been completed for the project, as covered in 24 CFR Part 58.15. (UDAG Application Contents, p.15).

6. Application package consists of five parts: (1) Standard Form 424; (2) Description of Proposed Project: A. brief summary of project and its participants; B. detailed project description; (3) Evidence of Meeting Program Objectives: A. alleviation of physical distress; B. alleviation of economic distress; C. fiscal improvement; D. impact on the special problems of low- and moderate-income persons and minorities; $E$. employment plan to ensure that the private sector jobs established are available to the unemployed; F. record of applicant; (4) Project Approval Information: A. technical requirements; B. citizen participation, Civil Rights, Equal Employment, and Housing Authority; (5) Assurances. (UDAG application contents).

7. Submit a full application to the A-95 clearinghouse for review and comment at least 30 days prior to submission of all Action Grant applications. Submit A-95 comments to the Office of Action Grants with the application. (UDAG Application Contents, p.1).

8. Applications must be rcceived by HUD from metropolitan cities during the first month of each quarter and from small cities in the second month if they are to be considered for funding in the quarter. (The Action Grant Information Book, p.5).

9. All applications will be screened to assure they are complete before being officially accepted for revicw. Copies of complete applications will then be forwarded to the regional office and Washington. (The Action Grant Information Book, p.6).

10. The review period will take up a large part of the quarter. The area office will review and comment on the capacity of the applicant to carry out the project and complete it in a timely manner, the adequacy of the proposed resources, the relevance of the proposed project to selection critcria in $570.457(\mathrm{C})$ through $(\mathrm{K})$, and the A-95 comments. Area office comments and recommendations will be forwarded to Washington for review. (The Action Grant Information Book, p.6).

11. Regional offices may also submit comments and recommendations on the proposed project. Regional Administrators, along with area office staff, will participate in the negotiations with applicants and in the final recommendations for funding. (The Action Grant Information Book, p.6).

12. Washington will have the primary responsibility for (1) reviewing all applications against the selection criteria listed in the regulations $-570.457(\mathrm{C})$ (K); (2) assessing the recommendations and comments from the field; (3) negotiations between the applicant and the department; and (4) making recommendations to the Assistant Secretary for Community Planning and Development. (The Action Grant Information Book, p.6)

13. During the review process, negotiations with the applicant may be necessary. HUD will make the final decisions on approvals no later than the last day of each quarter.

14. An approved applicant will be notified in writing and will receive an award contract which must be completed and returned to the HUD area office.

\section{Economic Development Administration Luan Application Process (See Figure A-5)}

1. All prospective applicants should forward project assistance requests to the Economic Development Representative (EDR) in their State or area. The request should indicate the type and amount of EDA assistance desired, the project location, and 
the applicant's assessment of the local economic development benefits to be derived from the project.

2. The EDR will set up an appointment with each prospective applicant and local community officials, if appropriate. The preapplication conference enables a quick check on the economic development benefits, project feasibility, the matching with EDA goals and strategy, and the available funding.

3. Feasibility studies are required prior to filing ar, application for assistance. EDA's primary aim in setting this requirement is to assure that: (1) the project can be economically successful; (2) the production technology can meet established cost and production targets; (3) a viable local or regional market exists; and (4) the particular applicant's operation is so designed as not to pose a thrcat to eitlieı tlat environment or the satety of its employees.

4. Once the feasibility study is completed, the EDR will forward it through the appropriate regional office to DOE headquarters for a technical evaluation.

5. All project applications must include an acceptable employmcnt plan. Preference will be given to projects that exceed the established agency goal for hiring the long-term unemployed. The Department of Labor is to be asked for a critique early in this process.

6. After the feasibility study is reviewed at headquarters DOE, EDA will select projects for funding not only on the basis of DOE recommendations, but review of the local economic development benefits commensurate with its existing budgetary capabilities.

7. No EDA funds will be disbursed until the applicant has met the bonding requirements for and subsequently obtained a commercial distilled spirits permit from BATF, or sufficient evidence is provided that a perfected application with MATF is in the process of adjudicatiun.

8. Once initial EDA project considerations are made, project application matcrials will be presented by the RegionalOffice Development Finance Staff at an initial application conference.

9. Most plants larger than one million gallons of alcohol per year will be subject to final review by the National Office Development Financing Staff. Applicants and their consultants may be required to furnish additional information at this time.

10. EDA is required by statute to make a finding that reasonable assurancc of repayment exists for each loan guarantee extended.

11. Alcohol fuel plants require an additional approval by the Office of Private Investment at headquarters EDA since they are new to EDA.

12. The letter of notice of award is signed by the Assistant Secretary for Economic Development (EDA).

13. The Office of Congressional Affairs, EDA, notifies the State representatives in Congress of the loan guarantee offer.

14. Finally, the applicant receives wrillen notifijcation and must contacl regional development counsel and arrange for closing.

\section{Department of Energy Loan Guarantee Application Process (See Figure A-6)}

1. DOE will publish an Annomnrement in tho Federal Register soliciting applications for loan guarantees. A synopsis of the Announccment will be published simultaneously in the Commerce Business Daily. In addition, copies of the Announcement will be mailed to any person known to be interested in responding. The solicitation announcement will contain: (1) a brief description of the size and type of projects covered; (2) the time pcriod during which responses may be filed; and (3) the nante and address of the $\mathrm{DOE}$ representalive who may be contacted.

2. The applicant must provide sufficient detail to establish credibility that: (1) the project will be in compliance witl eslablished environmental regulations; (2) the project will conform to provisions of' Executive Urders dealing with Floodlands Management, and Protection of Wetlands; (3) the project is environmentally acceptable; (4) any affected Indian Trihs(s) has hecii involved in the planning; (5) there is sufficient evidence that the applicant will initiate and complete the project in a timely, efficient, and acceptable manner; and (6) the project will be built and operated in the United Statcs.

3. Upon receiving an application for a loan guarantee for a demonstration facility, DOE determines whether: (1) the application is complete and in compliance with the sulicitation request; (2) the type of technology, scope, size, 


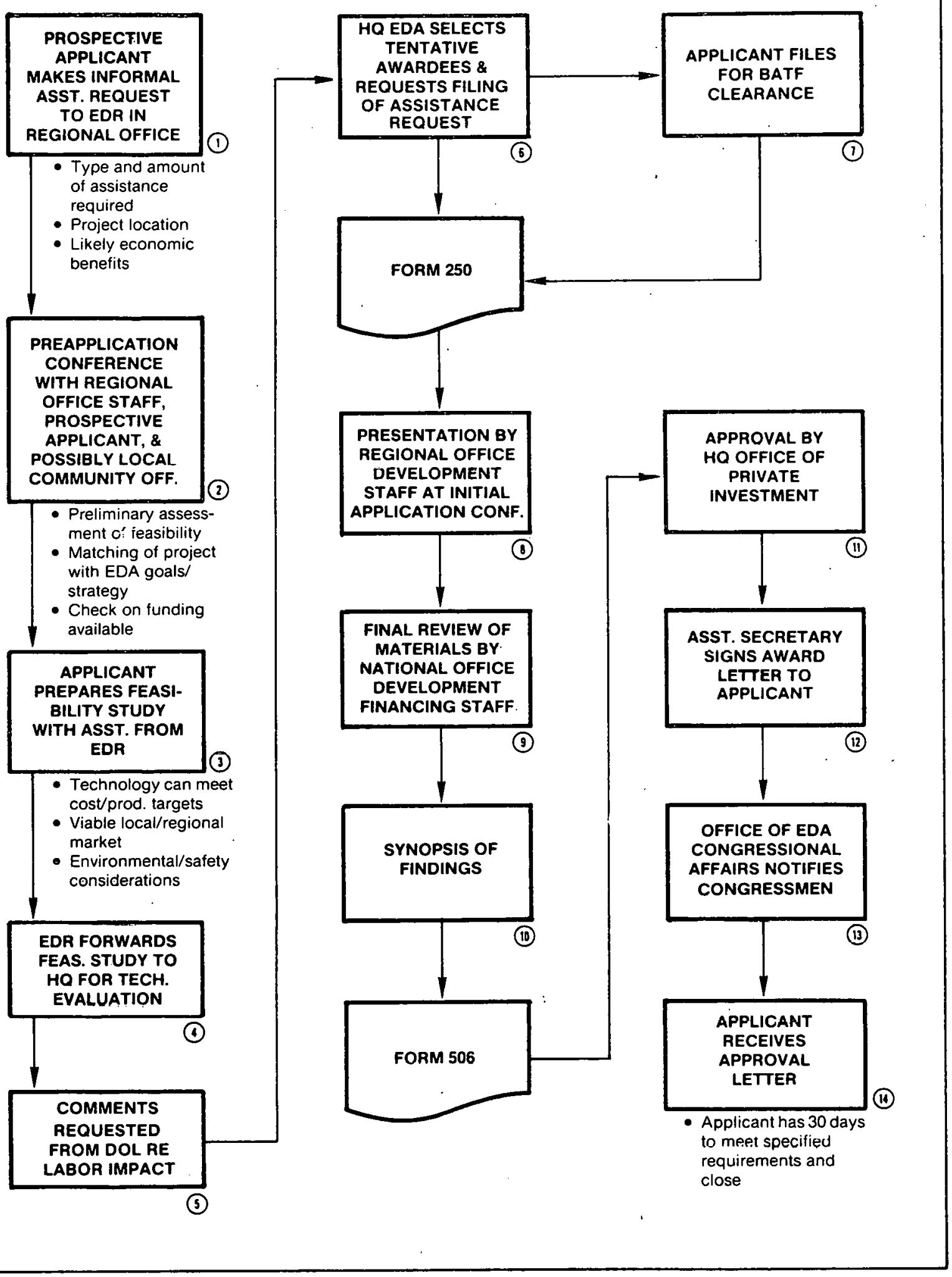

Figure A-5. EDA Loan Application Procedure 
financial assistance sought, and geographic location of the project fall within the solicitation objectives; (3) sufficient loan guarantee authority and appropriations are available to conduct the project; (4) the adverse community impacts resulting from the proposed facility have been adequately evaluated by the applicant; and (5) the terms and conditions of the proposed loan as set forth in the application are generally acceptable to DOE; and (6) whether there is satisfactory evidence that the lender is willing, competent, and capable of performing the terms and conditions of the loan guarantee agreement. DOE will notify the applicant whether its application meets the initial requirements. It may be necessary to disapprove the application or request additional information.

4. When the application meets the requirements, DOE will inform: (1) the guvernoi ol the state, officials of cach pulitical subdivision, and Indian tribe(s), as appropriate; (2) the general public by notice in the Federal Register and in local newspapers to the extent appropriate; (3) the Secretary of Interior, if the facility is to be located on Indian land or if a substantial portion of the feedstock is to be obtained pursuant to an agreement with any Indian tribe; and (4) the Advisory Council on Historic Preservation for any project which affects property listed or cligible for listing in the National Register of Historic Places.

5. The governor of the state in which the proposed facility would be located shall he requested to submit a recommendation for or against the location of such facility in his state within a reasnnable period after the initial notification. DOE shall uul guarantee or make a commitment to guarantee a loan if the governor recommends, within a reasonable period, that such action not be taken unless the Secretary, DOE, finds that there is an overriding national interest in taking such action. DOE may provide the following forms of community impact assistance to aggrieved parties: (1) a planning assistance grant to a governor of a state and Indian tribe, as appropriate; (2) a nianagement grant to a political subdivision or Indian tribe, as appropriate; (3) a loan guarantee to a political subdivision or Indian tribe, as appropriate; (4) a requirement that the applicant obtaining financial assistance advance funds for management and essential community development; and (5) direct loans by DOE for financing essential community development.

6. If the total cost of each individual project from which the selection is to be made is $\$ 50$ million or less, then the selection official shall be the ap- propriate Assistant Secretary of Energy, or designated representative, and the evaluation will be conducted by an appointed panel. If the total cost exceeds $\$ 50$ million, then the selecting official shall be the Secretary, or designated representative, and the application evaluation will be conducted by a specifically constituted Source Evaluation Board.

7. If DOE decides to guarantee or make a commit ment to guarantee despite the affected governor's recommendation that such action not be taken, DOE presents its reasons for such determination to the govcrnor in writing. The decision is final unless otherwise determined upon judicial review by the U.S. Court. of Appeals upon application made within 90 days from the date of the Secretary's decisirn.

8. DUE lorwards the selected applications to the U.S. Attorney General and to the Chairman of the FTC. Written views, comments, and rccommendations are requested for each application selected and forwarded from both of these officials concerning the impact of a loan guarantee on competitiou and concentration in the production of energy.

9. The Secretary, after considering a negative recommendation from the Attorney General or Chairman of the FTC, may nevertheless proceed with the award of the guarantee to such applicant if the Secretary determines that the energy project meets the overall goals of DOE and out weighs the negative recommendations. Alternatively, the Secrctary niday nutify the applicant of the disannrnval af its applisation with seasuns fur such disapproval.

10. If the Secretary determines to award the guarantee 10 an applicant in spite of the negative recommendation by the Attorncy General or the Chairman of the FTC, the Secretary shall forward the decision and negatlve recommendation papers to the President for a written decision on whether it is in the national intcrest to have the Secretary award a loan guarantee to the applicant. If the President upholds the negative recommendation, the Secretary will notify the applicant that the application has been disapproved and the reasons for the disapproval.

11. If the President upholds the Secretary's determination to proceed, or the Secretary has selected an applicant after receiving favorable recommendations from both the Attorney General and the Chairman of the FTC, DOE forwards the relevant documents to the Secretary of the Treasury 


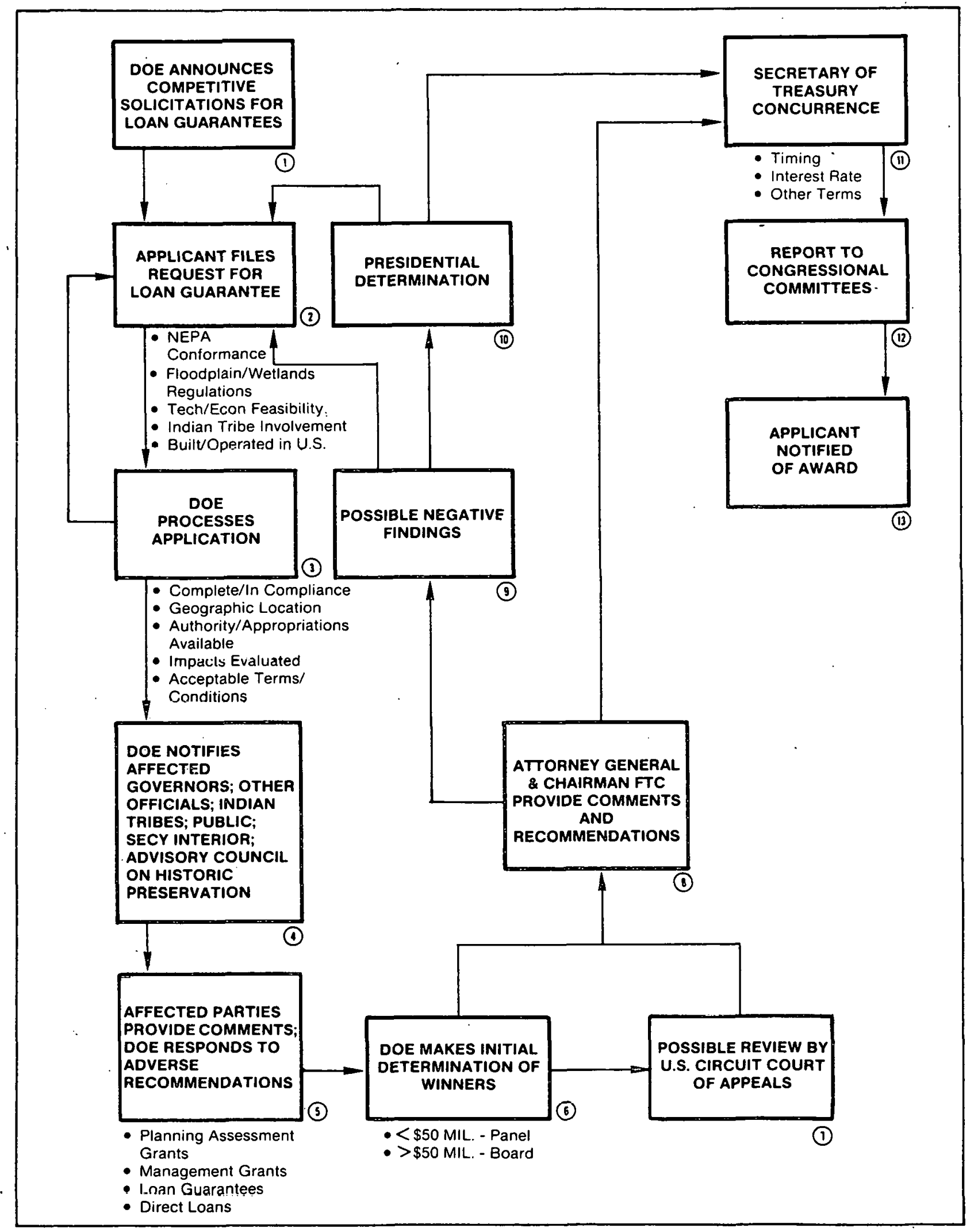

Figure A·6. DOE Loan Application Procedure 
for concurrence, with respect to the timing, interest rate, and other such terms. The Secretary of Treasury shall ensure to the maximum extent feasible that such terms will have the minimum possible impact on the capital markets of the United States.

12. DOE will forward a full and complete report on eaclı project to the Chairman of the Committee on Science and Technology of the House of Representatives, and to the Chairman of the Committee on Energy and Natural Resources of the Senate. DOE cannot finalize the loan guarantee or commitment to guarantee until 90 days after receipt by Congress.
13. Upon obtaining the concurrence of the Secretary of Treasury and the expiration of the time specified for Congressional reaction, the Secretary of DOE may award the loan guarantee or commitment to guarantee to the successful applicant.

The characteristics of Financial Assistance Programs discussed in this Appendix are shown in Figure A-7. 
THIS PAGE

\section{WAS INTENTIONALLY LEFT BLANK}




\begin{tabular}{|c|c|c|c|}
\hline & LOAN OBJECTIVES & INTEREST RATE & ELIGIBILITY \\
\hline $\begin{array}{l}\text { A. SBA PRINCIPAL } \\
\text { LENDING PROGRAMS } \\
\text { - LOCAL DEVELOP- } \\
\text { MENT COMPANIES } \\
\text { Authorization: } \\
\text { Public Law: } \\
699 \text { SB1A } \\
15 \text { USC Sec. } 661\end{array}$ & $\begin{array}{l}\text { To help a development } \\
\text { company acquire land and } \\
\text { building: construct a new } \\
\text { plant. purchase necessary } \\
\text { machinery and equipment; } \\
\text { expand or convert an cxisting } \\
\text { plant, provided the project will } \\
\text { assist a specific small } \\
\text { business. }\end{array}$ & $\begin{array}{l}\text { (a) Guaranteed loans: legal } \\
\text { and reasonable rate on entire } \\
\text { loan balance: (b) immediate } \\
\text { participation: legal and } \\
\text { reasonable rate on bank share } \\
\text { and published rate ori SBA } \\
\text { share: (c) first mortgage: legal } \\
\text { and reasonalbe rate on bank } \\
\text { loan. published rate on SBA } \\
\text { loan: (d) direct SBA loan: } \\
\text { published rate. }\end{array}$ & $\begin{array}{l}\text { Any Corporation which: (a) is } \\
\text { formed by public-spirited cit- } \\
\text { izens interested in planned } \\
\text { economic growth of a commu- } \\
\text { nity with at least } 75 \text { percent } \\
\text { ownership and control held by } \\
\text { persons living or doing busi- } \\
\text { ness in the community; b) has } \\
\text { been incorporated either for } \\
\text { profit or non-profit under } \\
\text { laws of the state in which it } \\
\text { expects to do business: (c) } \\
\text { is authorized to promote and } \\
\text { assist the growth and devel- } \\
\text { opment of small business in } \\
\text { its area of operations; and } \\
\text { (d) has a minimum of } 25 \\
\text { stockholders or members. }\end{array}$ \\
\hline $\begin{array}{l}\text { BUSINESS LOANS } \\
\text { Authorization: } \\
\text { Publie Law: } \\
\text { 85-5.35 SRA } 1 \\
15 \text { USC } 636\end{array}$ & $\begin{array}{l}\text { Business construction, } \\
\text { conversion or expansion. } \\
\text { purchase of equipment. } \\
\text { l'ticilities, machinery, supplies } \\
\text { u Irlaturials arlu working } \\
\text { capital. }\end{array}$ & 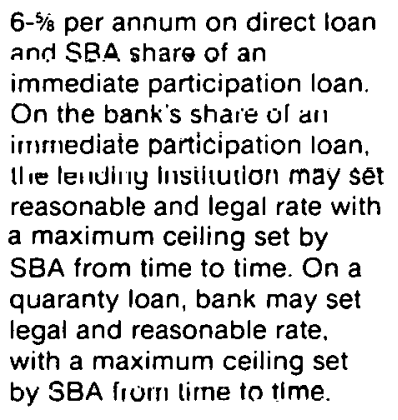 & $\begin{array}{l}\text { Most businesses including } \\
\text { farms that are: (1) } \\
\text { independently owned and } \\
\text { operated and not domınant in } \\
\text { their fields; ( } 2 \text { ) unable to } \\
\text { obtàın prıvate tınancing on } \\
\text { reasonable terms; ( } 3 \text { ) qualified } \\
\text { as "small" under SBA's size } \\
\text { standards, based on dollar } \\
\text { volume of busines or number } \\
\text { of employees. }\end{array}$ \\
\hline $\begin{array}{l}\text { - STATE DEVELOP. } \\
\text { MENT COMPANIES } \\
\text { Authorization: } \\
\text { Public Law: } \\
600 \text { ED1 A } \\
15 \text { IISC. SFC. } 661\end{array}$ & $\begin{array}{l}\text { To help state development } \\
\text { company provide equity } \\
\text { capital and long-term loans to } \\
\text { small business involved in the } \\
\text { production of alcohol fuels. }\end{array}$ & $\begin{array}{l}\text { Published annually, but not to } \\
\text { exceed } 8 \text { percent. }\end{array}$ & $\begin{array}{l}\text { Any corporation organized } \\
\text { under or pursuant to a special } \\
\text { act of the State Legislature, } \\
\text { with authority to operate } \\
\text { statewide and to assist the } \\
\text { growth and development of } \\
\text { business concerns. including } \\
\text { small businesses, in its area. }\end{array}$ \\
\hline $\begin{array}{l}\text { - SMALL BÚSINESS } \\
\text { INVESTMENT } \\
\text { Authorization: } \\
\text { Public Law: } \\
699 \text { SB 1A } \\
15 \text { IISS. Soc. } 661 \\
\text { Title } 3\end{array}$ & $\begin{array}{l}\text { To provide an SBIC or } \\
\text { Section } 301 \text { (d) SBIC with } \\
\text { funds for financing eligible } \\
\text { small business for their } \\
\text { growth, modernization, } \\
\text { and/or expansion, in the area } \\
\text { of alcohol fuels. }\end{array}$ & $\begin{array}{l}\text { Debentures sold to the Fed- } \\
\text { eral Financing bank bear in- } \\
\text { terest at comparable Agency } \\
\text { rates for paper of a similar } \\
\text { maturity. Section } 301(d) \text { SBIC } \\
\text { debentures sold to SBA bear } \\
\text { interest at a rate not less than } \\
\text { a rate determined by the Secre- } \\
\text { tary of Treasury plus any ad- } \\
\text { ditional charge towald cuvering } \\
\text { other costs of the program } \\
\text { which SBA may determine con- } \\
\text { sistent with its purpose. Sec- } \\
\text { tion } 301 \text { (d) SBICs are eligible } \\
\text { for a subsidlzed interest rate } \\
\text { for the first five years on their } \\
\text { debentures sold to SBA, sub- } \\
\text { ject to repayment of that } \\
\text { subsidy before any distri- } \\
\text { bution is made to stock- } \\
\text { holders other than SBA. }\end{array}$ & $\begin{array}{l}\text { A regular small business } \\
\text { investment company (SBIC) } \\
\text { or small business investment } \\
\text { company organized under } \\
\text { Section } 301 \text { (d) of the SBIC } \\
\text { Act, solely to assist } \\
\text { disadvantaged ellli epreneurs. } \\
\text { Although statutory minimum } \\
\text { capitai Is less. SBA, by policy, } \\
\text { requires d minimum capital ot } \\
\text { at least } \$ 500,000 \text {. An SBIC } \\
\text { must show that such capita! is } \\
\text { adequate to operate actively } \\
\text { and profitably. A Section } 301 \\
\text { (d) Licensee with limited } \\
\text { capital miusl sliow that funds } \\
\text { will be provided to cover its } \\
\text { operating expenses without } \\
\text { depleting its capital. }\end{array}$ \\
\hline
\end{tabular}

Figure A-7. Financial Assistance Programs Characteristics 


\begin{tabular}{|c|c|c|c|}
\hline SOURCE OF FUNDS & MATURITY & CEILING & COLLATERAL/SECURITY \\
\hline $\begin{array}{l}\text { (a) Bank loan guaranteed } \\
\text { by SBA to } 90 \text { percent of } \\
\text { the loan or } \$ 500,000 \\
\text { whichever is the lesser: (b) } \\
\text { bank loan with immediate } \\
\text { participation by SBA; (c) } \\
\text { bank first mortgage loan } \\
\text { and SBA direct second } \\
\text { mortgage loan; or (d) } \\
\text { direct from SBA }\end{array}$ & $\begin{array}{l}\text { Maximum maturity of } 25 \\
\text { years plus estimated time } \\
\text { required to complete } \\
\text { construction. conversion, } \\
\text { or expansion. Usually } 15 \\
\text { to } 20 \text { years. }\end{array}$ & $\begin{array}{l}\$ 500,000 \text { for each identifiable } \\
\text { small business to be assisted... } \\
\text { as a prerequisite to obtaining } \\
\text { SBA financing, a development } \\
\text { company must provide a rea- } \\
\text { sonable share of cost of pro- } \\
\text { ject in funds raised by sale of } \\
\text { stock, debentures, member- } \\
\text { ships, or cash equivalent (e.g.. } \\
\text { land). Minimum amount to be } \\
\text { provided by development } \\
\text { company will generally be } 20 \\
\text { percent of cost of project. SBA } \\
\text { will take a second lien position } \\
\text { when the local lending institu- } \\
\text { tions will participate in the } \\
\text { SBA's first mortgage plan. }\end{array}$ & $\begin{array}{l}\text { A lien on the fined assests } \\
\text { acquired with loan } \\
\text { proceeds so as to } \\
\text { reasonably assure } \\
\text { repayment of the loan. }\end{array}$ \\
\hline $\begin{array}{l}\text { Banks and other lending } \\
\text { institutions, excluding } \\
\text { small business investment } \\
\text { companies licerised by } \\
\text { SBA. }\end{array}$ & $\begin{array}{l}\text { Maximum of } 10 \text { years as a } \\
\text { rule. However, working } \\
\text { capital loans generally are } \\
\text { limited to } 6 \text { years, while } \\
\text { portions of loans for } \\
\text { construction and } \\
\text { acquisition of real estate } \\
\text { may have maximum of } 20 \\
\text { years. }\end{array}$ & $\begin{array}{l}\$ 350,000 \text { to any one borrower } \\
\text { is the maximum SBA share of } \\
\text { an immediate participation } \\
\text { loan. where SBA and private } \\
\text { lending institution each put up } \\
\text { part of loan funds immedi. } \\
\text { ately; and the maximum SBA } \\
\text { direct loan, one made by the } \\
\text { agency. For guaranteed loans, } \\
\text { made by a bank and partially } \\
\text { guaranteed by } S B A \text {, the maxi- } \\
\text { mum is also } \$ 350,000 \text { normally } \\
\text { but may be up to } \$ 500,000 \text { for } \\
\text { exceptional circumstances. }\end{array}$ & $\begin{array}{l}\text { Real estate or chatel } \\
\text { mortgage: assignment of } \\
\text { warehouse receipts for } \\
\text { marketable merchandise: } \\
\text { assignment of certain } \\
\text { types of contracts: } \\
\text { guarantees or personnel } \\
\text { endorsements; in some } \\
\text { instances assignment of } \\
\text { current receivables. }\end{array}$ \\
\hline Direct from SBA. & $\begin{array}{l}\text { Maximum of } 20 \text { years, in } \\
\text { actual practice these loans } \\
\text { are usually requested from } \\
\text { a } 5 \text { to } 10 \text { year term. }\end{array}$ & $\begin{array}{l}\text { As much as state develop- } \\
\text { ment company's total out- } \\
\text { standing borrowings from all } \\
\text { other sources. Based on } \\
\text { experience. the average loan } \\
\text { request from a State develop- } \\
\text { ment company is } \$ 500,000 \text { to } \\
\$ 1,000,000 \text {. (Total available } \\
\text { limited by annual budget } \\
\text { allocations). }\end{array}$ & $\begin{array}{l}\text { Security for SBA loan on } \\
\text { an equal basis with funds } \\
\text { borrowed by development } \\
\text { company trom any other } \\
\text { sources after August } 21 \text {, } \\
1958 \text {. (SBA funds may be } \\
\text { secured on a ratable basis } \\
\text { with other borrowings of } \\
\text { the State development } \\
\text { company.) }\end{array}$ \\
\hline $\begin{array}{l}\text { SBA provides the } \\
\text { authorized leverage funds } \\
\text { to an SBIC through its } 100 \\
\text { percent gurantee of the } \\
\text { debentures sold to the } \\
\text { Federal Financing Bank. }\end{array}$ & Maximum 15 years. & $\begin{array}{l}\text { An SBIC is eligible to } \\
\text { borrow } \$ 3 \text { for every } \$ 1 \text { of } \\
\text { private capital up to a } \\
\text { maximum of } \$ 35 \text { million. } \\
\text { An SBIC which has } 65 \\
\text { percent or more of its total } \\
\text { funds available invested in } \\
\text { venture capital is eligible } \\
\text { to borrow } \$ 4 \text { for every } \$ 1 \\
\text { of its private capital. up to } \\
\text { a total maximum of } \$ 35 \\
\text { million, provided it has } \\
\text { private capital of } \$ 500,000 \\
\text { or more. The same } \\
\text { eligibiliy applies to Section } \\
301 \text { (d) Licensees. except } \\
\text { that the required venture } \\
\text { capital investment is } 30 \\
\text { percent and there is no } \\
\text { limit on funding. }\end{array}$ & $\begin{array}{l}\text { Evidence of indebtedness is a } \\
\text { debenture of the SBIC or } \\
\text { Section } 301 \text { (d) Licensee sub- } \\
\text { ordinated to any other deben- } \\
\text { ture bonds. promissory notes, } \\
\text { or other debts and obligations } \\
\text { of the SBIC or Section } 301 \text { (d) } \\
\text { SBIC unless the SBA, in the } \\
\text { exercise of reasonable invest- } \\
\text { ment prudence. determines } \\
\text { otherwise. Adequately capital- } \\
\text { ized Section } 301 \text { (d) Licensees } \\
\text { are eligible for SBA purchases } \\
\text { of their } 3 \text { percent cumulative } \\
\text { preferred stock in an amount } \\
\text { equivalent to a portion or all of } \\
\text { their paid-in capital and paid- } \\
\text { in surplus, the proceeds there- } \\
\text { of constituting a part of their } \\
\text { a!.thorizent leverage. }\end{array}$ \\
\hline
\end{tabular}

Figure A.7. Financial Assistance Programs Characteristics (Continued) 


\begin{tabular}{|c|c|c|c|}
\hline & LOAN OBJECTIVES & INTEREST RATE & ELIGIBILITY \\
\hline $\begin{array}{l}\text { ECONOMIC } \\
\text { OPPORTUNITY } \\
\text { Authorization: } \\
\text { Public Law: } \\
\quad 93-3 R 4 \text { SRA } 1 \\
15 \text { USC 636 ( })\end{array}$ & $\begin{array}{l}\text { Any use which will carry out } \\
\text { the purposes the same as } \\
\text { other business loans. }\end{array}$ & $\begin{array}{l}\text { On direct loans and SBA } \\
\text { share of immediate } \\
\text { participation plans, the rate is } \\
\text { set periodically. based on a } \\
\text { statutory formula. Bank rate } \\
\text { same as on other business } \\
\text { Inans }\end{array}$ & $\begin{array}{l}\text { Low income or disadvantaged } \\
\text { persons who have lacked the } \\
\text { oppontunity to start or } \\
\text { strengthen a small busines } \\
\text { and cannot obtain the } \\
\text { necessary financing from } \\
\text { other sourccs oli iésisuirable } \\
\text { terms. }\end{array}$ \\
\hline $\begin{array}{l}\text { B. FmHA LOANS AND } \\
\text { GUARANTEES FOR } \\
\text { ALCOHOL FUELS } \\
\text { Authorization: } \\
\text { Rural Development ACt } \\
\text { of } 1972 \\
\text { SEC } 3108 \text { USE } 1932 \\
\text { PL92-419 TITLE } 1\end{array}$ & $\begin{array}{l}\text { The Farmers Home } \\
\text { Administration (FmHA) } \\
\text { makes loans under the Farm } \\
\text { Loan Program and } \\
\text { guarantees loans by private } \\
\text { lenders under the Business } \\
\text { and Industrial (B\&L) Loan } \\
\text { Guarantee Program for plants } \\
\text { for the production of fuel } \\
\text { alcohol. }\end{array}$ & $\begin{array}{l}\text { Guaranteed loan rates will be } \\
\text { negotiated between lender } \\
\text { and borrower. They may be } \\
\text { fixed or variable. } \\
\text { Insured loan rates to public } \\
\text { bodies, nonprofil assuciations. } \\
\text { and Indian tribes are at the } \\
\text { rate of } 5 \% \text { per annum. Other } \\
\text { insured loans will be at the } \\
\text { rate presented by FmHA at } \\
\text { the time. }\end{array}$ & $\begin{array}{l}\text { Loans made by private } \\
\text { lenders but guaranteed by } \\
\text { FmHA may be made to any } \\
\text { legal entity, including } \\
\text { individuals, public and private } \\
\text { organizations and Federally } \\
\text { recognized Indian tribal } \\
\text { groups. Priority is given to } \\
\text { projects in the country and in } \\
\text { communities of } 25,000 \\
\text { population and smaller, } \\
\text { although loans may be } 1 \text { liade } \\
\text { in cities and towns of less } \\
\text { than } 50,000 \text { population and its } \\
\text { immediately adjacent } \\
\text { urbanized areas with a } \\
\text { population density or less } \\
\text { than } 100 \text { persons per square } \\
\text { mile. }\end{array}$ \\
\hline $\begin{array}{l}\text { Authorization: } \\
\text { Agricultural and Credit } \\
\text { Act of } 1978\end{array}$ & $\begin{array}{l}\text { Intended to finance } \\
\text { production of alcohol for on- } \\
\text { farm usc; or for partial off- } \\
\text { farm use and sale, only if it is } \\
\text { necessary to make the farm } \\
\text { operation commercially } \\
\text { viable. }\end{array}$ & $\begin{array}{l}\text { Farm operating loans. Interest } \\
\text { rates currently at } 10.5 \text { percent } \\
\text { for operating luans. } \\
\text { Farm ownership loans. } \\
\text { Interest rates are } 10 \text { percent } \\
\text { annually. } \\
\quad ;\end{array}$ & $\begin{array}{l}\text { Operators of family farms } \\
\text { who are U.S. citizens, are of } \\
\text { legal age, who cannot obtain } \\
\text { sufficient credit elsewhere at } \\
\text { reasonable rates and terms, } \\
\text { and who otherwise meet the } \\
\text { requirements for an FmHA } \\
\text { farm loan may bc eligible. The } \\
\text { county or area committee of } \\
\text { FmHA - consisting of three } \\
\text { persons who know lucal } \\
\text { farming and credit conditions } \\
\text { determines eligibility of } \\
\text { applicants. }\end{array}$ \\
\hline $\begin{array}{l}\text { C. HOUSING \& URBAN } \\
\text { DEVELOPMENT, } \\
\text { UHBAN DEVELOP. } \\
\text { ACTIOIV GRAITS } \\
\text { Authorization; } \\
\text { Title } 1 \text { of the Housing } \\
\text { and Community Devel- } \\
\text { opment Act of } 1974 \\
\text { Public Law } 93-383,42 \\
\text { U:E: G. E301 } 6317 \\
\text { as amended by Title } 1 \text { of } \\
\text { the Housing and } \\
\text { Cuilimumlly Develup. } \\
\text { Act of } 1977, \text { Section } 110, \\
\text { Public Law } 93-128, \\
\text { HL U.S.C. } 5304\end{array}$ & $\begin{array}{l}\text { To assist severely distressed } \\
\text { cities and severely distressed } \\
\text { urban counties in alleviating } \\
\text { pnysical and economic } \\
\text { deterioration through } \\
\text { economic development and } \\
\text { neighborhood revitalization. } \\
\text { Alcohol fuel production.is an } \\
\text { example of slich efforts. }\end{array}$ & Not applicable - grant. & $\begin{array}{l}\text { Applicant Eligibility: Eligible } \\
\text { applicants are distressent } \\
\text { cities and distressed urban } \\
\text { counties which meet the. } \\
\text { following criteria specified in } \\
\text { Section } 470.452 \text { of the } \\
\text { regulations: (a) Minimum } \\
\text { standards of physical and } \\
\text { eronomic distress: (b) } \\
\text { demonstrated results in } \\
\text { providing housing for persons } \\
\text { of low and moderate income. } \\
\text { and (c) demonstraled results } \\
\text { in providing equal opportunity } \\
\text { in housing and employment } \\
\text { for low and moderate income } \\
\text { persons and mcmbers nf } \\
\text { minority groups. } \\
\text { Beneficiary Eligibility: Same } \\
\text { as Applicant Eligibility. }\end{array}$ \\
\hline
\end{tabular}

Figure A.7.Financial Assistance Programs Characteristics (Continued) 


\begin{tabular}{|c|c|c|c|}
\hline SOURCE OF FUNDS & MATURITY & CEILING & COLLATERAL/SECURITY \\
\hline $\begin{array}{l}\text { Direct from SBA and/or } \\
\text { banks and other lending } \\
\text { institutions, excluding } \\
\text { small business investment } \\
\text { companies licensed by } \\
\text { SBA. }\end{array}$ & $\begin{array}{l}\text { Maximum of } 15 \text { years. } \\
\text { Working capital loans } \\
\text { generally limited to a } 10- \\
\text { year maximum. }\end{array}$ & $\begin{array}{l}\$ 100,000 \text { to any one } \\
\text { borrower. as SBA share of } \\
\text { loan. }\end{array}$ & $\begin{array}{l}\text { Any worthwhile collateral } \\
\text { which is available or will } \\
\text { be acquired with the } \\
\text { proceeds of the loan. }\end{array}$ \\
\hline $\begin{array}{l}\text { FmHA may guarantee up to } \\
90 \text { percent of a loan, with the } \\
\text { applicant responsible for } \\
\text { furnishing a minimum of } 10 \\
\text { percent of equity. The } \\
\text { maximum guarantee for } \\
\text { alcohol fuel production is } \\
\text { expected to be lower. }\end{array}$ & $\begin{array}{l}\text { Maximim terms are } 30 \text { years } \\
\text { for land, buildings and } \\
\text { permanent fixtures; } 15 \text { years } \\
\text { for machinery or equipment, } \\
\text { or the life of the machinery or } \\
\text { equipment, whichever is } \\
\text { shorter; } 7 \text { years for working } \\
\text { capital. The interest rate will } \\
\text { he determined between the } \\
\text { lender and borrower }\end{array}$ & $\begin{array}{l}\text { No ceilings: pre-screening for } \\
\$ 5,000,000 \text {. }\end{array}$ & $\begin{array}{l}\text { Whatever the bank requires } \\
\text { for loan guarantees. such as a } \\
\text { lien on fixed assets. }\end{array}$ \\
\hline $\begin{array}{l}\text { Guaranteed loans are made } \\
\text { and serviced by legally } \\
\text { organized private lending } \\
\text { institutions, such as } \\
\text { commerclal barıks, Federal } \\
\text { Land Banks, Production } \\
\text { Credit Assoriations. } \\
\text { insurance companies, and } \\
\text { savings and loan associations. } \\
\text { FmHA provides the lender } \\
\text { with a guarantee to reimburse } \\
\text { up to } 90 \text { percent of any loss } \\
\text { the lender takes on a loan. }\end{array}$ & $\begin{array}{l}\text { Farm operating loans. } \\
\text { Operating loans may be } \\
\text { repaid in from } 1 \text { to } 7 \text { years. In } \\
\text { some cases, borrower may be } \\
\text { given an additional } 7 \text { years to } \\
\text { repay. } \\
\text { Farm ownership loans. Farm } \\
\text { ownership loans have a } \\
\text { maximum term of } 40 \text { years. }\end{array}$ & $\begin{array}{l}\text { Farm operating loans. The } \\
\text { limit on an operating loan } \\
\text { made directly by FmHA is } \\
\$ 100,000 \text { : a private loan } \\
\text { guaranteed by FmHA has a } \\
\text { limit of } \$ 200,000 \\
\text { Farm ownership loans. The } \\
\text { limit on a farm ownership } \\
\text { loan made directly by FmHA } \\
\text { is } \$ 200,000 \text { on a guaranteed } \\
\text { loan } \$ 300,000 \text {. }\end{array}$ & $\begin{array}{l}\text { Farm operating loans. } \\
\text { Fixtures } \\
\text { Farm ownership loans. Real } \\
\text { estate, security, or liens on } \\
\text { fixed assets. }\end{array}$ \\
\hline $\begin{array}{l}\text { Projects which include } \\
\text { financial assistance from the } \\
\text { State or other public entities } \\
\text { will receive more favorable } \\
\text { consideration. Other public } \\
\text { resource may be provided by } \\
\text { matching other Federal } \\
\text { grants, or by firm } \\
\text { commitments or other Federal } \\
\text { or local resources. No } \\
\text { activities will be funded unless } \\
\text { there is a firm commitment of } \\
\text { private resource to the } \\
\text { proposed project. }\end{array}$ & $\begin{array}{l}\text { Assistance is for a discrete } \\
\text { project which can be } \\
\text { completed in approxirnalely } 4 \\
\text { years. No additional funding } \\
\text { will be available in } \\
\text { subsequent years to complete } \\
\text { a project approved in a prior } \\
\text { yed. Funds are madc } \\
\text { available through a Letter of } \\
\text { Credit. }\end{array}$ & $\begin{array}{l}\text { FY } 78 \text { small cities range: } \\
\$ 77,700-\$ 5,700,000 ; \text { average: } \\
\$ 934,300 \text {. FY } 78 \text { metro cities } \\
\text { range } \$ 85,000-\$ 13,500,000 ; \\
\text { average } \$ 2,950,000 \text {. }\end{array}$ & Not apolicable - grant. \\
\hline
\end{tabular}

Figure A-7.Financial Assistance Programs Characteristics (Continued) 


\begin{tabular}{|c|c|c|c|}
\hline & LOAN OBJECTIVES & INTEREST RATE & ELIGIBILITY \\
\hline $\begin{array}{l}\text { D. ECONOMIC DEVEL- } \\
\text { OPMENT ADMIN. } \\
\text { PUBLIC WORKS } \\
\text { GRANTS TO RURAL } \\
\text { COMMUNITIES \& } \\
\text { NON-PROFIT RURAL- } \\
\text { BASED ORGANIZA- } \\
\text { TIONS }\end{array}$ & $\begin{array}{l}\text { To sustain industrial and } \\
\text { commercial viability in } \\
\text { designated areas by providing } \\
\text { financial assistance to } \\
\text { business that create or retain } \\
\text { permanent jobs. expand or } \\
\text { establish plants in } \\
\text { redevelopment areas for } \\
\text { projects where financial } \\
\text { assistance is not available } \\
\text { from other sources, on terms } \\
\text { and conditions that would } \\
\text { permit accomplishment of the } \\
\text { project and further economic } \\
\text { development in the area. }\end{array}$ & $\begin{array}{l}\text { Interest rates are negotiable } \\
\text { - may be fixed for variable }\end{array}$ & $\begin{array}{l}\text { Any individual. private or } \\
\text { public corporation, or Indian } \\
\text { tribe. provided that the project } \\
\text { to be funded is physically } \\
\text { situated in an area designated } \\
\text { as eligible under the } \wedge \text { ct at } \\
\text { the time the application is } \\
\text { filed. Neither business } \\
\text { development loans nor } \\
\text { guarantees of any kind will be } \\
\text { extended to applicants who: } \\
\text { (1) have, within the previous } 3 \\
\text { years, relocated any or all of } \\
\text { their facilities to another city, } \\
\text { or Statc. (2) contemplate } \\
\text { relocating part or all of their. } \\
\text { existing facilities with a } \\
\text { resultant loss of employment } \\
\text { at such facilities; and (3) } \\
\text { produce a product or service } \\
\text { for which there is a sustained } \\
\text { and prolonged excess of } \\
\text { supply over demand. }\end{array}$ \\
\hline $\begin{array}{l}\text { E. DEPARTMENT OF } \\
\text { ENERGY, ALTERNA- } \\
\text { TIVE FUELS } \\
\text { PRODUCTION } \\
\text { Aulhorization: } \\
\text { Public Law } 96-126\end{array}$ & $\begin{array}{l}\text { To expedite the domestic. } \\
\text { development and production } \\
\text { of alternative fuels and to } \\
\text { reduce dependence on } \\
\text { foreign supplies of energy } \\
\text { resource by establishing such } \\
\text { domestic production at } \\
\text { maximum levels at the earliest } \\
\text { time practicable. }\end{array}$ & $\begin{array}{l}\text { A rate, determined by the } \\
\text { Secretary in consulltation with } \\
\text { the Secretary for Treasury, to } \\
\text { be reasonable taking into } \\
\text { account the range of interest } \\
\text { rate prevailing in the private } \\
\text { sector for similar government } \\
\text { guaranteed obligations of } \\
\text { comparable risk. }\end{array}$ & $\begin{array}{l}\text { Organlzations interested in } \\
\text { pursuing commercial } \\
\text { production of alternative fuels } \\
\text { who are capable of providing } \\
\text { development and production } \\
\text { facilities at the earliest time } \\
\text { practicable. }\end{array}$ \\
\hline $\begin{array}{l}\text { P. ENERGY SECUHITY } \\
\text { ACT OF } 1000 \\
\text { Authorization: } \\
\text { Public Law } 96-294 \\
\text { Title II }\end{array}$ & $\begin{array}{l}\text { To reduce the dependence of } \\
\text { ithe Unltea States on imported } \\
\text { petroleum and natural gas by } \\
\text { all economically and environ- } \\
\text { mentally feasible moans, } \\
\text { including the use of biomass } \\
\text { energy resources; and to for- } \\
\text { mulate and implement a } \\
\text { national program for increased } \\
\text { production and use of biomass } \\
\text { energy that does not impare } \\
\text { the nation's ability to produce } \\
\text { innd and fiber on a euctainablic } \\
\text { basis for domestic and export } \\
\text { use. }\end{array}$ & 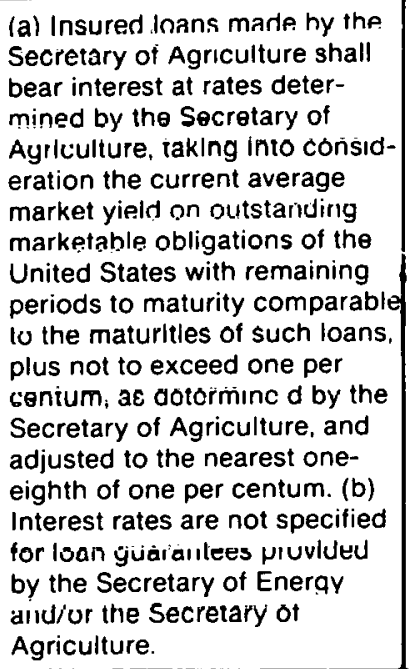 & $\begin{array}{l}\text { Nll intcrested persons. e.y., } \\
\text { defined as any individual, } \\
\text { company, cooperative, part- } \\
\text { nersil tip, curporation, assoclà- } \\
\text { tion, consortium, unincor- } \\
\text { porated organization, trust, } \\
\text { estate, or any entily urgan- } \\
\text { ized for a conimun business } \\
\text { purpose, and state or local } \\
\text { government or any agency or } \\
\text { instrumentability thereof, or } \\
\text { any Indian trihe or tribal } \\
\text { urganlzarlon. }\end{array}$ \\
\hline
\end{tabular}

Figure A-7.Financial Assistance Programs Characteristics (Continued) 


\begin{tabular}{|c|c|c|c|}
\hline SOURCE OF FUNDS & MATURITY & CEILING & COLLATERAL/SECURITY \\
\hline $\begin{array}{l}\text { The Federal participation in a } \\
\text { direct, fixed asset loan may } \\
\text { not exceed } 65 \text { percent of } \\
\text { project fixed asset costs. A } \\
\text { local development } \\
\text { corporation or State agency } \\
\text { usually participates to the } \\
\text { extent of five percent. Of the } \\
\text { remaining } 30 \text { percent. } 10 \\
\text { percent or } 15 \text { percent if no } \\
\text { local or State participation } \\
\text { must be in the form of } \\
\text { applicant's equity and the } \\
\text { balance from a conventional } \\
\text { commercial lender. } \\
\text { Applicants are encouraged to } \\
\text { increase their equity } \\
\text { participation beyond the } \\
\text { minimum. Comparable } 15 \\
\text { percent equity requirements } \\
\text { also apply to guarantees. }\end{array}$ & $\begin{array}{l}\text { Fixed asset loans, } 25 \text { years, } \\
\text { maximum; working capital } \\
\text { loans } 5 \text { years; guarantees, life } \\
\text { of loan or lease. EDA loan } \\
\text { funds will only be disbursed } \\
\text { after all other funds have been } \\
\text { injected into project. }\end{array}$ & $\begin{array}{l}\text { Long-term business } \\
\text { development loans up to } 65 \\
\text { percent of the cost may be } \\
\text { used for the acquisition of } \\
\text { fixed assets only (i.e.. land. } \\
\text { building. machinery. and } \\
\text { equipment. including land } \\
\text { preparation and building } \\
\text { rehabilitation). Funds may be } \\
\text { used for most kinds of new } \\
\text { industrial or commercial } \\
\text { facilities or to expand one } \\
\text { already in existence. Loans } \\
\text { for working capital needs are } \\
\text { not limited by statute. but are } \\
\text { available only for short } \\
\text { periods. In addition. the } \\
\text { government will guarantee up } \\
\text { to } 90 \text { percent of the unpaid } \\
\text { balance of loans for the } \\
\text { acquisition of fixed assets or } \\
\text { for working capital: and up to } \\
90 \text { percent of the rental } \\
\text { payments required by } \\
\text { guaranteed lease. } \\
\text { Fy } 78 \text { range: } \\
\$ 260,000 \text { to } \$ 5,200,000 \text { : } \\
\text { Fy } 78 \text { Average: } \\
\$ 1,500,000\end{array}$ & $\begin{array}{l}\text { Personal guarantees usually } \\
\text { will be required in order to } \\
\text { ensure an ongoing } \\
\text { management commitment } \\
\text { over the life of the credit. }\end{array}$ \\
\hline $\begin{array}{l}\text { Federal guarantee up to } 75 \\
\text { percent of the estimated } \\
\text { construction, startup, and } \\
\text { related costs, lendet is any } \\
\text { individual, partnership, } \\
\text { corporation, fenterai entity or } \\
\text { other legal entity formed for } \\
\text { the purpose or engaged in the } \\
\text { business of lending money. }\end{array}$ & $\begin{array}{l}\text { Full repayment is to be } \\
\text { made over the lesser of } 20 \\
\text { years or a period equal to } 90 \\
\text { percent of the expected } \\
\text { average useful economic life } \\
\text { of the project's major physical } \\
\text { assets. }\end{array}$ & $\begin{array}{l}\text { The amount of the loan } \\
\text { guaranteed, when combined } \\
\text { with other funds available to } \\
\text { the applicant, shall be } \\
\text { sufficient to carry out the } \\
\text { project, including adequate } \\
\text { contingency funds. }\end{array}$ & $\begin{array}{l}\text { The project assets and other } \\
\text { collateral or surety as } \\
\text { determined by the Secretary } \\
\text { to be necessary. }\end{array}$ \\
\hline $\begin{array}{l}\text { To the extent provided in } \\
\text { advance in appropriation Acts } \\
\text { for the two year period begin- } \\
\text { ning October } 1,1980 \text {. there is } \\
\text { authorized to be appropriated } \\
\text { and transferred } \$ 1.45 \text { billion } \\
\text { from the Energy Security } \\
\text { Reserve established in the } \\
\text { Treasury of the United States. } \\
\text { under P.L. } 96-126 \text { as follows: } \\
\text { (1) } \$ 600 \text { million to the Secre- } \\
\text { tary of Agriculture: (2) } \$ 600 \\
\text { million to the Secretary of } \\
\text { Energy of which at least } \$ 500 \\
\text { million shall be available to the } \\
\text { Office of Alcohol Fuels: and (3) } \\
\$ 250 \text { million to the Secretary of } \\
\text { Energy for municipal waste } \\
\text { biomass energy. }\end{array}$ & Not specified. & $\begin{array}{l}\text { (a) Insured loans made by the } \\
\text { Secretary of Agriculture may } \\
\text { not exceed } 90 \text { per centum of } \\
\text { the total estimated cost of con- } \\
\text { struction and may not exceed } \\
\$ 1 \text { million per project. In the } \\
\text { event the construction costs } \\
\text { exceed the original estimates. } \\
\text { the Secretary may make an } \\
\text { insured loan for so much of the } \\
\text { additional total costs. not to } \\
\text { excecd } 10 \text { por centum of the } \\
\text { initial estimates. (b) Any gua- } \\
\text { rantee of a loan made by either } \\
\text { Secretary may not exceed } 90 \\
\text { per centum of the cost of con- } \\
\text { struction as estimated by the } \\
\text { Secretary on the date of the } \\
\text { guarantee or commitment to } \\
\text { guarantee. In the event the } \\
\text { construction costs exceed the } \\
\text { original estimates. the Secre- } \\
\text { tary may guarantee a loan for } \\
\text { up to } 60 \text { per centım of the dif- } \\
\text { ference between the original } \\
\text { and final estimates. }\end{array}$ & Not specified. \\
\hline
\end{tabular}

Figure A-7.Financial Assistance Programs Characteristics (Continued) 
THIS PAGE

\section{WAS INTENTIONALLY LEFT BLANK}




\section{APPENDIX B}

\section{Regulations and Permits}

This section reviews regulations which affect the ethanol production industry. It includes BATF, FDA, transportation regulations and local building codes. 


\section{BATF REGULATIONS}

The design, construction, and operation of alcohol fucl plants require attention from Federal, State, and local authorities in order to ensure maintenance of the public good. Specific aspects of alcohol fuel production relating to safety and environmental concerns have been addressed in the main body of this document; other more general requirements, such as meeting building codes and zoning regulations, are site-specific and must be complied with, based on the individual case. Again, specific to alcohol fuels, this appendix addresses BATF regulations and other regulations and permits as they concern the potential investor.

In the Energy Tax Act of 1978 (Public Law 95-618), Congress required the Secretary of the Treasury to propose legislative recommendations to facilitate fupl usse of distilled spirits. In compliance with this mandate, the BATF submitted a proposal in 1979. Congress incor porated the proposed legislation, with modifications, in Public Law 96-223.

Public Law 96-223 added a new section to Subchapter B of Chapter 51 of the Internal Revenue Code of 1954. New Section 5181, Distilled Spirits for Fuel Use, provides for the establishment of distilled spirits plants solely for the purpose of producing, processing and storing. and using or distributing distilled spirits to be used exclusively for fuel use. The Secretary of the Treasury is directed to expedite all applications, establish a minimum bond, and generally encourage and promote (through regulation or otherwise) the production of alcohol for fuel purposes The Law gives the Secretary authority to provide by tegulation for the waiver of any provision of Chapter 51 (except Section $S|z|$ or any provision requiring the payment of $\operatorname{tax}$ ). This waiver authority may be exerciscd with respect to alcohol fuel plants as necessary to carry out the provisions of Section 5181.

Plants which are established for the production of alcohol for purposes other than fuel, such as beverage or other industrial use, mus! qualify to operate under perviuusly existing provisions of the law. You may wish to contact BATF for further details (see Appendix E).

The law exempls alcohol fuel plants which produce less than 10,000 proof gallons of distilled spirits annually from furnishing a bond to cover the tax liability on the spirits. Also, persons wishing to establish such plants are assured by law that their applications for permits to operate will be acted upon within 60 days after receipt of a complcted application. If this limit is exceeded, the application is automatically approved.

Distilled spirits may be withdrawn from alcohol fuel plants free of tax after having been rendered unfit for bevcrage use. The term "rendered unfit for beverage use" is used to clearly distinguish this requirement for fuel spirits from "denaturation", which is required for spirits withdrawn from other distilled spirits plants.

A principal reason for encouraging production of distilled spirits for fuel use is that these spirits are substituted for scarce fossil fuels. Therefore, in defining distilled spirits for purposes of the alcohol fuel provisions, the law excludes distilled spirits produced from petroleum, natural gas, or coal.

Finally, Public Law 96-223 amended Section 5601 to impose criminal penallies on any person who withdraws, uses, sells, or otherwise disposes of distilled spirits produced under Section 5181 for other than fuel use.

This section addresses those portions of regulations dealing with large alcohol fuel plants (defined by BATF as more than 500,000 pruof gallurss of spirits per calendar year). We will cover the following permits; bonds; construction, equipment, and securily; supervision; accounting for spirits; transfers and withdrawals; and transfers between plants. Our intent is to be informative, but we suggest that the Bureau be contacted for more specific interpretation and guidance where needed.

\section{The following is a brief summary of the regulations now in force:}

\section{DEPARTMENT OF THE, TREASURY}

\author{
Bureau of Alcohol, Tobacco, and Firearms \\ (2) CFK Part 19) \\ T.U. AlF-71
}

FUEL USE OF DISTILLED SPIRITS IMPLEMENTING A PORTION OF THE CRUDE: OIL.

\section{WINDFALL, PROFITS TAX ACT OF 1980 (PUBLIC LAW 96-223)}

AGENCY: Bureau of Alcohol, Tobacco, and Firearms, Department of the Treasury.

ACTION: Temporary rule (Treasury decision).

SUMMARY: This temporary rule implements Section 232, Alcohol Fuels, in Part III of Title II of the Crude Oil Windfall Profits Tax Act of 1980 (Public Law 96-223). The temporary rule provides for the establishment and operation of distilled spirits plants solely for producing, processing and storing, and using or distributing distilled spirits (ethyl alcohol) exclusively for fuel use. Public Law 96-223 vests the Secretary of the Treasury with authority to simplify and liberalize statut ory requirements for such alcohol fuel plants. The BATF will issue final regulations only after careful consideration of the comments re. ceived on these temporary regulations. 
EFFECTIVE DATE OF TEMPORARY REGULATIONS: July 1, 1980.

\section{FOR FURTHER INFORMATION CONTACT:}

John V. Jarowski, Alcohol Fuels Coordinator

Bureau of Alcohol, Tobacco, and Firearms

Washington, DC 20226

Telephone 202-566-7626

(Persons interested in applying for a permit should contact their BATF regional office. A list of addresses and toll-free telephone numbers is provided in Appendix $E$.)

SUPPLEMENTARY INFORMATION: This document contains temporary regulations implementing a portion of the Crude Oil Windfall Profits Tax Act of 1980 (Public Law 96-223). The temporary regulations provided by this document will remain in effect until superseded by final regulations on this subject.

\section{REGULATIONS}

\section{New Subpart $Y$ of 27 CFR Part 19.}

Regulations applicable to alcohol fuel plants have been included in a new subpart, Subpart Y, of Part 19, Distilled Spirits Plants. Fxcept for those portions of Subparts $A$ through $X$ of Part 19 which have been incorporated in the new subpart by reference, alcohol fuel plants are not subject to the provisions applicable to other distilled spirits plants. While this document provides simplified BATF regulations for alcohol fuel plants, persons wishing to establish a plant should check with other Federal (EPA), state, and local authorities as to their specific requirements.

\section{Definitions.}

Where necessary, terms have been defined as used in the new subpart. In some instances, BATF needed to redefine a term used elsewhere in Part 1Y. For instance, the term "distilled spirits", as used in Subpart Y, does not include distilled spirits produced from petroleum, natural gas, or coal. In addition, BATF introduces some new terms. For example, the term "alcohol fuel plant" means a distilled spirits plant established under Subpart Y solely for producing, processing and storing, and using or distributing distilled spirits to be used exclusively for fuel use. The term "fuel alcohol" means spirits which have been rendered unfit for beverage use as provided in Subpart $Y$ and are eligible to be withdrawn free of tax exclusively for fuel use.

\section{Permits.}

Any person wishing to cstablish an alcohol fuel plant must first make application for and obtain an Alcohol
Fuel Producer's Permit. For purposes of the type of application required (as well as for bonding and other requirements), BATF classifies alcohol fuel plants into three categories:

(a) Small plants - produce (including receipts of) not more than 10,000 proof gallons per calendar ycar;

(b) Medium plants - produce (including receipts of) more than 10,000 but not more than 500,000 proof gallons per calendar year; and,

(c) Large plants - produce (including receipts of) more than 500,000 proof gallons per calendar year.

These classes are based on the tax liabilities incident to the various levels of activity, as well as differences in capital expenditures and attendant technical sophistication required to set up plants of different sizes. By law, small plants are exempt from bonding and special rules apply to their applications.

In determining the level of activity at a plant for purposes of bonding and qualification, BATF considers spirits received from another plant as additional production. With respect to small plants, this approach has no elfect on a proprietor who will receive no spirits from other plants. Proprietors of other small plants, however, may wish to distill less than 10,000 proof gallons of spirits per year and receive additional spirits frort other plants. Those proprietors may produce and receive up to a total of 10,000 proof gallons per year and still be exempt from bonding. Counting receipts as additional production simplifies the regulations for bonds and qualification of plants.

\section{Application Requirements.}

Applications are filed on BATF Form 5110.74 furnished by the Bureau (See Figure B-1). For small plants, only the form needs to be filed. For medium and large plants, a bond must be placed and some additional information (to be identified in Section 6) must be provided. Also, the law requires bonds for the medium and large plants. Applications are to be submitted to the regional regulatory administrator of the BATF region in which the plant is located.

Having an application form should avoid confusion as to the information required to be submitted and serve to expedite processing of applications.

Although BATF expects numerous applications to be filed in response to the temporary regulations, BATF anticipates that permits will be issued expeditiously. With respect to the small plants in particular, action well within the 60-day statutory limitation should be possible. 
In general, a permit will be issued to any person who files a completed application (together with a bond for medium and large plants). Criteria for denial of applications, and for subsequent suspension or revocation of permits in the case of false or incomplete applications, are set forth in Sections 19.936 and 19.953 of the regulations. Time permitting, BATF may conduct an investigation and on-site inspection prior to issuance of the permit.

\section{Changes Affecting Permits.}

Permits may not be sold or transferred. If a different person purchases or acquires control of the plant, that person must file a new application. Also, BATF issues permits to cover specified plant premises. Any change in the location or extent of plant premises requires submission of an application to the regional regulatory administrator to amend the permit. Sections 19.945 through 19.953 provide more details on changes affecting permits and administratrive and procedural matters relative to permits.

\section{Bonds.}

Bonds give the government security against possible loss of distilled spirits tax revenue. While tax is not collected on distilled spirits for fuel use lawfully produced and used as fuel, liability for tax, by law, attaches to the spirits on creation. The proprietor generally obtains a bond from a surety or insurance company, by paying a premium based on the penal sum required for the bond.

The law exempts small plants producing (including teieipls of noi more than 10,000 proof gallons per year from furnishing bonds. For medium and large plants which are required to file bonds, the penal sum required is based on the tax liability to be covered. There are two sources of this tax liability:

(a) The tax on spirits that will be produced (including spirits rendered unfit for beverage use in the process of production, as provided in Section 19.98.3); and,

(b) The tax on spirits that will be received by transfer in bond (see Sections 19.996 through 19.999).

In the temporary regulations, the penal sum of the bond is based on the quantity in proof gallons of spirits that will be produced (including receipts) in a calendar year.

The bond for a medium plant producing (including receipts of) between 10,000 and 20,000 proof gallons per year is $\$ 2,000$. For each increase of 10,000 proof gallons (or fraction thercof) in total annual production (including receipts), the bond penal sum is increased $\$ 1,000$. The maximum bond for a medium plant is
$\$ 50,000$ (applicable to plants producing (including receipts) between 490,000 and 500,000 proof gallons per year).

For large plants, the amount of the bond is $\$ 50,000$ plus an additional $\$ 2,000$ for each 10,000 proof gallons (or fraction) produced and received in excess of 500,000. The maximum bond for a large plant is $\$ 200,000$. Any plant producing (including receipts) in excess of $1,240,000$ proof gallons of spirits in a calendar year must furnish a bond in the amount of $\$ 200,000$.

Documentation required is BATF Form 5110.56, as shown in Figure B-2.

\section{Premises, Equipment, and Security.}

The premiscs of an alcohol fuel plant include all areas where distilled spirits are produced, processed, stored, used, or held for distribution. BATF reguires buildings and equipment used in alcohol fucl plant operations to be constructed and arranged to enable the proprietor to maintain security adequate to deter diversion of the spirits. Regional regulatory administrators can require additional measures if security at a plant is found to be inadequate.

\section{Supervision of Operations.}

Regional regulatory administrators may assign BATF officers to alcohol fuel plants to supervise operations or to conduct inspections and audits. Authorities of BATF officers to carry out their duties have been incorporated by reference in the tempurary regulations. BATH oftıcers have a right of access to plant premises at all times to perform their official duties. The regulations require proprietors to render assistance to BATF officers in perforining gauges and examining equipment and containers, as necessary, to determine that all spirits are lawfully accounted for.

\section{Accounting for Spirits.}

The regulations require proprietors to determine and record the quantities of spirits produced, received, rendered unfit for beverage use, and used or removed from the premises. The records must be adequate to allow BATF officers to verlfy that the proprietor has lawfully disposed of all spirits. BATF requires no government forms or specific formats for these records. Commercial invoices, books of account, and other proprietary records are sufficient, so long as they show the information required by the regulations.

The regulations also require proprietors to file periodic reports of their operations. Frequency of reporting varies with the size of the plant: annually for small plants, semiannually for medium plants, and quarterly for large 
plants. The required form is BATF Form 5110.75, as shown in Figure B-3.

\section{Withdrawal of Spirits.}

Distilled spirits withdrawn from alcohol fuel plants may be used only for fuel purposes. Before withdrawing spirits from plant premises, the proprietor must render the spirits unfit for beverage use. The only exception to this requirement is for spirits transferred to other plants.

The regulations in Section 19.992 provide that fuel alcohol is considered unfit for beverage use when, for each 100 gallons of spirits, the proprietor has added to the spirits five gallons or more of gasoline, automotive gasoline, kerosene, deodorized kerosene, rubber hydrocarbon solvent, methyl isobutyl ketone, mixed isomers of nitropropane, any combination of the foregoing, or 5 gallons of isopropyl alcohol and 1/8-ounce of denatonium benzoate N.F. (Bitrex). BATF selected these substances based on denatured alcohol and solvent formulations currently provided by regulation or ruling, and on requests and inquiries from persons currently involved in producing alcohol fuels. Proprietors may request authorization to use substitute materials under Section 19.993 of the regulations.

Once rendered unfit for beverage use, fuel alcohol is eligible to be withdrawn free of tax. However, BATF does require proprietors to account for fuel alcohol remaining on plant premises and keep records of all sales and other dispositions of fuel alcohol.

\section{Use on Premises.}

Proprietors may use spirits for fuel on the premises of an alcohol fuel plant without rendering the spirits unfit for beverage use. The proprietor must record the quantities of spirits so used.

\section{Transfers in Bond.}

Proprietors may transfer spirits to another alcohol fuel plant. The proprietor need not render the spirits unfit for beverage use prior to transfer. Generally, liability for the $\operatorname{tax}$ on the spirits while in transit is the responsibility of the receiving proprietor.

The temporary regulations prescribe procedures to be followed when transferring spirits between alcohol fuel plants. A commercial invoice or shipping document is required to cover each shipment of spirits. These procedures are necessary to guard against diversion of spirits to beverage use.

Spirits also may be transferred between other distilled spirits plants and alcohol fuel plants. For such transfers, procedures and forms are prescribed in Sections 19.506 through 19.510 of the regulations.
The following are the Bureau of Alcohol, Tobacco, and Firearms regulations now in force, effective date of temporary regulations is July 1, 1980.

\section{DEPARTMENT OF THE TREASURY}

Bureau of Alcohol, Tobacco and Firearms

\author{
FUEL USE OF DISTILLED SPIRITS- \\ IMPLEMENTING A PORTION OF THE CRUDE \\ OIL \\ WINDFALL PROFIT TAX ACT OF 1980 \\ (Public Law 96-223)
}

AGENCY: Bureau of Alcohol, Tobacco and Firearms, Department of the Treasury

ACTION: Temporary rule (Treasury decision)

SUMMARY: This temporary rule implements Section 232, Alcohol Fuels, in Part III of Title II of the crude Oil Windfall Profit Tax Act of 1980 (P.L. 96-223). The temporary rule provides for the establishment and operation of distilled spirits plants solely for producing, processing and storing, and using or distributing distilled spirits (ethyl alcohol) exclusively for fuel use. P.L. 96-223 vests the Secretary of the Treasury with authority to simplify and liberalize statutory requirements for such alcohol fuel plants. The Bureau of Alcohol, Tobacco and Firearms (ATF) will issue final regulations only after careful consideration of the comments received on these temporary regulations.

\section{FOR FURTHER INFORMȦTION CONTACT:}

John V. Jarowski, Research and Regulations Branch, Bureau of Alcohol, Tobacco and Firearms, Washington, DC 20226, Telephone 202-566-7626.

(Persons interested in applying for a permit should contact their ATF regional office. A list of addresses and toll free telephone numbers is provided in Appendix E.)

SUPPLEMENTARY INFORMATION: This document contains temporary regulations implementing a portion of the Crude Oil Windfall Profit Tax Act of 1980 (Public Law 96-223). The temporary regulations provided by this document will remain in effect until superseded by tinal regulations on this subject. A notice of proposed rulemaking with respect to final regulations appears elsewhere in this issue of the Federal Register.

\section{Legislative Background}

In the Energy Tax Act of 1978 (P.L. 95-618) Congress required the Secretary of the Treasury to propose legislative recommendations to facilitate fuel use of distilled spirits. In compliance with this mandate, the 
Bureau submitted a proposal in 1979. Congress incorporated the proposed legislation, with modifications, in P.L. 96-223.

Public Law 96-223 added a new section to Subchapter B of Chapter 51 of the Internal Revenue Code of 1954. New Section 5181, Distilled Spirits for Fuel Use, provides for the establishment of distilled spirits plants solely for the purpose of producing, processing and storing, and using or distributing distilled spirits to be used exclusively for fuel use. The Secretary of the Treasury is directed to expedite all applications, to establish a minimum bond, and to generally encourage and promote (through regulation or otherwise) the production of alcohol for fuel purposes. The law gives the Secretary authority to provide by regulation for the waiver of any provision of Chapter 51 (except section 5181 or any provision requiring the payment of tax). This waiver authority may be exercised with respect to alcohol fuel plants as necessary to carry out the provisions of Section 5181.

The law exempts alcohol fuel plants which produce not more than 10,000 proof gallons of distilled spirits annual. ly from furnishing a bond to cover the tax liability on the spirits. Also, persons wishing to establish such plants are assured by law that their applications for permits in operatc will be acted upon within 60 days or less after receipt of a completed application. If this limit is exceeded, the application is automatically approved.

Distilled spirits may be withdrawn from alcohol fuel plants free of tax after having been rendered unfit for beverage use. The term "rendered unfit for beverage use" is used iv clearly distinguish this requirement for fuel spirits from "denaturation," which is required for spirits withdrawn from other distilled spirits plants.

A principal reason for encouraging production of distilled spirits for fucl use is that these spirits are substituted for scarce fossil fuels. Therefore, in defining distilled spirits for purposes of the alcohol fuel provisions, the law excludes distilled spitiis produced trom petroleum, natural gas, or coal.

Finally, P.L. 96-223 amended Section 5601 to impose criminal penalties on any person who withdraws, uses, sells, or otherwise disposes of distilled spirits produced under Section 5181 for other than fuel use.

\section{Regulations}

1. New Subpart Y of 27 CFR Part 19. Regulations applicable to alcohol fuel plants have been included in a new subpart, Subpart Y, of Part 19, Distilled Spirits Plants. Except for those portions of Subparts A through $X$ of Part 19 which have been incorporated in the new subpart by reference, alcohol fuel plants are not subject to the provisions applicable to other distilled spirits plants. Whilc this document provides simplified ATF regulations for alcohol fuel plants, persons wishing to establish a plant should check with other Federal (EPA), State and local authorities as to their specific requirements.

2. Definitions. Where necessary, terms have been defined as used in the new subpart. In some in stances, ATF needed to redefine a term used elsewhere in Part 19. For instance, the term "distilled spirits" as used in Subpart $Y$ does not include distilled spirits produced from petroleum, natural gas, or coal. In addition, ATF introduces some new terms. For example, the term "alcohol fuel plant" means a distilled spirits plant established under Subpart $\mathrm{Y}$ solely for producing, processing and storing, and using or distributing distilled spirits to be used cxclusively for fuel use. The term "fuel alcohol" means spirits which have been rendered unfit for beverage use as provided in Subpart $Y$ and are eligible to be withdrawn free of tax exclusively for fuel use.

3. Permits. Any person wishing to establish an alcohol fuel plant must first make application for and obtain an Alcohol Fuel Producer's Permit. For purposes of the type of application required (as well as for bonding and other requirements), ATF classifies alcohol fuel plants into three categories:

(a) Small plants-producing (including receipts of) not more than 10,000 proof gallons per calendar year;

(b) Medium plants-produce (including receipts of) more than 10,000 but not more than 500,000 proof gallons pescalendar yeăr; and

(c) Large plants-produce (including receipts of) more than 500,000 proof gallons per calendar year.

Thcse classes ate based on the tax labulties incident to the various levels of activity, as well as differences in capital expenditures and attendant technical sophistication required to set up plants of different sizes. By law, small plants are exempt from bonding and special rules apply to their applications.

In determining the level of activity at a plant for purposes of bonding and qualification, ATF considers spirits received from another plant as additional production. With respect to small plants, this approach has no effect on a proprietor who will receive no spirits from other plants. Proprietors of other small plants, however, may wish to distill less than 10,000 proof gallons of spirits per year and receive additional spirits from other plants. Those proprietors may produce and receive up to a total of 10,000 proof gallons per year and still bc exempt from 
bonding. Counting receipts as additional production simplifies the regulations for bonds and qualification of plants.

4. Application Requirements. Applications are filed on a form (ATF Form 5110.74) furnished by the Bureau. For small plants, only the form needs to be filed. For medium and large plants, some additional information must be provided. Also, the law requires bonds for the medium and large plants. Applications arc to be submitted in the regional regulatory administrator of the ATF region in which the plant is located.

Having an application form should avoid confusion as to the information required to be submitted and serve to expedite processing of applications. Comments as to the design of the form, the information required, and as to whether the use of form is desirable, are specifically requested. Although ATF expects numerous applications to be filed in response to the temporary regulations, ATF anticipates that permits will be issued expeditiously. With respect to the small plants in particular, action well within the 60 day statutory limitation should be possible.

In general, a permit will be issued to any person who filcs a completed application (together with a bond for medium and large plants). Criteria for denial of applications, and for subsequent suspension or revocation of permits in the case of false or incomplete applications, are set forth in Sections 19.936 and 19.953 of the regulations. Time permitting, ATF may conduct an investigation and on-site inspection prior to issuance of the permit.

5. Changes Affecting Permits. Permits may not be sold or transferred. If a different person purchases or acquires control of the plant, that person must file a new application. Also, ATF issues permits to cover specified plant premises. Any change in the location or extent of plant premises requires submission of an application to the regional regulatory administrator to amend the permit. Sections 19.945 through 19:953 provide more details on changes affecting permits and administrative and procedural matters relative to permits.

6. Bonds. Bonds give the Government security against possible loss of distilled spirits tax revenue. While tax is not collected on distilled spirits for fuel use lawfully produced and used as fuel, liability for tax, by law, attaches to the spirits on creation. The proprietor generally obtains a bond from a surety or insurance company, by paying a premium based on the penal sum required for the bond.

The law exempts small plants producing (including receipts of) not more than 10,000 proof gallons per year from furnishing bonds. For medium and large plants which are required 10 file bonds, the penal sum required is based on the tax liability to be covered. There are two sources of this tax liability:

(a) The tax on spirits that will be produced (including spirits rendered unfit for beverage use in the process of production, as provided in Sec. 19.983); and,

(b) The tax on spirits that will be received by transfer in bond (see Sections 19.996 through .19.999).

In the temporary regulations, the penal sum of the bond is based on the quantity in proof gallons of spirits that will be produced (including receipts) in a calendar year.

The bond for a medium plant producing (including receipts of) between 10,000 and 20,000 proof gallons per ycar is $\$ 2,000$. For each increase of 10,000 proof gallons (or fraction thereof) in total annual production (including receipts), the bond penal sum is increased $\$ 1,000$. The maximum bond for a medium plant is $\$ 50,000$ (applicable to plants producing (including receipts) between 490,000 and 500,000 proof gallons per year).

For large plants, the amount of the bond is $\$ 50,000$ plus an additional $\$ 2,000$ for each 10,000 proof gallons (or fraction) produced and received in excess of 500,000 . The maximum bond for a large plant is $\$ 200,000$. Any plant producing (including receipts) in excess of $1,240,000$ proof gallons of spirits in a calendar year must furnish a bond in the amount of $\$ 200,000$.

7: Premises, Equipment and Security. The premises of an alcohol fuel plant includes all areas where distilled spirits are produced, processed, stored, used or held for distribution. ATF requires buildings and equipment used in alcohol fuel plant operations to be constructed and arranged to enable the proprietor to maintain security adequate to deter diversion of the spirits. Regional regulatory administrators can require additional measures if security at a plant is found to be inadequate.

8. Supervision of Operations. Regional regulatory administrators may assign ATF officers to alcohol fuel plants to supervise operations or to conduct inspections and audits. Authorities of ATF officers to carry out their duties have been incorporated by reference in the temporary regulations. ATF officers have a right of access to plant premises at all times to perform their official duties. The regulations require proprietors to render assistance to ATF officers in performing gauges and examining equipment and containers, as necessary to determine that all spirits are lawfully accounted for. 
9. Accounting for Spirits. The regulations require proprietors to determine and record the quantities of spirits produced, received, and rendered unfit for beverage use, and used or removed from the premises. The records must be adequate to allow ATF officers to verify that the proprietor has disposed of all spirits lawfully. ATF requires no Government forms or specific formats for these records. Commercial invoices, books of account, and other proprietary records are sufficient, so long as they show the information required by the regulations.

The regulations also require proprietors to file periodic reports of their operations. Frequency of reporting varies with the size of the plant: annually for small plants, semiannually for medium plants, and quarterly for large plants.

10. Withdrawal of Spirits. Distilled spirits withdrawn from alcohol fuel plants may be used only for fuel puirposes. Before withdrawing spirits from plant premises, the proprietor must render the spirits unfit for beverage use. The only exception to this requirement is for spirits transferred to other plants.

The regulations in Sec. 19.992 provide that fuel alcohol is considered unfit for beverage use when for each 100 gallons of spirits, the proprietor has added to the spirits five gallons or more of gasoline, automotive gasoline, kerosene, deodorized kerosene, rubber hydrocarbon solvent, methyl isobutyl ketone, mixed isomers of nitropropane, any combination of the foregoing, or 5 gallons of isopropyl alcohol and $1 / 8$ ounce of denatonium hen moate N.F. (Bitrex). ATF selected these suhstances based on denatured alcohol and solvent formulations currently provided by regulation or ruling, and on reguests and inquirites from persons currently involved in producing alcohol fuels. Proprletors may request authorization to use substitute materials under Sec. 19.993 of the regulations.

Once rendered unfit for beverage use, fuel alcohol is eligible to be withdrawn free of tax. Hnwever, ATF does require proprietors to account for fuel alcohol remaining on plant premises and to keep records of all sales and other dispositions of fuel alcohol.

11. Use on Premises. Proprietors may use spirits for fucl on the premises of an alcohol fuel plant without rendering the spirits unfit for beverage use. The proprietor must record the quantities of spirits so used.

12. Transfers in Bond. Proprietnrs may transfer spirits to another alcohol fuel plant. The proprietor need not render the spirits unfit for beverage use prior to transfer. Generally, liability for the tax on the spirits while in transit is the responsibility of the receiving proprietor.
The temporary regulations prescribe procedures to be followed when transferring spirits betwecn alcohol fuel plants. A commercial invoice or shipping document is requircd to cover each shipment of spirits. These procedures are necessary to guard against diversion of spirits to beverage use.

Spirits also may be transferred between other distilled spirits plants and alcohol fuel plants. For such transfers, procedures and forms are prescribed inSections 19.506 through 19.510 of the regulations.

\section{Issues for Comment}

While all comments on these regulations are welcome and will receive careful consideration before final regulations are issued, ATF specifically requests comments on the following two issues.

1. Location of Plants in dwellings. Under existing regulations in 27 CFR Part 19, plants may not he located in any dwelling house, in any yard, shed, or enclosure connected with a dwelling house, or in certain other areas. Since ATF has not incorporated these restrictions in the temporary regulations, they do not apply to alcohol fuel plants.

As to yards, sheds, or enclosures, ATF feels the existing restrictions would place undue constraints on farm production of alcohol fuel. For urban and suburban areas, ATF feels that local zoning ordinances, fire codes, and similar provisions will preclude establishment of plants at inappropriate Incations. The alcohol fuel privducel's permit does not relieve the proprietrio of lie ubligatlons imposed by State or local law.

However, ATF will cousider prohibiting the establishment of plants in residential dwclling units. Accordingly, comments are requcsted as to whether such a prohibition is necessary or desirable.

2. Specifications for fuel alcohol and materials aüllıuized for use in rendering spirits unfit for beverage use. In contrast to existing denatured alcohol regulations in 27 CFR Parts 211 and 212, the temperary regulations do not require fuel alcohnl to be of any particular proof. In addition, proprietors have the uptiun to choose among a number of materials or combinations thereof to use in rendering spirits unfit. Proprietors will dccide both on the proof of the spirits and on what materials to use to render the spirits unfit, based on cost factors and on what works effectively for the particular fuel uses selected by themselves or their customers. The regulations do point out, however, that if gasoline is to be added to the spirits, unleaded gasoline may be required if the fuel alcohol will be used in certain engines. 
For some uses higher proof spirits (anhydrous or nearly so) are necessary. For other uses, lower proof spirits may be adequate.

ATF gives the proprietor options in this area because, beyond the blended motor fuels (e.g., gasohol) which are coming into widespread use, there is interest in using alcohol (once rendered unfit) for fuel purposes without blending with other fuels. ATF recognizes, however, that there may be a demand for tighter controls. For this reason, ATF will consider modifying the requirements for spirits rendered unfit, including specifying minimum proof levels for fuel alcohol. Accordingly, ATF specifically requests comments on the following questions:

(a) Are minimum proof standards necessary or desirable for fuel alcohol?

(b) Should the list of materials authorized for rendering spirits unfit for beverage use be broadened to include other substances, or sould some materials or options permitted under the temporary regulations be deleted?

(c) Are more detailed specifications for rendering spirits unfit necessary? If adopted, should these specifications be geared to the end use of the fuel alcohol?

\section{Experimental Plants}

1. General.Many persons have obtained permits to operate experimental distilled spirits plants (Section 5312) to produce distilled spirits for fuel purposes. The majority of these operations would qualify as small alcohol fuel plants under the temporary regulations. The authorized operations for experimental plants are generally more limited than under these temporary regulations, particularly as to removal or distribution of any spirits produced. The proprietor must furnish a bond. Also, experimental distilled spirits plant permits are issued for a limited time, usually two years. In contrast to experimental distilled spirits plants, alcohol fuel plants:

(a) Hold a permit which generally continues in effect indefinitely with no renewal required:

(b) Are authorized to sell or distribute the fuel alcohol they produce;

(c) Are exempt from bonding of annual production (including receipts) totals not more than 10,000 proof gallons; and,

(d) May transfer spirits between plants. Given the ad. vantages of operating as an alcohol fuel plant, ATF has developed a simplified procedure to convert outstanding experimental distilled spirits plant permits to alcohol fuel producer's permits, on the assumption that most proprietors will elect conversion. The proprietor of an experimental plant does not have to file an application to have the permit converted. With respect to any bond that was furnished, ATF regional offices will advise proprietors how to cancel surety bonds or secure refunds of cash or securities deposited in lieu of obtaining a surety bond.

2. Status of Existing Experimental Plants. Effective July 1,1980 , any person holding a permit to operate an experimental distilled spirits plant for fuel purposes will be considered as authorized to operate under these regulations. ATF regional offices are notifying all affected proprietors. Before expiration of the outstanding permit, a new alcohol fuel producer's permit will be issued to each such proprietor. Applications which are currently pending to establish experimental distilled spirits plants for fuel purposes will be treated as applications for alcohol fuel producer's permits. Proprietors who do not wish to be converted to alcohol fuel plant status should file a written request with the regional regulatory administrator.

\section{Addresses of Regional Regulatory Administrators}

Any person who wishes to apply for a permit under the regulations in this document may obtain the required forms and further information from the regional regulatory administrator of the region in which the plant will be located. A list of addresses and toll-free telephone numbers is provided in Appendix E.

\section{Effective Date}

The Energy Tax Act of 1978 (Pub. L. 95-618, 92 Stat. 3174) directed the Secretary to expedite, to the maximum extent possible, the applications of persons desiring to produce distilled sirits for fuel use, and to suggest legislative amendments which could reduce the amount of regulation to which such fuel producers would be subject. In furtherance of the first mandate, existing waiver authority under 26 U.S.C. 5312 was used to facilitate establishment of alcohol fuel plants on an experimental basis. The proposed legislative amendments have not been enacted as part of Pub. L. 96-223.

Pub. L. 96-223 gives the Secretary broad authority to waive or reduce existing regulatory requirements for plants which will produce distilled spirits exclusively for fuel use, such as, by allowing simplified application and recordkeeping procedures, and by providing reduced control and bonding requirements. In addition, an expedited application procedure (with no bond) is provided for small producers. For such producers, the law 
requires action on the issuance of a permit within sixty days of submission of a completed application. Pub. L. 96-223 is effective July 1, 1980.

Immediate guidance is necessary for the affected parties, both potential new applicants to produce distilled spirits for fuel purposes and persons currently operating as proprietors of experimental distilled spirits plants, to reap the benefits of the new law upon its becoming effective.

The issuance of this Treasury decision with notice and public procedure under 5 U.S.C. 553(d) is impracticable and not in the public interest, because absence of these regulations would create a serious delay in the production of alcohol fuel, inconsistent with the intent of the Energy Tax Act of 1978 (Pub. L. 95-618, 92 Stat. 3174) and the Crude Oil Windfall Profit Tax Art of 1980 (Pub. L. 96-223, 94 Stat. 229) to encourage the expeditious production of alcohol fuels. Immediate action is necessary to avoid delay and facilitate production of alcohol fuel, in implementing the Crude Oil Windfall Profit Tax Act of 1980, which is effective July 1, 1980. Accordingly, this Treasury decision becomes effective on July $1,1980$.

\section{Authority and issuance}

These regulations are issued under the authority contained in 26 U.S.C. 5181 (94 Stat. 278) and 26 U.S.C. 7805. (68A Stat. 917, as amended).

Accordingly, Title 27 Code of Federal Regulations is amended as follows:

\section{PART 19-DISTILLED SPIRITS PLANTS}

Paragraph 1. The table of sections is amended to reflect the addition of $\$ 19.63 \mathrm{a}$ immediately following $\$ 19.63$ and the addition of Subpart Y-Distilled Spirits for Fuel Use. As amended, the table of sections reads as follows:

Subpart D-Administrative and Miscellaneous Provisịons

\$19.63a Alcohol fuel plants.

Subpart Y-Distilled Spirits for Fuel Use

$\$ 19.931$ Scope of subpart

$\$ 19.932$ Taxes

$\$ 19.933$ Status of existing experimental distilled spirits plants

$\$ 19.934$ Meaning of terms
Permits

$\$ 19.935$ Application for permit required

$\$ 19.936$ Criteria for issuance of permit

$\$ 19.937$ Small plants

$\$ 19.938$ Waiver of bond requirement for small plants

$\$ 19.939$ Medium plants

$\$ 19.940$ Large plants

$\$ 19.942$ Information already on file and supplemental information

Changes Affecting Permits

$\$ 19.945$ Automatic termination of permits

$\$ 19.946$ Change in type of alcohol fuel plant

$\$ 19.947$ Change in name of proprietor

$\$ 19.948$ Changes in officers, directors, or principal perisurs

$\$ 19.949$ Change in proprietorship

$\$ 19.950$ Cuntlnuing partnerships

$\$ 19.951$ Change in location

\section{Permanent Discontinuance of Business}

$\$ 19.952$ Notice of permanent discontinuance

Suspension or Revocation of Permits

$\$ 19.953$ Suspension or revocation

Bonds

$\$ 19.956$ Ronds

$\$ 19.957$ Amount of bond

$\$ 19.958$ Instructions to compute bond penal sum

$\$ 19.959$ Conditions of bond

$\$ 19.960$ Additional provisions with respect to bonds

\section{Construction, Equipment and Security}

$\$ 19.972$ Construction and equipment

$\$ 19.973$ Security

\$19.974 Additional security

\section{Supervision}

\section{$\$ 19.975$ Supervision of operations}

\section{Accounting for Spirits}

\begin{tabular}{|ll}
$\$ 19.980$ & Gauging \\
$\$ 19.981$ & Inventories \\
$\$ 19.982$ & Records \\
$\$ 19.983$ & Spirits rendered unfit in the production \\
& process \\
$\$ 19.984$ & Record of spirits received \\
$\$ 19.985$ & Record of spirits rendered unfit for beverage \\
& use
\end{tabular}


$\$ 19.986$ Record of dispositions

$\$ 19.987$ Maintenance and retention of records

$\$ 19.988$ Reports

Transfers and Withdrawals

$\$ 19.989$ Withdrawal free of tax

$\$ 19.990$ Other uses prohibited

$\$ 19.991$ Requirement for rendering spirits unfit for beverage use

$\$ 19.992$ Authorized formulas for fuel alcohol

$\$ 19.993$ Substitute materials

$\$ 19.994$ Marks

$\$ 19.995$ Container size

Transfers Between Plants

$\$ 19.996$ Transfer in bond

$\$ 19.997$ Consignor premises

$\$ 19.998$ Reconsignment in transit

$\$ 19.999$ Consignee premises

Paragraph 2. A new $\$ 19.63 \mathrm{a}$ is added immediately following $\$ 19.63$. The new section incorporates authority to waive provisions of law and regulations with respect to alcohol fuel plants under the authoritites of the Director in Part 19. As added, $\$ 19.63$ a reads as follows:

\section{\$19.63a Alcohol fuel plants}

Under the provisions of Subpart $Y$ of this part, distilled spirits plants may be established solely for producing, processing and storing, and using distributing distilled spirits to be used exclusively for fuel use. To the extent the Director finds it necessary to carry out the provisions of 26 U.S.C. 5181, the Director may waive any provision of 26 U.S.C. Chapter 51 or this part (other than 26 U.S.C. 5181, this section, Subpart Y, or any provisions requiring the payment of tax).

(\$232, Pub. L. 96.233, 94 SLat. 278 (26 U.S.C. 5181))

Paragraph 3. $\$ 19.505$ is amended to provide for the transfer of spirits between plants qualified under 26 U.S.C. 5171 and alcohol fuellants. The statutes at large citation is also amended. As amended, $\$ 19.505$ reads as follows:

\section{$\$ 19.505$ Authorized transfers.}

(a) Spirits. Pursuant to approval of an application as provided for in $\$ 19.506$, bulk spirits (including denatured spirits) may be transferred in bond between bonded premises in bulk conveyances, or by pipeline, or in bulk containers into which spirits may be filled on bonded premises. However, spirits (including denatured spirits) produced from petroleum, natural gas, or coal, may not be transferred to alcohol fuel plants. Spirits transferred in bond from alcohol fuel plants to plants qualified under 26 U.S.C. 5171 shall be accounted for separately by the consignee proprietor, and shall not subsequently be withdrawn, used, sold or otherwise disposed of for other than fuel use.

(b) $* * *$

(\$201, P'ub. 1. 85-859, 72 Slal. 1362, as amended, 1380, as amended (26 U.S.C: 5212, 5362); \$232, Pub. L. 96-223, 94 Stal. 278 (26 U.S.C. $518(1))$.

Paragraph 4. A new Subpart $Y$-Distilled Spirits for Fuel Use, is added to provide regulations for alcohol fuel plants. As added, Subpart $Y$ reads as follows:

\section{Subpart Y-Distilled Spirits for Fuel Use}

$\$ 19.931$ Scope of subpart.

This subpart relates to the qualification and operation of distilled spirits plants established solely for producing, processing and storing, and using or distributing distilled spirits to be used exclusively for fuel use. Except where incorporated in this subpart by reference, the provisions of Subparts $A$ through $X$ of this part do not apply to alcohol fuel plants (see $\$ 19.63 a$ ).

(\$232, Pub. L. $96 \cdot 223,94$ Siat. 278 (26 U.S.C. 5181))

\section{$\$ 19.932$ Taxes}

(a) Distilled spirits tax. Distilled spirits may be withdrawn free of tax from the presmises of an alcohol fuel plant exclusively for fuel use in accordance with this subpart. Payment of tax will be required in the case of diversion of spirits to beverage use or other unauthorized dispositions. The provisions of Subpart $C$ of this part are applicable to distilled spirits for fuel use as follows:

(1) Imposition of tax liability ( $\$ 19.21$ through 19.25 );

(2) Assessment of tax ( $\$ 19.31$ and 19.32); and,

(3) Claims for tax ( $\$ 19.41$ and 19.44).

(b) Still tax. A commodity tax is imposed by 26 U.S.C. 5101 on the manufacturer for each still or condenser for distilling made by him. Manufacturers of stills are subject to a special occupational tax. However, a proprietor manufacturing stills or condensers exclusively for use in his plant or plants is exempt from these taxes. In addition, proprietors of alcohol fuel plants are exempt from the requirement of 26 U.S.C. 5105 to file an application and obtain a permit belore setting up distilling apparatus. Provisions relating to stills are contained in 27 CFR Part 196.

(\$201, Pub. L. 85-859, 72 Stat. 1314, as amended, $1339(26$ U.S.C. $5001,5101,5103) ; \$ 232$, Pub. L. $96-223,94$ Siai. $278(26$ U.S.C. 51811$)$ 
\$19.933 Status of existing experimental distilled spirits plants

Notwithstanding any other provisions of this subpart, effective July 1, 1980, the prior application and permit of existing experimental plants for alcohol fuel production under Section 5312 will be considered as approved applications to operate under the provisions of 26 U.S.C. 5181 as alcohol fuel plants. Such existing plants may continue to operate and the operations shall be conducted pursuant to the provisions of this subpart. A new permanent permit as an alcohol fuel plant will be issued in lieu of, and prior to the expiration date of, the existing permit as an experimental plant. However, persons who.wish to retain their permits under 26 U.S.C. 5312 as experimental distilled spirits plants, instead of converting to alcohol fuel plant status, may do so by filing a written request with the regional regulatory administrator.

\section{\$19.934 Meaning of terms}

When used in this subpart, and in forms prescribed under this subpart, terms shall have the meaning given in this section. Words in the plural form include the singular and vice versa, and words indicating the masculine gender include the feminine. The terms "includes" and "including" do not exclude things not enumerated which are in the same general class.

Alcohol fuel plant or plant. An establishment qualified under this subpart solely for producing, processing and storing, and using or distributing distilled spirits to be used exclusively for fuel use.

Alcohol fuel producer's permit. The document issued pursuant to 26 U.S.C. 5181 authorizing the person named therein to engage in business as an alcohol fuel plant.

ATF officer. An officer or employee of the Burealu of Alcohol, Tobacco and Firearms (ATF) authorized to perform any function relating to the administration or enforcement of this subpart.

Bonded Premises. The premises of an alcohol fuel plant where distilled spirits are produced, processed and stored, and used or distributed. Premises of small alcohol fuel plants, which are exempt from bonding under $\$ 19.938$, shall be treated as bonded premises for purposes of this subpart.

CFR. The Code of Federal Regulations.

Director. The Director, Bureau of Alcohol, Tobacco and Firearms, the Department of the Treasury, Washington, D.C.
Fuel alcohol. Distilled spirits which have been rendered unfit for beverage use at an alcohol fiel plant as provided in this subpart.

Gallon or wine gallon. The liquid measure equivalent to the volume of 231 cubic inches.

Person. An individual, trust, estate, partnership, association, company or corporation.

Proof. The ethyl alcohol content of a liquid at 60 degrees Fahrenheit, stated as twice the percent of ethyl alcohol by volume.

Proof gallon. A gallon of liquid at 60 degrees Fahrenheit which contains 50 percent by volume of ethyl alcohol having a specific gravity of 0.7939 at 60 degrees Fahrenheit referred to water at 60 degrees Fahrenheit as unity, or the alcoholic equivalent thereof.

Propriator. The person qualified undet this subpart to operate the alcohol fuel plant.

Region. A Bureau of Alcohol, Tobacco and Firearms region.

Regional regulatory administrator. The principal regional official responsible for administering regulations in this subpart.

Secretary. The Secretary of the Treasury or his delegate.

Spirits or distilled spirits. That substance known as ethyl alcohol, ethanol, or spirits of wine in any form (including all dilutions and mixtures thereof by whatever process produced), but not fucl alcoliol unless specificaily stated. For purposcs of this subpart, the term does not include spirits produced frum petroleum, natural gas, or coal.

This chapter. Title 27, Code of Federal Regulations, Chapter 1 (27 CHR Chapter I).

Transfer on bond. The transfer of spirits between alcohol fucl plants or between a distilled spirits plant. qualified under 26 U.S.C. 5171 and an alcohol fuel plant.

Type of plant. The following three types of alcohol fuel plants are recognized in this subpart:

(a) Small plant. An alcohol fuel plant which produces -including receipts) not morc than 10,000 proul gallons of spirits per calendar year.

(b) Medium plant. An alcohol fuel plant which produces (including receipts) more than 10,000 and not more than 500,000 proof gallons of spirits per calendar year. 
(c) Large plant. An alcohol fuel plant which produces (including receipts) more than 500,000 proof gallons of spirits per calendar year.

\section{U.S.C. The United States Code}

\section{Permits}

\$19.935 Application for permit required.

Any person wishing to establish an alcohol fuel plant shall first make application for and obtain an alcohol fuel producer's permit. Alcohol fuel producers permits are continuing. The permit continues in effect unless automatically terminated under $\$ 19.945$, suspended or revoked as provided in $\$ 19.953$, or voluntarily surrendered.

(\$232, Pub. L. 96-223, 94 Stat. 278 (26 U.S.C. 5181))

\section{$\$ 19.936$ Criteria for issuance of permit.}

In general, an alcohol fuel producer's permit will be issued to any person who completes the required application for permit and who furnishes the required bond (if any). However, the regional regulatory administrator may institute proceedings for the denial of the application, if the'regional regulatory administrator detcrmines that:

Persons wishing to establish a small plant shall apply for a permit as provided in this section. Except as provided in paragraph (d) of this section, operations may not be commenced until the permit has been issued.

(a) The applicant (including, in the case of a corporation, any officer, director, or principal stockholder, and in the case of a partnership, a partner) is, by reason of husiness experience, financial standing, or trade connections, not likely to maintain operations in compliance with 26 U.S.C. Chapter 51, or regulations issued thereunder; or

(b) The applicant has failed to disclose any material information required, or has made any false statement, as to any material fact, in connection with the application; or

(c) The premises on which the applicant proposes to conduct the operations are not adequate to protect the revenue. The procedures applicable to denial of applications are set forth in 27 CFR Part 200.

(\$201, Pub. L. 85-859, 72 Stat. 1370, as amended (26 U.S.C. 5271); \$232, Pub. L. 96-223, 94 Stat. 278 (26 U.S.C. 5181))

\section{$\$ 19.937$ Small plants.}

Persons wishing to establish a small plant shall apply for a permit as provided in this section. Except as provided in paragraph (d) of this section, operations may not be commenced until the permit has been issued. (a) Application for permit. The application (ATF Form 5110.74) shall be submitted to the regional regulatory administrator and shall set forth the following information:

(1) Name and mailing address of the applicant, and the location of the alcohol fuel plant, if not apparent from the mailing address;

(2) A diagram of the plant premises and a statement as to the ownership of the premises (if the premises are not owned by the proprietor, the owner's consent to access by ATF officers must be furnished);

(3) A description of all stills and a statement of their maximum capacity;

(4) The materials from which spirits will be produced;

(5) A description of the security measures to be used to protect premises, buildings, and equipment where spirits are produced, processed, and stored; and,

(6) A statement as to the environmental impact of the proposed operation.

\section{(b) Receipt by the regional regulatory administrator}

(1) Notice of receipt-Within 15 days of receipt of the application, the regional regulatory administrator shall send a written notice of receipt to the applicant. The notice will include a statement as to whether the application meets the requirements of paragraph (a). If the application does not meet those requirements, the application will be returned and a new 15-day period will commence upon receipt by the regional regulatory administrator of the amended or corrected application.

(2) Failure to give notice-If the required notice of receipt is not sent, and the applicant has a receipt indicating that the regional regulatory administrator has received the application, the 45-day period provided for in paragraphs (c) and (d) will commence on the fifteenth day after the date the regional regulatory administrator received the application.

(3) Limitation-The provisions of subparagraphs (1) and (2) will apply only to the first application submitted with respect to any one small plant in any calendar quarter. However, an amended or corrected first application will not be treated as a separate application. 
(c) Determination by the regional regulatory administrator. Within 45 days from the date the regional regulatory administrator sent the applicant a notice of receipt of a completed application, the regional regulatory administrator shall either (1) issue the permit, or (2) give notice in writing to the applicant, stating in detail the reason that a permit will not be issued. Denial of an application will not prejudice any further application for a permit made by the same applicant.

(d) Presumption of approval. If, within -45 days from the date of the notice to the applicant of receipt of a completed application, the regional regulatory administrator has not notified the applicant of issuance of the permit or denial of the application, the application shall be deemed to have been approved and the applicant may proceed as if a permit had been issued.

(\$2.32, Piih I. 96.323, 94 Stat. 278 (26 U.3.C. $518 \mathrm{i}$ )

\section{$\$ 19.938$ Waiver of bond requirement for small plants.}

No bond is required for small plants.

(§232, Pub. L. 96-223, 94 Stat. 278 (26 U.S.C. 5181))

\section{$\$ 19.939$ Medium plants.}

Any person wishing to establish a medium plant shall make application for and obtain an alcohol fuel producer's permit and furnish a bond as provided in this scetion. Operations may not be commenced until the applicaliun has beeni approved and the permit issued.

(a) Application for permit. The application (ATF Form 5110.74) shall be submitted to the regional regulatory administrator and shall set forth the fulluwing information:

1) The information required by $\$ 19.937(a)$;

(2) Statement of maximum total proof gallons of spirits that will be produced and received during a calendar year;

(3) Information identifying the principal persons involved in the business and a statement as to whether the applicant or any such person has ever been convicted of a felony or misdemeanor under Federal or State law; and,

(4) Statement of the amount of funds invested in the business and the source of those funds. (b) Bond required. A bond of sufficient penal sum, as prescribed in 19.958, must be submitted and approved before a permit may be issued.

(\$232, Pub. L. 96-223, 94 Stat. 278 (26 U.S.C. 5181))

\section{$\$ 19.940$ Large Plants.}

Any person wishing to establish a large plant shall make application for and obtain an alcohol fuel producer's permit and furnish a bond as provided in this section. Operations may not be commenced until the application has been approved and the permit issued.

(a) Application for permit. The application (ATF Form 5110.74 ) shall be submitted to the regional regulatory administrator and shall set forth the following information:

(1) The information required by $\$ 19.937(a)$;

(2) Statement of the maximum proof gallons of spirits that will be produced and received during a calendar year (not required if the bond is in the maximum sum);

(3) Information identifying the principal persons involved in the business and a statement as to whether the applicant or any such person has ever been convicted of a felony or misdemeanor under Federal or Statc law;

(4) Statement of the amount of funds invested in the business and the sourse of those funds; and,

(5) Statement of the type of business organization and of tlie persons interested in the business, supported by the ltems of information listed in $\S 19.941$.

(b) Bond required. A bond of sufficient penal sum, as prescribed in $\$ 19.958$, must be submitted and approved before a permit may be issued.

(\$232, Pul. L. 98-223, 94 Stat. 278 (26 U.S.C. 5181))

\section{$\$ 19.941$ Organizational documents.}

The supporting information required by paragraph (a)(5) of $\$ 19.940$, includes, as applicable, copies of-

\section{(a) Corporate documents.}

(1) Corporate charter or certificate of corporate existence or incolpuration.

(2) List of directors and officers, showing their names and addresses. However, do not list officers who have no responsibilities in connection with the operation of the alcohol fuel plant. 
(3) Certified extracts or digests of minutes of meetings of board of directors, authorizing certain individuals to sign for the corporation.

(4) Statement showing the number of shares of each class of stock or other evidence of ownership, authorized and outstanding, and the voting rights of the respective owners or holders:

\section{(b)Statement of interest.}

(1) Names and addresses of the 10 persons having the largest ownership or other interest in each of the classes of stock in the corporation, or other legal entity, and the nature and amount of the stockholding or other interest of each, whether the interest appears in the name of the interested party or in the name of another for him. If a corporation is wholly owned or controlled by another corporation, those persons of the parent corporation who meet the above standards are considered to be the persons interested in the business of the subsidiary, and the names thereof need be furnished only upon request of the regional regulatory administrator.

(2) In the case of an individual owner or partnership, the name and address of each person interested in the plant, whether the interest appears in the name of the interested party or in the name of another for that person.

(c) Availability of additional documents. The originals of documents required to be submitted under this section and additional items required under $\$ 19.942$ such as the articles of incorporation, bylaws, State certificate authorizing operations, or articles of partnership or association (in the case of a partnership where required by State law) shall be made available to any ATF of ficer upon request.

( $\$ 201$, Pub. L. 85-859, 72 Stat. 1349, as amended, 1370, as amended (26 U.S.C. 5172, 5271); §232, Pub. L. 96-223, 94 Stat. 278 (26 U.S.C. 5181))

$\$ 19.942$ Information already on file and supplemental information

If any of the information required by $\S \S 19.937$ through 19.941 is on file will the regional regulatory administrator, that information, if accurate and complete, may be incorporated by reference and made a part of the application. When required by the regional regulatory administrator, the applicant shall furnish as a part of the application for permit, additional information as may bc necessary to determine, whether the application should be approved.

(\$232, Pub. L. 96-223, 94 Stat. 278, (26 U.S.C. 5181))
Changes Affecting Permits

\section{$\$ 19.945$ Automatic termination of permits.}

(a) Permits not transferable. Permits issues under this subpart shall not be transferred. In the event of the lease, sale, or other transfer of such a permit, or of the authorized operations, the permit automatically terminates.

(b) Corporations. In the case of a corporation holding a permit under this subpart, if actual or legal control of the permittee corporation changes, directly or indirectly, whether by reason of change in stock ownership or control (in the permittee corporation or in any other corporation), by operation of law, or in any other manner, the permittee shall, within 10 days of such change, give written notice, executed under the penalties of perjury, to the regional regulatory administrator; the permit may remain in effect until the expiration of 30 days after the change, whereupon the periait will automatically terminate. However, if operations are to be continued after the change in control, and an application for a new permit is filed within 30 days of the change, then the outstanding permit may remain in effect until final action is taken on the new application. When final action is taken on the application, the outstanding permit automatically terminates.

(\$201, Pub. L. 85-859, 72 Stat. 1370, àsamended (26 U.S.C. 5271))

\section{\$19.946 Change in type of alcohol fuel plant.}

(a) Small plants. If the proprietor of a small plant wishes to increase production (including receipts) to a level in excess of 10,000 proof gallons of spirits per calendar year, the proprietor shall first furnish a bond and obtain an amended permit by filing application under $\$ \$ 19.939$ or 19.940 , as applicable. Information filed with the original application for permit need not be resubmitted, but may be incorporated by reference in the new application.

(b) Medium plants. Where the proprietor of a medium plant intends to increase production (including receipts) above 500,000 proof gallons of spirits per calendar year, the proprietor shall first obtain an amended permit by filing an application under $\$ 19.940$. A new or strengthening bond may be required (see $\$ 19.957(a)$ ). Information already on file may be incorporated by reference in the new application.

(c) Curtailment of activities. Proprietors of large or medium plants who have curtailed operations to a level where they are eligible to be requalified as medium or small plants may, on approval of a letter 
of application by the regional regulatory administrator, be relieved from the additional requirements incident to their original qualification. In the case of a change to small plant status, termination of the bond and relief of the surety from further liability shall be as provided in Subpart $\mathbf{H}$ of this part.

(\$201, Pub. L. 85-859, 72 Stat. 1370, as amended (26 U.S.C. 5271); $\S 232$, Pub. L. 96-223, 94 Stat. 278 (26 U.S.C. 5181))

\section{$\$ 19.947$ Change in name of proprietor.}

Where there is to be a change in the individual, firm, or corporate name, the proprietor shall, within 30 days of the change, file an application to amend the permit; a new bond or consent of surety is not required.

(\$101, Pub. L. 85-859, Stat. 1349, as amended, 1370, as amended (26 U.S.C. 5172, 5271); §232, Pub. L. 96-223, 94 Stat. 278 (26 U.S.C. $5181))$

$\$ 19.948$ Changes iti officers, directors, or principal persuns

Where there is any change in the list of officers, direclurs, or principal persons, furnished under the provisions of $\S \S 19.939,19.940$, or 19.941 , the proprietor shall submit, within 30 days of any such change, a notice in letter form including the new list of officers and a statement of the changes reflected in such list.

(\$232, Pub. L. 96-233, 94 Stat. 278 (26 U.S.C. 5181))

\section{$\$ 19.949$ Clıange in proprietorship.}

(a) General. If there is a change in the proprietorship of a plant qualified under this part, the outgoing proprietor shall comply wills the requirements of $\$ 19.952$ and the successor shall, before commencing operations, apply for and obtain a permit and file the required bond (if any) in the same manner as a person qualifying as the proprietor of a new plant.

(b) Fiduciary. A successor to the proprietorship of a plant who is an administrator, executor, receiver, trustee, assignee or other fiduciary, shall comply with the applicable provisions of $\$ 19.186(\mathrm{~b})$.

(\$201. Pub. L. 85-859, 72 Stat. 1349; as amended (26 U.S.C. 5172))

\section{$\$ 19.950$ Continuing partnerships.}

If under the laws of the particular State, the partnership is not terminated on death or insolvency of a partner, but continues until the winding up of the partnership affairs is complcted, and the surviving partner has the exclusive right to the control and possession of the partnership assets for the purpose of liquidation and settlement, the surviving partner may continue to operate the plant under the prior qualification of the partnership. However, in the case of a large or medium plant, a consent of surety must be filed, wherein the surety and the surviving partner agree to remain liable on the bond. If the surviving partner acquires the business on completion of the settlement of the partnership, he shall qualify in his own name from the date of acquisition, as provided in $\$ 19.949$ (a). The rule set forth in this section shall also apply where there is more than onc surviving partner.

(\$201, Pub. L. $85-859,72$ Stat. 1349 , as amended (26 U.S.C. 5172); §232, Pub. L. 96-223, 94 Stat. 278 (26 U.S.C. 5181))

\section{\$19.951 Change in location.}

Where there is a change in the location of the plant or of the area included within the plant premises, the proprietor shall file an application to amend the permit and, if a bond is required, either a new bond or a consent of surety on ATF Form 1533 (5000.18). Operation of the plant may not be commenced at the new location prior to issuance of the amended permit.

( $\$ 201$, Pub. L. 85-859, 72 Stat. 1349, as amended, 1370, as amended (26 U.S.C. 5172, 5271); $\$ 805(c)$, Pub. L: 96-39, 93 3tal. 296 (26 U.S.C. 5173); \$232, Pub. I.. 96-2.23, 94 Stat. 278 (26 U.S.C. 5181))

\section{Permanent Discontinuance of Business}

\section{$\$ 19.952$ Notice of permanent discontinuance.}

A proprietor who permanently discontinues operations as an alcohol fuel plant shall, after completion of the operations, file a letter head notice with the regional regulatory administrator. The notice shall be accompanied (a) by the alcohol fuel producer's permit, and by the proprietor's request that such permit be canceled; (b) by a written statement disclosing, as applicable. whether (1) all spirits (including fuel alcohol) have been lawfully disposed of, and (2) any spirits arc in transit to the premises; and (c) by a report covering the discontinued operations (the report shall be marked "Final Report").

( $\$ 201$, Pub. L. $85-859,72$ Stat. 1349 , as amended, 1370 , as amended (26 U.S.C. 5172, 5271); §232, Pub. L. 96-223, 94 Stat. 278 (26 U.S.C. 5181))

\section{Suspension or Revocation of Permits}

\section{$\$ 19.953$ Suspension or revocation}

Whenever the regional regulatory administualur has reason to believe that any person holding an alcohol fuel producer's permit-

(a) Has not in good faith complied with the applicable provisions of 36 U.S.C. Chapter 51, or regululions issued thereunder, or

\section{(b) Has violated conditions of the permit; or}

(c) Has made any false statement as to any material fact in the application therefore; or 
(d) Has failed to disclose any material information required to be furnished; or

(e) Has violated or conspired to violate any law of the United States relating to intoxicating liquor or has been convicted of any offense under Title 16, U.S.C. punishable as a felony or of any conspiracy to commit such offense: or

(f) Has not engaged in any of the operations authorized by the permit for a period of more than 2 years; the regional regulatory administrator may institute proceedings for the revocation or suspension of the permit in accordance with the procedures set forth in 27 CFR Part 200.

(\$201, Pub. L. 85-859, 72 Stat. 1370, as amended (26 U.S.C. 5271))

\section{Bonds}

\section{$\$ 19.956$ Bonds.}

An operations bond is required for medium and large plants. Surety bonds may be given only with corporate sureties holding certificates of authority from, and subject to the limitations prescribed by, the Secretary as set forth in the current revision of Treasury Department Circular 570. However, in lieu of corporate surety the proprietor may pledge and deposit as surety for his bond, securities which are transferable and are guaranteed as to both interest and principal by the United States, in accordance with the provisions of 31 CFR Part 225. The regional regulatory administrator will not release such securities until liability under the bond for which they were pledged has been terminated.

(\$805(c), Pub. L. 96-39,93 Stat. 276 (26 U.S.C. 5173); CH. 390, Pub. L. 80-280, 61 Stat. 648, 650 (6 U.S.C. 6, 7, 15); §232, Pub. L. 96-223, 94 Stat. 278 (26 U.S.C. 5181 ))

\section{\$19.957 Amount of bond.}

The penal sum of the bond is based on the total quantity of distilled spirits to be produced (including reseipts) during a calendar year. If the level of production and/or receipts at the plant is to be increased, and the bond shall be obtained.

(a) Medium plants. A medium plant which will produce (including receipts of) between 10,000 and 20,000 proof gallons of spirits per year requires a bond in the amount of $\$ 2,000$. For each additional 10,000 proof gallons (or fraction thereof), the bond amount is increased $\$ 1,000$. The maximum bond for a medium plant is $\$ 50,000$.

(b) Large plants. The minimum bond for a large plant is $\$ 52,000$ more than 500,000 , but not more than 510,000 proof gallons annual production (including receipts)). For each additional 10,000 (or fraction) proof gallons, the amount of the bond is increased
$\$ 2,000$. The maximum bond for a large plant is $\$ 200,000$ (more than $1,240,000$ proof gallons).

(§805(c, Pub. L. 96-39, 93 Stat. 276 (26 U.S.C. 5173); §232, Pub. L. 96-233, 94 Stat. 278 (26 U.S.C. 5181))

\section{\$19.958 Instructions to compute bond penal sum.}

(a) Medium plants. To find the required amount of your bond, estimate the total proof gallons of spirits to be produced and received in a calendar year. The amount of the bond is $\$ 1,000$ for each 10,000 proof gallons (or fraction), subject to a minimum of $\$ 2,000$ and a maximum of $\$ 50,000$. The following table provides some examples:

Annual production and receipts in proof gallons
More than but not over

$$
\begin{array}{r}
10,000 \text { to } 10,000 \\
20,000 \text { to } 30,000 \\
90,000 \text { to } 100,000 \\
190,000 \text { to } 200,000 \\
490,000 \text { to } 500,000
\end{array}
$$

Amount of bond

$$
\begin{array}{r}
\$ 2,000 \\
3,000 \\
10,000 \\
20,000 \\
50,000
\end{array}
$$

(b) Large plants. To find the required amount of your bond, estimate the total proof gallons of spirits to be produced and received in a calendar year. The amount of the bond is $\$ 50,000$ plus $\$ 2,000$ for each 10,000 proof gallons (or fraction) over 500,000 . The following table provides some examples:

Annual production and receipts in proof gallons

$\begin{array}{cc}\begin{array}{c}\text { More than but not } \\ \text { over }\end{array} & \text { Amount of bond } \\ 500,000 \text { to } 510,000 & \$ 52,000 \\ 510,000 \text { to } 520,000 & 54,000 \\ 740,000 \text { to } 750,000 & 100,000 \\ 990,000 \text { to } 1,000,000 & 150,000 \\ 1,240,000 & 200,000\end{array}$

(\$805(c), Pub. L. 96-39, 93 Stat. 276 (26 U.S.C. 5173); §232, Pub. L. 96-223, 94 Stat. 278 (26 U.S.C. 5181 ')

\section{$\S 19.959$ Conditions of bond.}

The bond shall be conditioned on payment of all taxes (including any penalties and interest) imposed by 26 U.S.C. Chapter 51, on compliance with all requirements of law and regulations, and on payment of all penalties incurred or fines imposed for violation of any such provisions.

(\$805(c), Pub. L. 96-39, 93 Stat. 276 (26 U.S.C. 5173); §232, Pub. L. 96-223, 94 Stat. 278 (26 U.S.C. 5181))

\section{$\$ 19.960$ Additional provisions with respect to bonds.}

Subpart II of this part contains further provisions applicable to bonds which, where not inconsistent with 
this subpart, are applicable to bonds of alcohol fuel plants.

\section{Construction, Equipment and Security}

\section{$\$ 19.972$ Construction and equipment.}

Buildings and enclosures where distilled spirits will be produced, processed, or stored shall be constructed and arranged to enable the proprietor to maintain security adequate to deter diversion of the spirits. Distilling equipment shall be constructed to prevent unauthorized removal of spirits, from the point where distilled spirits come into existence until production is complete and the quantity of spirits has been determined. Tanks and other vessels for containing spirits shall be equipped for locking and be constructed to allow for determining the quantities of spirits therein.

(\$201, Pub. L. $85-859,72$ Stat. 1353, as amended (26 U.S.C. 5178 ))

\section{$\$ 19.973$ Security.}

Proprietors shall provide security adequate to deter the unauthorized removal of spirits. The proprietor shall store spirits either in a building, a storage tank, or within an enclosure, which the proprietor will keep locked when operations are not being conducted.

( $\$ 201$, Pub. L. $85-859,72$ Stat. 1353, as amended (26 U.S.C. 5178); \$806, Pub. L. 96-39, 93 Stat. 279 (26 U.S.C. 5202))

\section{$\$ 19.974$ Additional security.}

If the regional regulatory administrator finds that security is inadequate to deter diversion of the spirits, as may be evidenced by the occurrence of break-ins or by diversion of spirits to unauthorized purposes, additinnal security measures may be required. Such additional measures may include, but are not limited to, the following:

(a) The erection of a fence around the plant or the alcohol storage facility;

(b) Flood lights;

(c) Alarm systems;

(d) Watchman services; or,

(e) Locked or barred windows.

The exact additional security requirements would depend on the extent of the security problems, the volume of alcohol produced, the risk to tax revenue, and safety requirements.

( $\$ 201$, Pub. L. $85-859,72$ Stat. 1353, as amended (26 U.S.C. 5178); $\S 806$, Pub. L. 96-39, 93 Stat. 279 (26 U.S.C. 5202))

\section{Supervision}

\section{$\$ 19.975$ Supervision of operations.}

The regional regulatory administrator may assign ATF officers to premises of plants qualified under this subpart. The anthnrities of ATF officcrs, provided in $\$ \$ 19.80$ through 19.84 , and the requirement that proprietors keep premises accessible to and furnish facilities and assistance to ATF officers, provided in $\$ \$ 19.85$ and 19.86 , apply to plants qualified under this subpart.

( $\$ 201$, Pub. L. 85-859, 72 Stat. 1320, as amended, 1357, as amended, 1358, as amended 1375, as amended (26 U.S.C. 5006, 5203, 5204, 5213))

\section{Accounting for Spirits}

\section{\$19.980 Gauging.}

(a) Equipment and method. Proprietors shall gauge spirits by accurately determining the proof and quantity of spirits. The proof of the spirits shall be determined using a glass cylinder, hydrometer, and thermometer. However, fuel alcohol may be accounted for in wine gallons, so it is not necessary to determine the proof of fuel alcohol manufactured, on-hand, or removed. The proprietor may determine quantity either by volume or weight. A tank or receptacle with a calibrated glass scale installed, a calibrated dipstick, conversion charts, or (subject to approval by the Director) meters, may be used to determine quantity by volume. Detailed procedures for gauging spirits are provided in 27 CFR Part 13.

(b) When Required. Proprietors shall gauge spirits and record the results in their records at the following times:

(1) On completion of production of distilled spirits;

(2) On receipt of spirits at the plant;

(3) On addition of materials to render the spirits unfit for beverage use;

(4) Before withdrawal of spirits (including fuel alcohol) from plant premises or other disposition thereof; and,

(5) When spirits are to be inventoried.

\section{$\$ 19.981$ Inventories.}

Proprietors shall take actual physical inventory of all spirits (including fuel alcohol) on bonded premises at least once during each period for which a report is required by $\$ 19.988$. The results of the inventory shall be 
posted in the applicable reocrds required by $\$ 19.982$. (\$201, Pub. L. 85-859, 72 Stat. 1356, as amended (26 U.S.C. 5201))

\section{$\$ 19.982$ Records.}

(a) All plants. All proprietors shall maintain records with respect to:

(1) The quantity and proof of spirits produced;

(2) The proof gallons of spirits on-hand and received;

(3) The quantities and types of materials added to render the spirits unfit for beverage use;

(4) The quantity of fuel alcohol manufactured; and,

(5) All dispositions of spirits (including fuel alcohol). Fuel alcohol may be recorded in winc gallons.

(b) Medium and large plants. Proprietors of medium and large plants shall also record the kind and quantity of materials used to produce spirits.

(c) General requirements. The records must contain sufficient information to allow ATF officers to determine the quantities of spirits produced, received, stored, or processed and to verify that all spirits have been lawfully disposed of or used. However, the proprietor need not prepare records specifically to meet the requirements of this subpart. Records which the proprietor prepares for other purposes (i.e., invoices or other commercial records) are sufficient, so long as they show all the required information.

(\$807, Pub. L. 96-39, 93 Stat. 284 (26 U.S.C. 5207))

\section{$\$ 19.983$ Spirits rendered unfit in the production process.}

If the proprietor renders spirits unfit for beverage use before removal from the production system, the production records shall also include the kind and quantity of materials added to each lot of spirits. In such a case, a separate record under $\$ 19.985$ is not required. This paragraph applies to in-line addition of materials and to systems in which, before any spirits come off the production equipment, the proprietor adds materials for rendering the spirits unfit for beverage use to the first receptacle where spirits are to be deposited.

(\$807, Pub. L. 96-39, 93 Stat. 284 (26 U.S.C. 5207); \$232, Pub. L. 96-223, 94 Stat. 278 (26 U.S.C. 5181))

\section{$\$ 19.984$ Record of spirits received.}

The proprietor's copy of the consignor's involce or other document received with the shipment, on which the proprietor has noted the date of receipt and quantity received, constitutes the required record.

(\$807, Pub. L. 96-39, 93 Stat. 284 (26 U.S.C. 5207))

\section{\$19.985 Record of spirits rendered unfit for beverage} use.

The proprietor shall record the kind and quantity of materials added to render each lot of spirits unfit for beverage use and the quantity of fuel alcohol manufactured (which may be given in wine gallons).

( $(8007$, Pub.L. 96-39, 93 Stat. 284 (26 U.S.C. 5207)).

\section{$\$ 19.986$ Record of dišpositions.}

(a) Fuel alcohol. For fuel alcohol distributed, used, or otherwise disposed of the proprietor shall record the-

(1) Quantity of fuel alcohol;

(2) Date of disposition; and

(3) Name and address of the person to whom distributed or, if used or otherwise disposed of by the proprietor, the purpose for which used or the nature of the other disposition (e.g., destruction or redistillation). Commercial invoices, sales slips, or similar documents are acceptable if they clearly show the required information.

(b) Spirits.

(1) For spirits transferred in bond to another alcohol fuel plant, the commercial invoice or other document required by $\$ 19.997$ constitutes the required record. For transfers to other distilled spirits plants, the form required by $\$ 19.508$ is the required record.

(2) For spirits used or otherwise disposed of (e.g., lost, destroyed, redistilled) on the premises of the alcohol fuel plant, the proprietor shall maintain a record as follows:

(i) the quantity of spirits (in proof gallons) and the date of disposition;

(ii) the purpose for which used or the nature of the other disposition.

(\$807, Pub. L. 96-39, 93 Stat. 284 (26 U.S.C. 5207))

\section{$\$ 19.987$ Maintenance and retention of records.}

The proprietor shall retain the records required by this subpart for a period of not less than three years from the date thereof or from the data of the last entry made 
thereon, whichever is later. The records shall be kept at the plant where the operation or transaction occurs and shall be available for inspection by any ATF officer during business hours. For records maintained on data processing equipment, the provisions of $\$ 19.743$ apply. ( $\$ 807$, Pub. L. 96-39, 93 Stat. 284 (26 U.S.C. 5207)).

\section{\$19.988 Reports.}

Proprietors shall file reports of their operations, depending on the type of plant, as follows:

Type of Plant and Reporting Periods

Small plant-Annually (December 31 )

Medium plant-Semiannually (June 30 and

December 31)

Large plant-Quarterly (Close of each cạlendar quarter)

The proprietor shall submit each required report to the regional regulatory administrator within 30 days after the close of the applicable reporting period. The report shall be submitted on a form provided for that purpose. (\$807, Pub. L. 96-39, 93 Stat. 284 (26 U.S.C. 5207))

\section{Transfers and Withdrawals}

\section{$\$ 19.989$ Withdrawal free of tax.}

Fuel alcohol produced under this subpart, may be withdrawn free of tax from plant premises exclusively for fuel use.

(\$201, Pub. L. 85-859, 72 Stat. 1362, as amended (26 U.S.C. 5214); \$232, Pub: L. 96-223, 94 Stat. 278 (26 U.S.C. 5181))

\section{$\$ 19.990$ Other uses prohihite.f.}

The law imposes criminal penalties on any person who withdraws, uses, sells or otherwise disposes of distilled spirits (including fuel alcoho1) produced under this subpart for other than fuel use.

(§201, Pub. L. 85-859, 72 Stat. 1398, as amended (26 U.S.C. 5601); 8232, Pub. L. 96-223, 94 Stat. 278 (26 U.S.C. 5181))

\section{\$19.991 Requirement for rendering spirits unfit for beverage use.}

Before spirits may be withdrawn from plant premises, the spirits must contain, or the proprietor shall add, substances to render the spirits unfit for beverage use as provided in this subpart. However, spirits used for fuel on the premises of the alcohol fuel plant and spirits transferred to other plants need not be rendered unfit for beverage use.

(§232, Pub. L. 96-223, 94 Stat. 278 (26 U.S.C. 5181))

\section{$\$ 19.992$ Authorized formulas for fuel alcohol.}

Spirits will be considered rendered unfit for beverage use and eligible for tax-free withdrawal as fuel alcohol, when for every 100 gallons of spirits, there has been added:

(a) 5 gallons or more of-

(1) Gasoline or aulumulive gasoline (for use in engines which require unleaded gasoline. Environmental Protection Agency regulations and manufacturer's specifications may require that unleaded gasoline be used to render the spirits unfit).

(2) Kerosene

(3) Deodorized kerosene

(1) Rubber hydrücáıbuiı sulvent,

(5) Methyl isobutyl ketone,

(6) Mixed isomcrs of nitrupıupane, or

(7) Any combination of (1) through (6); or,

(b) $1 / 8$ ounce of denatonium benzoate N.F. (Bitrex) and 5 gallons of isopropyl alcohol.

(§232, Pub. L. $96-233$, 94 Stat. 278 (26 U.S.C. 5181))

\section{\$19.993 Substitute Materials.}

Other materials may be used to render spirits unfit for beverage use subject to approval by the Director. A proprictor who wislıes to use substitutc materials to render spirits unfit for beverage use may submit a letter requesting authorization to the Director through the regional regulatory administrator. The letter should state the materials, and the quantity of each, which the proprietor proposes to add to each 100 gallons of spirits. The Director may require the proprietor to submit a sample of the proposed substitute material. The proprietor shall not use any proposed substitute material prior to its approval.

(\$232, Pub. L. 96-233, 94 Stat. (26 I I S r. 5181))

\section{$\$ 19.994$ Marks.}

'The proprietor shall conspicuously and permanently mark or securely label each container of fuel alcohol containing $\mathbf{5 5}$ gallons or less, as follows:

\section{WARNING - FUEL ALCOHOL-MAY BE HARMFUL OR FATAL IF SWALLOWED}

The mark or label shall be placed on the head or side of the container, and shall be in plain legible letters. Proprietors may place other marks or labels on containers 
so long as they do not obscure the required mark.

(\$232, Pub. L. 96-233, 94 Stat. 278 (26 U.S.C. 5181);

$\S 201$, Pub. L. 85-859, 72 Stat. 1360, as amended (26 U.S.C. 5206))

\section{\$19.995 Container size.}

Spirits, including fuel alcohol, shall not be filled at alcohol fuel plants into containers holding less than five gallons. However, smaller containers may be used for reasonable quantities of samples held or removed to a bonafide laboratory for testing or analysis, so long as the containers are marked as samples.

(§232, Pub. L. 96-223, 94 Stat. 278 (26 U.S.C. 5181))

\section{Transfers Between Plants}

\section{\$19.996 Transfer in bond.}

(a) Transfers between alcohol fuel plants. Proprietors may remove spirits from the bonded premises of an alcohol fuel plant (including the premises of a small plant) for transfer to another alcohol fuel plant. Bulk conveyances in which spirits are transferred shall be secured with locks or seals. The spirits need not be rendered unfit for beverage use prior to transfer. Spirits so transferred may not be withdrawn, used, sold, or otherwise disposed of from the consignee plant for other than fuel use.

(b) Transfers to or from other distilled spirits plants. Spirits (not including spirits produced from petroleum, natural gas, or coal) may be transferred in bond from distilled spirits plants qualified under Subpart $G$ of this part to alcohol fuel plants. Alcohol fuel plants may transfer spirits in bond to distilled spirits plants qualified under Subpart G. Spirits so transferred may not be withdrawn, used, sold, or otherwise disposed of for other than fuel use.

(c) Transfer procedures. The procedures in $\$ \$ 19.997$ through 19.999 apply only to the transfers between two alcohol fuel plants. See $\$ \$ 19.506$ through 19.510 for requirements where one plant is a distilled spirits plant qualified under subpart $G$ of this part.

( $\$ 201$, Pub. L. $85-859,72$ Stat. 1362, as amended (26 U.S.C. 5212); \$232, Pub. L. 96-223, 94 Stat. 278 (26 U.S.C. 5181))

\section{$\$ 19.997$ Consignor premises.}

The consignor shall prepare, in triplicate, a commercial invoice or shipping document to cover each shipment of spirits. The consignor shall enter on the document the quantity of spirits transferred, a description of the shipment (for example, number and size of drums or barrels, tank truck, etc.), the name, address, and permit number of the consignee, and the serial numbers of any seals, locks, or other devices used to secure the con- veyance. The consignor shall forward the original and one copy of the document to the consignee with the shipment, and retain a copy as a record.

(\$201, Pub. L. 85-859, 72 Stat. 1362, as amended (26 U.S.C. 5212))

\section{$\$ 19.998$ Reconsignment in transit.}

When, prior to or on arrival at the premises of a consignee, spirits transferred in bond are found to be unsuitable for the intended purpose, were shipped in error, or, for any other bona fide reason, are not accepted by such consignee, or are not accepted by a carrier, they may be reconsigned, by the consignor, to himself, or to another qualified consignee. In such case, the bond, if any, of the proprietor to whom the spirits are reconsigned shall cover such spirits while in transit after reconsignment on his copy of the document covering the original shipment. Where the reconsignment is to another proprietor, a new document shall be prepared and prominently marked with the word "Reconsignment."

(\$201, Pub. L. 85-859, 72 Stat. 1362, as amended (26 U.S.C. 5212); $\S 232$, Pub. L. 96-223, 94 Stat. 278 (26 U.S.C. 5181))

\section{$\$ 19.999$ Consignee premises.}

(a) General. When spirits are received by transfer in bond, the proprietor shall examine each conveyance to determine whether the locks or seals, if any, are intact upon arrival at this premises. If the locks or seals are not intact, he shall immediately notify the area supervisor, before removal of any spirits from the conveyance. The consignee shall determine the quantity of spirits received and record the quantity and the date received on both copies of the document covering the shipment. The consignee shall return one receipted copy to the consignor and retain one copy as the record of receipt required by $\$ 19.984$.

(b) Portable containers. When spirits are received in barrels, drums, or similar portable containers, the proprietor shall examine each container and unless the transfer was made in a sealed conveyance and the seals or other devices are intact on arrival, verify the contents of container. The proprietor shall record the quantity received for each container on a list, and attach a copy of the list to each copy of the invoice or other document required by $\$ 19.997$ covering the shipment.

(c) Bulk conveyances and pipelines. When spirits are received in bulk conveyances or by pipeline, the consignee shall gauge the spirits received and record the quantity so determined on each copy of the invoice or other document covering the shipment. However, the regional regulatory administrator may waive the requirement for gauging spirits on 
receipt by pipeline if, because of the location of the premises, there will be no jeopardy to the revenue. (\$201, Pub. L. 85-859, 72 Stat. 1358, as amended 1362, as amended (26 U.S.C. 5204, 5212); \$232, Pub. L. 96-223, 94 Stat. 278 (26 U.S.C. 5181))

Signed: $\quad$ May 21,1980

G. R. Dickerson, Director

Appluved: Jüne 9,1980

Richard J. Davis, Assistant Secretary

(Enforcement Operations)

\section{DEPARTMENT OF TREASURY}

Bureau of Alcohol, Tobacco and Fireàrms

27 CFT Part 19

(Notice No. 345)

Fuel Use of Distilled Spirits-Implemeting a Portion of the Crude Oil Windfall Profit Tax Act of 1980

(Public Law 96-223)

AGENCY: Bureau of Alcohol, Tohacco and Firearms, Department of the Treasury.

ACTION: Proposed rulemaking cross-reference to temporary regulations.

SUMMARY: In the Rules and Regulations portion of this Federal Register, the Bureau of Alcohol, Tobacco and Firearms (ATH) is issuing temporary regulations regarding implementation of Section 232, Alcohol Fuels, in Part III of Title II of the crude Oil Wind fall Profit Tax $\Lambda c t$ of 1980 (Pub. L. 96-223). The temporary regulations also scrve as a notice of proposed rulemaking for final regulations.

DATES:The effective date of the temporary regulations is July 1, 1980. Written comments must be delivered or mailed by October 20, 1980.

ADDRESS: Send comments to Chief, Regulations and Procedures Division, Bureau of Alçohol, Toharco and Firearms, P.O. Box 385, Washington, DC 20044

Disclosure of comments: Any person may inspect the written comments or suggestions during normal business hours at the ATr Reraling Room, Office of Public Affairs, Room 4407, Federal Building, 12th and Pennsylvania Avenue, NW, Washington, DC. 20226.

\section{FOR FURTHER INFORMATION CONTACT:}

John V. Jarowski, Research and Regulations Branch, Bureau of Alcohol, Tobacco and Firearms, Washington, DC 20226, Telephone: 202-566-7626.

\section{SUPPLEMENTARY INFORMATION:}

Public Participation: Interested persorns may submit written comments and suggestions regarding the temperary regulations. All communications received within the comment period will be considered before final regulations are issued. Any person who desires an opportunity to comment orally at a public hearing on the temperary regulations should submit a written request to the Director within the comment period. However, the Director reserves the right to determine whether public hearing should be held.

ATF plans to contact State regulatory of ficials to obtain their comments on these regulations. ATF seeks to coordinate Federal and State regulation of alcohol fuels in an effort to minimize conflicting or duplicative regulatinns.

The temporary regulations in the Rules and Regulations portion of this issue of the federal Register revise and add new regulations in $27 \mathrm{CF}$. Parl 19. For the text of the temporary regulations, sec 45 FR (T.D. AlF-71) published in the Rules and Regulations portion of this issuc of the Federal Register.

Signed: $\quad$ May 21, 1980

G. R. Dickerson, Director

Approved: June 9, 1980

Richard I. Davis, Assistant Secrctary (Enforcement and Operations)

\section{FDA AND OTHER ANIMAL FEED REGULATIONS}

Most plants designed for the production of fuel alcohol from grain will be designed to produce coproducts in the form of grain residues suitable for use as animal feeds. Therefore, a substantial portion of the alcuhol plant's activities will be concerned with producing and marketing these products. Most states have adopted commercial feed laws governing the production and marketing of animal leeds. In addition, the sale of feeds on an interstate basis is regulated at the federal level by vativus agencies, primarily the Food and Drug Administration (FDA). Thus, regulatory compliance will be an important consideration in developing the plant's animat feed operatiuns.

The regulations in each Statc should be checked for particular requirements; however, the regulations in the majority of States are very similar. In many States, the State legislators have adopted all or part of the Uniform State Feed Bill.' These statutes incorporate by reference provisions of the Food, Drug, and Cosmetic Act and the of-

'Officially adopted by the Association of American Feed Control Officials and endorsed by the American Feed Manufacturers Association and the National Feed Ingredients Association. 
ficial definitions of feed ingredients as defined by the Association of American Feed Control Officials (AAFCO).

For the alcohol plant, as a manufacturer of animal feeds, ther are three primary areas of concern with regard to feed regulation-registration, adulteration, and misbranding. Registration (licensing) is in most instances quite simple and involves registering the products to be manufactured and paying the fees required. The statutory language in some states may require fee tags or stamps to be purchased and attached to the labeling used on packaged feeds or, in the case of feeds sold in bulk, to provide these tags or stamps to the buyer along with the invoice or bill of lading. The fees charged are, for the most part, nominal. They are either set at a flat rate for each product produced and sold or are based on tonnage. Some states have registrations involving a combination of a flat rate plus a tonnage fee. ${ }^{2}$ A number of states may also require the filing of affidavits of tonnage on a regular basis in order to advise the state on the levcl of production at a given plant. In each state the actual mechanism of registration is usually a simple matter of following the statutory guidelines and associated regulations. ${ }^{3}$

After the initial registration has been completed, the primary concerns of management, to ensure continued compliance, will be in the area of quality control. From a licensing standpoint, lapses in quality control can produce charges of adulteration and misbranding. To ensure continuing compliance, most States have (by statute) provided for inspecting, sampling, and analyzing production. Discovery of a violation of the provisions of the Feed Law can result in various penalties (fines) or in detention of the feed (i.e. withholding the feed from sale or distribution).

Contamination of the feed can result in a charge of adulteration. The definition of adulteration is usually specifically provided by statute. The Uniform Feed Bill provides the following definition:

\section{Section 7. Adulteration.}

A commercial feed shall be deemed to be adulterated:

(a)(1) If it bears or contains any poisonous or deleterious substance which may render it injurious to health; but in case the substance is not an added substance, such commercial feed shall not be considered adulterated under this subsection if the quantity of such substance in such commercial feed does not ordinarily render it injurious to health; or
(2) If it bears or contains any added poisonous, added deleterious, or added nonnutritive substance which is unsafe within the meaning of Section 406 of the Federal, Food, and Cosmetic Act (other than one which is (i) a pesticide chemical in or on a raw agricultural commodity; or (ii) a food additive); or

(3) If it is, or it bears or contains any food additive which is unsale within the meaning of Section 409 of the Federal Food, Drug, and Cosmetic Act; or

(4) If it is a raw agricultural commodity and it bears or contains a pesticide chemical which is unsafe within the meaning of Section 408(a) of the Federal Food. Drug, and Cosmetic Act: Provided, that where a pesticide chemical has been used in or on a raw agricultural commodity in contormity with an exemption granted or a colerance prescribed under Section 408 of the Federal Food, Drug, and Cosmetic Act and such raw agricultural commodity has been subjected to processing such as canning, cooking, freezing, dehydrating, or milling, the residue of such pesticide chemical remaining in or on such processed feed shall not be deemed unsafe if such residue in or on the raw agricultural commodity has been removed to the extent possible in good manufacturing practice and the concentration of such residue in the processed feed is not greater than the tolerance prescribed for the raw agricultural commodity unless the feeding of such processed feed will result or is likely to result in a pesticide residue in the edible product of the animal, which is unsafe within the meaning of Section 408(a) of the Federal Food, Drug, and Cosmetic Act.

(5) If it is, or it bears or contains any color additive which is unsafe within the meaning of Section 706 of the Federal Food, Drug, and Cosmetic Act.

(b) If any valuable constituent has been in wholc or in part omitted or abstracted therefrom or any less valuable substance substituted therefor.

"For example, Wisconsin assesses $\$ 10.00$ per plant per year plus $\$ 0.10$ per ton inspection fee for all feed produced annually. By contrast, Georgia simply charges a hat fee of $\$ 2.00$ annually per product produced.

"Most States have provided authority under the respective Administrative Procedures Act for the agencies to pass regulations further defining or implementing legislation and these regulations should be checked. 
(c) If its composition or quality falls below or differs from that which it is purported or is represented in possess by its labeling.

(d) If it contains a drug and the methods used in or the facilities or controls used for its manufacture, processing, or packaging do not conform to current good manufacturing practice regulations promulgated by the (authorized State agency) to ensure that the drug meets the requirement of this Act as to safety and has the identity and strength and meets the quality and purity characteristics which it purports or is represented to possess. In promulgating such regulations, the (authorized State agency) shall adopt the current good manufacturing practice regulations for medicated feed premixes and for medicated feeds established under authority of the Federal Food, Drug, and Cosmetic Act. unless he determines that they are not ap propriate to the conditions which exist in this State.

(e) If it contains visable weed seeds in amounts exceeding the limits which the (authorized state agcncy) shall establish by, rule or regulation.

The above statute, in addition to the enumerated provisions, incorporates by reference two important areas of federal regualtion.

First, the feed could be aduilterated by containing an added subsiance not on the list of substances Generally Recognized as Safe by the FDA (The GRAS List) or if it contains a substance on the GRAS list in excess of the limits prescribed for that substance in the Code of Federal Regulations (CFR). Thus, a violation could occur if a plant were to utilize a process that added a substance to the feed during the process of manufacturing which is not in compliance with the above regulations. For example, a process for drying feed residue which utilizes waste gases might produce unacceptable levels of contamination or contamination with some substance not on the GRAS List.

Second, a problem could also arise if the grain used as a substrate contained excessive levels of pesticides. The processing might not eliminate enough of the residue to bring the quantity in the final product within the acceptable linits. ${ }^{+}$

In addition to avoiding the charge of adulteration, quality control is essential to ensure regulatory compliance in other areas. To ensure compliance, it is necessary that a feed that purports to be a certain product must meet the definition established for that product.
Failure to meet the definition or standard could result in the charge of misbranding. The Uniform State Feed Bill provides the following definition for misbranding:

\section{Section 6. Misbranding.}

A commercial fccd shall be deemed to be misbranded:

(a) If its labeling is false or misleading in any particular.

(b) If it is distributed under the name of another commercial feed.

(c) If it is not labeled as required in Section 5 of this Act.

(d) If it purports to be or is represented as a cullmercial feed, or if it purports to contain or is represented as containing a connmercial feed ingicidient, unless such commercial teed or feed ingredient conforms to the definition, if any, prescribed by regulation by the (authorized state agency).

(e) If any word, statement, or othcr information tequired by or under authority of this Act to appear on the label or labeling is not prominently placed theron with such conspicuousness (as comapred with other words, statements, designs, or devices in the labeling) and in such terms as to render it likely to be read and understood by the ordinary individual under customary conditions of purchase and use.

The definitions referred to in the above statutory provisions for feed products hiave been established by AAFCO and are incorporated by reference. ${ }^{5}$

This discussion of feed regulations briefly outlines the areas of interest to investors in alcohol fuel plants. Compliance with thcse regulations can be achieved by properly designing and operating the plant. The grain and feeed portions of the operation can be designed to minimize problems with contamination and provide adequate controls to monitor and manage product quality in order to eliminlate or minımıze regulatory complaince problems. ny recugnising and considcring these regulatory requirements during the planning and design phases, new plants can do a great deal to minimize potential problems in this area.

+Limits on pesticides under Section 408 of FDCA are determined by the EPA and are set forth in the CFR's.

'Official and tentative definitions of feed ingredients as cstablished by the Association of American Feed Control Officials (AAFCO) contains definitions for a wide variety of products. These include: Maize (corn products) 48.1 to 48.30; Fermentation Products 36.1 to 36.12 ; Distiller's Products 27.1 to 27.7. 


\section{TRANSPORTATION REGULATIONS}

The surface transportation of raw materials and finished product may be regulated by State and Federal agencies, depending upon the location of the plant and its proximity to the source of materials and its markets. If the plant, material source, and the market are located in the same State, it is highly probable that only the individualistic State law will apply to regulate surface transportation, at least insofar as for-hire motor truck transportation is concerned. Some States, such as Texas, Nebraska, and South Dakota, choose to regulate truck transportation rather extensively, while others have little or no concern for regulation of the basic types of commodities flowing to and from a plant. Generally, grain transportation is not regulated, while coal and alcohol fuel are. Several States, including Florida, have recently deregulated the transporting of all commodities within their borders, while several others are actively studying deregulation proposals.

Assuming interstate commerce is involved in either obtaining materials or in reaching the market place, the nature of regulation is determined by the Interstate Commerce Commission. Currently, the truck transportation of grain is exempt (or not regulated), while, under the Motor Carrier Reform Act of 1980 (H.R. 6418), the movement of DDG will likely also be exempt. Truck movement of coal and alcohol, on the other hand, is currently regulated. In this context, lawful interstate movements of such commodities can be performed only by a carrier holding Federal ICC authority.*

Primary transportation considerations will necessarily include plant site selection vis a vis existing, visible rail facilities. This is particularly critical where a plant is to be located any distace (perhaps more than 200 or 250 miles) from the primary source of any major raw material (grain or coal).

\section{LOCAL BUILDING CODES}

Like zoning matters, the State's jurisdictional power is the basic authority under which building codes are enacted. Some State legislatures enact statewide building codes while others delegate the authority to the local governments. One or a combination of the four model building codes has been adopted by most States or municipalities. These codes (and the geographic area) dominated by their association/author are: (1) the Uniform Building Code written by the International Conference of Building Officials (adopted primarily in the West); (2) the Basic Building Code compiled by the Building Officials and Code Administrators, International, Inc. (found in the Northeast and North Central areas); (3) the Southern Standard Building Code enacted by the Southern Building Code Conference (adopted in the South); and (4) the National Building Code, developed by the National Board of Fire Underwriters. Local variations exist despite the model codes. Some municipalities have adopted selected provisions rather than the entire code. Interpretations of the same code differ from city to city.

Unlike zoning ordinanaces, most building codes apply retroactively. Three types of information are provided in most codes: definition of terms; licensing requirements; and standards. Taken together, the definitions and licensing requirements have the effect of prescribing who is authorized to conduct particular sorts of construction activity. For example, the International Association of Plumbing and Mechanical Officials Code states that only licensed plumbers may do work defined as plumbing. Many codes require that structural design plans be prepared by a state certified engineer.

Two types of code standards exist: technical specifications and performance standards. Codes prescribing technical specifications set out how, and with what materials, a building is to be constructed. Performance standards represent a more progressive and technically more flexible approach. Codes based on these standards state product requirements that do not prescribe designs and materials. For example, "the structural frame of all buildings, signs, tanks and other exposed structures shall be designed to resist the horizontal pressures due to wind in any direction. . . "Typical construction components specified in codes are structural and foundation loads and stresses, construction material, fireproofing, building height (this represents a common duplication of the zoning ordinance), and electrical installation. The developer is likely to be required to comply with the standards for structural and foundation loads and stresses, as standards set out the minimum force measure in poundsper-square-inch that the design must bear under certain circumstances, e.g., wind or snow. The electrical code regulates the use of all electrical wiring when voltage levels are above 36 volts.

Dissatisfaction with the building inspector's denial of a permit may result in an appeal before the local board of building appeals. The common bases of appeal provided by the codes are: an incorrect interpretation of the code by the building official; the availability of an equally good or better form of construction not specified in the code; and the existence of practical difficulties in carrying out the requirements of the code. The local board members are usually appointed experts in the field of construction. The local board may uphold, modify, or reverse the building official's decision. Further appeals to the state board of building appeals or to the courts are also available.

* As a corollary to this, the rate stuuctures on such transportation are also regulated. 


\section{GASOLINE ALLOCATIONS}

A letter containing the following information is required from the applicant interested in obtaining a gasoline allocation for gasohol:

The office that is final arbiter on increasing gasoline allocation for gasohol usage is:

\section{Office of Hearings and Appeals}

\section{U. S. DEPARTMENT OF ENERGY 2000 M Street, N.W. \\ Washington, D.C. 20461 \\ (202) 254-3008}

\section{(a) Investment}

1. What is the amount of investment already made?

2. How is/was this investment financed?

3. What would be the value of the investment if approval for reallocation is not granted?

4. Provide photographs of production facilities.

5. For what purpose(s) will the investment be used-gasohol blending, ethanol production, facility construction, feedstock purchase, etc.?

\section{(b) Alcohol}

1. Where ate the sources of alcohol?

2. What will be the cost of obtaining the alcohol for each source listed?

3. Supply copies of supply contracts, if any exist.

4. What is the efficiency of the alcohol produitiun techniques(s) to be used?

5. What feedstock will be utilized in producing the alcohol? (c) Unleaded Gasoline

1. What is the availability of unleaded gasoline in the intended marketing area?

2. List refiners in the marketing area.

3. Describe the contacts already made in attempting to obtain unleaded gasoline.

4. List your preferred supplier(s) for unleaded gasoline.

5. Of the gasoline you obtain, what percentage is unleaded?

6. What is your selling price for unleaded gasoline?

7. What quantities of unleaded gasoline do ynu anticipate needing in the next 12 months? Specify month-by-month.

\section{(d) Marketing}

1. Describe the intended marketing area.

2. Describe your plans for the marketing of gasohol.

3. What is the anticipated sales of gasohol for 12-month period?

4. Describe any feasibility studies showing depmand for gasohol in marketing area.

5. List retailers in the marketing area that would sell gasohol. Describe any contracts that exist with them.

6. What is the expected selling price for the gasohol"?

A copy of this letter of application (with confidential information deleted) should be sent to the hase supplier of gàsoline. 
DEPARTMENT OF THE TREASURY - BUREAU OF ALCOHOL, TOBACCO AND FIREARMS

APPLICATION AND PERMIT FOR ALCOHOL FUEL PRODUCER UNDER 26 U.S.C. 5181

INS'TRUCTION SHEET FOR ATF FORM 5110.74

PLEASE READ CAREFULLY. AN INCOMPLETE OR INCORRECT APPLICATION WILL DELAY YOUR ALCOHOL FUEL PRODUCER'S PERMIT.

1. PURPOSE. The application is completed by a person (applicant) who would like to establish a plant to produce, process, and store, and use or distribute distilled spirits to be used exclusively for fuel use under 26 U.S.C. 5181 . Distilled spirits means only ethanol or ethyl alcohol. The production of methanol does not require a permit from the Bureau of Alcohol, Tobacco and Firearms. The production of distilled spirits from petroleum, natural gas, or coal is not allowed by the Alcohol Fuel Producers Permit.

2. GENERAL PREPARATION. Prepare this form and any at tachments in duplicate. Use separate sheets of approximately the same size as this form when necessary or as required. Identify these separate sheets with your name, and attach to form.

3. WHERE TO FILE. Submit application to the appropriate regional regulatory administrator. (A listing of their offices and the areas they are responsible for is on the reverse.)

4. TYPE OF APPLICATION. (See item 1. of application). The type of permit you need, small, medium, or large, depends on how many proof gallons of distilled spirits you intend to produce and receive by transfers from other plants during one calendar year. The number of proof gallons may be calculated by taking the proof of the spirits multiplied by the wine gallons (your standard American gallon) and dividing by 100 . For example:

50 gallons of $190^{\circ}$ proof spirits $=$

$190 \times 50 \div 100=95$ proof gallons.

After determining the quantity of spirits to be produced and received by transfers from other plants, check applicable box in item 1 .

5. AMENDED PERMIT. Item 2. is only completed when changing or amending an existing permit.

6. INFORMATION ABOUT APPLICANT CURRENTLY ON FILE WITH REGIONAL REGULATORY ADMINISTRATOR NEED NOT BE RESUB. MITTED. State in item requesting such information the rype and the number of the license or permit for which the information was filed

7. CAPACITY OF STILLS. Item 9.d. asks for the capacity of your still(s) in proof gallons. The capacity should be given as the greatest number of proof gallons of spirits that could be distilled in a 24 hour period. Capacity of column still may be shown by giving the diameter of the base and the number of plates or packing material. The capacity of a pot or kettle still may be showil by giving the volumetric (wine gallon) capacity of the pot or kettle.

8. SAMPLE DIAGRAM OF PREMISES. Item 12. requires a diagram of your plant premises. It can be drawn by hand and does not have to the drawn to scale. Below is a sample of such a diagram.
9. ITEM 15-SIGNATURE OF/FOR APPLICANT. (a) Individual owners sign for themselves; (b) partnerships have all partners sign, or have one partner who has attached an authorization to act on behalf of all the partners (unless this authorization is provided by State law); (c) corporations have an officer, director, or other person who is specifically authorized by the corporate documents sign; (d) any other person who signs on behalf of the applicant must submit ATF F 1534 (5000.8). Power of Attorney or other evidence of their authority.

10. ADDITIONAL INSTRUCTIONS FOR APPLICANT OF SMALL ALCO. HOL FUEL PLANT. Complete all items on the application form. Be sure that you sign and date the form in items 15. and 16. NO ADDI. TIONAL INFORMATION IS REQUIRED.

11. APPLICANT FOR PERMIT OF MEDIUM AND LARGE ALCOHOL FUEL PLANT. Complete oll items on the form Sunply in duplicate the additional information and forms as stated below.

a. The following information is requested for an individual proprietor. each partner, or each director of a corporation or similar entity and each officer of the corporation or similar entity who will have responsibilities and connection with the operations covered by the permit. In addition applicants for large plants shall show the same information for each interested person who is an individual as listed in the statement of interest in the organizational documents required by 27 CFR 19.941

(1) full name including middle name:

(2) title in connection with applicants' business;

(3) social security number;

(4) date of birth.

(5) place of birth; and

(6) address of residence.

b. A statement as to whether the applicant or any person required to be listed by the instructions above has beenpreviously convicted of any violation of Federal or State law lother than minor traffic violations).

c. A statement of the maximum quantity of distilled spirits to be produced and received from other plants during a calendar year.

d. A Distilled Spirits Bond. ATF F 5110.56, as required by 27 CFR 19.956.

e. Any other information required by the regional regulatory administrator after examination of this application.

\section{SPECIAL INSTRUCTIONS FOR ALL APPLICANTS}

12. OPERATIONS BEFORE ISSUANCE OF PERMIT. Unless otherwise specifically authorized by law or regulations. an applicant for an Alcohol Fuel Producer Permit may not engage in operations until the permit has been issued by the regional regulatory administrator.

13. STATE AND LOCAL LAWS. This permit does not allow you to operate in violation of State or local laws. Applicants should check with appropriate State and local authorities before engagıng in alcohol fuel plant operations.

14. ATF FORMS AND REGULATIONS FOR ALCOHOL FUEL PLANTS. ATF forms and publications including regulations for alcohol fuel producers may be ordered from the ATF Distribution Center, $3800 \mathrm{~S}$. Four Mile Run Drive, Arlington, VA 22206

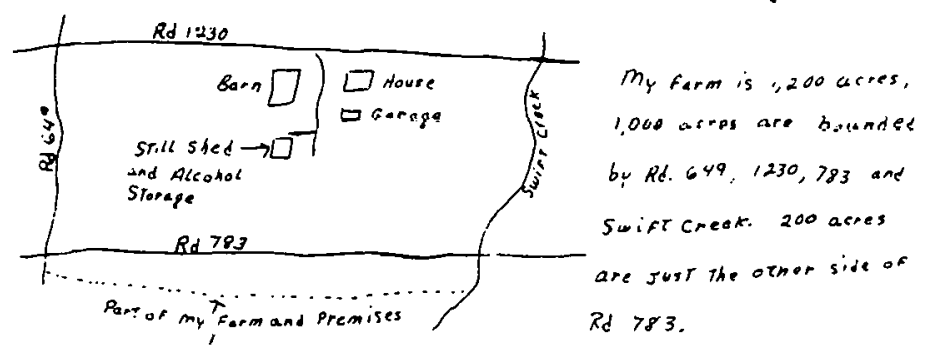

ATF F $5110.74(6.80)$

Figure B-1.-BATF Form 5110.74 
12. DIAGRAM OF PLANT PREMISES (In the space provided or by attached map or diagram. show the area to be included for the alcohol fuel plant. Identify
roads, streams, lakes, railroads, buildings, and other structures or topographical features on the diagram. Show location(s) where alcohol fuel plant operations will occur. The diagram should be in sufficient de tail to locate your operations and premises.) (See directions for sample diagram.)

13. I WILL COMPLY WITH THE CLEAN WATER ACT (33 U.S.C. 1341 (a)). (Will not discharge into navigable waters of the U.S.)
$\square$ YES
$\square$ No

14. IF THIS APPLICATION IS APPROVED AND THE PERMIT IS ISSUED. I CONSENT TO THE DISCLOSURE OF THE NAME AND ADDRESS SHOWN ON THE APPLICATION IN AN ATF PUBLICATION, "ALCOHOL FUEL PRODUCERS", WHICH MAY BE DISTRIBUTED ON REQUEST TO THE NENERAL PUBLIC (incliding

$\sqcup$ YES $\square$ NO (A no response will have no effect on the consideration given this anplication) APPLICANTS FOR MEDIUM AND LARGE ALCOHOL FUEL PLANTS MUST ATTACH THE AODITIONAL INFORMATION REQUIRED IN INSTRUCTIONS Under the penalties of perjury, I declare that I have examined this application, including the documents submitted in support thereof or incorporated therein by reference, and, to the best of $\mathrm{my}$ knowledge and belief, it is true, correct, and complete.

\begin{tabular}{l|l} 
10. 3ignature uffruh APrlicant & 16. TITLE (Owner, Partner, Corporate Officer)
\end{tabular} STOP

MAKE NO FURTHER ENTRIES ON THIS FORM

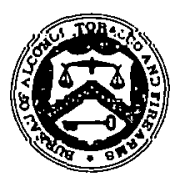

\section{ALCOHUL FUEL PRODUCERS PERMIT} UNDER 26 U.S.C. 5181

1. EFFECTIVE DATF
2. PERMIT NUMBER
AFP -

Pursuant to the above application and subject to applicahle law and regulations and to the conditions set foilli below you are hereby authorized and permitted at the premises described in your application to produce, process and store, and use or distribute distilled spirits (Not including distilled spirits produced from petroleum, natural gas or coal) exclusively for fuel use. The quantity to be produced and received from other plants during the calendar year is limited to the quantity stater in this application.

This permit is continuing, and will remain in force until suspended, revoked. voluntarily sırrenderad, or automatioally tcrmineted. Tl is Nei ull dues not aiiow you to operate in violation of State nr Ins:al laws.

THIS PEHMIT IS NOT TRAANSFERABLE. In the event of any lease, sale, or other transfer of the operations authorizcd, or of any other chariye in the ownership or control of such operations, this permit shall automatically terminate. (See 27 CFR 19.145 AND 19.949)

3. SIGNATURE OF REGIONAL REGULATOPYY AQMINISTRATOR, RIIREAII OF MLGOHOL, TOUACCO MINU FIHEAHMS

\section{CONDITIONS}

1. That the permittee in good faith complies with the provisions of Chapter 51 of Title 26 of the United States Code and regulations issued thereunder.

2. That the permittee has made no false statement as to any material fact in his application for this permit.

3. That the permittee discloses all the material information required by law and regulation

4. That the permittee shall not viclate or conspire to violate any law of the United States relating to intoxicating liquor and shall not be convicted of any offense under the United States Code nunishable as a felony or of any conspiracy to commit such an offense.

5. That all persons employed by the permittee in good faith observe and conform to all of the terms and conditinns nf this permit.

6. That the permittee engages in the operations authorized by this permit within a 2 year period.

7. This permit is conditioned on compliance by you with the Clean Water Act (33 U.S.C. 1341 (a)) 


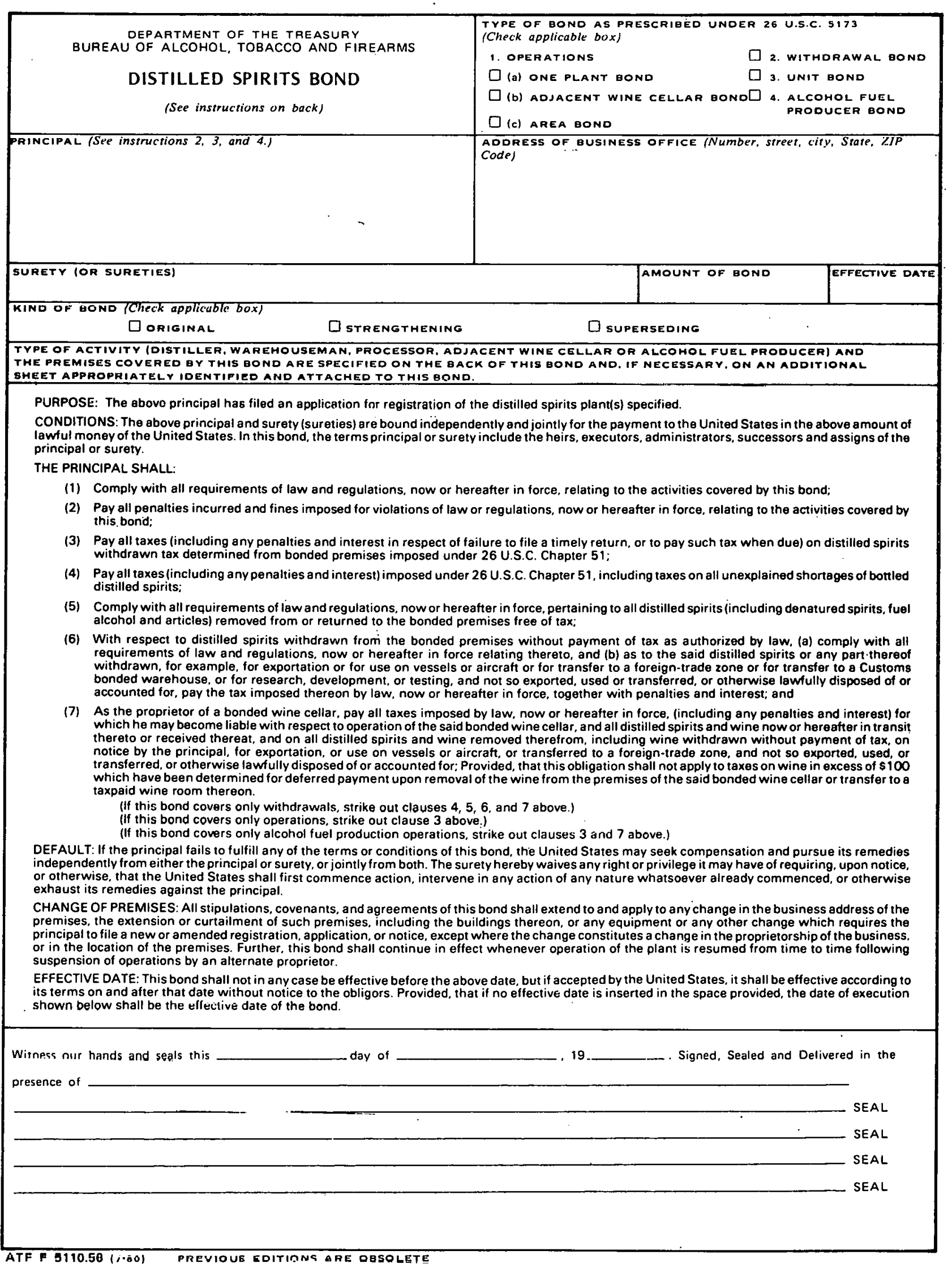

Figure B.2.-BATF Form 5110.56 


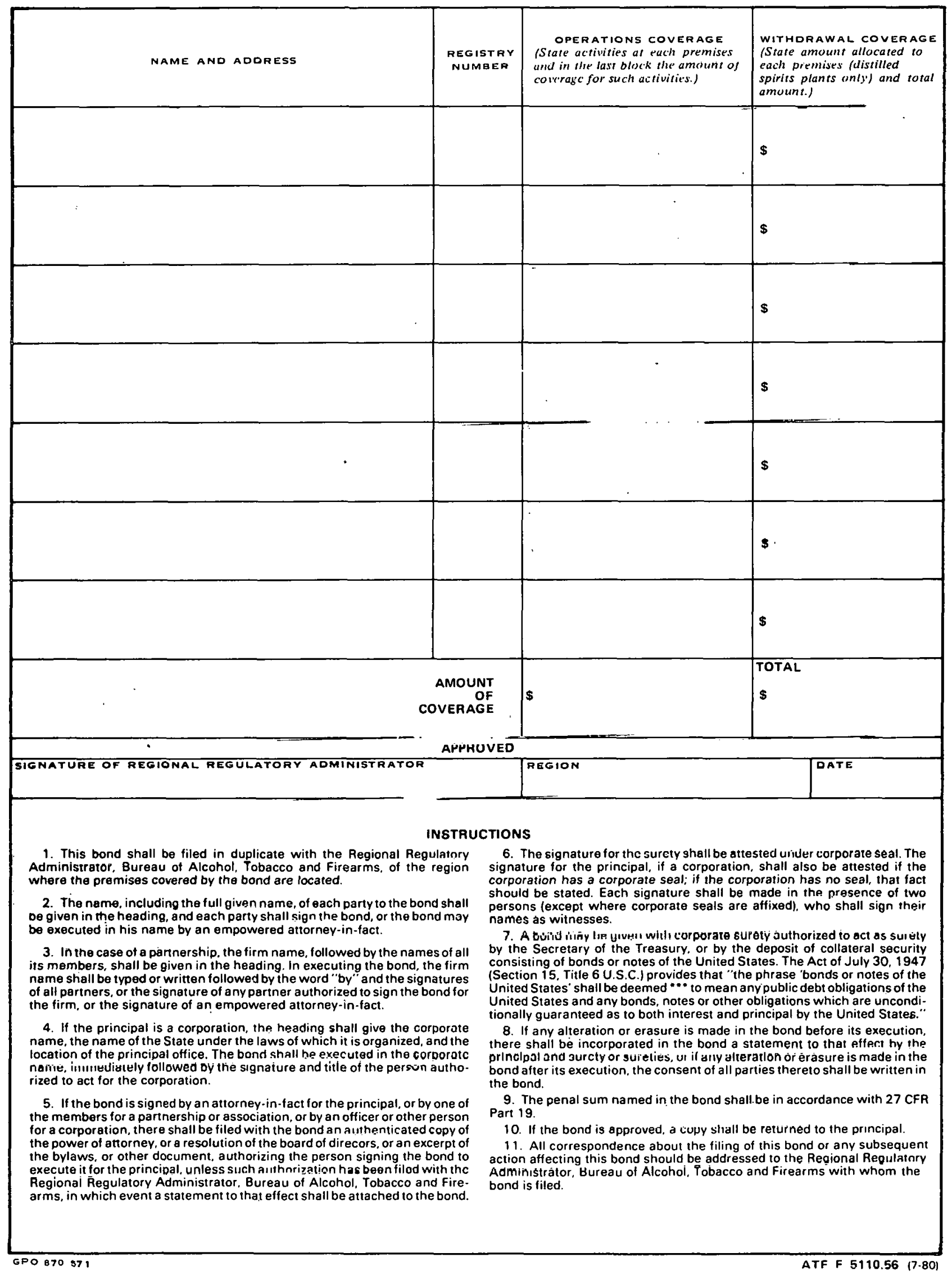

Figure B-2.-BATF Form 5110.56 (continued) 


\section{BUREAUEPARTMENTOOF THE TREASURY \\ ALCOHOL FUEL PLANT REPORT}

GENERAL INSTRUCTIONS

1. Each proprietor of an alcohol fuel plant shall file this report of plant operations. The period covered by the report depends on the size of the alcohol fuel plant. A report is due even if no operations were conducted during the period.

2. Prepare in duplicate. Send the original to the Regional Regulatory Administrator, Bureau of Alcohol, Tobacco and Firearms. Keep the copy with your alcohol fuel plant records.

3. The report is due by the 30th day following the end of the reporting period.

4. Report spirits in prouf gallons and alcohol fuel in wine gallons. Round to the nearest whole number.

5. Small and medium plants complete Parts I and II. Large plants complete Parts I and III.

WHEN TO FILE REPORTS

SMALL PLANT

1. Proprietors of small.plants will prepare and file a report once a vear to cover all operations for the calendar year.

2. Peport is due by January 30th following the end of the calendar year.

MEDIUM PLANT

1. Proprietors of medium plants will prepare and file a report twice a year. Each report will covar all operations for period reported (January 1 thru June 30 or July 1 thru December 31 ) and will be due 30 days after the end of the reporting period.
LARGE PLANT

1. Proprietors of large plants will prepare and file a report 4 times a year. Reports will cover calendar quarters (example Jan - March) and refloct all transections in that period.

2. Reports are due 30 days after the end of the reporting period.

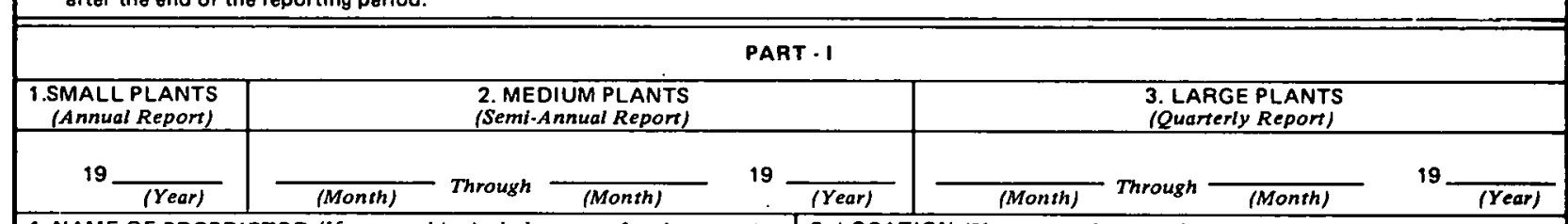

4. NAME OF PROPRIETOR (If partnership, include name of each partner)

5. LOCATION (If no street show rural route)

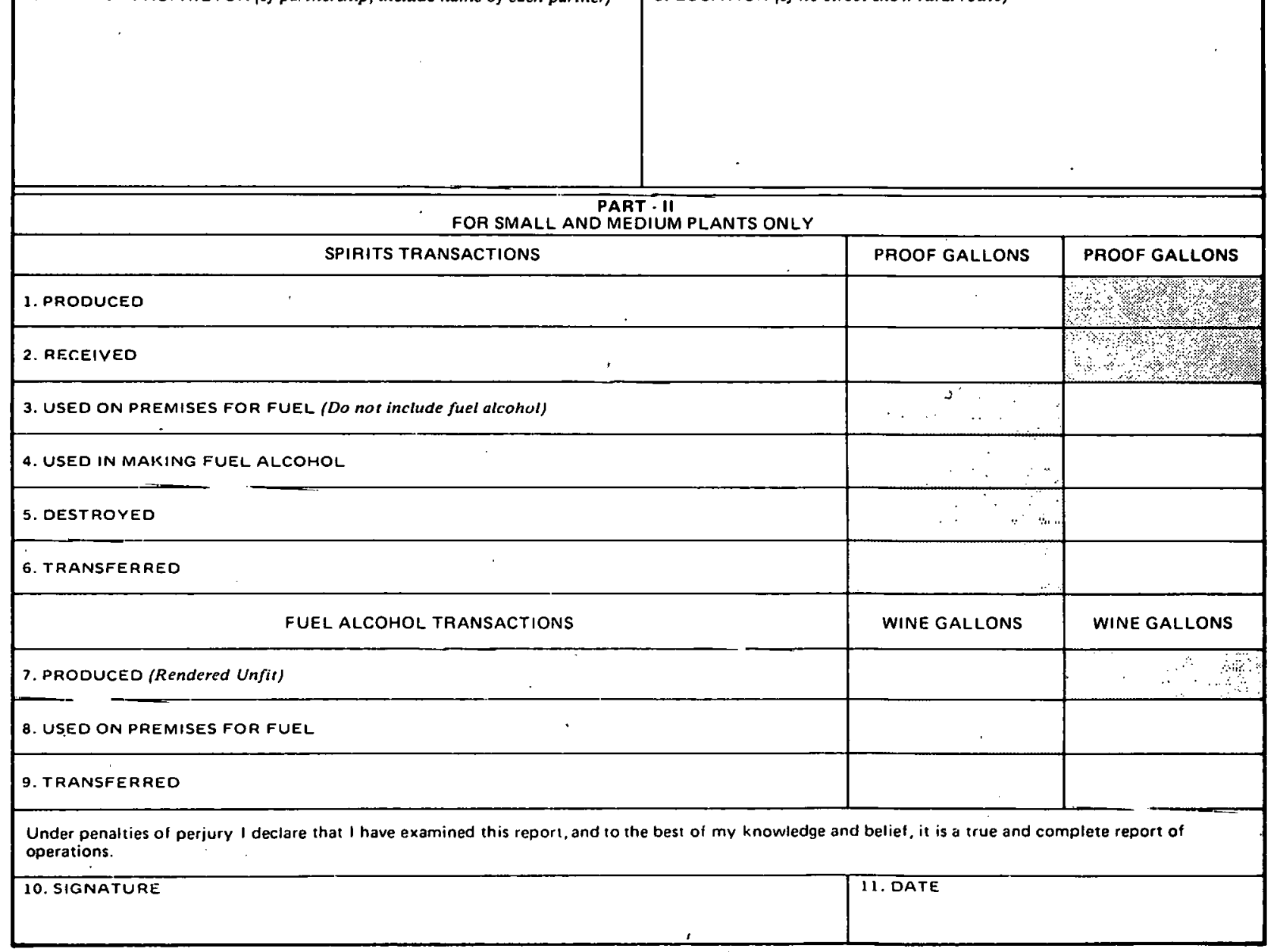

$A T+F 5110.75(7.00)$

Figure B.3.-BATF Form 5110.75 
PART - III

FOR LARGE PLANTS ONLY

Report the loss (line 11 ) or the gain (line 4 ) of spirits found by taking the required physical inventory for the repor liuy period. Heport any losses by theft separately (line 10). Report and identify on liné 5 the quantily of any imported spirits received from customs custody.

separately line 10). Report and identify an line S the quantily of any imported spirits recelved from cuscoms custody.

1. ON HAND BEGINNING OF REPORTING PERIOD

2. PROOUCED BY DISTILLING

3. RECEIVED FROM OTHER PLANTS

4. INVENTORY GAIN

5.

6. TOTAL - (Lines / through 5 )

7. UŚED IN MAKING FUEL ALCOHOL

o. USEU UN PLÁNT PREMISES FOR FUEL (Do not include fupl alrahn',

9. USED AS DISTILLING MATERIAL OR FOR REDISTILLING

10. LOST BY THEFT

11. INVENTORY LOSS

12. TRANSFERRED TO OTHER PLANTS

13. DESTROYED

14.

15. TOTAL - (Lines 7 through 14)

16. ON HAND END OF PERIOD (Subtract line is frem linc ú)

FUEL ALCOHOL TRANSACTIÓNS

17. MÄNUFACTURED

18. DISTRIBUTED OR SOLD FOR FUEL PURPOSES

19. USED ON PLANT PREMISES FOR FUEL PURPOSES

2O. DESTROYED

21. ALL OTHER DISPOOSITIONS

22. REMARKS

Under penalties of perjury I declare that I have examined this report, and to the best of my knnwlodgo and beliel, it is a true and complete report of operations.

\begin{tabular}{|l|l|}
\hline 23. SIGNATURE & 24. DATE
\end{tabular} 


\section{APPENDIX C}

\section{National Alcohol Fuels Program}

This chapter reprinted from the Department of Energy's

Office of Alcohol Fuels Program Plan, of August 1980. 


\section{INTRODUCTION}

A critical economic and national security problem facing the nation is dependence on imported oil and the outflow of dollars to purchase that oil. This dependence must be reduced as rapidly as possible. The use of alcohol fiels can substantially contribute to the reduction of this critical problem. Every dollar prudently invested in this Program will enhance energy security. The agressive Program presented in the Plan will cost less than one percent per year of the estimated $\$ 90$ billion the nation will spend in 1980 to pay its imported oil bill and will have the effect of decreasing imported oil payments.

In addition to reducing our costly dependence on imported petroleum, the National Alcohol Fuels Program will assist in creating a new domestic fuels industry. The creation of this new industry has the potential to help revitalize the manufacturing sector of our economy. Development of domestic commercial-scale alcohol production capability, the major objective of this Program, extends current fuel supplies in the near term, and provides a non petroleum high grade liquid fuel suitable for transportation use. The Alcohol Fuels Program envisioned can thus revitalize the transportation sector of our nation.

On July 8, 1980, the President signed P.L. 96-304 into law making available $\$ 525$ million for biomass and alcohol fuels activities, of which at least $\$ 500$ million is available to the DOE Office of Alcohol Fucls. These funds are available for expenditure in FY 80 and can be carried over into FY 81 .

On August 1, 1980, an independent Office of Alcohol Fuels was cstablished.

This Appendix describes the Program Implementation Plan of the Office of Alcohol Fuels (AFO). The plan is designed to achieve Program goals and objectives as an independent Office within the Department. The plan continues to support a "grass roots" Program with decentralized responsibilities. Primary responsibilities are assigned to INEL, SERI, ANL, ORNL and BETC, I'VA and NASA. In addition, Alcohol Fuels Technical Support Centers and Alcohol Fuels Research Institutes are planned for selected regions on based leedstock availability.

The alcohol fuels program plan will be updated as the program evolves. The implementation plan and other aspects of the program will be reviewed by the alcohol fuels community, a diverse group of scientists, producers, farmers, educators and manufacturing companies and the recommendations will be included in thcsc updates as appropriate. This process will also provide input into the joint DOE/USDA comprehensive plan for maximizing biomass energy production and use, mandated by the Congress.
The alcohol fuels industry has advanced largely as a result of private sector initiatives stimulated by financial, tax, and other production incentives now in place through the Federal and State governments. The government's role has been and should continue to be responsive to these private sector initiatives. The program implementation plan also recognizes the need for an aggressive research and development program to assure the timely development and use of new feedstocks and processes which enhance production and reduce fuel costs.

\section{AFO GOALS AND OBJECTIVES}

\section{Goals}

a. Achieve energy security for the Unites States and significantly reduce dependence on foreign eneryy resources" by achieving the following national alcohol production goals (see Table $\mathrm{C}-1$ ):

1. Quadrupling the January 1980 domestic production capacity of ethanol from biomass from about 80 million gallons per year during $1980^{2}$

2. Achieve a domestic production capacity of 500 million gallons of ethanol per year during $1981^{2}$

3. Achieve a total level of alcohol production and use of at least 60,000 barrels per day $(920$ million gallons per year) of alcohol by December 31, 1982:

4. Achicve a domestic production capacity of two billion gallons per $y$ car by the mid-1989's

5. Displace ten percent of gasoline consumption with alcohol by $1990^{\prime}$

b. Increasc food availability, inainlain environmental quality and improve alcohol production process efficiency.

c. Protect the consumer and industry from growth problems that normally accompany the establishment and development of a new industry.

\section{Objectives}

a. Achieve the alcohol production capacity goals established by the President and the Congress.

'Energy Security Act (P.L. 96-294), June 30, 1980.

"President's Alcohol fuels Progran, January II. 1980.

This chapter reprinted from the Office of Alcohol Fuels Progran Plan, August 1980. 
1. Provide financial, tax, and other production incentives to industry and otherwise stimulate financial investment in the production, distribution, and use of alcohol fuels

2. Continue to encourage process efficiency for alcohol fuels production.

3. Reduce or eliminate institutional and market barriers and constraints to production, distribution, and use of alcohol fuels

4. Demonstrate efficient production techniques which have the potential to make significant contributions to the industry

5. Develop markets for alcohol, formulated alcohol fuels, and co-products

6. Reduce the cost of production and distribution through improved technology

7. Provide technical assistance to alcohol fuels producers and distributors

b. Favorably affect food prices, feedstock availability, and envirommental quality.
1. Accelerate commercialization of cellulosic conversion

\section{Develop new feedstocks}

3. Work with the Environmental Protection Agency to develop environmentally sound alcohol production technologies and environmental guidelines

c. Protect the consumer and industry from growth problems that normally accompany the establishment and development of a new industry.

1. Ensure the timely dissemination of consumer information

2. Maintain a national alcohol fuels information center and data base

3. Establish product, process, and equipment standards for the industry

4. Develop an alcohol fuels educational program for vocational technical schools, community colleges, and universities

Table C.1. Presidential, Congressional, and AFO Production Capacity Milestones for the National Alcohol Fuels Program (in Billions of Gallons Per Year)

\begin{tabular}{|c|c|c|c|c|c|c|}
\hline ITEM & 1980 & 1981 & 1982 & 1985 & 1990 & 2000 \\
\hline $\begin{array}{l}\text { Presidential Goal } \\
21 \text { June } 1979\end{array}$ & \multicolumn{5}{|c|}{$\begin{array}{l}\text { (20 Percent of U.S. Energy } \\
\text { Consumption from Renewables) }\end{array}$} & 40 \\
\hline $\begin{array}{l}\text { Presidentıal Goais } \\
11 \text { January } 1980\end{array}$ & 0.3 & 0.5 & & 2 & & \\
\hline $\begin{array}{l}\text { Congressional Goals } \\
30 \text { June } 1980\end{array}$ & & & 1 & & 10 & \\
\hline $\begin{array}{l}\text { National Goals } \\
\text { (Established Above) }\end{array}$ & 0.3 & 0.5 & 1 & 2 & 10 & 40 \\
\hline $\begin{array}{l}\text { ArO Goals* } \\
15 \text { August } 1980\end{array}$ & & 1 & 2 & 10 & 20 & 40 \\
\hline \multicolumn{7}{|c|}{$\begin{array}{l}\text { Imnnrted Oil Payment Savings ** } \\
\text { (in Millions of Dollars Per Year) } \\
\text { for the National Alcohol Fuels Program }\end{array}$} \\
\hline Savings with National Goals & $\$ 535$ & $\$ 892$ & $\$ 1,785$ & $\$ 3,750$ & $\$ 17,855$ & $\$ 71,428$ \\
\hline Savings with AFO Goals & $\$ 892$ & $\$ 1.785$ & $\$ 3,750$ & $\$ 17,855$ & $\$ 35,855$ & $\$ 71,428$ \\
\hline
\end{tabular}

* These are internal AFO yuals that will assuro achiovement nf Congressional and Administration production capacity goals.

-* Imported oil payment savings based on estimated $\$ 50$ marginal cost per barrel (in 1980 dollars). 


\section{STATUS}

The following financial, tax, and other production incentives are now in place and other Congressional and Administration actions have been taken to stimulate alcohol production and to implement AFO programs:

1. A 4 cent per gallon excise tax exemption for Gasohol

2. An income tax credit of 30 or 40 cents per gallon

3. A 10 percent Energy Investment Tax Credit

4. Feasibility studies, cooperative agreements, loan and price guarantees, and purchase agreements under P.L. 96-126, P.L. 96-294, and P.L. 96-304

5. Use of Gasohol in Federally-owned or leased vehicles

6. An alcohol fuels education and training program in vocational technical schools, community oriented colleges and universities

7. A small grants program for alcohol technology development with 450 projects from over 1400 proposals with superior technical reviews

8. Proposed Department of Energy and Department of Agriculture loan guarantee regulations for alcohol fuels and other biomass energy projects

9. Proposed Economic Regulatory Administration regulations on Gasohol pricing and allocation

10. Proposed Federal Eilengy Regulatory C'ommission regulativis exempring certain distillers from natural gas incremental pricing rules

By Memorandum of July 31, 1980, the Secretary estahlished the Office of Alcohol Fuels as an independent component of the Department, effective August 1, 1980. The Office reports directly to the Secretary. A scparate line item in the budgets for fiscal years 1980, 1981, and 1982 was established for the Office as of August 8,1980 . The Secretary also immediately approved staff positions and lifted staff hiring restrictions.

\section{PROGRAM IMPLEMENTATION PLAN}

\section{Headquarters Role}

The Alcohol Fuels Program is fully operational. There are four Program Offices in AFO Headquarters-Production Incentives, Technology Development and Utilization, Market Development, and Management Program Control. Headquarters AFO will provide overall policy, management and program guidance, market development, and program control. Headquarters $\Lambda F O$ maintains sole responsibility and authority for the applicable Federal financial assistance programs. This includes development, administration, execution, and management of loan guarantees, purchase agreements, price guarantees, and cooperative agreements. Figure $\mathrm{C}-1$ illustrates the organization of the Headquarters Office.

AFO will direct its programs through a network of existing DOE Field Offices and educational institutions throughout the country. AFO will establish new organizations when existing DOE or other field institutions cannot perform the needed work.

On November 30,1980, DOE and USDA are required under P.L. 96-294 to jointly submit a plan to Congress for maximizing biomass energy production and use. Thereforc. a Ninely Day Implementation Plan was inlstituted when the independent office was established. This Ninety Day Plan will be completed before the DOE/USDA biomass energy plan is due. This Implementation Plan can then be revised consistent with the DOE/USDA biomass energy plan and other inputs. In addition to the Ninety Day Plan, there is a six-month plan of major Program actions that will be completed by January 30, 1981 .

\section{Field Office Role}

The alcohol fuels initiative began in communities across llie 1lation, gaining support within Congress and the Administration. It is important that this Program be supported with a strong field structure. Becausc of the urgency of the Program, those Field Offiecs and Na= tional Laboratories with existing knuwledgc, skill, and expertise in alcohol fuels werc chosen anong other alternatives, to perform the field work necessary to accomplish Program objectives. The following describes the plannied use of the DUE field organization, which is also shown in Table C-2.

\section{IDAHO NATIONAL ENGINEERING LABORATORY}

The Idahn National Enginecring Laboratory (INEL) provides engineering and technology support for the design, construction and testing of alcohol fuels plants, and technical assistance to the industry. INEL has also been the primary resource for the review of solicited and unsolicitcd propusals for technical and financial assistance programs. It will also administer, execute and monitor the various financial assistance programs, including feasibility studies, cooperative agreements, loan guarantees, purchase agreements, and price guarantees. It is appropriate that all of this work continue and expand at INEL. 


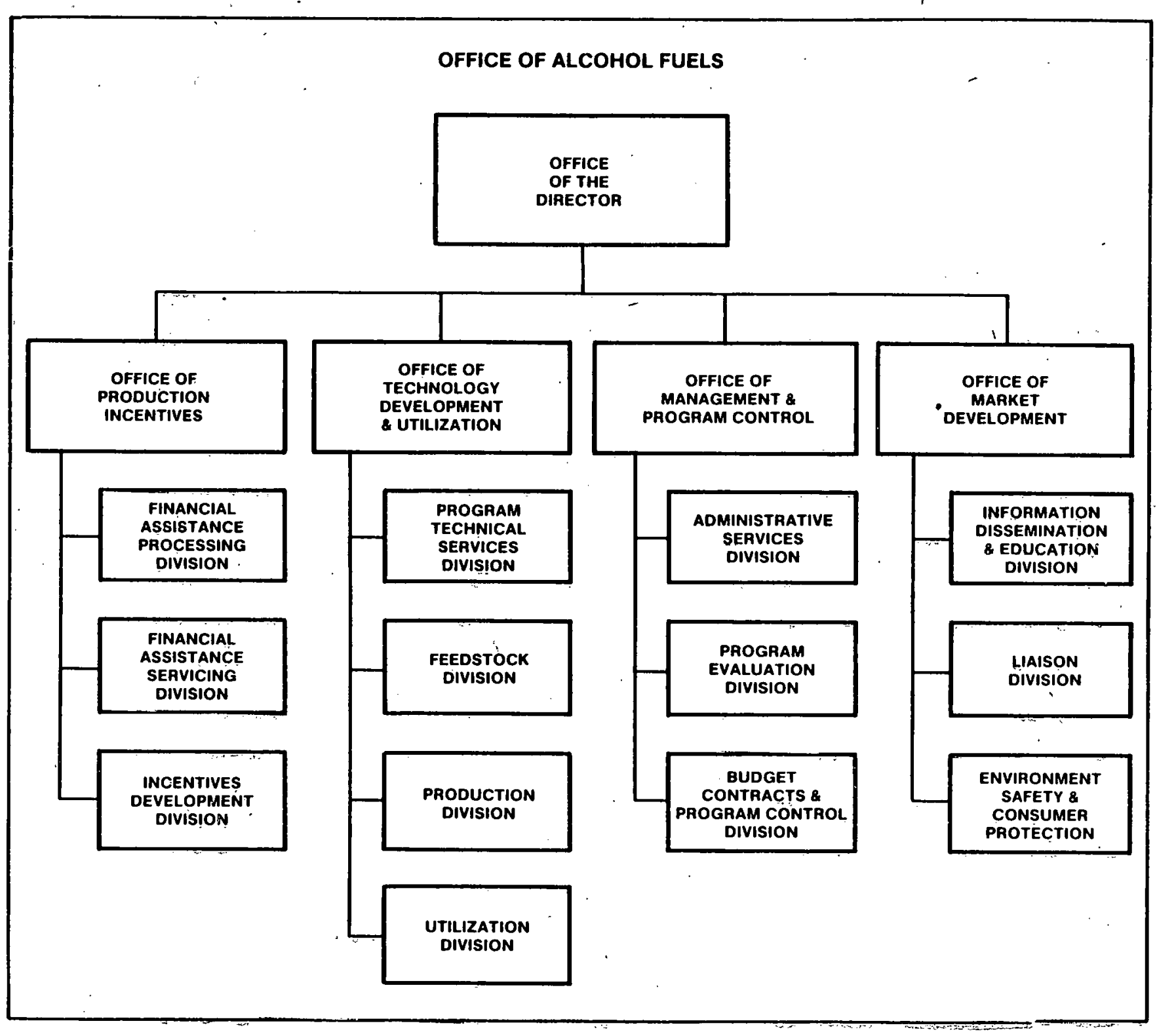

Figure C.1. Organizational Chart for the Office of Alcohol Fuels 


\section{SOLAR ENERGY RESEARCH INSTITUTE}

The National Alcohol Fuels Information Center has been established as a part of the Solar Energy Information Data Bank at the Solar Energy Research Institute (SERI) in Golden, Culorado to support the Office of Alcohol Fuels. In addition to the Information Ccnter, SERI has major responsibility for managing research and development in fermentation distillation technology and related applications.

\section{OAK RIDGE AND ARGONNE NATIONAL LABORATORIES}

Environmental research and studies have been carried out at the Argonne and Oak Ridge National Laboratories. Discussions are now underway to have Argonne and Oak Ridge oversee the alcohol fuels envirnnment and satety research and development program. It is appropriate that these and other important functions continue and expand at these lahnratories.

\section{ALCOHOL FUEL RESEARCH INSTITUTES}

Several regional Alcohol Fuel Research Institutes are planned to encourage the production and use of alcohol fuels through research on technology and process efficiency techniques. These Institutes will provide more emphasis on overall process improvements such as fermentation and distillation research. Localized feedstock handling and demonstration will be emphasized at Technical Support Centers.

\section{TECHNICAL SUPPORT CENTERS}

Technical Support Centers (TSC) will be established to operate with the assistance of DOE Field Offices. The diversity and geographic dispersion of alcohol fuel feedstocks requires localized feedstock demonstration projects through local Technical Support Centers. For example, the production of ethanol from potatoes in Idaho is mechanirally and biologically diffelent from the production of ethanol from sorghum in Georgia. The TSC's will he responsive to these differences and will trancfer tcehnolugical and feedstock advances to the community level as rapidly as possible. The TSC's serve as demonstration centers wheie hands on experience can be gained; by contrast the emphasis at the Alcohol Fuel Research Institutes is focused on applications research.

Table C-2. Initial Delegate Agency Services

\begin{tabular}{|c|c|c|c|c|c|c|c|c|}
\hline & $\begin{array}{c}\text { DOE } \\
\text { REGIONAL } \\
\text { OFFICES }\end{array}$ & $\begin{array}{c}\text { DOE } \\
\text { FIELD } \\
\text { OFFICE }\end{array}$ & INEL & SERI & ANL & ORNL & BETC & OTHER \\
\hline $\begin{array}{l}\text { I. PRODUCTION INCENTIVES } \\
\text { A. Financial Incentives } \\
\text { Implementation } \\
\text { II. IECHNOLOGY DEVELOPMENT } \\
\text { AND UTILIZATION } \\
\text { A. Capacity Expansions and } \\
\text { Retrofits } \\
\text { B. Test, Evaluation and } \\
\text { Engineering Applications } \\
\text { C. Feedstock Development and } \\
\text { I.ltilization } \\
\text { D. Research and Development } \\
\text { and Techniral Support } \\
\text { III. MARKET DEVELOPMENT } \\
\text { A. Information Gathering. } \\
\text { Analysis and Dissemination } \\
\text { B. Consturit Protection } \\
\text { C. Environment and Safety } \\
\text { D. Educational Program } \\
\text { E. Market and Economic Analysis } \\
\text { IV. MANAGEMENT AND } \\
\text { PROGRAM CONTROL } \\
\text { A. Technical Services } \\
\text { B. Extension Services } \\
\text { C. Program Direction } \\
\text { D. Headquarters Data Base }\end{array}$ & $\begin{array}{l}\mathrm{s} \\
\mathrm{s} \\
\mathrm{s} \\
\mathrm{s}\end{array}$ & $\begin{array}{l}\mathrm{L} \\
\mathrm{L} \\
\mathrm{L} \\
\mathrm{L}\end{array}$ & $\begin{array}{l}\mathrm{S} \\
\mathrm{s} \\
\mathrm{s} \\
\mathrm{s}\end{array}$ & $\begin{array}{l}s \\
s \\
s \\
s\end{array}$ & $\begin{array}{l}s \\
s\end{array}$ & $\begin{array}{l}S \\
S \\
S \\
S\end{array}$ & $\begin{array}{l}\mathbf{s} \\
\mathbf{s}\end{array}$ & $\begin{array}{l}\text { SWAFI } \\
\text { USDA } \\
\text { SWAFI } \\
\text { TVA }\end{array}$ \\
\hline
\end{tabular}

Legend: L - Lead

S - Support 


\section{DOE REGIONAL OFFICES}

Producing alcohol from biomass is a uniquely local activity because of regional variances in feedstocks, production technologies, and end use of coproducts. State involvement is, therefore, necessary and desirable. To encourage that involvement, the Office is conducting cooperative State feasibility studies and developing a model State alcohol fuels plan. Since DOE Regional Offices historically have strong working relationships with the States, it is logical that the Regions play a significant role. Applications for financial assistance received at the Regional Offices will be forwarded to INEL for appropriate review and evaluation. Each DOE Regional Office will have at least one Alcohol Fuels Coordinator, a person dedicated to the Alcohol Fuels Program who will disseminate information, respond to public inquiries, provide technical assistance, oversee educational programs and local grants, and act as liaison with State and local government agencies and officials.

\section{NINETY DAY IMPLEMENTATION PLAN}

The Office of Alcohol Fuels must accomplish several major tasks within ninety days to ensure continued momentum of the alcohol fuels movement and the continued development and commercialization of the alcohol fuels industry. Department support is essential to ensure that the Office achieves the goals outlined in this Ninety Day Plan.

Pursuant to the Ninety Day Implementation Plan, financial commitments will be made as described. For each commitment, the Office within AFO charged with program responsibility is identified and a brief explanation provided. The tasks described below are illustrated in Table C-3. Each office's activities are described in the statement of missions and functions.

Table C-3. Ninety Day Implementation Plan

\begin{tabular}{|c|c|c|c|c|}
\hline & $\begin{array}{l}\text { FY } 80 \text { FUNDING } \\
\text { (IN MILLIONS) }\end{array}$ & $\begin{array}{l}\text { NUMBER OF } \\
\text { PROJECTS }\end{array}$ & $\begin{array}{l}\text { ADDITIONAL } \\
\text { CAPACITY BY } \\
1981 \text { (MILLIONS } \\
\text { OF GALLONS) }\end{array}$ & $\begin{array}{c}\text { ADDITIONAL } \\
\text { CAPACITY BY } \\
1982 \text { (MILLIONS } \\
\text { OF GALLONS) }\end{array}$ \\
\hline \multicolumn{5}{|l|}{ PRODUCTION INCENTIVES } \\
\hline Award Loan Guarantees, up to & $\$ 400.0$ & 10 & & 200 \\
\hline P.L. 96-126 Cooperative Agreements & 35.0 & 2 & 80 & \\
\hline P.L. 96-304 Cooperative Agreements & 70.0 & 5 & & 120 \\
\hline \multicolumn{5}{|l|}{$\begin{array}{l}\text { TECHNOLOGY DEVELOPMENT } \\
\text { AND UTILIZATION }\end{array}$} \\
\hline Fund Brewery Conversions & 10.0 & 2 & 38 & 1 \\
\hline Award Small Grants & 15.0 & 450 & 20 & \\
\hline $\begin{array}{l}\text { Fund Alcohol Fuels Plants at } \\
\text { INEL and TVA }\end{array}$ & 1.5 & 12 & 1 & \\
\hline Award Unsolicited Proposals & 100.0 & 50 & & 200 \\
\hline $\begin{array}{l}\text { Fund Accelerated Research and } \\
\text { Development for Cellulose } \\
\text { Conversion }\end{array}$ & 6.0 & 6 & * & \\
\hline MARKET DEVELOPMENT ' & & . & & \\
\hline $\begin{array}{l}\text { Fund SERI National Alcohol Fuels } \\
\text { Information Center }\end{array}$ & 2.0 & 1 & - & \\
\hline $\begin{array}{l}\text { Fund Additional Educational } \\
\text { Programs }\end{array}$ & 1.5 & 30 & * & \\
\hline $\begin{array}{l}\text { Fund Small, Disadvantaged and } \\
\text { Minority Business Program }\end{array}$ & 1.5 & 8 & 1 & \\
\hline $\begin{array}{l}\text { Fund State Feasibility Studies and } \\
\text { Model State Piogrem }\end{array}$ & 1.5 & 13 & - & \\
\hline $\begin{array}{l}\text { Fund Technical Support Center } \\
\text { Planning }\end{array}$ & 1.5 & 10 & * & \\
\hline PROGRAM CONTROL & & & & 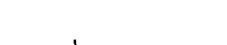 \\
\hline $\begin{array}{l}\text { Manage Programs and Provide } \\
\text { General Support }\end{array}$ & 3.0 & 10 & - & \\
\hline
\end{tabular}

- The Rescarch and Development, Informatiun, Eucestion and Supmert activities do not make first order contributions to commercial ethanol production capacity. In the chemical industry, it is common practice to use a factor of 20 timiss the research investment to estimate the future contribution of research. 


\section{OFFICE OF PRODUCTION INCENTIVES}

\section{Award Loan Guarantees}

The first solicitation for loan guarantees and the proposed regulations were published in the Federal Register on August 14, 1980. The final rule is planned to bc published on October 1, 1980. Up to $\$ 400$ million of loan guarantee commitments would be awarded in the next ninety days, provided that worthy applications are received. The proposed loan guarantee regulations permit the Office to accept voluntary loan guarantee applications at this time and begin their evaluation. Projects which demonstrate high commercial viability and meet the other requirements of the regulations, as determined by the evaluation, may be awarded a loan guarantee. As a general rule, for each two dollars of loan guarantee commitment, onc gallon of ethanol production capacity will come on line.

\section{Evaluate Projectś for Feasibility Studies and Cooperative Agreements}

Review and evaluate the current solicitation under P.L. 96-304 for alternative fuels production feasibility studies ( $\$ 100$ million) and cooperative agreements $(\$ 200$ million). The closing date for this solicitation is September 30,1980, and selections will be announced soon thereafter.

\section{OFFICE OF TECHNOLOGY DEVELOPMENT AND UTILIZATION}

\section{Fund Brewery Conversions}

Brewery conversions will provide an almost immediate increase in the nation's alcohol production capacity in terms of millions of gallons per year. The Office of Technology Development and Utilization (TD\&U) will fund the design and construction of one brewery conversion project which will ultimately produce up to 20 million gallons per year, and the preliminary design of another brewery conversion for production of 18 million gallons per year. These projects will provide excellent demonstration activities for other breweries to replicate throughout the country. These activitics require funding of $\$ 10$ million. The two proposed projects wili requuire careful monitoring by TD\&U, INEL and TVA.

\section{Award Small Grants}

The Alcohol Technology Small Grants Program has received over 1400 unsolicited proposals requesting approximately $\$ 45$ million. Hundreds of additional proposals are expected in the next 2 months. Most of the proposals received have been reviewed at this time and almost one-third were technically sound and worthy of funding. It is expected that approximately 450 awards in the next 2 months will be made. Funding these proposals can be expected to bring 20 million gallons of annual production capacity on line by the end of 1981 .

\section{Fund Alcohol Fuel Plants at TVA and INEL}

The Administration and Congress are strongly committed to the development of alcohol fuels from biomass. Small-scale and on-farm producers are expected to play a vital role in meeting the production capacity goals established. This Department, in cooperation with the Department of Agriculture, is developing benchmark alcohol fuels plant designs for use by the industry. Work has begun on the design and construction of a ten gallon per hour plant at TVA and a twenty-five gallon per hour plant at INEL. Substantive prugress has been made at both locations and this important work must be continued. These projects require funding of $\$ 1.5$ million.

\section{Award Unsolicited Proposals}

The Office of Technology Developmant and Utilization has received over 220 unsolicited proposals that have required individual processing, evaluation, and final disposition. It would require $\$ 320$ million to fund proposal requests that have been evaluated and determined worthy of funding. The Office has requested $\$ 100$ million to fund a portion of the highest qualified proposals. This funding will bring 200 million gallons of annual production capacity on line by the end of 1982 . The continued processing, evaluation, funding, and monitoring of present and future unsolicited proposals will require the support of the DOE Field Offices and National Laboratories.

\section{Fund Accelerated Research and Development for Cellulose Conversions}

It is estimated that the production potential of available cellulose as a feedstock is three times that of carbohydrates. TD\&U is providing management support to ongoing research and development efforts at SERI, Natick Army Laboratory, and the University of Arkan sas. This will require $\$ 6$ million in immediate funding. Study efforts at these locations consists of both enzymatic and acid hydrolysis. Continuing management support for these activities will be performed by TD\&U.

\section{OFFICE OF MARKET DEVELOPMENT}

\section{Fund SERI National Alcohol Fuels Information Center}

The Office has assisted in the development of the Solar Energy Research Institute's National Alcohol Fuels Information Center which is now providing general and 
technical information relating to alcohol fuels and government programs to the public and industry. The Center will require additional funding of $\$ 2$ million to continue its activities.

\section{Fund Additional Educational Programs}

The alcohol fuels educational program will plan, develop and implement educational programs and course materials. At least forty-five educational collegelevel programs on alcohol fuels production currently exist, and this will be expanded to more than one hundred institutions by 1981 . To accomplish this task, $\$ 1.5$ million must be committed within the next ninety days.

\section{Fund Small, Disadvantaged, and Minority Business Program}

It is essential that in this developing industry, small, minority and disadvantaged businesses be given an equal opportunity to enter the alcohol fuels market. Any delay in instituting this program will act to inhibit small and minority business from entering this field. This program will require $\$ 1.5$ million for implementation.

\section{Fund State Feasibility Studies and Model State Programs}

Alcohol fuel production will require State and local programs to encourage development and commercialization of the industry. The Office has already conducted cooperative statewide feasibility studies in four States, and is developing a model State alcohol fuels plan. This model plan is an essential component of current state liaison efforts. It is proposed that $\$ 1.5$ million be committed to completion of those Statc feasibility studies now being conducted and for the implementation of the model State plan in several interested States.

\section{Fund Technical Support Center Planning}

Technical Support Centers located at communityoriented colleges and schools will act as a communitybased alcohol fuel technology transfer center. The Centers will also transfer feedstock application. The planning and development of the Technical Support Center concept will require a commitment of $\$ 1.5$ million at this time.

\section{OFFICE OF MANAGEMENT AND PROGRAM CONTROL}

The Office of Management and Program Control will require funding of $\$ 3$ million to provide support and establish needed financial and administrative systems and activities.

\section{SUMMARY}

The above actions will commit a majority of the funds available to the Office for fiscal year 1980 and will initiate several hundred projects this year.

\section{MAJOR PROGRAM ACTIONS}

In addition to the Ninety Day Implementation Plan, the following major Program actions will be pursued:

Staff the Office of Alcohol Fuels;

Establish the field support structure;

Convene a meeting of alcohol fuels producers, equipment manufacturers, scientists, educators, and trade association representatives to chart a course for research and development efforts and to revicw the Program;

Accelerate interagency coordination to effectively utilize available Federal resources to advance the Program. Cooperation between USDA and DOE is of primary importance;

Accelerate research, development and demonstration of cellulose conversion to alcohol;

Fund a maximum number of unsolicited alcohol fuels proposals with the financial resources available;

Issue final loan guarantee regulations as required by the Energy Security Act (P. L. 96-294) and implement programs authorized by the Congress under all existing alcohol fuels legislation;

Provide loan guarantees to projects with high commercial viability;

Accelerate the retrofitting of existing foud and beverage facilities to alcohol production;

Provide for adequate participation by small, minority and disadvantaged businesses, including set asides;

Encourage the development and manufacturing of engines that will efficiently use formulated alcohol fuels;

Establish alcohol fuels education programs in universities, colleges and vocation-technical schools; and

Foster competitive practices throughout the alcohol fuels industry. 


\section{OFFICE OF ALCOHOL FUELS MISSION AND FUNCTIONS}

Mission. Manages all Department of Ėnergy programs dealing with alcohol fuels produced from biomass. Responsible for the research, development, engineering, testing, evaluation, and demonstration programs that primarily support biomass derived alcohol fuels industry; defines the market and encourages the development and utilization of alcohol fuels. Manages the removal of any institutional or market barriers which delay commercialization of alcohol fuels; disseminates information on alcohol fuels; and develops, executes, and administers Federal assistance programs for alcohol fuels, including loan guarantees, purchase agreements, price guarantees, contracts, grants, and cooperative agreements in direct support of the mission. Acts as primary coordinator for alcohol fucls progranss with the Department of Agriculture, other Federal agencies, and liaison with State. and locial government.

\section{Otfice of the Director}

Manages the biomass-derived Alcohol Fuels Program. Is the overall cxeculor of the Prcsident's Alcohol Fuels and Rural Incentives (as related to alcohol) Programs. Provides general policy dircction and Program management.

\section{Office of Production Incentives}

- Provides fur flnancial and economic analysis and evaluation activities related to alcohol fuels;

- Ensures continuing market development through monitoring, review, analysis and development of all financial and other innovative production incentive programs;

- Has sole responsibility for Develonment, execution and administration of applicable Federal assistance programs. These may include but are not limited to: loan guarantees, purchase agreements, price guarantees, cooperative agreements; and feasibility study grants;

- Develops and administers supporting activities for the financial assistance programs including extcrnal support through interagency agreements, contracts, grants, and cooperative agitements;

- Reviews and recommends improvements in current processes and procedures for providing Federal financial assistance and production incentives across Departments and Agencies; and
- Continuously reviews all financial and other assistance programs relating to alcohol fuels to ensure policy coordination and effective administration of program.

\section{Office of Technology Development and Utilization}

- Coordinates all research, development, demonstration, and other technical activities with Headquarters staff, the Department's national and regional laboratories, field offices, other Federal agencies and extcrnal resources through interagency agreements, contracts, grants, and cooperative agreements;

- Manages an extensive program of research, develnpment, enginccring, testing, evaluation, and demonstration for alcohol fuels, to assure utilizatinn in surface velicles and aviation and space applicatiuns, generation of electricity, heating and cooling of builidngs, and industrial process heat;

- Provides technical support for the various loan and grant programs;

- Develops production and utilization technology applications to optimize environmental quality related to alcohol production, distribution, and use;

- Manages small-scale alcohol fucls appropitiate technology programs;

- Seeks and develops technningy applications to decrease wastc, inprove energy use efficiency and promote utilization of non-fossil fuel energy inputs in alcohol fuel production;

- Identifies techniques and methnds to remove technological and other impediments for production and use of alcohol fucls; and

- Performs technical evaluations, upon request, for all agencies for awards for alcohol fuels activitics.

\section{Office of Market Development}

- Acts as the Department's liaison and principal point of contact on alcohol fuels with the general public and the alcohol fuels industry;

- Responsible for the alcohol fuels information dissemination program;

- Conducts market and economic research and analysis to facilitate the development and growth of a viable market environment for alcohol fuels; 
- Carries out liaison activities with Congressional, Federal, regional, State and local agencies, promoting alcohol fuels development and commercialization and developing new initiatives for Federal programs;

- Acts to reduce regulatory impediments to the production, distribution, and utilization of alcohol fuels;

- Coordinate assessments of environmental impact of the Alcohol Fuels Program, as well as works to maintain environmental quality and interfaces with occupational safety and health regulation of the alcohol fuels industry;

- Establishes, maintains, and oversees a National Alcohol Fuels Information Center and Data Bank;

- Conducts industry liaison activities, including market and economic research, analysis, and forecasts for industry;

- Develops and implements programs to ensure free competition and an open market and stimulate entry into the alcohol fuels market by small, disadvantaged, and minority businesses;

- Provides for the development and conduct of alcohol fuels educational programs; and

- Develops and implements product quality assurance and consumer protection programs.

\section{Office of Management and Program Control}

- Plans, programs, budgets, and evaluates Office programs and activities;

- Provides preprocurement guidance and processing assistance in contractual and grant agreements. Performs as the Office's primary point of contact with the Department procurement component;

- Responsible for continuing assessment, audit, and evaluation of all agreements entered into by the Office, including loans and price guarantees, purchase agreements, inter-agency agreements, contracts, grants, and cooperative agreements;

- Develops management information systems and acquisition of required data and information for Program use;

- Provides for administrative support to meet Office needs;

- Provides assistance in all personnel matters;

s Coordinates all alcohol fuels commercial application and marketing activities with AFE, RA, and the Synthetic Fuels Corporation, as appropriate; and

- Provides assistance to minority and small disadvantaged and minority businesses wishing to participate in the programs of the Office. 


\section{THIS PAGE}

\section{WAS INTENTIONALLY \\ LEFT BLANK}




\section{Summary of Ethanol Legislation}

- National Legislation

- State Legislation

This appendix provides a summary of the National and State Legislation on alcohol fuel. Significant portions of this material was initially prepared and published by the National Alcohol Fuel rommisșion. 


\section{NATIONAL LEGISLATION}

The Federal programs available for increasing our alcohol fuels production capacity are described in this appendix. This appendix identifies 10 existing programs within the Department of Agriculture, the Department of Commerce, the Small Business Administration, the Dcpartment of Housing and Urban Development, the Department of Energy, and the Department of the Treasury. It also identifies four items of authorizing legislation for the Departments of Agriculture, Commerce, and Energy.

The 96th Congress has provided new programs for the stimulation of alcohol fuel production. In addition, existing legislation has been interpreted by the agencies affected which will enable and increase the number of commercial scale plants in the near-term.

Two new major laws have heen passed: The $\Lambda$ Itcrnative Fuels Produstion Appropriations Acl, P.L. 96-126, Titlc II; and The Biomass Energy and Alcohol Fuels Act of 1980, P.L. 96-294, Title II.

The Alternative Fuels Act is oriented toward the Department of Energy and sets aside $\$ 1.5$ billion for the development of alternative fuels consisting of $\$ 100$ million for cooperative agreements with non-Federal entites, and $\$ 500$ million for a reserve to cover any defaults from loan guarantees. A portion of these funds will be spent on alcohol fuel projects. The Biomass Energy and Alcohol Fuels Act applies to both the Department of Agriculture and the Department of Energy and provides authority to enter into loan guarantees, price guarantees, and purchase agreements for alcohol fuels and other biomass energy projects. Additionally, the Department of Agriculture may provide insured loans for small-scale projects. A total of $\$ 1.05$ billion has been appropriated for use over the next two years for biomass projects, including assistance for alcohol fuels projects.

Under existing legislation, the Department of Agriculture provides financial assistance for alcohol production through farm ownership loans, farm operating loans, and business and industrial loans under the responsibility of the Farmers Home Administration, and other loans under the responsibility of the Commodity Credit Corporation. For economic development, the Department of Commerce has directed its attention to providing grants, loans, and loan guarantees for creating and retaining jobs by financing the construction and operation of alcohol plants. The Small Business Administration is attempting to finance plant construction, expansion, conversion, or startup and the Department of Housing and Urban Development endeavors to achieve its mission of economic development and neighborhood revitalization.
In addition, the Department of the Treasury encourages the construction of domestic alcohol production facilities through its powers to provide tax exemptions and credits, the Economic Regulatory Administration of DOE cncourage alcohol production through its power to regulate cash entitlements.

This section of the Appendix identifies the existing public laws and highlights some currently planned legislation which could impact on the near-term alcohol fuels production outlook. The following legislation is not addressed in this section.

- Current and pending legislation dealing with research, development, and small-scale testing (e.g., Economic Opportunity Act of 1964, Title II, Section 22(a), P.L. 95-568, Community 3etvices Administration; and the Urban Waste Program, P.L. 93-577, Department of Encrgy).

- Administrative details such as establishing a Federal infrastructure (e.g., the Priority Energy Project Act; Energy Mobilization Board, S.1308; and Surface Transportation Assistance Act of 1978; the National Alcohol Fuel Commission, P.L. 96-106).

- Those appropriation acts which, in effect, deal only with funding the programs already dealt with in authorization bills (e.g., the U.S. Department of Agriculture Appropriations Act for FY 1980, P.L. 96-108; and the Energy and Water Development Appropriations Act of 1980, P.L. 96-69). Table D-1 summarizes the current Federal Programs.

\section{PUBLIC LAWS}

\section{DEPARTMENT OF AGRICULTURE, FARMERS HOME ADMINISTRATION}

\section{LLGISLATION}

RURAL DEVELOPMENT ACT OF 1972; P.L. 92-419, TITLE I, FARM OPERATING LOANS, AND FARM OWNERSHIP LOANS.

\section{ECONOMIC/FINANCIAL BEṄEFIT(S)}

Direct loans; loan guarantees; insured loans.

\section{OBJECTIVE(S)}

Interpreted to be appropriate to finance production of alcohol for on-farm use, or for partial off-farm use and sale, only if it is necessary to make the farm operation commercially viable. (See S.985/HR 3683). 


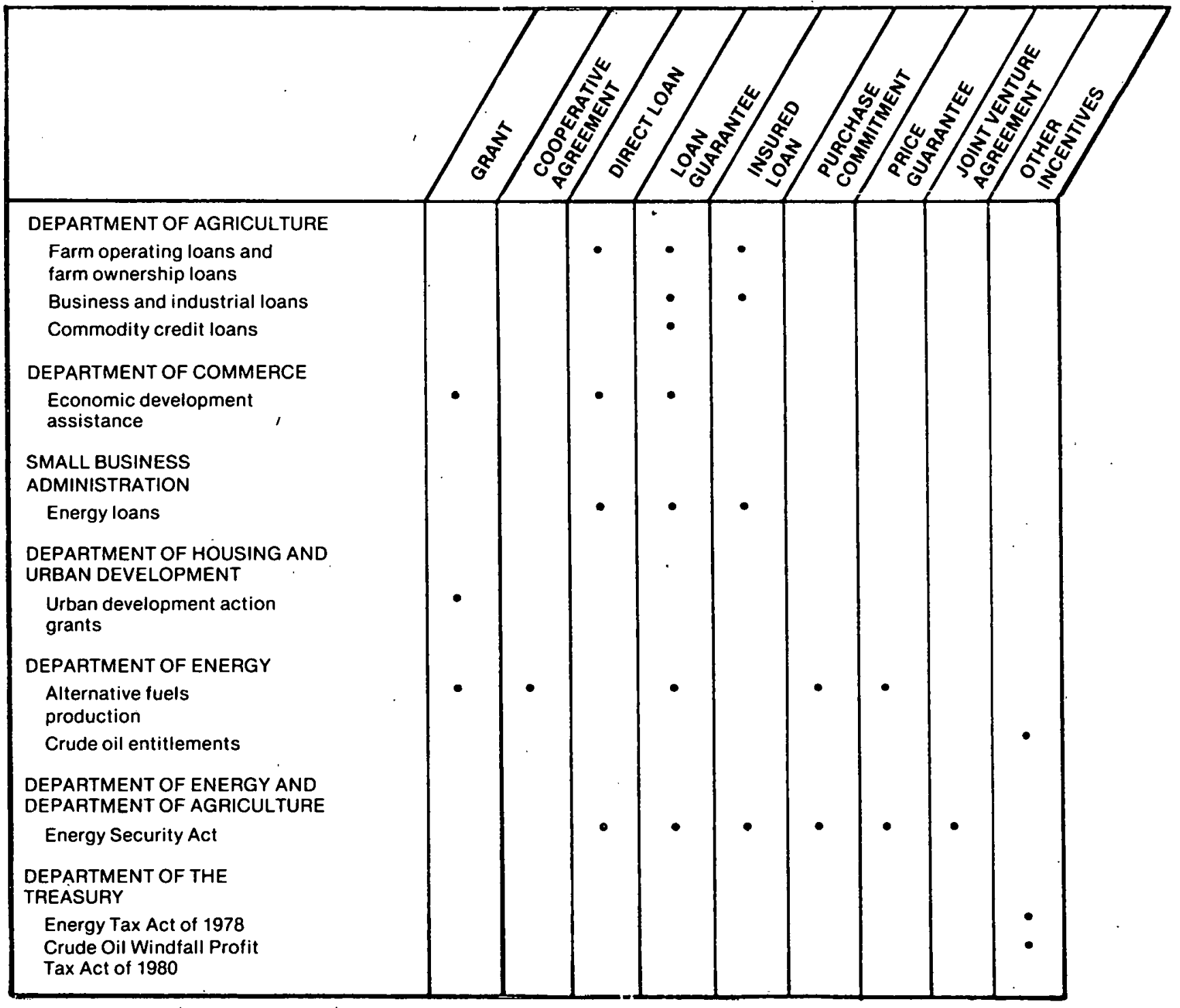

\section{ELIGIBILITY}

After financial assistance is received, must be operators of family farms who are U.S. citizens, are of legal age, cannot obtain sufficient credit elsewhere at reasonable rates and terms, and otherwisc meet the requirements for an FmHA farm loan. If the item for which financial assistance is sought is considered chattel property or operating expense (e.g., an alcohol fueled tractor, or a portable still) then the applicant files for a farm operating loan; if the item is considered a permanent installation on the real estate (e.g., an alcohol plant, methane digestor) then the applicant files for a farm ownership loan.

\section{FINANCIAL TERMS}

Guranteed/insured loans are made and services by legally organized private lending institutions, such as commercial banks, Federal land banks, production credit assnciations, insurance companies, and savings and loan associations. FmHA provides the lender with a guarantee to reimburse up to 90 percent of any loss the lender takes on a loan.

Farm operating loans may be repaid in from one to seven years. In some cases, borrowers may be given an additional seven years to repay. The interest ratc currently is at 10.5 percent. The limit of an operating loan 
made directly by FmHA is $\$ 100,000$; a private loan guarantee by FmHA has a limit of $\$ 200,000$.

Farm ownership loans have a maximum term of forty years. Interest rates are currently 10 percent annually. The limit on a farm ownership loan made directly by FmHA is $\$ 200,000$; on a guaranteed loan is $\$ 300,000$.

\section{DEPARTMENT OF AGRICULTURE, FARMERS HOME ADMINISTRATION}

\section{LEGISLATION}

RURAL DEVELOPMENT ACT OF 1972; P.L. 92-419, TITLE I, BUSINESS AND INDUSTRIAL LOAN PROGRAM.

\section{ECONOMIC/IINANCIAL BENEFIT(S)}

Loan guarantees; inşurcd Inans.

\section{OBJECTIVE(S)}

To assist public, private, or cooperative organizations organized for profit or nonprofit, Indian tribes or individuals in rural areas to obtain quality loans for the purpose of improving, developing, or financing business, industry, and employment and improving the economic and environmental climate in rural communities.

\section{ELIGIRII.ITY}

Applicant must be located in the fifty states, Puerto Rico, or the Vurgin Islands, in areas other than cities having a population of more than 50,000 and its immediately adjacent urbanized areas with a population density of more than 100 persons per square mile. Gasohol projects located on farms are not appropriate for funding here. (See FmHA Farm Operating and Farm Ownership loans.) Non-farm distilleries can qualify under this program.

Guidelines have been established that the operating prototypes for pre-engineered plant designs must meet. Prototype plants producing 500,000 gallons a year. or less must havc operated for 60 days at the rated annual capacity, produced a minimum 160 proof alcohol, convert 75 percent of the fermentable carbohydrates, be inspected on-site, and have an insurable design.

Pre-engineered alcohol fuel plants. qualifying for loan guarantees will have proven successful in prototype plants operating for at least 60 days. Custom- or selfbuilt plants must be based on plans that have been certified by technical experts or on FmHA approved generic plans that are available at no charge.
Plants producing from 500,000 to 5 million gallons a year must produce 190 or higher proof alcohol, must convert 85 percent of the fermentable carbohydrates, have a designer performance guarantee mechanism, and have an insurable design.

\section{FINANCIAL TERMS}

FmHA may guarantee up to 90 percent ( 80 percent in the case of gasohol) of a loan with applicant responsible for furnishing a minimum of 10 to 20 percent of equity. Maximum terms are 30 years for land, buildings, and permanent features; 15 years for machinery or equipment or the life of the machinery or equipment, whichever is shorter; 7 years for working capital. The interest rate for guaranteed loans may be fixed or variable and the amount will be determined between the lender and borrower. No loan guarantee application may exceed $\$ 50$ million.

Insured loan rates to public bodies, non-profit associations, and Indian tribes are at the rate of 5 percent per annum. The maximum allowable maturity of an FmHA insured loan for community facilities shall not exceed 40 years.

\section{DEPARTMENT OF AGRICULTURE, COMMODITY CREDIT CORPORATION}

\section{LEGISLATION}

FOOD ANŨ AGIRICULTURE ACT OF 1977: P.L.. 95-113, SEC'I'ION 1420

\section{ECONOMIC./FINANCIAL BENEFIT(S)}

Loan guärantees.

\section{OBJECTIVE(S)}

To encourage farmers to make additional uses uf their commodities in order to achieve greater crop handling and markeling hexibllity.

\section{FI.IGIBILITY}

Any person who as owner, landlord, tenant, or sharecropper produces one or more applicable commodities. Project must be designed to produce industrial hydrocia buns and alcohol from "agricultural commodities and forest products." (Biomass). The industrial hydrocarbons and alcohol must be for nonfood and nonfeed purposes, such as fuels or industrial energy-type raw materials. Total energy content of the products must exceed the total energy input from fossil fuels used in the manufacture of the products. 


\section{FINANCIAL TERMS}

This act provides $\$ 60$ million in loan guarantees to build four pilot alcohol plants in the U.S. The four projects are not to exceed $\$ 15$ million for each. The loan guarantee covers 90 percent of the estimated aggregate cost of the project. Efforts are underway to expand this program (see S.892/HR 3580).

\section{DEPARTMENT OF COMMERCE, ECONOMIC DEVELOPMENT ADMINISTRATION}

\section{LEGISLATION}

PUBLIC WORKS AND ECONOMIC DEVELOPMENT ACT OF 1965; P.L. 89-136, as amendẹd.

\section{ECONOMIC/FINANCIAL BENEFIT(S)}

Grants; direct loans; loan guarantees.

\section{OBJECTIVE(S)}

To assist in the construction of public facilities needed to initiate and encourage long-term economic growth and to sustain industrial and commercial viability in designated areas by providing financial assistance to public and private organizations that create or retain permanent jobs by expanding or establishing facilities and plants in redevelopment areas. Financial assistance must not be available from other sources on terms and conditions that would permit accomplishment of the project and further economic development in the area.

\section{ELIGIBILITY}

Any individual private or public corporation, or Indian tribe, provided that the project to be funded is physically situatcd in an area designated as eligible under the Act at the time the application is filed. Neither business development loans nor guarantees of any kind will be extended to applicants who: (1) have, within the previous three years, relocated any or all of their facilities to another city or state; (2) contemplate relocating part or all of their existing facilities with resultant loss of cmployment at such facilities; and (3) produce a product or service for which there is a sustained and prolonged excess of supply nver demand.

For public works grants (Title I), a proposed alcohol plant must be designed to produce less than one million gallons of ethanol per year. For private sector direct loans and loan guarantees, eligibility is generally confined to plants which produce between 500,000 and 50 million gallons pcr year unless applicants are ineligible for assistance under FmHA and SBA funding programs.

\section{FINANCIAL TERMS}

The basic public sector grant rate may be up to 50 percent of the project cost. Severely depressed areas that cannot match Federal funds may receive supplementary grants to bring the Federal contribution up to 80 percent of the project cost, with designated Indian Reservations eligible for 100 percent assistance. EDA's share is usually limited to $\$ 300,000$ per project.

Direct, long-term business development loans up to 65 percent of the cost may be used for the acquisition of fixed assets only (i.e., land, building, machinery, and equipment, including land preparation and bulding rehabilitation). Direct loans for working capital needs are not limited by statute, but are available only for short periods.

The guvernment will guarantee up to 90 percent of the unpaid balance of loans for the acquisition of fixed assets or for working capital; and up to 90 percent of the rental payments required by guaranteed lease arrangements. The maximum amount of the loan principal eligible for the Federal guarantee is limited to $\$ 5$ million.

Efforts are underway to extend this program (see S.914).

\section{SMALL BUSINESS ADMINISTRATION}

\section{LEGISLATION}

SMALL BUSINESS ACT, AS AMENDED; P.L. 95-315, SMALL BUISNESS ENERGY LOANS, SECTION 7(L).

\section{ECONOMIC/FINANCIAL BENEFIT(S)}

Direct loans; loan guarantees; insured loans.

\section{OBJECTIVE(S)}

To assist small business concerns to finance plant construction expansion, conversion, or startup; and the acquisition of equipment, facilities, machinery, supplies or materials to enable such concerns to manufacture, design, market, install or service specific energy measures.

\section{ELIGIBILITY}

Applicant must be a small business concern as described in SBA regulations and must furnish evidence of being engaged in an eligible energy measure.

A direct loan cannot be made if an immediate participation loan is available, and an immediate participation 
loan cannot be made if a guaranteed loan is available. No loan may be made under this program unless the financial assistance is not otherwise available on reasonable terms from non-Federal sources.

An applicant must pledge collateral and give such personal guarantee as may be required. Since greater risk is associated with energy loans, emphasis is placed on the applicant's technology, capability of its employees, quality control, and the financial status of the firm.

Energy loans are not available for installing or undertaking energy conservation measures; for this purpose, SBA requests that small firms apply under SBA's regular business loan program. Additionally, energy loans generally cannot be used for research and development. However, under special circumstances, up to 30 percent of a loan may be approved for such purposcs. Only 25 percent of any direct energy loan may be used fur working canital

\section{FINANCIAL TERMS}

$\$ 350,000$ to any one borrower is the maximum SBA share of an immediate participation loan where SBA and privatc lending institutions each put up part of loan funds immediately; and is the maximum SBA direct loan made by the agency. For guaranteed loans made by a bank and partially guaranteed by SBA, the maximum is $\$ 500,000$. SBA's share of an immediate participation loan cannot exceed 75 percent, and not greater than 90 percent for loan guarantees. No more than 30 percent of the funds can be used for research and development and working rapital in any combination.

In FY 79, interest rates were set at 8-1/4 percent on direct luans and SBA's share of immediate participation ioans. On the bank's share of an immediate participation loan, and on guaranteed loans, the lending institution may set reasonable and legal rates with a maximum ceiling rate set by SBA from time to time. Repayment period is a maximum of 15 years as a rule, however, woiking capital loans generally are limited to 6 years, while portions of loans for construction and acquisition of real estate may have a maximum of 20 years.

\section{DEPARTMENT OF HOUSING AND URBAN DEVELOPMENT, COMMUNITY PLANNING AND DEVELOPMENT}

\section{LEGISLATION}

TITLE I OF 'THE HOUSİNG AND COMMUNITY DEVELOPMENT ACT OF 1974, P.L. 93-383, AS AMENDED BY TITLE I OF THE HOUSING AND COMMUNITY DEVELOPMENT ACT OF 1977, P.L. 93-128, URBAN DEVELOPMENT ACTION GRANTS.

\section{ECONOMIC/FINANCIAL BENEFIT(S)}

Grants.

\section{OBJECTIVE(S)}

To assist severely distressed cities and urban counties in alleviating physical and economic deterioration through economic development and neighborhood revitalization. Alcohol fuel production support is an example of such efforts.

\section{ELIGIBILITY}

Eligible applicants are distressed cities and distressed urban counties which meet the following criteria specified in Section 470.452 of the regulations: (a) minimum standauds of physical and economic distress; (b) demonstratsed results in providing housing for persuns uf low and moderate income; and (c) demonstrated resuilts in providing equal opportunity in housing and employment for low and moderate income persons and members of minority groups.

Projects which include financial assistance from the State or other public entities will receivc more favorable consideration. Other public resources may be provided by matching other Federal grants, or by firm commitments or other Federal or local resources. No activities will be funded unless there is a firm commitment of private resources to the proposed project. Typical projects would include modification, reopening of inner city breweries, distilleries.

\section{FINANCIAL TERMS}

Assistance is tor a discrete project which san he completed in approximately 4 years. No additional funding will be available in subsequent years to complete a project approved in a prior year. Funds are made available through a Letter of Credit.

There are no dollar limits for each award, and they have ranged from less than $\$ 100,000$ to over $\$ 18$ million; however, an amount of funding at least two and onehalf times the amount requested from HUD must be provided by the private sector to be eligible for an award. Twenty-five percent of the allocated funds must be given to small cities (population less than 50,000). Urban Development Action Grants (UDAG) funds cannot be used for working capital.

\section{DEPARTMENT OF ENERGY, ASSISTANT SECRETARY FOR RESOURCE APPLICATIONS}

\section{LEGISLATION}

DEPARTMENT OF THE INTERIOR AND 
RELATED AGENCIES APPROPRIATIONS FOR FISCAL YEAR 1980; P.L. 96-126, TITLE II, DEPARTMENT OF ENERGY, ALTERNATIVE FUELS PRODUCTION. P.L. 96-304, SUPPLEMENTAL APPROPRIATIONS

\section{ECONOMIC/FINANCIAL BENEFIT(S)}

Grants; cooperative agreement (plus others not applicable to alcohol fuels).

\section{ELIGIBILITY}

Alternative fuel produced must be derived from one of the following resources: coal/lignite, shale, tar sands, unconventional gases, peat, biomass, solid wastes (industrial and municipal), or other mineral or organic materials. Biomass (alcohol) projects must be commercial scale, i.e., at least one million gallons per year for ethanol production or its energy equivalent $(85 \times 109$ Btu/year). Fuels which are derived from crude oil or derivatives therefrom are not eligible nor would be producing energy from the direct burning of any of the above resources.

\section{FINANCIAL TERMS}

This Act established an Energy Security Reserve for alternative fuels production in the amount of $\$ 19$ billion. $\$ 2.2$ billion of this reserve have been made available to the Secretary of Energy to stimulate domestic, commercial production of alternative fuels. This appropriation is divided into the following areas pertinent to alcohol fuels:

-- $\$ 100$ million for project development feasibility studies, not to exceed $\$ 4$ million each;

-- $\$ 100$ million for cooperative agreements with non-Federal entitites, the Government share not to exceed $\$ 25$ million each, to support commercial scale development of alternative fuels facilities (note, however, that $\$ 22$ million of this amount has been set aside for the Great Plains Gasification Project pursuant to the legislative history of P.L. 96-126); and

-- P.L. 96-304 provides that (a) not to exceed $\$ 100$ million shall be available for project development feasibility studies, such individual awards not to exceed $\$ 10$ million; and (b) not to exceed $\$ 100$ million shall be available for cooperative agreements with non-Federal entitites, such individual agreements not to exceed $\$ 25$ million, to support commercial scale development of alternative fuels facilities.
The following DOE policies concerning the Government's financial participation in any project selected for award of a cooperative agreement as a result of the solicitation are: Government funds shall only be used for the Federal share of the total estimated cost for design and construction; and Government funds may not be used to pay any profit or. fee to the participant.

It is anticipated that the proposer will share at least 50 percent of the costs of the activities specified in the statement of work. The proposer will set forth in this total cost proposal the amount of costs of this project which he proposed that the Government share. This cost share shall be expressed in terms of dollars and percentage of the total cost.

The schedule of the cost sharing shall be also set out.

Prior work, patents or proprietary data will not be valued in determining the proposer's cost sharing in the cooperative agreement project.

In the event that the cost of providing the site for the project shall be borne by the offeror alone, it shall not be included in the estimated cost which will be cost shared by the Government.

Cost participation by the proposer may be accomplished by a contribution to either direct or indirect costs provided such costs are otherwise allowable in accordance with the cost principles of the award. Allowable costs which are absorbed by the participant-as its share of cost participation may not be charged directly or indirectly or may not have been charged in the past to the Federal Government under other contracts, agreements, or grants, nor may other Federal funds be used as cost participation unless specifically authorized by statute.

The proposer shall submit in detail his recommended terms and conditions for repayment of the Government's share of the cost of the cooperative agreement. These terms and conditions shall be the subject of negotiation.

In addition, the grants for feasibility studies must also be repaid (with interest as determined by DOE) if the project becomes a successful and profitable operation. In exceptional cases, the repayment of the cooperative agreement loan and the feasibility study grant may be waived.

\section{DEPARTMENT OF ENERGY, ECONOMIC REGULATORY ADMINISTRATION}

\section{LEGISLATION}

CRUDE OIL ENTITLEMENTS PROGRAM (43 FR 21429, May 18, 1978; EFFECTIVE DATE JULY 1, 1978. 44 FR 63515, NOVEMBER 5, 1979). 


\section{ECONOMIC/FINANCIAL BENEFIT(S)}

Cash transfers

\section{OBJECTIVE(S)}

To remove the regulatory disincentive to the production and use of petroleum substitutes caused by crude oil price regulations.

\section{ELIGIBILITY}

The benefits are available for ethanol derived from domestic biomass which is mixed with gasoline for use as fuel in the United States.

\section{FINANCIAL TERMS}

The entitlements earned by eligible firms are equivalent, on a Btu basis, to the entitlements earned on unsonntrollcd crude oil, i.e., approximately 8 cents per gallon of alcohol at curient entitlement levels.

\section{DEPARTMENT OF ENERGY OFFICE OF ALCOHOL FUELS}

\section{DEPARTMENT OF AGRICULTURE, FARMERS HOME ADMINISTRATION}

\section{LEGISLATION}

THE ENERGY SECURITY ACT, P.L. 96-294, TITLE II, THE BIOMASS ENERGY AND ALCOHOL FUELS ACT OF 1980.

\section{ECONOMIC/FINANCIAL BENEFIT(S)}

Direct loans; loan guarantees; insured loans; purchase commitments; price guarantees; joint venturc agreements.

\section{ODJECTIVE(S)}

lo promote energy conservation and the development of a domestic synthetic fuels industry, thereby reducing our reliance on imported petroleum.

\section{ELIGIBILITY}

Biomass energy projects using a primary fuel other than petroleum or natural gas in the production of fuel include geothermal and solar energy, waste heat, coal, wood, bagasse, and corn stover. Primary fuel is the predominant fuel used by the project, and does not include the incidental use of petroleum or natural gas (such as for flame stabilization).
Projects using new technologies that expand possible biomass feedslocks, produce new forms of biomass energy, or produce biomass fuel using improved or new technologies will be given the same priority.

This priority does not exclude from financial assistance a project not using an alternative primary fuel or applying a new technology.

The Btu content of motor fuels used in the project must not be greater than the Btu content of the biomass fuel produced. This applies only to the biomass energy project and excludes from consideration motor fuels used in the production and transportation of feedstocks. Any displacement of motor fuel or other petroleum products which occurs after the biomass fuel is produced is also to be considered.

For a project to receive financial assistance, the Department must find that necessary feedsrocks are available and it is reasonable to expect they will continue to be available in the future. A project must extract the protein content of the feedstock for use as food or feed by readily available markets, if to do so is technically and economically practicable.

Alcohol fuel projects eligible for financial assistance from the Department of Energy must have an anticipated annual production capacity of at least 15 million gallons of ethanol, or use aquatic plants as feedstocks. Biomass energy projects eligible for financial assistance from the Department of Agriculture must have an anticipated annual production capacity of less than 15 million gallons of ellianul, or have an anticipated annual proiluction cupacity of 15 million gallons or more if the project is (1) owned and operated by a cooperative and will use feedstocks other than aquatic plants, or (2) will use wood or wood wastes or residues as a feedstock (projects under this catcgory may also be funded by the Department of Energy) and do not use aquatic plants as feedstocks.

\section{FINANCIAL TERMS}

The Departments of Energy and Agriculture nuw have authority to enter into loan guarantees, price guarantees, and purçhase agreements for alcohol fuels and other biomass energy projects. Additionally, the Deparıment of Agriculture may provide insured loans for small scale projects. A total of $\$ 1.05$ billion has been appropriated for use over the next two years by the Departments for biomass energy activities, including financial assistance for biomass alcohol fuels projects.

\section{- Loan Guarantees}

The Departments of Energy and Agriculture may guarantee, against loss of principal and interest, 
loans made to provide funds for the construction of biomass energy projects. The following provisions apply to all loan guarantees made by both departments for alcohol fuels and biomass energy projects:

-- A loan may be for up to ninety percent of the project's estimated construction costs guarantees made for up to 90 percent of the loan.

-- In the event that total estimated construction costs exceed the originally estimated costs, the Department may guarantee an additional loan for an amount up to sixty percent of the difference between the currently estimated costs and the total costs originally estimated.

-- The borrower must establish that without the Department's guarantee the lender is unwilling to extend credit, at reasonable rates and terms, for construction of the project.

-- The lender must bear a reasonable degree of risk in the financing of the project. This is to ensure (1) that the lender fully participates in the financing, (2) that the lender will fully evaluate and scrutinize the loan for viability, and (3) that the lender will fully service the loan during the life of the loan.

-- In the event that the Department determines that the borrower is unable to meet payments but is not in default, then the Department may elect to pay to the lender the amount of principal and interest the borrower is obligated to pay. However, the borrower must first agree to reimburse the Department on terms and conditions the Department deems necessary to protect the financial interests of the United States.

\section{- Price Guarantees}

The Departments of Energy and Agriculture may guarantee a sales price for all or part of the production of a biomass energy project.

The following provisions apply to all price guarantees made by the Departments for alcohol fuels or biomass energy projects:

-- The price guaranteed may not be determined on the basis of the cost of production plus a profit, or other similar arrangement that guarantees a profit to the owner or operator.

-- Any price guarantee must specify the maximum dollar amount of liability of the Federal Government.

-- The price guaranteed and the maximum liability of the Federal Government under that guarantee may be renegotiated to ensure con- tinuation of a project deemed necessary to achieve the purposes of this program.

\section{- Purchase Agreements}

The Departments of Energy and Agriculture may make purchase agreements for all or part of the production of a biomass energy project. The following provisions apply to all purchase agreements made by either Department for alcohol fuels or biomass energy projects:

-- The sales price specified in a purchase agreement may not exceed the estimated prevailing market price as of the date of delivery, unless the Department determines that the sales price must be higher in order to ensure the production of alcohol fuels or biomass energy to achieve the purposes of this program, including national production goals.

-- The alcohol fuels or biomass energy purchased must meet quality standards.

-- The Department may take delivery of alcohol fuels or biomass energy pursuant to a purchase agreement only if arrangements have been made for its distribution to and use by Federal agencies.

-- The Department retains the right to refuse delivery of the alcohol fuels or biomass energy upon such terms and conditions as are specified in the purchase agreement.

-- Any purchase agreement must specify the maximum dollar amount of liability of the Federal Government.

-- The sales price in a purchase agreement and the maximum liability of the Federal Government under that agreement may be renegotiated to ensure continuation of a project deemed necessary to achieve the purposes of this program.

\section{- Insured Loans}

Insured loans are available only from the Department of Agriculture for small scale alcohol fuels and biomass energy projects. "Small scale" is limited to projects with an anticipated annual production capacity of not more than $1,000,000$ gallons. The following provisions apply to all insured loans made by the Department of Agriculture for alcohol fuels and biomass energy projects.

-- They may be for up to $\$ 1$ million per project.

-- They may be for up to 90 percent of the total estimated construction costs of the project. 
-- Loans for cost overruns are limited to 10 percent of original costs.

-- The applicant must establish that without an insured loan, sufficient credit at reasonable rates and terms is unavailable.

-- The interest rate on an insured loan shall be determined by the Department of Agriculture, taking into consideration the current interest rate charged to the Federal Government to borrow money plus up to one percent additional rate of interest.

\section{DEPARTMENT OF THE TREASURY, INTERNAL REVENUE SERVICE}

\section{LEGISLATION}

ENERGY TAX ACT OF 1978; P.L. 95-618, CRUDE OIL WINDFALL PROFIT TAX ACT OF 1980; P.L. 96-2.23.

\section{ECONOMIC/FINANCIAL BENEFIT(S)}

Excise tax exemption; Income tax credit; Investment tax credit.

\section{OBJECTIVE(S)}

To encourage energy conservation and promote industrial and agricultural conversions from oil and gas to alternative forms of energy, specifically, by encouraging the construction of domestic alcohol fuels production facilities.

\section{LLIGIBILITY}

Taxpayers who produce and sell gasoline for blending into gasohol, and those who produce and sell gasoline, provided that the blend contains at least 10 percent alcohol made from any product other than petroleum, natural gas, or coal. Any person who purchases tax-paid gasoline and uses it to make a tax-exempt alcoholgasoline blend may claim a refundable income tax credit equal to the taxes paid on such gasoline.

To be eligible for a regular investment tax credit and a new energy investment tax credit, the property in question must be depreciable property with a useful life of three years or more. In order to qualify for the energy investment tax credit, the property must be new and be placed in service after September 30, 1978 and before January 1, 1983.

\section{FINANCIAL TERMS}

The Energy Tax Act provides that gasohol is exempt from its 4-cent-a-gallon Federal excise tax on motor fuels sold after December 31, 1978, and before October
1, 1984. The Crude Oil Windfall Profit Tax Act of 1980 extends the exemption through December 31, 1992.

The Windfall Profit Tax Act further states that a person who blends alcohol fuel with gasoline or any other liquid fuel suitable for use in an internal combustion engine may claim an income tax credit. The credit is 40 cents per gallon of alcohol of at least 190 proof, and 30 cents per gallon of alcohol of at least 150 proof but less than 190 proof. The tax credit is also applicable to a person (1) who uses straight alcohol fuel (100 percent) as a fuel in his trade or business, or (2) who sells straight alcohol fuel at retail to one who uses it directly. In situations where the retail seller is eligible for the credit, no credit is allowable for the user.

The Energy Tax Act also includes a 10 percent energy investment tax credit in addition to the regular 10 percent investment credit already available. The energy credit applies to costs incurred for the period from October 1, 1978 through December 31, 1982. There is no termination date för the regular investment tax credit.

\section{PENDING LEGISLATION}

\section{DEPARTMENT OF AGRICULTURE}

\section{BILL}

Rural Development Authorization Act; S.892. Rural Development Policy Act; HR 3580. (Soon to be P.L. 96-355)

\section{ECONOMIC.FINANCIAI, BFNF,FIT(S)}

Loan guarantees

\section{MAJOR PROVISIONS}

S.892 - Authorizes $\$ 500$ million in loan guarantees for production of industrial hydrocarbons and alcohols from agricultural commodities and forest products; $\$ 30$ million maximum loan guarantee per project; at least 2.5 percent of all loans guaranteed must be for projects that produce no more than 2.5 million gallons of alcohol per year. IIR 3580 - Piovides $\$ 180$ million in loan guarantees for production of alcohol fuels from agricultural and forest products.

\section{DEPARTMENT OF AGRICULTURE}

\section{BILL}

Consolidated Farm and Rural Development Act; S.985. Consolidated Farm and Rural Development Act Amendments; HR 3683.

\section{ECONOMIC/FINANCIAL BENEFIT(S)}

Direct loans; Loan guarantees. 


\section{MAJOR PROVISIONS}

Makes explicit that alcohol fuel production is eligible under the loan programs of the Farmers Home Administration.

\section{DEPARTMENT OF COMMERCE}

\section{BILL}

The Public Works and Economic Development Act; S.914.

\section{ECONOMIC/FINANCIAL BENEFIT(S)}

Grants; Direct loans.

\section{MAJOR PROVISIONS}

Under the House version of S.914, $\$ 100$ million is authorized in each of two years for EDA grants and loans for construction and operation of facilities that produce alcohol or methane from renewable resources. The Senate version authorizes about $\$ 39$ million annually in EDA grants for alcohol fuel production facilities when such grants will create or preserve jobs in small communities.

\section{DEPARTMENT OF ENERGY}

\section{BILL}

Department of Energy Authorization Act, FY 80-81; S.688 and HR 3000.

\section{ECONOMIC/FINANCIAL BENEFIT(S)}

Purchase commitments.

\section{MAJOR PROVISIONS}

The Senate version (S.688) emphasizes biomass research and development ( $\$ 57$ million); HR 3000 required DOE to seek suppliers of alternative fuels which would be used to fuel DOE motor vehicles. 


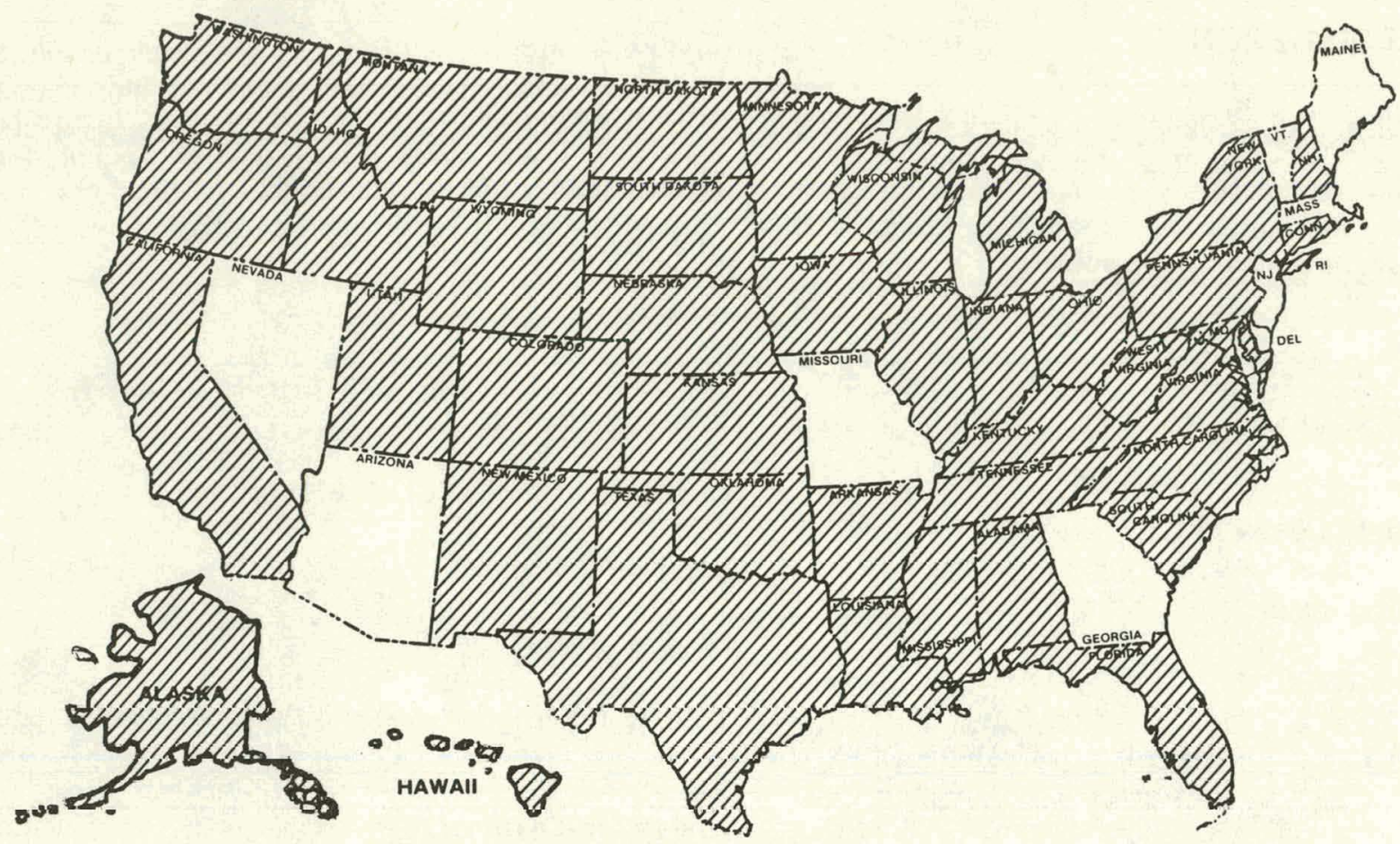

States Which Have Enacted Alcohol Fuels Legislation

QIIIA States Which Have Enacted Laws

States Which Have Not Enacted Laws

Figure D-1. States Which Have Enacted

SOURCE: U.S. National Alcohol Fuels Commission, July 1980 Alcohol Fuels Legislation

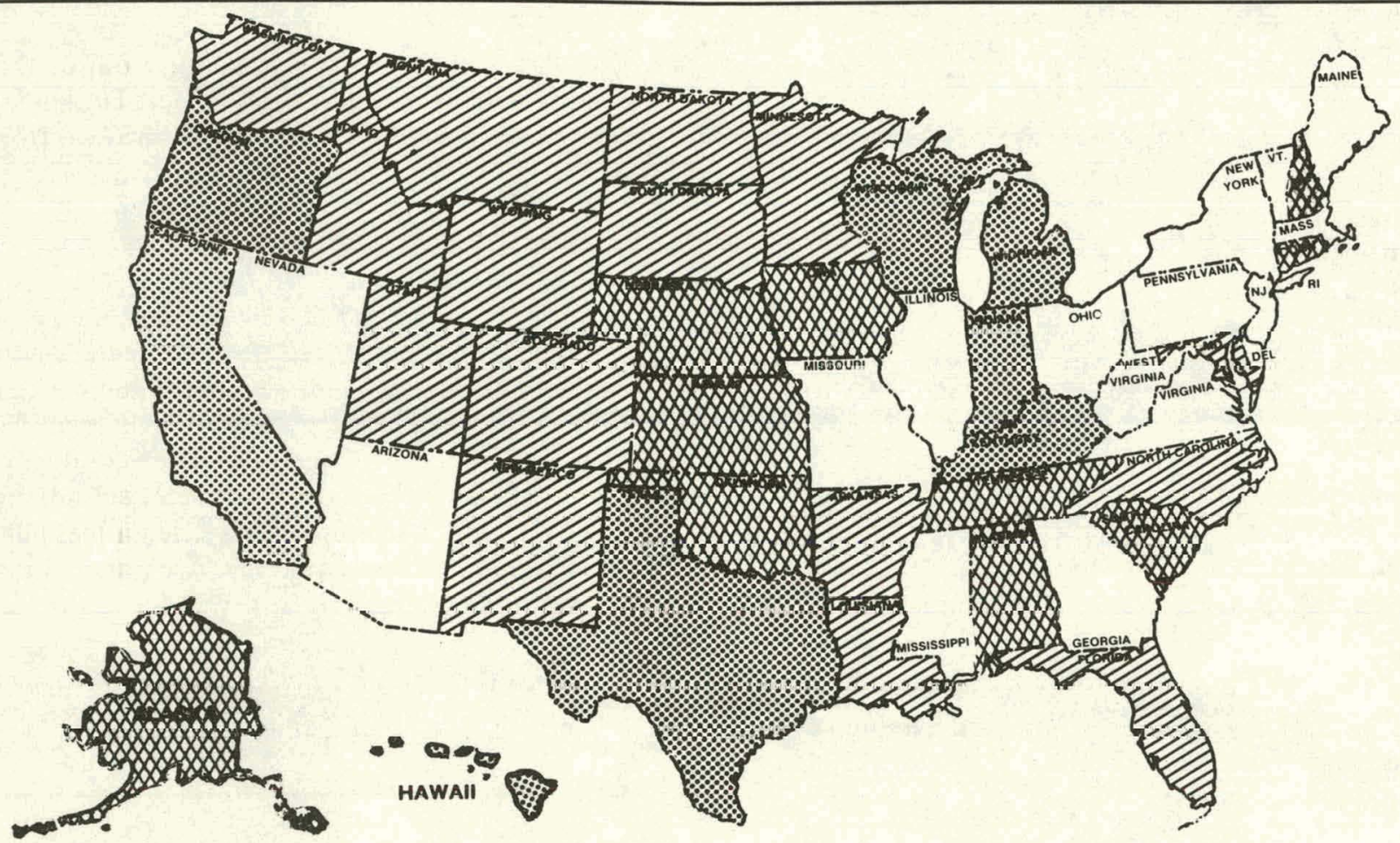

States Which Have Not Enacted Alcohol Fuels Tax Legislation

Both Exemption and Incentives

Excise Tax Exemptions for Gasohol (No other tax incentives)

Property, Sales and/or income Tax Incentives for Alcohol fuels

SOURCE: U.S. National Alcohol Fuels Commission. July 1980

Figure D-2. States Which Have Enacted Tax Incentives for Alcohol Fuels 
This section provides a summary of ethanol legislation for each State. The key points included for each state are the current state laws, pending legislation, state regulations, other important alcohol fuel activity, and the name, address, and phone number of a responsible official to contact for further information. Figure D-1 illustrates which states have enacted alcohol fuels legislation. Figure D-2 illustrates which states have enacted tax incentives for alcohol fuels.

\section{ALABAMA}

\section{LAWS}

\section{$\dot{S B} 354$}

Exempts gasohol from 3 cents of the 8 cents per gallon state motor fuel tax. The gasohol must contain at least 10 percent ethyl alcohol produced from agricultural, forest or other renewable resources and be at least 99 percent pure. Effective July 1, 1980.

\section{$S B 286$}

Creates the Alabama State Department of Energy which will be responsible for alcohol fuels and other alternative energy sources.

\section{PENDING LEGISLATION}

\section{HB 37}

Exempts ethyl alcohol produced and sold for motor fuel and the accompanying distillery operation from all municipal, county, and state sales taxes.

\section{HB 198}

Exempts alcohol used for fuel purposes produced in Alabama from taxation and from Alabama alcohol regulatory provisions.

\section{$H B 952$}

Exempts gasohol from the 8 cents per gallon state motor fuel tax. The gasohol must be manufactured in Alabama or produced in a state which exempts Alabama produced gasohol.

\section{STATE REGULATION}

Permit Procedure-A permit is required by the Alabama Alcoholic Beverage Control Board for the production of fuel alcohol. A $\$ 100$ fee, payable October 1 , is required each year. All alcohol provided for fuel use must be denatured in the final state of distilling.

State Volatility Requirements-Alabama requires that all gasoline (including gasohol) meet ASTM Distillation and Reid Vapor Pressure requirements. ASTM D439 not required.

\section{OTHER IMPORTANT ALCOHOL FUELS ACTIVITY IN ALABAMA}

The Johnson Environmental and Energy Center at the University of Alabama at Huntsville is conducting tests on small scale commercial alcohol fuels stills manufactured in Alabama. The center is also conducting research on vacuum distillation and potential end uses of alcohol fuels, and has recently completed a feasibility study on comparative feedstock values of agricultural resources grown in Alabama.

Universities and Colleges offering alcohol fuels workshops, seminars and courses: Auburn University; University of Alabama at Tuscaloosa; University of Alabama at Huntsville; Talledega College.

\section{Responsiblg Official for Further Information:}

Fred Braswell (205) 832-5010

Program Coordinator

Alabama Energy Management Board

3734 Atlanta Highway

Montgomery, Alabama 36130 


\section{LAWS}

\section{SB 438}

Exempts gasohol from the 8 cents per gallon state motor fuel tax. The gasohol must contain at least 10 percent alcohol. Effective January 1, 1981.

\section{$H B 687$}

Authorizes funding for alternative fuels (including gasohol) research and development. Establishes the Alaska Energy Center. Effective July 1; 1980.

\section{PENDING LEGISLATION}

The legislative session adjourned June 6, 1980. The legislature will convene on January 12, 1981.

\section{STATE REGULATION}

Permit Procedure-No state permit is required for the production of fuel alcohol.

State Volatility Requirements-Alaska has no state volatility requirements for gasoline or gasohol.

\section{OTHER IMPORTANT ALCOHOL FUELS ACTIVITY IN ALASKA}

Feasibility studies on alcohol fuels are being conducted by the state and the University of Alaska.

The Alaska Council on Science and Technology has appropriated funds for the construction of a small scale model methanol plaril.

The U.S. Department of Energy Appropriate Technology Program has provided funds for the construction in Alaska of a new methane production plant using crab waste. The plant is now operational and the first test is underway.

Universities and Colleges offering alcohol fuels workshops, seminars and courses: University of Alaska at Fairbanks; University of Alaska Kenai Community College at Soldotna; Matanuska-Susitna Community College at Palmer.

\section{Responsible Official for Further Information}

Paula Wellen (907) 452-4761

Community Information Center

Fairbanks North Star Borough

P.O. Box 1267

520 Fifth Avenue

Fairbanks, Alaska 99707

\section{LAWS}

No laws have been enacted as of July 1, 1980.

\section{PENDING LEGISLATION}

The legislative session adjourned May 1, 1980.

\section{STATE REGULATION}

Permit Procedures-A state permit is required for the production of alcohol. All distilling apparatus used in the production of fuel alcohol must be registered with the State Department of Liquor Licenses and Control.

State Volatility Requirements-Arizona requires that gaoline (including gasohol) meet ASTM D439 specifications which include Distillation and Reid Vapur Pressure specifications.

\section{LOCAL GOVERNMENT REQUIREMENTS AND INCENTIVES}

The City of Wilcox has set aside property for the development of a municipal industrial park which will lease land at competitive rates for alcohol fuels production facilities.

\section{OTHER IMPORTANT ALCOHOL FUELS ACTIVITY IN ARIZONA}

The Arizona Department of Transportation is using gasohol in approximately 750 state vehicles and is also conducting a fleet test on alcohol fuels using gasohol and dicsclhol in three vehicles.

A "Biofuels Task Force" was established by the Arizona legislature on January 1, 1980, to research the production and use of alcohol fuels in Arizona.

The Arizona Solar Energy Commission has funded a research project on the production of ethanol from biomass and is operating a small scale solar powered ethanol still.

Universities and Colleges offering alcohol fuels workshops, seminars, or courses: University of Arizona at Tucson; Mohave Community College; Yavapai College.

\section{Responsible Official for Further Information:}

Rich Wetzel (602) 255-5705

Arizona Office of Economic Planning \& Development $1700 \mathrm{~W}$. Washington

Executive Tower, Room 505

Phoenix, Arizona 85007 


\section{LAWS}

\section{$S B 454$}

Exempts gasohol from all 9.5 cents per gallon of the state motor fuel tax and special motor fuel tax. The gasohol must contain at least 10 percent alcohol produced in Arkansas from agricultural or forest resources distilled or manufactured in Arkansas, or must be manufactured or distilled in a state which exempts from its motor fuel tax such a mixture produced within the State of Arkansas. Effective Març 20, 1979.

\section{SB 28}

Authorizes the establishment and maintenance of a state Alcohol Fuels Production Registry and requires all persons manufacturing fuels containing alcohol, or manufacturing alcohol for use in or as a fuel, to register with this new department. Effective April 1, 1980.

\section{$H B 742$}

Authorizes a state income tax deduction for qualified energy conservation and renewable energy source expenditures madc between January 1, 1979, and December 31, 1984. (Bioconversion energy devices qualify for this deduction.) Effective April 6, 1979.

\section{$S B 545$}

Appropriates additional funds to the Arkansas Department of Energy (including $\$ 100.000$ to be used for the creation of an Energy Innovation Grant Program).

\section{PENDING LEGISLATION}

The legislative session adjourned January 29, 1980.

\section{STATE REGIU,ATION}

Permit Procedure-The state beverage law permit requirement for the production of alcohol has been waived for alcohol used as a motor fuel April 1, 1980, and replaced by the regulations and procedures set forth in the alcohol fuels produrtion registry (see SB 28 above). No fee is required.

State Volatility Requirements-Arkansas requires that gasoline (including gasohol) meet ASTM D439 specifications, which include Distillation and Reid Vapor Pressure specifications.

Environmental Regulations-The by-products of alcohol production are subject to state environmental control regulations.

\section{OTHER IMPORTANT ALCOHOL FUELS ACTIVITY IN ARKANSAS}

Stevens Inc. is conducting a feasibility study for five to six county cooperatives on a 40 million gallon per year, $\$ 30$ million dollar corn/ethanol plant.

The Arkansas State Department of Energy has published a "how to" manual for alcohol fuel producers.

The Arkansas Joint Legislative Interim Committee on Energy appropriated $\$ 10,000$ for alcohol fuels workshops in 1980.

Delta-Vocational Technical College in Marked Tree, Arkansas, is conducting research on engine retrofitting.

Van Buren, Arkansas Project-Highly automated alcohol fuel production using the chambers ACR advanced distillation process.

University of Arkansas (Gulf Chemical) Project Dr. George Emert is conducting research on the conversion of cellulosic waste to alcohol by enzymatic hydrolysis.

Unversities and Colleges offering alcohol fuels workshops, seminars, or courses: Mississippi County Community College; East Arkansas Community College at Forrest City; Phillips County Community College.

\section{Responsible Official for Further Information:}

Alford Drinkwater (501) 371-1370

Biomass/Resource Recovery Coordinator

Arkansas Department of Energy

3000 Kavanaugh

Little Rock, Arkansas 72205 


\section{LAWS}

\section{AB 2004}

Exempts from any law or regulations, for the three-year period from June 13, 1980 to June 13, 1983, any blend of gasoline consisting of at least 10 percent ethanol, if the gasoline used in the blend meets the 9 pounds per square inch Reid Vapor Pressure standard. The law requires the Legislative Analyst to submit a report to the Legislature two years after the effective date of the bill on the impact of the use of gasohol on the ambient air quality in California. Effective June 13, 1980.

\section{$A B 1401$}

Authorizes the use of methanol and methanol/gasoline blends in vehicles, and permits vehicles to be modified to run on these fuels as of January 1, 1980. The law also establishes a 10-year experimental methanol program in Califorinia, and permits vehicles registered with the California Division of Motor Vehicles to operate exclusively on methanol or methane and a mixture of gasoline or diesel. The law requires manufacturers or distributors of pollution control or engine modification devices to submit such devices to the California Air Resources Board for testing. The state board must report test results to the legislature within 120 days after receiving the device for testing. Effective January 1, 1980.

\section{$S B 318$}

Requires the Department of General Services to develop a gasohol plan for converting 25 percent of the state fleet to be run on alcohol fuel by January 1,1980 .

\section{$S B 620$}

Allocates $\$ 10$ million for an investigation of the practicality and cost effectiveness of alternative motor vehicle fuels.

\section{SB 1324}

Exempts gasohol from the state sales tax on a decreasing scalc basis. The exemption for gasohol will be as follows: January 1, 1981 - January 1, $1982=54$, January 1, 1982 - January 1, $1983=44$, January 1, 1983 - January $1,1984=3 \mathrm{c}$. The gasohol must contain at least $10 \%$ methyl or ethyl alcohol distilled from agricultural commodities, renewable resources or coal. The alcohol must be rendered unsuitable for human consumption at the time of its manufacture or immediately thereafter and be dyed a different color from the color of other gasolines. Effective January 1, 1981. Expires January 1, 1984.

\section{PENDING LEGISLATION}

$S B 1420$ (AB 2348)

Allows franchisees to purchase gasoline, diesel, and gasohol from any available source.

\section{AB 2093 (SB 1324)}

Exempts the sale of gasohol from sales and use taxes.

\section{AB 2603 (SB 1626)}

Provides that any alcohol produced for use as a motor vehicle fuel will be taxed as motor vehicle fuel and not subject to beverage taxes.

\section{$A B 2882$}

Establishes an alcohol fleet in Ventura County and provides for a reimbursement of costs incurred with this profect to the Ventura County government.

\section{$S B 1205$}

Provides funding for the development of alternative energy sources, including alcohol fuels.

\section{$S B 1922$ (SB 3158)}

Exempts synthetic fuel manufacturing plants from district Air Quality Board emission standards.

\section{STATF, RFGULATION}

Permit Procedure-A state permit is required for the production of fuel alcohol. A $\$ 6.60$ fee is required.

Gasohol containing at least 10 percent ethanol is exempted from any Reid Vapor specification laws or regulations from June 13, 1980 to June 13, 1983, if the base gasoline meets the 9 pounds per square inch Reid Vapor Pressure standard. 1'rior to this ruling, gasohol was required by the California Air Resources Board to meet the same Reid Vapor Pressure specifications as gasoline ( 9 pounds per square inch) only during the summer months (April-October). This ruling in effect banned the sale of gasohol during these "summer" months.

State Volatility Requirements-California requires that gasoline meet ASTM D439 specifications, which include distillation and Reid Vapor Pressure specifications.

\section{OTHER IMPORTANT ALCOHOL FUELS ACTIVITY IN CALIFORNIA}

Los Angeles County is conducting a vehicle fleet test using gasohol and methanol blends in 100 vehicles. 
The Bank of America is conducting a vehicle fleet test using pure methanol and methanol blends in approximately 120 vehicles.

The Los Angeles Times sponsored a vehicle fleet test from November 1979 to January 7, 1980, using gasohol in 125 vehicles.

The California General Services Department sponsored a vehicle fleet test during July 1979 using gasohol in 120 vehicles.

Contra Costa County is conducting a vehicle fleet test (August 1, 1979, to August 1, 1980) using gasohol in 30 vehicles.

The Coordination Research Council for the U.S. Department of Energy is conducting a vehicle fleet test in Anaheim, California, using gasohol in 14 vehicles.

The California State Legislature sponsored a vehicle fleet test in 1979 using methanol X (methanol + higher alcohols) in two vehicles.

The University of Santa Clara conducted a vehicle fleet test in December 1978 using ethanol and methanol blends in seven vehicles.

The California Energy Resources and Conservation Development Commission conducted a vehicle fleet test from November 1978 to November 1979 using ethanol and methanol blends in five state vehicles. The Commission will conduct three additional fleet tests using pure methanol and ethanol in 50-150 vehicles altered to achieve maximum efficiency and to meet emission standards.

The California Department of Transportation conducted a vehicle fleet test from November 1979 to July 1980 using gasohol in 500 vehicles.

Oakton Community College in association with University Extension (University of California at San Diego) has received, grants from the National Endowment for the Humanities and the National Science Foundation for a research project evaluating the costs and benefits of synthetic fuels and other related issues.

The California Resources and Conservation Developments Commission is jointly funding with private industry the construction of ethanol plants.

Universities and Colleges offering alcohol fuels workshops, seminars, and courses: University of California at Berkeley; University of California at Davis; University of California at Santa Cruz; LaVerne
College; Cabrillo Junior College; Modesto JuniorCollege; College of Siskiyous.

Responsible Official for Further Information:

Dick DeZeeuw (916) 920-6033

California Energy Commission

1111 Howe Avenue, MS 68

Sacremento, California 95825

Peter Ward (916) 920-6031

California Energy Commission

Development Division

1111 Howe Ave.

Sacramento, California 95825 
LAWS

\section{$H B 1135$}

Exempts gasohol from 5 cents of the 7 cents per gallon stätè motor tuel tax. To be eligible gasohol must contain at least 10 percent ethyl or methyl alcohol produced in Colorado from agriculture or forest resources, petroleum coke, waste coke, or coal waste, and be at least 95 percent pure. Originally, this exemption contained a 200,000 maximum population ceiling restriction and 20 million gallon ceiling; however, these provisions were removed by additional legislation in 1979. (See HB 1463 below.) Effective July 1, 1978. The exemption expires July 1, 1985.

\section{$H B 1607$}

Extends the state motor fuel tax reduction in gasnhol made from petroleum coke, waste coke, coal waste, coal, etc. The law also extends the property tax reduction to apply to these types of plants. Effective July 1, 1979.

\section{$S B 80$}

Creates a nine-member board, the Colorado Gasohol Promotion Committee, which will promote ethanol fuels. Effective July 1, 1978. The board expires, July 1, 1985.

\section{$H B 1463$}

Remuves HB 1135's population and gallonage ceilings. It also requires all state and local government agencies and units to use gasohol in their vehicles when such fuel becomes rcadily available, provided this conversion does not necessitate the mechanical modifications of vehicles.

The law also authorizes a temporary reduction for property tax purposes in an assessed valuation for alcohol plants producing 2.5 million gallons or less of alcohul annually on a decreasing scale basis. The reduction is as follows: 2 percent of actual value for the first year, 9 percent the second year, 16 percent the third year, 23 percent the fourth ycar, and 30 percent thereafter.

The law establishes a special fund under the Gasohol Promotion Committee to promote gasohol and provides a check off option for off-road users of motor fuel on the refund of the motor fuel tax. Effective July 1, 1979.

\section{LEGISLATION INTRODUCED AND NOT ENACTED}

The legislative session adjourned May 2, 1980.

\section{HB 1145}

Energy Appropriation Act. Appropriates funds for the creation of a state operated "Energy Farm" demonstration alcohol plant.

\section{STATE REGULATION}

Permit Procedure-No state permit required for the production of fuel alcohol.

A retailer planning to sell gasohol in his station must file and receive approval with the State Gasoline and Alcohol Inspection Board of the Colorado Revenue Service.

State Volatility Requirements-Colorado requires that all gasoline (including gasohnl) meet only ASTM Distillation requirements. No Reid Vapor Pressure or other ASTM 0439 requircments.

\section{OTHER IMPORTANT ALCOHOL FUELS ACTIVITY IN COLORADO}

The Colorado Gasohol Promotion Committee has conducted research on alcohol fuels and presented recommendations to the Colorado State Legislature on February 15, 1980.

Public Service Co. in Denver, Colorado, conducted a vehicls fleet test during May 1979, úsing methanolgacoline mixture ( $i-10$ percent methanol). in 400 vehicles.

The Police Department of Denver, Colorado conducted a vehicle fleet test from Septcmber 1979 lo October 1979 using 10 percent methanol in 400 vehicles.

Rockwell Institute of Colorado Springs, Colorado is conducting a vehicle fleet test using gasohol in 106 vehicles.

Universities und Colleges offering alcohol fuels workshops, seminars, and courses: Northeastern Junior College at Sterling (developing one-year and two-year programs in alcohol fuels technology); Lamar Community College (conducting nine intensive three-day workshops in conjunction with an operating on-farm alcohol plant in southeastern Colorado); University of Colorado at Boulder.

Responsible Official for Further Information:

Bob Merten (303) 839-3218

Department of Agriculture.

525 Sherman Street, 4th Fl.

Denver, Colorado 80203 


\section{CONNECTICUT}

\section{LAWS}

$H B 7188$

Exempts gasohol from 1 cent of the 11 cents per gallon state motor fuel tax. The gasohol must contain at least 10 percent ethyl or methyl alcohol. Effective July 1, 1979.

\section{PENDING LEGISLATION}

The legislative session adjourned May 7, 1980.

\section{STATE REGULATION}

Permit Procedures-No state permit is required for the production of fuel alcohol. However, producers must file a notice of alcohol fuel production with the State Tax Department.

State Volatility Requirements-Connecticut requires that all gasoline (including gasohol) meet only Distillation requirements. No Reid Vapor Pressure or other ASTM D439 requirements.

\section{OTHER IMPORTANT ALCOHOL FUELS ACTIVITY IN CONNECTICUT}

Universities and Colleges offering alcohol fuels workshops, seminars, and courses: Wesleyan University.

\section{Responsible Official for Further Information:}

Joe Belanger (203) 566-5898

Director, Energy Research \& Policy

81 Washington Street

Hartford, Connecticut 06115

\section{DELAWARE}

\section{LAWS}

No laws have been enacted as of July 1, 1980.

\section{PENDING LEGISLATION}

\section{HB 679}

Exempts gasohol from 9 cents of the 19 cents per gallon state motor fuel tax.

$H B 784$

Encourages the State of Delaware to use gasohol in all state vehicles.

\section{STATE REGULATION}

Permit Procedure-No state permit is required for the production of fuel alcohol. The Delaware Alcoholic Beverage Control Commission requires fuel alcohol producers submit copies of the Federal Bureau of Alcohol, Tobacco and Firearms permit, permit approval notice, and a copy of the Federal bond.

State Volatility Requirements-Delaware has no state volatility requirements for gasoline or gasohol.

\section{OTHER IMPORTANT ALCOHOL FUELS ACTIVITY IN DELAWARE}

Universities and Colleges offering alcohol fuels workshops, seminars, and courses: Delaware Technology and Community College (will also construct three alcohol stills on campus).

Responsible Official for Further Information:

Dan Anstine (302) 736-5647

Delaware Energy Office

P.O. Box 1401

$114 \mathrm{~W}$. Walter Street

Dover, Delaware 19901 


\section{LAWS}

\section{$S B 903$}

(Ch 77) Exempts gasohol from 5 cents of the 8 cents per gallon state motor fuel tax on a decreasing scale basis. The exemption for gasohol will be as follows: July 1, i 980 -July 1,1983 = 5 cents; July 1, 1983-July 1, 1985 $=4$ cents; July 1, 1985-July $1,1987=2$ cents. The exemption expires July 1, 1987. The gasohol must contain at least 10 percent ethyl alcohol and be 99 percent pure.

Provides for a corporate income tax credit for new or expanded businesses engaged in the distillation of ethyl alcohol for use in motor fuels or in the manufacture of equiprnent for the processing or distillation of ethyl alcohol for use in motor fuels. The credit is limited to seven years and is available from January 1, 1981 through January 1, 1988

Requires that oil companies which permit the use of credit cards for the purchase of gasoline must also allow the use of credits for the purchase of gasohol.

Provides an exemption for gasohol from the Florida statute which prohibits the blending or adultering of petroleum products by distributors or retailers, provided that the alcohol blended fuel meets the following temporary specifications (until ASTM approves specifications for gasohol): 90 percent unleaded gasoline; 10 percent ethyl alcohol; the alcohol must be a minimum of 198 proof; a maximum of 50 parts per million acetic acid. 'The gasoline blend stock must meet Florida volatility specifications until the ASTM gasohol specifications are approved.

\section{PENDING LEGISLATION}

None

\section{STATF, REGIU,ATION}

Permit Procedure-No state permit is required for the production of fuel alcohol.

State Volatility Requirements-Florida requires that gasoline (including gasohol) meet ASTM D439 specifications which include Distillation and Reid Vapor Pressure specifications.

\section{OTHER IMPORTANT ALCOHOI, FIJFI.S ACTIVITY IN FLORIDA}

Brevard Community College is conducting research on alcohol fuels.
Universities and Colleges offering alcohol fuels workshops, seminars, and courses: University of Florida at Gainsville (Cooperative Extension Service/Institute of Food and Agricultural Services).

\section{Responsible Official for Further Information:}

Doug Roberts (904) 488-6146

Governor's Energy Office

Capitol Building

Talahassee, Florida 32301 


\section{GEORGIA}

\section{LAWS}

No laws have been enacted as of July 1, 1980 .

\section{PENDING LEGISLATION}

The legislative session adjourned May 8, 1980 .

\section{STATE REGULATION}

Permit Procedures-The State Department of Revenue Motor Fuel Tax Division requires producers of fuel alcohol to submit a copy of the Federal Bureau of Alcohol, Tobacco, and Fircarms permit. Producers must also obtain a nonbeverage alcohol manufacturer's license from the State of Georgia, Department of Revenue, Alcohol and Tax Department, and a motor fuel distributor's special fuels license.

State Volatility Requirements-Georgia requires that gasoline (including gasohol) meet ASTM D439 specifications, which include Distillation and Reid Vapor Pressure specifications.

\section{OTHER IMPORTANT ALCOHOL FUELS ACTIVITY IN GEORGIA}

The University of Georgia at Athens is conducting research on the use of membrane reactors in enzymatic hydrolysis for alcohol production.

The Lieutenant Governor of Georgia has established a five member committee which will assess the feasibility of alcohol production.

Universities and Colleges offering alcohol fuels workshops, seminars, and courses: University of Georgia (Cooperative Extension Service); Georgia Tech (Continuing Education Department).

Responsible Official for Further Information:

Rob Harvey (404) 656-5176

Office of Encrgy Resources 270 Washington Street, SW

Room 615

Atlanta, Georgia 30334
HAWAII

\section{LAWS}

SB 1906

Exempts gasohol from the $4 \%$ state excise tax imposed on the gross proceeds of retail sales. The State Director of Taxation has the authority to terminate the exemption at his discretion. Effective July 1, 1980. The exemption expires June 30, 1985.

\section{PENDING LEGISLATION}

The legislative session adjourned April 17, 1980.

\section{STATE REGULATION}

Permit Procedure-No permit is required for the production of fuel alcohol.

State Volatility Requirements-Hawaii requires that gasoline (including gasohol) meet ASTM D439 specifications, which include Distillation and Reid Vapor Pressure specifications.

\section{OTHER IMPORTANT ALCOHOL FUELS ACTIVITY IN HAWAII}

Maui County conducted a vehicle fleet test during November 1979, using gasohol in county vehicles.

Responsible Official for Further Information:

Takeshi Yoshihara (808) 546-3730

Hawaii Representative

Department of Energy

4322 Prince Kuhio Federal Building

Honolulu, Hawaii 96850 


\section{LAWS}

\section{SB 1359}

Exempts gasohol from 4 cents of the $91 / 2$ cents per yallun statë motor fuel tax. Gasohol must contain at least 10 percent anhydrous ethyl produced in Idaho from agricultural or forest products grown in Idaho. Effective July 1, 1980.

\section{$S B 1247$}

Provides for a credit against individual or corporate income taxes for any personal property or improvements to real property used or constructed for the purpose of manufacturing ethanol alcohol. The credit is available according to the following schedule. During the first year of use: 0.8 percent of the gross value of ethatiul produced in that year; the second year of usi: 0.6 percent of the property value, but not to exceed 0.6 percent of the gross ethanol value; the third year of use: $0.4 \mathrm{pcr}$ cent of the property value, but not to exceed 0.4 percent of the gross ethanol value; the fourth year: 0.2 percent of the property value, but not to exceed 0.2 percent of the gross ethanol value; the fifth and succeeding years of use: no credit.

$H B 531$

Includes gasohol containing 10 percent anhydrous ethanol from agricultural, forest, or waste products in the definitivil of "motor tuels" for tax purposes. Effective . Iuly $1,1980$.

\section{PENDING LEGISLATION}

The legislative session adjourned March 31, 1980. The legislature will convene on January 12, 1981.

\section{STATE REGULATION}

Permit Procedure-No state permit is required for the profuction of fucl alculiul.

State Volatility Requirements-Idaho requires that gasoline (including gasohnl) meet ASTM D479 spiecifications, which include Distillation and Reid Vapor Pressure specifications.

\section{OTHER IMPORTANT ALCOHOL FUELS ACTIVITY IN IDAHO}

In January 1980, the Governor issued a directive requiring the use of gasohol in all state vehicles where gasohol is available and requested that a fleet test (on 100 percent alcohol) be conducted.
The State Energy Department has issued several alcohol fuels information brochures.

An informal inter-agency committee was created by the state lcgislatuie in March 1980 to conduct research on the feasibility of gasohol as a motor vehicle fuel.

Universities and Colleges offering workshops, seminars and courses: University of Idaho at Moscow (Cooperative Extension Service). The College of Southern Idaho in Twin Falls has received a grant from DOE to conduct alcohol fuel workshops.

\section{Responsible Official For Further Information:}

Gail Dameworth (208) 334-3800

Restedrch Analyst

Idaho Office of Energy

State House Mail

Boise, Idaho $8372 n$ 


\section{LAWS}

SR 364

Directs the Governor to promote the establishment of an interagency task force, which will focus on disseminating information on alcohol fuels to individuals and businesses.

\section{HD 3403}

Directs the Illinois Institute of Natural Resources to serve as a clearinghouse for information on alcohol production technology, develop information packets for the public, and sponsor seminars on alcohol fuels. Effective January $1,1981$.

\section{PENDING LEGISLATION}

\section{HB 171}

Requires oil companies to mix ethyl alcohol with unleaded gasoline for motor fuel purposes. Requires that motor fuel sold in Illinois must contain 2 percent alcohol by 1980,5 percent by 1983 , and 10 percent by 1984. Makes a "willful violation" of this law a Class A misdeameanor in addition to punishment by forfeiture of the franchise for the petroleum products seller.

\section{$H B 464$}

Exempts gasohol from the motor fuels tax law, Retailers Occupation Tax, Use Tax, Service Occupation Tax, and Service Use Tax Acts.

\section{HB 1599}

Requires that all motor fuels contain 10 percent alcohol by July 1, 1980.

\section{$H B 1611$}

Directs the University of Illinois to conduct research on gasohol.

\section{HB 2530}

Directs the Illinois Institute of Natural Resources to develop an "alternative fuels incentive program" to investigate tax incentives for gasohol in Illinuis.

\section{$H B 2731$}

Amends the state motor fuel tax to provide that such tax does not apply to alcohol manufactured and used by an individual solely for his or her own use as a motor fuel.

$H B 2866$ (SB 1500) (HB 2920)
Requires retailers of motor fuel to accept credit cards for sales of gasohol if they accept such credit cards for the sale of any form of motor fuel.

\section{HB 2911}

Exempts gasohol from 5 cents of the $71 / 2$ cents per gallon state motor fuel tax.

\section{$S B 1464$}

Exempts gasohol from 2 cents of the state motor fuel tax of $71 / 2$ cents per gallon.

\section{HB 3351}

Exempts gasohol from 4 cents of the $71 / 2$ cents per gallon state motor fuel tax.

\section{HB 2931}

Exempts gasohol from the State Occupation and Use Tax Acts for the period of July 1, 1980, through June $30,1982$.

\section{SB 1518}

Exempts gasohol from the State Occupation and Use Tax Acts.

\section{HR 400}

Establishes an Alternative Fuels Task Force.

\section{STATE REGULATION}

Permit Procedure-That State Department of Revenue requires a permit for the production of fuel alcohol. The Motor Fuels Revenue Act of 1927 allows the Illinois Department of Revenue to tax all fuel producers (including on-farm producers). A $\$ 1,000 \cdot \$ 40,00 \mathrm{~m}$ hond (depending on volume) must be posted and fuel alcohol producers must report all sales on a monthly basis.

State Volatility Requirements-Illinois has no state volatility requirements for gasoline or gasohol.

\section{OTHER IMPORTANT ALCOHOL FUELS ACTIVITY IN IL.LINOỊS}

The Coal and Energy Development Bond Fund was established by the state legislature in 1974. In FY 1977 , $\$ 5$ million of this fund was set aside for alternative energy projects. In 1979, the state General Assembly voted to spend $\$ 1$ million of this fund. Several alcohol fuels projects have been submitted for lunding under this program. 
The State Task Force on Alcohol Production is planning to construct at Vienna, Illinois a 500,000 - 1 million gallons per year alcohol fuels plant. The alcohol produced at this plant will be used to fuel state fleet vehicles.

On November 2, 1979, the Governor of Illinois issued an executive order requiring that 10,000 state vehicles operate on gasohol by October 1980.

Pursuant to SR364, May 22, 1980, the Governor established an interagency task force on alcohol fuels.

National Car Rental at Chicago O'Hare airport is conducting a vehicle fleet test using gasohol in shuttle buses.

Illinuis Bell Tclephone Co. in Peoria, Illinois, conducted a vehicle fleet test from .January 1979 to January 1980 using gasohol in 30 vans and trucks.

The Illinois Institute of Technology conducted a vehiclc tleet test from July 1979 to September 1979 using gasohol (20 percent ethanol) in vehicles.

Maken Lumber Co. of Wooddale, Illinois, conducted a vehicle fleet test from February 1979 to September 1979 using gasohol in 15 flatbed trucks and private vehicles.

Universities and Colleges offering alcohol fuels workshops, seminars and courses: Parkland. Community College; Lincoln Land Community College; Lakeland Community College; Illinois Eastern Community College at Olıeu; Illinoois Lentral College at East Peoria; Sangamon State University.

\section{Responsible Officials. For Further Information:}

John Lehman (217) 782-6675

Alternative Fuels Coordinator

Division of Markcting \& Agricultural Services

Department of Agriculture

Emerson Building - State Fairgrounds

Springfield, Illinois 62706

Larry Metzroth (217) 782-8220

Acting Staff Director

Illinuis Ënergy Resources Commission

612 S. 2nd Street, 2nd floor

Springfield, Illinois 62706

Nicholas Hall (217) 785-2800

Illinois Institute of Natural Resources

$325 \mathrm{~W}$. Adams

Springfield, Illinois 62706
INDIANA

2

\section{LAWS}

\section{$S B 218$}

Exempts gasohol from the 4 percent state sales tax. The gasohol must contain at least 10 percent ethyl alcohol produced from agricultural resources. Effective July 1, 1979.

\section{HB 1334}

Provides that persons allowed a Federal income tax depreciation deduction for a coal conversion system which processes coal into a gaseous or liquid fuel (e.g., methanol) are entitled to a grnss income tax deduction for that same year. Effective July 1, 1980. The provison expires .January 1, 1990.

\section{SB 315}

Establishes vapor pressure ceilings for gasohol. For the months of December, January, February and March: $15.5 \mathrm{psi}$; for the months of April, October and November: $14.5 \mathrm{psi}$; for the month of May. June, July, August and September: 12.5 psi. The gasohol must be a blend of 90 percent unleaded gasoline and 10 percent anhydrous alcohol. Effective July 1, 1980.

\section{$S B 362$}

Establishes the "Indiana Energy Development Board" to develop in-state "1ses of energy resourccs (including alcohol fuels). Appropriates $\$ 1$ million for FY 1980-81 for this program. Effective January 1, 1980.

\section{PENDING LEGISLATION}

The legislative session adjourned February 26, 1980.

\section{STATE REGULATION}

Permit Procedures-No state permit is required for the productivin of fuel alcohol. 'The state requircs producers of fuel alcohol to submit a copy of the Federal Bureau of Alculiul, Tobacco and Firearms permit.

State Volatility Requirements-Indiana requires that all gasoline (including gasohol) meet Distillation and the Reid Vapor Pressure requirements in the SB 315 legislation. No ASTM D439 requirements.

\section{OTHER IMPORTANT ALCOHOL FUELS ACTIVITY IN INDIANA}

1978 - A $\$ 750,000$ grant was appropriated by the state legislature to Purdue University for the development of alcohol fuels technology (cellulosic conversion). 
$1979-\$ 500,000$ in additional funds were appropriated by the state legislature to Purdue for the continuation of their cellulosic conversion research.

Vincennes University is conducting research on alcohol still designs.

The U. S. Navy conducted a vehicle fleet test in 1979 using gasohol (12.5 percent ethanol) in 17 vehicles in Crane, Indiana.

The City of Indianapolis conducted a vehicle fleet test from August 1979 to October 1979 using gasohol in 10 vehicles.

Universities and Colleges offering alcohol fuels workshops, seminars and courses: Vincennes University; Purdue University at Lafayette; Taylor University at Upland.

\section{Responsible Official For Further Information:}

Ms. Mary Failey (317) 232-8954

Department of Commerce

$440 \mathrm{~N}$. Meridian

Indianapolis, Indiana 46201

\section{LAWS}

SF 2376

Exempts gasohol from 10 cents of the state road use tax, (but imposes a 3 percent sales tax). At current prices, the net examption if approximately 6.4 cents. The gasohol must contain at least 10 percent ethyl alcohol distilled from agricultural resources. Effective July 1, 1979, through June 30, 1981. An April 23, 1980 amendment to SF 2376 modifies the exemption for the period May 1, 1981, through June 30, 1983: sales tax is eliminated and gasohol is exempt from 5 cents of the 10 cents road use tax on gasoline. (Net exemption is 5 cents per gallon).

HF 734

Appropriates $\$ 50,000$ for FY 1979 - FY 1981 for the promotion of gasohol and associated by-products. This money has been granted to the Iowa Development Commission. Effective July 1, 1979. The exemption expires June 30, 1980.

\section{PENDING LEGISLATION}

The legislative session adjourned April 15, 1980.

\section{STATE REGULATION}

Permit Procedure-The state code requires alcohol producers to obtain a permit for the production of alcohol and pay a $\$ 350$ fee. This requirement is not enforced when the alcohol produced is used for fuel. The State Attorney General has directed the Iowa Bureau of Liquor Control to continue this non-enforcment policy until the legislature acts to revise the state code. Producers of fuel alcohol must register with the lowa Bureau of Liquor Control. Fuel alcohol blenders must obtain a blender's license and maintain records of gallonage distributed.

State Volatility Requirements-lowa requires that all gasoline (including gasohol) meet Distillation and Reid Vapor Pressure requirements. No ASTM D439 requirements.

\section{OTHER IMPORTANT ALCOHOL FUELS ACTIVITY IN IOWA}

lowa State University is conducting research on alcohol fuels and has constructed and is operating a small scale alcohol fuels plant.

Luther College is conducting research on alcohol fuels and has constructed a small scale solar-powered ethanol plant. 
Northwest Bell Telephone Co. in Des Moines is conducting a vehicle fleet test using gasohol in 24 vehicles.

Iowa Department of General Services conducted a vehicle fleet test during 1979 and 1980 using gasohol in state vehicles.

The Des Moines Police Department is conducting a vehicle fleet test using gasohol in 12 vehicles.

The lowa Corn Promotion Board is promoting the development of gasohol through a corn check-off fund system.

Universities and Colleges offering alcohöl workshops, seminars and courses: Iowa Central Community College.

\section{Responsible Officials For Further Informatinn;}

Mr. Tom Pcarson (515) 281-3151

Iowa Department of Commerce

250 Jewett Building

Des Moines, lowa 50309

Mr. Doug Getter (515) 281-3251

Director, Administrative Services Iuwa Development Commission 250 Jewett Building

Des Moines, lowa 50309
KANSAS

\section{LAWS}

HB 2324

Exempts gasohol from the state motor fuel tax of 8 cents on a decreasing scale basis. The exemption for gasohol will be as follows: July 1, 1979 - July 1, $1980=$ 5 cents; July 1,1980 - July $1,1981=4$ cents; July 1 , 1981 - July 1,1982 = 3 cents; July 1, 1982 - July 1, 1983 - 2 cents; July 1, 1983 - July $1,1984=1$ cent; July 1 , 1985 - no exemption. The bill contains a maximum ceiling provision which provides that if and when the tax revenue loss resulting from the exemption equals $\$ 5$ million, the exemption will automatically expire. The gasohol must contain at least 10 percent ethyl alcohol produced from grain producte grown in Kansas thiruele the use of 10 less energy units than that which would be contained in the converted motor vchiclc fuel. Effective July 1, 1979.

\section{HB 2345}

Appropriates $\$ 55,000$ to the Kansas Energy Office for research on the potential energy resource value of grains. Effective July 1, 1979. 2

\section{PENDING LEGISLATION}

The legislative session adjourned April 13, 1980.

\section{STATE REGULATION}

Permit Prucedure-No state permit is required for the prouluction of fuel alcohol. The state requircs producers of fuel alcohol to submit a cony of the Federal Burcau of Alcohol, Tobaccu \& Firearms permit. A state pcrmit is required to blend and distribute gasohol.

State Volatility Requirements-Kansas requires that all gasoline (including gasohol) meet only Distillation requirements. Nú Reid Vapor Pressure or other ASTM D439 requirements.

\section{OTHER IMPORTANT ALCOHOL FUELS ACTIVITY IN KANSAS}

The Kansas Energy Office has published several alcohol fuels brochures.

Universities and Colleges offering alcohol fuels workshops, seminers and courses: Colby Community College; Kansas State University at Manhattan.

\section{Responsible Official For Further Information:}

Randy Noon (913) 296-2496

State Energy Office

$214 \mathrm{~W}$. 6th Street

Topeka, Kansas 66603 


\section{KENTUCKY}

HB 838

Exempts gasohol producers from the state 5 . percent sales and use tax, the state property tax (except for a one percent minimum), and the state corporate license tax. Exempts gasohol producers from local property taxes. The gasohol must contain at least 10 percent ethyl alcohol produced from grain or other agricultural resources and be at least 198 proof. All provisions expire eight years after the granting of an exemption certificate. Fuel alcohol plants must burn Kentucky coal or convert to such use within two years of certificate receipt in order to qualify for the exemptions.

\section{HR 29}

Resolution directing state officials to encourage the U.S. Department of Energy to convert distilleries to alcohol fuel production.

\section{- PENDING LEGISLATION}

The legislative session adjourned April 1, 1980. The legislature will convene in February 1981.

\section{STATE REGULATION}

Permit Procedure-No permit is required by the state for the production of fuel alcohol. The state requires producers of fuel alcohol to submit a copy of the Federal Alcohol, Tobacco \& Firearms permit.

The HB 838 exemption certificate is required to receive the financial incentives of HB 838 . See HB 838 above.

State Volatility Requirements-Kentucky has no state volatility requirement for gasoline or gasohol.

\section{LOCAL GOVERNMENT REQUIREMENTS AND INCENTIVES}

No local property taxes apply to alcohol fuel producers who are eligible for the incentives of $\mathrm{HB} 838$.

\section{OTHER IMPORTANT ALCOHOL FUELS ACTIVITY IN KENTUCKY}

Universities and Colleges offering alcohol fuels workshops, seminars and courses: Paducah Community College.

\section{Responsible Official For Further Information:}

Bruce Sauer (606) 252-5535

Kentucky Dept. of Energy

P.O. Box 11888/Iron Works Pike

Lexington, Kentucky 40578
LOUISIANA

\section{LAWS}

HB 571 (Act 793)

Exempts gasohol from the state sales and use taxes and the entire 8 cents per gallon state motor fuel tax. The gasohol must contain at least 10 percent alcohol distilled in Louisiana from agricultural products of which at least 10 percent must have been grown in Louisiana. The alcohol must also be rendered unsuitable for human consumption at the time of its manufacture or immediately thereafter and be dyed a distinctive color. Effective September 7, 1979, for a period not to exceed 10 years, unless extended by the legislature.

\section{HB 540}

Amends Act 793 to exempt gasohol from the 8 cents per gallon state motor fuels tax where the agricultural resources used to produce the alcohol are not available in Louisiana. Effective July 23, 1980

\section{PENDING LEGISLATION}

The legislative session adjourned July 14, 1980.

\section{STATE REGULATION}

Permit Procedure-No state permit is required for the production of fuel alcohol. Alcohiol for industrial use, including fuel, is exempt from state alcohol production regulations and laws.

State Volatility Requirements-Louisiana requires that all gasoline (including gasohol) meet Distillation and Reid Vapor Pressure requirements. No ASTM D439 requirements.

Dye Color-The Louisiana Department of Revenue requires that a green dye must be used to differentiate between gasohol which qualifies for the Louisiana excise tax exemption and all other gasolines.

\section{OTHER IMPORTANT ALCOHOL FUELS ACTIVITY IN LOUISIANA}

The Louisiana Department of Natural Resources has spent $\$ 150,000$ of its $\$ 2$ million FY 1980 appropriation on alcohol fuels research. This department plans to allocate a similar amount for alcohol fuels research for FY 1981.

Louisiana State University (Audubon Sugar Institute) is conducting research on alcohol fuels, including the use of molasses as an alcohol feedstock, and spillage disposition. 
Nicholls State University is conducting research on alcohol fuels.

Universities and Colleges offering alcohol fuels workshops, seminars and courses: Nicholls State University.

\section{Responsible Official For Further Information:}

Thomas Landrum (504) 342-4594

Director, Department of Natural Resources

Research and Division

P.O. Box 44156

Capital Station

Baton Rouge, Louisiana 70804
MAINE

\section{LAWS}

No laws have been enacted as of July 1, 1980.

\section{PENUING LEGISLATIÓN}

The legislative session adjourned on April 3, 1980. The legislature will convene June 5, 1981.

\section{STATE REGULATION}

Permit Procedure-No state permit is required for the production of fuel alcohol. The State Bureau of Alcoholic Beverages grants authority to operate an alcohol fuels plant upon receipt of a producer's Federal Bureau of Alcohol, Tobacco \& Firearms permit.

State Volatibity Requirements-Maine requires that all gasoline (including gasohol) meet only Distillation requirements. No Reid Vapor Pressure or other ASTM D439 requirements.

\section{OTHER IMPORTANT AICOHOL FUELS ACTIVIIYY IN MAINE}

The State "Alcohol Fuels Task Force" established Novemher 1979 by the Governor will issue recommen dations to the State Office of Energy Resources and the Governor on the issue of whether or not the State should support an alcohol fuels industry. This Task Force will issue its recommendations and its final repnrt to the OE$R$ and the Govcrnor in November 1980.

The Maine Nepartment of Transportation conducled a vehicle fleet test from June 1979 to September 1979 using gasohol.

Universities and Colleges offering alcohol fuels workshops, seminars and courses: University of Mainc at Drnnn

\section{Responsible Offlclal For Further Inlormation:}

Nancy Holmcs (207) 289-3811

Office of Fnergy Resources

55 Capitol Street

Augusta, Maine 04330 


\section{LAWS}

\section{$S B 807$}

Exempts gasohol from one cent of the 9 cents per gallon state motor fuel tax. Effective July 1, 1979. SB 9 (HB 423) enacted May 1, 1980, increased the exemption for gasohol 3 additional cents (or a total net exemption of 4 cents per gallon). The gasohol must contain at least 10 percent ethyl or methyl alcohol. The 2 cent exemption expires May 1, 1981.

\section{Chapter 331, Acts of 1980}

Exempts ethyl and methyl alcohol which is not mixed with gasoline and is sold as a motor fuel from all 9 cents of the state 9 cents per gallon motor fuel tax and the state sales tax. Effective July 1, 1980.

\section{$S B 823$}

Authorizes the Maryland Industrial Development Financing Authority to insure loans for the development and production of gasohol. Effective July 1, 1979.

\section{SJR 24}

Appoints a Maryland study commission on gasohol through the Maryland Secretary of Agriculture. Effective July 1, 1979.

\section{$H B 628$}

Establishes a gasohol testing program through the Maryland Department of Agriculture. The results of this program were submitted to the legislature January 1, 1980. Effective July 1, 1979.

\section{Chapter 437, Acts of 1980}

Includes gasohol In thuse jiuvisions of the annotated tax code and state regulations which affect gasoline. Effective July 1, 1980.

\section{SJR 7}

Urges the United States Congress to pass legislation which promotes the development of alcohol fuels. Effective July 1, 1980.

\section{LEGISLATION INTRODUCED AND NOT ENACTED}

The legislative session adjourned April 8, 1980. The legislature will convene Januery 14, 1981.

\section{$S B 492$}

Requires retailers of motor fuel to accept credit cards for the purchase of gasohol if they accept credit cards for the purchase of any other motor fuel.

\section{STATE REGULATION}

Permit Procedure-No state permit is required for the production of fuel alcohol. Producers of fuel alcohol are required to send a copy of the Federal Bureau of Alcohol, Tobacco and Firearms permit to the state. Blenders and distributors are required to register with the state motor fuel tax division.

State Volatility Requirements-Maryland requires that gasoline (including gasohol) meet ASTM D439 specifications, which include Distillation and Reid Vapor Pressure specifications.

\section{LOCAL GOVERNMENT REQUIREMENTS AND INCENTIVES}

The government of St. Mary's County has received a grant to build a demonstration still. The Tri-County Council (St. Mary's, Charles and Calvert Counties) sponsored this project.

\section{OTHER GOVERNMENT ALCOHOL FUELS ACTIVITY IN MARYLAND}

The Maryland Department of General Services conducted a vehicle fleet test from September 1979 to September 1980 using gasohol in 8 state vehicles.

The Maryland Chapter of AAA is conducting a vehicle fleet test using gasohol in 22 vehicles.

Universities and Colleges offering alcohol fuels workshops, seminars and courses: Cecil Community College.

\section{Responsible Officials For Further Information:}

Bruce Williams (301) 787-7307

Maryland Department of Transportation

Public Affairs

P.O. Box 8755

Baltimore-Washington International Aìiport, Maryland 21240

Marvin Bond (301) 269-3885

Assistant to the Comptroller

P.O. Box 466

Annapolis, Maryland 21404 
MASSACHUSETTS

\section{LAWS}

No laws have been enacted as of July 1, 1980.

\section{PENDING LEGISLATION}

\section{HB 1772}

Exempts gasohol from 4.5 cents of the 8.5 cents per gallon state motor fuel tax. The alcohol must be produced from feedstocks indigenous to Massachusetts.

\section{STATE REGULATION}

Permit Procedure-No state permit is required for the production of fuel alcohol.

State Volatility Requirements-Massachusetts requircs that all gasoline (including gasohol) meet only Distillation requirements. No Reid Vapor Pressure or other ASTM D439 requirements.

\section{OTHER IMPORTANT ALCOHOL FUELS ACTIVITY IN MASSACHUSETTS}

Springfield Technical and Community College is conducting research on alcohol fuels.

Clark University is conducting research on alcohol fuels.

The University of Lowell is conducting research on alcohol fuels and is operating an alcohol plant using waste paper as a feedstock.

Universities and Colleges offering alcohol fuels workshops, seminars and courses: University of Lowell.

Responsible Official for Further Information:

Mr. Chris Hansen (617) 727.1990

Executive Office of Energy Resources

73 Tremont Street

Boston, Massachuselts 02108

\section{MICHIGAN}

\section{LAWS}

Public Act 198 of 1974 (as amended)

Tax benefits under the act are granted by the legislative body of the city, township or village in which the facility will be located. Allows producers of new alcohol plant facilities a 50 percent property tax exemption for new plant construction (industrial plants only).

\section{PENDING LEGISLATION}

HB 5451

Exempts gasohol from all 11 cents of the state 11 cents per gallon motor fuel tax.

HR 5450

Excmpts gasohol from the state sales tax.

\section{$S B 414$}

Requires all motor vehicle fuel sold in Michigan to contain 3 percent alcohol by January 1, 1980, and 10 percent alcohol by January $1,1984$.

\section{$S B 480$}

Imposes a 6 cents per gallon tax on alcohol/gasoline blended fuel for the development of a demonstration still and research on the by-products of alnohol production.

\section{STATE REGULATION}

Permit Procedure-No state permit is required for the production of fuel alcohol.

State Volatility Requirements-Michigan has no State Volatility Requirements for gasoline or gasohol.

\section{LOCAL GOVERNMENT REQUIREMENTS AND INCENTIVES}

No local infurmation is avāilable.

\section{OTHER IMPORTANT ALCOHOL FUELS ACTIVITY IN MICHIGAN}

$\$ 195,000$ was appropriated by the state to the State Department of Agriculture for research, demonstration, grants and clearinghouse activities. $\$ 118,000$ of this total has been allocated for a contract with Michigan State University for the development of a demonstration still and related byproducts and a computer research project. 
The Michigan Gasohol Committee completed a factfinding analysis titled "Gasohol, Options and Prospects" which was submitted to the Michigan Legislature on April 15, 1980. This report provides information from which appropriate legislative actions can be taken.

Universities and Colleges offering alcohol fuels workshops, seminars and courses: Jordan College at Cedar Springs; University of Michigan at Flint; Michigan State University at East Lansing; Mott Community College.

\section{Responsible Official For Further Information:}

Mr. Randy Harmson (517) 373-1054

Assistant Chief of Marketing and

International Trade Division

Michigan Department of Agriculture

P.O. Box 30017

Lansing, Michigan 48909

\section{LAWS}

\section{HF 112I "Omnibus Tax Bill"}

Exempts gasohol from 4 cents of the 11 cents per gallon state motor fuel tax. The alcohol must contain at least 10 percent ethyl alcohol distilled in Minnesota from agricultural resources produced in Minnesota and be at least 190 proof. Effective May 1, 1980. The exemption expires December 31, 1984.

Minnesota statutes 1978, Section 290.06, Subdivision 13

Provides for a 20 percent income tax deduction on the first $\$ 10,0 \times 0$ spent by a producer of renewable energy (including methane, methanol and ethanol) not offered for sale. Effective July 1, 1979. The exemption expires December 31, 1982.

Laws of 1978 - $\mathrm{CH} 786$

Appropriates $\$ 84,500$ for two alcohol fuels feasibility studies in conjunction with U.S. Department of Agriculture.

Laws of 1979, CH 2, extra session

Appropriates $\$ 50,000$ to the University of Minnesota at St. Paul Department of Agricultural and Applied Economics for alcohol fuels research:s.

HF 1710

Appropriates $\$ 200,000$ to the University of Minnesota at Morris for small scale demonstration plants. Effective April 16, 1980.

\section{PENDING LEGISLATION}

The legislative session adjourned April 12, 1980. The legislature will convene January 6, 1981.

\section{STATE REGULATION}

Permit Procedure-Producers of fuel alcohol must obtain a permit from the Liquor Control Division of the State Department of Public Safety. A $\$ 5.00$ fee is required.

The Minnesota Department of Revenue, Petroleum Division, requires that producers of ethanol for use as a non-blended fuel on public highways pay all 11 cents of the state motor fuel tax.

The Boiler License Code of the Department of the Labor \& Industry requires that all boilers and boiler operations be licensed. Fees range from $\$ 8.00$ (30 horsepower) to $\$ 15.00$ (300 horsepower). 
State Volatility Requirements-Minnesota requires that all gasoline (including gasohol) meet only Distillation requirements. No Reid Vapor Pressure or other ASTM D439 requirements.

\section{OTHER IMPORTANT ALCOIIOL FUELS ACTIVITY IN MINNESOTA}

Canby Atvi, Granite Falls Avti, and Mankato Atvi are experimenting with Alcohol fuels.

The agronomy division of the Minnesota Dept. of Agriculture requires a permit to sell distillers grains.

Universities and Colleges offering alcohol fuels workshops; seminars and courses: Lakewood Community College; University of Minnesota; Southwest State University; Mankato State University; Austin Community College.

Responsible Official for Further Information:

Dennis Devereaux (612) 296-9078

Alternative Energy Projects

Minnesota Energy Agency

980 American Center Building

150 E. Kellogg Blvd.

St. Paul, Minnesota 55101

\section{MISSISSIPPI}

\section{LAWS}

$H B 366$

Legalizes the production and blending of alcohol for fuel in Mississippi. Effectivi July 1, 1980. The inteit of this law is to clarify that previous statutes which limited the production and transportation of alcohol do not apply to alcohol fuels.

\section{PENDING LEGISLATION}

The legislative session adjourned May 12, 1980.

\section{STATE REGULATION}

Permit Procedure-A state license is required for the production of fuel alcohol by the Motor Vehicle Comptroller's Office.

State Volutility Requirements-Mississippi regitires that gasoline (including gasohol) meet ASTM D439 specifications, which include Distillation and Reid Vapor Pressure specifications.

\section{OTHER IMPORTANT ALCOHOL FUELS ACTIVITY $\cdot$ IN MISSISSIPPI}

Universities and Colleges offering alcohol fuels workshops, seminars and courses: Mississippi State; Univer: sity of Southern Mississippi; University of Mississippi.

\section{Responslble Offlctal for Further Intorimátion:}

\author{
Mi. Rubeil Smira (601) 961-4403 \\ Conservation Director \\ Officc of Fnergy \\ Department of Natural Resources \\ 300 Watkins Building \\ 510 George Street \\ Jackson, Mississipni 39202
}




\section{LAWS}

No laws have been enacted as of July 1, 1980 .

\section{LEGISLATION INTRODUCED AND NOT ENACTED}

The legislative session adjourned April 30, 1980.

\section{$H B 1272$}

Exempts gasohol from 4 cents of the state 7 cents per gallon motor fuel tax. The gasohol must contain at least 10 percent alcohol.

\section{STATE REGULATION}

Permit Procedure-All producers of fuel alcohol must obtain a permit from the State Department of Revenue. A $\$ 5,000$ bond must be posted.

State Volatility Requirements-Missouri requires that all gasoline (including gasohol) meet Distillation and Reid Vapor Pressure requirements. No ASTM D.439 requirements.

\section{OTHER IMPORTANT ALCOHOL FUELS ACTIVITY IN MISSOURI}

The Governor of Missouri has issued a directive requiring that gasohol be used in the state fleet if the price of gasohol does not exceed the price of gasoline by 3 cents.

Universities and Colleges offering alcohol fuels workshops, seminars, and courses: State Fair Community College; Sedalia Crowder College; and Southern State College at Joplin.

\section{Responsible Official for Further Information:}

Ms. Deborat: Goldhunnuer (314) 751-4000

Manager of Program Development

Division of Energy

P.O. Box 176

Jefferson City, Missouri 65102

\section{LAWS}

$H B 402$

Exempts gasohol from the 9 cents per gallon state motor fuel tax on e decreasing scale basis. The gasohol must contain at least 10 percent anhydrous alcohol produced in Montana from Montana resources. The exemption for gasohol will be: April 1, 1979 - April 1, $1985=7$ cents; April 1, 1985 April 1, $1987=5$ cents; April 1, 1987 - April 1, $1989=3$ cents. The governor has the authority to suspend the law at his discretion. The exemption is effective April 12, 1979 and expires April 1, 1989.

$S B 523$

Authorizes a property tax reduction for property used primarily in the production - of gasohol. Qualifying properties are taxed at 3 percent (rather than the nonexempt 100 percent level) of their market value. A decreasing scale rate of reductions is included in the law's provisions. The tax reduction is for the taxable years beginning after December 1, 1979, and applies to the period beginning with construction and the first three years of operation. Effective July 1, 1979.

\section{$S B 520$}

Authorizes funding for the Montana Department of Agriculture to contract for research and development on the feasibility of obtaining fuel from wheat and barley. Approximately $\$ 200,000$ will be appropriated for this project each year.

\section{SB 86}

Establishes a state program to provide grants for research, development and demonstration of renewable energy resources. The program is funded by coal severance tax funds (approximately $\$ 800,000$ per year).

\section{PENDING LEGISLATION}

No regular session was held in 1980 . The legislature will convene January 5, 1981.

\section{STATE REGULATION}

Permit Procedure-No state permit required for the production of fuel alcohol. Distributors of gasohol must obtain a permit and post a $\$ 1,000$ bond with the Montana Department of Revenue.

State Volatility Requirements-Montana requires that gasoline (including gasohol) meet ASTM D439 specifications, which include Distillation and Reid Vapor Pressure specifications. 


\section{OTHER IMPORTANT ALCOHOL FUELS ACTIVITY IN MONIANA}

The U.S. Community Services Administration operates a demonstration still in Butte, Montana.

Montana State University at Bozeman is conducting research on alcohol fuels and has established an interdepartmental Biofuels Committee.

Universities and Colleges offering workshops, seminars and courses: University of Montana at Missoula; Flathead Valley Community College.

\section{Responsible Official for Further Information:}

Ms. Georgia Brensbal (406) 449-4624

Program Engineer

Renewable Energy Bureau

State Department of Natural Resources

32 S. F.wing

Helena, Muntana 59601

\section{NEBRASKA}

\section{LAWS}

\section{LB 571}

Enacted May 23, 1979, increases the net tax exemption for gasohol to 5 cents. Requires that gasohol contain at least 10 percent ethyl alcohol produced from agricultural resources and be at least 99 percent pure. Beginning February 1, 1982, the 5 cent exemption applies only to agricultural ethanol produced in Nebraska by a plant in operation or under construction by July 1, 1982. The law also authorized the state of Nebraska to underwrite bonds issued by cities and counties which sponsor the construction of alcohol fuel plants, but the state supreme court overruled this bond provision in 1979.

\section{LB 776}

Exempts gasohol from 3 cents of the $101 / 2$ cents statc motor fuel tax. The láw cuntains maxinum ceillng pruvlsions. Created a "Grain Alcohol Fuel Tax Fund," which is to be used to promote a grain alcohol industry in Nebraska. This fund contained an initial $\$ 40,000$ appropriation and 1/8 of one cent of all collected motor fuel tax revenues in the future. Created "Agricultural Products Industrial Utilization Committee" to administer this program. Effective May 26, 1971.

\section{LB 424}

Establishes a Nebraska Gasohol and Energy Program to be administered by the Agricultural Products Industrial Urllization Comimittee. Establishes a matching grant ( $\$$ sUU, UU) per grant) program for alcohol fuels. No appropriatlons blll was passed to fund this program: F.tfer.live April 21, 1978.

\section{LB 74}

Requires the use of gasohol in the Nebraska Department of Rnads' vehicles The department is required to comply with this act and purchase gasohol only if the cost of gasuliol dues not exceed the cost of other usual fuels by 10 cents. Effective April 5, 1979. Conditions of the bill were to be met by .Iuly $1,1980$.

\section{$L B 876$}

Increases the amount of funds transferred to the Agricultural Alcohol Fuel Tax Fund by $1 / 8$ cent (total amount transferred $=1 / 4$ cent of each gallon on which the tax is collected). Effective July 19, 1980.

\section{LB 954}

Provides for an exemption from the state sales and use taxes for the purchase of alternative energy equipment including alcohol production equipment. Effective April 23, 1980. 


\section{PENDING LEGISLATION}

The legislative session adjourned April 18, 1980.

\section{STATE REGULATION}

Permit Procedure-A boiler permit is required by the Nebraska Department of Labor for the production of fuel alcohol if the production unit exceeds 15 psi. A $\$ 10.00$ fee is required.

State Volatility Requirements-Nebraska requires that all gasoline (including gasohol) meet only Distillation requirements. No Reid Vapor Pressure or other ASTM D439 requirements.

\section{OTHER IMPORTANT ALCOHOL FUELS ACTIVITY IN NEBRASKA}

The University of Nebraska is conducting research on the potential energy source of distillers dried grains. $\$ 10,000$ was appropriated for 1980 for this project by the Nebraska Gasohol Commission.

The Nebraska Gasohol Commission is providing equipment to the Southeast Community College in Milford for the construction of an on-farm alcohol plant.

The National Gasohol Commission is conducting a marketing study in Lincoln, Nebraska, on consumers' reactions to gasohol.

Sarpy County is conducting a fleet test using gasohol in 20 county cars.

The Nebraska Agricultural Products Industrial Utilization Committee (NAPIUC) conducted the first major gasohol vehicle fleet test in the U.S., from December 1974 to October 1977, using gasohol in 74 vehicles over two million miles.

In November 1979, the Governor of Nebraska issued an administrative order requiring all state government vehicles to use gasohol whenever possible.

Universities and Colleges offering alcohol fuels workshops, seminars, and courses: Southeast Community College; Midplains Community College; Scottsbluff Western College; Northeast Community College; Central Nẹhraska Technical College.

Responsible Official For Further Information:

Mr. Steve Sorum (402) 471-2941

Agricultural Products Industrial

Utilization Committee

301 Centennial Mall, South

Third Floor

Lincoln, Nebraska 68509

\section{NEVADA}

\section{LAWS}

No laws have been enacted as of July 1, 1980

\section{PENDING LEGISLATION}

No regular session was held in 1980

\section{STATE REGULATION}

Permit Procedure-No state Permit is required for the production of fuel alcohol. A permit is required to become a "dealer" or distributor of gasohol or ethanol.

State Volatility Requirements-Nevada requires that all gasoline (including gasohol) meet only Distillation requirements. No Reid Vapor Pressure or other ASTM D439 requirements.

\section{OTHER IMPORTANT ALCOHOL FUELS ACTIVITY IN NEVADA}

$\$ 140,000$ in state funds was appropriated for matching funds in March 1980 by the state legislature for the construction of an alcohol fuels plant.

\section{Responsible Official for Further Information:}

Mr. Kelly Jackson (702) 885-5157

Nevada Department of Energy

400 West King Street

Room 106

Carson City, Nevada 89710 


\section{NEW HAMPSHIRE}

LAWS

$H B 201$

Exempts gasohol from 5 cents of the 11 cents per gallon state motor fuel tax. The gasohol must contain at least 10 percent alcohol and be prodiced in New Hampshire. Effective 1979.

\section{PENDING LEGISLATION}

No regular session was held in 1980 .

\section{STATE REGULATION}

Permit Procedure-A state permit is required for commercial production of fuel alcohol by the state Siting Evaluation Committee (Law 162-14).

State Volatility Requirements-New Hampshire has nn volatility requirements for gasoline or gasohol.

\section{OTHER IMPORTANT ALCOHOL FUELS} ACTIVITY IN NEW IIAMPSHIRE

Dartmouth College is conducting a research project on ethanol production from biomass using acid hydrolysis.

The Department of Public Works and Highways conducted a vehicle fleet test on 10 vehicles using gasohol and on two trucks using 100 percent ethanol.

\section{Responsible Official For Further Information:}

Ms. Tina Oleson (603) 271-2771

Government's Council on Energy

$1 / 2$ Beacon Street

Concord, New Hampshire 03310
NEW JERSEY

\section{LAWS}

No laws have been enacted as of July 1, 1980 .

\section{PENDING LEGISLATION}

\section{$S 1030$}

Exempts gasohol from the 8 cents per gallon state gasoline tax.

A 325

Exempts motor vehicles fueled by alternative energy sources from the state sales tax.

A 777

Exempts gasohol from 6 cents of the 8 cents per gallon state gasoline tax.

A 1549

Imposes a one cent per gallon tax on gusohol.

A.136

Provides tax incentives for alcohol fuel production and consumption.

\section{STATE REGULATION}

Permit Procedure-No state permit is required for the production of fuel alcoliol.

State Volatility Requirements-New Jersey has no state volatility requirements for gasoline or gasohol.

\section{OTHER IMPORTANT ALCOHOL FUFIIS ACTIVITY IN NEW JERSEY}

Gilassboro State College plans to build a demonstration still in cooperation with local farmers.

Pintutiun Unlversity is conducting research on alcohol fucls.

The State of New Jersey conducted a vehicle fleet test using gasohol in state vehicles from June 1979 to September 1979.

Universities and Colleges offering alcohol fuels workshops, seminars and courses: Glassboro State College; Ramapo College of New Jersey; Southern New Jersey College. 


\section{Responsible Official for Further Information:}

Mr. Louis Jarecki (201) 648-6293

New Jersey Department of Energy

Office of Alternate Technology

101 Commerce Street

Newark, New Jersey 07102

\section{LAWS}

SB 39

Exempts gasohol from entire 8 cents per gallon state motor fuel tax. The gasohol must contain at least 10 percent ethyl alcohol produced in New Mexico and be at least 190 proof. Exempts gasohol from the state gross receipts and compensation taxes. Effective July 1, 1980. The exemptions expire June 30, 1985.

$H M 41$

Directs the New Mexico .Energy and Mineral Department to undertake research on alcohol fuels. Effective July $1,1980$.

\section{PENDING LEGISLATION}

The legislative session adjourned February 14, 1980.

\section{STATE REGULATION}

Permit Procedure-No state permit is required for the production of fuel alcohol.

State Volatility Requirements-New Mexico requires that all gasoline (including gasohol) meet only Distillation requirements. No Reid Vapor Pressure or other ASTM D439 requirements.

\section{OTHER IMPORTANT ALCOHOL FUELS ACTIVITY IN NEW MEXICO}

In December $1979, \$ 200,000$ was appropriated by the state legislature for four alcohol fuels projects.

In November 1979, the Governor appointed an Alcohol Fuels Task Force to research the production and use of alcohol fuels in New Mexico and to prepare recommendations to be submitted to the Governor.

Several alcohol fuels brochures have been issued by the New Mexico Energy \& Minerals Department.

The University of New Mexico is conducting research on the enzymatic conversion of cellulose.

Navajo Community College is conducting research on alcohol fuels.

New Mexico State University plans to construct a small scale alcohol fuels still.

The U.S. Department of Defense is conducting a vehicle fleet test at the Los Alamos Lab using gasohol in 1,062 vehicles. 
Universities and Colleges offering alcohol fuels workshops, seminars and courses: University of New Mexico at Albuquerque.

Responsible Official for Further Information:

Mr. Gerald Bradley (505) 827-3221, Ext. 217

Tax Research \& Statistics Office

of Taxation Revenue Department

P.O. Box 630

Sante Fe, New Mexico 87509

\section{NEW YORK}

\section{LAWS}

A 11139

Removes the $\$ 625$ annual alcohol manufacturer's permit fee if alcohol is produced from biomess feedstock and is used for the producers own fuel use. Reduces the fee to $\$ 312.50$ for alcohol producers who manufacture less than 100,000 gallons per year if the alcohol is produced for commercial distribution. Effective June 26, 1980.

\section{PENDING LEGISLATION}

None

\section{STATE REGULATION}

Permit Procedure-Producers and blenders of fuel alcohol must obtain an industrial alcohol manufacturer's permit from the state liquor authority to produce fuel alcohol. Commercial producers of fuel alcohol are required to pay a $\$ 625$ fee (commercial producers over 100,000 gallons per year) or a $\$ 312.50$ fee (commercial producers under 100,000 gallons per year).

State Volatility Requirements-New York requires that all gasoline (including gasohol) meet only Distillation requirements. No Reid Vapor Pressure or other ASTM D439 requirements.

\section{OTHER IMPORTANT ALCOHOL FUELS ACTIVITY IN NEW YORK}

Cornell University is conducting technical and economic feasibility studies on the production of ethanol in five regions of New York State from agricultural wastes, including apples, beets, potatoes, brewery wastes and cheese whey. The New York State Energy Resedrch and Development Authority has partially funded this program.

New York Statc's Antonio Ferri Laboratory is conducting research on alcohol fuels.

GUHR Distributing Inc. in Buffalo is conducting a vehicle fleet test using gasohol in 60 trucks.

Brookhaven National Labs conducted a vehicle fleet test from March 1979 to March 1980 using methanol and ethanol blends in 300 vehicles.

New York State conducted a vehicle fleet test from July 1979 to March 1980 using gasohol in 62 vehicles. 
The New York City Police Department is conducting a vehicle fleet test (test began August 1979) using methanol and ethanol blends in three vehicles.

New York City conducted a vehicle fleet test in 1979 using gasohol in 80 vehicles.

The NY-NJ Port Authority conducted a vehicle fleet test (beginning in May 1979) using gasohol in airport and police vehicles at Kennedy Airport.

Universities and Colleges offering alcohol fuels workshops, seminars and courses: Onondaga Community College; New York Inniversity; CUNY Brooklyn College; SUNY College at Binghamton; SUNY College at Plattsburgh; SUNY Agricultural and Technical College al Delhi.

\section{Responsible Official for Further Inforamtion:}

Mr. Mark Bagdon (518) 474-7875

State Energy Office

Agency Building 2

Rockefeller Plaza

Albany, New York 12210

\section{LAW}

\section{$H B 1556$}

Exempts gasohol from the state 9 cents per gallon gasoline tax on a decreasing scale basis. The exemption for gasohol will be as follows: January 1, 1981 - June $30,1981=8$ cents; July 1,1981 - June $30,1982=7$ cents; July 1, 1982 - June 30, 1983 - 6 cents; July 1,1983 - June 30, $1984=5$ cents. The gasohol must contain at least 10 percent anhydrous ethyl alcohol. Exempts nonanhydrous ethyl alcohol from all 9 cents of the 9 cents per gellon state motor fuel tax if the ethanol produced for on-farm use. Effective January 1, 1981. The exemptions expire July 1, 1984.

\section{$H B 1554$}

Establishes a credit against corporate income tax for corporations that construct in North Carolina fuel ethanol distilleries which make ethyl alcohol from agricultural or forestry products for use as a motor fuel. The tax credit equals 20 percent of the installation of equipment costs and an additional 10 percent of those costs if the distillery is powered primarily by use of an alternative fuel source. Establishes a credit against personal income tax for construction of a fuel ethanol distillery for any person who constructs in North Carolina a distillery to make ethanol, from agricultural or forestry products for use as a motor fuel. The tax credit equals 20 percent of the installation and equipment costs of construction and an additional 10 percent of those costs if the distillery is powered primarily by use of an alternative fuel source. Effective date: retroactive to January 1, 1980. The exemptions expire January $1,1985$.

\section{PENDING LEGISLATION}

None.

\section{STATE REGULATION}

Permit Procedures-No state permit is required for the production of fuel alcohol.

State Volatility Requirements-North Carolina requires that gasoline (including gasohol) meet ASTM D439 specifications, which include Distillation and Reid Vapor Pressure specifications. 
OTHER IMPORTANT ALCOHOL FUELS ACTIVITY IN NORTH CAROLINA

Pitt Community College in Greenville has received a $\$ 10,000$ grant from the U.S. Department of Energy for the construction of an alcohol fuels demonstration plant.

Universities and Colleges offering alcohol fuels workshops, seminars and courses: Carteret Technical Institute.

\section{Responsible Official For Further Information:}

Mr. John Manuel (919) 733-4493

Energy Division

Dept. of Commerce

P.O. Box 25249

Ralcigh, North Carolina 27611
NORTH DAKOTA

\section{LAWS}

HB 1384

Exempts gasohol from entire 4 cents per gallon motor fuel tax. 'The gasohol must contain at least 10 percent ethyl alcohol produced from agricultural resources. Establishes an Agricultural . Products Utilization Commission which will promote and research the production and distribution of gasohol. Establishes an agriculturally derived alcohol motor vehicle fuel tax fund which will finance the commission and appropriates $\$ 50,000$ for this fund. Authorizes a sales tax refund (excepting a 1/8 cent charge) to persons who purchase agriculturally derived alcohol fuels for agriculture or industrial purposes. Effective July 1, 1979.

\section{PENDING LEGISLATION}

No régular session held in 1980.

\section{STATE REGULATION}

Permit Procedure-A joint cooperative permit between the Federal Bureau of Alcohol, Tobacco and Firearms and the State Department of Treasury is required by the state for the production of fuel alcohol. No fee is required. The Attorney General has waived licensing requirements.

State Volatility Requirements-North Dakota requires that gasoline (insluding gasohol) meet. ASTM D439 sperifirations, which include Distillation and Reid Vapor Pressure specifications.

\section{OTHER IMPUK'AN'T ALCOHOL FUELS ACTIVITY IN NORTH DAKOTA}

Several state end junior colleges are trying to establish demonstration and/or research projects; Lake Region Junior College (Devils Lake, N.D.), State School of Sclence (Wahpcton, N.D.), Cuuperative Exteñision Service at North Dakota State University (Fargn, N.D.).

Responsible Officials For Further Information:

Mr. Mike Mahlum (701) 224-2250

Federal \& Coordinators Ofțice

Energy Management Conservation Programs

1533 W. 12th Street

Bismarck, North Dạkota 58501

Mr. Dean Mcilroy (701) 224-2232

Executive Director

Agriculture Products Utilization Commission

Department of Agriculture

State Capital

Bismarck, North Dakota 58505 


\section{LAWS}

HB 602

Establishes an Alcohol Fuels Advisory Council within the Ohio Department of Energy to study the development, production, distribution and use of alcohol fuels in Ohio and the feasibility of using agricultural commodities grown in Ohio as a feedstock for such fuels. The Council will terminate July 1, 1981. It is staffed, funded and chaired by the Ohio Department of Energy. $\$ 50,000$ has been appropriated for this Council. Effective February 28, 1980.

\section{PENDiNG LEGISLATION}

$H B 529$ (HB 796, SB 266)

Amends Section 5735.01 of the Revised Code to exempt gasohol from the state 7 cents per gallon motor fuel tax. The gasohol must contain at least 10 percent alcohol.

\section{$H B 986$}

Authorizes the Ohio Department of Energy to design and implement a plan for small-scale alcohol production plants on Ohio farms and appropriates $\$ 100,000$ for this study. Ohio feedstocks are to be used in this project.

\section{$S B 348$}

Prohibits oil companies from disallowing the purchase of gasohol through credit card mechanisms.

\section{STATE REGULATION}

\section{State Code 3717.31}

It is illegal to sell, exchange or deliver milk from cows fed on wet distillery waste or starch waste. Effective October 1, 1953.

Permit Procedure-No state permit is rcquired for the production of fuel alcohol.

State Volatility Requirements-Ohio has no state volatility requirements for gasoline and gasohol.

\section{OTHER IMPORTANT ALCOHOL FUELS ACTIVITY IN OHIO}

Ohio State University is conducting research on alcohol fuel blends.

Universities and Colleges offering alcohol fuels workshops, seminars and courses: Ohio State University (Cooperative Extension Service).
Responsible Official for Further Information:

Mr. Bob Yaekle (614) 466-4573

Ohio Legislative Service Commission

State House, 5th Floor

Columbus, Ohio 42315 


\section{LAWS}

$S B 248$

Exempts gasohol from 6-1/2 cents of the state 6-5/8 cents per gallon motor fuel tax. The gasohol must contain at least 10 percent ethyl alcohol distilled from agricultural resources, and be at least $198^{\circ}$. The distributor of the gasohol must be licensed in Oklahoma and obtain a bond in support of this license. Effective October 1, 1979. Expires October 1, 1984.

\section{$S B 428$}

Establishes permit procedures for fuel alcohol producers. Assigns authority for the enforcement of alcohol fuel regulations to the Oklahoma Department of Agriculture. Effective February 6, 1980.

\section{PENDING LEGISLATION}

None.

\section{STATE REGULATION}

Permit Procedures-Producers of fuel alcohol must obtain a permit from the OkJahoma Department of Agriculture. A $\$ 25.00$ fee is required for an experimental plant permit and a $\$ 250$ fee is required for a distilled spirits plant permit. Whereas distilled spirit plant permit holders may blend alcohol with gasoline and sell the product as a motor fuel, experimental plant permit hülders must retain the product for their own use.

State Volatility Requirements-Oklahoma requires that all gasoline (including gasohol) meet only Distillation requirements. No Reid Vapor Pressure or other ASTM D439 requirements.

\section{OTHER IMPORTANT ALCOHOL FUELS ACTIVITY IN OKLAHOMA}

The U.S. Department of Energy conducted a vehicle fleet test from November 1978 to December 1979 in Bartlesville, Oklahomas, using methanol blends and neat methanol in 76 vehicles.

Univcrsities and Colleges offering alcohol fuels workshops, seminars and courses: Oklahoma State University at Stillwater. (Agricultural Engineering Dept.)

\section{Responsible Official for Further Information:}

Mr. Rex Privett (405) 427-3829

State Gasohol Coordinator

State Department of Energy

4400 N. Lincoln Blvd., Suite 35

Oklahoma City, Oklahoma 73105

\section{LAWS}

HB 2780

Provides for a property tax exemption for commercial alcohol fuel plant property $(100$ percent exemption through 1984). Provides for an income tax exemption (100 percent exemption through 1985) for the taxable income from alcohol fuels production if the fuel is methanol, ethanol, or other substitute fuel not produced from petroleum, natural gas, or coal and 75 percent of the total-production yield is used for making gasohol. Effective October 3, 1979.

\section{HB 2779}

Requires the Oregon state motor vehicle fleet to use gasohol when it is commercially availeble. Effective January 1, 1980.

\section{SB 515}

Provides for a 50 percent investment tax credit over five years $(20$ percent first year, 10 percent second and third years, 5 percent remaining two years) for alternative energy development projects including alcohol fuels. Effective January 1, 1980. Expires January 1, 1985.

\section{$S B 611$}

Ballot measure 3 was voted on May 20, 1980 (and passed) by the general electorate. Allows the State Department of Energy to issue bonds for alternative energy dëvelopment projects, including alcohol fuels.

\section{PENDING LEGISLATION}

No regular session was held in 1980 .

\section{STATE REGULATION}

Permit Procedure-No state permit is required for the production of fuel alcohol. Produccrs of fuel alcohol are required to send a copy of the Federal Bureau of Alcohol, Tobacco and Firearms permit to the Oregon Liquor Control Commission.

State Volatility Requirements-Oregon has no state volatility requirements for gasoline and gasohol.

\section{LOCAL GOVERNMENT REQUIREMENTS AND INCENTIVES}

Several Port districts in Oregon issue "development bonds." The Port of Morrow, Port of Umatilla and Klamath Co. Economic Development district in Klamath Falls are involved in alcohol fuel projects. 


\section{OTHER IMPORTANT ALCOHOL FUELS ACTIVITY IN OREGON}

Oregon General Services Administration conducted a vehicle fleet test (beginning October 1979) using gasohol in 15 vehicles.

Bonneville Power Authority in Portland, Oregon, conducted a vehicle fleet test (beginning July 1979) using methanol blends in seven vehicles.

The University of Oregon is conducting a vehicle fleet test using methanol/gasoline blends.

Universities and Colleges offering alcohol fuels workshops, seminars and courses: Linn-Benton Community College; Eastern Oregon Statc College at Labrande.

\section{Responsible Official For Further Information:}

Mr. Richard Durham (503) 378-4998

Oregon Department of Energy

Labor and Industries Building

Salem, Oregon 97370

\section{LAWS}

SB 111 (Act 129 of 79)

Reduces the state license fee for small scale (on-farm use) ethanol stills from $\$ 2,500$ to $\$ 25.00$. Effective December 14, 1979.

\section{PENDING LEGISLATION}

HB 1428

Authorizes a tax credit of up to 6 cents on the gasoline pump price of gasohol. The gasohol must contain 10 percent alcohol.

\section{HB 1541}

Requires the Pennsylvania Department of General Services to use gasohol in all state vehicles.

\section{HB 1897}

Requires the Pennsylvania liquor control board to issue licenses for the limited manufacture and use of ethanol or methanol for liquid fuel purposes and provides for alcohol licensing fees for farm vehicle use only.

\section{HR 2444 (HR 2443)}

Establishes a Pennsylvania Energy Development Authority and provides for this agency's powers and duties regarding the implementation and development of energy and energy conservation technologies. Authorizes the issuance of bonds and appropriates funds for this program.

\section{HR 2405}

Establishes a Pennsylvania Energy Development Office within the Pennsylvania Industrial Development Authority and gives this office the power to administer grants.

\section{STATE REGULATION}

Permit Procedure-Small scale producers of fuel alcohol are required to obtain a permit from the Pennsylvania liquor control board. A $\$ 25$ fee is required. Large-scale producers and those producers who commercially distribute their product must pay a $\$ 2,500$ fee.

State Volatility Requirements-Pennsylvania has no state volatility requirements for gasoline and gasohol. 
OTHER IMPORTANT ALCOHOL FUELS ACTIVITY IN PENNSYLVANIA

In August 1979 the Governor's office issued a directive encouraging the Pennsylvania Department of General Services to conduct a gasohol vehicle fleet test.

The University of Pennsylvania is conducting research on alcohol fuels (cellulosic conversion).

Pennsylvania Power and Light Company is conducting a vehicle fleet test (November 1979 through the summer of 1980) using gasohol in 26 vehicles.

Universities and Colleges offering alcohol fuels workshops, seminars and courses: Lehigh University; Gettysburg College; University of Pennsylvania at Philadelphia.

\section{Responsible Officlal For Further Information:}

Mr. David L. Krantz (717) 787-3735

Research Analyst

Minority Research Unit

House of Representatives

Box 250

Harrisburg, Pennsylvania 17120

\section{RHODE ISLAND}

\section{LAWS}

No laws have been enacted as of July 1, 1980 .

\section{PENDING LEGISLATION}

\section{SB 2274}

Exempts gasohol from the 10 cents per gallon state motor fuel tax.

\section{STATE REGULATION}

Permit Procedure-No state permit required for the production of fuel alcohol.

State Volatility Requirements-Rhode Island requires that gasoline (including gasohol) mect ASTM 0439 specifications, which include Distillation and Reid Vapor Pressure specifications.

\section{Responsible Official for Further Information:}

Ms. Shelly Greenfield (401) 277-3374

Solar Information Specialist

Governor's Energy Office

80 Dean Street

Providence, Rhode Island 02903 


\section{LAWS}

\section{HB 2442}

Exempts gasohol from the 10 cents per gallon state motor fuel tax on a decreasing scale basis. The exemption for gasohol is as follows: October 1, 1979 - July 1, $1985=4$ cents; July 1,1985 - July $1,1987=3$ cents. The exemptions will expire when the state realizes a $\$ 5$ million loss of revenue. The gasohol must contain at least 10 percent ethyl alcohol produced from agricultural resources and be at least 99 percent pure. Effective October 1, 1979.

HB 2976 Establishes a \$5 million state capital improvement bond program. (Subject to revision in the ncar future. Guidelines for this money are being proposed.) Effective November 1, 1979. See HB3843 below.

\section{HB 3843}

Amends HB 2976 to provide for bond issuance procedures for alcohol fuel development.

\section{PENDING LEGISLATION}

None.

\section{STATE REGULATION}

Permit Procedure-No state permit is required for the production of fuel alcohol.

State Volatility Requirements-South Carolina requires that all gasoline (including gasohol) meet Distillation and Reid Vapor Pressure requirements. No ASTM D4399 requirement.

\section{OTHER IMPORTANT ALCOHOL FUELS ACTIVITY IN SOUTH CAROLINA}

Clemson University was awarded a $\$ 28,700$ grant from the U.S. Department of Agriculture to conduct research on the potential feedstock value of sweet potatoes.

Between March 15, 1980, and March 17, 1980, the Clemson University cooperative extension service canvassed the state for potential alcohol fuels production sites for small scale production.

The state of South Carolina is conducting a vehicle fleet test using gasohol in state vehicles.
Universities and Colleges offering alcohol fuels workshops, seminars and courses: Clemson University; Orangeburg Calhoun Technical College.

\section{Responsible Official For Further Information:}

Mrs. Cathy Twilley (803) 758-8110

Administrative Assistant

Governor's Division of Energy Resources

1122 Lady Street

Columbia, South Carolina 29201

(803) $758-8110$ 


\section{LAWS}

SDCL 10-49-2.1

Exempts gasohol from 4 cents of the 12 cents per gallon state motor fuel tax. The gasohol must contain at least 10 percent ethyl alcohol and be at least 98 percent pure. Exempts ethyl alcohol mixed with motor fuel used to produce gasohol from the 5 percent state use tax. Effective July 1,.1979. The exemptions expire June 30, 1982.

\section{$S B 175$}

Requires that 98 percent alcohol (196 proof) be used in the blending of gasohol. Effective August 1, 1980.

\section{HB 1008.4}

Authorizes a property tax assessment credit for alcoliol plants that produce alcohol for fuel use on a decreasing scale basis. For on-farm alcohol plants, the credit applies for three continuous years at 100 percent, then (beginning with the fourth year) decreases each succeeding year to 75 percent, 50 percent, 25 percent, 0 percent. Large scale commercial plants receive 50 percent (first three years) then each succeeding year, 30 percent, 25 percent, 12 percent, 0 percent. Effective July 1, 1980.

\section{PENDING LEGISLATION}

The legislative session adjourned March 12, 1980. The legislature will convene January 20, 1981.

\section{SIATIE REGULATION}

Permit Procedure-Both producers and blenders of fuel alcohol arc required by the South Dakota Department of Revenue to obtain a motor fuel dealer license. The initial bond requirement is $\$ 250$. Then each succeeding year the bond requirement equals $1 / 6$ of the motor fuel tax for which the dealer is responsible. Motor fuel tax liability for the preceding calentar year is used in calculating the bond requirement.

State Volatility Requirements-South Dakota requires that all gasoline (including gasohol) meet Distillation and Reid Vapor Pressure requirements. No ASTM D 439 requirement.

\section{OTHER IMPORTANT ALCOHOL FUELS ACTIVITY IN SOUTH DAKOTA}

The South Dakota Office of Energy Policy has available a handbook entitled "South Dakota Alcohol Fuel Production Handbook - Permits, Regulations, and Assistance".

In November 1979, the Governor of South Dakota established a South Dakota Alcohol Fuels Commission to promote the production of alcohol fuels.

South Dakota State University at Brookings has a demonstration still for public observation on its campus and is conducting research on alcohol fuels.

The Soutlı Dakota Farmers Union has established a task force to investigate alcohol fuels.

\section{Responsible Official For Further Information:}

Mr. Verne Brakke

Office of Energy Policy

Capitol Lake Plaza

Pierre, South Dakota 57501

(605) 773-3603 


\section{LAWS}

\section{SB 2081 (HB 1966)}

Prevents gasoline retailers from disallowing the use of credit cards for the purchase of gasohol. Prohibits distributors from restricting retailers' voluntary sales of gasohol. July 1, 1980.

\section{$S B 1927$ (HB 1778)}

Legalizes the production of alcohol for fuel purposes, requires the denaturing and coloring of alcohol, adds ethanol and methanol to the list of petroleum products that must be inspected and provides for licensing procedures and accompanying fine schedules. This law does not set up alcohol proof requirements, but provides that the state's provisions be consistent with the requirements of the Federal Bureau of Alcohol, Tobacco and Firearms.

Provides that a manufacturer of alcohol for fuel use who produces less than 1000 gallons annually for his own personal use or for sale to a bonded distributor is exempt from all 7 cents of the state 7 cents per gallon motor fuel tax. The gasohol must contain ethyl or methyl alcohol distilled in accordance with standard Federal Bureau of Alcohol, Tobacco and Firearms levels and be at least 188 proof. Effective April 3, 1980.

\section{PENDING LEGISLATION}

The legislative session adjourned April 18, 1980.

\section{STATE REGULATION}

Permit Procedures-Producers of fuel alcohol who produce less than 1000 gallons/year of alcohol must register with the State Department of Revenue. A permit is required if moite than 1000 gallons is produced annually. A $\$ 50.00 \mathrm{fec}$ must be paid to the Department of Revenue if 1000-2500 gallons per year are produced and a $\$ 100.00$ fee is required if more than 2500 gallons per year are produced (SB 1927).

Fuel alcohol must be denatured and colored pursuant to the quality control provisions in SB 1927 must be followed.

State Volatility Requirements-Tennessee requires that gasoline including gasohol) meet ASTM D439 specifications, which include Distillation and Reid Vapor Pressure specifications.

\section{OTHER IMPORTANT ALCOHOL FUELS ACTIVITY IN TENNESSEE}

Pursuant to House Joint Resolution 161 (1979) the state established a one-year Alcohol Fuels Legislative study Committee.

The Tennessee Valley Authority conducted a vehicle fleet test from March 1979 to April 1980 using gasohol in 185 vehicles.

\section{Responsible Official For Further Information:}

Ms. Margot Myrick

Research Analyst

Legislative Plaza, Suite 2

Nashville, Tennessee 37219

(615) 741-2354 


\section{LAWS}

HB 1986

Legalizes the production of ethanol for fuel use in gasohol. The intent of this law is to clarify that previous statutes which limited the production and transportation of alcohol do not apply to fuel alcohol. Effective September 1979.

\section{HB 1803}

Grants authority for a loan guarantee program. No money to date has been appropriated for this program, which became effective in September 1979.

Texas revised civil statutes annotated article 7510.1. (The general electorate passed an amendment to the Texas constitution November 1978; the enabling legislation passed the legislature the following year.) Provides for exemptions of property and sales taxes for producers of alcohol fuels for the purchase of equipment used in the production of ethanol for on-site use. In this bill, the equipment must meet the definition of a "solar device" (which includes biomass) as defined in the law. Effective September 1979.

\section{PENDING LEGISLATION}

No regular session was held in 1980.

\section{STATE REGULATION}

Permit Procedure-Producers of fuel alcohol are required to obtain a Local Industrial Producers Permit from the State Alcoholic Beverage Commission. A fee of $\$ 100$ per year is required.

Dry county regulations-Alcohol used for fuel can be transported through dry county jurisdictions.

State Volatility Requirements-Texas requires that all gasoline (including gasohol) meet only Distillation requirements. No Reid Vapor Pressure or other ASTM D439 requirements.

\section{OTHER IMPORTANT ALCOHOL FUELS ACTIVITY IN TEXAS}

Texas Energy and Natural Resources Advisory Council (TENRAC) is considering funding several small state demonstration projects for alcohol fuels through the Texas Energy Development Fund. It is anticipated that the funding will be authorized during the summer of 1980.

\section{Responsible Official For Further Information:}

Mr. Bob Avant (512) 475-5588

Coordinator of Biomass and Wind Programs

TENRAC

411 W. 13th Street, Suite 900

Austin, Texas 78701 
UTAH

\section{LAWS}

$S B 11$

Exempts gasohol from 5 cents of the state 9 cents per gallon motor fuel tax. The gasohol must contain at least 10 percent alcohol produced in Utah. No more than 25 percent of the energy value of the alcohol may be derived from electricity, distillable liquid or gaseous fuels in the production of the alcohol. Effective July 1, 1980. The exemption expires June 30, 1985.

\section{$S B 10$}

Provides for an income tax reduction (deduction, and depletion allowances) for alcohol fuel producers. Effective April 16, 1980.

\section{PENDING LEGISLATION}

The legislative session adjourned February 2, 1980.

\section{STATE LEGISLATION}

Permit Procedure-A state permit is required for the production of alcohol by the State Liquor Control Commission. No more than 25 percent of the energy value of the alcohol in an alcohol plant may be derived from electricity, distillable liquid or gaseous. fuels. The Liquor Control Commission requires producers of fuel alcohol to submit a copy of the Federal Bureau of Alcohol, Tobacco, and Firearms permit. A $\$ 1.00$ fee is required.

State Volatility Requirements-Utah requires that all gasoline (including gasohol) meet Distillation and Reid Vapor Pressure requirements. No ASTM D 439 requirement.

\section{Responsible Official For Further Information:}

Mr. Jim Byrne (801) 533-5424

Deputy Director

Utah Energy Office

231 E. 400 South

Salt Lake City, Utah 84111

\section{VERMONT}

\section{LAWS}

No laws have been enacted as of July 1, 1980 .

\section{PENDING LEgISLATION}

The legislative session adjourned April 26, 1980.

\section{STATE REGULATION}

Permit Procedure-No state permit is required for the production of fuel alcohol.

State Volatility Requirement-Vermont has no volatility requirements for gasoline or gasohol.

\section{Responsible Official For Further Information:}

Mr. Larry Ogden

State Energy Office

State Office Building

Montpelier, Vermont 05602

(802) 828-2393 


\section{LAWS}

$H B 68$

Requires the registration of all industrial alcohol (includıng fuel alcohol) plants. Éffective March 31, 1980.

\section{PENDING LEGISLATION}

The legislative session adjourned March 8, 1980. The legislatiure will convene January 14, 1981.

\section{STATE REGULATION}

Permit Procedure-A state permit is required for the production of fuel alcohol. No fee is requied.

State Volatility Requirements- -Virginia requires that all gasolinc (including gasohol) meet Distillation and Reid vapor Pressure requirements. No ASTM D439 requirement.

\section{OTHER IMPROTANT ALCOHOL FUELS ACTIVITY IN VIRGINIA}

Virginia State University at Blacksburg has established a research and development ${ }^{\circ}$ alcohol fuels task force and constructed an alcohol fueis demonstration still on its campus.

The Virginia Department of Agriculture and Consumer Services has established a 30-member task force on alcohol fuels production, marketing and regulation.

NASA is conducting a vehicle fleet test at Langley Research Center using gasohol in 100 vehicles.

\section{Kesponsible Officials for Further Information:}

For information and regulation:

Mr. Penn Zentmeyer

Supervisor of Fertilizers, Time \& Motor Fuels

VA Department of Agriculture 203 North Governors Street

Richmond, Virginia 23219

(804) 786-3511

All other:

Mr. IRWL Smith

Director of Rural Afairs/

State Director of Alcohol Fuels

VA Department of Agriculture \&

Consumer Services

203 Norther Governors Street

Richmond, Virginia 23219

(804) 786-3519

\section{LAWS}

\section{ESSB 3629}

Exempts gasohol from 1.2 cents of the state 12, cents per gallon motor fuel tax (only the alcohol content of gasohol is exempt). Exempts gasohol from the state retail sales and use taxes. The gasohol must contain at least 9-1/2 percent alcohol. Effective March 1980. The exemption expires December 31, 1986.

\section{$H B 1568$}

Requires the "widest possible use of gasohol and costeffective alternative fuels" in all motor vehicles. Effective March 19, 1980.

\section{ESSB 3551}

Exempts from state property taxation and leasehold taxation property used for manufacturing facilities which produce alcohol for fuel use and other purposes, at an annually determined rate based on the percentage of the total gallons produced per year that is sold or used as an alcohol fuel. No claims under this exemption may be filed after December 31, 1986. Exempts gasohol from state business and occupation taxes through December 31, 1986.

\section{$S H B 1630$}

Exempts alcohol manufactured for fuel from the state liquor control laws. The exemption expires December 31, 1986. Effective June 1, 1980.

\section{PENDING LEGISI,ATION}

The legislative session adjourned March 13, 1980.

\section{STATE REGULATIÓN}

Permit Procodure- No state pcrmit is required for the production of fuel alcohol. Gasoline retailers that sell gasohol must register with the State Department of Licensing.

\section{OTHER IMPORTANT ALCOHOL FULLS ACTIVITY IN WASHINGTON}

$\$ 73,000$ was allocated by the Pacific Northwest Regional Commission for research on the potential ethanol production capacity in Washington State. The Washington State Department of Commerce and Economic Development published the results of this study in April 1980.

The Washington State Motor Transport Divison is using gasohol in 100 state vehicles. 
The City of Everett is conducting a vehicle fleet test using methanol (10 percent methanol/gasoline blends) in 175 vehicles.

Universities and Colleges offering alcohol fuels workshops, seminars and courses: Tacoma Community College; Skegit North Shore Community College; Washington State University; Central Washington State University.

Responsible Official For Further Information:

Mr. Paul Juhasz

State Energy Office

400 E. Union Street

Olympia, Washington 98504

(206) $754-0700$

\section{LAWS}

SB $112 E$

Eliminates the $\$ 250$ state fee for production of ethanol if the alcohol fuel produced is used for personal fuel use. Effective June 5, 1980.

\section{PENDING LEGISLATION}

The legislative session adjourned March 11, 1980.

\section{STATE REGULATION}

Permit Procedure-A state permit is required by the Alcohol Beverage Control Commission (SB 112) for the production of fuel alcohol.

State Volatility Requirements-West Virginia has no volatility requirements for gasoline or gasohol.

\section{OTHER IMPORTANT ALCOHOL FUELS ACTIVITY IN WEST VIRGINIA}

West Virgina University is conducting research on coal liquefaction and gasification with state funds.

Universities and colleges offering alcohol fuels workshops, seminars and courses: West Vjrginia University.

\section{Responsible Official For Further Information:}

Ms. Rebecca Scott

Information Representative

West Virginia Fuel \& Energy Office

$12621 / 2$ Greenbrier Street

Charleston, West Virginia 25311

(304) $348-8860$ 


\section{LAWS}

\section{Budget Bill, $\mathrm{CH}$ 34, Laws of 1979}

Appropriated $\$ 75,000$ to the Wisconsin Department of Administration for feasibility studies on alcohol plant facilities to be built in Wisconsin. Appropriates $\$ 225,000$ for an alternative energy grant program which will include projects or waste. Lowers the annual state permit fee for small scale ethanol fuel producers from $\$ 750$ to $\$ 10.00$. Effective July 29,1979 .

\section{$A B 456$}

Requires that gasoline-alcohol fuel blends be regulated as other fuels by the Department of Industry, Labor and Human Relations. Effective March 29, 1980.

\section{$A B 777$}

Expands the use of the reduced state permit fee for production of ethanol for gasohol to all fuel uses. Allows alcohol production facilities to qualify for municipal revenue bonds. Allows alcohol fuel production systems and coopertives to qualify for the same benefits as do corporations for renewable energy systems as of March 1, 1980. Directs the State Division of Energy to compile and distribute information on gasohol and the availability of existing financial assistance for alcohol fuel producers, and report to the legislature on the desirability of state financial assistance programs. Effective Mạy 22. 1980.

\section{Budget Review Bill, $\mathrm{CH} 221$}

Allows alcohol fuel production systems to qualify for individual and corporate income tax credits. Requires that all state fleet cars be run on fuel containing at least 10 percent ethanol (unless ethanol is unavailable) by January 1, 1984. Exempts alcohol fuel producers who manufacture and use alcohol fuels for their own use from the requirement to obtain water discharge, air pollution, and solid waste permits if they dispose of the waste on their own property in an environmentally accepted way. Effective March 30, 1980.

\section{Budget Review Bill, CH 144}

Exempts alcohol fuel production systems which consume all the alcohol fuel produced from permits, license, and plant approval requirements.

\section{PENDING LEGISLATION}

The legislative session adjourned April 13, 1980.

\section{STATE REGUI.ATION}

Permit Procedure-A state permit is requircd for the production of fuel alcohol. A $\$ 10.00$ fee is required.

If the distillers by-product is to be sold as animal feed, a permit is required.

Stare Volatility Requirements-Wisconsin requires that all gasoline (including gasohol) meet Distillation and Reid Vapor Pressure requirements. No ASTM D439 requirement.

\section{OTHER IMPORTANT ALCOHOL FUELS ACTIVITY IN WISCONSIN}

The Alcohol liuels Task Fulce of llie State Division of Energy is conducting research on alcohnl fuel use.

On April 1, 1980, \$75,000 was allocated by the Wisconsin Department of Administration (Divison of State) for feasibility studies of alcohol fuels production facilities.'

$\$ 225,000$ was appropriated by the state legislature for 1980 biomass research and production grants.

Universities and colleges offering alcohol fuels workshops, seminars and courses: University of Wisconsin (Extension Division); Wisconsin Vocational Technical Adult Education Service; Univers University of Wisconsin at Greein Bay; Universiiy of Wisconsin at Whitewater.

\section{Responsible Officials For Further Information:}

Mr. George Plaza

Biomass Analyst

Divison of State Energy

$101 \mathrm{~S}$. Webster Street

Madison, Wisconsin 53702

(608) 266-0985

Ms. Ann Bogar-Rieck

Science Analyst

Wisconsin Legislative Council

State Capitol

Room 147 North

Madison, Wisconsin 53702

(608) 266-0985 


\section{LAWS ,}

$\mathrm{HB} 114$

Exempts gasohol from 4 cents of the state 8 cents per gallon motor fuel tax. The gasohol must contain at least renewable resources. Effective July 1, 1979. The exemption expires July 1, 1984.

\section{HB 91}

Exempts gasohol from the state sales tax. Effective March 5, 1980.

\section{PENDING LEGISLATION}

The legislative session adjourned March 5, 1980.

\section{STATE REGULATION}

Permit Procedure-No state permit is required for the production of fuel alcohol.

State Volatility Requirements - Wyoming requires that all gasoline (including gasohol) meet Distillation and Reid Vapor Pressure requirements. No ASTM D439 requirement.

\section{OTHER IMPORTANT ALCOHOL FUELS ACTIVITY IN WYOMING}

Universities and Colleges offering alcohol fuels workshops, seminars and courses: Powell Junior College; Farrington Junior College, Western Wyoming Community College.

\section{Responsible Official For Further Information:}

Mr. Butch Keadle

Fuel Allocation Specialist

Energy Conservation Office Capitol Hill Office Building 25th \& Pioneer

Cheyenne, Wyoming 80002 (307) 777.7284
Appendixes D-1 through D-4 summarize state éthanol legislation. Appendix D-1 provides a summary of state tax exemptions. Restrictions on state tax incentives are shown in Appendix D-2. A summary of state permit requirements is delineated in Appendix D-3. Appendix D 4 identifies the volatility specifications by state. 
APPENDIX D-1

Summary of State Tax Exemptions

\begin{tabular}{|c|c|c|c|c|c|}
\hline \multirow[b]{2}{*}{ State } & \multicolumn{2}{|c|}{ Excise Tax } & \multirow{2}{*}{$\begin{array}{l}\text { Sales, use or } \\
\text { gross receipts } \\
\text { for exemptions } \\
\text { for gasohol }\end{array}$} & \multirow[b]{2}{*}{$\begin{array}{l}\text { Property tax } \\
\text { reduction ** }\end{array}$} & \multirow[b]{2}{*}{$\begin{array}{l}\text { Income tax } \\
\text { reduction }\end{array}$} \\
\hline & $\begin{array}{l}\text { Exemption for } \\
\text { gasohol/gal. }\end{array}$ & $\begin{array}{l}\text { Total tax/ } \\
\text { gal. motor fuel }\end{array}$ & & & \\
\hline Alabama & 34 & 114 & no & no & no \\
\hline Alaska & 84 & 84 & no & no & no \\
\hline Arizona & $O_{\Phi}$ & $8 \leftarrow$ & no & no & no \\
\hline Arkansas & $9.5 c^{126}$ & $9.5 c$ & no & no & yes' \\
\hline California & $\mathbf{O}_{\mathfrak{q}}$ & $7 \lessdot$ & yes & no & no \\
\hline Colorado & $5 q^{12}$ & $7 థ$ & no & yes $(98 \%)^{1}$ & no \\
\hline Connecticut & 14 & $11 \Phi$ & no & no & no \\
\hline Delaware & $\mathrm{O}_{4}$ & 94 & no & no & no \\
\hline Florida & $5 q^{1}$ & 84 & no & no & $\operatorname{yes}^{17}$ \\
\hline Georgia & $\mathbf{O}_{\mathbb{c}}$ & $7.5 t$ & no & no & no \\
\hline Hawaii & $0_{\Phi}$ & $11.5-15.04$ & yes (sales) $(4 \%)^{1}$ & no & no \\
\hline Idaho & $4 q^{2}$ & $9.5 q$ & no & no & yes $(0.8 \%)^{1}$ \\
\hline Illinois & $\mathbf{O}_{\hookrightarrow}$ & $7.5 q$ & no & no & no \\
\hline Indiana & $0_{\leftarrow}$ & 8.54 & yes (sales) $(4 \%)$ & no & $\operatorname{yes}^{1} 10$ \\
\hline Iowa & $10 \Phi^{12}$ & $10 c$ & no & no & no \\
\hline Kansas & $44^{12}$ & 84 & no & no & no \\
\hline Kentucky & $0 \%$ & $\begin{array}{l}9 \% \text { of the } \\
\text { avg. wholesale } \\
\text { price }\end{array}$ & yes (sales) $(5 \%)^{1}$ & yes $(99 \%)^{12}$ & no \\
\hline Louisiana & $8 q^{12}$ & $8 \mathrm{c}$ & $\begin{array}{l}\text { yes (sales) } \\
3 \% 0^{1}=3\end{array}$ & no & no \\
\hline Maine & $0_{\uparrow}$ & 94 & no & no & no \\
\hline Maryland & $4 \tau^{2} 9 \tau^{24}$ & 94 & yes & nn & no \\
\hline Massachúsétts & $\mathrm{O}_{4}$ & $9.8 \mathrm{c}$ & yes & nn & no \\
\hline Michigan & $\mathrm{O}_{q^{12}}$ & .114 & no & no & no \\
\hline Mintleștâ & 4 & 114 & no & no & yes $(20) \%)$ \\
\hline Missippi & 04 & 94 & no & no & no \\
\hline Missouri & O4 & $7 థ$ & no & no & no \\
\hline Montana & $7 \Phi^{12}$ & 94 & no & yes $(97 \%)^{12}$ & no \\
\hline Nebraska & $5 q^{12}$ & $\begin{array}{l}10.44 \text { and } 2 \% \\
\text { of the average } \\
\text { statewide cost } \\
\text { of fuel. }{ }^{2 n}\end{array}$ & no & no & no \\
\hline Nevada & $0_{4}$ & 64 & no & no & no \\
\hline New IIampshiire & $54^{2}$ & 114 & no & no & no \\
\hline New Jersey & $0 q$ & 84 & no & no & no \\
\hline New Mexice & $8 \oplus^{12}$ & 84 & $\begin{array}{l}\text { yes }(3 \%) \text { (gross } \\
\text { receipts)! a }\end{array}$ & no & no \\
\hline New York & $\mathrm{O}_{\uparrow}$ & 84 & no & no & no \\
\hline North Carolina & $4 \varsigma^{16}$ & $9 q^{113}$ & no & no & yes $(20 \%))^{1812}$ \\
\hline North Dakota & 44 & 84 & yes (sales) ${ }^{9} 914$ & no & no \\
\hline Ohio & $0 q$ & $7 \nsubseteq$ & no & no & no \\
\hline Oklahoma & $6.50 t^{12}$ & 6.584 & no & no & no 1,15 \\
\hline Oregon & $0_{4}$ & $7 \nsubseteq$ & no & yes $(100 \%)^{1}$ & $\begin{array}{l}\text { yes }(100 \%)^{145} \\
(20 \%)^{116}\end{array}$ \\
\hline Pennsylvania & $\mathrm{O}_{\mathcal{q}}$ & $11 \nsubseteq$ & no & no & no \\
\hline Rhode Island & $\mathrm{Oq}$ & 104 & no & no & no \\
\hline South Carolina & $5 \boldsymbol{q}^{1}$ & $11 \Phi^{20}$ & no & no & no \\
\hline
\end{tabular}




\begin{tabular}{|c|c|c|c|c|c|}
\hline \multirow[b]{2}{*}{ State } & \multicolumn{2}{|c|}{ Excise Tax } & \multirow{2}{*}{$\begin{array}{l}\text { Sales, use or } \\
\text { gross receipts } \\
\text { for exemptions } \\
\text { for gasohol* }\end{array}$} & \multirow[b]{2}{*}{$\begin{array}{l}\text { Property tax } \\
\text { reduction* * }\end{array}$} & \multirow[b]{2}{*}{$\begin{array}{l}\text { Income tax } \\
\text { reduction }\end{array}$} \\
\hline & $\begin{array}{l}\text { Exemption for } \\
\text { gasohol/gal. }\end{array}$ & $\begin{array}{l}\text { Total tax/ } \\
\text { gal. motor fuel }\end{array}$ & & & \\
\hline South Dakota & $4-5 c^{\prime}$ & $12-13 c$ & yes (use) $(4 \%)^{\prime}$ & yes $(100 \%)^{\prime}$ & no \\
\hline Tennessee & $7 c^{5}$ & $7 \ltimes$ & no & no & no \\
\hline Texas & $0 \mathfrak{c}$ & $5 \%$ & yes $(4 \% 0)^{17}$ & yes, $(100 \%)^{17}$ & no \\
\hline Utah & $5 \mathbb{c}^{12}$ & $9 \mathbb{q}$ & no & no & yes ${ }^{\prime \prime \prime}$ \\
\hline Vermont & Oc & $9 c$ & no & no & no \\
\hline Virginia & $0 t$ & $11 \mathbb{c}^{1 ! !}$ & no & no & no \\
\hline Washington & $1.8 c$ & $12 \varangle$ & $\begin{array}{l}\text { yes (sales \& use) } \\
(4.5 \%)^{\prime}\end{array}$ & yes ${ }^{\prime}$ in & no \\
\hline West Virginia & $0 c$ & $10.5 c$ & no & no & no \\
\hline Wisconsin & $O_{\mathbb{C}}$ & 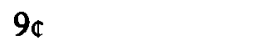 & no & no & yes ${ }^{1:}$ \\
\hline Wyoming & $4 \mathbb{C}^{\prime}$ & $8 \mathfrak{c}$ & $\begin{array}{l}\text { yes (sales) } \\
(3 \%)\end{array}$ & nó & no \\
\hline
\end{tabular}

- Sales, use and gross receipts tax exemptions-Percent listed is the sales tax rate in that state. In all cases, the entire amount of the lax is exempled.

** Property tax reduction-The percent listed equals the percent of the state property tax applicable to qualifying fuel alcohol production facilities which is exempted.

*** Income tax exemptions, credits and deductions-The percent listed equals the percent of the exemption, deduction, or credit with respect to taxable income attributable to qualifying fuel alcohol production.

1 The enabling legislation contains a decreasing scale, sunset provision, an expiration date and/or a maximum ceiling provision which limits the total amount of excise tax refunds which the state can lose as a result of the gasohol excise tax exemption.

2 Gasohol's exemption is restricted in some manner to alcohol produced from state crops, produced within the statc or blended within the state.

3 Applies to agricultural use only.

+ Includes only unmixed ethyl and methyl alcohol.

If production does not exceed 1000 gallons annually.

"Effective in 1981.

7 The corporate income tax reduction is based on the amount of property taxes paid by producers of fuel alcohol for production costs incurred in the manufacture of fuel alcohol.

" An additional 10\% income tax reduction is credited to those producers of fuel alcohol whose distilleries are powered primarily by the use of an alternative fuel snitre.

A $1 / 8$ cent sales tax charge is levied on gasohol exempted from the $3 \%$ state sales tax.

E. "No standard amount of reduction is stated in the law. Certain business expenses incurred in the production of luel alcohol qualily as deductions in the calculation of the producer's next corporate income tax.

"A gross income tax deduction for a coal conversion system to process coal into liquid fuel applies only to those who receive the federal depreciation deductions for a coal conversion system.

12 The law provides for both coprorate and personal income tax reductions.

1.3 A 9 cent excise tax exemption is provided for nonanhydrous alcohol which is not used for sale or distribution.

$1+$ The exemption only applies when the gasohol is used for agricultural or indust rial purposes.

$15100 \%$ income tax exemption-applies only to alcohol fuels production.

Ii $50 \%$ investment tax credit -applies to all alternative energy development projects.

17 The exemption only applies to the purchase of equipment used in the production of ethyl alcohol.

18 This exemption includes leasehold tax exemptions.

19 A 2 cent increase in the gasoline excise tax is imposed in Northern Virginia.

20 Effective October 1, 1980.

Source: U.S. National Alcohol Fuels Commission. July IÝ8̄ 
Restrictions on State Tax Incentives

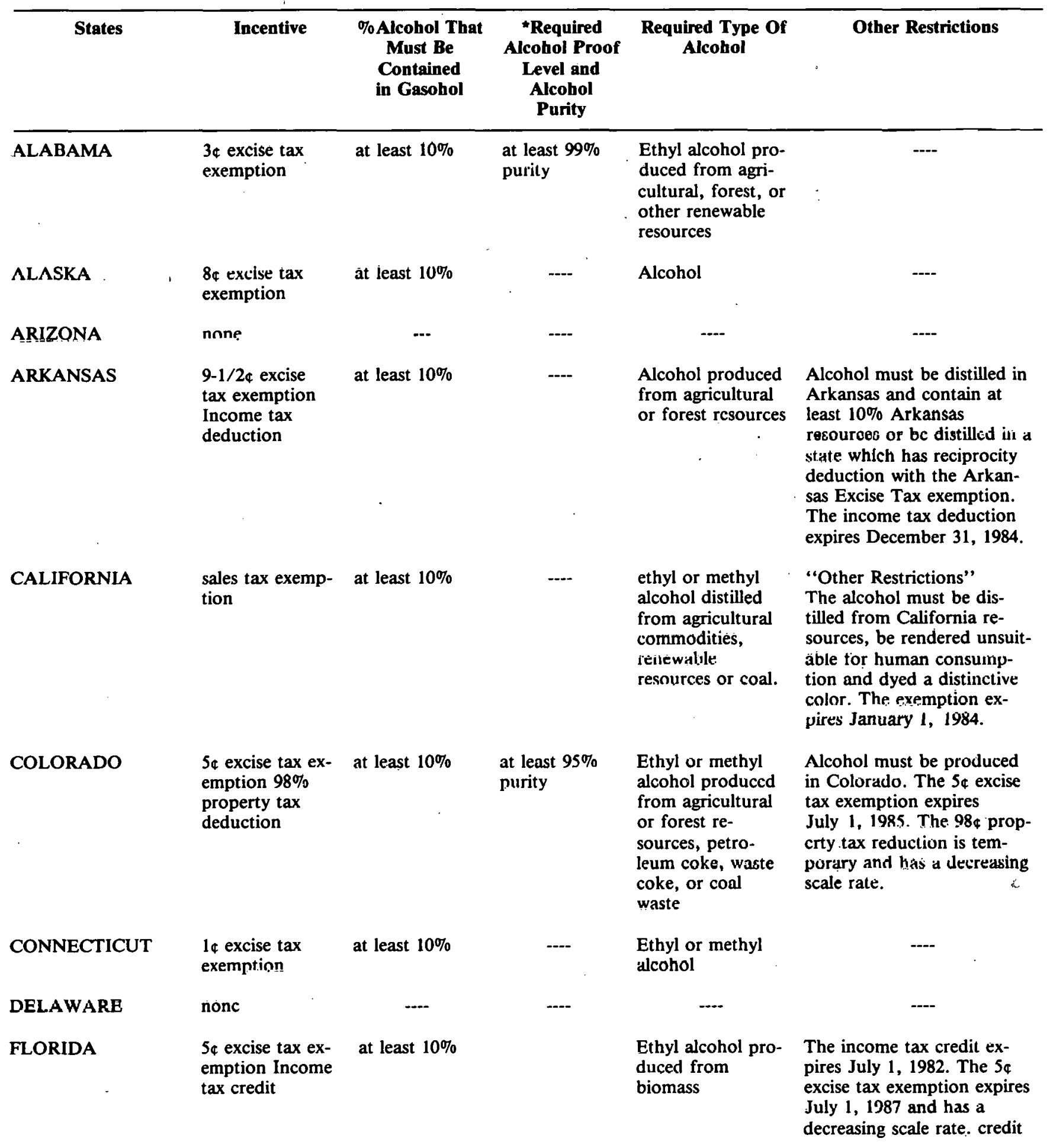

"In many cases the terms "proof" and "purity" are used interchangeably. However, technically, "proof" refers only to water content, and "purity" refers to the presence in the alcohol of all non-ethanol matter. This chart uses the statutory terms for each state. In some instances the exact meaning is not specified. 


\begin{tabular}{|c|c|c|c|c|c|}
\hline States & Incentive & $\begin{array}{l}\text { \% Alcohol That } \\
\text { Must Be } \\
\text { Contained } \\
\text { in Gasohol }\end{array}$ & $\begin{array}{l}\text { "Required } \\
\text { Alcohol Proof } \\
\text { Level and } \\
\text { Alcohol } \\
\text { Purity }\end{array}$ & $\begin{array}{c}\text { Required Type Of } \\
\text { Alcohol }\end{array}$ & Other Restrictions \\
\hline GEORGLA & none & $\cdots$ & --- & ---- & ---- \\
\hline HAWAII & $\begin{array}{l}4 \% \text { sales tax ex- } \\
\text { emption }\end{array}$ & ---- & ---- & Alcohol & $\begin{array}{l}\text { The } 4 \% \text { sales tax exemption } \\
\text { expires June } 30,1985 \text {. The } \\
\text { state Director of Taxation } \\
\text { has the authority to termi- } \\
\text { nate the exemption at his } \\
\text { discretion. }\end{array}$ \\
\hline IDAHO & $\begin{array}{l}4 \leftarrow \text { excise tax ex- } \\
\text { emption } 8 \% \text { in- } \\
\text { come tax credit }\end{array}$ & at least $10 \%$ &.-- & $\begin{array}{l}\text { Anhydrous ethyl } \\
\text { alcohol produced } \\
\text { from agricultural } \\
\text { or forest resources }\end{array}$ & $\begin{array}{l}\text { The alcohol must be pro- } \\
\text { duced in Idaho from Idaho } \\
\text { products. The } 8 \% \text { income } \\
\text { tax credit expires July } 1 \text {, } \\
1985 \text { and has a decreasing } \\
\text { credit scale rate. }\end{array}$ \\
\hline ILLINOIS & none & $\cdots$ & --- & --- & --- \\
\hline INDLANA & $\begin{array}{l}4 \% \text { sales tax ex- } \\
\text { emption Income } \\
\text { tax deduction }\end{array}$ & at least $10 \%$ & ---- & $\begin{array}{l}\text { Anhydrous ethyl } \\
\text { alcohol produced } \\
\text { from agricultural } \\
\text { or forest resources }\end{array}$ & $\begin{array}{l}\text { Income tax deduction ap- } \\
\text { plies only to coal conver- } \\
\text { sion, liquid fuels and ex- } \\
\text { pires January } 1,1990 \text {. }\end{array}$ \\
\hline IOWA & 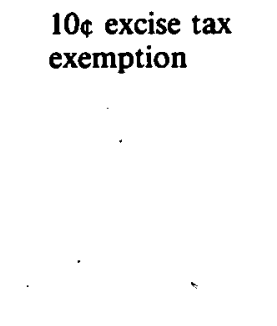 & at least $10 \%$ & $--\cdot$ & $\begin{array}{l}\text { Ethyl alcohol pro- } \\
\text { duced from agri- } \\
\text { cultural or forest } \\
\text { resources }\end{array}$ & $\begin{array}{l}\text { A } 3 \% \text { sales tax charge ac- } \\
\text { companies the } 10 \text { excise } \\
\text { tax exemption through } \\
\text { May } 1,1981 . \text { May } 1,1981 \\
\text { through June } 30,1983 \text { the } \\
\text { excise tax exemption has a } \\
\text { decreasing scale rate and } \\
\text { the exemption expires } \\
\text { June } 30,1983 \text {. }\end{array}$ \\
\hline KANSAS & $\begin{array}{l}3 \notin \text { excise tax ex- } \\
\text { emption }\end{array}$ & at least $10 \%$ & $\begin{array}{l}\text { at least } 190 \\
\text { proof }\end{array}$ & $\begin{array}{l}\text { Ethyl alcohol pro- } \\
\text { duced from ag- } \\
\text { ricultural or forest } \\
\text { resources }\end{array}$ & $\begin{array}{l}\text { The alcohol must be pro- } \\
\text { duced from grain products } \\
\text { grown in Kansas. Produc- } \\
\text { tion of alcohol must utilize } \\
10 \text { less energy units than } \\
\text { would be contained in the } \\
\text { converted motor vehicle } \\
\text { fuel. The } 3 థ \text { excise tax ex- } \\
\text { emption has a decreasing } \\
\text { scale rate, a maximum ceil- } \\
\text { ing, and expires July } 1 \text {, } \\
1985 \text {. }\end{array}$ \\
\hline KENTUCKY & $\begin{array}{l}5 \uparrow \text { sales tax ex- } \\
\text { emption } 99 \% \\
\text { state property } \\
\text { tax reduction } \\
99 \% \text { local prop- } \\
\text { erty tax reduc- } \\
\text { tion }\end{array}$ & at least $10 \%$ & $\begin{array}{l}\text { at least } 198 \\
\text { proof }\end{array}$ & $\begin{array}{l}\text { Ethyl alcohol pro- } \\
\text { duced from grain } \\
\text { or other } \\
\text { renewable } \\
\text { resources }\end{array}$ & $\begin{array}{l}\text { The exemptions expire eight } \\
\text { years after the granting of } \\
\text { exemption certificates. } \\
\text { Alcohol plants must burn } \\
\text { coal produced in KY. or } \\
\text { convert to such use within } \\
\text { two years of certificate } \\
\text { receipt to quality for the } \\
99 \notin \text { local exemptions. }\end{array}$ \\
\hline
\end{tabular}




\begin{tabular}{|c|c|c|c|c|c|}
\hline States & Incentive & $\begin{array}{l}\text { \%Alcohol That } \\
\text { Must Be } \\
\text { Contained } \\
\text { in Gasohol }\end{array}$ & $\begin{array}{l}\text { *Required } \\
\text { Alcohol Proof } \\
\text { Level and } \\
\text { Alcohol } \\
\text { Purity }\end{array}$ & $\begin{array}{c}\text { Required Type Of } \\
\text { Alcohol }\end{array}$ & Other Restrictions \\
\hline LOUISLANA & $\begin{array}{l}\text { 84 excise tax ex- } \\
\text { emption } 3 \% \\
\text { sale tax exemp- } \\
\text { tion }\end{array}$ & at least $10 \%$ & --- & $\begin{array}{l}\text { Alcohol distilled } \\
\text { from agricultural } \\
\text { resources }\end{array}$ & $\begin{array}{l}\text { The alcohol must be dis- } \\
\text { tilled in Louisiana and con- } \\
\text { tain at least } 10 \% \text { agricul- } \\
\text { tural resources produced in } \\
\text { LA unless such products are } \\
\text { not available. The alcohol } \\
\text { must be "rendered un- } \\
\text { suitable for human con- } \\
\text { sumption at the time of its } \\
\text { manufacture or immediately } \\
\text { thereafter" and be dyed a } \\
\text { distinctive color. The ex- } \\
\text { emptions expire after ten } \\
\text { years unless it is extended } \\
\text { by the legiolaturc. }\end{array}$ \\
\hline MAINE & none & --- & ---- & 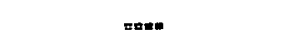 & 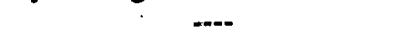 \\
\hline MARYLAND & $\begin{array}{l}44 \text { excise tax ex- } \\
\text { emption } 94 \text { ex- } \\
\text { cise tax exemp- } \\
\text { tion }\end{array}$ & at least $10 \%$ & --- & $\begin{array}{l}\text { Ethyl or methyl } \\
\text { alcohol }\end{array}$ & $\begin{array}{l}\text { The } 4 \leftarrow \text { excise tax exemption } \\
\text { expires May } 1,1981 \text {. The } 94 \\
\text { excise tax exemption applies } \\
\text { only to alcohol not mixed } \\
\text { with gasoline and expires } \\
\text { June } 1,1982 \text {. }\end{array}$ \\
\hline
\end{tabular}

\begin{tabular}{|c|c|c|c|c|}
\hline MASSACHUSETTS & none &.-- & -- & ---- \\
\hline MICHIGAN & $\begin{array}{l}50 \% \text { property } \\
\text { tax exmption }\end{array}$ & $-\cdots$ & -- & $-\cdots$ \\
\hline
\end{tabular}

$\begin{array}{lllll}\text { MININESUIA } & \begin{array}{l}4 \text { excise tax } \\ \text { exemption } 20 \%\end{array} & \text { at least } 10 \% & \begin{array}{l}\text { at least } 190 \\ \text { proof }\end{array} & \begin{array}{l}\text { Ethyl alcohnl prn- } \\ \text { duced from } \\ \text { income tax } \\ \text { credit }\end{array} \\ & & & \begin{array}{l}\text { agricultural } \\ \text { rcsources }\end{array}\end{array}$

The $50 \%$ property tax cxemption applies to new construction of industrial size plants.

The alcohol muet bo distilled from Minnesota resources. Fuel must be blended to quality for the 44 excise tax exemption.

$\begin{array}{llccc}\text { MISSISSIPPI } & \text { none } & \cdots & \cdots & \\ \text { MISSOURI } & \text { none } & \cdots & \cdots & \text { Anhydrous } \\ \text { MÓNTANA } & \begin{array}{l}7 \uparrow \text { excise tax } \mathrm{ex}- \\ \text { emption } 97 \%\end{array} & \text { at least } 10 \% & \cdots & \begin{array}{l}\text { Ancohol } \\ \text { alcohol }\end{array}\end{array}$

property tax reduction 
Restrictions on State Tax Incentives - Continued

\begin{tabular}{|c|c|c|c|c|c|}
\hline States & $\begin{array}{c}\text { Incentive } \\
.\end{array}$ & $\begin{array}{c}\text { \% Alcohol That } \\
\text { Must Be } \\
\text { Contained } \\
\text { in Gasohol }\end{array}$ & $\begin{array}{l}\text { "Required } \\
\text { Alcohol Proof } \\
\text { Level and } \\
\text { Alcohol } \\
\text { Purity }\end{array}$ & $\begin{array}{c}\text { Required Type Of } \\
\text { Alcohol }\end{array}$ & Other Restrictions \\
\hline NEBRASKA & $\begin{array}{l}54 \text { excise tax ex- } \\
\text { emption }\end{array}$ & at least $10 \%$ & $\begin{array}{l}\text { at least } 99 \% \\
\text { purity }\end{array}$ & $\begin{array}{l}\text { Ethyl alcohol pro- } \\
\text { duced from } \\
\text { agricultural or } \\
\text { forest resources }\end{array}$ & $\begin{array}{l}\text { The alcohol must be pro- } \\
\text { duced in Nebraska. Begin- } \\
\text { ning in } 1982 \text {, the } 5 \uparrow \text { excise } \\
\text { tax exemption applies only } \\
\text { to alcohol produced in a } \\
\text { plant under construction or } \\
\text { in operation by July } 1 \text {, } \\
\text { 1980. The } 5 \leftarrow \text { excise tax ex- } \\
\text { emption has a decreasing } \\
\text { scale rate and maximum } \\
\text { cciling levels. }\end{array}$ \\
\hline NEVADA & none & $\cdots$ & - & --- & ---- \\
\hline NEW HAMPSHIRE & $\begin{array}{l}\text { 5t excise tax ex- } \\
\text { emption }\end{array}$ & at least $10 \%$ & ---- & Alcohol & $\begin{array}{l}\text { Alcohol must be produced } \\
\text { in New Hampshire. }\end{array}$ \\
\hline NEW JERSEY & none & -- & --- & -- & $\cdots$ \\
\hline NEW MEXICO & $\begin{array}{l}8 \% \text { excise tax ex- } \\
\text { emption } 5 \% \\
\text { sale tax exemp- } \\
\text { tion }\end{array}$ & at least $10 \%$ & $\begin{array}{l}\text { at least } 190 \\
\text { proof }\end{array}$ & Ethyl alcohol & $\begin{array}{l}\text { Alcohol must be produced } \\
\text { in New Mexico. The exemp- } \\
\text { tions expire June } 30,1985 \text {. }\end{array}$ \\
\hline NEW YORK & none & - & - & $\cdots$ & - \\
\hline $\begin{array}{l}\text { NORTH } \\
\text { CAROLINA }\end{array}$ & $\begin{array}{l}44 \text { excise tax } \\
\text { exemption } 94 \\
\text { excise tax ex- } \\
\text { emption } 20 \% \\
\text { corporate and } \\
\text { personal income } \\
\text { tax }\end{array}$ & at least $10 \%$ & -- & $\begin{array}{l}\text { To qualify for the } \\
\text { 4cexcise tax ex- } \\
\text { emption the alco- } \\
\text { hol must be } \\
\text { anhydrous ethyl } \\
\text { alcohol. To quali- } \\
\text { fy for the } 9 q \text { ex- } \\
\text { cise tax exemption } \\
\text { the alcohol must } \\
\text { be non-produced } \\
\text { for on-farm use } \\
\text { and may be non- } \\
\text { anhydrous } \\
\text { alcohol. To } \\
\text { qualify for the in- } \\
\text { come tax credits } \\
\text { the alcohol must } \\
\text { be produced from } \\
\text { agricultural or } \\
\text { forest resources. }\end{array}$ & $\begin{array}{l}\text { The } 4 \text { excise tax exemp- } \\
\text { tion has a decreasing scale } \\
\text { rate and expires June } 30 \text {, } \\
\text { 1984. The income tax credit } \\
\text { expires January } 1,1985 \text {. }\end{array}$ \\
\hline NORTH DAKOTA & $\begin{array}{l}44 \text { excise tax ex- } \\
\text { emption } 3 \% \\
\text { sales tax exemp- } \\
\text { tion }\end{array}$ & at least $10 \%$ & $\begin{array}{l}\text { at least } 199 \\
\text { proof }\end{array}$ & $\begin{array}{l}\text { Ethyl alcohol pro- } \\
\text { duced from agri- } \\
\text { cultural resources }\end{array}$ & $\begin{array}{l}\text { The } 3 \% \text { sales tax exemption } \\
\text { only applies when the } \\
\text { gasohol is used for exemp- } \\
\text { tun agricultural or in. } \\
\text { dustrial purposes. }\end{array}$ \\
\hline OHIO & none & --- & -- & --- & $\cdots$ \\
\hline OKLAHOMA & $\begin{array}{l}6.5 \uparrow \text { excise tax } \\
\text { exemption }\end{array}$ & at least $10 \%$ & $\begin{array}{l}\text { at least } 99 \% \\
\text { at least } 198^{\circ}\end{array}$ & $\begin{array}{l}\text { Ethyl alcohol } \\
\text { distilled from } \\
\text { agricultural } \\
\text { resources }\end{array}$ & $\begin{array}{l}\text { To qualify for the } 6.5 \uparrow \text { excise } \\
\text { tax exemption the distributor } \\
\text { of the gasohol must be } \\
\text { licensed in Oklahoma. The } \\
6.5 c \text { excise tax exemption ex- } \\
\text { pires October } 1,1984 \text {. }\end{array}$ \\
\hline
\end{tabular}


Restrictions on State Tax Incentives - Continued

\begin{tabular}{|c|c|c|c|c|c|}
\hline States & Incentive & $\begin{array}{c}\text { \% Alcohol That } \\
\text { Must Be } \\
\text { Contained } \\
\text { in Gasohul }\end{array}$ & $\begin{array}{l}\text { "Required } \\
\text { Alcohol Proof } \\
\text { Level and } \\
\text { Alcohol } \\
\text { Purity }\end{array}$ & $\begin{array}{c}\text { Required Type of } \\
\text { Alcohol }\end{array}$ & Other Restrictions \\
\hline OREGON & $\begin{array}{l}100 \% \text { income } \\
\text { tax exemption } \\
50 \% \text { investment } \\
\text { tax credit } 100 \% \\
\text { property tax } \\
\text { reduction }\end{array}$ & at least $10 \%$ & ---- & $\begin{array}{l}\text { To qualify for the } \\
100 \% \text { income tax } \\
\text { exemption or } \\
100 \% \text { property } \\
\text { tax reduction } \\
\text { alcohol must be } \\
\text { ethyl or methyl } \\
\text { alcohol or other } \\
\text { substitute fuel not } \\
\text { produced from } \\
\text { petroleum, natural } \\
\text { gas or coal. } \\
\text { Several types of } \\
\text { alternative fuels } \\
\text { qualify for the } \\
\text { 50\% investinent } \\
\text { tax credit. }\end{array}$ & $\begin{array}{l}\text { The } 50 \% \text { investment credit } \\
\text { has a decreasing scale rate } \\
\text { and expires January } 1 \text {, } \\
1985 \text {. The } 100 \% \text { property } \\
\text { tax reduction applies only } \\
\text { to commercial plants and } \\
\text { expires October } 3,1985 \text {. }\end{array}$ \\
\hline PENNSYLVANIA & none & ---- & $\cdots$ & --- & $\therefore$ \\
\hline RHODE ISLAND & none & $\cdots$ & --- & --- & \\
\hline $\begin{array}{l}\text { SOUTH } \\
\text { CAROLINA }\end{array}$ & $\begin{array}{l}44 \text { excise tax cx- } \\
\text { emption }\end{array}$ & at least $10 \%$ & $\begin{array}{l}\text { at least } 99 \% \\
\text { purity }\end{array}$ & $\begin{array}{l}\text { Ethyl or methyl } \\
\text { alcohol produced } \\
\text { from agricultural }\end{array}$ & $\begin{array}{l}\text { The } 4 c \text { excise tax exemption } \\
\text { has a decreasing scale rate } \\
\text { and expires when the total } \\
\text { revenue loss realized reaches } \\
\text { a maximum of } \$ 5 \text { million. }\end{array}$ \\
\hline TENNESSEE & $\begin{array}{l}7 \leftarrow \text { excise tax ex- } \\
\text { emption }\end{array}$ & $-\cdots$ & $\begin{array}{l}\text { at least } 188 \\
\text { proof }\end{array}$ & $\begin{array}{l}\text { Ethyl or methyl } \\
\text { alcohol }\end{array}$ & $\begin{array}{l}\text { Alcohol used in gasohol } \\
\text { must be dyed a distinctive } \\
\text { color and be denatured. } \\
\text { Only manufacturers of } \\
\text { alcohol who produce less } \\
1000 \text { gallons annually and } \\
\text { use this gasobol for their } \\
\text { nwn personal use or for sale } \\
\text { to a bonded distributor } \\
\text { qualify for the } 7 \uparrow \text { excise tax } \\
\text { exemption. }\end{array}$ \\
\hline TEXAS & $\begin{array}{l}100 \% \text { property } \\
\text { tax exemption } \\
4 \% \text { sales tax ex- } \\
\text { emption }\end{array}$ & --- & --- & Ethyl alcohol & $\begin{array}{l}\text { The sales and property tax } \\
\text { exemptions only apply to } \\
\text { the purchase of equipment } \\
\text { used in the production of } \\
\text { ethyl alcohol. }\end{array}$ \\
\hline
\end{tabular}


Restrictions on State Tax Incentives - Continued

\begin{tabular}{|c|c|c|c|c|c|}
\hline States & Incentive & $\begin{array}{c}\text { \%Alcohol That } \\
\text { Must Be } \\
\text { Contained } \\
\text { in Gasohol }\end{array}$ & $\begin{array}{c}\text { *Required } \\
\text { Alcobol Proof } \\
\text { Level and } \\
\text { Alcohol } \\
\text { Purity }\end{array}$ & $\begin{array}{c}\text { Required Type Of } \\
\text { Alcohol }\end{array}$ & Other Restrictions \\
\hline UTAH & $\begin{array}{l}\text { 5t excise tax ex- } \\
\text { emption Income } \\
\text { tax reduction }\end{array}$ & at least $10 \%$ & $\cdots$ & Alcohol & $\begin{array}{l}\text { Alcohol must be produced } \\
\text { in Utah. The } 5 ₫ \text { excise tax } \\
\text { exemption expires June } 30 \text {, } \\
1985 \text {. No more than } 25 \% \text { of } \\
\text { the energy value of the } \\
\text { alcohol may be derived } \\
\text { from electricity, distillable } \\
\text { liquid, or gaseous fuels in } \\
\text { the production of alcohol. }\end{array}$ \\
\hline VERMONT & none & -- & --- & ---- & ---- \\
\hline VIRGINIA & none & --- & --- & --- & $-\cdots$ \\
\hline WASHINGTON & $\begin{array}{l}1.2 థ \text { excise tax } \\
\text { exemption, } \\
4.5 \% \text { sales tax } \\
\text { exemption } 4.5 \% \\
\text { use tax exemp- } \\
\text { tion property } \\
\text { tax exemption } \\
\text { state business } \\
\text { and occupation } \\
\text { taxes exemption }\end{array}$ & at least $91 / 2 \%$ & ---- & Alcohol & $\begin{array}{l}\text { The } 1.2 \$ \text { excisc tax exemp- } \\
\text { tion, } 4.5 \% \text { sales tax exemp- } \\
\text { tion and } 4.5 \% \text { use tax ex- } \\
\text { emption expire December } \\
31,1986 . \text { The property tax } \\
\text { exemption expires } \\
\text { December } 31,1986 \text {. }\end{array}$ \\
\hline WEST VIRGINLA & none & ---- & $\cdots$ & ---- & $\cdots$ \\
\hline WISCONSIN & $\begin{array}{l}\text { corporate in- } \\
\text { come tax credit } \\
\text { personal income } \\
\text { tax credit }\end{array}$ & $\cdots$ & ---- & Alcohol & ---- \\
\hline WYOMING & $\begin{array}{l}4 \leftarrow \text { excise tax } \\
.3 \% \text { sale tax ex- } \\
\text { emption }\end{array}$ & at least $10 \%$ & $-\ldots$ & $\begin{array}{l}\text { Alcohol produced } \\
\text { from agricultural } \\
\text { or other } \\
\text { renewable } \\
\text { resources }\end{array}$ & $\begin{array}{l}\text { The } 4 \uparrow \text { excise tax exemption } \\
\text { expires July } 1,1984 \text {. }\end{array}$ \\
\hline
\end{tabular}

Source: U.S. National Alcohol Fuels Commission, July 1980 


\section{APPENDIX D-3}

Summary of State Permit Requirements

\begin{tabular}{|c|c|c|c|}
\hline STATE & PERN & REQUIRED & PERMIT FEE \& BONDING REQUIREMENT \\
\hline Nlabama & & yes & $\$ 100 / y r$ \\
\hline Alaska & & no & 0 \\
\hline Arizona & & yes & 0 \\
\hline Arkansas & & yes & 0 \\
\hline California & & yes & $\$ 6.60$ \\
\hline Colorado & & no & 0 \\
\hline Connecticut & & no & 0 \\
\hline Delaware & & yes & no \\
\hline Florida. & & no & 0 \\
\hline Gcorgia & & yes & $\begin{array}{l}\text { Post } \$ 1,000-\$ 150,000 \text { bond (depending on size of } \\
\text { plant) }\end{array}$ \\
\hline Hawaii & & no & 0 \\
\hline Idaho & & no & 0 \\
\hline Illinois & & yes & $\begin{array}{l}\text { Post } \$ 1, U(U)-\$ 40,000 \text { bond (depending on size of } \\
\text { plant) }\end{array}$ \\
\hline Indiana & & no & 0 \\
\hline lowa & & no & 0 \\
\hline Kansas & & no & 0 \\
\hline Kentucky & & no & 0 \\
\hline Lousiana & & no & 0 \\
\hline Maine & & no & 0 \\
\hline Maryland & . & no & 0 \\
\hline Massachusetts & & no & 0 \\
\hline Michigan & & no & 0 \\
\hline Minnesota & & yes & $\$ 5$ \\
\hline Mississippi & & yes & $\begin{array}{l}\$ 2.500 \text { for large scale production - } \$ 25 \text { for suladl } \\
\text { scale production }\end{array}$ \\
\hline Missouri & & yes & Post $\$ 5,000$ bond. \\
\hline Montana & & no & 0 \\
\hline Neliaska & & no & 0 \\
\hline Nevada & & no & 0 \\
\hline New Hampshire & & yes & 0 \\
\hline New Jcrsey & & no & 0 \\
\hline New Mexico & & no & 0 \\
\hline New York & & yes & $\$ 625$ \\
\hline North Carolina & & no & 0 \\
\hline North Dakota & & no & 0 \\
\hline Ohio & $\cdot$ & no & 0 \\
\hline Oklahoma & & yes & $\begin{array}{l}\$ 25 \text { (experimental plants) } \$ 250 \text { (distilled spirits } \\
\text { plants) }\end{array}$ \\
\hline Oregon & . & no & 0 \\
\hline Pennsylvania & & yes & $\begin{array}{l}\$ 25 \text { (on-farm production and use) } \$ 2,500 \text { (commer- } \\
\text { cial production and use) }\end{array}$ \\
\hline Rhode Island & & no & 0 \\
\hline South Carolina & & no & 0 \\
\hline South Dakota & & yes & $\begin{array}{l}\text { Pust } \$ 250 \text { bond and obtain a Dept. of Revenue } \\
\text { motor fuel dealer license. }\end{array}$ \\
\hline Tennessee & & yes & $\begin{array}{l}\$ 50 \text { (production of } 1000-2500 \mathrm{gal} / \mathrm{yr} \text { ) }-\$ 1000 \text { (Pro- } \\
\text { duction of more than } 2500 \mathrm{gal} / \mathrm{yr} \text {.) Notification re- } \\
\text { quired only if production less than } 1000 \\
\text { gallon/year. }\end{array}$ \\
\hline
\end{tabular}


Summary of State Permit Requirements - Continued

STATE

PERMIT REQUIRED

PERMIT FEE \& BONDING REQUIREMENT

\begin{tabular}{lll}
\hline Texas & yes & $\$ 100$ \\
Utah & yes & $\$ 1$ \\
Vermont & no & 0 \\
Virginia & yes & 0 \\
Washington & no & 0 \\
West Virginia & yes & 0 \\
Wisconsin & yes & $\$ 10$ \\
Wyoming & no & 0 \\
\hline
\end{tabular}

Source: U.S. National Alcohol Fuels Commission, July 1980 


\section{APPENDIX D-4}

State Volatility Specifications

\begin{tabular}{|c|c|c|c|}
\hline STATE & D439' & DISTILLATION" & REID VAPOR PRESSURE: \\
\hline Nlabama & No & Yes & Yes \\
\hline Alaska & No & No & No \\
\hline Arizona & Yes & Yes* & Yes* \\
\hline Arkansas & Yes & Yes* & Yes* \\
\hline California & Yes & Yes* & No** \\
\hline Colorado & No & Yes & No \\
\hline Connecticut & No & Yes & No \\
\hline Delaware & No & No & No \\
\hline Florida & Yes & Yes* & Yes* \\
\hline Georgia & Yes & Yes* & Yes* \\
\hline Hawaii & Yes & Yes* & $Y \mathrm{cs}^{*}$ \\
\hline Idaho & Yes & Yes* & Yes* \\
\hline Illinois & No & No & Nis \\
\hline Indiana & No & Yes & Yes \\
\hline lowa & No & Yes & Yes \\
\hline Kansas & No & Y'es & $\mathrm{Nn}$ \\
\hline Kentucky & No & INO & No \\
\hline Louisiana & No & Y'es & Yes \\
\hline Mainc & No & Yes & No \\
\hline Maryland & Yes & Yes* & Yes* \\
\hline Massachusetts & No & Yes & No \\
\hline Michigan & No & $\mathrm{Nn}$ & No \\
\hline Minnesota & No & Yes & No \\
\hline Mississippi & Yes & Yes* & Yes* \\
\hline Missouri & No & Yes & Yes \\
\hline Montana & Yes & Yes* & Yes* \\
\hline Nebraska & No & Yes & No \\
\hline Nevada & No & Y'es & No \\
\hline New Hampshire & No & No & No \\
\hline New Jersey & No & Yes & No \\
\hline New Mexico & No & Yes & $\mathrm{Nn}$ \\
\hline New York & No & Yes & Nọ \\
\hline North Carolina & Yes & Yes* & Yes $^{*}$ \\
\hline INurth Uakota & Yes & Yes* & Yes* \\
\hline Ohio & No & No & No \\
\hline Uklahoma & No & Ycs & No \\
\hline Oregüı! & No & No & No \\
\hline Pennsylvania & No & No & No \\
\hline Rliude Island & Yes & Yes & Yes \\
\hline South Carolind & No & Yes & Yes \\
\hline South Dakota & No & Yes & Ycs \\
\hline Tennessee & Y'es & No & No \\
\hline Texas & No & Yes & No \\
\hline IItah & No & Yes & Yes \\
\hline Vermont & No & $\mathrm{Nn}$ & No \\
\hline Virginia & No & Yes & Yes \\
\hline Washington & No & No & No \\
\hline West Virginia & $\mathrm{Nn}$ & No & No \\
\hline Wiscónsın & No & Yes & Yes \\
\hline Wyoming & Nó & Yes & Yes \\
\hline
\end{tabular}

Part of $D+39$

** (iasohol exelupsed from KVP from June 13, 1980 10 June 13, 1983.

' 3434 - Specifications recommended by the American Society for Testing and for autmotive gasoline governing volatility, distillation refuirsment:, lleid Vallu Presure, lead content, corrosion resistance, gum content. sulfur content, oxidation sitability and antl-kinock index.

¿ Bistllation - Specificutions which control the vaporizution characteristic of gasoline:

- Reid Vapor Pressure - Recommended pounds per square inch of pressure of the gasoline. While designed by ASTM primarily to presen vapor lock. some restm Staic ceilings on RVP are designed to reduce pollution.

Somrie: U.S. National Alcohol Fucls Commission, July 1980 


\section{APPENDIX E}

\section{Resource People and Organizations}

- Associations and Organizations

- Biologists

- Blending Terminals

- Chemists

- Consultants for Report

- Consultants/Design Engineers

- DDG Purchasers

- Economists

- Engineering Firms

- Enzyme and Yeast Producers

- Ethanol Producers/Distributors

- Feedstock Sources

- Plant Operation Consultants

- BATF Regional Offices

- DOE Regional Offices

- SBA Regional Offices

- FmHA State Offices

- HUD Regional Offices

- EDA Regional Offices

\section{NOTICE}

The following list of resource people and organizations is provided for your information. Neither DOE nor SERI recommends or vouches for these sources. We would appreciate receiving additions or revisions to this information. 


\section{ASSOCIATIONS AND ORGANIZATIONS}

American Agriculture

Movement

308 Second Street, SE

Washington, DC. 20515

(202) $544-5750$

The Bio-Energy Council 1625 Eye Street, NW

Suite 825A

Washington, DC 20006

Contact: Carol Canelio

(202) 833-5656

Brewers Grain Institute

$1750 \mathrm{~K}$ Street, NW

Washington, DC 20006

Corn Development Commission

Route 2

Holdrege, NE 68949

Distillers Feed Research

Council

1535 Enquirer Building

Cincinnati, OH 45202

Contact: Dr. William Ingrigg

(513) $621-5985$

International Biomass Inștitute

$1522 \mathrm{~K}$ Street. NW

Suite 600

Washington, DC 20005

Contact: Dr. Daruld Albright

(202) 783-1133

National Farmers Organization

Surprisc, NE 68667

National Farmers Union

Denver, CO 80251

National Alcohol Fuel Institute 5716 Jonàthan Mitchell Rd.

Fairfax Station, VA 22039

(703) $250-5136$

National Alcohol Fuels

Commission

492 lst St., S.E.

Washington, DC 20003

Contact: Jim Childress

(202) 426-6490
National Alcohol Fuels

Information Center

Solar Energy Research Institute

1617 Cole Boulevard

Golden, CO 80401

(800) 525-5555 - Continental U.S.

(800) 332-8339 - Colorado

National Gasohol Commission, . Inc.

521 South 14th St., Suite 5

Lincoln, NE 68508

Contact: Myron Reamon

(402) $475-8044$ or 8055

Northeast Solar Energy Center

470 Atlantic Ave

Boston, MA 02110

(617) 292-9250

Solär Encrgy Research Institute

161/ Cole Boulevard

Golden, CO 80401

Contact: Cecil Jones

Southern Solar Energy Center

61 Perimeter Park

Atlanta, GA 30341

(404) $458-8765$

Western Solar Utilization Network

Pioneer Park Building

715 S.W. Morrison

Portland, OR 97205

(SUis) 241-1222

The Wheat Growers

Route \#1, Box 27

Hemingford, NE 69438

Contact: Vic Haas

(308) 487-3794

\section{BIOLOGISTS}

Dr. Pearse Lyons

ALLTECH, INC.

271 Goldrush Rd.

Lexington, KY 40503

(606) $276-3414$

Micro-TEC Lab, Inc.

Route 2, Box 19L

Logan, IA 51546

Contact: John W. Rago

(712) 644-2193

Len Spano

The Army/Navy Lab

Natick, MA 01760

(617) 653-1000, Ext. 2914
BLENDING TERMINALS

GATX Terminals Corporation

P.O. Box 409

Argo, IL 60501

(312) 458-1330

\section{CHEMISTS}

Dr. Harry P. Gregor

Columbia University

353 Sceley West Mudd Building

New York, NY 10027

(212) 280-4716

Antüia R. Moreira

Colorado State University

Furr Cóllıns, CO 80523

(303) $491-5252$

Dr. Richard Spencer

Southwest State University

Marshall, MN 56258

(507) $537-7217$

\section{CONSULTANTS \\ FOR REPORT}

TRW, Inc.

Energy Systems Group

TRW, Inc.

8301 Greensboro Dr.

McLean, VA 22102

Cuntacts: Mr. V. Daniel Hunt

Mr. Warren Standley

Dr. Ed Goretsky

Dr. Jean-Francois Henry

Ms. Ann Heywood

Dr. Jean Simons

Mr. Arch Wuod

(703) 734-6554

Development Planning and

Research Associales

200 Research Drive

P.O. Box 727

Manhattan, KS 66502

Contact: Mr. Milton David

(913) 539-3565

The Eakin Corporation

401 Delphine St.

Baton Rouge, LA 70806

Contact: Mr. Sam Eakin

(504) 346-0453 
Center for the Biology of Natural

Systems

Washington University

St. Louis, MO 63130

Contact: Mr. David Freedman

(314) 889-5317

A. T. Kearney, Inc.

699 Prince St.

Alexandria, VA 22314

Contact: Dr. Cathryn Goddard et al.

(703) 836-6210

Battelle Memorial Institute

505 King Avc.

Columbus, $\mathrm{OH} 43201$

Contact: Mr. David Jenkins

(614) 424-6424

Raphael Katzen Associates

1050 Delta Ave.

Cincinnati, $\mathrm{OH} 45208$

Contact: Dr. Raphael Katzen

(513). $871-7500$

Quaintance and Swanson

Suite 210, Van Brunt Building

226 N. Phillips Ave.

Sioux Falls, SD 57101

Contact: Mr. Robert Mabee, Attorney

(605) 335-1777

E.F. Hutton

3340 Peachtree St. Rd., N.E.

Atlanta, GA 30026

Contact: Mr. Strud Nash

(404) $262-2110$

Solar Energy Research Institute 1617 Cole Blvd.

Golden, CO 80401

Contact: Cecil Jones

(303) 231-1205

PEDCo International

1149 Chester Rd.

Cincinnati, OH 45246

Contact: Dr. William Stark

(513) 782-4717

Office of Alcohol Fuels

U.S. Department of Energy

Room 6A-211

1000 Independence Ave.

Washington, DC 20585

Contact: Mr. Ted Tarr

(202) 252-9487
Arthur Young and Company

235 Peachtree St., N.E.

Atlanta, GA 30303

Contact: Mr. Michael Thomas

(404) $577-8773$

\section{CONSULTANTS/DESIGN ENGINEERS}

ACR Process Corp.

808 South Lincoln, \#14

Irbana, IL 61801

Contact: Robert Chambers

(217) $384: 8003$

Alltech, Inc.

271 Goldrush Rd.

Lexington, KY 40503

Contact: Dr. Pearse Lyons

(606) 276-3414

Bartlesville Energy

Technology Center

Bartlesville, OK 74003

Contact: Jerry Allsup

(918) $336-4268$

Center for Biology of Natural Systems

Washington University

St. Louis, MO 63130

Contact: David Freedman

(314) 889-5317

Chemapec, Inc.

230 Crossways Park Drive

Woodbury, NY 11797

Contact: Dr. Ing. Hans Muellcr

(516) $364-2100$

Development Planning and

Research Associates

200 Research Drive

P.O. Box 727

Manhattan, KS 66502

Contact: Milton David

(913) 539-3565

Raphael Katzen Assoc.

1050 Delta Avenue

Cincinnati, OH 45208

Contact: George Moon

(513) $871-7500$
Resource Planning Associates Inc.

1901 L Street, NW

Washington DC 20036

Contact:

Mr. Robert T. McWhinney Jr. (202) $452-9770$

TRW Energy Systems Group

8301 Greensboro Drive

McLean, VA 22102

Contact: Mr. V. Daniel Hunt

(703) 734-6554

Vulcan Cincinnati, Inc.

2900 Vernon Place

Cincinnati, $\mathrm{OH} 45219$

Contact: Donald Miller

(513) 281-2800

\section{DDG PURCHASERS}

The Pillsbury Company

3333 South Broadway

St. Louis, MO 63118

(314) $772-5150$

\section{ECONOMISTS}

Resource Planning Associates Inc.

1901 L Street, NW

Washington DC 20036

Contact:

Mr. Robert T. McWhinney Jr. (202) 452-9770

\section{ENGINEERING FIRMS}

Bohler/Vogelhusch 1625 West Belt North

Houston, TX 77043

Contact: Jerry Korff

(713) $465-3373$

Chemapec Inc.

230 Crossways Park Drive

Woodbury, NY 11797

Contact: Rene Loser

(516) $364-2100$

Hydrocarbon Research Inc.

134 Franklin Corner Rd.

P.O. Box 6047

Lawrenceville, NJ 08648

Contact: Maurice Innes

(609) 896-1300 
Raphael Katzen Associates.

1050 Delta Ave.

Cincinnati, $\mathrm{OH} 45208$

Contact: George Moon

(513) $871-7500$

Keep Chemical Cumpany

Box 441

Cornwall, NY 12518

Contact: Peter J. Ferrara

(914) 534-4755

A. G. McKee Corporation

10 South Riverside Plaza

Chicago, IL 60606

Contact: Edward A. Kirchner

(312) 454-3685

PEDCo International, Inc. 11199 Chestcr Rd.

Cincinnal, ÜH 45246

Contact: Timothy Devitt

(513) $782-4717$

Power Engineering Co.

1.313 S.W. 27th Avc.

Miami, FL 33145

Contact: John Scopetta

Vulcan Cincinnati, Inc.

2900 Vernon Plaza

Cincinnati, OH 45219

Contact: Donạld Miller

(513) 281-2800

\section{ENZYME AND YEAST PRODUCERS}

Alltech, Inc.

271 Goldrush Road

Lexington, KY 40503

(606) 276-3414

Anheuser Busch, Inc.

721 Pestalozzi Street

St. Loujis. MO 63118

(314) $577-2000$

Biocon, Inc.

261 Midland Ave.

Lexington, KY 40507

(606) 254-0517

Chemapec, Inc.

230 Crossways Park Drive

- Woodbury, NY 11797

Contact: Rene Loser

(516) 364-2100
Norbert Haverkamp

Compost Making Enzymes

Rural Route 1, Box 114

Horton, KY 66439

(913) 486-3302

Miles Laboratories, Inc.

Enzyme Products Division

P.O. Box 932

Elkhart, IN 56515

(219) $564-8111$

Novo Laboratory, Inc.

59 Danbury Road

Wilton, CT 06897

(203) 762-2401

Sicientific Products Co.

North Kansas City, MO 64116

(816) 221-25.3.

\section{ETHANOL PRODUCERS/ DISTRIBUTORS}

Amoco Production Company

P.O. Box 5340a

Chicago, IL 60680

(312) 856-2222

APCO Oil Corporation

Houston Natural Gas Building

Iloustion, TX 77002

(713) 658-0610

Archer Daniels Midland Company

Box 1470

Decatur, IL 62525

(217) $424-5700$

Tincoue Energy Resourccs, Incorporated

11951 Mitchell Road, Mitchell Island

Richmond, British Columbia

(604) $3227-8394$

Exxon Corporation

Exxon Research and Engineering

Public Relations

P. O. Box 639

Linden, NJ 07036

Georgia-Pacific

900 Southwest 5th Avenue

Portland, OR 97204

(503) 222-5561
Georgia Pacific Company

Bellingham Division

P.O. Box 1236

Bellingham, WA 98225

(206) 733-4410

Grain Processing Corporation

Muscatine, IA 52761

(918) 264-4211

Hiram Walker

31275 Northwestern Highway

Farmington Hills

Detroit, MI 48018

Marcam Industries

527 North Easton Road

Glenside, PA 19038

(215) 88.5-54m

Midwest Solvents Company

1300 Main Street

Atchison, KS 66002

(913) $367-1480$

Milbrew, Incorporated

330 South Mill Street

Juneau, WI 53039

(414) $462-3700$

Mode, Ronald C.

Box 682

Glen Alpine, NC 28628

(701) 584-1432

Publicker Industries

777 W. Putnam Avenue

Greenwich, C.T $\$ 6830$

(203) $531-4500$

Quntcrnoin Clemical Industries

72026 Livingston Street

Oakland, rA 91604

Contact: Louis Nagel

(415) 535-2311

Sigmor Corporation

P.O. Box 20267

San Anturrio, $\mathrm{TX} 78220$

(512) 223-2631

Texaco, Incorporated

135 East 42nd Street

New York, NY 10017

(212) $953-6000$ 
TIPCO

9000 N. Pioneer Rd.

Peoria, IL 61614

(309) 692-6543

Worum Chemical Company

2130 Kasoto Avenue

St. Paul, MN 55108

Contact: Mr. Ritt

(612) 645-9224

\section{FEEDSTOCK SOURCES}

\section{General}

Distillers Feed Research Council 1435 Enquirer Bldg.

Cincinnati, $\mathrm{OH} 45202$

(513) 621-5985

\author{
Sorghum \\ Grain Sorghum Producers \\ Association \\ 1708 - A 15 th Street \\ Lubbock, TX 79401 \\ Contact: Elbert Harp \\ Executive Director
}

(806) 763-4425

Producers Grain Corp.

P.O. 111

Amarillo, TX 79105

(806) 374-0331

\section{Potatoes}

National Potato Council

45th \& Peoria Denver, CO 80239

(303) 373-5639

\section{Grains}

National Council of Farmer ${ }^{\circ} \mathrm{Co}$ ops

1800 Massachusetts Ave. NW

Washington, DC 20036

(202) 659-1525

\section{PLANT OPERATION CONSULTANTS}

Alltech, Inc.

271 Goldrush Road

I.exington, KY 40503

Contact: Dr. Pearse Lyons

(606) 276-3414
Chemapec, Inc.

230 Crosways Park Drive

Woodbury, NY 11797

Contact: Dr. Ing. Hans Mueller

(516) 364-2100

PEDCo International

1149 Chester Road

Cincinnati, OH 45246

Contact: Dr. William Stark

(513) $782-4717$

\section{BUREAU OF ALCOHOL, TOBACCO, AND FIREARMS REGIONAL OFFICES}

\section{Central Region}

(Indiana, Kentucky, Michigan, Ohio, West Virginia)

Regional Regulatory Administrator

Bureau of Alcohol, Tobacco, and Firearms

550 Main Street

Cincinnati, OH 45202

(513) 684-3334

\section{Mid-Atlantic Region}

(Delaware, District of Columbia, Maryland, New Jersey,

Pennsylvania, Virginia)

Regional Regulatory Administrator

Bureau of Alcohol, Tobacco. and Firearms

2 Penn Center Plaza, Room 360

Philadelphia, PA 19102

(215) 597-2248

\section{Midwest Region}

(Illinois, lowa, Kansas, Minnesora, Missouri, Nebraska, North

Dakota, South Dakota, Wisconsin)

Regional Regulatory Administrator

Bureau of Alcohol, Tobacco, and Firearms

230 S. Dearborn Street, 15th Floor

Chicago, IL 60604

(312) 353-3883
North-Atlantic Region

(Connecticut, Maine,

Massachusetts, New Hampshire,

New York, Rhode Island,

Vermont, Puerto Rico,

Virgin Islands)

Regional Regulatory Administrator

Bureau of Alcohol, Tobacco, and Firearms

6 World Trade Center, 6th Floor

For letter mail:

P.O. Box 15 ,

Church Street Station

New York, NY 10008

(212) 264-1095

\section{Southeast Region}

(Alabama, Florida, Georgia, Mississippi, North Carolina, South Carolina, Tennessee)

Regional Regulatory Administrat or

Bureau of Alcohol, Tobacco, and Firearms

3835 Northcast Expressway

For letter mail:

P.O. Box 2994

Atlanta, GA 30301

(404) 455-2670

\section{Southwest Region}

(Arkansas, Colorado, Louisiana, New Mexico, Oklahoma, Texas, Wyoming)

Regional Regulatory Administrator

Bureau of Alcohol, Tobacco, and Fircarms

Main Tower, Room 345

1200 Main Street

Dallas, TX 75202

(214) $767-2285$

\section{Western Regiouı}

(Alaska, Arizona, California, Hawaii, Idaho, Montana, Nevada, Oregon, Utah, Washington)

Regional Regulatory Administrator

Bureau of Alcohol, Tobacco, and Firearms

525 Market Street, 34th Floor

San Frälcisco, CA 94105

(415) 556-0226 


\section{DEPARTMENT OF ENERGY REGIONAL OFFICES}

Region I

Regional Representative

150 Causeway Street

Analcx Building, Room 700

Boston, MA 02114

(617) 223-3701

(Use same 7-digit number for FTS)

Region 2

Regional Representative

26 Federal Plaza

Room 3206

New York, NY 10007

(212) 264-1021

(Use same 7-digit number for FTS)

Regiun 3

Regional Representalive

1421 Cherry Street

Room 1001

Philadelphia, PA 19102

(215) $597-3890$

(Use same 7-digit number for FTS)

Region 4

Regional Representative

1655 Peachtree Street N.E.

8th Floor

Atlanta, GA 30309

(404) 881-2838

FTS $257-2838$

Region 5

N. Regionial Representative

175 West Jackson Boulevard

Room A-333

Chicago, IL 60604

(312) 353-0540

(Use same 7-digit number for FTS)

Region 6

Regional Representative

P.O. Box 35228

2626 West Muckinguind Lante

Dallas, TX 75739

(214) $749-7345$

(Use same 7-digit number for FTS)

Region 7

Regiưrál Representative

Twelve Grand Building

P.O. Box 2208

112 East 12 th Street

Kansas City, MO 64142

(816) $374-2061$

FTS 758-2061
Region 8

Regional Representative

P.O. Box 26247,

Belmar Branch

Lakewood, CO 80226

(303) 234-2420

(Use same 7-digit number for FTS)

Region 9

Regional Representative

111 Pine St., Third Floor

San Francisco, CA 94111

(415) 556-7216

(Use same 7-digit number for FTS)

Region 10

Regional Representative

1922 Federnl Bldg.

915 Second Ave.

Seattle, WA 98174

(206) 442-7285

FTS 399-7280

\section{SMALL BUSINESS ADMINISTRATION REGIONAL OFFICES}

Region 1

(Connecticut, Maine,

Massachusetts, New Hampshire,

Rhode Island, Vermont)

John F. Kennedy Federal Bldg.,

Room 2113

Boston, MA 02203

(617) 223.2100

Region 2

(New Jersey, New York, Puerto

Rico, Virgin Islands)

26 Federal Plaza, Room 3930

New Yǘth, NY 10007

(212) $460-0100$

Region 3

(Delawarc, District of Columbia, Maryland, Pennsylvania, Virginia, West Virginia)

1 Decker Square, East Lobby,

Suite $\mathbf{4 0 0}$

Bala Cynwyd, PA 19004

(215) 597-3311
Region 4

(Alabama, Florida, Georgia,

Kentucky, Mississippi, North

Carolina, South Carolina,

Tennessee)

1401 Peachtree St. N.E., Room 441

Atlanta, GA 30309

(404) 526-0111

Region 5

(Illinois, Indiana, Michigan,

Minnesota, Ohio, Wisconsin)

Federal Bldg.

219 South Dearborn St., Room 437

Chicago, IL 60604

(312) 353-4400

Region 6

(Aıkansas, Luuisiania, New

Mexico, Oklahoma, Texas)

1100 Commerce St., Room 300

Dallas, TX 75202

(214) $749-5611$

Region 7

(lowa, Kansas, Missouri,

Nebraska)

911 Walnut St., 24th Floor

Kansas City, MO 64106

(816) 374-7000

Region 8

(Colorado, Montana, North

Dakota, South Dakota, Utah,

Wyoming)

721 19th St., Room 426A

Denver, CO 80202

(303) 837-0111

Region 9

(Arizona, California, Hawaii, Nevada, Pacific Islands)

rederal Bldg.

450 GuldeII Oale Avé.

San Francisco, CA 94102

(415) $556-9000$

Region 10

(Alaska, Idaho, Oregon,

Washington)

710 2nd Ave., 5th Floor

Dexter Horton Bldg.

Scattle, WA 98104

(206) 442-0111 


\section{DISTRICT OFFICES}

\section{Region 1}

1326 Appleton St.

Holyoke, MA 01040

(413) 536-8770

Federal Bldg.

40 Western Ave., Room 512

Augusta, ME 04330

(207) 622-6171

55 Pleasant St., Room 213

Concord, NH 03301

(603) 224-4041

Federal Bldg.

450 Main St., Room 710

Hartford, CT 06103

(203) 244-2000

Federal Bldg.

87 State St., Room 210

Montpelier, VT 05602

(802) 223-7472

57 Eddy St., Room 710

Providence, RI 02903

(401) 528-1000

\section{Region 2}

225 Ponce de Leon Ave.

Hato Rey, PR 00919

(809) 765-0404

970 Broad St., Room 1635

Newark, NJ 07102

(201) 645-3000

Hunter Plaza

Fayette and Salina Sts., Room 308

Syracuse, NY 1.3202

(315) 473-3350

Chamber of Commerce Bldg.

55 St. Paul St.

Rochester, NY 14604

(716) $546-4900$

\section{Region 3}

109 North 3rd St.

Room 301, Lowndes Bldg.

Clarksburg, WV 26301

(304) 624-3461
Federal Bldg.

1000 Liberty Ave., Room 1401

Pittsburgh, PA 15222

(412) 644-3311

Federal BIdg.

400 North 8th St., Room 3015

Richmond, VA 23240

(703) $782-2000$

1310 L St., N.W., Room 720

Washington, DC 20417

(202) 382-3731

\section{Kegion 4}

908 South 20th St., Room 202

Birmingham, AL 35205

(205) 325-3011

222 South Church St.

Room 500, Addison Bldg.

Charlotte, NC 28202

(704) 372-0711

1801 Assembly St., Room 117

Columbia, SC 29201

(803) $765-5376$

Petroleum Bldg., Suite 690

Pascagoula and Amite Sts.

Jackson, MS 39205

(601) 948-7821

Federal Bldg.

400 West Bay St., Room 261

Jacksonville, FL 32202

(904) 791-2011

Federal RIdg.

600 Federal Pl., Room 188

Louisville, KY 40202

(502) 582-5011

Federal Bldg.

51 Southwest 1st Ave., Room 912

Miami, FL 33130

(305) 350-5011

500 Union St., Room 301

Nashville, TN 37219

(615) 749-9300

502 South Gay St.

Room 307, Fidelity Bankers Bldg.

Knoxville, IN 37902

(615) 524-4011

\section{Region 5}

502 East Monroe St.

Ridgely Bldg., Room 816

Springfield, IL 62701

(217) $525-4200$

1240 East 9th St., Room 5524

Cleveland, $\mathrm{OH} 44199$

(2.16) $522-3131$

34 North High St.

Columbus, OH 43215

(614) 469-6600

Federal Bldg.

550 Main St .

Cincinnati, $\mathrm{OH} 45202$

(513) 684-2200

1249 Washington Blvd.

Room 1200, Book Bldg.

Detroit, MI 48226

(313) 226-6000

36 South Pennsylvania St.

Room 108, Century Bldg.

Indianapolis, IN 46204

(317) $633-7000$

122 West Washington Ave.,

Room 713

Madison, WI 53703

(608) 256-4441

12 South 6th St., Plymouth BIdg. Minneapolis, MN 55402

(612) $725-4242$

\section{Regivn 6}

Federal Bldg. and Courthouse 500 Gold Ave., S.W.

Albuquerque; NM 87101

(505) 843-0311

808 Travis St., Room 12.19

Niels Esperson Bldg.

Houston, TX 7700 ?

(713) 226-4011

Post Office and Court House

Bldg.

West Capital Ave., Room 377

Little Rock, AK 72201

(501) 378-5871 
1205 Texas Ave.

Lubbock, TX 79408

(806) $747-311$

219 East Jackson St. (Lower Rio Grande Valley)

Harlingen, TX 78550

(512) 423-8933

505 East Travis St.

Room 201, Travis Terrace Bldg. Marshall, TX 75670

(214) $935-5257$

Plaza Tower, 17th Floor

1001 Howard Ave.

New Orleans, LA 70113

(504) 527-2611

30 North Hudson St.

Kóorn SU1, Mercantile Bldg.

Uklahoma City, OK 73102

(405) $231-4011$

301 Broadway

Room 300, Manion Bldg.

San Alllonio, TX 78205

(512) 225-5511

\section{Region 7}

New Federal Bldg.

210 Walnut St., Room 749

Des Muines, IA 50309

(51.5) $784-4000$

Federal Bldg.

215 North 17th St., Room 7419

Omaha, NE 68102

(402) 221-1221

Federal Bldg.

210 North 12th St., Room 520

St. Louis, MO 63101

(314) 622-8100

120 South Market St., Ronom 301

Wichita, KS 67202

(316) 267-6311

\section{Reginn 8}

Federal Bldg.

Room 4001, 100 East B St.

Casper, WY 82601

(307) 265-5550
Federal Bldg.

653 2nd Ave., North, Room 218

Fargo, ND 58102

(701) 237-5771

Power Block Bldg.

Corner Main and 6th Ave.,

Room'208

Helena, MT 59601

(406) $442-9040$

Federal Bldg.

125 South State St., Room 2237

Salt Lake City, UT 84111

(801) 524-5500

National Bank Bldg.

8th and Mainc Ave., Ruum 402

Sinux Falls, SD 57102

(605) $336=2980$

Region 9

149 Bethel St., Room 402

Honolulu, HI 96813

(808) 546-8950

849 South Broadway

Los Angeles, CA 90014

(213) 688-2121

112 North Central Ave.

Phoènix, AL 85004

(602) 261-3900

110 West r.St

San Diego, CA 92101

(714) 293-5000

\section{Region 10}

1016 West 6th Ave., Suite 200

Anchorage Legal Center

Anchorage, AK 99501

(907) 272-5561

503 3d Ave.

Fairbanks, AK 99701

(907) 452-5561

216 North 8th St., Room 408

Boise, ID 83701

(208) 342-2711

921 Southwest Washington St.

Portland, OR 97205

(503) 221-2000
Courthouse Bldg., Room 651

Spokane, WA 99210

(509) 456-0111

\section{FARMERS HOME ADMINISTRATION.STATE OFFICES}

\author{
ALABAMA \\ Elizabeth Wright \\ Room 717, Aronov Bldg. \\ 474 South Court St. \\ Montgomery, AL 36102 \\ (205) 832-7077 \\ FTS 534-7077
}

ALASKA

John R. Roḍcrick

P.O. Box 1289

Palmer, $\Lambda K 90645$

(907) $745-2176$

\section{ARIZONA}

Manual O. Dominquez

Room 3433, Federal Bldg.

230 North First Ave.

Phoenix, AZ 85025

(602) 271-6701

(Use sume 7-digit number for FTS)

\section{ARKANSAS}

Sherman Williams

5529 Federal Office Bldg.

700 W. Capitol

For letter mail:

P.O. Box 2778

Little Rock, AR 72203

(501) 378-6281

\section{CALIFORNIA}

Lowell Pannell

459 Cleveland St.

Wondland, CA 95695

(916) 666-2650

FTS 448-3223

\section{COLORADO}

Ernest C. Phillips

Room 231, No. 1 Diamond Plaza

2490 West 26th Ave.

Denver, CO 80211

(303) 837-4347

FTS $327-4347$ 


\section{DELAWARE}

(Delaware, District of Columbia, Maryland)

John D. Daniello

151 E. Chestnut Hill Rd., Suite 2

Newark, DE 19713

(302) 573-6694

FTS 487-6694

\section{FLORIDA}

Michael R. Hightower

Federal Bldg.

401 S.E. 1st Ave., Room 214

For letter mail:

P.O. Box 1088

Gainesville, FL 32602

(904) $376-3218$

FTS 946.7221

\section{GEORGIA}

Robert L. Bialock

355 E. Hancock Ave.

Athens, GA 30601

(404) $546-2162$

FTS 250-2162

\section{HAWAII}

Megumi Kin

345 Kekuanaoa St.

Hilo, HI 96720

(808) $961-4781$

\section{IDAHO}

Joe T. McCarter

Room 429, Federal Bldg.

304 N. Eighth St.

Boise, ID 83702

(208) 384-1730

FTS 554-1318

\section{ILLINOIS}

John W. Lindfield

$2106 \mathrm{~W}$. Springfield Ave.

Champaign, IL 61820

(217) 356-1891

FTS 958-9149
INDIANA

James E. Posey

Suite 1700 ,

5610 Crawfordsville Rd.

Indianapolis, IN 46224

(317) 269-6415

FTS 331-6415

\section{IOWA}

Max L. McCord

Room 873, Federal Bldg. 210 Walnut St .

Des Moines, IA 50309

(515) 284-4663

FTS 862-4663

\section{KANSAS}

John T. Denyer

444 S.E. Quincy St.

Topeka, KS 66683

(913) 295-2870

FTS $752-2870$

\section{KENTUCKY}

William E. Burnette

333 Waller Ave.

Lexington, KY 40504

(606) 233-2733

FTS 355-2733

\section{LOUISIANA}

Nimrod T. Andrews

3727 Government St .

Alexandria, LA 71301

(318) 448-3421

FTS 497-6611

\section{MAINE}

Seth H. Bradstreet

USDA Office Bldg.

Orono, ME 04473

(207) 866-4929

FTS 833-7445

\section{MASSACHUSETTS}

(Connecticut, Massachusetts,

Rhode Island)

William.E. Curry

358 N. Pleasant Street

Amhersi, MA 01002

(413) $549-2820$

\section{MICHIGAN}

Robert L. Mitchell

Room 209

1405 South Harrison Rd.

East Lansing, MI 48823

(517) 372-1910, Ext. 272

FTS 374-4272

\section{MINNESOTA}

John Apitz

252 Federal Office Bldg. and

Courthouse

316 N. Robert St.

St. Paul, MN 55101

(612) $725-5842$

(Use same 7-digit number for FTS)

\section{MISSISSIPPI}

Mark G. Hazard

Room 830, Milner Bldg.

Jackson, MS 39201

(601) 969-4316

FTS $190-4316$

\section{MISSOURI}

Allan H. Brock

555 Vandiver Dr.

Columbia, MO 65201

(314) 442-2271, Ext. 3241

FTS 276-3241

\section{MONTANA}

Wallace B. Edland

Federal Bldg.

P.O. Box 850

Bozeman, MT 59715

(406) 587-5271, Ext. 4211

FTS 585-4211

\section{NEBRASKA}

Leonard T. Hanks

Room 308, Federal Bldg.

100 Centennial Mall North

Lincoln, NE 68508

(402) 471-5551

FTS 541-5551 


\section{NEW JERSEY}

Lawrence E. Suydam

1 Vahlsing Center

Robbinsville, NJ 08691

(609) 259-3076

FTS 342-0232

\section{NEW MEXICO}

David W. King

Room 3414, Federal Bldg.

517 Gold Ave., S.W.

Albuquerque, NM 87102

(505) 766-2462

FTS 474-2462

\section{NEW YORK}

(New Yurk, Virgin Islands)

Karen N. Hanson

Room 871, U.S. Courthouse and Federal Bldg.

100 So. Clinton St.

Syracuse, NY 13202

(315) 432-5290

FTS $950-5290$

\section{NORTH CAROLINA}

James 'I'. Johnson

Rouni 514, Federal Bldg.

310 New Bern Ave.

Raleigh, NC 27601

(191) 755-4740

FTS $672-4640$

\section{NORTH DAKOTA}

Frederick S. Gengler

Federal BIdg., Room 208

For letter mail:

P.O. Box 1737

Bismarck, ND 58501

(701) 255-4011, Ext. 4237

FTS 783-4781

\section{OHIO}

Gene R. Abercrombic

Federal Bldg., Room 507

200 N. High St.

Columbus, OH 43215

(614) 469-5606

FTS 943-5606
Gene F. Earnest

Agricultural Center Office Bldg.

Stillwater, $\mathrm{OH} 74074$

(405) 624-4250

FTS 728-4250

\section{OREGON}

Kenneth Keith Keudell

Room 1590, Federal Bldg.

1220 S.W. 3rd Ave.

Portland, OR 97204

(503) 221-2731

FTS 423-2731

\section{PENNSYLVANIA}

J. Fred King

Federal Blug.

Room 728, 228 Walnut St.

For letter mail:

P.O. Box 905

Harrisburg, PA 17108

(717) $782-4476$

FTS 590-4476

\section{PUERTO RICO}

Juan Jose Jimenez

Federal Bldg.

Carlos Chardon Street

Hato Rey, PR 00918

For letter mail:

G.P.O. Bü 61060

San Juan, PR 00936

(809) 753-4308

(Use same 7-digit number for FTS)'

\section{SOUTH CAROLINA}

Karl G., Smith

240 Stoneridge Rd.

For letter mail:

P.O. Box 21607

Columbia, SC 29221

(803) $7635-58^{\prime} / 6$

FTS $677-5876$

\section{TENNESSEE}

Eaıl Wayne Avery

538 U.S. Court House Bldg.

801 Broadway

Nashville, TN 37203

(615) 251-7341

FTS 852-7341

\section{TEXAS}

Willaim H. Pieratt

W. R. Poage Bldg.

$101 \mathrm{~S}$. Main

Temple, 'TX 76501

(817) 774-1301

FTS 736-1301

\section{UTAH}

(Nevada, Utah)

Reed J. Page

Room 5311, Federal Bldg.

125 South State St.

Salt Lake City, UT 84138

(801) 524-5027

FTS 588-5057

\section{VERMONT}

(New Hampshire, Vermont)

Brian D. Burns

141 Main St.

P.O. Box 588

Montpelier, VT 05802

(802) 223-2371

FTS 832-4454

\section{VIRGINIA}

Edward A. Ragland

Federal Bldg., Room 8213

100 N. 8th St.

For letter mail:

P.U. Box 20206

Richmond, VA 23240

(804) 782-2451

FTS 925-2451

\section{WASHINGTRN}

Keith P. Sattler

Room 319. Federal Office Bldg.

301 Yakima St.

Wenatchee, WA 98801

(509) 662-4353

FT'S 390 $=0353$

\section{WEST VIRGINIA}

James Vacemire

Room 320, Federal Bildg.

For letter mail:

P.O. Box 678

Morgantown, WV 26505

(304) 559-7791

FTS 923-7791 
WISCONSIN

Lawrence E. Dahl

P.O. Box 639

Suitc 209, First Financial Plaza

Stevens Point, WI 54481

(715) 341-5900

FTS $360-3889$
WYOMING

Rudolph W. Knoll

Federal Bldg.

100 East B St.

For letter mail:

P.O. Box 820

Casper, WY 82601

(307) 265-5550, Ext. 3272

FTS 328-5271 
To locate County Farmers Home Administration Officers, consult your telephone directory under U.S. Department of Agriculture, or the State Office of the Farmers Home Administration listed above.

\section{DEPARTMENT OF HOUSING AND URBAN DEVELOPMENT REGIONAL OFFICES}

\section{Region 1}

(Connecticut, Maine Massachusetts, New Hampshire, Rhode Island, Vermont)

Boston Regional Office

Carlton H. Hovey

800 John F. Kennedy Federal Bldg.

Boston, MA 02203

(617) 223-4066 (Use same 7-digit number for FTS)

Boston Area Office (Massachusetts, Rhode Island)

Bulfinch Bldg.

15 New Chardon St.

Boston, MA 02114

(617) 223-4111

Hartford Area Office (Connecticut)

Lawrence L. Thompson

999 Asylum Ave., 1 Financial Plaza

Hartford, CT 06103

(203) 244-3638 (Use same 7-digit number for FTS)

Manchester Area Office (Maine, New Hampshire,

Vermont)

Creeley S. Buchanan

New Federal Bldg.

Chestnut St.

Manchester, NH 03101

(603) 666-7681

FTS 834-7681

Bangor Insuring Office (Maine)

Fedcral Bldg: and Post Office

202 Harlow St.

Dåıgưı, ME 04401

(207) $942-8271$

Burlington Insuring Office (Vermont)

Federal Bldg.

Elmwood Ave.

P.O. Box 989

Burlington, VT 05401

(807.) 862-6501

Providence Insuring Office (Rhode Island)

330 Post Office $\Lambda$ nnex

Providence, RI 02903

(401) 528-4351

\section{Region 2}

(New York, New Jersey, Panama Canal Zone, Puerto Rico, Virgin Islands)

New York Regional Office

S. Willian Green

26 Federal Plaza, Room 3541

New York, NY 10007

(212) 264-8068 (Use same 7-digit number for FTS)

(212) 264-8086 (Use same digit number for FTS)

Buffalo Area Office (western New York State)

Frank C. Cerabone

Grant Bldg., 560 Main St.

Buffalo, NY 14202

(716) $842-3510$

FTS 432-3510

Camden Area Office (southern New Jersey)

Robert E. Hazelwood

The Parkade Bldg., 519 Federal St.

Camden, NJ 08103

(609) 757-5081

FTS 488-5081

(609) 757-5085

FTS 488-5085

Newark Area Office (northern New Jersey)

Thomas Verdon Gateway 1 Bldg., Raymond Plaza

Newark, NJ 07102

(201) 645-3010 or 3899

FTS 3413899

New York Area Office (eastern Ncw York Statc)

J. Nugent Lopes

666 Fifth Ave.

Ncw York, NY 10019

(212) 399-5290

FTS $662-5290$

(716) $399-5283$

FTS $662-5283$

San Juan, Commonwealth Area Office

(Panama Canal Zone, Pucrto Rico, Vir yiu Islaulds)

New Pan Am Rldg., 255 Ponce de Leon Ave.

Hato Rey, PR

Mailing Address:

P.O. Box 3869, GPO

San Juan, PR 00936

(809) 763-6.363

Albany Insuring Office (northern New York State) 30 Russell Rd., Westgate North

Albany, NY 12206

(518) 472-3567 


\section{Region 3}

(Delaware, District of Columbia, Maryland,

Pennsylvania, Virginia, West Virginia)

Philadelphia Regional Office

General Information Center

Curtis Bldg, 625 Walnut St.

Philadelphia, PA 19106

(215) 597-2560 or 2528

(Use same 7-digit number for FTS)

- Baltimore Area Office (Maryland, except Montgomery and Price Georges Counties)

Everett Rothschild

Mercantile Bank and Trust Bldg.

Two Hopkins Plaza

Baltimore, MD 21201

(301) 962-2121 (Use same 7-digit number for FTS)

District of Columbia Area Office (District of

Columbia, Montgomery and Prince Georges Counties

in Maryland, and northern Virginia State)

James E. Clay

Universal North Bldg.

1875 Connecticut Ave., N.W.

Washington, DC 20009

(202) 673-5837

Philadelphia Area Office (eastern Pennsylvania,

Delaware)

Abner Rappoport

Curtis Bldg., Room 892

625 Walnut St.

Philadelphia, PA 19106

(215) 597-2665 or 2633

(Use same 7-digit number for FTS)

Pittsburgh Area Office (western Pennsylvania, Wẹst

Virginia)

Debra Krol

Two Allegheny Center, Room 1100

Pittsburgh, PA 15212

(412) 644-2802

FIS 722-2802

(412) $644-2818$

FTS $722-2818$

Richmond Area Office (southern Virginia State)

701 East Franklin St.

Richmond, VA 23219

(804) $782-2721$

Charleston Insuring Office (West Virginia)

New Federal Bldg.

500 Quarrier St.

Mailing address:

P.O. Bnx 2948

Charleston, WV 25330

(304) 343-6181
Wilmington Insuring Office (Delaware)

Farmers Bank Bldg.

919 Market St.

Wilmington, DE 19801

(302) $571-6330$

\section{Region 4}

(Alabama, Florida, Georgia, Kentucky, Mississippi, North Carolina, South Carolina, Tennessee)

Atlanta Regional Office (Georgia)

Room 211, Pershing Point Plaza

1371. Peachtree St., N.E.

Atlanta, GA 30309

(404) $526-5585$

Atlanta Area Office (Georgia)

1100 Peachtree Center Bldg.

230 Peachtree St., N.W.

Atlanta, GA 30303

(404) $526-4576$

Birmingham Area Office (Alabama)

Daniel Bldg., 15 South 20th St.

Birmingham, AL 35233

(205) 325-3264

Columbia Area Office (South Carolina)

1801 Main St., Jefferson Square

Columbia, SC 29202

(803) $765-5591$

Greensboro Area Office (North Carolina)

2309 West Cone Blvd., Northwest Plaza

Greensboro, NC 27408

(919) 275-9111

Jackson Area Office (Mississippi)

101-C Third Floor Jackson Mall

300 Woodrow Wilson Ave., West

Jackson, MS 39213

(601) 366-2634

Jacksonville Area Office (Florida)

Peninsular Plaza, 661 Riverside Ave.

Jacksonville, FL 32204

(904) $791-1616$

Knoxville Area Office (Tennessee)

1 Northshore Bldg., 1111 Northshore Dr.

Knoxville, TN 37919

(615) $584-8527$

Louisville Area Office (Kentucky)

Virgil G. Kinarel

Children's Hospital Foundation Bldg.

601 South Floyd St., P.O. Box 1044

Louisvillc, KY 40201

(502) $582-5251$ 
Memphis Insuring Office (western Tennessee State) $100 \mathrm{~N}$ : Main St.

Memphis, TN 38103

(901) 534-3143

Nashville Insuring Office (central Tennessee State) 801 Broadway

Nashville, TN 37203

(615) 749-5521

Tampa Insuring Office (central Florida State) 224028 Henderson Blvd.

P.O. Box 18165

Tampa, FL 33679

(813) 228-1501

\section{Region 5}

(Illinois, Iiidiäna, Michigan, Mllnnesora, Ühió, Wiscunsiil)

Chicago Regional Office

300 South Wacker Dr.

Chicago, IL 60606

Referral No. (312) 353-5680

FTS $353-5680$

Chicago Area Office (Illinois)

Edward Bush

17 N. Dearborn St., Room 1201

Chicago, IL 60602

(312) 353-7660 or 6979

(Use same 7-digit number for FTS)

Columbus Area Office (Ohio)

60 East Main St.

Culumbus, $\mathrm{OH} 43215$

(614) $469-7345$

Detroit Area Office (Michigan)

Kenneth Barnard

McNamara Federal Bldg.

Michigan Ave., 17th Floor

Detroit, MI 48226

(313) 226-7900 (Use same 7-digit number for FTS)

Indianápolis Area Öffice (Indiana)

Choice Elwalds

Willowbrook 5 Bldg.

Room 301, 4720 Kingsway Dr.

Indianapolis, IN 46205

(317) $269-6303$

FTS 331-6303

Milwaukee Area Office (Wisconsin)

744 North 4th St.

Milwaukee, WI 53203

(414) 224-3221
Minneapolis-St. Paul Area Office (Minnesota)

Margaret Wolszon

Griggs-Midway Bldg.,

1821 University Ave.

St. Paul, MN 55104

(612) $725-4701$ or 4801

(Use same 7-digit number for FTS)

Cincinnati Insuring Office (southwestern Ohio State) 9009 Federal Office Bldg., 550 Main St.

Cincinnati, $\mathrm{OH} 45202$

(513) 684-2884

Cleveland Insuring Office (northern Ohio State)

777 Rockwell

Cleveland, $\mathrm{OH} 44114$

(216) $552-4065$

Grand Rapids Insuring Office (wçstern and

northern Michigani 3 lale)

Pdüillibiuuk Bluy., INu. 11

2922 Fuller Ave., N.E.

Grand Rapids, MI 49505

(616) 456-2225

Springfield Insuring Office (central and southern Illinois State)

Lincoln Tower Plaza

542 South Second St., Room 600

Springfield, IL 62704

(217) 525-4414

\section{Region 6}

(Atkảnsảs, Louısıana, New Mexico, Oklahıma, Texas)

Fort Worth Regional Office

Jackie Bransford

1100 Commerce St.

Dallas, TX 75242

(214) $749-7401$ or 7406

(Use same 7-digit number for FTS)

Dallas Area Office (New Mexico; castern, northern, and western Texas)

2001 Bryan Tower, 4th Floor

Dallas, TX 75201

(214) $749-1601$

FTS 740-1601

Public Information: (214) 749-1625

(Use same 7-digit number for FTS)

Little Rock Area Office (Arkansas and

Bowie County, Texas)

Sterling R. Cockrill, Jr.

Union National Bank Bldg., One Union Nationall Plaza

Little Rock, AR 72201

(501) 378-5401

FTS 740-5401 
New Orleans Area Office (Louisiana)

Bruno Lohrmann

Plaza Tower, 1001 Howard Ave.

New Orleans, LA 70113

(504) 589-2063

FTS 682-2063

Oklahoma City Area Office (Oklahoma)

Maxwell D. Harris

301 North Hudson St.

Oklahoma City, OK 73102

(405) 231-4891 or 4168

FTS 736-4168

San Antonio Area Office (Southwest Texas)

Finnias E. Jolly (Area Director)

James Byam (Deputy Director) .

Kallison Bldg., 410 South Main Ave.

P.O. Box 9163

San Antonió, TX 78285

(512) 229-6800

FTS $730-6800$

Albuquerque Insuring Office (New Mexico)

625 Truman St., N.E.

Albuquerque, NM 87110

(505) 766-3251

\section{.}

Fort Worth Insuring Office (northcentral Texas State) 13A0l Federal Bldg.

819 Taylor St.

Fort Worth, TX 76102

(817) $334-3233$

Houston Insuring Office (East Central Texas State)

Two Greenway Plaza East

Houston, TX 77046

(713) 226-4335

Lubbock Insuring Office (Northwest Texas State)

514 Courthouse and Federal Ottice Bldg.

1205 Texas Ave., P.O. Box 1647

Lubbock, TX 79408

(806) $762-7265$

Shreveport Insuring Office (northern L.nuisiana and 5 counties in eastern Texas)

New Federal Bldg.

500 Fannin, 62nd Floor

Shreveport, LA 71120

(318) 226-5011

Tulsa Insuring Office (eastern Oklahoma State)

1708 Utica Square, P.O. Box 52554

Tulsa, OK 74152

(918) $581-7435$

\section{Region 7}

(Iowa, Kansas, Missouri, Nebraska)

Kansas City Regional Office

300 Federal Office BIdg.

911 Walnut St.

Kansas City, MO 64106

(816) 374-2661

FTS 758-2661

Public Information Desk: (816) 374-4391

FTS 758-4391

Kansas City Area Office (Kansas, western Missouri)

Carleta Foltz.

Two Gateway Center, 4th and State St .

Kansas City, KS 66101

(816) 374-4355

FTS $758-4355$

(816) $374-4220$

FTS 7584220

Omaha Area Office (lowa, Nebraska)

Sue Burkett

Univac Bldg., 7100 West Center Rd., 3rd Floor

Omaha, NE 68106

(402) 221-9301

FTS 864-9301

(402) 221-9345

FTS 864-9345

St. Louis Area Office (eastern Missouri)

Craig Rydgig

210 North 12th St.

St. Louis, MO 63101

(314) $622-4761$

FTS 279-4761

Des Moines Insuring Office (lowa)

259 Federal Bldg.

210 Walnut St.

Des Moines, IA 50309

(515) 284-4512

'Topeka Insuring Office (Kansas, except Johnson and Wyandotte Counties) 700 Kansas Ave.

Topeka, KS 66603

(913) 234-8241

\section{Region 8}

(Colorado, Montana, North Dakota. South Dakota, Utah, Wyoming)

Denver Regional Office

2500 Executive Towers, 1405 Curtis Si.

Denver, CO 80202

(303) 837-4881

FTS 327-2391 
Casper Insuring Office (Wyoming)

Federal Office Bldg.

100 East B St.

Casper, WY 82601

(307) $265-5550$

Denver Insuring Office (Colorado)

4th Floor Title Bldg., 909 17th St.

Denver, CO 80202

(303) 837-2441

Fargo Insuring Office (North Dakota)

Federal Bldg.

653 2nd Ave., N.

P.O. Box 2483

Fargo, ND 58102

(701) 237-5136

Helena Insuring Office (Montana)

616 Helena Ave.

Helena, MT 59601

(406) 442-3237

Salt Lake City Insuring Office (Utah)

125 South State St.

P.O. Box 11009

Salt Lake City, UT 84111

(801) 524-5237

Sioux Falls Insuring Office (South Dakota) 119 Federal Bldg., U.S. Courthouse

400 S. Phillips Ave.

Sioux Falls, SD 57102

(605) 336-2223

\section{Region 9}

(Arizona, California, Hawaii, Nevada, Guam, American Samoa, Pacific Trust Territories)

San Francisco Regional Office

450 Golden Gate Ave., P.O. Box 36003

San Francisco, CA 94102

(415) 556-4752

Los Angeles Area Office (Arizona, soúthern

California)

Gilbert Meza

2500 Wilshire Blvd.

Los Angeles, C.A 900.57

(213) 688-5973 or 3836

FTS 798-3836
San Francisco Area Office (northern California, Hawaii, Nevada, Guam, American Samoa, Pacific Trust Territories)

Suite 1600, 1 Embarcadero Center

San Francisco, CA 94111

(415) 556-2238 (Use same 7-digit number for FTS)

Public Information: (415) 556-5900

(Use same 7-digit number for FTS)

Honolulu Insuring Office (Hawaii, Guam, American

Samoa)

1000 Bishop St., P.O. Box 3377

Honolulu, HI 96813

(808) $546-2136$

Phoenix Insuring Office (Arizona)

244 W. Osborn Rd., P.O. Box 13468

Phoenix, AZ 85002

(602) 261-3900

Reno Insuring Office (Nevada)

1050 Bible Way, P.O. Box 4700

Reno, NV 89505

(702) $784-5356$

Sacramento Insuring Office (northeastern California)

$801 \mathrm{l} \mathrm{St}$.

P.O. Box 1978

Sacramento, CA 95809

(916) 449-3471

San Diego Insuring Office (Imperial and

San Diego Counties, California)

110 West C St., P.O. Box 2648

San Diego, CA 92112

(714) $293-5310$

Santa Ana Insuring Office (Orange, Riverside, and San Bernardino Counties, California, for home mortgages)

1440 East First St.

Santa Ana, CA 92701

(714) $836-2451$

\section{Region 10}

(Alaska, Idaho, Oregon, Washington)

Seattle Regional Office

Merrill Ash

Arcade Plaza Bldg., 1321 Second Ave., Stop 329

Seattle, WA 98101

(206) $442-5415$

FTS $399-5415$

(216) 442-0934

FTS 399-0934 
Portland Area Office (southern Idaho, Oregon, Washington Counties of Clar, Klickitat, and

Skamania)

Harold Stephens

520 Southwest 6 th Ave.

Portland, OR 97204

(503) 221-2561

FTS $423-2561$

(503) 221-2552

FTS 423-2552

Seat le Area Office (Alaska, northern Idaho, Washington except Clark, Klickitat, and Skamania Counties)

Richard Berinck

Arcade Plaza Bldg.

1321 Second Ave., Stop 409

Seattle, WA 98101

(206) $442-7456$

FTS 399-7456

Anchorage Insuring Office (Alaska)

334 W. 5th Ave.

Anchorage, AK 99501

(907) 272-5561

Boise Insuring Office (west-central Idaho, Baker and Malheur Counties in Oregon)

331 Idaho St., P.O. Box 32

Boise, ID 83707

(208) 342-2711

Spokane Insuring Office (northern Idaho, eastern

Washington)

920 Riverside Ave., West

Spokane, WA 99201

(509) 456-2510

\section{ECONOMIC DEVELOPMENT}

\section{ADMINISTRATION REGIONAL OFFICES}

\section{Colorado}

(Rocky Mountain: Colorado, lowa, Kansas, Missouri, Montana, Nebraskà, North Dakota, South Dakota, Utah, Wyoming)

Craig Smith, Regional Director

Suite 505, Title Bldg., 909 17th St .

Dénver, CO 80202

(303) $837-4717$

FTS $327-4717$

\section{Georgia}

(Southeastern: Alabama, Florida, Georgia, Kentucky, Mississippi, North Carolina, South Carolina,

Tennessee)

Ann Crighton, Regional Director

Suite 700

1365 Peachtree St., N.E.

Atlanta, GA 30309

(404) 881-7401

FTS $257-7401$

Illinois

(Midwestern: Illinois, Indiana, Michigan, Minnesota, Ohio, Wisconsin)

Edward Jeep, Regional Director

175 W. Jackson Blvd., Suite A 1630

Chicago, IL 60604

(312) 353-7706 (Use same 7-digit number for FTS)

\section{Pennsylvania}

(Atlantic: Connecticut, Delaware, District of Columbia, Maine, Maryland, Massachusetts, New Hampshire, New Jersey, New York, Pennsylvania, Puerto Rico, Rhode Island, Vermont, Virgin Islands, Virginia, West Virginia)

John E. Corrigan, Regional Director

10424 Federal Bldg.

600 Arch St.

Philadelphia, PA 19106

(215) 597-4603 (Use same 7-digit number for FTS)

Texas

(Southwestern: Arkansas, Louisiana, New Mexico, Oklahoma, Texas)

Joseph B. Swanner, Regional Director

Suite 600, American Bank Tower

221 West Sixth St.

Austin, TX 78701

(512) $397-5461$

FTS 734-5461

\section{Washington}

(Western: Alaska, American Samoa, Arizuna,

California, Guam, Hawaii, Idaho, Nevada, Oregon, Washington)

Phyllis Lamphere, Regional Director

1700 Westlake Ave., North, Suite 500

Seattle, WA 98109

(206) 442-0596

FTS 399-0596 


\section{THIS PAGE}

\section{WAS INTENTIONALLY \\ LEFT BLANK}




\section{APPENDIX F}

\section{Bibliography}

- General

- Conversion

- Coproducts

- Design

- Distillation

- Economics

- Energy Balance

- Environmental Conslderations

- Feedstocks

- Fermentation

- International

- Regulatory

- Transportation Use 


\section{GENERAL}

\section{Introductory}

Pimental, D. et al.; 1975 (November 21) "Energy and Land Constraint in Food Production; Science. Vol. 190 (no. 4126): pp. 754-761.

Solar Energy Research Institute. 1980. Fuel from Farms: A Guide to Small-Scale Ethanol Production. Golden, Co. SERI. Stock No. 061-000-00372-0. Available from: Superintendent of Documents of U.S. Government Printing Office, Washington, DC 20402.

U.S. Department of Agriculture. 1980. Small-Scale Fuel Alcohol Production. Washington, DC: USDA. Stock no. 001-000-04124-0. Available from: Superintendent of Documents, U.S. Government Printing Office, Washington, DC. 20402 .

\section{Reports}

Baratz B., Oullette, R., Park, W., Stokes, B. 1975 (November). Survey of Alcohol Fuel Technology. Volume I. McLean, VA: Mitre Corporation. Report No. PB-256007. 117p. Available from: National Technical Information Service, 5285 Port Royal Road, Springfield, VA 22161

Freeman, J. H. et al. 1976 (July). Alcohols - A Technical Assessment of Their Application as Fuels. Washington, DC: American Petroleum Institute. Publication no. 4261 . 32 p. Available from: American Petroleum Institute, 2101 L Street, N.W., Washington, DC 20037

Office of Technology Assessment. 1979. Gasohol - A Technical Memorandum. Washington, DC: OTA, U.S. Congress. Stock No. 052-003-00706-1. Available from: Superintendent of Documents, U.S. Government Printing Office, Washington, DC 20402

Park, W., Price, E., Salo, D. 1978 (August) Blomass-Based Aicohol Fuels: The Near Term Potential for Ust with Gasoline McLean, VA: Mitre Corporation. Report no. HCP/T4101-3. 84 p. Available from: National Technical Information Service, 5285 Port Royal Road, Springfield, VA 22161.

Proceedings of the Third International Symposium on Alcohol Fuels Technology. 1980. Asilomar, California; May 29-31, 1979. Washington, DC: U.S. Department of Energy. Report no. CONF-790520. Available from: National
Technical Information Service, 5285 Port Royal Road, Springfield, VA 22161.

U.S. Department of Energy. 1979 (June) The Report of the Alcohol Fuels Policy Review: Washington, DC: US DOE. Report no. DOE/PE-0012.119p. Available from National lechnical Intormation Service, 5285 Port Royal Road, Springfield, VA 22161.

\section{Books}

Cheremisnoff, N.P. 1979 Gasohol for Energy Production. Ann Arbor, MI: Ann Arbor Science. $140 \mathrm{p}$.

Paul, J.K. 1979 Ethyl Alcohol Production and Use as A Motor Fuel. Chemical Technology Review. No. 144. Park Ridge, NJ: Noyes Data Corporation. $354 \mathrm{p}$.

\section{Magazines}

Alcohol Update. Semi-monthly. August 1980t. $\$ 25.00 /$ yr. Available from: Alcohol Update, P.O. Box 35211, Minneapolis, MN 55435.

Biomass Digest. Monthly \$87.00/yr. Available from: Technical Insights, P.O. Box 1304, Fort Lee, NJ 07024.

Alcohol Week. Weekly-December 1980+. $\$ 245.00 / y r$. Available from; Alcohol Week, P.O. Box 7167, Benjamin Franklin Station, Washington, DC. 20044

Biotimes. Bimonthly, January 1979+; 10.00/yr. Available from: International Biomass Institute, 1522 K St.; N.W., Suite 600, Washington, DC 20005.

Gasohol USA Monthly; June 1979+, \$12.00/yr. Available from: Box 9547, Kansas City, MO 64133.

\section{Congressional Hearings.}

U.S. House of Representatives. Ninety-fifth Congress, Second Session. Alcohol Fuels: Hearings Before the Subcommittee on Advanced Energy Technologies and Energy Conservation Research, Development and Demonstration of the Committee on Science and Technology. Washington, DC: U.S. House of Representatives; 11-13 July 1978. Stock no. 35-520. Available from: House Committee on Science and Technology. Room 3154, House Annex \#2, Washington, DC 20515. 
U.S. House of Representatives. Ninety-sixth Congress, First Session. National Fuel Alcohol and Farm Commodity Production Act of 1979: Hearings Before the Subcommittees on Conservation and Credit Department Investigations Oversight and Research, and Livestock and Grains, of the Committee on Agriculture. Washington, DC: U.S. House of Representatives; 15-16 May 1979. Stock No. 052-070-05071-3. Available from: Superintendent of Documents, U.S. Government Printing Office, Washington, DC 20402.

U.S. House of Representatives. Ninety-sixth Congress, First Session. Oversight - Alcohol Fuel Options and Federal Policies. Hearings Before the Subcommittee on Energy Development and Applications of the Committee on Science and Technology. Washington, DC: U.S. House of Representatives. 4 May, 12 June 1979. Stock No. 49-650. Available from: Superintendent of Documents, U.S. Government Printing Office, Washington, DC 20402.

U.S. Senate. Ninety-fifth Congress, Second Session. Alcohol Fuels: Hearing Before the Committee on Appropriations. Washington, D.C. U.S. Scnate. 13 January 1978. Stock no. 052-070-04679-1. Available from: Superintendent of Documents, U.S. Government Printing Office, Washington, DC 20402.

U.S. Senate. Ninety-fifth Congrss, Second Session. The Gasohol Motor Fuel Act of 1978: Hearings Before the Subcommittee on Energy Research and Development of the Committee on Energy and Natural Resources. Washington, DC: U.S. Senate. 7-8 August 1978. Publication No. 95-165. Available from: Superintendent of Documents, U.S. Government Printing Office, Washington, D C 20402.

\section{BIBLIOGRAPHY}

National Technical Information Service. 1979 (July). Alcohol Fuels: (Citations from the NTIS Data Base), Volume 1 1964-1977. Washington, DC: NTIS Report no. NTIS/PS-79/0712. 170p. Available from: National Technical Information Service, 5285 Port Royal Road, Springfield, VA 22161.

National Technical Information Service. 1979 (July): Alcohol Fuels (Citations from the NTIS Data Base), Volume 2, 1978-June 1979. Washington, DC: NTIS. Report No. NTIS/PS-79/0713. 144 p. Available from: National Technical Information Service, 5285 Port Royal Road, Springfield, VA 22161.
National Technical Information Service. 1979 (July). Alcohol Fuels (Citations from the NTIS Data Base), Report for 1970-June 1979. Washington, DC: NTIS. Report no. NTIS/PS-79/0714. 247p. Available from: National Technical Information Service, 5285 Port Royal Road, Springfield, VA 22161.

\section{NATIONAL ALCOHOL FUELS COMMISSION REPORTS}

U.S. National Alcohol Fuels Commission "Farm and Cooperative Alcohol Plant Study: Technical and Economic Assessment as a Commercial Venture." 1980, 200 pp. Prepared by Raphael Katzen Associates International, Inc. Available from NTIS.

U.S. National Alcohol Fuels Commission. "Fuel Alcohol: Report and Analysis of Plant Conversion Potential to Fuel Alcohol Production." 1980, 123 pp. Prepared by Davy McKee Corporation. Available from NTIS.

U.S. National Alcohol Fuels Commission. "Ethanol: Farm and Fuel Issues." 1980, 145 pp. Prepared by Schnittker Associates. Available from NTIS, Report No. PB 80-215692, \$11.00.

U.S. National Alcohol Fuels Commission. "Energy Balances in the Production"and End-Use of Alcohols Derived from Biomass." 1980, 75 pp. Prepared by TRW.

\section{Conversion}

Brushke, H. "Direct Processing of Sugarcane into Ethanol" in: Proceedings of the International Symposium of Alcohol Fuel Technology: Methanol and Ethanol. Wolfsburg, Federal Republic of Germany. November 21-23, 1977 Report No. CONF-771175, paper 5-5. Entire report available from: National Technical Information Service, 5285 Port Royal Road, Springfield, VA 22161

Nathan, R. A. 1978. Fuels from Sugar Crops: Systems Study for Sugarcane, Sweet Sorghum, and Sugar Beets. Oak Ridge, TN: Technical Information Center, U.S. Department of Energy. Report no. TID-22781. 137p. Available from: National Technical Information Service, 5285 Port Royal Road, Springfield, VA 22161.

\section{Coproducts}

Colorado State University, 1979. Analysis of Alcohol Fermentation By-Products for Livestock 
and Poultry Feeding in Colorado. Fort Collins, CO: Colorado State University. Available from: Department of Animal Sciences, Colorado State University, Fort Collins, CO 80523.

Paturau, J. M., 1969. By-products of the Cane Sugar Industry., Amsterdam, The Netherlands: Elsevier Publishing Co., 274p.

Reilly, P. J. 1978 Conversion of Agricultural ByProducts to Sugars, Progress Report Ames, IA: Iowa State University, Available from: Department of Chemical Engineering, Engineering Research Institute, Iowa State University, Ames, Iowa. 50010.

Wisner, R. N. and Gidel, J. O. 1977 (June) Economics Aspects of Using Grain Alcohol as a Motor Fuel, with Emphasis on By-product Feed Murkets. Ames, 1A: Iowa Agriculture Experiment Station. Report no. 9. Available from: Agriculture Engineering, Extension, Davidson Hall, Ames, IA, 50010.

\section{Design}

Brackett, A. T. et al. 1978 Indiana Grain Fermentation Alcohol Plant. Indianapolis, IN: Department of Commerce. 80p. Available from: Indiana Department of Commerce, State House, Room 336, Indianapolis, IN 46204.

Chambers, K.S. 1979 The Small-Fuel-Alcohol Distillery: General Description and Economic Feasibility Workhook. Urbana, IL: ACR Process Corporation. 21p. Availahle from: ACR Process Corporation, $808 \mathrm{~S}$. Lincoln Ave., Urbana, IL 61801 .

Grain Motor Fuel Alcohol Technical and Economic Assessment Study. 1978 (December). Cincinnati, OH: Raphael Katzen Associates. Report no. HCP/J6639-01. 341p. Available from: National Technical Information Service, 5285 Port Royal Road, Springfield, VA 22161.

\section{Distillation}

King, C. J. 1971. Separation Process. New York, NY: McGraw Hill Book Publishing Co. 809 p.

Tassios, D. P. 1972. "Rapid Screening of Extractive Distillation Solvents." Extractive and Azeotropic Distillation. Advances in Chemistry Series, No. 115. Washington, DC: American Chemical Society. pp. 46-63.
McCabe, W. and Smith, J. C. 1976 Unit Operatons in Chemical Engineering 3rd Edition. New York, NY: McGraw Hill Book Publishing Co. 1028 p.

\section{ECONOMICS}

David, M. L., et al. 1978 (July) Gasohol: Economic Feasibility Study-Final Report. Manhattan, KS: Development Planning and Research Associates, Inc. Report no. SAN-1681T1. 280p. Available from: National Technical Information Service, 5285 Port Royal Road, Springfield, VA 22161.

Gasohol from Grain-The Economic Issues. 1978 (January 19). Washington, DC: Economics, Statistics and Cooperative Service. Report no. PB280120/7ST. 23p. Available from: National Technical Information Service, 5285 Pnrt Royal Koad, Springfield, VA 22161.

\section{ENERGY BALANCE}

Alich, J.A., et al. 1978 (January). An Evaluation of the Use of Agricultural Residues as an Energy Feedstock: $A$ Ten Site Survey. Palo Alto, CA: Stanford Rcsearch Institute - International. Report no. TID-27904/2. 402p. Available from: National Technical Information Service, 5285 Port Royal Road, Springfield, VA 22161.

Commoner, Barry. 1979 (July 23) Testimony before United States Senate Committee on Agriculture, Nutrition and Forestry, Subcommittee on Agricultural Research and General Legislation on "The Potential for Energy Production by U.S. Agriculture." St. Louis, MO: Center for the Biology of Natural Systems, Washington University. Report No. CBNS-AEP-5. Available from: Center for the Biology of Natural Systems, Washington University, St. Louis, Mo.

Ladisch, M. R., Dyck, K. 1979 (August 3). "Dehydration of Ethanol: New Approach Gives Positive Energy Balance." Science. Vol. 205 (no. 31): pp. 898-900.

Lewis, C. W. 1977 (September). "Fuels from Biomass-Energy Outlays vs. Energy Returns: A Critical Appraisal." Energy Vol. 2 (no. 3): pp. 241-248.

\section{ENVIRONMENTAL CONSIDERATIONS}

Aerospace Corporation. 1980 (June). Environmental Control Perspective for Ethanol Production from Biomass. (Draft). Germantown, MD: Report no. ATR-80 (7848-01)-1. 
Brown, D., McKay, R., and Weir, W. 1976. "Some Problems Associated with the Treatment of Effluents from Malt Whiskey Distilleries. Progress in Water Technology. Vol. 8 (no. 2/3): pp. 291-300.

Council on Environmental Quality. 1979 (December). Environmental Quality: The Tenth Annual Report of the Council of Environmental Quality. Washington, DC.

Hagey, G., et al. "Methanol and Ethanol Fuels: Environmental, Health and Safety Issues," in: Proccedings of the International Symposium on Alcohol Fuel Technology: Methanol and Ethanol. Wolfsburg, Federal Republic of Germany. November 21-23, 1977. Report no. CONF-771175, paper 8-2. Entire report available from: National Technical Information Service, 5285 Port Royal Road, Springfield, VA 22161.

Jackson, E. A. 1977 (April). “Distillery Effluent Treatment in the Brazilian National Alcohol Programme" Chemical Engineer. no. 319: pp. 239-242.

Kant, F.H. et al.1974. Feasibility Studies of Alternative Fuels for Automotive Transportation. Washington, DC: U.S. Environmental Protection Agency. Report no. EPA-460/374-009. Available from: National Technical Information Service. 5285 Port Royal Road, Springfield, VA 22161.

Grain Motor Fuel Alcohol Technical and Economic Assessment Study. 1978 (December). Cincinnati, OH: Raphael Katzen Associates. Report no. HCP/J6639-01. 341p. Available from: National Technical Information Service, 5285 Port Royal Road, Springfield, VA 22161.

Lee, Linda K. 1978. A Perspective on Cropland Availability. Washington, DC: Economics, Statistics, and Cooperative Services, U.S. Department of Agriculture. Report no. 406. 23 p. Available from: Superintendent of Documents, U.S. Government Printing Office, Washington, DC 20402.

Lowrey, S. P. and Deroto, R. S. 1976. "Exhaust Emissions frum a Single Cylinder Engine Fueled with Gasoline, Methanol, and Ethanol." Combustion Science and Technology. Vol. 12 (no. 4, 5, 6): pp. 177-182.

A. J. Moriarty. Toxicological Aspects of Alcohol Fuel Utilization in: Proceedings of the International Symposium on Alcohol Fuel Technology: Methanol and Ethanol. Wolfsburg, Federal
Republic of Germany. November 21-23, 1977. Report no. CONF-771175, paper 8-1. Entire report available from: National Technical Information Service, 5285 Port Royal Road, Springfield, VA 22161 .

Scarberry, R.M. and Papai, M.P, 1980 (January). Source Test and Evaluation Report: Alcohol Synthesis Facilty for Gasohol Production. McLean, VA: Radian Corporation. Available from Radian Corporation.

Sittig, M. 1979. Hazardous and Toxic Effects of Industrial Chemicals. Park Ridge, NJ: Noyse Data Corporation.

Office of Technology Assessment. 1979. Gasohol-A Technical Memorandum. Washington, DC: OTA, U.S. Congress. Stock no. 052-003-00706-1. Available from: Superintendent of Documents, U.S. Government Printing Office, Washington, DC 20402.

Unger, S. G. 1977 (October). Environmental Implications of Trends in Agriculture and Silviculture, Volume 1: Trend Identification and Evaluation. Manhattan, KS: Development Planning and Research Associates. Report no. PB-274-233. 232 p. Available from: National Technical Information Service, 5285 Port Royal Road, Springfield, VA 22161.

U.S. Environmental Protection Agency. 1978 (December). Report to Congress, Industrial Cost Recovery. Washington, DC: Office of Water Program Operations. Report no. PR80-204746. 61p. Available from: National Technical Information Service, 5285 Port Royal Road, Springfield, VA 22161.

\section{FEEDSTOCKS}

Atchison, J. E. 1977. Preliminary Investigation of New Process for Separation of Components of Sugarcane Sweet Sorghum, and Other Plant Stalks. Columbus, OH: Battelle. Report no. TID-28734. 315 p. Available from: National Technical Information Service, 5285 Port Royal Road, Springfield, VA 22161.

Atlas of Nutritional Data of United States and Canadian Feeds. 1971. Washington, DC: National Academy of Science. 772 p.

Chubey, B. B. and Dorrell, D. G. 1974. "Jerusalem Artichoke A Potential Fructose Crop for the Prairies" Journal of the Canadian Institute of Food Science Technolugy. Vol. 7 (no. 2): pp. 98-100. 
Jones, J.L. 1978 (December). Mission Analysis for the Federal Fuels from Biomass Program. Volume 1: Summary and Conclusions. Menlo Park, CA: Stanford Research Institute International. Report no. SAN-0115-T2. 76 p. Available from: National Technical Information Service, 5285 Port Royal Road, Springfield, VA 22161.

Hertzmark, D. 1980 (March). Agricultural Sector Impacts of Making Ethanol from Grain. Golden, CO: Solar Energy Research Institute. Report no. SERI/TR-352-554. 64p. Available from: National Technical Information Service, 5285 Port Royal Road Springfield, VA 22161

Lee, Linda K. 1978. A Perspective on Cropland Availability. Washington, DC: U.S. Department of Agriculture. Report no. 406. 23 p. Available from: Superintendent of Documents. U.S. Government Printing Offiçe. Washington, nr. 20402.

Lipinsky, E. S. et al. 1977 (July 29). Fuels from Sugar Crops: First Quarterly Report. Columbus, OH: Battelle. Report no. TID-28414. 140p. Available from: National Technical Information Service, 5285 Port Royal Road, Springfield, VA 22161.

Lipinsky, E. S. et al., 1977 (October 31).Fuels from Sugar Crops-Second Quarterly Report. Columbus, OH: Battelle. Report no. TID-27834. 160p. Available from: National Techniçal Information Service, 5285 Port Royal Road, Springfield, VA 22161

Lipinsky, E.S. et al. 1978. Fuels from Sugar Crops-Third Quarterly Report. Columbus, OH: Battelle. Report no. TID-28191. Available from: National Technical Information Service, 5285 Port Royal Road, Springfield, VA 22161.

Lipinsky, E. S. et al. 1977 (March). Systems Study of Fuels from Sugarcane, Sweet Sorghum, and Sugar Beets. Volume 1: Comprehensive Evaluation. Columbus, OH: Battelle Report no: BMI 1957 (Vol. 1). 167p. Available from: National Technical Information Service 5285 Port Royal Road, Springfield, VA 22161.

Lipinsky, E.S. et al. 1976 (December 31). Systems Study of Fuels from Sugarcane, Sweet Sorghum, and Sugar Beets. Volume 2: Agriculture Considerations. Columbus, $\mathrm{OH}$ : Battelle. Report no. BMI-1957 (Vol. 2) 245 p. Available from: National Technical Information Service, 5285 Port Royal Road, Springfield, VA 22161
Lipinsky, E. S. et al. 1976 (December 31). Systems Study of Fuels from Sugarcane, Sweet Sorghum, and Sugar Beets. Volume 3: Conversion to Fuels and Chemical Feed Stocks. Columbus, $\mathrm{OH}$ : Battelle. Report no. BMI-1957 (Vol. 3). 175 p. Available from: National Technical Information Scrvice, 5285 Puil Ruyal Road, Springfield, VA 22161

Lipinsky, E. S. et al. 1977 (March 31). Systems Study of Fuels from Sugarcane, Sweet Sorghum, and Sugar Beets. Volume 4: Corn Agriculture. Columbus, OH: Battelle. Report no. BMI-1957A (Vol. 4). 203 p. Available from: National Technical Information Service, 5285 Port Royal Road, Springfield, VA 22161.

Lipinsky, E. S. et al. 1977 (March 31) Systems Study of Fuels from Sugarcane, Swret Sorghum, Sugar Beets, and Corn. Vnlume 5: Comprchcnsive Evaluation of Corn. Columbus, $\mathrm{OH}$ : Battelle Report no. BMI-1957A (Vol. 5). 168 p. Available from: National Technical Information Service, 5285 Port Royal Road, Springfield, VA 22161.

Nathan, R.A. 1978. Fuels from Sugar Crops: Systems Study for Sugar Cane, Sweet Sorghum, and Sugar Beets. Oak Ridge, TN: Technical Information Center, U.S. Department of Energy. Report no. TID-22781. 137p. Available from National Technical Information Service, 5285 Port Royal Road, Springfield, VA 22161.

U.S. Department of Agriculture 1979 Agricultural Statistics, 1979. Washington, DC: USDA. Stock no. 001-000-03775-7. Availahle from: Superintendent of Documents, U.S. Government Printing Office, Washington, DC 20402.

\section{FERMENTATION}

Engelbart, W. "Basic Data on Continuous Alcoholic Fermentation of Sugar Solutions and of Mashes from Starch Containing. Raw Materials " in: Proceedings of the International Symposium on Alcohol Fuel Technology: Methanol and Ethanol. Wolfsburg. Federal Republic of Germany. November 21-23, 1977. Report no. CONF-7/1175, paper 5-3. Entire report available from: National Technical Information Service, 5285 Port Royal Road, Springfield, VA. 22161.

Lipinsky, E. S. et al. 1979 (June 4).Systems Study of the Potential Integration of U.S. Corn Production and Cattle Feeding with Manufacture of Fuels via Fermentation. Columbus, $\mathrm{OH}$ : Battelle. Report no. BMI-2033. 147 p. Available from National Technical Information Service, 5285 Port Royal Road, Springfield, VA 22161. 
Miller, D.L. "Ethanol Fermentation and Potential.''in: Wilke, C. R., ed. Biotechnology and Bioengineering Symposium No. 5. Cellulose as a Chemical and Energy Resource Conference. Berkeley, CA, June 25-27, 1974. New York NY: pp. 345-352. John Wiley and Sons.

\section{INTERNATIONAL}

Ribeiro, Filho F. A., "The Ethanol-Based Chemical Industry in Brazil" in: Workshop on Fermentation Alcohol for Use as Fuel and Chemical Feedstock in Developing Countries. Vienna, Austria. 26-30 March 1979. Paper No. ID/WG. 293/4 UNIDO. Available from: UN Publications, Room A 3315, New York, NY 10017.

Sharma, K.D. "Present Status of Alcohol and Alcohol Based Chemicals Industry in India." in: Workshop on Fermentation Alcohol for Use as a Fuel and Chemical Feedstock in Developing Countries. Vienna, Austria: 26-30 March 1979. Paper No. ID/WG.293/14 UNIDO Available from: UN Publications, Room A 3315, New York, NY 10017.

\section{REGULATORY}

Abeles, T. P. and King, Janna R. 1978 (February). Paramenters for Legislature Consideration of Bioconversion Technologies. St. Paul, MN: Minnesota Legislature Science and Technology Project. Report No. PB 284742/45T. 45 p. Available from: National Technical Information Project, 5285 Port Royal Road, Springfield, VA 22161.

Bureau of Alcohol, Tobacco and Firearms. Ethyl Alcohol for Fuel Use. Washington, DC: BATF. Brochure available from: BATF Distribution Center, 3800 S. Four Mile Run Drive, Arlington, VA 22206.

Bureau of Alcohol, Tobacco, and Firearms. 1979 (August). Alcohol Fuel and ATF. Washington, DC: BATF. Brochure No. ATF 5000.2. 4 p. Available from: ATF Distribution Center, 3800 S. Four Mile Run Drive, Arlington, VA 22206.

Denaturants for Ethanol/Gasoline Blends. 1978 (April). Baltimore, MD: Mueller Associates. Report No. HCP/M2098-01. 16 p. Available from: National Technical Information Service, 5285 Port Royal Road, Springfield, VA 22161.

"Fuel Use of Distilled Spirits-Inplementing a Portion of the Crude Oil Windfall Profit Tax Act of 1980 (Pub. L96-223); Temporary and Proposed Rule." 1980 (20 June) Federal Register. Vol. 45 (No. 121): pp. 41837-41850.

\section{TRANSPORTATION USE}

Adt, R. R. Jr., et al. 1978. Effects of Blending Ethanol with Gasoline on Automotive Engines Steady State Performance and Regulated Emissions Charctersssssstics. Troy, MI: Report No. CONF-7805102. p. 68-76. Entire report available from: National Technical Information Center, 5285 Port Royal Road, Springfield, VA 22161.

Allsup, J.R. and Eccleston, D.B. 1979 (May). Ethanol/Gasoline Blends as Automotive Fuel. Asilomar, CA: International alcohol fuels technology. Report No. BETC/R1-79/2. 13 p. Available from: National Technical Information Service, 5285 Port Royal Road, Springfield, VA 22161 .

Bernhardt, W. 1977. "Future Fuels and Mixture Preparation Methods for. Spark Ignition Automobile Engines." Progress in Energy and Combustion Science. Vol. 3 (no. 3): pp. 139-150.

Bushnell, D., Simonsen, J. M. 1976 “Alcohol Assisted Hydrocarbon Facilities: A Comparison of Exhaust Emissions and Fuei Consumption Using Study State and Dynamic Engine Test Facilities." Energy Communications. Vol. 2 (no. 2): pp. 107-132.

Ecklund, E.E. 1978 (May). Comparative Automotive Engine Operation When Fueled with Ethanol and Methanol. Washington, DC: U.S. Department of Energy. Report No. HCP/ W1737-01. 5 p. Available from: National Technical Information Service, 5285 Port Royal Road, Springfield, VA 22161.

Panchapakesan, N. R. and Gopalakrishnan, K. V. "Factors that Improve the Performance of an Etharıl-Diescl Oil Dual Fuel Engine." in: Proceedings of the International Symposium on Alcohol Fuel Technology: Methanol and Ethanol. Wolfsburg. Federal Republic of Germany November 21-23, 1977. Report No. CONF-771175, paper 2-2. Entire report available from: National Technical Information Service, 5285 Port Royal Road Springficld, VA 22161

Rutäl, Al. 1980 Alcohol Car Conversion. Minneapolis, MN: Rutan Publishing Co. 47 p.

Scott, W.M. "Alternative Fuels for Automotive Diesel Engines." in: Colucci, Joseph M. and Gallopoulos, Nicholas E., eds. 1977. Future Automotive Fuels; Prospects, Performance, Perspective. New York, NY: Plenum Press. pp. 263-290. 


\section{THIS PAGE \\ WAS INTENTIONALLY \\ LEFT BLANK}


APPENDIX G.

\section{Glossary}


AAFCO: Association of American Feed Control Officials

ABSOLUTE ALCOHOL: completely dehydrated ethyl alcohol of the highest proof obtainable $\left(200^{\circ}\right.$ proof); also "neat" alcohol. (See ANHYDROUS.)

ACID HYDROLYSIS: decomposition or alteration of a chemical substance by water in the presence of acid.

ACIDITY: the measure of how many hydrogen ions a solution contains per unit volume; may be expressed in terms of $\mathrm{pH}$.

AFLATOXIN: the substance produced by some strains of the fungus Aspergillus flavus; the most potent carcinogen yet discovered; a persistent contaminant of corn that renders ciüps uissalable.

AFO: Office of Alcohol Fuels.

ALCOHOL: the family name of a group of organic chemical compounds composed of carbon, hydrogen, and oxygen; a series of molecules that vary in chain length and are composed of a hydrocarbon plus a hydroxyl group, $\mathrm{CH}_{3}-\left(\mathrm{CH}_{2}\right) \mathrm{n}-\mathrm{OH}$; includes methanol, ethanol, isopropyl alcohol, and others; see ETHANOI..

defined in the Crude Oil Windfall Profit Tax Act of 1980 (26 USC 44E P.L. 96-223) to include "methanol and ethanol but does not include alcohol produced from petroleum, natural gas, or coal or alcohol with a proof less than $150 . "$

defined in the Energy Security Act (42 USC 8802, P.L. 96-294) as "alcohol (including methanol and ethainul) which is produced trom biomass and which is suitable for use by itself or in combination with other substances as a fuel or as a substitute for petroleum or petrochemical feed stocks."

ALCOHOL FUEL PLANT: under BATF regulations, a distilled spirits plant established solely for producing, processing, and using or distributing distilled spirits to be used extensively for fuel use.

ALCOHOL FUEL PRODUCER'S PERMITS: the document issued by BATF pursuant to the Crude Oil Windfall Profit Tax Act (26 USC 5181, P.L. 96-223) authorizing the person named to engage in busincss as an alcohol fuel production facility.

ALDEHYDES: any of a class of highly reactive organic chemical compounds obtained by controlled oxidation of primary alcohols, characterized by the common group $\mathrm{CHO}$, and used in the manufacture of resins, dyes, and organic acids.
ALKALI: soluble mineral salt of a low-density, lowmelting point, highly reactive metal; characteristically "basic" in nature.

ALPHA-AMYLASE: enzyme which liquefies starch by conversion to dextrins.

AMBIENT: the prevalent surrounding conditions usually expressed as functions of temperature, pressure, and humidity.

AMINO ACIDS: the naturally occurring, nitrogencontaining building blocks of protein.

AMYLACEOUS FEEDSTOCKS: materials, such as cereal grains and potatoes, that are composest of salcharides in the form of starches.

AMYLAGE: any of the enzymes that accelerate the hydrolysis of starch and glycogen.

AMYLODEXTRINS: see DEXTRINS.

ANAEROBIC DIGESTION: a type of bacterial degradation of nrganic matter that occurs in the absence of air (oxygen) and produces primarily carbon dioxide and methane.

ANHYDROUS: devoid of water; refers to a compound that does not contain water either absorbed on its surface or as water of rrystallization.

ANHYDROUS ETHANOL: 100-percent alcohol, neat alculıul, $200^{\circ}$-proof alcohol.

APPARENT PROOF: the proof indicated by a hydrometer after correction for temperature hut without correction of the obscuration caused by the presence of solids.

ATF: Should refer to BATF (Bureau of Alcohol Tobacco and Firearms) for proper usage.

ATMOSPHERIC PRESSURE: pressure of the air (and atmosphere surrounding us) which changes from day to day; it is equal to 14.7 psia.

AZEOTROPE: the chemical term for two or more liquids that, at a certain concentration, boil as though they are a single substance; alcohol and water cannot be separated further than $194.4^{\circ}$ proof because at this concentration, alcohol and water form an azeotrope and vaporize togcther. 
AZEOTROPIC DISTILLATION: distillation in which a substance is added to the mixture to be separated in order to form an azeotropic mixture with one or more of the components of the original mixture; the azeotrope formed will have a boiling point different from the boiling point of the original mixture and will allow separation to occur.

BACKSET (also called set back): the liquid portion of the stillage recycled as part. of the process liquid in mash preparation.

BACTERIAL SPOILAGE: occurs when bacterial contaminants take over the fermentation process in competition with the yeast.

BAGASSE: the cellulosic residue left after sugar is extracted from sugar cane.

\section{BALLING HYDROMETER OR BRIX HYDRO-} METER: a triple-scale wine hydrometer designed to record the specific gravity of a solution containing sugar.

BANKABLE DEBT: debt which is sufficiently collateralized to allow financing through normal commercial bank channels.

BARREI:: a liquid measure equal to 42 American gallons or about 306 pounds of crude oil; one barrel equals 5.6 cubic feet or 0.159 cubic meters.

BASIC HYDROLYSIS: decomposition or alteration of a chemical substance by water in the presence of alkali.

BATCH FERMENTATION: fermentation of a specific quantity of material conducted from start to finish in a single vessel.

BATr: Burcau of Alcohol, Tobacrn, and Firearms, under the U.S. Department of the Treasury; responsible for the issuance of permits, for both experimental and commercial facilities, for the production of alcohol.

BEER: the product of fermentation by microorganisms; the raw fermented mash, which contains about 7 to $12 \%$ alcohol; usually refers to the alcohol solution remaining after yeast fermentation of sugars.

BEER STILL: the stripping section of a distillation column for concentrating ethanol, or the first column of a two (or more) column system, in which the first separation from the mash takes place.

BEER WELL: the surge tank used for storing beer prior to distillation.
BETA - AMYLASE: enzyme which converts dextrins into glucose.

BIOMASS: Organic matter, such as trees, crops, manure, and aquatic plants, that is available on a renewable basis.

defined in the Energy Security Act (42 USC 8802, P. L. 96-294) as "any organic matter which is available on a renewable basis, including agricultural crops and agricultural wastes and residues, wood and wood wastes and residues, animal wastes, municipal wastes, and aquatic plants."

BIOMASS ENERGY PROJECT: defined in the Energy Security Act (42 USC 8802, P. L. 96-294) as "any facility (or portion of a facility) located in the United States which is primarily for (a) the production of biomass fuel (and byproducts); or (b) the combustion of biomass for the purpose of genterating industrial process heat, mechanical power, or electricity (including cogeneration).

BIOMASS FUEL: defined in the Energy Security Act (42 USC 8802, P. L. 96-294) as "any gaseous, liquid, or solid fuel produced by conversion of biomass."

BOD: Biochemical Oxygen Demand; a measure of organic water pollution potential.

BOILING POINT: the temperature at which the transition from the liquid to the gaseous phase occurs in a pure substance at fixed pressure.

BOND: a type of insurance which gives the government security against possible loss of distilled spirits tax revenue; not required for alcohol fuel plants producing less than 10,000 proof gallons per year.

BRITISH THERMAL UNIT (Btu): the amount of heat required to raise the temperature of one pound of water one degree Fahrenheit under stated conditions of pressure and temperature (equal to 252 calories, 778 foot-pounds, 1055 joules, and 0.293 watt-hours); it is a standard unit for measuring quantity of heat energy.

BULK DENSITY: the mass (weight) of a material divided by the actual volume it displaces as a whole substance, expressed in $\mathrm{lb} / \mathrm{ft}^{3} ; \mathrm{kg} / \mathrm{m}^{3}$; etc.

CALORIE: the amount of heat required to raise the temperature of one gram of water one degree Centigrade.

CARBOHYDRATE: a chemical term describing certain neutral compounds made up of carbon, hydrogen, and oxygen; includes all starches and sugars; a general formula is $\mathrm{C}_{\mathbf{x}}\left(\mathrm{H}_{2} \mathrm{O}\right) \mathrm{y}$. 
CARBON DIOXIDE: a gas produced as a byproduct of fermentation; chemical formula is $\mathrm{CO}_{2}$.

CASSAVA: a starchy root crop used for tapioca; can be grown on marginal croplands along the southern coast of the United States.

CATALYSIS: the effect produced by a small quantity of a substance (catalyst) on a chemical reaction, after which the substance (catalyst) appears unchanged.

CELL RECYCLE: the process of separating yeast from fully fermented beer and returning it to ferment a new mash; can be done with clear worts in either batch or continuous operations.

CELLULASE: an enzyme capable of decomposing cellulose into simpler carbohydrates.

CELLULOSE: the main polysaccharide in living plants, forms the skeletal structure of the plant cell wall; can be hydrolyzed to glucose.

CELLULOSIC FEEDSTOCKS: materials, such as wood, crop stalks, and newsprint, containing sugar units linked by bonds that are not easily ruptured.

CELSIUS (Centigrade): a temperature scale commonly used in the sciences; at sea level, water freezes at $0^{\circ} \mathrm{C}$ and boils at $100^{\circ} \mathrm{C} . \mathrm{C}^{\circ}=5 / 9(\mathrm{~F}-32)$.

CENTRIFUGE: a rotating device for separating liquids of different specific gravities or for separating suspended colloidal particles according to particle-size fractions by centrifugal force.

CETANE NUMBER (cetane rating): measure of a fuel's ease of self-ignition; the higher the number the better the fuel for a diesel engine.

\section{CFR: Code of Federal Regulations}

COD: Chemical Oxygen Demand; a measure of water pollution.

COLLATERAL VALUE: the resale value of alcohol equipment and/or plants; specifically, the ability of the equipment to derive from sale the amount necessary to pay off the debt borrowed against the unit.

COLUMN: vertical, cylindrical vessel containing a series of perforated plates or packed with materials through which vapors may pass, used to increase the degree of separation of liquid mixtures by distillation or extraction.
COMPLETELY DENATURED ALCOHOL (CDA): ethyl alcohol which is at least $160^{\circ}$ proof blended, pursuant to formulas prescribed by BATF, with sufficient quantities of various denaturants to make it unfit for and not readily recoverable for beverage use; this may then be distributed through retail outlets without permits. (Compare to SPECIALLY DENATURED ALCOHOL).

COMPOUND: a chemical term denoting a specific combination of two or more distinct elements.

CONCENTRATION: ratio of mass or volume of solute present in a solution to the amount of solvent.

CONDENSER: a heat-transfer device that reduces a fluid substance from its vapor phase to its liquid phase by reducing its temperature as it contacts cooling surfaces in its path.

CONTINUOUS FERMENTATION: a steady-state fermentation system that operates without interruption; each stage of fermentation occurs in a separate section of the fermenter, and flow rates are set to correspond with required residence times.

COOKER: a tank or vessel designed to cook a liquid or extract or digest solids in suspension; the cooker usually contains a source of heat, and is fitted with an agitator; its purpose is to aid in breaking down starches into fermentable sugars.

COPRODUCTS: the resulting substances and materials that accompany the production of ethanol by fermentation processes.

CORPORATE BONDS: bonds issued and sold to the public which are backed by the corporation which issues them; instruments which provide debt financing to the private sector from institutions such as insurance companies, mutual funds, pension funds, etc.

DCF-IROR: Discounted Cash Flow - Interest Rate of Return

DnG; see Distillers Dried Grains.

DDGS: see Distillers Dried Grains with Solubles.

DDS: see Dried Grains with Solubles.

DEHYDRATION: the process of removing water from any substance by exposure to high temperature or by chemical means.

DENATURANT: a substance added to ethanol to make it unfit for human consumption so that it is not subject to alcohol beverage taxes. 
DENATURE: the process of adding a substance to ethyl alcohol to make it unfit for human consumption; the denaturing agent may be gasoline or other substances specified by the Bureau of Alcohol, Tobacco, and Firearms.

DEPARTMENT OF ENERGY: In October 1977, the Department of Energy (DOE) was created to consolidate the multitude of energy-oriented government programs and agencies; the Department carries out its mission through a unified organization that coordinates and manages energy conservation, supply development, information collection and analysis, regulation, research, development, and demonstration.

DESICCANT: a substance having an affinity for water; used for drying purposes.

DEWATERING: removal of the free water from a solid substance.

DEXTRINS: a polymer of D-Glucose which is intermediate in complexity between starch and maltose and formed by partial hydrolysis of starches.

DEXTROSE: the same as glucose.

DISACCHARIDES: the class of compound sugars which yield two monosaccharide units upon hydrolysis; examples are sucrose, maltose; and lactose.

DISPERSION: the distribution of finely divided particles in a medium.

DISTILLATE: that portion of a liquid which is removed as a vapor and condensed during a distillation process.

DISTILLATION: the process of separating the components of a mixture by differences in boiling point; a vapor is formed from the liquid by healing the liquid in a vessel and the vapor is successively collected and condensed into liquids.

DISTILLERS DARK GRAINS: see DISTILLERS DRIED GRAINS WITH SOLUBLES (DDGS).

DISTILLER DRIED GRAINS (DDG): the waterinsoluble, dried distillers grains coproduct of the grain fermentation process which may be used as a high-protein (28 percent) animal feed. (see DISTILLERS GRAINS).

DISTILLERS DRIED GRAINS WITH SOLUBLES (DDGS): a grain mixture obtained by mixing distillers dried grains and distillers dried solubles.
DISTILLERS DRIED SOLUBLES (DDS): a mixture of water-soluble oils and hydrocarbons obtained by condensing the thin stillage fraction of the solids obtained from fermentation and distillation processes.

DISTILLERS FEEDS: coproducts resulting from the fermentation of cereal grains by the yeast Saccharomyces cerevisiae; the nonfermentable portion of grain mash.

DISTILLERS GRAIN: the nonfermentable portion of a grain mash comprised of protein, unconverted carbohydrates and sugars, and mineral material.

\section{DOE: Department of Energy}

DRAWBACK: a refund of part of the tax given when tax-paid alcohol is used to produce approved products unfit for beverage purposes.

DRY MILLING: a process of separating various components of grains, such as germ, bran, and starch without using water.

DSP (DISTILLED SPIRITS PLANT): a plant, including fuel alcohol plants, authorized by the Bureau of Alcohol, Tobacco, and Firearms to produce, store, or process ethyl alcohol in any of its forms.

ECONOMIC REGULATORY ADMINISTRATION (ERA): a regulatory agency within the Department of Energy administering petroleum pricing and allocation programs, oil and gas fuel conversion programs, and other programs as assigned by the Secretary of Energy.

EDA: Economic Development Administration

ENERGY CROPS: includes such agricultural crops as corn and sugar cane; also non-food crops such as poplar trees. (See BIOMASS).

ENERGY SECURITY ACT: (42 USC 8701, et seq., P. L. 96-294) June 30, 1980 legislation authorizing, inter alia, a U.S. biomass and alcohol fuel program; established independent Office of Alcohol Fuels within DOE, and authorized program including loan guarantees, price guarantees, and purchase agreements with producers of fuel alcohol.

ENRICHMENT: the increase of the more volatile component in the condensate of each successive stage above the feed plate.

ENSILAGE: immature green forage crops and grains which are preserved by alçohol formed by dll dllâeıobic fermentation process. 
ENTITLEMENT PROGRAM: a DOE program administered by the Economic Regulatory Administration which pays producers of ethanol for gasohol an entitlement per gallon through September, 1981.

ENZYMES: the group of catalytic proteins that are produced by living microorganisms; enzymes mediate and promote the chemical processes of life without themselves being altered or destroyed.

EPA: Environmental Protection Agency

EQUITY CAPITAL: that portion of the total debt of a corporation in which stock is given in return for invested capital.

ETHANOL: chemical formula $\mathrm{C}_{2} \mathrm{H}_{5} \mathrm{OH}$; the alcohol product of fermentation that is used in alcoholic beverages and for industrial purposes; blended with gasoliné to make gasohol; alșo known as ethyl alsohol $\mathrm{nr}$ grain alrohnl

ETHYL ALCOHOL: see ETHANOL.

EVAPORATION: conversion of a liquid to the vapor state by the addition of latent heat of vaporization; usually refers to vaporization into the atmosphere.

EXCISE TAX, GASOLINE: a tax collected at the pump to support the construction and maintenance of highways. Gasohol is' exempt through 1992 from the \$.04 Federal excise tax and in some States from the State excise tax.

FACULTATIVE (ANAEROBE): a microorganism that grows equally well under aerobic and anaerobic conditions.

FAHRENHEIT SCALE: a temperature scale in which the boiling point of water is 212 and its freezing point $32^{\circ}$; to convert ${ }^{\circ} \mathrm{F}$ to ${ }^{\circ} \mathrm{C}$, subtract 32 , multiply by 5 , and divide the product by 9 (at sea level). $\mathrm{C}^{\circ}$ $=\left(F^{\circ}-32\right) \times 5 / 9$.

FDA: Food and Drug Administration

FEEU PLATE: the theoretical position in a distillation column above which enrichment occurs and below which stripping occurs.

FEEDSTOCK: the base raw material that is the source of sugar for fermentation.

FERMENTABLE SUGAR: sugar (usually glucose) derived from starch or cellulose that can be converted to ethanol (also known as reducing sugar or monosaccharide).
FERMENTATION: a microorganically mediated enzymatic transformation of organic substances, especially carbohydrates, generally accompanied by the evolution of a gas; the conversion of simple sugars to ethanol with the aid of enzymes.

FERMENTATION ETHANOL: ethyl alcohol produced from the enzymatic transformation of organic substances.

FLASH HEATING: very rapid heating of material by exposure of small fractions to high temperature and using high flow rates.

FLASH POINT: the temperature at which a combustible liquid will ignite when a flame is introduced; anhydrous ethanol will flash at $51^{\circ} \mathrm{F}, 90^{\circ}$-proof ethanol will flash at $78^{\circ} \mathrm{F}$.

FLOCCULATION: the aggregation of fine suspended particles tu furm fluating clusters or clumps.

FmHA: Farmers Home Administration

FOSSIL FUEL: any naturally occurring fuel of an organic nature which originated in a past geologic age (such as coal, crude oil, or natural gas).

FRACTIONAL DISTILLATION: a process of separating alcohol and water (or other mixtures) by boiling and drawing off vapors from different levels of the distilling column.

FRUCTOSE: a fermentahle monosascharide (simple) sugar of chemical formula $\mathrm{C}_{6} \mathrm{H}_{12} \mathrm{O}_{6}$; fructose is a ketohexose.

FUEL GRADE ALCOHOL: usually refers to ethanol of $160^{\circ}$ to $200^{\circ}$ proof, although $100^{\circ}$ to $200^{\circ}$ proof can be used with diesel fuel. See DIESELHOL.

FUSEL OIL: a clear, colorless, poisonous liquid mixture of alcohols obtained as a byproduct of grain fermentation; major constituents are amyl, isoamyl, propyl, isopropyl, butyl, and isobutyl alcohols.

GASOHOL (GASAHOL): a registered trademark held by the State of Nebraska for a fuel mixture of agriculturally derived 10 percent anhydrous fermentation ethanol and 90 percent unleaded gasoline; it is often incorrectly used to mean any mixture of alcohol and gasoline to be used for motor fuel.

GASOLINE: a volatile, flammable liquid obtained from petroleum that has a boiling range of approximately $200^{\circ}$ to $216^{\circ} \mathrm{C}$ and is used as fuel for sparkignition internal combustion engines. 
GELATINIZATION: the rupture of starch granules by heat to form a gel of soluble starch and dextrins.

GLUCOSE: a monosaccharide; occurs free or combined and is the most common sugar; chemical formula $\mathrm{C}_{6} \mathrm{H}_{12} \mathrm{O}_{6}$; glucose is an aldohexose.

GLUCOSIDASE: an enzyme that hydrolyzes polymers of glucose monomers (glucoside); specific glucosidases must be used to hydrolyze specific glucosides; e.g., $\beta$-glucosidases are used to hydrolyze cellulose; $\alpha$-glucosidases are used to hydrolyze starch.

GRAIN ALCOHOL: see ETHANOL.

GUARANTEED DEBT: $100 \%$ versus $90 \%$ : a distinction made to the structure of government-guaranteed debt; i.e., under the FmHA program the government guarantees $90 \%$ of the debt which the lender loans to the corporation; contrast to a $100 \%$ guarantee which eliminates risk from the bank altogether.

HEAT EXCHANGER: a device that transfers heat from one fluid (liquid or gas) to another, or to the environment.

HEAT OF CONDENSATION: the same as the heat of vaporization, except that the heal is given up as the vapor condenses to a liquid at its boiling point.

HEAT OF VAPORIZATION: the heat input required to change a liquid at its boiling point to a vapor at the same temperature (e.g., water at $212^{\circ} \mathrm{F}$ to steam at $\left.212^{\circ} \mathrm{F}\right)$.

HEATING VALUE: the amount of heat obtainable from a fuel and expressed, for example, in Btu/lb.

HEXOSE: any of various simple sugars that have six carbon atoms per molecule.

HHV: higher heating value; the heat released during combustion of fuel if all products are cooled to room temperature and water is condensed to liquid.

\section{HUD: Housing and Urban Development}

HYDRATED: chemically combined with water.

HYDROCARBON: a chemical compound containing hydrogen and carbon.

HYDROLYSIS: the decomposition or alteration of a substance by chemically adding a water molecule to the unit at the point of bonding.
HYDROMETER: a long-stemmed glass tube with a weighted bottom; it floats at different levels depending on the relative weight (specific gravity) of the liquid; the specific gravity or other information is read where the calibrated stem emerges from the liquid.

INDOLENE: a standard mixture of chemicals used in comparative tests of automotive fuels.

INDUSTRIAL ALCOHOL: ethyl alcohol produced and sold for other than beverage purposes; depending on the use, may or may not be denatured.

INDUSTRIAL REVENUE BONDS (IDR BONDS): debt incurred through industrial revenue authorities in numerous states; since such authorities are permitted to issue bonds for sale to the public which are payable in tax-exempt interest rates, IDR or taxexempt bonds normally reflect an interest rate substantially below the prime rate.

INEL: Idaho National Engineering Laboratory

INOCULUM: a small amount of bacteria produced from a pure culture which is used to start a new culture.

INULIN: a polymeric sarbohydrate comprised of fructose monomers found in the roots of many plants, particularly Jerusalem artichokes.

INVENTORY: refers to the supplies of all factors of production which must be maintained in storage; i.e., grain, wood, enzymes, etc.

LACTIC ACID: $\mathrm{C}_{3} \mathrm{H}_{6} \mathrm{O}_{3}$, the acid formed from milk sugar (lactose) and produced as a result of fermentation of carbohydrates by bacteria called Lactobacillus.

LACTOSF : a crystalline disaccharide made from whey and used in pharmaceuticals, infant foods, bakery products, and confections; also called "milk sugar", $\mathrm{C}_{12} \mathrm{H}_{22} \mathrm{O}_{11}$.

LEADED GASOLINE: gasoline containing tetraethyllead to raise octane value.

LEAN FUEL MIXTURE: an excess of air in the air/fuel ratio; gasohol has a leaning effect over gasoline because the alcohol adds oxygen to the system.

LEASING: a form of financing whereby debt and ownership are retained by a third party who is normally not involved in the management of the operation; allows for the loan of both debt and equity capital to the market. 
LHV: lower heating value; the heat released during combustfon of fuel if all products are cooled to room temperature while water remains as steam; the lower heating value is more representative of typical fuel burning than $\mathrm{HHV}$.

LIGNIFIED CELLULOSE: cellulose polymer wrapped in a polymeric sheath and extremely resistant to hydrolysis because of the strength of its linkages.

LIGNIN: a polymeric, noncarbohydrate constituent of wood that functions as a binder and support for cellulose fibers.

LIMITED PARTNERSHIP: legal mechanism in which investors can limit their liability by investing in a "managing partner"' who operates the company; the managing partner is usually a corooration and limited partners are allocated tax credits and deprcciation in a raliu which may exceed their prorata shàs, basically used for tảx-shelter-type investments, since the limited partners can be allocated depreciation, tax credits/losses which exceed their original investments.

LINKAGE: the bond or chemical connection between constituents of a molecule.

LIQUEFACTION: the change in the phase of a substance to the liquid state; in the case of fermentation, the conversion of water-insoluble carbohydrate to water-soluble carbohydrate.

MALT: barley softened by steeping in water, allowed to germinate, and used especially in brewing and distilling as a source of antylase.

MALTOSE: a dlsaccharide of glucose.

MASH: a mixture of grain and other ingredients with water to prepare wort for brewing operations.

MEAL: a granular substance produced by grinding.

MEMBRANE: a sheet polymer which separates components of solutions by permitting passage of certain substalltes but preventing passage of others.

METHANOL: a light volatile, flammable, poisonous, liquid alcohol, $\mathrm{CH}_{3} \mathrm{OH}$, formed in the destructive distillation of wood or made synthetically and used especially as a fuel, a solvent, an antifreeze, or a dcnaturant for ellıyl alcuhol, and in the synthesis of other chemicals; methanol can be used as fuel for motor vehicles; also known as methyl alcohol or wood alcohol.

METHYL ALCOHOL: also known as methanol or wood alcohol; see METHANOL.
MOLECULAR SIEVE: a compound which separates molecules by selective penetration into the sieve space on the basis of size, charge, or both.

MOLECUI.F: the chemical term for the smallcst particle of matter that is the same chemically as the whole mass.

MONOMER: a simple molecule which is capable of combining with a number of like or unlike molecules to form a polymer.

MONOSACCHARIDES: see FERMENTABLE SUGAR.

MULTIPLE-EFFECT EVAPORATOR: a series of evaporators in which the vapors removed from each unit are used to supply heat to the next unit in the cerics.

MUNICIPAL SOLID WASTE (MSW): combined resi= dential and commercial wastes generated within a municipal aren and consisting of any inaterials, including food wastes, that are discarded or rejected as spent, worthless, useless, or in excess and that are not wet enough to be free-flowing.

MUNICIPAL WASTE: defined in the Energy Security Act (42 USC 8802, P. L. 96-294) as "any organic matter, including sewage, sewage sludge, and industrial or commercial waste, and mixtures of such matter and inorganic refuse (i) from any publicly or privately operated municipal waste collection or similar disposal systéı, or (ii) from similàr wastes flows (other than such flows which constitute agricultural wastes or residues, or wood wastes or residues from wood harvesting activities or production of forest products).",

MUNICIPAL WASTE ENERGY PROJECT: defined in the Energy Security Act (42 USC 8802, P. L. 96-294) as "any facility (or portion of a facility) located in the United States primarily for (i) the production of biomass fuel (and byproducts) from municipal waste; or (ii) the combustion of municipal waste for the purpose of generating steam or forms of useful energy, including indıstrial proness heat, mechanical power, or electricity (including cogeneration)."

NAFI: National Alcohol Fuels Institute.

NET ENERGY BALANCE: the amount of energy avasuable from fuel when it is burned, less the amount of energy it takes to produce the fuel.

OCTANE NUMBER: a rating which indicates the tendency to knock when a fuel is used in a standard internal combustion engine under standard conditions. 
OFFERING STATEMENT: a prospectus of an investment in the form of an offering of stock or partnership in the investment in return for cash invested into the company.

OFFICE OF ALCOHOL FUELS: an independent Office within the Department of Energy responsible for administration of all alcohol fuels programs in the Department and coordination of related programs in other Federal agencies.

OSHA: Occupational Safety and Health Administration

OSMOTIC PRESSURE: applied pressure required to prevent passage of a solvent across a membrane which separates solutions of different concentrations.

OVERHEAD: the rclatively low-boiling-point liquids removed from the top of a distillation unit.

OVER-THE-COUNTER (OTC) STOCK MARKET: market for new or speculative stocks which are traded in the public sector but not to the extent which New York Stock Exchange or American Stock Exchange require for active trading.

PACKED DISTILLATION COLUMN: a column or tube constructed with a packing of ceramics, steel, copper, or fiberglass-type material to increase surface area through which vapors or liquid may pass.

PERSONAL VERSUS CORPORATE DEBT: under any loan agreement which involves high-risk capital speculation or unknown collateral values, personal endorsements are normally required by the lender, which allows the lender to have lien against other assets of the owners; corporate debt restricts the liability of the debt to the corporation and the assets in the corporation.

$\mathrm{pH}$ : a term used to describe the free hydrogen ion concentration of a system; a solution of $\mathrm{pH}$ less than 7 is acid; $\mathrm{pH}$ of 7 is neutral; pH over 7 is alkaline.

PLATE DISTILLATION COLUMN (sieve tray column): a distillation column constructed with perforated plates or screens.

POLYMER: a substance made of molecules comprised of long chains or cross-linked simple molecules.

POUNDS PER SQUARE INCH ABSOLUITE (psia): the measurement of pressure referred to a complete vacuum or 0 pressure.
POUNDS PER SQUARE INCH GAUGE (psig): the measurement of pressure expressed as a quantity measured from above atmospheric pressure.

POUND OF STEAM: one pound (mass) of water in the vapor phase, not to be confused with the steam pressure which is expressed in pounds per square inch.

PRACTICAL YIELD: the amount of product that can actually be derived under normal operating conditions; i.e., the amount of sugar that normally can be obtained from a given amount of starch or the amount of alcohol that normally can be obtained is usually less than theoretical yield.

PRIVATE PLACEMENTS: a security offering which is limited to a small group of investors and hence is not in the public markets or under the full scrutiny of the $\mathrm{SEC}$; such investments may be in Sub-chapter S corporations, standard corporations, limited partnerships, etc.

PROCESS GUARANTEE: refers to the financial ability of an engineering company to successfully make its process perform, within given tolerance levels, in the event that the process does not meet production levels originally agreed to in the contract.

PROOF: a measurement of the alcohol concentration in an alcohol-water mixture, equal to twice the percentage by volume of the alcohol; e.g., 80-percent alcohol equals $160^{\circ}$ proof, 100-percent alcohol equals $200^{\circ}$ proof.

PROOF GALLON: a U.S. gallon of liquid which is 50-percent ethyl alcohol by volume or the alcohol equivalent thereof; also one tax gallon.

PROTEIN: any of a class of high-molecular-weight polymer compounds comprised of a variety of amino acids joined by peptide linkages.

PURE ETHYL ALCOHOL: ethyl alcohol that has not been denatured and is usually sold as $190^{\circ}$ proof and $200^{\circ}$ proof (absolute).

QUAD: one quadrillion $\left(10^{15}\right.$ or $\left.1,000,000,000,000,000\right)$ Btu's (British thermal units).

RECTIFICATION: with regard to distillation, the selective increase of the concentration of a component in a mixture by successive evaporation and condensation.

RECTIFYING COLUMN: the portion of a distillation column above the feed tray in which rising vapor is enriched by interaction with a countercurrent falling stream of condensed vapor 
REFLUX: the condensate returned to a rectifying column to maintain the.liquid-vapor equilibrium.

\section{RELATIVE DENSITY: see SPECIFIC GRAVITY.}

RENEWABLE RESOURCES: renewable energy; resources that can be replaced after use through natural means; example: solar energy, wind energy, energy from growing plants.

ROAD OCTANE: a numerical value for automotive anti-knock properties of a gasoline; determined by operating a car over a stretch of level road.

S-18: a relatively new program of the Securities and Exchange Commission which is designed to allow small stock offerings to go to the public sector through private placement, or through brokers up to $\$ 5$ million on interstate placements: formerly, this was limited to $\$ 750,000$ within a single state.

SACCHARIDE: a simple sugar or a compound that can be hydrolyzed to simple sugar units.

SACCHARIFY: to hydrolyze a complex carbohydrate into simpler soluble fermentable sugars, such as glucose.

SACCHAROMYCES: a class of single-cell yeasts which selectively consume simple sugars.

\section{SBA: Small Business Administration}

SDIC. Burall Business Investment Lompany. Venture capital companies which are licensed by the Small Business Administration (SBA) for the purpose of investing in small businesses; requires a minimum of $\$ 500,000$ in capital for which the SBA will lend an additional $\$ 1.5$ million in investment capital to help small businesses; SBIC's can either lend to a small business or buy up to $49 \%$ of the stock in a small business, or a combination thereof.

SCRUBBING EQUIPMENT: equipment for countercurrent liquid-vapor contact of flue gases to remove chemical contaminants and particulates.

SECONDARY MARKET: market of institutional investors who buy government guaranteed debt for their portfolio.

SEIDB: Solar Energy Information Data Bank
SERI: Solar Energy Research Institute. The Solar Energy Research Development and Demonstration Act of 1974 called for the establishment of SERI, whose general mission is to support DOE's solar energy program and foster the widcspread use of all aspects of solar technology, including direct solar conversion (photovoltaics), solar heating and cooling, solar thermal power generation, wind conversion, ocean thermal conversion, and biomass conversion.

SET BACK: the liquid portion of the stillage that is recycled as a portion of the process liquid in the mash preparation.

SETTLING TIME: in a controlled system, the time required for entrained or colloidal material to separate from the liquid.

SIGHT GAUGE: a clear calibrated cylinder through which liquid level can be observed and measured.

SIMPLE SUGARS: see FERMENTABLE SUGARS.

SMALL-SCALE BIOMASS ENERGY PROJECT: defined in the Energy Security Act (42 USC 8802, P. L. 96-294) as "a biomass energy project with an anticipated annual production capacity of not more than 1,000,000 gallons of ethanol per ycar, or its energy equivalent of other forms of biomass energy."

SPECIAL FUEL; defined in the rrude Ril Windfall Profit Tax Act of 1980 (26 USC 44E, P. L. 96-223) as "any liquid fuel (other llian gasoline) which is suitablc for usc in an interinal cumbustion engine.

SPECIALLY DENATURED ALCOHOL (SDA): ethyl alcohol to which sufficient quantities of various denaturants have been added, pursuant to formulas prescribed by Federal regulations, to render it unfit for beverage purposes without impairing its usefulness for other purposes; specially denatured alcohol may be distributed only to persons holding BATF permits.

SPECIFIC GRAVITY: the ratio of the mass of a solid or liquid to the mass of an equal volume of distilled water at $4^{\circ} \mathrm{C}$.

SPECIFIC PERFORMANCE BONDS: refers to the ability of a contractor, through a third-party insurer, to eliminate the risk of non-performance on a construction job.

SPENT GRAINS: the nonfermentable solids remaining after fermentation of a grain mash. 
STANDARD CORPORATION: a corporation in which the investment tax credits, depreciation, or corporate losses stay within the corporate shell and cannot be deducted from personal income taxes.

STARCH: a carbohydrate polymer comprised of glucose monomers linked together by a glycosidic bond and organized in repeating units; starch is found in most plants and is a principal energy storage product of photo synthesis; starch hydrolyzes to several forms of dextrin and glucose.

STILL: an apparatus for distilling liquids, particularly alcohols; it consists of a vessel in which the liquid is vaporized by heat, and a cooling device in which the vapor is condensed.

STILLAGE: the nonfermentable residue from the fermentation of a mash to produce alcohol.

STOICHIOMETRIC RATIO: the ratio of chemical substances necessary for a reaction to occur completely.

STOVER: the dried staiks and leaves of a crop remaining after the grain has been harvested.

STRIPPING SECTION: the section of a distillation column below the feed in which the condensate is progressively decreased in the fraction of more volatile component by stripping.

SUB-CHAPTER S CORPORATION: a corporation which is limited to 15 or fewer investors who can use the tax credits, depreciation or losses which the corporation incurs in such a manner as to decrease personal income tax liability; the Sub-s election can be rescinded to convert the corporation at a later datc to a standard 1244 corporation in which any loss investors incur can be deducted from personal income taxes.

SUCROSE: a crystalline disaccharide carbohydrate found in many plants, mainly sugar cane, sugar beets, and maple trees; $\mathrm{C}_{12} \mathrm{H}_{22} \mathrm{O}_{11}$.

SURETY BOND: a type of insurance which satisfies the government's bonding requirements on distilled spirits production (see BOND); obtainable from U.S. Treasury-authorized insurance companies, surety bonds usually carry an annual premium of 1 to $2 \%$ of face value.

SURFACTANT: surface-active agent, a substance that alters the properties, especially the surface tension, at the point of contact between phases; e.g., detergents and wetting agents are typical surfactants.
TAX-FREE ALCOHOL: pure ethyl alcohol withdrawn free of tax for government, for hospital use, for science, or for humanitarian reasons; it cannot be used in foods or beverages; all purchasers must obtain BATF permits, post bonds, and exert controls upon storage and use of Tax-Free Alcohol.

TAX-PAID ALCOHOL: pure ethyl alcohol which has been released from Federal bond by payment of the Federal tax of $\$ 21.00$ per gallon at $200^{\circ}$ proof or $\$ 19.95$ per gallon at $190^{\circ}$ proof.

TETRAETHYLLEAD (TEL): an octane enhancer for gasoline now under environmental restriction.

THERMAL EFFICIENCY: energy heating value; the ratio of energy output to energy input.

THERMOPHILIC: capable of growing and surviving at high temperalures.

THIN STILLAGE: the water-soluble fraction of a termented mash plus the mashing water.

TRAY: one of several types of horizontal pieces in a distillation column.

UDAG: Urban Development Action Grant

USDA: U.S. Department of Agriculture

VACUUM DISTILLATION: the separation of two or more liquids under reduced vapor pressure: reduces the boiling points of the liquids being separated.

VAPORIZE: to change from a liquid or a solid to a vapor, as in heating water to steam.

VAPOR PRESSURE: the pressure at any given temperature of a vapor in equilibrium with its liquid or solid form.

VOLUMETRIC FUEL ECONOMY: miles per gallon.

WET MILLING: a process similar to dry milling except that the various components of grain are separated in water.

WHEY: the watery part of milk separated from the curd in the process of making cheese; it is produced commercially in large quantities and can be used as a fertilizer, animal feed, or feedstock in the production of ethanol.

WHOLE STILLAGE: the undried "bottoms" from the beer well comprised of nonfermentable solids, distillers solubles, and the mashing water. 
WINE GALLON: a United States gallon of liquid measure equivalent to the volume of 231 cubic inches.

WOOD ALCOHOL: see METHANOL

WORKING CAPITAL: capital which is used for initial training, inventory and labor.

WORT: the liquid remaining from a brewing mash preparation following the filtration of fermentable beer.
YEAST: single-cell microorganisms (fungi) that produce alcohol and $\mathrm{CO}_{2}$ under anaerobic conditions and acetic acid and $\mathrm{CO}_{2}$ under aerobic conditions; the microorganism that is capable of changing sugar to alcohol by fermentation.

ZYMOSIS: see FERMENTATION 


\section{APPENDIX H}

\section{Technical Reference Data}

Conversion Table Properties of Gasoline, Methanol, and Ethanol

Red Winter Wheat and All Wheat Production Costs, 1978

Barley Production Costs, 1978

Grain Sorghum Production Costs, 1978

Grain Sorghum Silage and Forage Use, 1976 to 1978

Grain Sorghum Area, Yield, and Production, 1977.1978

Corn Area, Yield, and Production, 1977-1978

Sugar Beet Area, Yield, and Production

Sugar Beet Production and Value, 1977

Production of Selected Fruit Crops

Components of Molasses

Nutritional Content of Distillers Feed from Corn in Percentages

Available Energy from Corn in Distillers Feeds 
Conversion Table

\begin{tabular}{|c|c|c|}
\hline To convert from & To & Multiply By \\
\hline barrels (oil) & gallons & 42 \\
\hline${ }^{\circ} \mathrm{C}$ & $\mathrm{F}$ & $1.8 \times\left({ }^{\circ} \mathrm{C}+32\right)$ \\
\hline centimeters & inches & 0.394 \\
\hline cubic feet & bushels & 0.804 \\
\hline cubic feet & cubic meters & 0.028 \\
\hline cubic feet & cubic yards & 0.037 \\
\hline cubic meters & bushels & 28.377 \\
\hline cubic meters & cubic feet & 35.314 \\
\hline cubic meters & cubic yards & 1.308 \\
\hline cubic meters & gallons & 264.17 \\
\hline cubic meters & liters & 1000 \\
\hline cubic.meters/kilogram & cubic feet/pound & 16.02 \\
\hline cubic meters/second & million gallons/day & 22.83 \\
\hline grams/liter & parts per million & 1000 \\
\hline grams/liter & pounds/cubic foot & 0.062 \\
\hline grams/liter & pounds $/ 1000$ gallons & 8.35 \\
\hline hectares & acres & 2.471 \\
\hline kilograms & püunds & 2.205 \\
\hline kilograms/cubic meter & pounds/cubic foot & 0.062 \\
\hline kilojoules & Btu & 0.948 \\
\hline kilojoules/cubic meter & Btu/cubic foot & 33.5 \\
\hline kilojoules/kilogram & Btu/pound & 0.447 \\
\hline kilojoules/liter & Btu/gallon & 3.589 \\
\hline kilopascals & atmospheres & $9.869 \times 10^{3}$ \\
\hline kilopascals & pounds/square inch & 0.145 \\
\hline kilowatthours & Btu & 3.413 \\
\hline kilowatthours & joules & $3.6 \times 10^{6}$ \\
\hline liters & gallons & 0.264 \\
\hline meters & feet & 3.281 \\
\hline metric tons & pounds & 2,205 \\
\hline meti'ic luns & tons & 1.102 \\
\hline iniciumerers & inches & 0.000039 \\
\hline millimeters & inches & 0.039 \\
\hline pounds/square inch & atmosjilıeı es & 0.068 \\
\hline proof & $\sigma_{0}$ alcohol by volume & 0.5 \\
\hline
\end{tabular}


Properties 'of Gasoline, Methanol, and Ethanol

\begin{tabular}{|c|c|c|c|}
\hline CHEMICAL PROPERTIES & GASOLINE & METHANOL & ETHANOL \\
\hline $\begin{array}{l}\text { Formula } \\
\text { Molecular Weight } \\
\% \text { Carbon (by Weight) } \\
\% \text { Hydrogen (by Weight) } \\
\% \text { Oxygen (by Weight) } \\
\text { C/H Ratio } \\
\text { Stoichiometric Air-to-Fuel Ratio }\end{array}$ & $\begin{array}{c}\mathrm{C}_{4}-\mathrm{C}_{12} \\
\text { Varies } \\
85-88 \\
12-15 \\
\text { Indefinite } \\
5.6-7.4 \\
14.2-15.1\end{array}$ & $\begin{array}{r}\mathrm{CH}_{3} \mathrm{OH} \\
32.04 \\
38.70 \\
9.70 \\
51.60 \\
3.00 \\
6.45\end{array}$ & $\begin{array}{c}\mathrm{C}_{2} \mathrm{H}_{5} \mathrm{OH} \\
46.1 \\
52.1 \\
13.1 \\
34.7 \\
4.0 \\
9.0\end{array}$ \\
\hline PHYSICAL PROPERTIES & GASOLINE & METHANOL & ETHANOL \\
\hline $\begin{array}{l}\text { Specific Gravity } \\
\text { Liquid Density } \\
\quad \mathrm{lb} / \mathrm{ft}^{3} \\
\quad \mathrm{~b} / \mathrm{gal} \\
\text { Vapur Pressure } \\
\quad \mathrm{psi} \text { at } 100^{\circ} \mathrm{F} \text { (Reid) } \\
\text { psi at } 77^{\circ} \mathrm{F} \\
\text { Boiling Point (OF) } \\
\text { Freezing Point (OF) } \\
\text { Solubility in Water (ppm) } \\
\text { Solubility of Water in Compound (ppm) } \\
\text { Viscosity at } 68^{\circ} \mathrm{F} \text { (Centipoise) }\end{array}$ & $\begin{array}{c}0.70-0.78 \\
\\
43.6 \text { Approx. } \\
5.8-6.5 \\
\\
7-15 \\
0.3 \text { Approx. } \\
80-440 \\
-70 \text { Approx. } \\
240 \\
88 \\
0.288\end{array}$ & $\begin{array}{c}0.79 \\
49.30 \\
6.59 \\
\\
\\
\\
149 \\
-208 \\
\text { Infinite } \\
\text { Infinite }\end{array}$ & $\begin{array}{r}0.794 \\
49.30 \\
6.59 \\
\\
2.50 \\
0.85 \\
173 \\
-173 \\
\text { Infinite } \\
\text { Infinite } \\
1.17\end{array}$ \\
\hline THERMAL PROPERTIES & GASOLINE & METHANOL & ETHANOL \\
\hline $\begin{array}{l}\text { Lower Heating Value } \\
\text { Btu/lb } \\
\text { Btu/gal } \\
\text { Higher Heating Value } \\
\text { Btu/lb at } 68^{\circ} \mathrm{F} \\
\text { Btu/gal } \\
\text { Heat of Vaporization } \\
\text { Btu/lb } \\
\text { Btu/gal } \\
\text { Octane Ratings } \\
\text { Research } \\
\text { Pump (RON + MON)/2 } \\
\text { Flammability Limits (\% by Volume in Air) } \\
\text { Spenific Heat (Btu/lh - OF) } \\
\text { Autoignition Temperature (OF) } \\
\text { Flash Point } \\
\text { Coefficient of Thermal Expansion at } 60^{\circ} \mathrm{F} \text { and } 1 \text { atm }\end{array}$ & $\begin{array}{r}18,900 \text { (Avg.) } \\
115,400 \text { (Avg.) } \\
20,260 \\
124,800 \\
150 \\
900 \\
\\
91-105 \\
86-90 \\
1.4-7.6 \\
0.48 \\
430-500 \\
-50 \\
0.0006\end{array}$ & $\begin{array}{r}10,258 \\
506 \\
3,340 \\
106 \\
92\end{array}$ & $\begin{array}{c}11,500 \\
73,560 \\
12,800 \\
84,400 \\
\\
396 \\
3,378 \\
106-108 \\
98-100 \\
3.3-19.0 \\
0.60 \\
685 \\
55 \\
0.00112\end{array}$ \\
\hline
\end{tabular}


Red Winter Wheat and All Wheat Production Costs, 1978

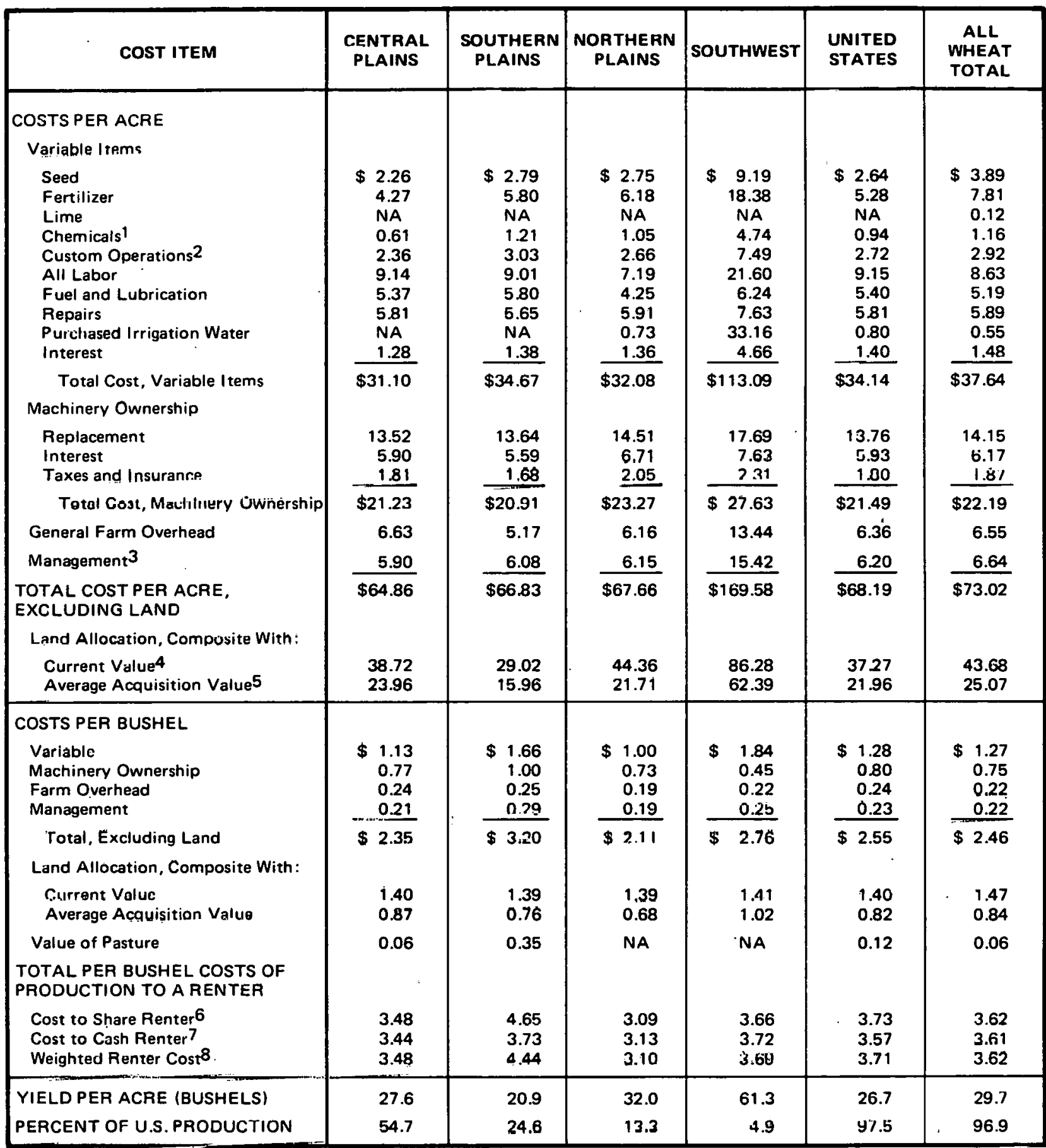

1 Includes herbicides, insecticides, and rodenticides not otherwise included under custom operations.

2 Includes custom application of crop chemicals, the cost of chemicals in snme caseg, and cilslin!! liarvecting and hauliıty.

3 Based an 10 percent of obovin ilusis.

1 based on prevailing tenure arrangements in 1974, reflecting actual combinations of cash rent, net share rent, and owner-operator land allocations, land values, land tax rates, and cash rents updated to current year.

5 Same as footnote 4, except average value of cropland during the last 35 years is used for owner-operated land instead of current land value.

6 Share-renter purtion of cost divided by share-renter portion of crop.

7 Cash-renter costs including cash rent divided by total yield.

8 Weighted average of share renter and cash renter based on prevailing tenure arrangements in 1974.

NA - Not applicable.

Source: USDA Agricultural Statistics 1979 
Barley Production Costs, 1978

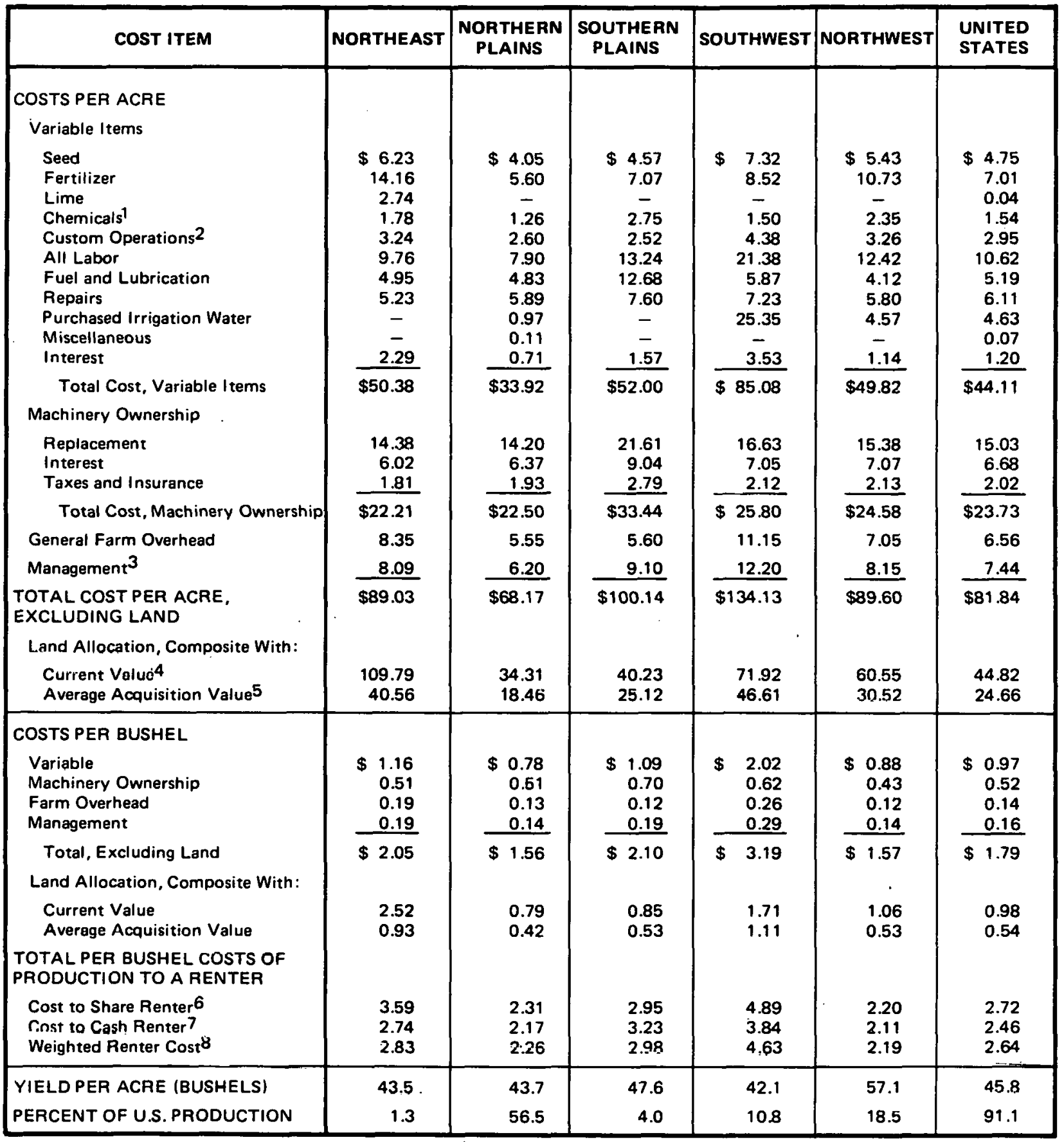

1 Includes herbicides, insecticides, and rodenticides not utherwise included under custom operations.

2 Includes custom application of crop chemicals, the cost of chemicals in some cases, and custom hervesting and hauling.

3 Based on 10 percent of above costs.

4 Based on provailing tenure arrangements in 1974, reflecting actual combinations of cash rent, net share rent, and owner-operator land allocations, land values, land tax rates, and cash rents updated to current year.

5 Same as footnote 4, except average value of cropland during the last 35 years is used for owner-operated land instead of current land value.

6 Share-renter mortion of cost divided by share-renter portion of crop.

7 Cash-renter costs including cash rent divided by total yleld.

8 Weighted average of share renter and cash renter based on prevailing tenure arrangements in 1974.

Source: USDA Agricultural Statistics 1979. 
Grain Sorghum Production Costs, 1978

\begin{tabular}{|c|c|c|c|c|}
\hline COST ITEM & $\begin{array}{l}\text { CENTRAL } \\
\text { PLAINS }\end{array}$ & $\begin{array}{l}\text { SOUTHERN } \\
\text { PLAINS }\end{array}$ & SOUTHWEST & $\begin{array}{l}\text { UNITED } \\
\text { STATES }\end{array}$ \\
\hline \multicolumn{5}{|l|}{ COSTS PER ACRE } \\
\hline $\begin{array}{l}\text { Géd } \\
\text { Fertilizer } \\
\text { Lime } \\
\text { Chemicals } 2 \\
\text { Custom Operations } 3 \\
\text { All Labor } \\
\text { Fuel and Lubrication } \\
\text { Repairs } \\
\text { Drying } \\
\text { Purchased Irrigation Water } \\
\text { Interest }\end{array}$ & $\begin{array}{r}\$ 3.56 \\
12.14 \\
0.02 \\
3.83 \\
4.73 \\
10.42 \\
7.37 \\
6.70 \\
2.17 \\
\\
1.29 \\
\end{array}$ & $\begin{array}{r}\$ 3.46 \\
11.89 \\
(1) \\
1.85 \\
4.82 \\
14.07 \\
12.51 \\
10.75 \\
\\
1.61 \\
\end{array}$ & $\begin{array}{r}\$ 7.57 \\
29.70 \\
(i) \\
2.00 \\
4.96 \\
39.04 \\
26.80 \\
12.55 \\
\\
23.28 \\
5.32\end{array}$ & $\begin{array}{r}\$ 3.60 \\
12.37 \\
0.01 \\
2.95 \\
4.77 \\
12.53 \\
9.94 \\
8.54 \\
1.20 \\
0.45 \\
1.50 \\
\end{array}$ \\
\hline Total Cost, Variable Items & $\$ 52.23$ & $\$ 60.96$ & $\$ 151.22$ & $\$ 57.86$ \\
\hline \multicolumn{5}{|l|}{ Machinery Ownership } \\
\hline $\begin{array}{l}\text { Replacement } \\
\text { Interest } \\
\text { Taxes and Insurance }\end{array}$ & $\begin{array}{r}15.82 \\
6.96 \\
2.12 \\
\end{array}$ & $\begin{array}{r}25.06 \\
10.13 \\
3.00 \\
\end{array}$ & $\begin{array}{r}25.96 \\
11.41 \\
\quad 3.39 \\
\end{array}$ & $\begin{array}{r}19.95 \\
8.40 \\
3.52 \\
\end{array}$ \\
\hline Tulal Cust, Niacnin̉ẻry Uwnership & $\$ 24.90$ & $\$ 38.19$ & $\$ 40.76$ & $\$ 30.87$ \\
\hline General Farm Overhead & 6.63 & 6.52 & 11.56 & 6.67 \\
\hline Management 4 & 8.38 & 10.57 & 20.35 & 9.54 \\
\hline TOTAL COSTS PER ACRE, EXCLUDING LAND & $\$ 92.14$ & $\$ 116.24$ & $\$ 223.89$ & $\$ 104.94$ \\
\hline \multicolumn{5}{|l|}{ Land Allocation, Composite With: } \\
\hline $\begin{array}{l}\text { Current Valuc } 5 \\
\text { Average Acquisition Value } 6\end{array}$ & $\begin{array}{l}42.00 \\
27.58\end{array}$ & $\begin{array}{l}28.56 \\
17.74\end{array}$ & $\begin{array}{l}82.01 \\
56.42\end{array}$ & $\begin{array}{l}37.04 \\
23.94\end{array}$ \\
\hline \multicolumn{5}{|l|}{ COSTS PER BUSHEL } \\
\hline $\begin{array}{l}\text { Variable } \\
\text { Machinery Owriérship } \\
\text { Farm Overhead } \\
\text { Management }\end{array}$ & $\begin{array}{l}\$ 0.91 \\
0.43 \\
0.12 \\
0.15 \\
\end{array}$ & $\begin{array}{l}\$ 1.34 \\
0.84 \\
0.14 \\
0.23 \\
\end{array}$ & $\begin{array}{r}2.16 \\
0.58 \\
0.16 \\
0.29 \\
\end{array}$ & $\begin{array}{r}\$ 1.10 \\
0.59 \\
0.13 \\
0.18 \\
\end{array}$ \\
\hline Total Cost, Excluding Land & $\$ 1.61$ & 52.55 & $\$ 3.19$ & $\$ 2.00$ \\
\hline \multicolumn{5}{|l|}{ Land Allocation, Comnosite With: } \\
\hline $\begin{array}{l}\text { Current Value } \\
\text { Averoge Acquisitiun Value }\end{array}$ & $\begin{array}{l}0.73 \\
0.48\end{array}$ & $\begin{array}{l}0.63 \\
0.39\end{array}$ & $\begin{array}{l}1.17 \\
0.80\end{array}$ & $\begin{array}{l}0.71 \\
0.16\end{array}$ \\
\hline \multicolumn{5}{|l|}{$\begin{array}{l}\text { TOTAL PER BUSHEL COSIS OF } \\
\text { PRODUCTION TO A RENTER }\end{array}$} \\
\hline $\begin{array}{l}\text { Cost to Share Renter } 7 \\
\text { Cost to Cash Renter } 8 \\
\text { Weighted Renter Cost } 9 \\
\end{array}$ & $\begin{array}{l}2.36 \\
2.05 \\
2.33\end{array}$ & $\begin{array}{l}3.48 \\
3.03 \\
3.42 \\
\end{array}$ & $\begin{array}{l}4.54 \\
3.71 \\
4.20 \\
\end{array}$ & $\begin{array}{l}2.83 \\
2.63 \\
2.81 \\
\end{array}$ \\
\hline YIELD PER ACRE (BUSHELS) & 57.2 & 45.5 & 70.2 & 52.5 \\
\hline PERCENT OF U.S, PRODUCTINN & 38.9 & 36.0 & 2.5 & 97.4 \\
\hline
\end{tabular}

1 Not applicable.

2 Includes herbicides, insecticides, and rodenticides not otherwise included under custom operationś.

3 Includes custom application of crop chemicals, the cost of chemicals in some cases, and custom harvesting ant hauling.

4 Based on 10 percent of above costs.

5 Baser on prevailing tenure arrangements in 1974, reflecting actual combinations of cash rent, net share ront. ond owrial :upurator land allocations, land values, land tax ratos. and c.nsil! ratus uposted to currurt year.

0 Gamie as footnote 5, except average value of cropland during the last 35 years is used for owner-operated land instead of current land

7 value.

7 Share-renter portion of cost divided by share-renter portion of crop.

8 Cash-renter costs including cash rent divided by total yield.

9 Weighted average of share renter and cash renter based on prevailing tenure arrangements in 1974.

Source: USDA Agricultural Statistics 1979 
Grain Sorghum Silage and Forage Use, 1976 to 1978

\begin{tabular}{|c|c|c|c|c|c|c|c|c|c|c|c|c|}
\hline \multirow{4}{*}{ STATE } & \multicolumn{9}{|c|}{ SILAGE } & \multirow{2}{*}{\multicolumn{3}{|c|}{$\begin{array}{l}\text { FORAGE AREA } \\
\text { HARVESTED }\end{array}$}} \\
\hline & \multicolumn{3}{|c|}{$\begin{array}{c}\text { AREA } \\
\text { HARVESTED }\end{array}$} & \multicolumn{3}{|c|}{$\begin{array}{c}\text { AVERAGE } \\
\text { YIELD PER ACRE }\end{array}$} & \multicolumn{3}{|c|}{ PRODUCTION } & & & \\
\hline & 1976 & 1977 & $1978 *$ & 1976 & 1977 & $1978 *$ & 1976 & 1977 & $1978^{*}$ & 1976 & 1977 & $1978 *$ \\
\hline & $\begin{array}{l}1,000 \\
\text { ACRES }\end{array}$ & $\begin{array}{l}1,000 \\
\text { ACRES }\end{array}$ & $\begin{array}{l}1,000 \\
\text { ACRES }\end{array}$ & TONS & TONS & TONS & $\begin{array}{l}1,000 \\
\text { ACRES }\end{array}$ & $\begin{array}{c}1,000 \\
\text { ACRES }\end{array}$ & $\begin{array}{l}1,000 \\
\text { ACRES }\end{array}$ & $\begin{array}{c}1,000 \\
\text { ACRES }\end{array}$ & $\begin{array}{c}1,000 \\
\text { ACRES }\end{array}$ & $\begin{array}{c}1,000 \\
\text { ACRES }\end{array}$ \\
\hline$A L$ & 18 & 15 & 18 & 11.5 & 10.5 & 10.0 & 207 & 158 & 180 & 11 & 18 & 10 \\
\hline$A Z$ & 5 & 6 & 5 & 16.5 & 17.0 & 17.0 & 83 & 102 & 85 & 2 & 2 & 1 \\
\hline AK & 13 & 17 & 12 & 9.5 & 10.5 & 10.5 & 124 & 179 & 126 & 10 & 11 & 13 \\
\hline$C A$ & 11 & 7 & 12 & 17.0 & 17.0 & 17.0 & 187 & 123 & 204 & 10 & 10 & 8 \\
\hline CO & 21 & 21 & 19 & 11.0 & 7.0 & 11.0 & 231 & 147 & 209 & 165 & 146 & 131 \\
\hline GA & 30 & 18 & 29 & 12.0 & 7.0 & 12.5 & 360 & 126 & 363 & 8 & 11 & 8 \\
\hline IL & 10 & 11 & 7 & 11.5 & 12.5 & 11.5 & 115 & 138 & 81 & 7 & 5 & 5 \\
\hline IN & 8 & 6 & 7 & 12.5 & 12.0 & 13.0 & 100 & 72 & 91 & - & - & - \\
\hline IA & 13 & 11 & 9 & 11.0 & 13.0 & 14.0 & 143 & 143 & 126 & 2 & 1 & 2 \\
\hline KS & 290 & 300 & 230 & 8.6 & 12.5 & 10.0 & 2,494 & 3,750 & 2,300 & 340 & 430 & 355 \\
\hline KY & 13 & 11 & 8 & 12.5 & 12.5 & 12.0 & 163 & 138 & 96 & 5 & 5 & 4 \\
\hline LA & 11 & 9 & 9 & 10.0 & 11.0 & 10.0 & 110 & 99 & 90 & 5 & 5 & 2 \\
\hline MS & 20 & 27 & 35 & 11.5 & 12.5 & 13.0 & 230 & 338 & 455 & 9 & 4 & 8 \\
\hline MO & 30 & 44 & 33 & 9.5 & 11.0 & 11.5 & 285 & 484 & 380 & 35 & 56 & 39 \\
\hline NE & 80 & 90 & 70 & 7.6 & 11.5 & 13.0 & 600 & 1,035 & 910 & 60 & 70 & 50 \\
\hline NM & 5 & 8 & 4 & 11.0 & 12.0 & 13.0 & 55 & 96 & 52 & 41 & 37 & 47 \\
\hline NC & 25 & 22 & 24 & 11.5 & 8.0 & 13.5 & 288 & 176 & 324 & 7 & 12 & 13 \\
\hline OK & 41 & 34 & 45 & 8.0 & 11.0 & 9.0 & 328 & 374 & 405 & 139 & 121 & 115 \\
\hline sc & 12 & 11 & 11 & 9.0 & 6.5 & 9.5 & 108 & 72 & 105 & 2 & 3 & 2 \\
\hline SD & 45 & 56 & 55 & 3.0 & 8.0 & 7.5 & 135 & 448 & 413 & 115 & 74 & 55 \\
\hline TN & 12 & 8 & 11 & 11.0 & 10.0 & 10.5 & 132 & 80 & 116 & 8 & 10 & 8 \\
\hline$T X$ & 50 & 100 & 50 & 12.0 & 8.0 & 10.5 & 600 & 800 & 515 & 900 & 600 & 700. \\
\hline VA & 9 & 10 & 11 & 10.0 & 9.0 & 11.0 & 90 & 90 & 121 & 2 & 2 & 2 \\
\hline U.S. & 772 & 842 & 714 & 9.3 & 10.9 & 10.9 & 7,168 & 9,168 & 7,747 & 1,883 & $1,6.33$ & 1,578 \\
\hline
\end{tabular}

* Preliminary.

Source: USDA Agricultural Statistics 1979. 
Grain Sorghum Area, Yield, and Production, 1977-1978

\begin{tabular}{|c|c|c|c|c|c|c|c|c|}
\hline \multirow{4}{*}{ STATE } & \multirow{2}{*}{\multicolumn{2}{|c|}{$\begin{array}{l}\text { AREA PLANTED FOR } \\
\text { ALL PURPOSES }\end{array}$}} & \multicolumn{4}{|c|}{ SORGHUM FOR GRAIN } & \multirow{2}{*}{\multicolumn{2}{|c|}{ PRODUCTION }} \\
\hline & & & \multicolumn{2}{|c|}{ AREA HARVESTED } & \multicolumn{2}{|c|}{$\begin{array}{c}\text { AVERAGE } \\
\text { YIELD PER } \\
\text { HARVESTED ACRE }\end{array}$} & & \\
\hline & 1977 & 1978 & 1977 & 1978 & 1977 & 1978 & 1977 & $1978^{*}$ \\
\hline & $\begin{array}{l}\text { THOUSAND } \\
\text { ACRES }\end{array}$ & $\begin{array}{l}\text { THOUSAND } \\
\text { ACRES }\end{array}$ & $\begin{array}{l}\text { THOUSAND } \\
\text { ACRES }\end{array}$ & $\begin{array}{l}\text { THOUSAND } \\
\text { ACRES }\end{array}$ & BUSHELS & BUSHELS & $\begin{array}{l}\text { THOUSAND } \\
\text { ACRES }\end{array}$ & $\begin{array}{l}\text { THOUSAND } \\
\text { ACRES }\end{array}$ \\
\hline $\begin{array}{l}A L \\
A Z \\
A R \\
C A \\
C O \\
G A \\
\text { IL } \\
\text { IN } \\
\text { IA } \\
K S \\
K Y \\
\text { LA } \\
\text { MS } \\
\text { MO } \\
\text { NE } \\
\text { NM } \\
\text { NC } \\
\text { OK } \\
\text { SC } \\
\text { SO } \\
\text { TN } \\
\text { TX } \\
\text { VA }\end{array}$ & $\begin{array}{r}75 \\
100 \\
285 \\
150 \\
460 \\
75 \\
80 \\
23 \\
45 \\
4,850 \\
50 \\
35 \\
60 \\
1,050 \\
2,300 \\
297 \\
110 \\
765 \\
23 \\
29 \\
40 \\
5,600 \\
24\end{array}$ & $\begin{array}{r}65 \\
80 \\
230 \\
210 \\
490 \\
85 \\
80 \\
25 \\
36 \\
4,700 \\
37 \\
30 \\
65 \\
930 \\
2,000 \\
336 \\
125 \\
700 \\
26 \\
29 \\
45 \\
5,700 \\
25\end{array}$ & $\begin{array}{r}27 \\
90 \\
252 \\
132 \\
263 \\
24 \\
64 \\
15 \\
32 \\
4,050 \\
32 \\
20 \\
24 \\
930 \\
2,070 \\
245 \\
72 \\
565 \\
12 \\
343 \\
20 \\
4,800 \\
10\end{array}$ & $\begin{array}{r}34 \\
73 \\
200 \\
185 \\
280 \\
43 \\
68 \\
15 \\
24 \\
4,020 \\
23 \\
17 \\
21 \\
050 \\
1,830 \\
267 \\
86 \\
485 \\
15 \\
340 \\
24 \\
4,650 \\
11\end{array}$ & $\begin{array}{l}27.0 \\
80.0 \\
52.0 \\
73.0 \\
31.0 \\
28.0 \\
64.0 \\
78.0 \\
74.0 \\
60.0 \\
57.0 \\
33.0 \\
32.0 \\
73.0 \\
71.0 \\
48.0 \\
37.0 \\
38.0 \\
16.0 \\
49.0 \\
51.0 \\
48.0 \\
43.0\end{array}$ & $\begin{array}{l}37.0 \\
78.0 \\
60.0 \\
71.0 \\
81.0 \\
29.0 \\
68.0 \\
65.0 \\
75.0 \\
52.0 \\
62.0 \\
34.0 \\
38.0 \\
80.0 \\
76.0 \\
46.0 \\
52.0 \\
36.0 \\
32.0 \\
50.0 \\
51.0 \\
49.0 \\
47.0\end{array}$ & $\begin{array}{r}729 \\
7,200 \\
13,104 \\
9,636 \\
8,153 \\
672 \\
4,096 \\
1,170 \\
2,368 \\
243,000 \\
1,824 \\
880 \\
768 \\
67,890 \\
146,970 \\
11,760 \\
2,664 \\
21,470 \\
192 \\
16,807 \\
1,020 \\
230,400 \\
430\end{array}$ & $\begin{array}{r}1,258 \\
5,694 \\
12,000 \\
13,135 \\
8,860 \\
1,247 \\
4,624 \\
975 \\
1,800 \\
209,040 \\
1,426 \\
576 \\
798 \\
68,000 \\
1,37.250 \\
12,282 \\
4,472 \\
17,460 \\
480 \\
17,000 \\
1,224 \\
227850 \\
517\end{array}$ \\
\hline
\end{tabular}

* Preliminary.

Source: USDA Agricultural Statistics 1979. 
Corn Area, Yield, and Production, 1977-1978

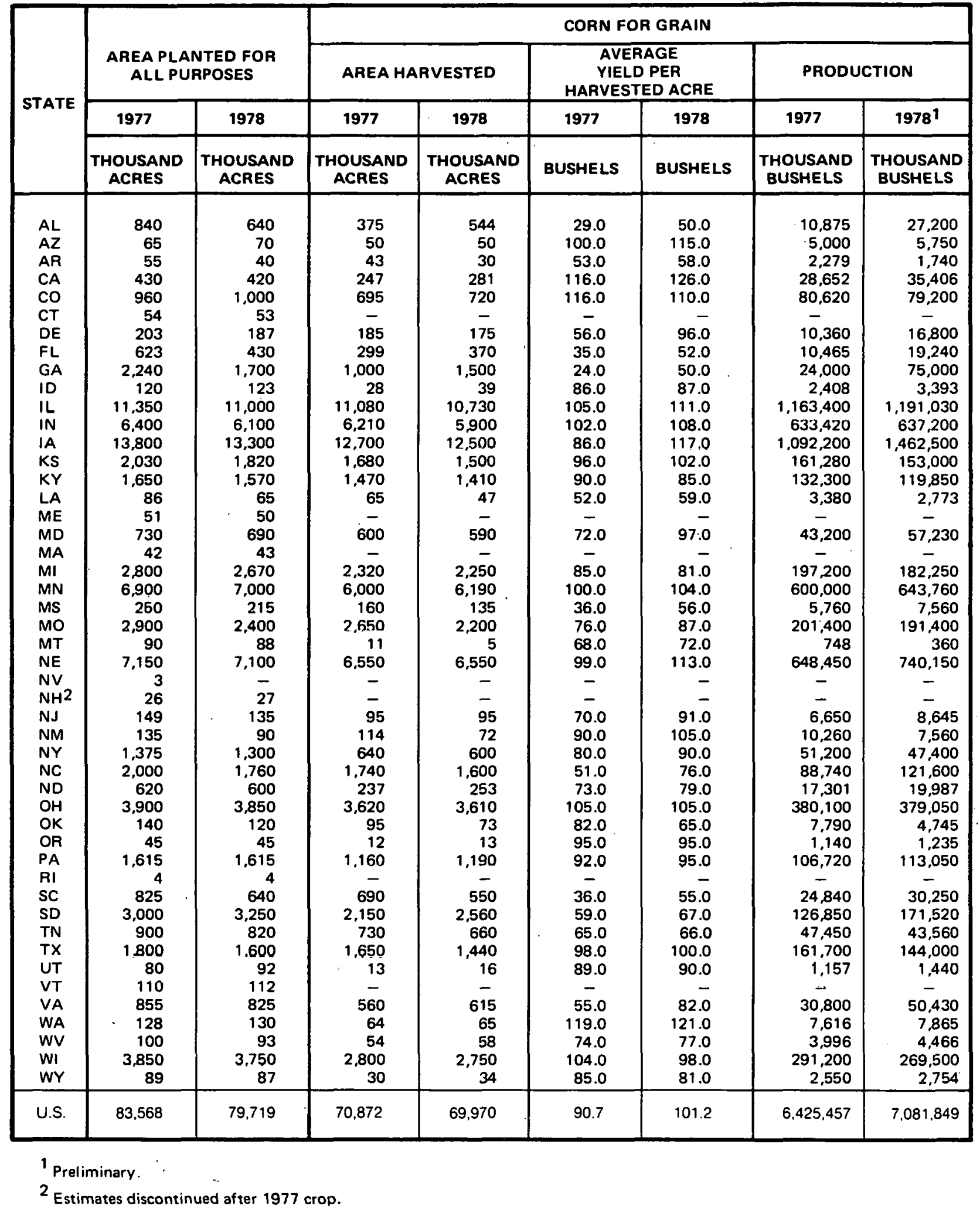

Source: USDA Agricultural Statistics 1979. 
Production of Selected Fruit Crops

\begin{tabular}{|c|c|c|c|c|}
\hline & $\begin{array}{c}\text { APPLES } \\
\text { YEAR }\end{array}$ & PEOMMERCIAL CROP) & PEARS & GRAPES \\
\cline { 2 - 5 } & THOUSAND TONS & THOUSAND TONS & THOUSAND TONS & THOUSAND TONS \\
\hline 1964 & 3,160 & 1,726 & 728 & 3,478 \\
1965 & 3,070 & 1,737 & 500 & 4,351 \\
1966 & 2,881 & 1,695 & 748 & 3,734 \\
1967 & 2,718 & 1,344 & 464 & 3,549 \\
1968 & 2,735 & 1,818 & 624 & 3,899 \\
1969 & 3,410 & 1,842 & 727 & 3,103 \\
1970 & 3,199 & 1,498 & 549 & 3,994 \\
1971 & 3,187 & 1,441 & 749 & 2,579 \\
1972 & 2,939 & 1,186 & 612 & $.4,198$ \\
1973 & 3,133 & 1,295 & 730 & 4,199 \\
1974 & 3,290 & 1,459 & 742 & 4,366 \\
1975 & 3.765 & 1,419 & 749 & 4,398 \\
1976 & 3,237 & 1,510 & 841 & 4,298 \\
1977 & 3,336 & 1,492 & 787 & 4,567 \\
1078 & 3,017 & 1,351 & 121. & - \\
\hline
\end{tabular}

Source: USUA Agricultural Statistics $19 \overline{99}$.

Sugar Beeí Production and Value, 1977

\begin{tabular}{|c|c|c|c|}
\hline \multirow[t]{2}{*}{ STATE } & PRODUCTION & $\begin{array}{l}\text { GEASON AVERAGE PRICE } \\
\text { PER TON RECEIVED } \\
\text { BY FARMERS }\end{array}$ & $\begin{array}{l}\text { VALUE OF } \\
\text { PRODUCTION }\end{array}$ \\
\hline & THOUSAND TONS & DOLLARS & THOUSAND DOLLARS \\
\hline $\begin{array}{l}A Z \\
C A \\
C O \\
\text { ID } \\
\text { KS } \\
\text { MI } \\
M N \\
M T \\
\text { NB } \\
\text { NM } \\
\text { ND } \\
\text { OH } \\
\text { OR } \\
\text { TX } \\
\text { UT } \\
\text { WA } \\
\text { WY }\end{array}$ & $\begin{array}{r}285 \\
5,664 \\
i, 404 \\
2,094 \\
401 \\
1,796 \\
4,732 \\
890 \\
1,365 \\
23 \\
2,769 \\
457 \\
206 \\
309 \\
173 \\
1,495 \\
949\end{array}$ & $\begin{array}{r}\$ 24.40 \\
26.40 \\
26.30 \\
25.50 \\
21.90 \\
21.10 \\
20.60 \\
29.10 \\
27.00 \\
25.00 \\
21.40 \\
20.20 \\
23.00 \\
23.40 \\
26.50 \\
26.50 \\
28.80\end{array}$ & $\begin{array}{r}\$, 954 \\
149,530 \\
36,925 \\
53,397 \\
8,792 \\
36,100 \\
97,479 \\
26,074 \\
36,668 \\
575 \\
59,257 \\
9,231 \\
4,738 \\
7,231 \\
4,619 \\
39,618 \\
27,331\end{array}$ \\
\hline U.S. & 25,048 & $\$ 24.20$ & $\$ 604,409$ \\
\hline
\end{tabular}

- Relates to year of harvest; includes some acreage planted previous fall.

Source: USDA Agricultural Statistics 1979. 
Sugar Beet Area, Yield, and Production

\begin{tabular}{|c|c|c|c|c|c|c|c|c|}
\hline \multirow{3}{*}{ STATE } & \multicolumn{2}{|c|}{ AREA PLANTED } & \multicolumn{2}{|c|}{ AREA HARVESTED } & \multicolumn{2}{|c|}{$\begin{array}{c}\text { AVERAGE } \\
\text { YIELD PER } \\
\text { HARVESTED ACRE } \\
\end{array}$} & \multicolumn{2}{|c|}{ PRODUCTION } \\
\hline & 1977 & $1978^{1}$ & 1977 & $1978^{1}$ & 1977 & $1978^{1}$ & 1977 & $1978^{1}$ \\
\hline & $\begin{array}{l}\text { THOUSAND } \\
\text { ACRES }\end{array}$ & $\begin{array}{c}\text { THOUSAND } \\
\text { ACRES }\end{array}$ & $\begin{array}{l}\text { THOUSAND } \\
\text { ACRES }\end{array}$ & $\begin{array}{c}\text { THOUSAND } \\
\text { ACRES }\end{array}$ & TONS & TONS & $\begin{array}{l}\text { THOUSAND } \\
\text { ACRES }\end{array}$ & $\begin{array}{c}\text { THOUSAND } \\
\text { ACRES }\end{array}$ \\
\hline $\begin{array}{l}A Z 2 \\
C A 2 \\
C O \\
I D \\
K S \\
M 1 \\
M N \\
M T \\
N B \\
\text { NM } \\
\text { ND } \\
\text { OH } \\
\text { OR } \\
T X \\
\text { UT } \\
\text { WA } \\
\text { WY }\end{array}$ & $\begin{array}{r}12.9 \\
227.0 \\
77.0 \\
115.4 \\
26.0 \\
92.3 \\
264.0 \\
46.4 \\
75.0 \\
1.3 \\
157.8 \\
24.9 \\
8.9 \\
19.9 \\
10.4 \\
63.9 \\
49.5 \\
\end{array}$ & $\begin{array}{r}15.7 \\
207.0 \\
89.0 \\
136.3 \\
18.0 \\
93.0 \\
265.0 \\
45.4 \\
79.0 \\
2.1 \\
156.2 \\
24.5 \\
9.2 \\
28.0 \\
14.9 \\
69.2 \\
49.5 \\
\end{array}$ & $\begin{array}{r}12.8 \\
217.0 \\
72.0 \\
107.4 \\
24.0 \\
85.5 \\
260.0 \\
45.0 \\
67.7 \\
1.2 \\
155.2 \\
23.3 \\
8.9 \\
23.5 \\
14.7 \\
68.5 \\
48.8 \\
\end{array}$ & $\begin{array}{r}15.0 \\
195.0 \\
84.0 \\
134.1 \\
26.0 \\
91.0 \\
263.0 \\
44.0 \\
67.7 \\
1.2 \\
155.2 \\
23.3 \\
8.9 \\
23.5 \\
14.7 \\
68.5 \\
48.8 \\
\end{array}$ & $\begin{array}{l}22.3 \\
26.1 \\
19.5 \\
19.5 \\
16.7 \\
21.0 \\
18.2 \\
19.9 \\
20.0 \\
19.2 \\
17.8 \\
20.3 \\
25.1 \\
17.3 \\
17.7 \\
24.3 \\
19.6 \\
\end{array}$ & $\begin{array}{l}20.5 \\
24.5 \\
18.3 \\
20.3 \\
17.0 \\
19.3 \\
18.9 \\
19.8 \\
18.0 \\
20.6 \\
19.7 \\
16.9 \\
24.0 \\
17.6 \\
17.0 \\
26.5 \\
18.9 \\
\end{array}$ & $\begin{array}{r}285 \\
5,664 \\
1,404 \\
2.094 \\
401 \\
1,796 \\
4,732 \\
896 \\
1,354 \\
23 \\
2.769 \\
457 \\
206 \\
309 \\
173 \\
1,495 \\
949 \\
\end{array}$ & $\begin{array}{r}308 \\
4,778 \\
1,538 \\
2,722 \\
442 \\
1,756 \\
4,971 \\
885 \\
1,368 \\
37 \\
3,056 \\
394 \\
214 \\
414 \\
250 \\
1,815 \\
922 \\
\end{array}$ \\
\hline U.S. & $1,272.6$ & $.1,302.0$ & $1,235.5$ & $1,263.9$ & 20.6 & 20.3 & 25,007 & 25,870 \\
\hline
\end{tabular}

1 Preliminary.

2 Relates to year of harvest.

Source: IISDA Agricultural Statistics 1979.

Components of Molasses

\begin{tabular}{|l|c|c|}
\hline \multirow{2}{*}{ COMPONENTS } & \multicolumn{2}{|c|}{ COMPOSITION \% } \\
\cline { 2 - 3 } & RANGE & AVERAGE \\
\hline Water & $17-25$ & 20 \\
Sucrose & $30-40$ & 35 \\
Dextrose (Glucose) & $4-9$ & 7 \\
Levulose (Fructose) & $5-12$ & 9 \\
Other Reducing Substrates & $1-5$ & 4 \\
Ash & $7-15$ & 12 \\
Nitrogenous Compounds & $2-6$ & 4.5 \\
Non-Nitrogenous Acids & $2-8$ & 5 \\
Waxes, Sterols, Phospholipids & $0-1$ & 0.4 \\
\hline
\end{tabular}

Source: Paturau, J. M., By-products of the Cane Sugar Industry. Amsterdam, The Netherlands: Elsevier Publishing; 1969. 
Nutritional Content of Distillers Feed from Corn in Percentages

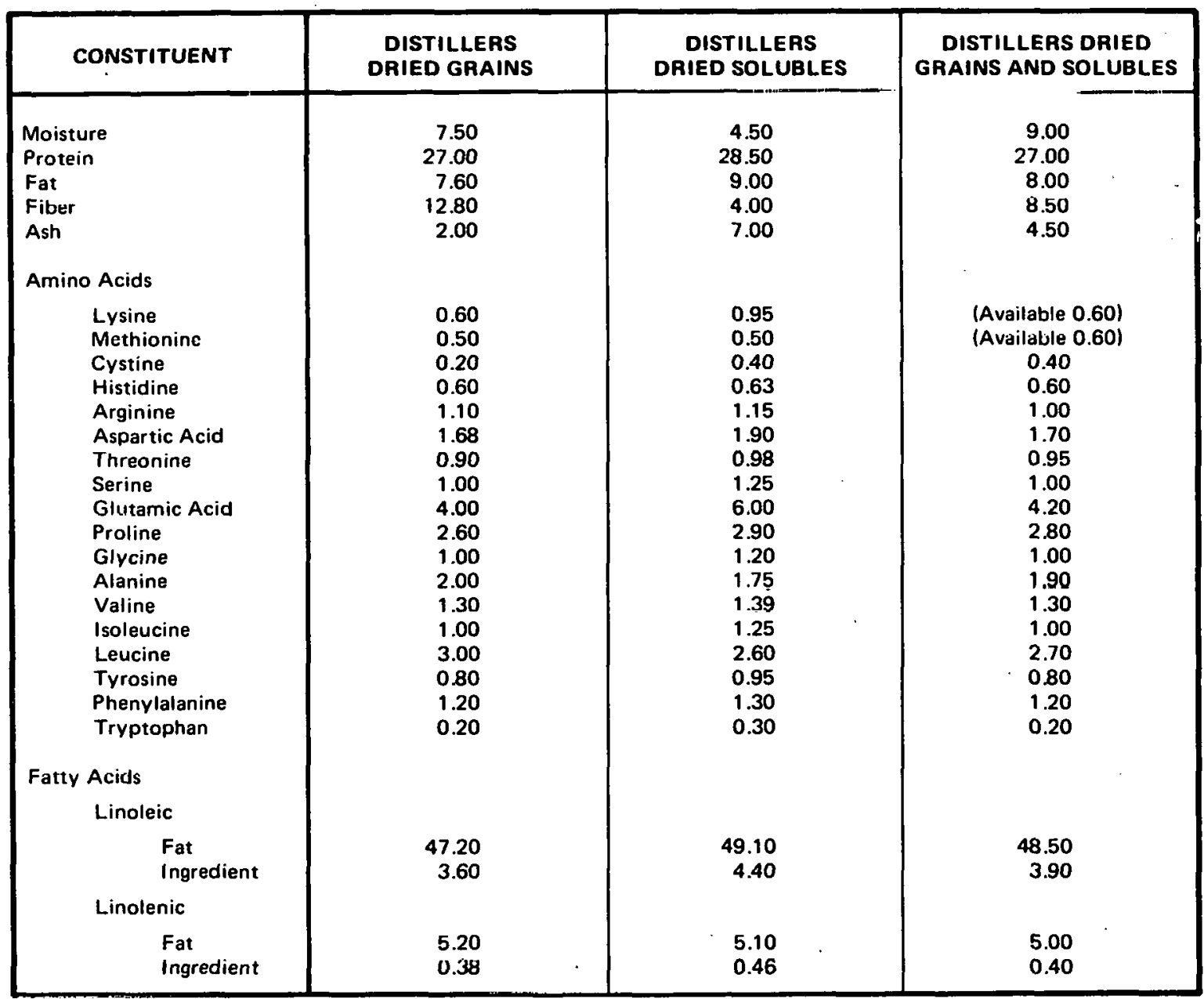

Eourco: Distillers Feed Mcsearch Council

Available Energy from Corn in Distillers Feeds

\begin{tabular}{|c|c|c|c|}
\hline CORN ENERGY & $\begin{array}{l}\text { DISTILLERS } \\
\text { DRIGD GRAINS }\end{array}$ & $\begin{array}{l}\text { DISTILLERS } \\
\text { DRIED GOLUBLES }\end{array}$ & $\begin{array}{l}\text { DISTILLERS DRIED } \\
\text { GRAINS AND SOLUBLES }\end{array}$ \\
\hline \multicolumn{4}{|l|}{ Cutte } \\
\hline $\begin{array}{l}\text { DE, kcal/kg } \\
M F_{\text {, kcal/kg }} \\
\text { TDN, \% }\end{array}$ & $\begin{array}{r}3,408 \\
3,704 \\
83\end{array}$ & $\begin{array}{r}3,608 \\
2,959 \\
80\end{array}$ & $\begin{array}{r}3,570 \\
2,327 \\
82\end{array}$ \\
\hline $\begin{array}{l}\text { NEmilk } \\
\text { NEm } \\
\text { NEp }\end{array}$ & $\begin{array}{l}2,150 \\
2,050 \\
1,347\end{array}$ & $\begin{array}{l}2,210 \\
2,030 \\
1,335\end{array}$ & $\begin{array}{l}2,210 \\
2,035 \\
1,335\end{array}$ \\
\hline \multicolumn{4}{|l|}{ Poultry } \\
\hline $\mathrm{ME}, \mathrm{kcal} / \mathbf{k g}$ & 1,631 & 2,750 & 2,620 \\
\hline \multicolumn{4}{|l|}{ Swine } \\
\hline $\begin{array}{l}\mathrm{DE}, \mathrm{kcal} / \mathrm{kg} \\
\mathrm{ME}, \mathrm{kcal} / \mathrm{kg} \\
\mathrm{TDN}, \%\end{array}$ & $\begin{array}{r}2,030 \\
1,835 \\
46\end{array}$ & $\begin{array}{r}3,305 \\
2,985 \\
75\end{array}$ & $\begin{array}{r}3,085 \\
2,790 \\
70\end{array}$ \\
\hline
\end{tabular}

Source: Distillers Feed Research Council 


\section{FOR MORE INFORMATION}

National Alcohol Fuels Information Center

Solar Energy Research Institute

1617 Cole Boulevard

Golden, CO 80401

(800) 525-5555 - Continental U.S., Alaska \& Hawaii

(800) 332-8339 - Colorado 


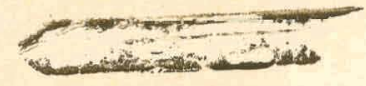

"x _...

A Product of:

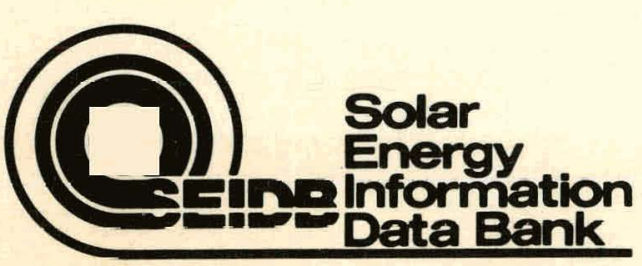

SERI/SP.751.877
Manlayed by

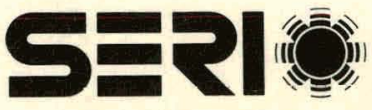

Solar Energy Research Institute A Division of Midwest Research Institute

Operated by

U.S. Department of Energy under Contract No. EG-77-C-01-4042 